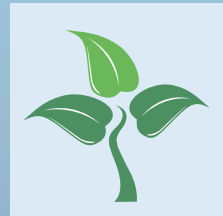

\title{
sustainability
}

Sustainable

Directions

in Tourism

Edited by

Tomás F. Espino-Rodríguez

Printed Edition of the Special Issue Published in Sustainability 
Sustainable Directions in Tourism 



\section{Sustainable Directions in Tourism}

Special Issue Editor

Tomás F. Espino-Rodríguez

MDPI • Basel • Beijing • Wuhan • Barcelona • Belgrade

\section{MDPI}


Special Issue Editor

Tomás F. Espino-Rodríguez

Universiy of Las Palmas de Gran Canaria

Spain

\section{Editorial Office}

MDPI

St. Alban-Anlage 66

4052 Basel, Switzerland

This is a reprint of articles from the Special Issue published online in the open access journal Sustainability (ISSN 2071-1050) from 2018 to 2019 (available at: https://www.mdpi.com/journal/ sustainability/special_issues/sustainable_directions_tourism)

For citation purposes, cite each article independently as indicated on the article page online and as indicated below:

LastName, A.A.; LastName, B.B.; LastName, C.C. Article Title. Journal Name Year, Article Number, Page Range.

ISBN 978-3-03921-772-4 (Pbk)

ISBN 978-3-03921-773-1 (PDF)

(C) 2019 by the authors. Articles in this book are Open Access and distributed under the Creative Commons Attribution (CC BY) license, which allows users to download, copy and build upon published articles, as long as the author and publisher are properly credited, which ensures maximum dissemination and a wider impact of our publications.

The book as a whole is distributed by MDPI under the terms and conditions of the Creative Commons license CC BY-NC-ND. 


\section{Contents}

About the Special Issue Editor $\ldots \ldots \ldots \ldots \ldots \ldots \ldots \ldots$ vii

Heng Zhang, Po-Chien Chang and Ming-Fong Tsai

How Physical Environment Impacts Visitors' Behavior in Learning-Based Tourism-The

Example of Technology Museum

Reprinted from: Sustainability 2018, 10, 3880, doi:10.3390/su10113880 _ . . . . . . . . . . 1

\section{Hou Jiang, Yaping Yang and Yongqing Bai}

Evaluation of All-for-One Tourism in Mountain Areas Using Multi-Source Data

Reprinted from: Sustainability 2018, 10, 4065, doi:10.3390/su10114065 . . . . . . . . . . . . 26

Gabriela Koľveková, Erika Liptáková, Ľubomír Štrba, Branislav Kršák, Csaba Sidor, Michal Cehlár, Samer Khouri and Marcel Behún

Regional Tourism Clustering Based on the Three Ps of the Sustainability Services Marketing Matrix: An Example of Central and Eastern European Countries

Reprinted from: Sustainability 2019, 11, 400, doi:10.3390/su11020400 . . . . . . . . . . . . . 45

Han-Shen Chen and Chu-Wei Chen

Economic Valuation of Green Island, Taiwan: A Choice Experiment Method

Reprinted from: Sustainability 2019, 11, 403, doi:10.3390/su11020403 . . . . . . . . . . . . . . .

\section{Nermin Kişi}

A Strategic Approach to Sustainable Tourism Development Using the A'WOT Hybrid Method:

A Case Study of Zonguldak, Turkey

Reprinted from: Sustainability 2019, 11, 964, doi:10.3390/su11040964 . . . . . . . . . . . . . 80

Ramona Ciolac, Tabita Adamov, Tiberiu Iancu, Gabriela Popescu, Ramona Lile, Ciprian Rujescu and Diana Marin

Agritourism-A Sustainable Development Factor for Improving the 'Health' of Rural Settlements. Case Study Apuseni Mountains Area

Reprinted from: Sustainability 2019, 11, 1467, doi:10.3390/su11051467 . . . . . . . . . . . . . . .

\section{Daxin Dong, Xiaowei Xu and Yat Fung Wong}

Estimating the Impact of Air Pollution on Inbound Tourism in China: An Analysis Based on Regression Discontinuity Design

Reprinted from: Sustainability 2019, 11, 1682, doi:10.3390/su11061682 .

Heesup Han, Taeyeon Eom, Amr Al-Ansi, Hyungseo Bobby Ryu and Wansoo Kim

Community-Based Tourism as a Sustainable Direction in Destination Development:

An Empirical Examination of Visitor Behaviors

Reprinted from: Sustainability 2019, 11, 2864, doi:10.3390/su11102864 . . . . . . . . . . . . . . 141

Tzu-Ming Liu and Chia-Mei Tien

Assessing Tourists' Preferences of Negative Externalities of Environmental Management

Programs: A Case Study on Invasive Species in Shei-Pa National Park, Taiwan

Reprinted from: Sustainability 2019, 11, 2953, doi:10.3390/su11102953 . . . . . . . . . . . . . 155

Yunduk Jeong, Suk-Kyu Kim and Jae-Gu Yu

Determinants of Behavioral Intentions in the Context of Sport Tourism with the Aim of Sustaining Sporting Destinations

Reprinted from: Sustainability 2019, 11, 3073, doi:10.3390/su11113073 . . . . . . . . . . . . 166 


\section{Eelco Buunk and Edwin van der Werf}

Adopters versus Non-Adopters of the Green Key Ecolabel in the Dutch Accommodation Sector Reprinted from: Sustainability 2019, 11, 3563, doi:10.3390/su11133563 . . . . . . . . . . . . . 181

\section{Oscar Trull, Angel Peiró-Signes and J. Carlos García-Díaz}

Electricity Forecasting Improvement in a Destination Using Tourism Indicators

Reprinted from: Sustainability 2019, 11, 3656, doi:10.3390/su11133656 . . . . . . . . . . . . . . 199

Manuel-Francisco Morales-Contreras, Paloma Bilbao-Calabuig, Carmen Meneses-Falcón and Victoria Labajo-González

Evaluating Sustainable Purchasing Processes in the Hotel Industry

Reprinted from: Sustainability 2019, 11, 4262, doi:10.3390/su11164262 . . . . . . . . . . . . . . . 215

Juan Pablo Vázquez Loaiza, Antonio Pérez-Torres and Karol Marylin Díaz Contreras

Semantic Icons: A Sentiment Analysis as a Contribution to Sustainable Tourism

Reprinted from: Sustainability 2019, 11, 4655, doi:10.3390/su11174655 . . . . . . . . . . . . . . . 239

Binru Zhang, Yulian Pu, Yuanyuan Wang and Jueyou Li

Forecasting Hotel Accommodation Demand Based on LSTM Model Incorporating Internet Search Index

Reprinted from: Sustainability 2019, 11, 4708, doi:10.3390/su11174708 . . . . . . . . . . . . . 260

Amélie Anciaux

"On Holidays, I Forget Everything... Even My Ecological Footprint": Sustainable Tourism through Daily Practices or Compartmentalisation as a Keyword?

Reprinted from: Sustainability 2019, 11, 4731, doi:10.3390/su11174731 . . . . . . . . . . . . . . 274 


\section{About the Special Issue Editor}

Tomás F. Espino-Rodríguez is Senior Lecturer in the School of Business, Economics and Tourism at University of Las Palmas of Gran Canaria, Spain, where he lectures on hospitality and tourism operations. He has also served as Visiting Researcher at the University of Strathclyde. His research focuses on outsourcing, supply chain, and operations management in the hospitality sector. His papers have been published in such international academic journals as International Journal of Management Reviews, Tourism Management, International Journal of Hospitality Management, International Journal of Contemporary Hospitality Management, Service Business, Sustainability, Tourism Economics, and The Services Industries Journals, and presented at numerous conferences around the world. He serves as a member of the Editorial Board of numerous international journals. He was awarded the Best Work Award at the 14th APAcHRIE conference 2016. 

Article

\title{
How Physical Environment Impacts Visitors' Behavior in Learning-Based Tourism-The Example of Technology Museum
}

\author{
Heng Zhang ${ }^{1, *}$, Po-Chien Chang ${ }^{2}$ and Ming-Fong Tsai ${ }^{1}$ \\ 1 Department of Architecture, National Cheng Kung University, No. 1, University Road, Tainan City 70101, \\ Taiwan; arch@nmth.gov.tw \\ 2 Department of Communications Management, Shih Hsin University, No. 17, Lane 1, Sec. 1 Mu Cha Rd., \\ Taipei 11641, China; pochien@mail.shu.edu.tw \\ * Correspondence: changlin@mail.ncku.edu.tw; Tel.: +886-917-798-255
}

Received: 24 September 2018; Accepted: 21 October 2018; Published: 25 October 2018

\begin{abstract}
Visiting a museum is a popular activity in the tourism industry, especially in cultural and learning-based tourism. To help plan museums effectively, this study investigated the underlying motivations and constraints and their impact on the perceived physical environment and visitor satisfaction toward a museum. The results suggest that the physical environment of museums serves as an axial mediator among motivations, constraints and visitor satisfaction. Six essential factors of physical environment are affected by motivations and constraints, further affecting visitor satisfaction in various patterns, in which architectural planning, exhibition, external environment, and entrance are clearly affected by basic motivations and constraints. Under motivations, family education and self-development are the most two profound influences on enhancing visitor satisfaction through the physical environment. Shops and café are worth special attention in meeting motivation of attractiveness, occasion and social interaction. The results could support the planning and design of a satisfactory museum.
\end{abstract}

Keywords: learning-based tourism; science museum; motivation; constraint; museum planning; physical environment (PhE); visitor behavior; visitor satisfaction

\section{Introduction}

In recent years, the role of the modern museum has transformed from the traditional functions of collection, exhibition and research into an emphasis on leisure, education, aesthetic experiences and entertainment [1-3]. On the other hand, a museum may have something different to offer from other leisure and tourism products, through unique features such as outdoor exhibitions or cultural learning experiences [4]. Economic, cultural and social demands also push museums to deal with the issues of visitor experience and profitability [3]. To create a pleasant museum experience, museum planners and managers must pay considerable attention to visitor satisfaction and service quality [5]. The latter has always been regarded as key to gaining a competitive edge in the service industry [6]. However, it is impractical to use the conventional generic assessment scale for service quality to evaluate individual satisfaction and quality of physical environment in a modern museum [7].

As museum managers tackle challenges emerging from limited resources and budget, they have to develop effective strategies to improve the museum's performance and visitor satisfaction in order to compete with other museums and leisure activities [8]. Tourists' choice of destination is driven by a variety of factors, such as the potential to learn, the diversity of facilities, the aesthetic experience, and the quality of environment [9]. Hence, to improve the museum services, it is important to understand the market responses $[1,2,10,11]$, namely, what affects visitors' decision to visit or not 
and how they evaluate the services delivered by the museum. Visitors' interest (e.g., motivation and perception) as well as the information provided by the museum (e.g., collection, exhibition and events) are key topics in the performance of a museum [12].

With this background, this study set out to meet three objectives: (1) identify the motivations and constraints that influence the decision to visit a museum; (2) suggest a demand-based list of physical environment which affect visitor satisfaction; and (3) construct a causal relationship among visitors' interests, physical environment, and visitor satisfaction as a whole.

\section{Literature Review}

\subsection{Motivations to Visit a Museum}

Understanding the motivation behind museum visits is essential for the planning, promotion, and pricing of the attractions [13]. Motivation has been characterized as a goal- and value-driven behavior, which can be grounded in biology, or a complex interaction with external stimuli that trigger various individual activities to accomplish a specific goal $[14,15]$. Derived from different orientations of human psychology theory, two distinct types of motivations have been identified to determine an individual's cognitive and affective responses, namely intrinsic and extrinsic motivations $[16,17]$. The former involves one's internal feelings, such as feeling interested or enjoyable, while the latter involves external incentives and interactions. Similar to intrinsic and extrinsic motivations, another taxonomy applied to travel choices is push and pull motivations [18-21]. Push motivations are driven by personal and internal psychological forces such as emotion and cognition, while pull motivations are associated with the features of the destination choices [21]. Previous studies indicate that motivations that drive visitors to museums include education, leisure, friends, work, physical facilities, and escapism [22-25], within which visitors seek to satisfy not only one objective but a variety of leisure incentives [26]. To regular visitors, experiencing the entire museum environment is more appealing than the collections within the museum [27]. Here, motivation is guided by neither internal nor external forces and is mostly self-oriented. Widely-used scales for quality of service may exclude some critical factors that also influence one's choice of destination, such as the reputation of attractions, perceived entertainment, and the cultural experience [28].

Researchers have not reached a consensus on how to classify the motivations to visit a formal or informal place [29-31], but they continue in the efforts to understand the reasons behind an individual's decision on whether to visit a museum [32].

\subsection{Constraints to Visiting a Museum}

From the socio-psychological perspective, motivations can be divided into factors of seeking and avoidance [33]. Hence, it is also essential to pay attention to the negative aspect of human psychology. Constraints, as opposed to motivations, hinder people's decision to visit a place, and have been the subject of another stream of research [34-39] which explores intrapersonal (lack of interest), interpersonal (lack of company) and structural factors (lack of time, high cost, crowding, dissatisfaction with or unattractiveness of the destination environment) [40-42]. Among them, intrapersonal and structural constraints affect visitors' intention significantly, while interpersonal ones do not [41].

Constraints are not necessarily barriers to leisure participation because people negotiate them [43-46] using various strategies [47,48]. Self-efficacy [49], social capital and motivation are factors affecting the negotiation and relative strategies [50].

Constraints that influence people's decision to visit a museum may comprise psychological and situational factors, as well as those attributed to the museum itself. Factors such as individual psychological status, preference, socioeconomic status, and interpersonal relationship are not dictated or controlled by the museum environment or staff. Other factors, such as promotion, image of the museum, the quality of service, and physical facilities can be manipulated and controlled by the museum, which should have been addressed through planning or management to reduce 
constraints during the visitors' museum experience. Although much research has been dedicated to the investigation of leisure constraints, few studies concurrently probe the effect of leisure constraints and motivation factors. To obtain a holistic view of the human decision-making process, researchers should not eliminate the constraining factors as determinants of human behavior.

\subsection{Museum Physical Environment (PhE) and Service Quality}

Physical environment (PhE) of a museum have not been widely discussed in marketing research. Researchers initially defined and identified the distinct features of service quality [51,52], followed by either verifying the measurement of service quality [52-57] or extending its relationship with antecedent and subsequent constructs, such as motivation [18,19,21,58,59], value [54,60-62], and satisfaction [63-67].

In marketing practice, service quality has been affirmed as an influencing factor to customers' evaluation and intention to maintain a relationship with business vendors [68]. Through the attainment of customer satisfaction and repeat purchase, companies obtain sustainable advantages over their competitors [51]. Zeithaml [62] defined perceived quality as "the consumer's judgment about a product's overall excellence or superiority." Researchers argue service quality is largely dependent upon the cognitive gap between expected and perceived performance [69]. The measurement of service quality is thus assessed by the difference between the two and mostly relies on customers' subjective and cognitive judgment [70]. Service quality is also evaluated by the level of service fulfillment between customers' expectation and perceived service delivery [71].

Due to difficulties in obtaining objective data on the standard of service and making a comparison between expectation and performance at the same time, most studies apply perceived service quality as the major determinants of behavioral consequences in their frameworks [72,73]. Referring to Swan and Combs's performance-based model [74], people may perceive both technical quality and functional quality during the delivery of service and consequently form an overall evaluation of service quality [72]. Besides, using only a performance scale to measure the construct of service quality yielded better analytical results than a comparative measurement of expectation versus perceived performance [55]. In studying leisure and tourism, researchers argue it is not precise enough to rely on only service quality scales [52] to study individual perception of service quality. Instead, it is necessary to evaluate the overall experience [7,73,75-77]. Acknowledging inconsistent results from different service quality measures, researchers engaged in leisure and tourism studies are inclined to develop their own quality constructs based on perception of service features and emotional experiences [75].

Physical environment (PhE) can be a constraint as well as an attraction for visitors. Hence, to better predict visitors' decision on whether to visit a museum, the service quality of the museum in this study is measured by using visitors' evaluation and perception of the quality of a museum's PhE. To probe the service factors of a museum, the construct "physical environment (PhE)" herein is defined as the service functions embedded in the museum's facilities, including both internal/external environment and information/exhibition, which can be perceived and evaluated by visitors.

\subsection{Visitor Satisfaction}

Cardozo [78] first introduced the concept of customer satisfaction into marketing research and concluded high customer satisfaction increases people's purchase intention, possibly extending it to other similar products or contributing to enhanced reputation through word-of-mouth. Consequently, marketing researchers have devoted efforts to formulate definitions of customer satisfaction [70,79-81].

Satisfaction may be represented by different models, such as individual psychological expectation-disconfirmation [82] (CS/D), expectation-desire congruency [83], equity [84], norm [85], and performance [86]. Satisfaction can be generally divided into feature satisfaction and information satisfaction [66]. Feature satisfaction refers to the consumer's subjective judgment based on the performance of the product features [87]. Information satisfaction, on the other hand, refers to the 
consumer's subjective judgment of information in choosing a product, which is outside the focus of this study.

Customer satisfaction can be established through a series of customer evaluations and comparison between their expectation and perceived performance in their use of a product or service. The service quality can be perceived differently based on the quality of product features or psychological outcome. Leisure satisfaction can be measured by how well leisure activities are perceived to fulfill the basic needs and motives that stimulated the desire to participate in an activity [76]. In the museum context, satisfaction can be evaluated via a visitor's experience in and perception of the museum environment within a certain period, e.g., during the museum visit. Museum visitors perceiving high quality and full satisfaction with the physical environment are more likely to recommend the museum to their friends or disseminate favorable comments to others [28]. Based on these notions, customers' satisfaction in museum services should be derived from their experience of a museum's facilities, functional services, and surroundings. Hence, the study concentrates on visitors' satisfaction with the performance of physical environment.

\subsection{Links between Motivation, Constraint, Physical Environment, and Visitor Satisfaction}

In the research of service marketing, especially in tourism, customer satisfaction is critical to both business practice and academic interest. Researchers have agreed visitor satisfaction is affected by his or her motivations [88]. Established motivations include seeking variety from the daily routine, recreational opportunities, and leisure experiences [88]. Tourists may share similar patterns of motivation and satisfaction, such as knowledge seeking, social interaction, and escape [89]. Such similarity between motivation and satisfaction may lead to high overall satisfaction [21,90]. Contrary to motivations, visit constraints have not been a major focus of investigation in marketing and management studies [32]. As a negative influence on the willingness to visit a museum, we can expect constraints to influence satisfaction negatively. A combination of various determinants of visitor satisfaction, including motivations and constraints, works together to influence the decision to visit a destination. Aside from museums, prior research on other destinations has also favored an approach that combines motivations and constraints because it provides a holistic view of individual decisions [91]. However, the causal relationship between the role of physical environment, motivations, constraints and satisfaction have been rarely explored. While past discussions focus on the linear relationship between service quality and individual satisfaction, the objective of this study was to delineate multiple factors of motivations, constraints and physical environment that influence one's satisfaction after a museum visit.

\subsection{The Hypothetical Model}

Previous studies reveal individual satisfaction is affected by one's motivations $[21,88,89]$ and is mediated by performance-based service quality [65-67,72,75,92]. Researchers have focused on either verifying the causal relationship between service quality and customer satisfaction or confirming the link between individual motivations and satisfaction. Little has been done that postulates a causal relationship between individual motivations, constraints, facility features and satisfaction in a museum context. In this study, motivations and constraints are hypothesized to influence visitor satisfaction in their visit as mediated through their perception of the museum physical environment (Figure 1). 


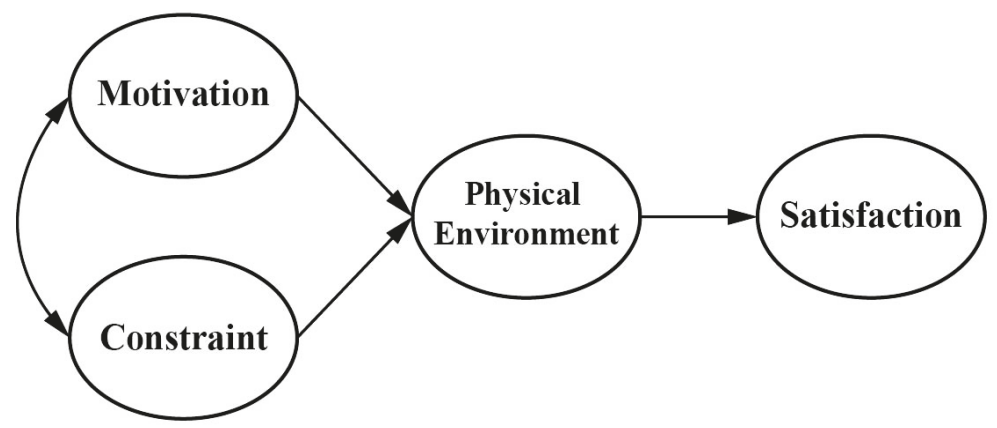

Figure 1. Proposed model on the relationship among motivations, constraints, physical environment of a museum and satisfaction.

\section{Methods}

\subsection{Design of Questionnaire}

A survey questionnaire was used as the instrument of study. The questions were designed based on literature review and were pre-tested to ensure satisfactory content validity [93]. The questionnaire comprised four sections, each measuring one of the four study constructs. All constructs were measured on a five-point Likert scale ranging from strongly disagree $(=1)$ to strongly agree $(=5)$. Demographic variables, i.e., age, gender, education, income, and marital status, were also investigated at the end of the questionnaire.

\subsection{Measurement of the Study Constructs}

Visitors' motivations were examined as factors that drive individuals' decision to visit a museum, with five sub-constructs: learning, leisure/entertainment, environment, social interaction, and promotion [23,94]; there is a total of 24 items (Appendix A, A1-A24). Constraints, on the other hand, were treated as negative influences that hinder individuals' decision to visit a museum. The constraints comprise 21 items (Appendix A, B1-B21).

For the assessment of physical environment (PhE), we developed a questionnaire to evaluate people's perception and experience in a museum context, done by synthesizing characteristics from previous studies and common planning features (e.g., a museum's image, open space, environment, displays, activities and service facilities). Thirty-four items were utilized to measure the PhE of a museum (Appendix A, C1-C34).

Positive recommendation and revisit intention are considered as behavioral responses of visitor satisfaction. For satisfaction measurement, this study rated visitors' attitudinal and behavioral responses by overall perception of their experience encounters during the time spent within the museum environment. The intention to revisit is another behavioral response that is commonly used in leisure and tourism studies to describe a visitor's psychological commitment to and preference for a place (or product) [21]. This study measured visitor satisfaction with three items, i.e., overall satisfaction with the museum, possibility of a re-visit, and intention to recommend the museum to friends or acquaintances (Appendix A, D1-D3).

\subsection{Survey Site and the Survey}

The survey was conducted on the National Science and Technology Museum (NSTM) in Kaohsiung, Taiwan. Opened in 1997 and employing 133 staffs, the museum has a total floor area of $20,756 \mathrm{~m}^{2}$ and a site area of 19.16 ha. It contains 18 permanents and 3 special exhibitions (Figure 2). Kaohsiung is a major industrial city in Taiwan, and NSTM is the first museum of applied science in Taiwan. Unlike most museums of art or history, the aim of NSTM is on industrial development and 
daily applications of science and technology. The exhibition is tailored closely to people's lives. This study covers the whole of the museum's environment and facilities as well as services given by all staff members.

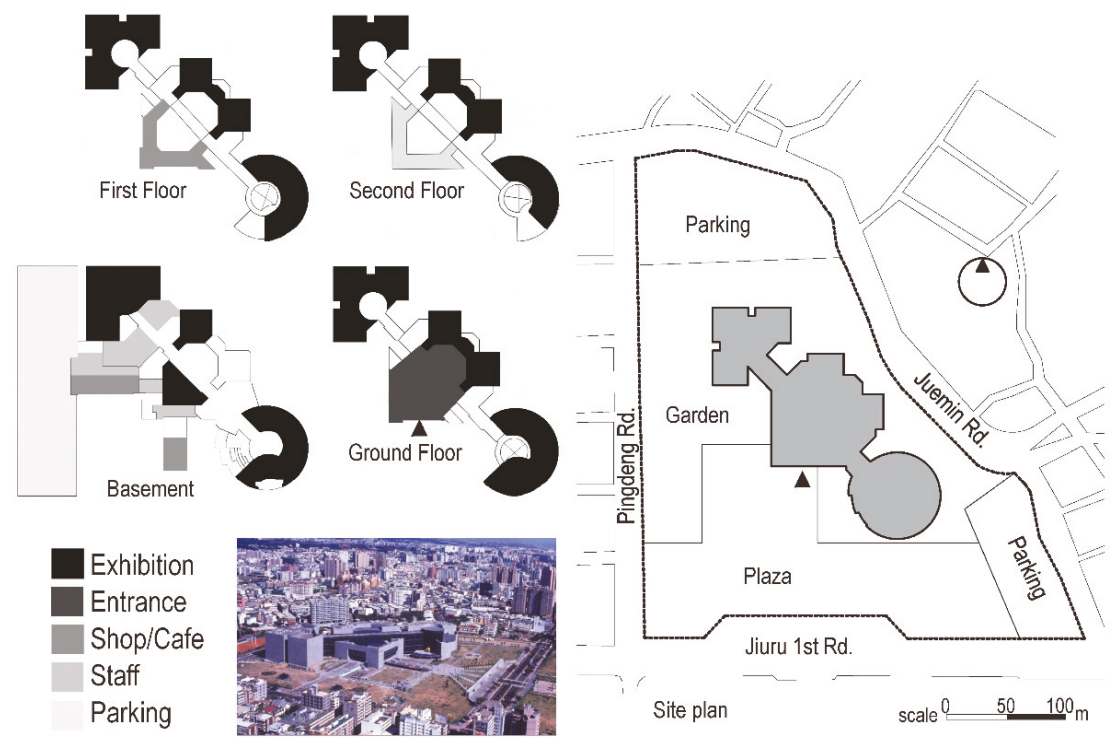

Figure 2. Site plan and major floor plans of the National Science and Technology Museum.

NSTM visitors were recruited for the survey. Data were collected through questionnaires conducted in the museum lobby while visitors complete their visits. Trained investigators explained to the participants the objective of the study, and the participants completed the questionnaire on a self-report basis. The investigators stayed in the lobby and responded to questions from the participants if they had any. When the questionnaire was completed, the participants would receive a small souvenir as requital for their participation. It took six days, which were mostly Saturdays or Sundays, to complete the survey. The questionnaires were distributed between 10:00 and 16:00 while the museum was open. To explore visitor behaviors, which are closer to actual tourism comparing to that of young pupils obligated to visit the museum for their homework, visitors younger than 15 were excluded from the survey, and 405 questionnaires were collected.

\subsection{Analytical Process}

Exploratory factor analysis (EFA) was used to identify the underlying factors of motivations, constraints, and the physical environment (PhE). Before EFA, item analysis was performed to raise the consistency and stability between multiple items of each construct. Barlett's test of sphericity and the Kaiser-Meyer-Olkin (KMO) measure of sampling adequacy were employed to determine the fitness of the factor analysis. Cronbach's alpha values were calculated to determine the reliability of each identified factor [95]. Factor analysis contributes to an understanding of the underlying latent construct and has been favored by researchers who wish to classify a mix of research items into groups of influential factors [21,32,96-98].

After EFA, the properties of the four research constructs-motivations, constraints, PhE and visitor satisfaction-were examined using structural equation modeling (SEM) [99] together with a two-stage testing process [100]. The validity of the measurement models was first tested to determine how measured variables logically and systematically represent the four constructs involved in the 
proposed model [95]. Then, a series of structural equation modeling (SEM) tests were run to estimate the structural model [95].

Finally, multiple regression was conducted to find the motivated and constrained determinants of perceived PhE for each factor extracted by EFA.

\section{Results and Discussion}

\subsection{Sample Profile}

In total, 405 questionnaires were distributed at the information desk of the museum. Forty-four responses were incomplete (e.g., over 1/3 of the questions unanswered or the same answers repeated in an entire section) and were excluded from the sample data. The final sample contained 361 questionnaires on which data analysis was conducted.

The demographic results of the survey indicate slightly more female visitors than male. Most of the visitors were between the age of 20 and $44(72.5 \%)$ and have a college degree (61.7\%); students accounted for a large proportion (Table 1).

Table 1. Demographic characteristics of the sample

\begin{tabular}{cccc}
\hline & Percentage & Percentage \\
\hline Gender & \multicolumn{3}{c}{ Occupation } \\
Male & 48.1 & Self-employed & 1.9 \\
Female & 51.9 & Blue-collar worker & 6.6 \\
& & White-collar worker & 14.2 \\
Age & & Technical worker & 16.1 \\
$15-19$ & 13.3 & Government worker & 17.7 \\
$20-24$ & 24.7 & Student & 35.8 \\
$25-34$ & 20.3 & Retiree & 7.9 \\
$35-44$ & 27.5 & Others & 1.9 \\
$45-54$ & 10.1 & Monthly income & \\
$55-64$ & 3.5 & $<$ NTD10,000 & 35.1 \\
$65+$ & 0.6 & NTD10,000-30,000 & 22.2 \\
& & NTD30,000-50,000 & 25.3 \\
Educational Level & 0.9 & NTD50,000-70,000 & 13 \\
Junior high & 19.6 & NTD70,000-90,000 & 2.2 \\
High school & 61.7 & NTD90,000-110,000 & 1.3 \\
College & 17.7 & Above NTD110,000 & 0.9 \\
Graduate & & & \\
Marital status & 53.8 & & \\
Single & 38.3 & & \\
Married with children & 7.9 & & \\
Married without children & & & \\
\hline
\end{tabular}

Note: NTD is the abbreviation for New Taiwan Dollar.

\subsection{Sample Profile}

Both Kaiser-Meyer-Olkin measure of sampling adequacy ( $>0.8)$ and Bartlett Test of Sphericity $(p<0.05)$ were used to assess whether the sample data were appropriate for conducting factor analysis. The results show motivations, constraints, and PhEs satisfy the assumptions in the factor analysis. Factors were extracted if their eigenvalues (or latent roots) were larger than 1 . Rotated items with low communality (factor loading < 0.40 ) or cross-loaded items were excluded. Finally, the factor structure for three constructs were confirmed and labeled (Appendix B, Table 2). Note that factor analysis was not performed for the construct "satisfaction" because it only has three items. 
Table 2. Factors under the motivation (Mo), constraint (Con), physical environment (PhE) and the explained variances of the three constructs.

\begin{tabular}{cccc}
\hline Construct & Factor & $\begin{array}{c}\text { Explained } \\
\text { Variance } \\
\mathbf{( \% )}\end{array}$ & $\begin{array}{c}\text { Total Variance } \\
\text { Explained } \\
\mathbf{( \% )}\end{array}$ \\
\hline Motivation (Mo) & Mo1 Self-development & 20.69 & \\
& Mo2 Occasion and social interaction & 14.48 & \\
& Mo3 Leisure and companionship & 12.32 & 61.47 \\
Mo5 Attractiveness or obligation & 6.67 & \\
\hline Constraint (Con) & Con1 Poor museum image & 28.66 & \\
& Con2 Unappealing soft content & 20.10 & \\
\hline & Con3 Unattractive service and cost & 14.67 & \\
\hline Physical & PhE1 Architectural planning & 15.44 & \\
& PhE2 Exhibition and marketing & 15.23 & \\
Environment (PhE) & PhE3 External environment and accessibility & 12.02 & \\
& PhE4 Entrance and ticketing & 9.03 & \\
& PhE5 Site planning & 6.99 & \\
\hline
\end{tabular}

This study extracted five factors from motivations to visit a museum, in which "self-development" (Mo1) is the strongest. Among them, "self-development" (Mo1), "occasion and social interaction" (Mo2), and "family education" (Mo4) are intrinsic, and "leisure and companionship" (Mo3) and "attractiveness or obligation" (Mo5) are extrinsic. "Leisure and companionship" (Mo3) and "occasion and social interaction" (Mo2) were established as motivations to visit a museum, which is consistent with prior research $[10,94]$. In recent years, the managerial philosophy of museums has undergone major changes, evolving from a historical role of collection and research into a competition for visitor attendance [5]. Visitors find it important to have a setting that makes them feel comfortable and at ease when deciding if a museum is where they want to spend their leisure time [101]. A museum's attractiveness (Mo5), such as its architecture and admission cost, was also found to be an effective motivation for visiting and crucial in meeting visitors' needs.

This study draws three factors from constraints which hinder people's willingness to visit the museum. All of them are structural constraints rather than personal or intrapersonal [35]. This suggests structural constraints are reasons hindering museum visits. Contrary to motivation, constraints toward visiting a museum are more extrinsic, while motivation to visit a museum is more intrinsic. What is noteworthy is "poor images of the museum" (Con1), rather than "unappealing soft content" (Con2), is the strongest factor hindering museum visits. That indicates the importance of the images in a museum. Another effective constraint to visiting a museum found in this study was "unattractive service and cost" (Con3), consisting of both admission charges and psychological efforts [102]. In line with prior assumptions, visitors weigh costs against the learning and recreational value they receive from the environment of a museum and the visit in general, and this assessment ultimately affects their level of satisfaction $[103,104]$.

The study further suggests physical environment (PhE) possesses six main factors which affect visitors' satisfaction: "architectural planning" (PhE1), "exhibition and marketing" (PhE2), "external environment and accessibility" (PhE3), "entrance and ticketing" (PhE4), "site planning" (PhE5), and "shop and café" (PhE6). It is to be noted that "shop and café" (PhE6) stands for one of the crucial elements for visiting museum, and therefore it is extracted as an independent factor.

\subsection{Structural Model of Proposed Visiting Behavior}

After confirming the interrelationship between the observed indicators, a confirmatory factor analysis (CFA) was conducted to evaluate the reliability and validity, and the relationship between 
the research constructs was redefined before the measurement and structural equation models were examined [100]. The reliability of the construct, which captures the degree to which a set of measures indicate the common latent construct, was tested by using the method proposed by Fornell and Larcker [105]. With CFA, the average variance extracted (AVE) of each construct (i.e., motivations, constraints, physical environment and satisfaction) was examined. The convergent validity is acceptable with the motivation value slightly under 0.50 [106], and the composite reliability (CR) for the four constructs are well within acceptable values for the criterion of reliability $(>0.70)[107,108]$ (Table 3). The discriminant validity was also tested by comparing the average of variance extracted (AVE) and squared correlation $\left(\chi^{2}\right)$ among the constructs. The results show no correlation is larger than the average of variance, which confirms the discriminant validity [105] of the three constructs is also satisfactory (Table 4). After verifying different validity and reliability criteria, the construct validity for applying the research instrument in this study is determined acceptable.

Table 3. Convergent validity of the measurement models.

\begin{tabular}{|c|c|c|c|c|c|}
\hline Construct/Indicator & $\begin{array}{c}\text { Factor } \\
\text { Loading }(\lambda)\end{array}$ & $\begin{array}{c}\text { Reliability } \\
\text { Coefficient } \\
\qquad\left(\lambda^{2}\right)\end{array}$ & $\begin{array}{c}\text { Measurement } \\
\text { Error } \\
\left(1-\lambda^{2}\right)\end{array}$ & AVE & CR \\
\hline Motivation (Mo) & & & & 0.416 & 0.778 \\
\hline Mo1 & $0.734^{\mathrm{a}}$ & 0.539 & 0.461 & & \\
\hline Mo2 & $0.502 * * *$ & 0.252 & 0.748 & & \\
\hline Mo3 & $0.635^{* * *}$ & 0.403 & 0.597 & & \\
\hline Mo4 & $0.67^{* * *}$ & 0.449 & 0.551 & & \\
\hline Mo5 & $0.661^{* * *}$ & 0.437 & 0.563 & & \\
\hline Constraint (Con) & & & & 0.679 & 0.862 \\
\hline Con1 & $0.858^{\mathrm{a}}$ & 0.736 & 0.264 & & \\
\hline Con2 & $0.923 * * *$ & 0.852 & 0.148 & & \\
\hline Con3 & $0.671^{* * *}$ & 0.450 & 0.550 & & \\
\hline $\begin{array}{l}\text { Physical environment } \\
\text { (PhE) }\end{array}$ & & & & 0.557 & 0.881 \\
\hline PhE1 & $0.899^{\mathrm{a}}$ & 0.808 & 0.192 & & \\
\hline PhE2 & $0.832 * * *$ & 0.692 & 0.308 & & \\
\hline $\mathrm{PhE3}$ & $0.644^{* * *}$ & 0.415 & 0.585 & & \\
\hline $\mathrm{PhE4}$ & $0.777^{* * *}$ & 0.604 & 0.396 & & \\
\hline PhE5 & $0.706^{* * *}$ & 0.498 & 0.502 & & \\
\hline PhE6 & $0.569 * * *$ & 0.324 & 0.676 & & \\
\hline Satisfaction (S) & & & & 0.684 & 0.882 \\
\hline S1 & $0.662^{a}$ & 0.438 & 0.562 & & \\
\hline S2 & $0.891^{* * *}$ & 0.794 & 0.206 & & \\
\hline S3 & $0.905^{* * *}$ & 0.819 & 0.181 & & \\
\hline
\end{tabular}

Note: ${ }^{a}$ Significance was not calculated because the unstandardized loading was set as 1.0 to fix construct variance. $* * * p<0.001$. 
Table 4. Discriminant validity of the measurement models.

\begin{tabular}{ccccc}
\hline & $\begin{array}{c}\text { Motivation } \\
\text { (Mo) }\end{array}$ & $\begin{array}{c}\text { Constraint } \\
\text { (Con) }\end{array}$ & $\begin{array}{c}\text { Physical Environment } \\
\text { (PhE) }\end{array}$ & $\begin{array}{c}\text { Satisfaction } \\
\text { (S) }\end{array}$ \\
\hline Motivation (Mo) & $0.416^{\mathrm{a}}$ & & & \\
Constraint (Con) & $0.013^{\mathrm{b}}$ & $0.679^{\mathrm{a}}$ & $0.557^{\mathrm{a}}$ & \\
Physical environment (PhE) & $0.189^{\mathrm{b}}$ & $0.064^{\mathrm{b}}$ & $0.684^{\mathrm{a}}$ \\
Satisfaction (S) & $0.142^{\mathrm{b}}$ & $0.027^{\mathrm{b}}$ & $0.333^{\mathrm{b}}$ & ${ }^{\mathrm{b}}$
\end{tabular}

The measurement model consists of two exogenous variables (i.e., motivations and constraints) and two endogenous variables (i.e., physical environment and visitor satisfaction). The proposed model revealed an acceptable data fit $\left(\chi^{2}=267.434, \mathrm{df}=113, \chi^{2} / \mathrm{df}=2.367, \mathrm{CFI}=0.940\right.$, IFI $=0.940$, $\mathrm{NFI}=0.901, \mathrm{GFI}=0.910, \mathrm{RMSEA}=0.066)$, indicating the proposed model adequately explains the empirical relationship between the study variables. Though $\chi^{2}$ is significant, which is sensitive to the sample size, the fit is deemed acceptable as $\chi^{2} / \mathrm{df}$ is less than 3 [109], and incremental indices (over 0.90. RMSEA ranging from 0.6 to 0.8 ) also indicate the model fits the data well [110].

The goodness-of-fit was assessed to evaluate the validity of the structural model [95] The indices demonstrate a good fit for the structural model $\left(\chi^{2}=267.54\right.$ with 114 degrees of freedom, CMIN/DF $\left(\mathrm{CN} ; \chi^{2} / \mathrm{df}\right)=2.347 . \mathrm{GFI}=0.909, \mathrm{AGFI}=0.879, \mathrm{RMR}=0.030, \mathrm{RMSEA}=0.065, \mathrm{NFI}=0.901, \mathrm{IFI}=0.941$, $\mathrm{CFI}=0.940, \mathrm{PNFI}=0.75, \mathrm{PNFI}=0.755)$. The path analysis of the structural model shows the relationship between visitors' motivations and constraints was insignificant $(\mathrm{r}=-0.12$ and $p=0.088)$. This result is reasonable as the two are counter but independent effects in determining visitors' experience and response. The causal link between determinants and physical environment is moderately strong and significant. The path coefficients from motivations and constraints to perceived quality of physical environment (PhEs) are $0.41(t=5.54, p<0.000)$ and -0.21 , respectively $(t=-3.38, p<0.000)$ (Figure 3$)$. Therefore, the motivation effect is shown to overpower the constraint effect in determining the perception of physical environment after a visit. Furthermore, the path coefficient between PhEs and visitor satisfaction is $0.51(\mathrm{t}=6.79, p<0.000)$. Motivations also appear to have a direct effect on satisfaction with an impact of $0.16(t=2.39, p=0.017)$, and an indirect effect of 0.21 through physical environment (Table 5). The two determinants, motivations and constraints, explain $23.1 \%$ variance in quality of physical environment and the three constructs explain $35.3 \%$ variance in visitor satisfaction.

Table 5. Direct and indirect effects among motivation, constraint, physical environment and satisfaction.

\begin{tabular}{cccc}
\hline Path & Direct Effect & Indirect Effect & Total Effect \\
\hline Motivation $\rightarrow$ Physical environment & 0.411 & & 0.411 \\
Constraint $\rightarrow$ Physical environment & -0.207 & & -0.207 \\
Physical environment $\rightarrow$ Satisfaction & 0.509 & & 0.509 \\
Motivation $\rightarrow$ Satisfaction & 0.156 & 0.209 & 0.365 \\
Constraint $\rightarrow$ Satisfaction & & -0.105 & -0.105 \\
\hline
\end{tabular}




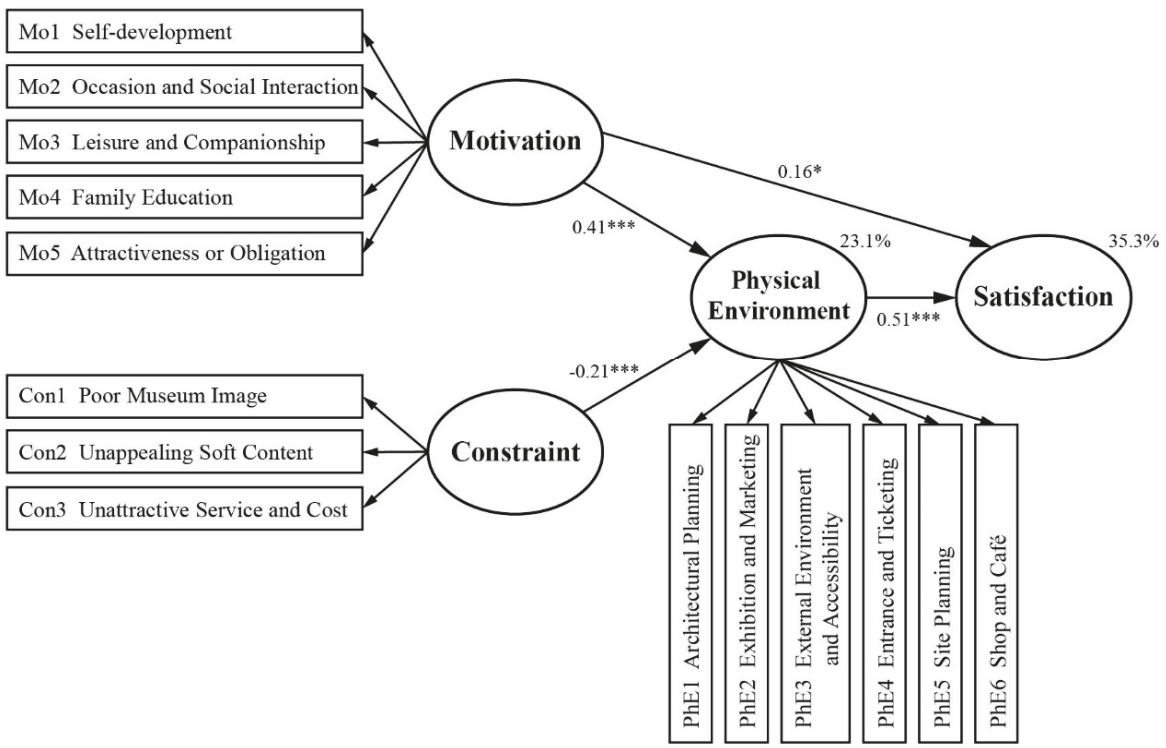

Figure 3. Estimated results of the study model. Physical environment forms a mediator among motivation, constraint and satisfaction. ${ }^{*} p<0.05,{ }^{* * *} p<0.001$.

This study posits a structural model in which motivations and constraints have a mediating effect on visitor satisfaction through physical environment (PhE). The PhE partially mediate the path from motivations to satisfaction, in which the direct effect of motivations on satisfaction is 0.16 and the indirect effect mediated through $\mathrm{PhE}$ is 0.21 , which is actually stronger than the direct one (Table 5). Therefore, the path mediated by physical environment may be deemed more important than the direct one.

The strong effect size of physical environment on visitor satisfaction (Table 5 and Figure 4) is consistent with previous theoretical results in which service quality is shown to be a vital determinant of individual satisfaction $[21,28,66,67,111]$. This result highlights the influence of physical environment on satisfaction. An individual's perception of a museum is derived from the evaluation of how well it performs on its various physical environment, such as exhibition environment, exhibition format, staff service and transportation, while the high level of satisfaction expressed by visitors who think the museum performed well in the quality of its physical environment confirms the theoretical assumption that the physical environment positively influence visitors' attitudinal and behavioral responses. The strength of the two explained variances in the model is also noteworthy. Motivations and constraints explain as high as $23.1 \%$ variance in the quality of physical environment, indicating careful consideration should be given to visitors' motivations and constraints in planning or managing a museum. As for visitor satisfaction, motivations, constraints and physical environment, they explain $35.3 \%$ of its variance. That is to say, over one third of visitor satisfaction can be achieved by paying more attention to motivations, constraint, and physical environment. In addition, though the effect of motivations on satisfaction is less than physical environment on satisfaction (0.51), motivations still have a relatively strong total effect (0.37) due to its compounded direct and indirect effects. Thus, to satisfy visitors, motivations of visit is another criterion to be considered besides physical environment. Compared to motivations, constraints have less effect on visitor satisfaction, and its influence is indirect. These results may fill the void in prior studies that are either dedicated to reveal the relationship between motivations and individual satisfaction $[20,21,58]$ or verifying the relationship between service quality and individual satisfaction [66,112]. 


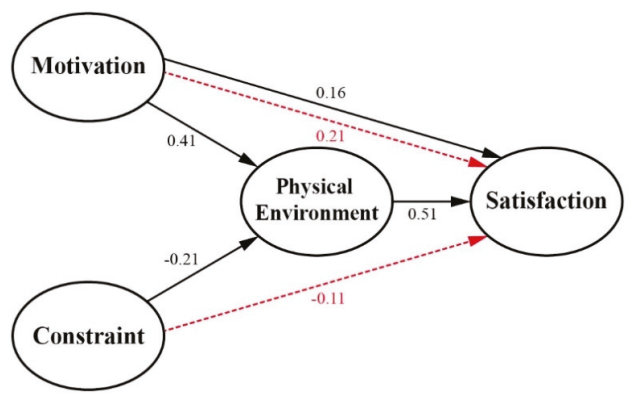

Figure 4. Interpretation of the structural model. Museum physical environment acts as an axial function in the model to transfer the impacts of motivation and constraint to visitor satisfaction. The indirect effect of motivation on satisfaction through physical environment is greater than its direct effect on satisfaction. Constraint has no direct effect on satisfaction.

\subsection{Impacts of Motivation and Constraint on the Planning of Museum Physical Environment}

To obtain the determinants of quality cognition towards a museum's physical environment, five factors in visiting motivations and three in visiting constraints were included and their relationships with six planning and management factors of physical environment for museum were tested. Multiple regression analysis with stepwise approach was conducted to select the most influential set of indicators in each factor of physical environment (Table 6) to generate appropriate planning and managing strategies.

Table 6. Relationship between motivation and constraint towards visiting a museum and perception of museum physical environment.

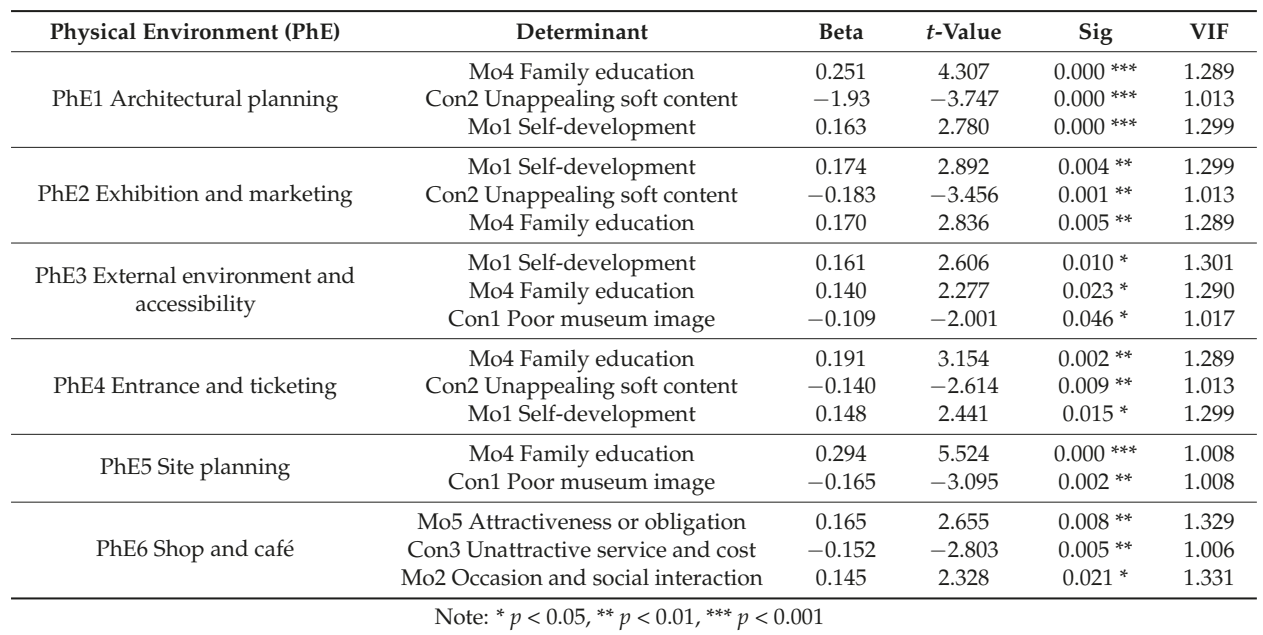

In motivations, "self-development" (Mo1) is conceived to be a fundamental factor that motivates people to visit a museum [22,30]. In this study, self-development is related to four of the six factors of $\mathrm{PhE}$ in a museum, including "exhibition and marketing" (PhE2)", "architectural planning" (PhE1), "External environment and accessibility" (PhE3), and "entrance and ticketing" (PhE4), at different strengths. "Family education" (Mo4) performed as the most profound motivation rather than self-development in relationship with the physical environment of a science museum. In the six factors of physical environment, family education affects five planning factors, even more than 
self-development does. Consequently, museum planners or managers should pay extra attention to family education functions in planning or running a modern museum. Visitors motivated by family education were also found to cherish the educational and leisure value offered by the whole site of the museum, i.e., both interiors of the museum building and its outdoor areas.

In contrast with motivations, constraints hinder people from visiting a museum and should be cautiously avoided. The results show "Unappealing Soft Content" (Con2), which is connected with three of the physical environment factors, PhE1, PhE2, and PhE4, is the most influential constraint among the three towards perception of the physical environment. This is consistent with the previous study, which suggested that the quality of exhibition is vital to the decision of visiting a museum or not [101]. "Poor Museum Image" (Con1) is found to be a major constraint that keeps people from visiting, and its impact is concentrated in the external environment, i.e., PhE3 and PhE5. External environment is found to be especially sensitive to "poor image of the museum" (Con1). Planners and managers should make more efforts on the external environment when they intend to improve the museum image.

The study results yield some interesting patterns. The "architectural planning" (PhE1), "exhibition and marketing" (PhE2), and entrance and ticketing (PhE4) of a museum share the same determinants, namely "self-development" (Mo1), "unappealing soft content" (Con2), and "family education" (Mo4). The findings indicate self-development (Mo1), family education (Mo4), and soft content (Con2) are the basic determinants of museum physical environment. This pattern of visitor behavior is consistent with the main goal of a modern museum, which is to provide new knowledge, family education and an enjoyable experience to visitors. Other factors of physical environment show, in contrast, a heterogeneous pattern in their determinants. Site planning (PhE5) of a museum is affected by "family education" (Mo4) and hindered by "poor museum image" (Con1). In addition, the museum shop and café (PhE6), as ancillary services, reveals a distinct pattern compared to other physical environments. Visitors' drive from "attractiveness or obligation" (Mo5), "occasion and social interaction" (Mo2), and halt from "unattractive service and cost" (Con3) are critical to the evaluation of shops and café. Although "leisure and companionship" (Mo3) is one of the main motivations to visit the museum, it affects none of the planning features of the museum. This motivational demand can be satisfied when others are also satisfied.

\section{Implications and Limitation}

\subsection{Practical Implications}

Compared to other tourist attractions, visitors to a museum are seeking a dynamic and unique experience. They come with different experiences and expectations, such as seeking new information or acquiring enjoyable, aesthetic and recreational experiences. Some motivation, such as family education, being with others, and cost, are listed as benefits of visiting a museum versus other tourist destinations [101]. The findings of this study show family education (Mo4) and self-development (Mo1) influence visitors' perception towards physical environment of museum most profoundly. Hence, museum planners and managers should incorporate suitable physical environment and corresponding activities to serve the two motivations.

The findings about constraints also identify certain factors that may improve museum services when avoided. "Unappealing soft content" (Con2) and "poor images of the museum" (Con1) are shown to be constraints to visitors. In addition, "unattractive service and cost" (Con3), including monetary as well as psychological and physical, were perceived as constraints which could impede a visit. Hence, it is suggested that characteristics contrary to the constraints should be introduced to bring intriguing, novel, exciting and enjoyable experiences to visitors to repair the hindrance. A museum should increase the opportunities for visitors to physically interact through its exhibition content and format (e.g., using hands-on workshops or interactive technology). A well-designed physical environment both inside and around the museum buildings may reduce visitor dissatisfaction. 
Enhancing the museum's general services and providing a flexible admission rate, such as discount for special events or rates varying according to age, visit timing, and frequency, could prove effective in encouraging attendance.

This study identifies six factors of physical environment that impact visitor satisfaction and deserve extra attention from museum managers and planners: Architectural Planning, Exhibition and Marketing, External Environment and Accessibility, Entrance and Ticketing, Site Planning, and Shop and Café. This examination of motivation and constraint as determinants of physical environment reveals distinct patterns, which equip planners and managers with tools to more precisely define the physical environment of a museum. The inherent planning issues of a museum, such as "architectural planning" (PhE1), "exhibition and marketing" (PhE2), as well as "entrance and ticketing" (PhE4) are related to motivations "self-development" (Mo1), "family education" (Mo4) and constraint "unappealing soft content" (Con2). While organizing these three factors of physical environment, planners and managers should pay extra attention to the functions of self-development (Mo1) and family education (Mo4) while specifically avoiding weak exhibition content (Con2).

Besides the interiors, the external environment of the museum is also found to have a significant impact on visitor satisfaction. Traditionally, planners and managers pay the most attention to the collection and visual elements of exhibitions and seldom note functions facilitating recreation and social interaction may also attract visitors. According to the study, the external environment of a museum should be designed specifically for family education (Mo4) and self-development (Mo1) while also emphasizing leisure functions. Enhanced external display areas in a natural environment can add to the museum experience. Facilitating walking and relaxing on the museum site and adding family-related facilities (e.g., family toilets and nursing room) will also be appreciated.

Additional services offered by a museum, such as catering, souvenir shops, barrier-free facilities, and special staff attention to seniors, as well as a comfortable environment all help create a warm and enjoyable experience for visitors. The study shows shop and café (PhE6), which have long been neglected, have a decisive influence on visitor satisfaction as well as meeting visitors' motivations including attractiveness and social interaction.

Research on tourism has confirmed visitor satisfaction and loyalty are two critical components of competitive sustainability in the tourism market [21]. Prior studies also confirm visitor satisfaction is vital to building customer loyalty in the service industry $[1,3,10,11]$. Those who visit the same museum over and over again are inclined to have high intention to revisit and are more likely to spread positive words to others. The study found the physical environment of a museum has an effective influence on visitor satisfaction. The results inform the museum planning or management as to which physical environment helps enhance visitor satisfaction.

\subsection{Limitations}

This study was conducted on a group of visitors to the National Science and Technology Museum, which is located in southern Taiwan. The results might be different compared to studies conducted across different locations and different types of museums (e.g., art museums). The proposed framework herein may be applied in future research to test different contexts.

The data collected were cross-sectional and non-experimental. Although SEM analysis provides a robust method for validating the causal relationships, the results should be reported with caution. Longitudinal observation and comparison were not possible due to the constraint of time and location. Future research will benefit from the collection of longitudinal and experimental data to measure the interrelationships between the research variables and provide more precise results in validation.

Though physical environment is verified as a mediator in this study, it explains already $35.3 \%$ variance of visitor satisfaction. Other factors also considered important for satisfaction, such as perceived value, corporate image, and quality of learning, were not included in the study. Future research may include and verify more constructs and extend or refine the relationships tested in this research. 


\section{Conclusions}

In tourism research, researchers have treated motivations and constraints as critical components of satisfaction. However, few studies incorporate constraints as inhibitors of perceived quality of physical environment and satisfaction in making a destination choice. Besides, no conceptual model has been established that explicitly examines the relationship among individuals' motivations, constraints, perceived quality and satisfaction toward the physical environment. This study conceptualizes the four as a whole.

Five factors are identified in motivations toward visiting a museum: "self-development", "occasion and social interaction", "leisure and companionship", "family education", and "attractiveness or obligation", in which "self-development" (Mo1) is the strongest motive to visit a museum. Three constraints tend to hinder visiting: "poor images of the museum", "unappealing soft content", and "unattractive services and cost", in which "poor images of the museum" (Con1) is found to be a major constraint that keeps people from visiting. Six essential factors in physical environment are found to influence visitor satisfaction: "Architectural Planning", "Exhibition and Marketing", "External Environment and Accessibility", "Entrance and Ticketing", "Site Planning", and "Shop and Café".

The structural model of the study suggests that physical environment serves an axial function among motivations, constraints and satisfaction. Physical environment has a strong effect (0.51) on the satisfaction of museum visitors, and, through the mediating effect, physical environment further transfers the influences of motivations and constraints on satisfaction. Although motivations have a direct effect on satisfaction, its indirect effect $(0.21)$ is stronger than the direct one (0.16). That is to say, physical environment mediates prevailingly between motivations and satisfaction. The impact of motivations on visitor satisfaction (total 0.37 ) is much more than that of constraints $(-0.11)$. The whole model can explain $35.3 \%$ of the satisfaction of museum visitors.

In motivations, self-development (Mo1) is the strongest motive for people to visit a museum, but it does not act as the most profound factor to affect physical environment of museum. Notably, family education (Mo4) does, followed by self-development. For constraints, poor museum image (Con1), which is the strongest constraint against visiting a museum, largely influences the external environment. When combining the impacts of motivation and constraints in planning a museum, planners and managers should pay attention to providing the functions under self-development (Mo1), family education (Mo4), and contain better soft content (Con2), through which the basic demands of museum visitors can be satisfied. Leisure and companionship (Mo3) has no significant effect on the physical environment of a museum. Shop and Café (PhE6) as ancillary facilities are shown to be important to attract visitors, especially those who come for attractiveness (Mo5) and social interaction (Mo2). The study carries practical implications on museum planning or management and helps define physical environment toward achieving better visitor satisfaction.

Author Contributions: H.Z. conceived and designed the study, and wrote the paper; P.-C.C. analyzed the data and wrote the original draft; and M.-F.C. conducted the survey.

Funding: This research was funded by a grant from the Ministry of Science and Technology Taiwan with the project number: NSC100-2511-S-006-002.

Conflicts of Interest: The authors declare no conflict of interest. The funders had no role in the design of the study; in the collection, analyses, or interpretation of data; in the writing of the manuscript, and in the decision to publish the results. 


\section{Appendix A. Visitors' Questionnaire}

This survey investigates visitors' motivation, constraint, and satisfaction toward physical environment in the National Science and Technology Museum (NSTM). Please rate each of the following statement using a scale from 1 to 5 ( 1 being "strongly disagree", 5 being "strongly agree" unless otherwise noted) by placing a " $\sqrt{ }$ " in the corresponding box.

\section{A. Motivation for visit}

A1. Improve my quality of life

A2. Experience new things

A3. Pursuit of interest

A4. Engage in a worthy activity

A5. Release stress and relax

A6. For leisure

A7. Attractive architecture

A8. Improve parent-child relations

A9. Work or school requirement

A10. Learn something

A11. Enhance social relations with accompanying person(s)

A12. Special exhibition

A13. Admission discount

A14. Children's leisure and education

A15. Make new friends

A16. Just passing by and decided to come in

A17. Kill time

A18. Famous destination

A19. Participate in a social activity

A20. Participate in a parent-child activity

A21. Invitation from the museum

A22. Acquire new knowledge and information

\section{B. Constraint from visit}

B1. Have bad impression about the museum

B2. Transportation to/from museum inconvenient

B3. Poor security around the museum

B4. Unsafe environment

B5. The museum environment is unclean

B6. Insufficient leisure facilities on site

B7. The museum site has too many barriers for moving around

B8. The museum site is too hot and has no tree shade or shelter for rain

B9. Must walk for a long line to enter the museum

B10. Hard to get information on museum events

B11. Opening hours not suitable for me

B12. Admission too expensive

B13. Poor restaurant service

B14. Not enough stamina for such long visit

B15. Exhibitions difficult to understand

B16. Exhibitions unappealing

B17. Not suitable for family

B18. The museum's activities do not help me relax

B19. Does not fulfill my social need

B20. Crowded

B21. Service quality unsatisfactory 


\section{Cognition of physical environment}

C1. Scenery on the museum site (include the surroundings)

C2. Relaxing and comfortable landscape

C3. Appealing environment

C4. Convenient transportation access

C5. Abundant parking

C6. Easy to enter the museum

C7. Bicycle parking provided

C8. The museum site offers facilities for leisure and amusement

C9. Beautiful and educational planting around the museum

C10. Easy to find the entrance

C11. Spacious and comfortable entrance

C12. Simple ticket buying procedures

C13. Reasonable admission price

C14. Clear exhibition route and signage

C15. Spacious and suitable environment for the exhibitions

C16. Comfortable air-conditioning and ventilation in the exhibition space

C17. Food service offered

C18. Souvenir shop

C19. Natural and artificial light utilized to create bright exhibition space

C20. Visual display for the exhibition

C21. Ample facilities to keep the place clean (e.g., trash bins)

C22. Clear, accurate and sufficient interpretive boards

C23. Clean and hygienic overall environment

C24. Appropriate level of security

C25. Secure indoor and outdoor spaces

C26. Guided tour easy to understand

C27. Ample information provided at the service desk

C28. Personalized service for disabled persons

C29. Information about museum easy to obtain

C30. Appropriate museum opening hours

C31. Interesting and vivid exhibition format

C32. Educational exhibition content

C33. Active promotion of activities and services

C34. Adequate resting spaces along visiting route 







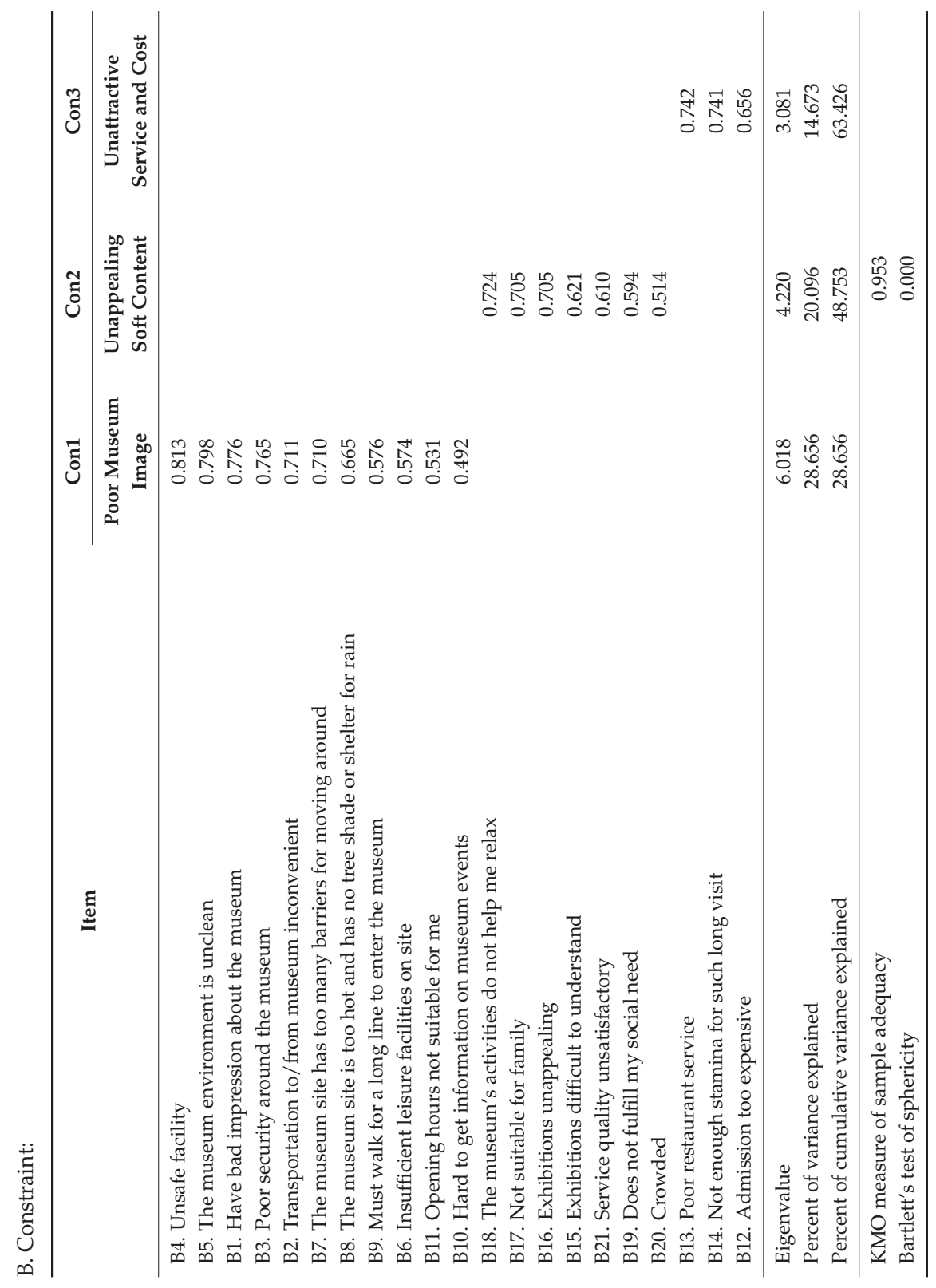




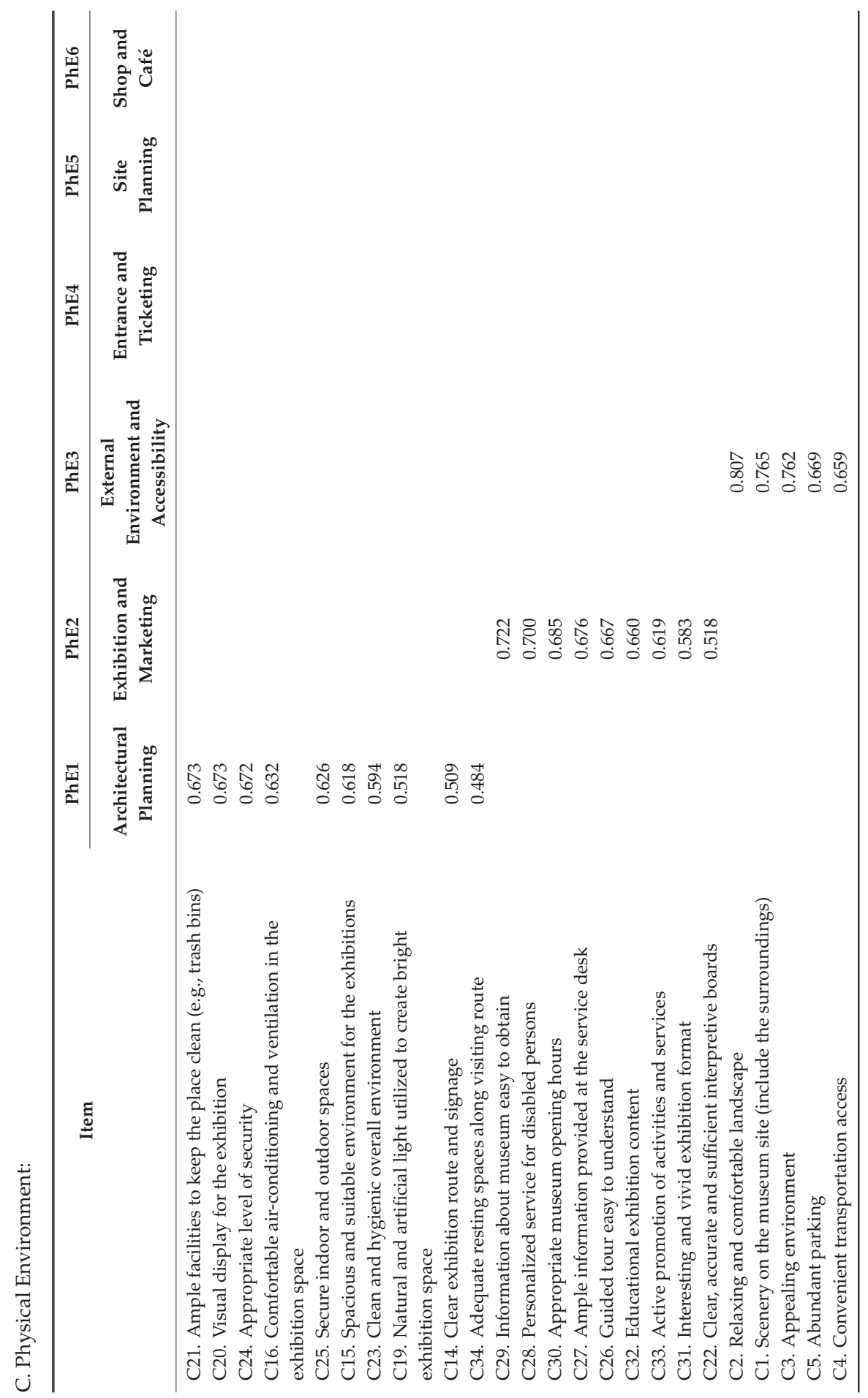


Sustainability 2018, 10, 3880

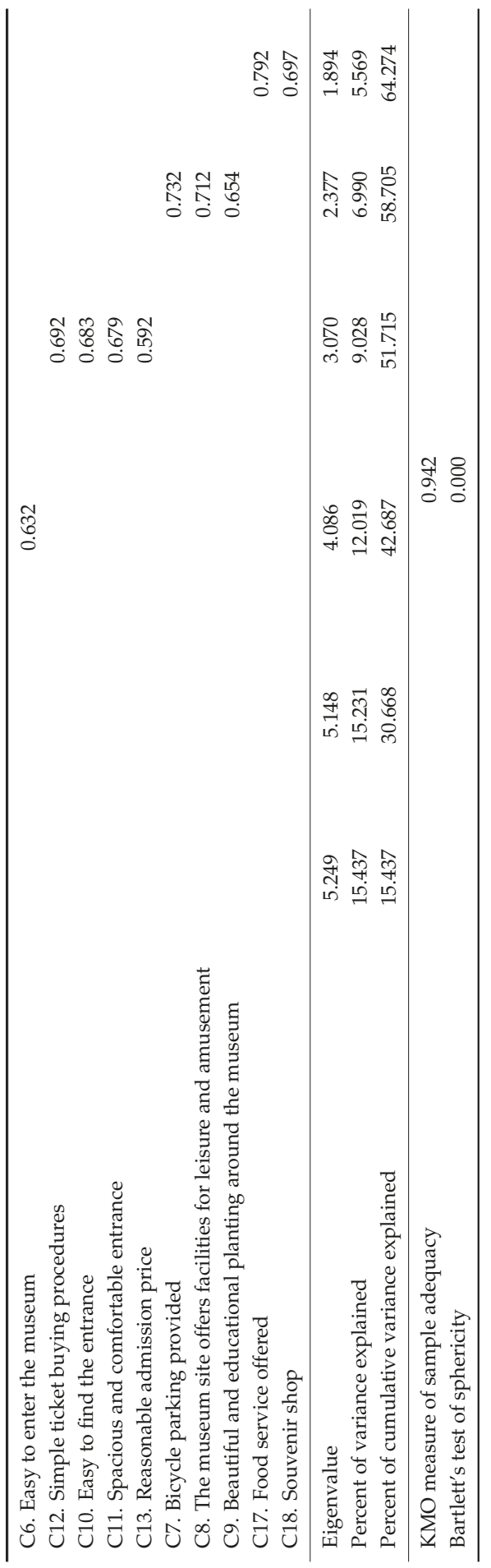




\section{References}

1. Kawashima, N. Knowing the public. A review of museum marketing literature and research1. Mus. Manag. Curatorship 1998, 17, 21-39. [CrossRef]

2. Kotler, N.; Kotler, P. Can museums be all things to all people? Missions, goals, and marketing's role. Mus. Manag. Curatorship 2000, 18, 271-287. [CrossRef]

3. McLean, F. Marketing in museums: A contextual analysis. Int. J. Mus. Manag. Curatorship 1993, 12, 11-27. [CrossRef]

4. Williams, C.; Buswell, J. Service Quality in Leisure and Tourism; CABI Pub.: Wallingford, UK, 2003.

5. Lewis, P. Museums and marketing. Museum Managagement; Routledge: London, UK, 1994; pp. 213-227.

6. Zeithaml, V.A.; Berry, L.L.; Parasuraman, A. The behavioral consequences of service quality. J. Mark. 1996, 60, 31-46. [CrossRef]

7. Qu, H.; Elsa Yee Ping, W. A service performance model of Hong Kong cruise travelers' motivation factors and satisfaction. Tour. Manag. 1999, 20, 237-244. [CrossRef]

8. Lin, Y.-N. Importance-performance analysis of the Taipei fine arts museum's services. Mus. Manag. Curatorship 2009, 24, 105-121. [CrossRef]

9. Augustyn, M.; Ho, S.K. Service quality and tourism. J. Travel Res. 1998, 37, 71-75. [CrossRef]

10. Bradford, H. A new framework for museum marketing. In Museum Management; Routledge: London, UK, 1994; pp. 41-51.

11. McLean, F. A marketing revolution in museums? J. Mark. Manag. 1995, 11, 601-616. [CrossRef]

12. Nowacki, M.M. Evaluating a museum as a tourist product using the servqual method. Mus. Manag. Curatorship 2005, 20, 235-250. [CrossRef]

13. Brida, J.G.; Meleddu, M.; Pulina, M. Understanding urban tourism attractiveness: The case of the archaeological ætzi museum in bolzano. J. Travel Res. 2012, 51, 730-741. [CrossRef]

14. Bouder-Pailler, D. A model for measuring the goals of theatre attendance. Int. J. Arts Manag. 1999, 1, 4-15.

15. Slater, A. 'Escaping to the gallery': Understanding the motivations of visitors to galleries. Int. J. Nonprofit Volunt. Sect. Mark. 2007, 12, 149-162. [CrossRef]

16. Calder, B.J.; Staw, B.M. Self-perception of intrinsic and extrinsic motivation. J. Personal. Soc. Psychol. 1975, 31, 599-605. [CrossRef]

17. Ryan, R.; Ryan, E.; Deci, E.L. Intrinsic and extrinsic motivations: Classic definitions and new directions. Contemp. Educ. Psychol. 2000, 25, 54-67. [CrossRef] [PubMed]

18. Crompton, J.L. Motivations for pleasure vacation. Ann. Tour. Res. 1979, 6, 408-424. [CrossRef]

19. Dann, G.M.S. Tourist motivation an appraisal. Ann. Tour. Res. 1981, 8, 187-219. [CrossRef]

20. Uysal, M.; Jurowski, C. Testing the push and pull factors. Ann. Tour. Res. 1994, 21, 844-846. [CrossRef]

21. Yoon, Y.; Uysal, M. An examination of the effects of motivation and satisfaction on destination loyalty: A structural model. Tour. Manag. 2005, 26, 45-56. [CrossRef]

22. Brida, J.G.; Disegna, M.; Scuderi, R. Visitors of two types of museums: A segmentation study. Expert Syst. Appl. 2013, 40, 2224-2232. [CrossRef]

23. Jansen-Verbeke, M.; Van Rekom, J. Scanning museum visitors: Urban tourism marketing. Ann. Tour. Res. 1996, 23, 364-375. [CrossRef]

24. Sheng, C.-W.; Chen, M.-C. A study of experience expectations of museum visitors. Tour. Manag. 2012, 33, 53-60. [CrossRef]

25. Thyne, M. The importance of values research for nonprofit organisations: The motivation-based values of museum visitors. Int. J. Nonprofit Volunt. Sect. Mark. 2001, 6, 116-130. [CrossRef]

26. Falk, J. Museum audiences: A visitor-centered perspective. Soc. Leis. 2016, 39, 357-370. [CrossRef]

27. Powell, R.; Kokkranikal, J. Motivations and experiences of museum visitors: The case of the imperial war museum, United Kingdom. In Cultural Tourism in a Digital Era; Springer: New York, NY, USA, 2015; pp. $169-181$.

28. Žabkar, V.; Brenčič, M.M.; Dmitrović, T. Modelling perceived quality, visitor satisfaction and behavioural intentions at the destination level. Tour. Manag. 2010, 31, 537-546. [CrossRef]

29. Falk, J.H.; Dierking, L.D. The Museum Experience; Whalesback Books: Washington, DC, USA, 1992.

30. Falk, J.H.; Dierking, L.D. Learning from Museums: Visitor Experiences and the Making of Meaning; Altamira Press: Walnut Creek, CA, USA, 2000. 
31. Graburn, N.H. Tourism: The Sacred Journey; Hosts and Guests: The Anthropology of Tourism; University of Pennsylvania Press: Philadelphia, PA, USA, 1977; pp. 21-36.

32. Prentice, R.; Davies, A.; Beeho, A. Seeking generic motivations for visiting and not visiting museums and like cultural attractions. Mus. Manag. Curatorship 1997, 16, 45-70. [CrossRef]

33. Iso Ahola, S.E. Toward a social psychological theory of tourism motivation: A rejoinder. Ann. Tour. Res. 1982, 9, 256-262. [CrossRef]

34. Crawford, D.W. Reconceptualizing barriers to family leisure. Leis. Sci. 1987, 9, 119-127. [CrossRef]

35. Crawford, D.W.; Jackson, E.L.; Godbey, G. A hierarchical model of leisure constraints. Leis. Sci. 1991, 13, 309-320. [CrossRef]

36. Hultsman, W.Z. The influence of others as barrier to recreation participation among early adolescents. J. Leis. Res. 1993, 25, 150-164. [CrossRef]

37. Jackson, E.L.; Crawford, D.W.; Godbey, G. Negotiation of leisure constraints. Leis. Sci. 1993, 15, 1-11. [CrossRef]

38. Shaw, S.M. Gender, leisure, and constraint: Towards a framework for the analysis of women's leisure. J. Leis. Res. 1994, 26, 8-22. [CrossRef]

39. Witt, P.A. The relationships between barriers to leisure enjoyment and family stages. Leis. Sci. 1981, 4, $29-49$. [CrossRef]

40. Chick, G.; Hsu, Y.-C.; Yeh, C.-K.; Hsieh, C.-M. Leisure constraints, leisure satisfaction, life satisfaction, and self-rated health in six cities in taiwan. Leis. Sci. 2015, 37, 232-251. [CrossRef]

41. Nuijten, M.; De Rooij, P.; Snoeckx, L. How do leisure constraints influence the revisit intentions of music festival visitors? Tour. Cult. Commun. 2016, 16, 123-135. [CrossRef]

42. Li, J.; Smith, A.E. Block layout for attraction-based enterprises. Eur. J. Oper. Res. 2018, 266, 1100-1112. [CrossRef]

43. Casper, J.M.; Bocarro, J.N.; Kanters, M.A.; Floyd, M.F. Measurement properties of constraints to sport participation: A psychometric examination with adolescents. Leis. Sci. 2011, 33, 127-146. [CrossRef]

44. Hubbard, J.; Mannell, R.C. Testing competing models of the leisure constraint negotiation process in a corporate employee recreation setting. Leis. Sci. 2001, 23, 145-163. [CrossRef]

45. McQuarrie, F.; Jackson, E.L. Connections between negotiation of leisure constraints and serious leisure: An exploratory study of adult amateur ice skaters. Soc. Leis. 1996, 19, 459-483. [CrossRef]

46. White, D.D. A structural model of leisure constraints negotiation in outdoor recreation. Leis. Sci. 2008, 30, 342-359. [CrossRef]

47. Chung, J.Y.; Baik, H.-J.; Lee, C.-K. The role of perceived behavioural control in the constraint-negotiation process: The case of solo travel. Leis. Stud. 2017, 36, 481-492. [CrossRef]

48. Kennelly, M.; Moyle, B.; Lamont, M. Constraint negotiation in serious leisure: A study of amateur triathletes. J. Leis. Res. 2013, 45, 466-484. [CrossRef]

49. Hung, K.; Petrick, J.F. Testing the effects of congruity, travel constraints, and self-efficacy on travel intentions: An alternative decision-making model. Tour. Manag. 2012, 33, 855-867. [CrossRef]

50. Tan, W.K.; Yeh, Y.D.; Chen, S.H. The role of social interaction element on intention to play mmorpg in the future: From the perspective of leisure constraint negotiation process. Games Cult. 2017, 12, 28-55. [CrossRef]

51. Parasuraman, A.; Zeithaml, V.A.; Berry, L.L. A conceptual model of service quality and its implications for future research. J. Mark. 1985, 49, 41-50. [CrossRef]

52. Parasuraman, A.; Zeithaml, V.; Berry, L. Servqual: A multiple-item scale for measuring consumer perceptions of service quality. J. Retail. 1988, 64, 12-40.

53. Babakus, E.; Boller, G.W. An empirical assessment of the servqual scale. J. Bus. Res. 1992, 24, $253-268$. [CrossRef]

54. Bolton, R.N.; Drew, J.H. A multistage model of customers' assessments of service quality and value. J. Consum. Res. 1991, 17, 375-384. [CrossRef]

55. Brady, M.K.; Cronin, J.J.; Brand, R.R. Performance-only measurement of service quality: A replication and extension. J. Bus. Res. 2002, 55, 17-31. [CrossRef]

56. Carman, J.M. Consumer perceptions of service quality: An assessment of the servqual dimensions. J. Retail. 1990, 66, 33-55.

57. Schneider, B.; White, S.S. Service Quality: Research Perspectives; SAGE Publications: Thousand Oaks, CA, USA, 2004 
58. Chon, K.S. Understanding recreational traveler's motivation, attitude and satisfaction. Tour. Rev. 1989, 44, 3-7. [CrossRef]

59. Gnoth, J. Tourism motivation and expectation formation. Ann. Tour. Res. 1997, 24, 283-304. [CrossRef]

60. Caruana, A.; Money, H.M.; Berthon, P.R. Service quality and satisfaction-The moderating role of value. Eur. J. Mark. 2000, 34, 1338-1353. [CrossRef]

61. Sweeney, J.C.; Soutar, G.N.; Johnson, W.L. Retail service quality and perceived value: A comparison of two models. J. Retail. Consum. Serv. 1997, 4, 39-48. [CrossRef]

62. Zeithaml, V.A. Consumer perceptions of price, quality, and value: A means-end model and synthesis of evidence. J. Mark. 1988, 52, 2-22. [CrossRef]

63. Andreassen, T.W.; Lindestad, B. Customer loyalty and complex services: The impact of corporate image on quality, customer satisfaction and loyalty for customers with varying degrees of service expertise. Int. J. Serv. Ind. Manag. 1998, 9, 7-23. [CrossRef]

64. Baker, D.A.; Crompton, J.L. Quality, satisfaction and behavioral intentions. Ann. Tour. Res. 2000, 27, 785-804. [CrossRef]

65. Bitner, M.J.; Hubbert, A.R. Encounter satisfaction versus overall satisfaction versus quality. Serv. Qual. New Dir. Theory Pract. 1994, 34, 72-94.

66. Spreng, R.A.; Mackoy, R.D. An empirical examination of a model of perceived service quality and satisfaction. J. Retail. 1996, 72, 201-214. [CrossRef]

67. Taylor, S.A.; Baker, T.L. An assessment of the relationship between service quality and customer satisfaction in the formation of consumers' purchase intentions. J. Retail. 1994, 70, 163-178. [CrossRef]

68. Bitner, M.J. Evaluating service encounters: The effects of physical surroundings and employee responses. J. Mark. 1990, 54, 69-82. [CrossRef]

69. Anderson, E.W.; Fornell, C.; Lehmann, D.R. Customer satisfaction, market share, and profitability: Findings from sweden. J. Mark. 1994, 58, 53-66. [CrossRef]

70. Churchill, G.A., Jr.; Surprenant, C. An investigation into the determinants of customer satisfaction. J. Mark. Res. 1982, 19, 491-504. [CrossRef]

71. Zeithaml, V.A.; Parasuraman, A.; Malhotra, A. Service quality delivery through web sites: A critical review of extant knowledge. J. Acad. Mark. Sci. 2002, 30, 362-375. [CrossRef]

72. Grönroos, C. A service quality model and its marketing implications. Eur. J. Mark. 1984, 18, 36-44. [CrossRef]

73. Lee, H.; Lee, Y.F.; Yoo, D. The determinants of perceived service quality and its relationship with satisfaction. J. Serv. Mark. 2000, 14, 217-231. [CrossRef]

74. Swan, J.E.; Combs, L.J. Product performance and consumer satisfaction: A new concept. J. Mark. 1976, 40, 25-33. [CrossRef]

75. Cole, S.T. Examining the mediating role of festival visitors' satisfaction in the relationship between service quality and behavioral intentions. J. Vacat. Mark. 2006, 12, 160-173. [CrossRef]

76. Crompton, J.L.; Love, L.L. The predictive validity of alternative approaches to evaluating quality of a festival. J. Travel Res. 1995, 34, 11-24. [CrossRef]

77. Mok, C.; Sparks, B.; Kadampully, J. Service Quality Management in Hospitality, Tourism, and Leisure; Routledge: Abingdon-on-Thames, UK, 2013.

78. Cardozo, R.N. An experimental study of customer effort, expectation, and satisfaction. J. Mark. Res. 1965, 2, 244-249. [CrossRef]

79. Engel, J.F.; Blackwell, R.D.; Miniard, P.W. Consumer Behavior, 8th ed.; The Dryden Press: New York, NY, USA, 1995.

80. Howard, J.A.; Sheth, J.N. The Theory of Buyer Behavior; Wiley: Hoboken, NJ, USA, 1969.

81. Kotler, P. Marketing Management, 11st ed.; Prentice Hall: Upper Saddle River, NJ, USA, 2003.

82. Oliver Richard, L. Satisfaction: A Behavioral Perspective on the Consumer; Irwin-McGraw-Hill: New York, NY, USA, 1997.

83. Spreng, R.A.; MacKenzie, S.B.; Olshavsky, R.W. A reexamination of the determinants of consumer satisfaction. J. Mark. 1996, 60, 15-32. [CrossRef]

84. Fisk, R.P. Disconfirmation of equity expectations: Effects on consumer satisfaction with services. Adv. Consum. Res. 1985, 12, 340.

85. Cadotte, E.R.; Woodruff, R.B.; Jenkins, R.L. Expectations and norms in models of consumer satisfaction. J. Mark. Res. 1987, 24, 305-314. [CrossRef] 
86. Tse, D.K.; Wilton, P.C. Models of consumer satisfaction formation: An extensive. J. Mark. Res. 1988, 25, 204-212. [CrossRef]

87. Oliver, R.L. Cognitive, affective, and attribute bases of the satisfaction response. J. Consum. Res. 1993, 20, 418-430. [CrossRef]

88. Mannell, R.C.; Iso-Ahola, S.E. Psychological nature of leisure and tourism experience. Ann. Tour. Res. 1987, 14, 314-331. [CrossRef]

89. Dunn Ross, E.L.; Iso-Ahoa, S.E. Sightseeing tourists' motivation and satisfaction. Ann. Tour. Res. 1991, 18, 226-237. [CrossRef]

90. Noe, F.P.; Uysal, M. Evaluation of outdoor recreational settings. J. Retail. Consum. Serv. 1997, 4, $223-230$. [CrossRef]

91. Tian, S.; Tian, J.L.; Witt, P.A. Integrating constraints and benefits to identify responsive target markets for museum attractions. J. Travel Res. 1996, 35, 34-45. [CrossRef]

92. Cronin, J.J., Jr.; Brady, M.K.; Hult, G.T.M. Assessing the effects of quality, value, and customer satisfaction on consumer behavioral intentions in service environments. J. Retail. 2000, 76, 193-218. [CrossRef]

93. Hunt, S.D.; Sparkman, R.D., Jr.; Wilcox, J.B. The pretest in survey research: Issues and preliminary findings. J. Mark. Res. 1982, 19, 269-273. [CrossRef]

94. Falk, J.H. The effect of visitors' agendas on museum learning. Curator 1998, 41, 107-120. [CrossRef]

95. Hair, J.F. Multivariate Data Analysis: A Global Perspective; Pearson Education: London, UK, 2010.

96. Backman, S.J. An investigation of the relationship between activity loyalty and perceived constraints. J. Leis. Res. 1991, 23, 332-344. [CrossRef]

97. Jackson, E.L. Leisure constraints: A survey of past research. Leis. Sci. 1988, 10, 203-215. [CrossRef]

98. Williams, D.R.; Schreyer, R.; Knopf, R.C. The effect of the experience use history on the multidimensional structure of motivations to participate in leisure activities. J. Leis. Res. 1990, 22, 36-54. [CrossRef]

99. Arbuckle, J.L. Amos 7.0 User's Guide; AMOS Development Corporation: Chicago, IL, USA, 2006.

100. Anderson, J.C.; Gerbing, D.W. Structural equation modeling in practice: A review and recommended two-step approach. Psychol. Bull. 1988, 103, 411-423. [CrossRef]

101. Hood, M.G. Staying away: Why people choose not to visit museums. Mus. News 1983, 61, 50-57.

102. Dickenson, V. The economics of museum admission charges. In Museum Management; Routledge: Abingdon-on-Thames, UK, 2005; pp. 116-125.

103. Bettman, J.R. Perceived price and product perceptual variables. J. Mark. Res. 1973, 10, 100-102. [CrossRef]

104. Voss, G.B.; Parasuraman, A.; Grewal, D. The roles of price, performance, and expectations in determining satisfaction in service exchanges. J. Mark. 1998, 62, 46-61. [CrossRef]

105. Fornell, C.; Larcker, D.F. Structural equation models with unobservable variables and measurement error: Algebra and statistics. J. Mark. Res. 1981, 18, 382-388. [CrossRef]

106. Bagozzi, R.P.; Yi, Y. On the evaluation of structural equation models. J. Acad. Mark. Sci. 1988, 16, 74-94. [CrossRef]

107. Lance, C.E.; Butts, M.M.; Michels, L.C. The sources of four commonly reported cutoff criteria: What did they really say? Organ. Res. Methods 2006, 9, 202-220. [CrossRef]

108. Nunnally, J.C. Psychometric Theory; McGraw-Hill: New York, NY, USA, 1978.

109. Carmines, E.G.; McIver, J.P. Analyzing models with unobserved variables: Analysis of covariance structures. Soc. Meas. Curr. Issues 1981, 80, 65-115.

110. Hair, J.F.; Black, W.C.; Babin, B.J.; Anderson, R.E.; Tatham, R.L. Multivariate Data Analysis; Pearson Prentice Hall: Upper Saddle River, NJ, USA, 2006; Volume 6.

111. Cronin, J.J.; Taylor, S.A. Measuring service quality: A reexamination and extension. J. Mark. 1992, 56, 55-68. [CrossRef]

112. Tian-Cole, S.; Crompton, J.L.; Willson, V.L. An empirical investigation of the relationships between service quality, satisfaction and behavioral intentions among visitors to a wildlife refuge. J. Leis. Res. 2002, 34, 1-24. [CrossRef]

(c) 2018 by the authors. Licensee MDPI, Basel, Switzerland. This article is an open access article distributed under the terms and conditions of the Creative Commons Attribution (CC BY) license (http:/ / creativecommons.org/licenses/by/4.0/). 
Article

\title{
Evaluation of All-for-One Tourism in Mountain Areas Using Multi-Source Data
}

\author{
Hou Jiang ${ }^{1,2}$, Yaping Yang ${ }^{1,3, *}$ and Yongqing Bai ${ }^{1,2}$ \\ 1 State Key Laboratory of Resources and Environmental Information System, Institute of Geographic Sciences \\ and Natural Resources Research, Chinese Academy of Sciences, Beijing 100101, China; \\ jiangh.18b@igsnrr.ac.cn (H.J.); baiyq@lreis.ac.cn (Y.B.) \\ 2 College of Resources and Environment, University of Chinese Academy of Sciences, Beijing 100049, China \\ 3 Jiangsu Center for Collaborative Innovation in Geographical Information Resource Development and \\ Application, Nanjing 210023, China \\ * Correspondence: yangyp@igsnrr.ac.cn; Tel.: +86-10-6488-9045
}

Received: 25 October 2018; Accepted: 4 November 2018; Published: 6 November 2018

\begin{abstract}
All-for-one tourism is a new viewpoint of tourism development involving overall planning and cooperative mechanisms. Over the past few years, the researchers have put forward many conceptual models to guide the top-level design and specific practice of all-for-one tourism. However, these studies mainly focus on social, economic and cultural effect in mature tourism areas, lacking comprehensive analysis from geographical perspective and neglecting the underdeveloped regions. In this paper, we attempt to apply geographic information system technology to tourism evaluation, exploring the approach of all-for-one tourism development in mountain regions. Zunyi city is selected as the research region and evaluated on the abundance, quality and spatial pattern of tourism resources, climate comfort, natural disaster possibility, and convenience of infrastructure or social service. Multi-source datasets collected from websites, reanalysis data, remote sensing products and observation stations are used. Based on data analysis, some recommendations including enriching cultural tourism products through cultural creativity, ensuring regional coordinated development through spatial optimization, respecting the spatiotemporal characteristics of climate and the laws of nature, and strengthening construction of infrastructure, are discussed to promote the healthy development of all-for-one tourism.
\end{abstract}

Keywords: all-for-one tourism; spatial analysis; tourism evaluation; mountain areas

\section{Introduction}

Tourism, an international industry and the biggest provider of jobs, plays a vital role in promoting national or regional economic growth [1]. Since the period of reform and opening up, the tourism industry has been flourishing in China, and large numbers of attractions, scenic spots, restaurants and hotels have been developed for international or domestic tourists. According to the statistics provided by Ministry of Culture and Tourism of the People's Republic of China, the annual comprehensive contribution of the national tourism industry is about 9.13 trillion yuan, contributing to $11.04 \%$ of the total GDP, and tourism provides employment opportunities for 108.15 million people directly or indirectly, accounting for $10.28 \%$ of the total employment-population in 2017. However, the traditional scenic spot tourism has sunk into difficulty in driving the development of the regional economy over the past decades [2,3]. Thus, all-for-one tourism is put forward to adapt to the trend of new changes and promote the transformation and upgrading of tourism [4,5]. It is a new tourism mode aiming at developing a project in partnership with all stakeholders and involving in overall planning and cooperative development of all industries [6-12]. In recent years, all-for-one tourism has attracted the attention of governments, enterprises and social problem researchers, as it is regarded as an effective 
and reliable approach to achieve rural revitalization and promote the coordinated and sustainable development of urban and rural areas [6].

Recently, various conceptual models have been presented to explain the connotation of all-for-one tourism. Li et al. [7] summed up all-for-one tourism as "four new ideas" (resources, products, industries and markets) and "eight constructive aspects" (all tourism elements, all professions, all processes, all levels, the entire space and time, the whole society, all participant departments and all latent tourists). They argued that all-for-one tourism should aim at providing tourists with sufficient product experiences by integrating various industries, cooperating different departments, uniting all participants in the region, and taking full use of tourism destinations. $\mathrm{Li}$ [8] pointed out that all-for-one tourism is a new regional coordinated development mode, where tourism is the dominant industry and promotes the development of the economy and society in the chosen region. The ultimate goal of all-for-one tourism is to achieve the scientific and reasonable integration of resources, industries and developments, as well as social co-construction and sharing through optimizing and upgrading the complex systematic structure within a specific region. Zhang et al. [9] emphasized the domain perspective of all-for-one tourism, including temporal-spatial domain, industry domain, element domain and management domain. Feng [5] unscrambled the necessity of all-for-one tourism development from the five characteristics of tourist destination summarized by Cooper et al. [10], and proposed to grasp development law, strengthen the problem-oriented principle and consider comprehensive impacts in the process of promoting transformation from scenic spots to all-for-one tourism. Wang [11] holds the view that all-for-one tourism is used to promote the innovation of ideas on tourism development and to push forward the reform of the administrative system of tourism in China. It advocates the idea of the sharing economy, developing a project in partnership with all stakeholders and protecting the freedom of individual participation in social life. These studies explored the connotation and development routes of all-for-one tourism, and describe the top-level design and developing blueprint of all-for-one tourism either in large natural regions or in small towns. However, these studies mainly focus on social, economic and cultural effects in mature tourism areas, while comprehensive evaluations from a geographic perspective are scarce.

For a long time, most attention has been paid to scenic spot tourism in the tourism community. For example, Potschin [12] analyzed how the quality of site-level environmental assessment could be improved by using the concept of natural capital. Yi and $\mathrm{Hu}$ [13] analyzed the relationship between tourist attractions and all-for-one tourism and put forward four development strategies of tourist attractions under the background of all-for-one tourism. Zhang [14] analyzed the internal factors affecting the development of the tourist attractions through a strengths weaknesses opportunities and threats (SWOT) analysis, qualitative analysis and quantitative analysis on China's tourism resources. Their research datasets are from in-situ survey, site observation and field sampling, usually lacking objectivity, comprehensiveness or temporal-spatial continuity, thus it is difficult to meet the demand of overall planning and decision-making for all-for-one tourism. With the arrival of the era of big data, tourism research has brought forth amazing improvements. Zhu et al. [15] established a tourism resources attraction evaluation system using collected relevant information from the internet and analyzed the spatial pattern of tourism resources' attraction in Beijing. Yang et al. [16] advocated that the large scale of big data could finely make up for the limitation of sample size issues faced by survey data users, providing a new way to understand tourist behavior. Similarly, Li et al. [17] argued that big data analytics could provide sufficient data without sampling bias, helping both academia and industries to better understand tourist behavior. Xiang et al. [18] claimed that big data analytics could develop new knowledge to reshape the understanding of hospitality industry and to support the corresponding decision-making. In all, big data allows a better understanding of tourism demand, tourist behavior, tourist satisfaction and other tourism issues.

In this paper a mountain tourism city, Zunyi, is chosen as the research region for a case study aiming to evaluate the suitability and explore the approach for all-for-one tourism development in mountain areas from a geographic perspective. The temporal-spatial analyses are based on multi-source datasets 
collected from websites, reanalysis data, remote sensing products and observation stations. Many specific factors related to development of tourism industry are taken into consideration in the process of temporal-spatial analysis, including abundance, quality and spatial distribution of tourism resource, local topography, temperature, precipitation, relative humidity, surface wind speed, sunshine hour per day, land cover types, traffic facilities, hotels etc. On the basis of data analysis, some recommendations are proposed for development of all-for-one tourism, such as improving cultural tourism products through cultural creativity, ensuring regional coordinated development through spatial optimization, respecting the spatiotemporal characteristics of climate and the laws of nature, and strengthening the construction of infrastructure.

\section{Data and Methods}

\subsection{Research Region}

Zunyi City covers an area of 30.7 thousand $\mathrm{km}^{2}$, locating in the northeast of Guizhou province, China (Figure 1). It possess abundant natural tourism resources, such as Chinese Jurassic Park, Liyuan Grassland Tourism Resort, Shuanghe Karst Cave National Geological Park, etc. At the same time, Zunyi is the national historical and cultural city in China, with world cultural heritage Hailongtun, world natural heritage Chishui Danxia. In addition, the subtropical monsoon climate is suitable for outdoor mountain tourism. It is cool and humid all year round, with abundant rainfall and sunshine, and there is no severe cold in winter and intense heat in summer $[19,20]$. In addition, Zunyi is a sacred place for red tourism in China [21], known as "the turning city, the capital of conference". In 1935, the Communist Party of China held the famous Zunyi Conference, which became a turning point of the party's life and death. In 2016, Zunyi was regarded as the national demonstration area of mountain all-for-one tourism by the Ministry of Culture and Tourism of the People's Republic of China. Therefore, Zunyi is selected as the research area to explore the approach to developing all-for-one tourism in mountain areas from the geographical aspects in this paper.
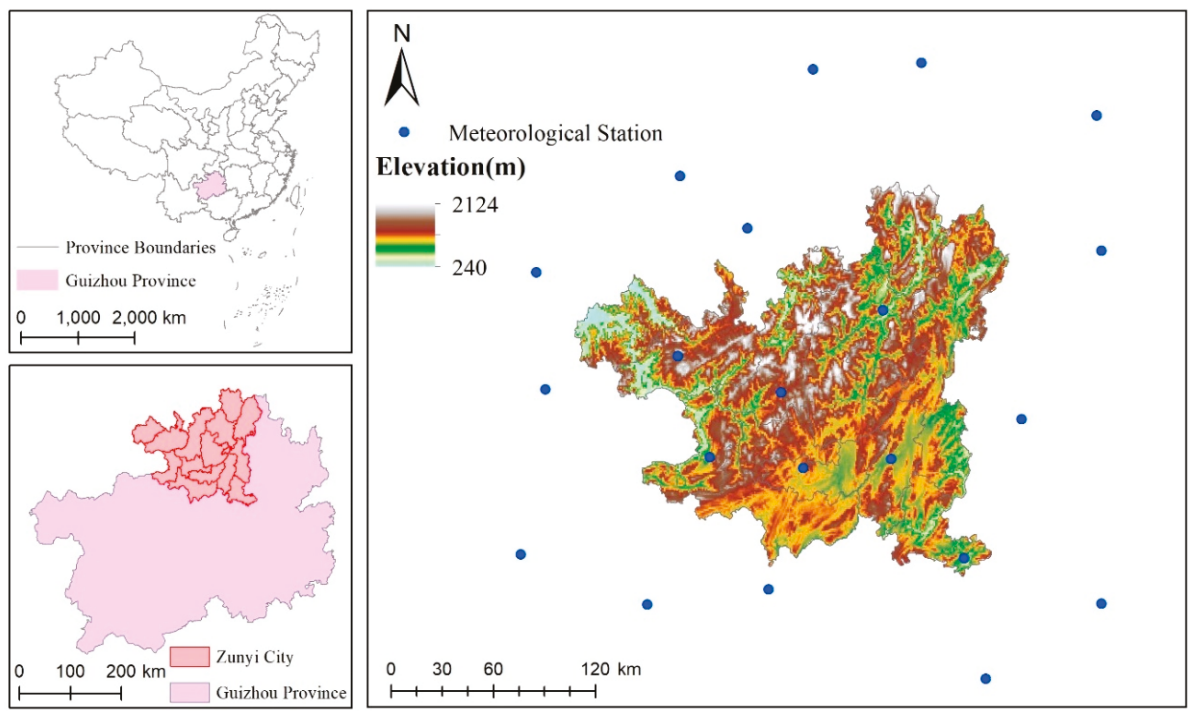

Figure 1. Location and DEM of Zunyi City. The meteorological stations are used for downscaling other raster datasets described in Section 2.3. 


\subsection{Basic Data}

From a collection of relevant literature, discussions with experts, professional research reports and on-site surveys, we organized the overall architecture for evaluation of all-for-one tourism as shown in Figure 2. Three main aspects are taken into consideration, i.e., tourism resources, natural conditions and social service. Specifically, we attempt to estimate the abundance, quality and spatial characteristics of tourism resources. Climate comfort reflects a tourist's feelings under different meteorological conditions and is of great importance to the tourism industry, especially vacation tours [22]. It is influenced by many factors, such as air temperature, relative humidity, surface wind speed, and solar radiation etc., and there exists complex relationships among different factors. Thus, thermal environment model and cold environment model are used for comprehensive evaluation of natural conditions in the following sections. Meanwhile, natural disaster risk is another important factor and it might relate to altitude, slope, precipitation, surface vegetation, etc. Similarly, various elements are involved in social service, such as transportation, accommodation, delicacies, medical treatment, communication, customs etc. To conduct the temporal-spatial continuous evaluation, multi-source datasets are utilized. The specific datasets are listed as follows:

- Digital Elevation Model (DEM). DEM data used in this study is SRTM data (Shuttle Radar Topography Mission, NASA-NGA, USA). SRTM successfully generates the most complete high-resolution digital topographic database of the Earth, covering over $80 \%$ of the Earth's land surface between $60^{\circ}$ north and $56^{\circ}$ south latitude with data points posted every 1 arc-second (approximately $30 \mathrm{~m}$ ). The elevation models are arranged into tiles, each covering one degree of latitude and one degree of longitude. The raw data can be obtained from the website: http:/ / srtm.csi.cgiar.org/SELECTION/inputCoord.asp. Figure 1 shows the elevation of Zunyi, which ranges from 240 to $2124 \mathrm{~m}$.

- NCEP/NCAR Global Reanalysis Products. It is a continually updated globally gridded data set that represents the state of the Earth's atmosphere, incorporating observations and numerical weather prediction (NWP) model output from 1948 to present. It is a joint product from the National Centers for Environmental Prediction (NCEP) and the National Center for Atmospheric Research (NCAR). Its monthly mean datasets are used in our study, including monthly mean air temperature, monthly mean of relative humidity and monthly surface wind speed. Their spatial resolution is about $2.5^{\circ}$. The data can be obtained at: ftp://ftp.cdc.noaa.gov/pub/Datasets/ncep. reanalysis.derived/surface/.

- Geospatial Data Cloud. It provides MODIS synthetic products in China. The datasets used in this paper includes China $1 \mathrm{KM}$ land surface temperature (LST) monthly synthetic products (MODLT1M) and China $500 \mathrm{M}$ normalized difference vegetation index (NDVI) monthly synthetic products (MODND1M). MODLT1M is the monthly average value of MODLT1T daily products while MODND1M is the maximum value of MODND1D daily products within a month. The data set is provided by International Scientific \& Technical Data Mirror Site, Computer Network Information Center, Chinese Academy of Sciences. Registered users can freely obtain data from the website: http://www.gscloud.cn.

- $\quad$ SPOT-NDVI Data. The SPOT VGT-S NDVI data at $1 \mathrm{~km}$ spatial resolution can be obtained from http:/ / www.spot-vegetation.com/. The VGT-S NDVI product is the synthesized NDVI for a 10-day period. The 10-day periods were defined as the 1st to 10th, the 11th to the 20th and the 21st to the end of each month. Thus, there are three NDVI images for each month. The monthly composite DNVI images were derived from corresponding three 10-day NDVI products through calculating their maximum value. The VGT-S product has been pre-processed for geometric, radiometric and atmospheric corrections. Therefore, no further pre-processing of the SPOT VGT-S product is needed for practical application.

- $\quad$ TRMM 3B43 Data. The Tropical Rainfall Measuring Mission (TRMM) was launched in November 1997 as a joint project by NASA and the Japanese Space Agency (JAXA). The mission uses five 
instruments: Precipitation Radar (PR), TRMM Microwave Imager (TMI), Visible Infrared Scanner (VIRS), Clouds \& Earths Radiant Energy System (CERES) and Lightning Imaging Sensor (LSI). The TRMM Multi-satellite Precipitation Analysis (TMPA) was designed to combine all available precipitation datasets from different satellite sensors and monthly surface rain gauge data to provide estimation of precipitation at spatial resolution of $0.25^{\circ}$. One of TMPA products is the TRMM 3B43 monthly data, covering $50^{\circ} \mathrm{N}$ to $50^{\circ} \mathrm{S}$ for $1998-$ present. The latest Version 7 was available to public in May 2012 and can be obtained freely from http:/ / mirador.gsfc.nasa.gov.

- In-situ Ground Meteorological Data. US National Climate Data Center is the world's largest provider of meteorological and climatic data. Its land-based observations are collected from instruments sited at locations on every continent. They include temperature, dew point, relative humidity, precipitation, wind speed and direction, visibility, atmospheric pressure, and types of weather occurrences. Data on sub-hourly, hourly, daily, monthly, annual, and multiyear timescales are available. All used stations are displayed in Figure 1. The related datasets are free on website: ftp:/ / ftp.ncdc.noaa.gov/pub/data/gsod.

- POI Data. A point of interest (POI) is a specific location that someone may find useful or interesting. In this study, related POIs include unitary tourism resource points, traffic facilities, hotels or homestays, hospitals or casualty stations, restaurants or farmsteads. These POIs are very important for assessment of tourism resources and social service, and for understanding tourist behavior and satisfaction. Many map service companies, such as Google (https:/ cloud.google. com/maps-platform/), Baidu (http://lbsyun.baidu.com/), Amap (https:/ /lbs.amap.com/) etc., support location-based services, and POIs can be obtained from their map open platforms through keyword retrieval.

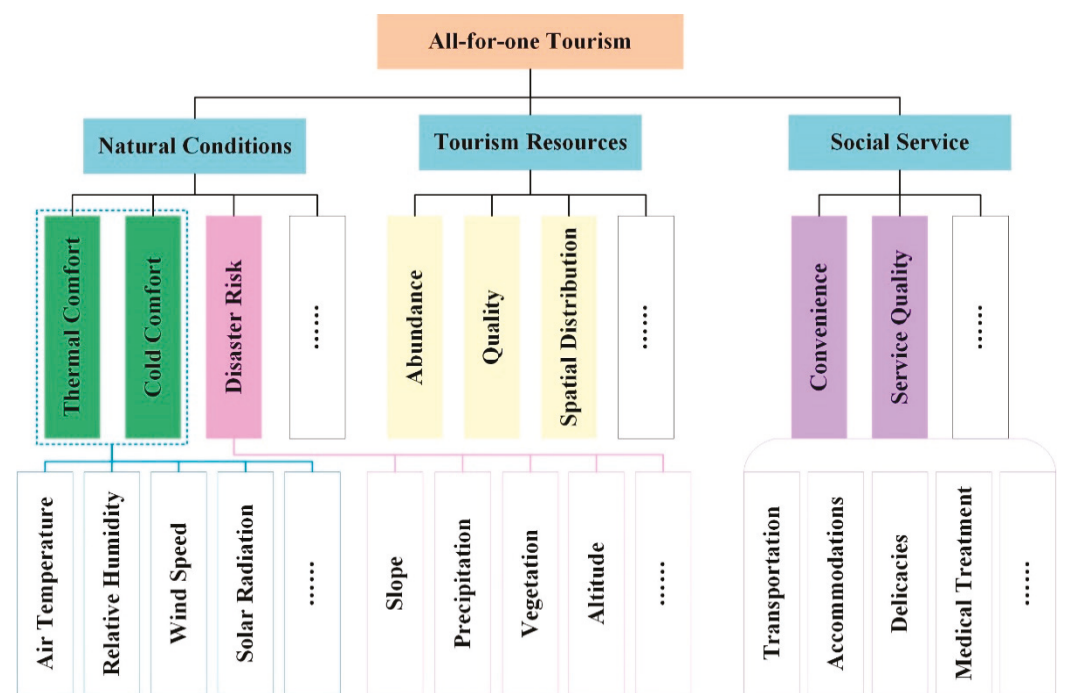

Figure 2. The overall architecture for assessment of all-for-one tourism development.

\subsection{Downscaling Method}

Over the past decades, development of satellite sensors has resulted in multiple sources of meteorological datasets, such as precipitation [23,24], land surface temperature [25,26], relative humidity $[27,28]$ etc., that provide more reliable estimations over un-gauged areas compared with other interpolation methods. However, their spatial resolutions (i.e., $0.25-0.5^{\circ}$ ) are still too coarse for hydrological simulation and environmental modeling when applied to local basins and regions. Great 
efforts have been made to advance the spatial downscaling algorithms of satellite-based meteorological datasets. For example, Immerzeel et al. [29] proposed an algorithm for downscaling TRMM-based annual precipitation datasets from $0.25^{\circ}$ to $1 \mathrm{~km}$ by using the exponential function between the precipitation and NDVI. Jing et al. [30] implemented random forests (RF) and support vector machine (SVM) separately to downscale the yearly TRMM 3B43 V7 precipitation data from $25 \mathrm{~km}$ to $1 \mathrm{~km}$ over the Tibetan Plateau area based on precipitation-land surface characteristics.

In our study, the method in Immerzeel et al. [29] is used to downscale TRMM 3B43 data from $0.25^{\circ}$ to $1 \mathrm{~km}$, and the result is taken as inputs of the SVM-based method [30] to downscale monthly mean air temperature (AT), monthly mean of relative humidity (RH) and monthly surface wind speed (SWS) of NCEP/NCAR Global Reanalysis Products. Downscaled data will be further used for evaluation of natural conditions. DEM and NDVI are used as variables for air temperature downscaling. DEM, NDVI, land surface temperature and average precipitation are considered as independent variables for relative humidity and wind speed. Before downscaling, an additional process [31,32] is introduced to correct residuals of original reanalysis products using in-situ ground meteorological data. The used meteorological stations are shown in Figure 1. Figure 3 illustrates the flowchart for downscaling NCEP/NCAR products. More details are described in references [30-32].

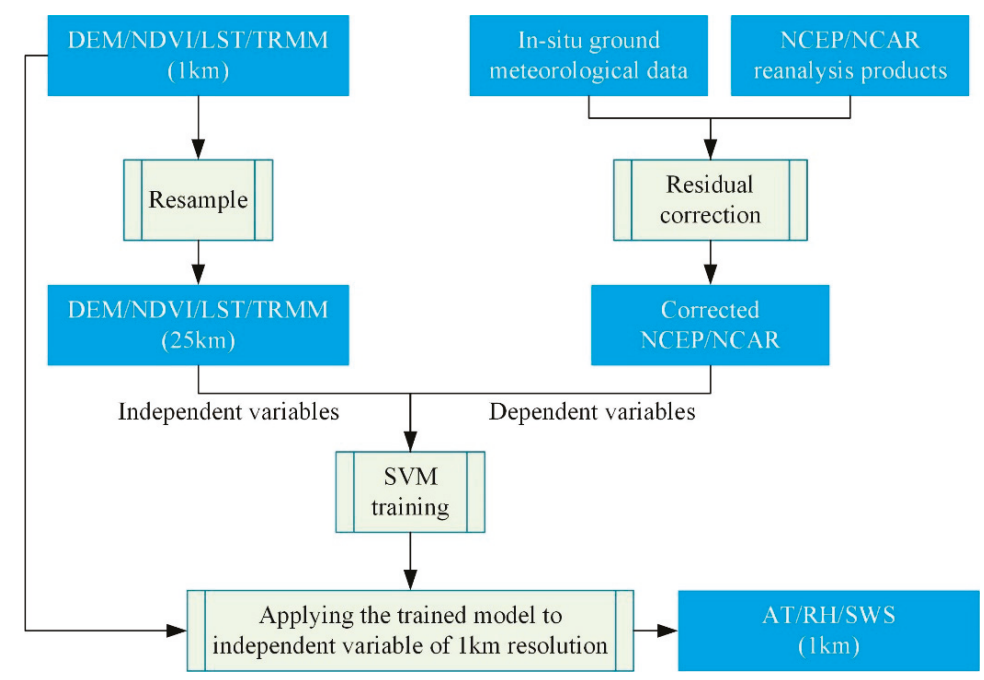

Figure 3. The flowchart of downscaling algorithm used in our study.

\section{Results and Discussion}

\subsection{Tourism Resources}

\subsubsection{Abundance and Quality}

In 2003, the Ministry of Culture and Tourism of the People's Republic of China promulgated Classification, Investigation and Evaluation of Tourism Resources (GB/T 18972-2017) [33] as the national standard. However, due to the rise of leisure vacation and the richness of tourism products, the traditional methods have been unable to meet the needs for classification of diverse new types of tourism resources, especially urban tourism resources. Based on the analysis of the concept, elements and characteristics of various tourism resources, and combined with other research $[34,35]$, we make some improvements and the final classification system is shown as Table 1. Furthermore, we invited 15 experts with tourism and geography background to assess the quality of 100 randomly sampled tourism resource units. This was a subjective process in which each expert evaluated the 
general quality of tourism resource units based upon their judgement and knowledge on tourism. The questionnaires (Appendix B in [33]) containing basic descriptions on natural characteristics, infrastructure and developing status, together with on-site pictures, are sent to the experts who are required to score to these units following the evaluation system in Table 2. The system limits the maximum score of each evaluation factor and the scoring range of their corresponding four-levels, representing "excellent", "perfect", "good" and "poor", respectively. Another added value can be optionally given to the unit concerning its situation on environmental protection or safety, i.e., negative 5 points for seriously polluted status, negative 4 points for moderately polluted status, negative 3 points for slightly polluted status, while positive 3 points for status existing environmental protection measures.

Table 1. Types of tourism resources in Zunyi City. No. = number, $\mathrm{P}=$ proportion of total.

\begin{tabular}{|c|c|c|c|c|c|}
\hline \multirow{2}{*}{\multicolumn{2}{|c|}{ Main Category }} & \multicolumn{3}{|r|}{ Subcategory } & \multirow{2}{*}{$\frac{\text { Basic Type }}{\text { Types }}$} \\
\hline & & No. & $\mathbf{P}(\%)$ & Subcategory Name (No. of Basic Types) & \\
\hline \multirow{3}{*}{$\begin{array}{l}\text { Natural } \\
\text { tourism } \\
\text { resources }\end{array}$} & $\begin{array}{l}\text { A. Geographical } \\
\text { Landscape }\end{array}$ & 142 & 17.66 & $\begin{array}{l}\text { AA. Comprehensive natural tourist destination (50) } \\
\text { AB. Sedimentary and tectonic (3) } \\
\text { AC. Geomorphic processes (79) } \\
\text { AD. Natural Changes (10) }\end{array}$ & $24 / 37$ \\
\hline & B. Water Landscape & 67 & 8.33 & $\begin{array}{l}\text { BA. Rivers (18) } \\
\text { BB. Natural wetlands and marshes (30) } \\
\text { BC. Waterfalls (13) } \\
\text { BD. Springs (6) }\end{array}$ & $9 / 15$ \\
\hline & $\begin{array}{l}\text { C. Ecological } \\
\text { Landscape }\end{array}$ & 39 & 4.85 & $\begin{array}{l}\text { CA. Woodland (17) } \\
\text { CC. Flowered areas (14) } \\
\text { CD. Wildlife habitat (8) }\end{array}$ & $8 / 11$ \\
\hline \multirow{3}{*}{$\begin{array}{l}\text { Manmade } \\
\text { and } \\
\text { cultural } \\
\text { tourism } \\
\text { resources }\end{array}$} & E. Heritage sites & 148 & 18.41 & $\begin{array}{l}\text { EA. Prehistoric site (6) } \\
\text { EB. Cultural and economic monument (142) }\end{array}$ & $7 / 12$ \\
\hline & $\begin{array}{l}\text { F. Architecture and } \\
\text { infrastructure }\end{array}$ & 367 & 45.65 & $\begin{array}{l}\text { FA. Comprehensive cultural tourism destinations (97) } \\
\text { FB. Dedicated activity sites (36) } \\
\text { FC. Landscape architecture and attached buildings (160) } \\
\text { FD. Residential areas and communities (50) } \\
\text { FE. Burial grounds (16) } \\
\text { FF. Transportation architecture (3) } \\
\text { FG. Hydraulic structures (5) }\end{array}$ & $35 / 49$ \\
\hline & G. Tourism products & 17 & 2.11 & GA. Local tourism products (17) & $2 / 7$ \\
\hline
\end{tabular}

Table 2. Evaluation system of tourism resources.

\begin{tabular}{cccc}
\hline Evaluation Item & Evaluation Factor & Score & Levels \\
\hline & Sightseeing \& recreation value & 30 & $30-22 ; 21-13 ; 12-6 ; 5-1$ \\
Resource element & Historical, cultural, science and Artistic value & 25 & $25-20 ; 19-13 ; 12-6 ; 5-1$ \\
value & Rare \& singularity & 15 & $15-13 ; 12-9 ; 8-4 ; 3-1$ \\
& Scale, abundance and probability & 10 & $10-8 ; 7-5 ; 4-3 ; 2-1$ \\
& Integrity & 5 & $5-4 ; 3 ; 2 ; 1$ \\
Resource influence & Visibility \& influence & 10 & $10-8 ; 7-5 ; 4-3 ; 2-1$ \\
\hline Added value & Environmental protection \& environmental safety & $4 /+$ & $-5 ;-4 ;-3 ; 3$ \\
\hline
\end{tabular}


Statistical results show that there are 804 tourism resource units, covering 8 main categories, 26 out of $31(83.87 \%)$ of subcategories and 95 out of 155 (61.94\%) of basic types. It reveals that Zunyi boasts of varied landscapes and a rich combination of tourism resource types. The final average score of expert evaluation is 87.74 out of 100 . According to these scores, tourism resources are divided into three grades according the standard [33] (Section 6.3.2.2). The units whose average score are larger than 90 are referred to as "excellent tourism resources"; if the average score is between 75 and 90, the unit is referred to as "perfect tourism resources"; while the others are treated as "general tourism resources". In total, 33 out of 100 evaluated tourism resources are excellent, 28 are perfect and 39 are general. Although the personal perception of experts might affect the objectivity of the final results, this generally shows that tourism resources in Zunyi are of high quality. It is evident that abundant categories and excellent quality of tourism resources have laid a solid foundation for tourism development in Zunyi.

However, it is notable that although the main categories A-F account for more than half of the basic types, the proportion of tourism products $(\mathrm{G})$ and cultural activities $(\mathrm{H})$ are lower than $50 \%$ (only $2 / 7$ and $6 / 16$, respectively). In addition, the excellent units are mainly from natural tourism resources, while most manmade resources are of low-quality, especially category $\mathrm{E}$ and $\mathrm{F}$. Therefore, it is particularly important to improve the quality of manmade tourism resources and enrich cultural tourism products through cultural creativity. Under the traditional tourism mode, tourists just visit the scenic spots and take pictures to record beautiful scenes or wonderful moments. It is difficult to satisfy tourists' multi-level and diversified modern requirements for beautiful natural scenes, unique local cultural experiences, or age-old minority amorous feelings [36]. Thus, all-for-one tourism should pay attention to the creation of innovative cultural tourism products and the interaction between tourists and local culture. Firstly, traditional cultural resources can be directly utilized as tourism products. We can use traditional villages, cultural relics, museums, memorials, art galleries, world cultural heritage, intangible cultural heritage exhibition halls and other cultural sites to carry out cultural experience activities. Secondly, existing tourism products can be upgraded through cultural integration, focusing on in-depth excavation of historical culture, regional characteristic culture, national folk culture, traditional farming culture, and traditional handicraft culture. Thirdly, tourism can be combined with other industries. For example, in the field of agriculture, it is strongly advocated to develop sightseeing agriculture, leisure agriculture, creative agriculture such as pastoral landscape or balcony agronomy, and other agricultural patterns with tourism function such as customized agriculture, exhibition agriculture, family farming or family pasture.

\subsubsection{Spatial Characteristics}

Tourism resources are the foundation of the tourism industry. Different from fragmented scenic spots, all-for-one tourism treats a whole region as a tourist destination with complete functions to satisfy various tourists to achieve the integration of inside and outside scenic spots. The aim is to make everyone become a tourist and everywhere become tourism landscapes. The ideal state is that all tourism resources are evenly distributed spatially. Thus, it is vital to get knowledge of the spatial distribution of all tourism resources. Figure 4a shows the spatial distribution of natural and cultural tourism resources. Overall, different types are cross-distributed spatially, blending together. It is helpful to provide tourists with diverse sightseeing experiences, containing not only the relaxation and beauty of nature, but also solemnity or joyfulness from colorful historical or national culture.

However, the regional distribution of tourism resources is uneven, i.e., abundant in the central and western regions while few in the eastern region, as shown in Figure $4 \mathrm{~b}$. We further analyze the spatial density of tourism resources at pixel level. The kernel density analysis is widely used in the analysis of spatial characteristics and spatial patterns of geographical features [37], which is helpful to judge regional imbalance. It calculates the density of features in a neighborhood around those features. 
Let $\left(x_{1}, x_{2}, \ldots, x_{n}\right)$ be a univariate independent and identically distributed sample drawn from some distribution with an unknown density $f$. Its kernel density at point $x$ is:

$$
\hat{f}_{h}(x)=\frac{1}{n h} \sum_{i=1}^{n} K\left(\frac{x-x_{i}}{h}\right), h>0
$$

where $K$ is the kernel, a non-negative function that integrates to one; $h$ represents the bandwidth, which should be finely selected in practice. In our study, $h$ is set to be the default value defined by the algorithm in ArcGIS [38]. Figure 4c shows the result of kernel density analysis. Multiple clustered centers are formed in space, especially in the northwestern and southwestern. The result is in agreement with results present in Figure $4 \mathrm{~b}$.

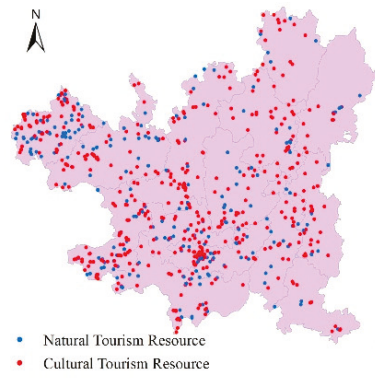

(a)

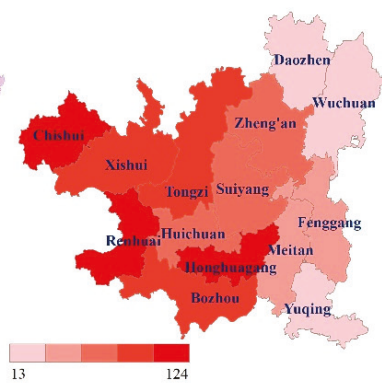

(b)

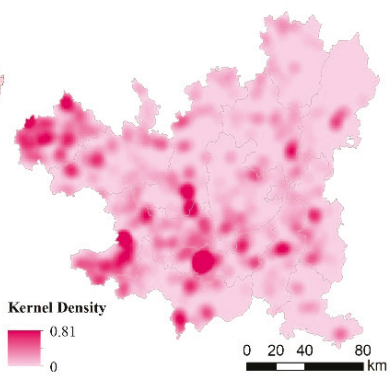

(c)

Figure 4. Spatial analysis of tourism resources. (a) Spatial distribution; (b) Regional statistics; (c) Kernel density.

The uneven spatial distribution of tourism resources remains a large obstacle to all-for-one tourism development. The government planning departments and tourism developers should pay more attention to discover and mine tourism landscapes in areas where tourism resources are scarce. Under the premise of ecological protection, natural landscapes must be developed appropriately. A more advisable approach is to integrate tourism industry with regional development. For example, in the process of rural revitalization, local residents can vigorously develop agricultural sightseeing, leisure tour, pastoral experience, or hold folk culture festivals, food tasting and feasting activities etc. Meanwhile, it must be emphasized that the development of all-for-one tourism must adjust to local conditions and highlight local characteristics. Every district should explore their unique approach through innovation to avoid having sluggish tourism attractions and products. The charm of all-for-one tourism lies in letting a hundred flowers bloom and being rich and colorful. For example, Danxia landform in Chishui and Xishui, red culture in Honghuagang and Bozhou, Gelao culture in Daozhen and Wuchuan, wine culture in Renhuai, and tea culture in Meitan can be the typical characteristics.

Currently, not all districts or towns in Zunyi meets the conditions to develop all-for-one tourism. Local tourism development committee should focus on constructing tourism infrastructure, creating top tourism products, widening the coverage of the tourism industry and improving the influence of tourism brands. To promote the development of all-for-one tourism, it is necessary to pay attention to the social and cultural impact of the tourism industry on tourism destinations and to take measures to promote the understanding of different cultures, protect the traditional cultural heritage, improve people's leisure level and life quality and eliminate the negative impact imposed by tourism development. It is also needed to attach great importance to the impact of tourism on the coordinated development of urban and rural areas. In the process of blending tourism into traditional rural and agricultural development, some problems and shortcomings, such as the guarantee of farmers' interests after excessive capitalization or semi-urbanization, should be taken seriously. 
Another way to eliminate unbalanced development is to strengthen regional cooperation. The idea of tourism development must be transformed from the traditional scene sightseeing to all-for-one tourism mode. All-for-one tourism emphasizes regional comprehensive development concept, which requires breaking through the simplicity and closeness of scenic spots and extending the radiative effects of central tourism areas. It is necessary to strengthen cooperation with adjacent regions and jointly develop typical tourist routes or areas by linking various tourist attractions. Relying on the special geographical location, Zunyi can combine the tourism resources of Chongqing, Sichuan and Guizhou to design top-quality tourism routes, such as the red tourism line of the Long March, ecological tour zone of the Golden Triangle, and ethnic cultural tourism areas.

\subsection{Natural Conditions}

\subsubsection{Climate Comfort}

Climate is a salient resource for tourism and a dominant attribute of a tourist destination [22,39]. It has a major effect on tourism demand, satisfaction and decision-making [40] since tourists are sensitive to climate and climate change [41]. Thus, it is vital to assess the suitability of climate for tourism for the sake of decision-making by tourism participants. For instance, tourism planners could better evaluate a destination for tourism development and incorporate climate in infrastructure planning and programming; the insurance industry might design diverse weather insurance products for the tourism industry; tourists can choose a destination and take out insurance on likelihood of poor weather conditions occurring while on holidays. Researchers have made considerable efforts to devise climate indices owing to the multifaceted nature of weather and the complex ways the weather variables come together to give meaning to climate for tourism. In this study, temperature-humidity index (THI) [42] and wind effect index (WEI) [43] are chosen to assess the thermal comfort and cold comfort, separately.

Thermal comfort is the condition of mind that expresses human physiological satisfaction under the influence of temperature and humidity. THI is calculated by mean of dry bulb temperature and relative humidity and its expression is as followed [42]:

$$
T H I=t_{d}-0.55(1-0.01 R H)\left(t_{d}-14.5\right)
$$

where $t_{d}$ represents the dry bulb temperature $\left({ }^{\circ} \mathrm{C}\right), R H$ is relative humidity $(\%)$. Herein, monthly mean air temperature and relative humidity of NCEP/NCAR reanalysis products preprocessed through method in Section 2.3 are used for calculation of THI. The values of 2013 locate in the range [9.2, 28.5] and are reclassified into five categories: Cold, cool, comfortable, warm and hot (Table 3) according to Kyle's study of the bioclimatic environment [44].

Table 3. Classification of temperature-humidity index (THI) and wind effect index (WEI).

\begin{tabular}{ccc}
\hline THI $\left({ }^{\circ} \mathrm{C}\right)$ & Category & WEI \\
\hline$-1.7 \sim 13.0$ & Cold & $-800 \sim-600$ \\
$13.0 \sim 14.0$ & Cool & $-600 \sim-300$ \\
$15.0 \sim 20.0$ & Comfortable & $-300 \sim-200$ \\
$20.0 \sim 26.5$ & Warm & $-200 \sim-50$ \\
$26.5 \sim 29.9$ & Hot & $-50 \sim 80$ \\
\hline
\end{tabular}

Cold comfort evaluates the suitability for outdoor activities by taking into consideration the effects of surface wind speed and solar radiation [45]. The expression of WEI is [43]:

$$
W E I=-(10 \sqrt{V}+10.45-V)(33-T)+8.55 S
$$


where $V$ means surface wind speed $(\mathrm{m} / \mathrm{s}), T$ is air temperature $\left({ }^{\circ} \mathrm{C}\right)$, and $S$ is sunshine hour per day $(\mathrm{h} / \mathrm{d})$. Herein, monthly mean air temperature and surface wind speed of NCEP/NCAR reanalysis products preprocessed through method in Section 2.3 are used for calculation of WEI. Spatial continuous sunshine hours are obtained by means of interpolating in-situ measured data through Kriging method. The WEI values of 2013 vary in the range $[-742,74]$ and are divided into five levels (Table 3) referring to Terjung's research [43].

Figure 5 shows the variation of THI of Zunyi in different seasons. It is clear that spring (April 2013) is the best, followed by autumn (October 2013). Although summer (July 2013) is overheating in local, most of the regions belong to warm. Winter (January 2014) tends to be cold and humid, with obvious boundary along the mountain from northeast to southwest. Such characteristics can mainly be attributed to the joint influence of topography and monsoon. In summer, Zunyi is affected by the southwest monsoon from the Indian Ocean, thus low-latitude areas in the southwest are obviously hotter than others, while high-altitude areas remain warm environments because of the vertical zonal effect. In winter, northwest monsoon dominates, but is greatly weakened by the Tibetan Plateau. Therefore, the northwest is much colder, but would not reach the freezing level. In contrast, the southeast is relatively warm as the northwest mountains further weaken the cold wind. In addition, Figure 5c shows the average THI from 2003 to 2013, indicating that the climate in Zunyi tends to be cool and comfortable. Figure 6 shows the spatial distribution of WEI in different seasons. We can draw a similar conclusion to THI. In contrast, a larger region tends to be comfortable and only high-altitude mountains above about $2000 \mathrm{~m}$ reach a cold level. Nevertheless, the average level of WEI from 2003 to 2013 belongs to the cool type in the entire space from the perspective of cold comfort. All in all, warm and comfortable environments create excellent conditions for mountain travel or outdoor hiking, attracting urban residents who are eager to return to nature and enjoy themselves.

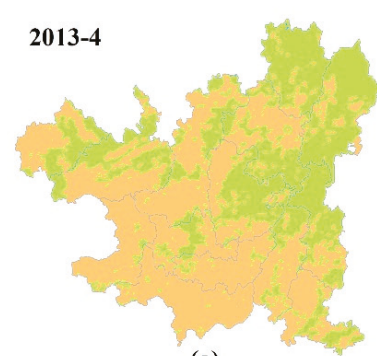

(a)

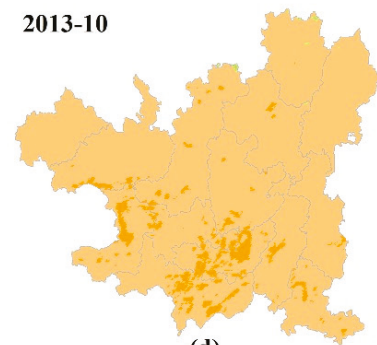

(d)

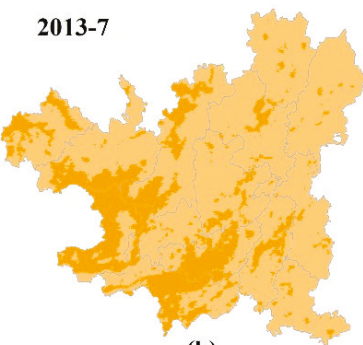

(b)

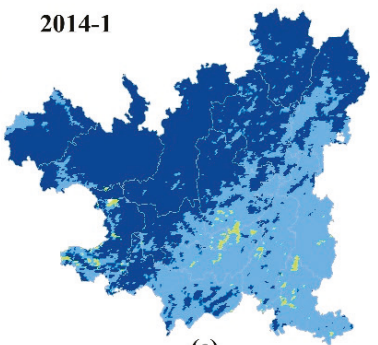

(e)



(c)

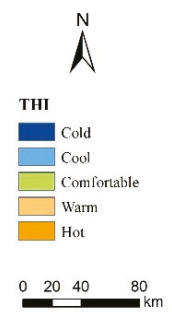

Figure 5. Variation of temperature-humidity index in different seasons. (a) Spring (April, 2013);
(b) Summer (July, 2013); (c) Multi-year average (2003-2013); (d) Autumn (October, 2013); (e) Winter (January, 2014). 


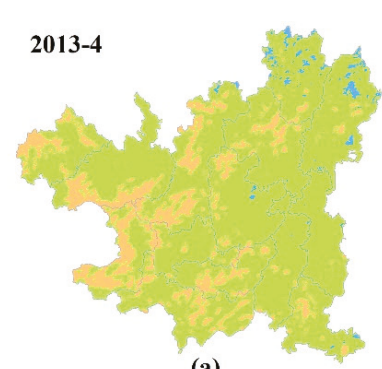

(a)

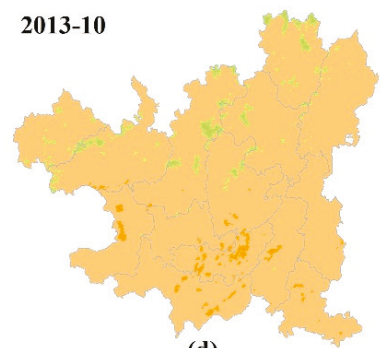

(d)

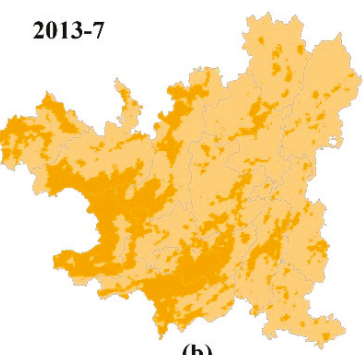

(b)

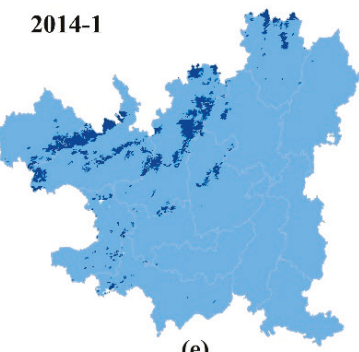

(e)



(c)

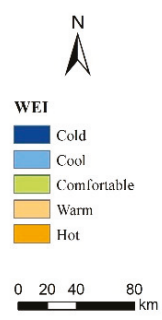

Figure 6. Variation of wind effect index in different seasons. (a) Spring (April, 2013); (b) Summer (July, 2013); (c) Multi-year average (2003-2013); (d) Autumn (October, 2013); (e) Winter (January, 2014).

The characteristics of the climate in Zunyi can be described as "four distinctive seasons, comfortable spring, warm autumn, no severe cold in winter, and no intense heat in summer". It means that Zunyi is suitable for developing tourism all the year round, without an obvious peak season and off season, but with different scenery in different seasons. Moreover, due to the complex topography and relative high altitude, the climate shows the characteristics of diversity and vertical zonality. Generally, the whole region can be roughly divided into four vertical climate zones: Mid-subtropical climate in hilly and valley areas, northern subtropical climate in low-altitude mountain areas, northern temperate climate in middle mountain areas, and the middle temperate climate in mountain areas above $1500 \mathrm{~m}$ of sea level. Different vertical climatic zones in mountain areas affect the distribution of temperature, moisture, soil, animals and plants, resulting in various and distinctive geographical, hydrographic, ecological, or climatic landscapes [46]. Tourism planners should grasp the distribution of tourism resources and master the spatial and temporal characteristics of different landscapes so that they are able to develop high-quality tourist attractions and design reasonable tourist sightseeing routes adapting to seasonal changes and spatial variation to avoid singularity and repetition of tourism products. Zunyi is strongly recommended to focus on "summer leisure tourism" comparing to the torrid climate in most areas of China during summer. According to the statistics provided by China Tourism Academy, the number of domestic tourists for summer vacation (July and August) reached 1 billion in 2017 in China, accounting for $20 \%$ of the total number of tourists in the year. In addition, global warming will positively affect mountainous plateau areas or middle- and high-latitude zones, attracting more tourists for summer vacation thanks to their relatively cool environments $[47,48]$.

\subsubsection{Evaluation of Disaster Risk}

Mountains provide a thoroughly challenging environment for special sports and leisure activities which attract aficionados such as mountaineers, paragliders, or downhill skiers [49]. Mountain tourism, especially mountain adventure tourism, differs from general mass tourism in lowland regions due to its higher requirements on the safety of the tourism area [50]. It is highly necessary to evaluate disaster risks for mountain tourism. Zunyi stands in the transition zones from the Yunnan-Guizhou Plateau to the Hunan hills and Sichuan basins with undulating topography and complex landforms. 
The area of mountains in Zunyi reaches $65.08 \%$, the hilly area accounts for $28.35 \%$, while the flat dam and valley basin is only $6.57 \%$. Meanwhile, rainfall is abundant in Zunyi. In summer, as southwest monsoon moves northward, the water vapor from the Bay of Bengal and the Indian Ocean increases dramatically, and Zunyi enters plum rains season with heavy and frequent rainfall. The statistics from Ministry of Natural Resources show that Zunyi is faced with a high possibility of geologic hazards, such as landsides, collapse, and mudslides.

This section intends to gain spatial continuous results of disaster possibility in Zunyi referring to the method in ref. [51]. Four inducing factors are taken into consideration: Slope (Figure 7a), precipitation (Figure 7b), NDVI (Figure 7c) and altitude (Figure 1). Note that the precipitation is a 10-year average value from 2005-2015 and NDVI is 1-year average value in 2015. Each factor is divided into five levels $(1,2,3,4,5)$ through the Jenks natural breaks classification method [52,53] and the higher level means a greater possibility of disaster risk. Then the weighted sum of all factors is used for evaluation of comprehensive disaster possibility. Herein, the weights are 0.574, 0.291, 0.090, and 0.045 for slope, precipitation, NDVI and altitude, respectively. All weights are determined by analytic hierarchy process (AHP) [54], a subjective method that can reflect difference of relative importance among indexes properly. Figure $7 \mathrm{~d}$ shows the final assessment results. Let the possibility $100 \%$ correspond to the maximum value 5 , then the possibility $90 \%, 80 \%, 70 \%, 60 \%$ equals $4.5,4,3.5$, and 3 , respectively. In the northeast and the central mountain area, the disaster possibility is over $90 \%$ due to large slope and excessive precipitation. In contrast, the possibility in the southwest is relatively small with a large slope but little precipitation and dense vegetation. Other regions have a low possibility, mainly thanks to the flat terrain.

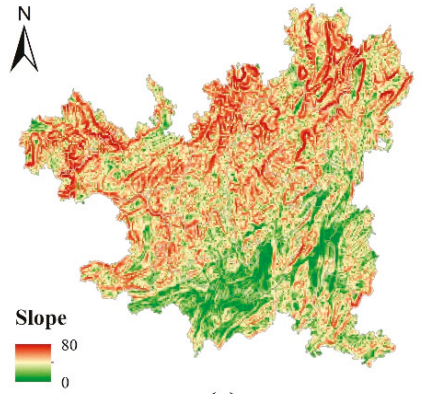

(a)

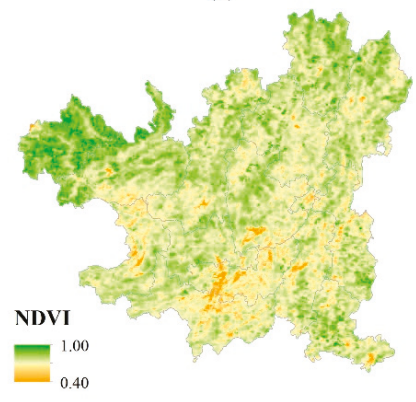

(c)

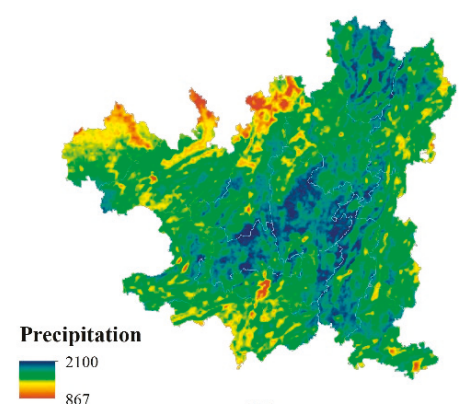

(b)

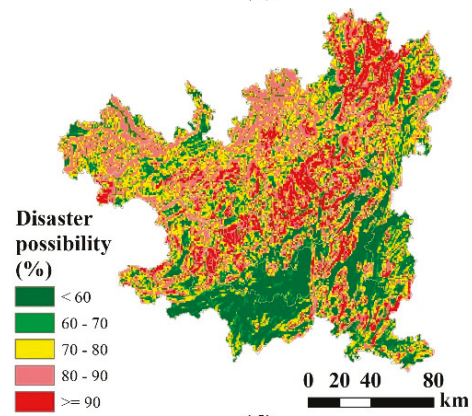

(d)

Figure 7. Evaluation of natural disaster risk. (a) Slope; (b) Precipitation; (c) NDVI; (d) Results of disaster risk. Note that the precipitation is 10-year average from 2005-2015 and NDVI is 1-year average in 2015.

During the development of tourism, humans should respect the laws of nature and avoid exploitation in areas with a fragile natural ecology and high risk of natural disasters. Promoting 
all-for-one tourism does not mean developing tourism everywhere. Tourism development must be compatible with the carrying capacity of resources and the environment. If damage from environmental pollution caused by development of the tourism industry exceeds an acceptable ecological security threshold, it will threaten ecological service functions and the sustainable development of tourism areas [55]. Unfortunately, the diverse stakeholders often violate the objective laws for their immediate interests and contrasting goals during the process of tourism development. Innovative approaches are required to aid in the conflict resolution process. Research has shown that as the level of agreement between groups of stakeholders increases, so does the likelihood of collaboration and compromise [56]. At the local level, communities represented by local government officials are usually responsible for coordinating the relationships between public authorities, business owners, and other social stakeholders. In addition, collaboration with the academic community needs to be enhanced. Professional planning measures are needed to realize rational layout and optimal allocation of resources, facilities, elements, functions and industries in an all-round way so as to better relieve and reduce the pressure on core resources and ecological environments. From the perspective of humanistic concern, tourist-warning signs should be set up in particular locations to remind tourists to stay away from danger. At the same time, administrative departments should establish early-warning system to monitor the main inducing factors and assess the risk of natural disaster in real time, thus proper preventions can be arranged in advance to minimize the economic loss and casualties.

\subsection{Social Service}

Satisfying tourists is the final goal of tourism service as well as an important guarantee for the long-term development of tourism industry. Tourist satisfaction is a comprehensive judgment and psychological evaluation on tourism landscapes, natural and cultural environments, infrastructure, and social services etc. Through map open platforms, we have accumulated a large number of POIs relating to tourism, which are classified into four categories: Traffic facilities, hotels or homestays, hospitals or casualty stations, restaurants or farmsteads. Note that traffic facilities include passenger stations, railway stations, airports, entrance to expressway or main road. In this section, we measure the convenience of every spatial point by calculating its nearest Euclidean distance to POIs, considering the difficulty of constructing topological relations of spatial paths. The weighted average distance of all types of POI is treated as the final convenience of social services. All weights are determined through AHP and the values are 0.537, 0.232, 0.139, and 0.092 for traffic, hotel, hospital and restaurant, respectively.

Figure $8 \mathrm{a}$ shows the direct results of weighted average distance, which is divided into five levels $(1,2,3,4,5)$ through the Jenks natural breaks classification method as shown in Figure $8 \mathrm{~b}$. Furthermore, the grading results are overlapped with results of land cover classification, containing urban construction areas and rural residential lands interpreted from Landsat 8 OLI images in 2015. Figure $8 \mathrm{~b}$ shows that almost all urban areas belong to level 5 , areas with the highest convenience of social services, while most rural areas are located in level 4 and 3, and extremely few people live in level 2 and 1. It indicates that the urban areas occupy most of the social resources while infrastructure in rural areas is relatively backwards.

Although this article only analyzes the limited resources, the problems reflected are universal. With the development of urban and rural economy and the improvement of farmers' living standards, the demand for public services is increasing. Currently, one of the most urgent need for the rural revitalization is the rural infrastructure construction related to the improvement of people's livelihood, including road construction, water supply, medical treatment, garbage collection, toilet improvement, street lighting, public transport etc. All-for-one tourism is an important approach to realize the strategy of rural revitalization. In order to revitalize the tourism industry, many initiatives need to be implemented simultaneously. On the one hand, great importance should be attached to rural infrastructure construction from the policy and investment. On the other hand, improvements are 
highly required to perfect the legislation on the tracking, management, implementation, maintenance, investigation and evaluation of relevant rural funds and policies.

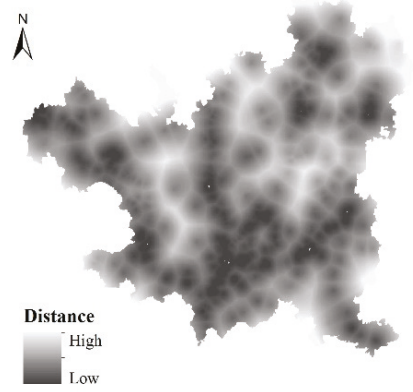

(a)

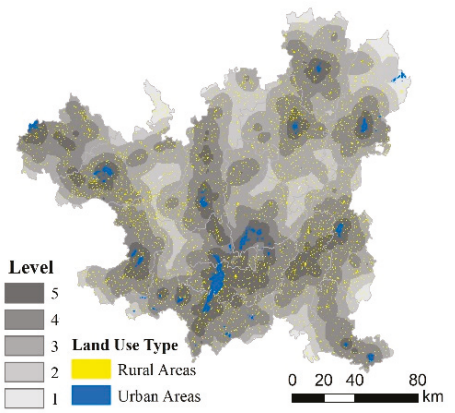

(b)

Figure 8. Evaluation of social service. (a) The results of weighted average distance; (b) The grading results of social convenience. Land cover types are interpreted from Landsat 8 OLI images in 2015.

The development of all-for-one tourism requires more convenient and high-quality transportation services. Transportation serves as a bridge to link tourists and tourism destination, especially with the rise of self-driving travelling the relationship between traffic and tourism becomes much closer. The local government must increase direct investment and guide enterprises' own investment to build up a complete tourism traffic network and improve public transport service facilities. Standardized traffic signs with distinctive visual effects and effective guidance should be set up on highways and main tour routes. Meanwhile, it is necessary to integrate traffic services with related tourism elements, such as tourism consultation, theme accommodation, the flavor of food and beverages, special shopping, and leisure and entertainment options. Parking lots, new energy vehicle charging piles, tourist toilets and other facilities are required to meet the traveling needs of tourists. It is also suggested to build an official tourism website, mobile phone app and public micro-signal in A-level scenic spots to provide tourists with a tour guide, route navigation and shopping services.

\section{Summary}

In this paper, we systematically analyzed the present situation of all-for-one tourism in Zunyi concerning tourism resources, natural conditions and social conditions from the geographical perspective. Some conclusions are drawn: (1) Zunyi possesses various high-quality landscapes and a rich combination of tourism resource types, but is relatively weak in providing cultural tourism products; (2) Different types of tourism resources are highly integrated, but the spatial distribution is uneven, i.e., abundant in the central and western while few in the eastern; (3) The climate is suitable for mountain tourism all year round and its variation in temporal and spatial domain breeds abundant natural tourism resources; (4) Some areas with large slope and excessive precipitation are in face of high risk of natural disaster; (5) The imbalance between urban areas and rural areas is a main obstacle to the development of all-for-one tourism. In fact, other regions in China are facing similar problems during the development of all-for-one tourism [15,20,34-37,40].

Based on the case study, some general recommendations are present to address the current problems for the healthy development of all-for-one tourism: (1) improving the quality of manmade tourism resources and enriching cultural tourism products through cultural creativity; (2) integrating tourism industry with regional development, strengthening regional cooperation with nearby tourism areas and focusing on construction of tourism infrastructure in backward areas; (3) designing tourist sightseeing routes adapting to the spatial and temporal characteristics of different landscapes; (4) respecting the laws of nature and avoiding exploitation in areas with fragile natural ecology 
and high risk of natural disasters; (5) strengthening construction of infrastructure and building up a complete tourism traffic network. All-for-one tourism is a new viewpoint of tourism development involving in overall planning and cooperative mechanism. In practice, every participant should be aware of the complexity and comprehensiveness of each problem. For example, we should not only focus on the quantity of tourism resources, but also pay attention to their quality and spatial layout. Apart from emphasizing the investment and construction of infrastructure, great importance must be attached to the spatial balance of social services and coordinated development between urban and rural areas.

All-for-one tourism is a highly comprehensive and recapitulative concept. Our study concentrates on revealing objective phenomena or situations in temporal and spatial domain. In order to reflect its development connotation in a more comprehensive way, it is better to evaluate and analyze all-for-one tourism from many other perspectives and dimensions, such as personnel training. Restricted by the cultural level, many tour guides cannot provide professional interpretation service to meet the differentiated expectations of tourists. It is necessary to strengthen the ability and quality of tourism practitioners and promote the transformation of tour guides from explanatory and reception services to cultural and professional services. Tourism schools must shoulder the responsibility of cultivating compound, modernized, and international tourism talents by means of strengthening effective links with tourism industry, enterprises and society, promoting cooperation with governments, enterprises, other schools and international organizations.

The limitation of our study is based on the fact that all findings rely on the specific case and thus cannot be generalized. These experiences should not be copied, but altered adaptively when applying to other application scenarios. In addition, more datasets should be integrated into the evaluation process, such as statistical data on the total volume, the market characteristics, the consumption situation and the market trends in the source of tourists. At present, tourism management departments are actively promoting the accumulation of tourism statistics, the construction of tourism big data, and the application of data science and technology in tourism industry. With the continuous improvement of tourism-related methods and technology, it is reasonable to believe that the evaluation of all-for-one tourism will be more systematic and complete.

Author Contributions: Conceptualization, H.J. and Y.B.; Data curation, Y.B.; Funding acquisition, Y.Y.; Investigation, Y.Y.; Methodology, H.J.; Validation, Y.Y. and Y.B.; Writing—original draft, H.J.; Writing—review \& editing, H.J. and Y.B.

Funding: This research was funded by the "Strategic Priority Research Program (A)" of the Chinese Academy of Sciences (No. XDA19020304), the Multidisciplinary Joint Expedition for China-Mongolia-Russia Economic Corridor (No. 2017FY101300), the Branch Center Project of Geography, Resources and Ecology of Knowledge Center for Chinese Engineering Sciences and Technology (No. CKCEST-2017-1-8), the National Earth System Science Data Sharing Infrastructure (No. 2005DKA32300), the Construction Project of Ecological Risk Assessment and Basic Geographic Information Database of International Economic Corridor Across China, Mongolia and Russia (No. 131A11KYSB20160091), and the National Natural Science Foundation of China (No. 41631177).

Conflicts of Interest: The authors declare no conflict of interest.

\section{References}

1. Navío-Marco, J.; Ruiz-Gómez, L.M.; Sevilla-Sevilla, C. Progress in information technology and tourism management: 30 years on and 20 years after the internet-Revisiting Buhalis \& Law's landmark study about eTourism. Tour. Manag. 2018, 69, 460-470.

2. Sheng, Y.; Ming-Ying, L.A.; Sheng, Z.T. The supply-side structural reform based on all-for-one tourism in minority areas. Reform Econ. Syst. 2015, 5, 11-17.

3. Wang, L.E.; He, L.; Cheng, S.K.; Min, Q.W. Driving force and development strategies of agro-tourism in china. Chin. J. Eco-Agric. 2012, 20, 681-687. [CrossRef]

4. Jiang, J.; Liu, H.; Tan, M. Research on the Science and Technology Innovation Path of Tourism Structural Transformation and Upgrading: As an Example of Guangdong Province. J. Chongqing Univ. 2014, 20, $16-24$. 
5. Feng, X. All-for-one tourism: The transformation and upgrading direction of regional tourism industry. J. Soc. Sci. Res. 2017, 11, 2374-2378. [CrossRef]

6. Tölkes, C. Sustainability communication in tourism-A literature review. Tour. Manag. Perspect. 2018, 27, 10-21. [CrossRef]

7. Li, X.J.; Zhang, L.Y.; Cui, L. Comprehensive tourism: Idea innovation on building a world-class tourism destination. Hum. Geogr. 2013, 3, 130-134.

8. Li, J.Z. The All-for-One Tourism Is Promising. Available online: http://www.xinhuanet.com/travel/201602/09/c_128710701.htm (accessed on 5 November 2018).

9. Zhang, H.; Yue, Y. The rational thinking about all-for-one tourism. Tour. Trib. 2016, 31, 15-17.

10. Cooper, C.P.; Fletcher, J.E.; Gilbert, D.C.; Wanhill, S. Tourism: Principles and Practice; Pitman Publishing: New York, NY, USA, 2013.

11. Wang, G.H. On the Path and Methods of the Strategic Implementation of All-for-one Tourism. J. Beijing Union Univ. 2017, 15, 12-18.

12. Potschin, M.B.; Haines-Young, R.H. Improving the quality of environmental assessments using the concept of natural capital: A case study from southern Germany. Landsc. Urban Plan. 2003, 63, 93-108. [CrossRef]

13. Yi, G.; Hu, E. Advancing and Retreating of Tourist Attractions under the Background of All-for-one Tourism. Chin. Anc. City 2018, 6, 19-24.

14. Zhang, Q. Research on tourist attractions performance promoting method based on the SWOT analysis method. Ieri Procedia 2012, 1, 254-260. [CrossRef]

15. Zhu, H.; Liu, J.M.; Tao, H.; Zhang, J. Evaluation and spatial analysis of tourism resources attraction in Beijing based on the internet information. J. Nat. Resour. 2015, 30, 2081-2094.

16. Yang, X.; Pan, B.; Evans, J.A.; Lv, B. Forecasting Chinese tourist volume with search engine data. Tour. Manag. 2015, 46, 386-397. [CrossRef]

17. Li, X.; Pan, B.; Law, R.; Huang, X. Forecasting tourism demand with composite search index. Tour. Manag. 2017, 59, 57-66. [CrossRef]

18. Xiang, Z.; Schwartz, Z.; Gerdes, J.H.J.; Uysal, M. What can big data and text analytics tell us about hotel guest experience and satisfaction? Int. J. Hospit. Manag. 2015, 44, 120-130. [CrossRef]

19. Long, M.X.; Sun, G.N.; Li-Jun, M.A. Evaluation on tourism climate comfort of Zunyi to develop the red tourism and leisure destination: The comparative analysis of the five red tourism cities. Econ. Geogr. 2011, 31, 701-704.

20. Ling, W. Analysis on Tourism Climate Comfort Degree of Chishui. J. Anhui Agric. Sci. 2010, 38, 14651-14654.

21. Zhang, Q.; Zhao, Y. Research on Exploitation of the Red Travel in Zunyi. Econ. Res. Guid. 2007, 2, 134-136.

22. DeFreitas, C.R.; Scott, D.; Mcboyle, G. A second generation climate index for tourism (CIT): Specification and verification. Int. J. Biometeorol. 2008, 52, 399-407. [CrossRef] [PubMed]

23. Huffman, G.J.; Adler, R.F.; Bolvin, D.T.; Nelkin, E.J. The TRMM Multisatellite Precipitation Analysis (TMPA): Quasi-Global, Multiyear, Combined-Sensor Precipitation Estimates at Fine Scales. J. Hydrometeorol. 2007, 8, 38. [CrossRef]

24. Aghakouchak, A.; Mehran, A.; Norouzi, H.; Behrangi, A. Systematic and random error components in satellite precipitation data sets. Geophys. Res. Lett. 2012, 39, 9406. [CrossRef]

25. Smith, W.L.; Woolf, H.M.; Jacob, W.J. A regression method for obtaining real-time temperature and geopotential height profiles from satellite spectrometer measurements and its application to nimbus 3 "sirs" observations. Mon. Weather Rev. 2013, 98, 582. [CrossRef]

26. Li, Z.L.; Tang, B.H.; Wu, H.; Ren, H.; Yan, G.; Wan, Z.; Trigo, I.F.; Sobrino, J.A. Satellite-derived land surface temperature: Current status and perspectives. Remote Sens. Environ. 2013, 131, 14-37. [CrossRef]

27. Ratnam, M.V.; Basha, G.; Murthy, B.V.K.; Jayaraman, A. Relative humidity distribution from SAPHIR experiment on board Megha-Tropiques satellite mission: Comparison with global radiosonde and other satellite and reanalysis data sets. J. Geophys. Res. Atmos. 2013, 118, 9622-9630. [CrossRef]

28. Brogniez, H.; Fallourd, R.; Mallet, C.; Sivira, R.; Dufour, C. Estimating confidence intervals around relative humidity profiles from satellite observations: Application to the SAPHIR sounder. J. Atmos. Ocean. Technol. 2016, 33, 1005-1022. [CrossRef]

29. Immerzeel, W.W.; Rutten, M.M.; Droogers, P. Spatial downscaling of TRMM precipitation using vegetative response on the Iberian Peninsula. Remote Sens. Environ. 2009, 113, 362-370. [CrossRef] 
30. Jing, W.; Yang, Y.; Yue, X.; Zhao, X. A spatial downscaling algorithm for satellite-based precipitation over the Tibetan plateau based on NDVI, DEM, and land surface temperature. Remote Sens. 2016, 8, 655. [CrossRef]

31. Duan, Z.; Bastiaanssen, W.G.M. First results from version 7 TRMM 3B43 precipitation product in combination with a new downscaling-calibration procedure. Remote Sens. Environ. 2013, 131, 1-13. [CrossRef]

32. Shi, Y.L.; Song, L. Calibration of TRMM 3B43 over Tibetan plateau during 1998-2012. Arid Land Geogr. 2015, 38, 900-911.

33. General Administration of Quality Supervision, Inspection and Quarantine of the People's Republic of China (CN-GB). Classification, Investigation and Evaluation of Tourism Resources (GB/T 18972-2017). Available online: http:/ / www.cssn.net.cn/ (accessed on 19 October 2018).

34. Wang, L.; Liu, J.M.; Wang, L.E.; Zhu, H.; Lin, J. Tourism resource assessment and spatial analysis of wine tourism development: A case study of the eastern foothills of china's Helan mountains. J. Mt. Sci. 2018, 15, 645-656. [CrossRef]

35. Huang, Z.F.; Zhu, Y.; Yuan, L.W.; Xiao-Hai, H.U.; Cao, F.D. The intention, classification and evaluation of leisure tourism resources: A case study of Changzhou, Jiangsu province. Geogr. Res. 2011, 30, 1543-1553.

36. Richards, G. Cultural tourism: A review of recent research and trends. J. Hospit. Tour. Manag. 2018, 36, $12-21$. [CrossRef]

37. Liu, R.; Wei-Ping, H.U.; Wang, H.L.; Chi, W.U.; Jin, H.E. The road network evolution of Guangzhou-Foshan metropolitan area based on kernel density estimation. Sci. Geogr. Sin. 2011, 30, 81-86.

38. How Kernel Density Works. Available online: http://pro.arcgis.com/en/pro-app/tool-reference/spatialanalyst/how-kernel-density-works.htm (accessed on 28 September 2018).

39. Bigano, A.; Hamilton, J.M.; Tol, R.S.J. The impact of climate on holiday destination choice. Clim. Chang. 2006, 76, 389-406. [CrossRef]

40. Gössling, S.; Hall, M.C. Tourism and Global Environmental Change: Ecological, Economic, Social and Political Interrelationships. Geogr. Res. 2007, 45, 203-204.

41. Maddison, D.; Maddison, D. In search of warmer climates: The impact of climate change on flows of British tourists. Clim. Chang. 2001, 49, 193-208. [CrossRef]

42. Gonzalez, R.R.; Nishi, Y.; Gagge, A.P. Experimental evaluation of standard effective temperature: A new biometeorological index of man's thermal discomfort. Int. J. Biometeorol. 1974, 18, 1-15. [CrossRef] [PubMed]

43. Terjung, W.H. Physiological climates of the conterminous us: A bioclimatic classification based on man. Ann. Assn. Am. Geogr. 1966, 56, 141-179. [CrossRef]

44. Kyle, W. The human bioclimate of Hong Kong. In Proceedings of the Contemporary Climatology Conference, Masaryk University, Brno, Czech, 15-20 August 1994.

45. Sun, M.S.; Li, S. Empirical indices evaluating climate comfortableness: Review and prospect. Tour. Trib. 2015, 30, 19-34.

46. Fang, Y. Adaptation Management of Mountain Tourism Service: The Case of the Source Regions of the Yangtze and Yellow River. J. Mt. Sci. 2009, 6, 299-310. [CrossRef]

47. Grillakis, M.G.; Koutroulis, A.G.; Seiradakis, K.D.; Tsanis, I.K. Implications of $2{ }^{\circ} \mathrm{C}$ global warming in European summer tourism. Clim. Serv. 2016, 1, 30-38. [CrossRef]

48. Liu, Y.; Jin, Y. A Summary of Industry Development on Summer Tourism. Ecol. Econ. 2010, 6, 114-123.

49. Mountain, Forum. International NGO Consultation on the Mountain Agenda: Summary Report and Recommendations to the United Nations Commission on Sustainable Development; Mountain Institute: Franklin, WV, USA, 1995.

50. Beedie, P.; Hudson, S. Emergence of mountain-based adventure tourism. Ann. Tour. Res. 2003, 30, 625-643. [CrossRef]

51. Chen, X.; Pei, Z.; Wang, F. GIS-based assessment of rainstorm-induced geological hazards risk in Enshi autonomous prefecture. J. Geo-Inf. Sci. 2016, 18, 343-352.

52. Jenks, G.F. The data model concept in statistical mapping. Int. Yearbook Cartogr. 1967, 7, 186-190.

53. Robert, M.M. In memoriam: George f. Jenks (1916-1996). Am. Cartogr. 1997, 24, 56-59.

54. Saaty, T.L. Relative measurement and its generalization in decision making: Why pairwise comparisons are central in mathematics for the measurement of intangible factors the analytic hierarchy/network process. Revista de la Real Academia de Ciencias Exactas, Fisicas y Naturales. Serie A. Matematicas 2008, 2, 215-318. [CrossRef] 
55. Tang, C.; Wu, X.; Zheng, Q.; Ning, L. Ecological Security Evaluations of the Tourism Industry in Ecological Conservation Development Areas: A case study of Beijing's ECDA. J. Clean. Prod. 2018, 999-1010. [CrossRef]

56. Kapera, I. Sustainable tourism development efforts by local governments in Poland. Sustain. Cities Soc. 2018, 40, 581-588. [CrossRef]



(C) 2018 by the authors. Licensee MDPI, Basel, Switzerland. This article is an open access article distributed under the terms and conditions of the Creative Commons Attribution (CC BY) license (http:/ / creativecommons.org/licenses/by/4.0/). 


\title{
Regional Tourism Clustering Based on the Three Ps of the Sustainability Services Marketing Matrix: An Example of Central and Eastern European Countries
}

\author{
Gabriela Kol'veková ${ }^{1}$, Erika Liptáková ${ }^{2}$, L'ubomír Štrba ${ }^{3, *}$, Branislav Kršák ${ }^{3}$, Csaba Sidor ${ }^{3}$, \\ Michal Cehlár ${ }^{4}$, Samer Khouri ${ }^{4}$ and Marcel Behún ${ }^{4}$ \\ 1 Department of Economic Theories, Faculty of Economics, Technical University of Košice, Letná 9, \\ 04200 Košice, Slovakia; gabriela.kolvekova@tuke.sk \\ 2 Department of Applied Mathematics and Business Informatics, Faculty of Economics, Technical University \\ of Košice, Letná 9, 04200 Košice, Slovakia; erika.liptakova@tuke.sk \\ 3 Department of Geo and Mining Tourism, Faculty of Mining, Ecology, Process Control and Geotechnologies, \\ Technical University of Košice, Letná 9, 04200 Košice, Slovakia; branislav.krsak@tuke.sk (B.K.); \\ csaba.sidor@tuke.sk (C.S.) \\ 4 Institute of Earth Resources, Faculty of Mining, Ecology, Process Control and Geotechnologies, \\ Technical University of Košice, Letná 9, 04200 Košice, Slovakia; michal.cehlar@tuke.sk (M.C.); \\ samer.khouri@tuke.sk (S.K.); marcel.behun@tuke.sk (M.B.) \\ * Correspondence: lubomir.strba@tuke.sk
}

Received: 2 November 2018; Accepted: 9 January 2019; Published: 14 January 2019

\begin{abstract}
The impact of tourism on quality of life standards in regions is significant in terms of people, planet, and profit. This paper examines the subnational NUTS 2 level regions, (in line with Eurostat) by applying several interlinked and connected indicators. Adopting the three Ps (people, planet, profit) of the Sustainability Services Marketing Mix, this article discusses the fusion of 54 regions of Central and Eastern Europe (Czech Republic, Slovakia, Hungary, Poland, Estonia, Lithuania, Latvia, Slovenia, Romania, and Bulgaria) into clusters according to the selected accommodation tourism indicators used by the European Statistical Agency (Eurostat) to evaluate tourism. Since many variables of the Prague region significantly exceed the values of the remaining regions, this region has been considered as an individual cluster, excluded from the cluster analysis. The cluster analysis resulted in the definition of six clusters consisting of regions with similar indicators' statistics characteristics. The presented approach changes the traditional approach to clusters in tourism and provokes thinking about new criteria of clustering and solutions in the field of tourism, especially when considering future cooperation, competitiveness, and sustainable development.
\end{abstract}

Keywords: sustainability services marketing matrix; cluster analysis; tourism indicators; regional disparity

\section{Introduction}

The demand for quality services and competitive business environments have led to the definition of several quality measurement methods. As summarized by Charles and Kumar [1], abundant research has been carried out to measure the quality of services in various sectors (e.g., banking services, medical services, travel and tourism, mobile communications, etc.). Most of the people, who travel, like to have information concerning a journey, accommodation, food, and even beyond these few necessities on the supply side. On the other hand, the people who prepare the journey, accommodation, food, and other services also need to acquire information on the demand side of market (preferences). The asymmetry of information may cause market failures. The production 
function in the tourism industry is the starting point for this quite complex analysis, for instance, the production function described by Smith [2].

The general statistics of demand and supply (e.g., overnights or bed places) are mostly known in a country that tries to open-up for tourists. Such statistics are presented in this paper with the help of the cluster analysis. This cluster analysis and its results should serve further research in the tourism industry. The main aim of the paper is to present an "alternative" approach to study and research in the field of clusters in tourism that are based on Porter's cluster theory [3,4].

The tourism sector combines a diversity of subsectors (transportation, food, culture entertainment, etc.). Also, in terms of tourism outputs, there may be a diversity of positive and negative effects. A prevalence of positive effects is desired in peoples' experiences and companies' profits. A counterbalance of these positives are negatives on the side of the planet (e.g., environmental load). Three "P": Planet, People, and Profit are taken into consideration as a triple line approach [5]. In Reference [5], authors discuss the Sustainability Services Marketing Matrix (SSMM) in detail. Based on this approach, the cluster analysis in the present study focuses on the following conjunctions: (1) Place vs. people (urban and rural tourism in variables used later), (2) product vs. people (nights—in variables used later-suggest the product of city breaks [6,7], weekend stays only, etc.), (3) participants vs. people (bed places in variables used later for cluster analysis that can lack a bit of detail $[8,9])$. The triple line approach (planet, people, and profit) is complex and rich and may lead to a variety of assessments. The understanding of tourism is of a regional character for most of the communities, this is why clusters formed of regions can be useful here. Furthermore, the proximity of Visegrad countries can use the advantage of a common marketing strategy and thus an SSMM. Such a manifold scale of research is not feasible for this paper. In this case, the hindrance is represented by the variables that need to be gathered and linked to the right position.

Xiao and Smith [10] have pointed out that one of the major limitations of research in tourism is caused by the fact that the research is, in most cases, concerned with a single case, location, nationality, etc. (e.g., [11,12]). The authors in Reference [10] prove this fact to be acceptable, however, they emphasize that a methodological implementation is beneficial to overall tourism research. One such complex methodology is comprehended by the Swedish Destination Management Information System (DMIS) [13], which is complex and relatively easy to implement thanks to information and communication technologies. Another example is the Destination Business Information System (DBIS) currently developed in Slovakia [14-16]. This shows that Online Analytical Processing (OLAP) presents results of data mining that can include these tools: Artificial neural networks, decision analysis, rule induction, K-nearest neighbor techniques, clustering, as well as association rules [17].

\section{Literature Review and Theoretical Considerations}

Clusters in tourism have become a relatively large subject of interest in the last two decades. As summarized by Ferreira and Estevao [18], the interest in cluster issues lies in the impact of the performance, regional development, and countries competitiveness [19]. In various regions or countries, clusters have played a significant role in tourism [20]. Moreover, Jackson and Murphy [20] argue that, applying the cluster theory in the tourism sector, the satisfaction of tourists does not only depend on the primary attraction of the place, but also on the quality and efficiency of related businesses (hotels, restaurants, etc.) [18].

Various authors have introduced a definition of the tourism cluster, specific approach of use, or an application of clustering in tourism. A classical approach to the clusters in tourism is primarily based on Porter's cluster theory (Figure 1) [3,4]. According to Porter [4], clusters are "geographic concentrations of interconnected companies, specialized suppliers, service providers, firms in related industries, and associated institutions (universities, standards agencies, and trade associations) in particular fields that compete but also cooperate". 


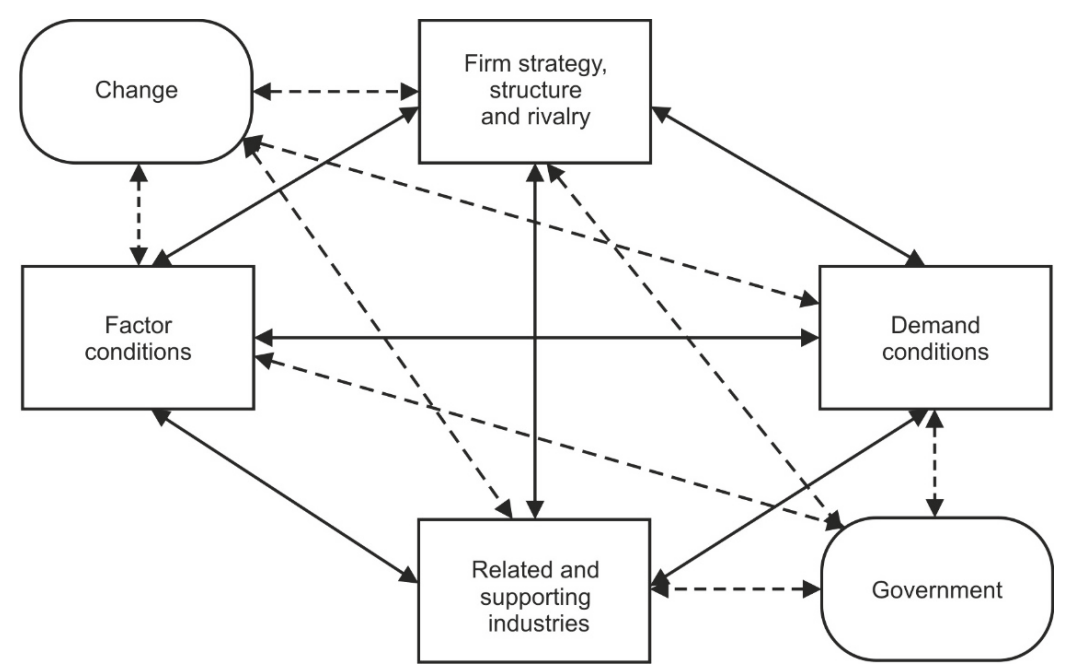

Figure 1. Porter's Diamond Model [3].

Jackson and Murphy [20] note that clusters have become significant forces in tourism development, particularly in cases where they have transformed or developed into active organizations or destination associations. As summarized by da Cunha and da Cunha [21], Monfort's tourism cluster concept [22] is based on characteristics and components. They define a cluster as "a complex group of different elements, including services carried out by tourism companies or business (lodging, restoration, travel agencies, aquatic and theme parks, etc.); richness provided by tourist holiday experiences; multidimensional gathering of interrelated companies and industries; communication and transportation infrastructures; complementary activities (commercial allotment, holiday traditions, etc.); supporting services (formation and information, etc.); and natural resources and institutional policies". Beni's approach [23] to the tourism cluster focuses on the cohesion between agents and cooperation, based on the following definition: "Tourism cluster is a group of highlighted tourism attractions within a limited geographic space provided with high quality equipment and services, social and political cohesion, linkage between productive chain and associative culture, and excellent management in company nets that bring about comparative and competitive strategic advantages." The European Commission [24] defines a cluster as "a progressive form of business network, which has strong business objectives focusing on improving sales and profits. It makes the exchange of information and technology possible, encouraging different ways of co-ordination and collaboration within them". According to Kachniewska [25], there is no one recommended cluster model that would be appropriate in every condition. She assumes that the formulation of attributes of the tourism cluster should refer to different cluster classifications, based on the following criteria:

- the economy sector,

- modernity of the industry,

- foundation motives,

- governance system,

- form of cooperational type,

- level of awareness,

- scope,

- life cycle stage,

- the structure of the cluster $[25,26]$. 
According to the characteristics of the tourism cluster, local development programs should consider it as a local strategy for combating regional disparities and social inequality [27].

Based on the regional competitiveness model of cluster introduced by Fereira and Estevao [18], if the interconnection links between tourism product and tourist destination are effective, the tourism cluster will work in a productive way [28].

Despite the general acceptance, popularity, and application of the Porter's Diamond Model, Davies and Ellis [29] criticize the model because "sustained prosperity may be achieved without a nation becoming 'innovation-driven', strong 'diamonds' are not in place in the home bases of many internationally successful industries and inward foreign direct investment does not indicate a lack of 'competitiveness' or low national productivity" [29].

In general, Porter's cluster theory $[3,4]$ is an approach that focuses on companies and results in finding competitive strengths. However, on a large scale, there are also other tools that can be used, e.g., input-output analyses, when studying the industry that comprises small and medium-sized enterprises (SMEs) and transnational corporations [30-32]. Another option can be data envelopment analysis for a truly microeconomic approach of only one part of a service, e.g., accommodation [33] This is the way for profit seeking companies that watch the signposts for efficiency. However, efficiency in tourism is sustainable if the product itself is sustainable [34].

Similar to companies, consumers are also willing to achieve a reasonable ratio that compares price and performance. In this regard, consumers in tourism may have various motivations for his/her willingness to undertake tourism experience. The reasons may range from discovering history and culture, through adventure, adrenaline, fun and health seeking, to the environmentally based cases $[35,36]$.

From a historical perspective, religious and/or health pilgrimage reasons (e.g., to Santiago de Compostela) can be considered the forerunners of European tourism. Already in the Middle Ages, the religious or health travelers were supported by simple accommodations and food facilities established on the way towards the destination. The development of facilities was notable especially in places where the healing effects of spring water, mud, ocean, or mountain air proved themselves as a cure. As "side effects", health travelers often noticed the landscapes and/or cultural events during their visits to different regions. This turned the attention of locals (one of the first stakeholders) towards enriching and diversifying facilities and services (e.g., for pleasure, gambling, etc.). In Europe, Thomas Cook introduced the first organized tourist trips among first tourists' products in 1842 [36]. Development in the tourism sector was driven by the increasing number of outbound travelers that led to the global tourism market (even Antarctica is on the map of tourism). Therefore, creating or defining geographical regions at different scales (e.g., for tourism development purposes, or competitiveness increase) represented by clusters or networks is reasonable.

Recent tourism development strategies are closely connected to various sustainability issues [37-41]. On the customer side, one of the most crucial points is tourist satisfaction. In this regard, the most complex approach has been introduced by Pomering, Noble and Johnson [5], recently updated by Pomering and Johnson [41] — the Sustainability Services Marketing Matrix. In this matrix, eight services marketing mix elements cross-reference the three pillars of the triple line to provide a sustainability-relevant services marketing framework for operationalizing sustainability (Table 1) [41].

The SSMM approach may significantly help solve various sustainability issues via decision-making captured within the elements of the services marketing mix [41]. The cluster product may well encompass the triple line and SSMM. A cluster product that helps to conserve nature and history needs good management based on well-timed information [42].

Understanding first two points regarding (1) companies and their profit, and (2) consumers and their utility, there is a third to the conundrum, and that is the planet. While profit and utility increase, the planet often suffers, e.g., residents living in cities crowded by tourists $[43,44]$. The number of visitors has been included in the cluster analysis presented in this paper. 
Table 1. The Sustainability Services Marketing Matrix [41].

\begin{tabular}{|c|c|c|c|c|c|c|c|c|}
\hline & Product & Price & Promotion & Place & Participants & Process & $\begin{array}{l}\text { Physical } \\
\text { Evidence }\end{array}$ & Partnerships \\
\hline Planet & $\begin{array}{c}\text { Service } \\
\text { product } \\
\text { impact on } \\
\text { Planet }\end{array}$ & $\begin{array}{c}\text { Pricing } \\
\text { impact on } \\
\text { Planet }\end{array}$ & $\begin{array}{c}\text { Promotion } \\
\text { impact on } \\
\text { Planet }\end{array}$ & $\begin{array}{c}\text { Place } \\
\text { impact on } \\
\text { Planet }\end{array}$ & $\begin{array}{c}\text { Participants } \\
\text { impact on } \\
\text { Planet }\end{array}$ & $\begin{array}{c}\text { Process } \\
\text { impact on } \\
\text { Planet }\end{array}$ & $\begin{array}{l}\text { PE impact } \\
\text { on Planet }\end{array}$ & $\begin{array}{c}\text { Partnership } \\
\text { impact on } \\
\text { Planet }\end{array}$ \\
\hline People & $\begin{array}{c}\text { Service } \\
\text { product } \\
\text { impact on } \\
\text { people }\end{array}$ & $\begin{array}{l}\text { Pricing } \\
\text { impact on } \\
\text { People }\end{array}$ & $\begin{array}{c}\text { Promotion } \\
\text { impact on } \\
\text { People }\end{array}$ & $\begin{array}{c}\text { Place } \\
\text { impact on } \\
\text { People }\end{array}$ & $\begin{array}{c}\text { Participants } \\
\text { impact on } \\
\text { People }\end{array}$ & $\begin{array}{c}\text { Process } \\
\text { impact on } \\
\text { People }\end{array}$ & $\begin{array}{l}\text { PE impact } \\
\text { on People }\end{array}$ & $\begin{array}{c}\text { Partnership } \\
\text { impact on } \\
\text { People }\end{array}$ \\
\hline Profit & $\begin{array}{l}\text { Service } \\
\text { product } \\
\text { impact on } \\
\text { long-term } \\
\text { Profitability }\end{array}$ & $\begin{array}{l}\text { Pricing } \\
\text { impact on } \\
\text { long-term } \\
\text { Profitability }\end{array}$ & $\begin{array}{l}\text { Promotion } \\
\text { impact on } \\
\text { long-term } \\
\text { Profitability }\end{array}$ & $\begin{array}{c}\text { Place } \\
\text { impact on } \\
\text { long-term } \\
\text { Profitability }\end{array}$ & $\begin{array}{l}\text { Participants } \\
\text { impact on } \\
\text { long-term } \\
\text { Profitability }\end{array}$ & $\begin{array}{l}\text { Process } \\
\text { impact on } \\
\text { long-term } \\
\text { Profitability }\end{array}$ & $\begin{array}{l}\text { PE impact } \\
\text { on long-term } \\
\text { Profitability }\end{array}$ & $\begin{array}{l}\text { Partnership } \\
\text { impact on } \\
\text { long-term } \\
\text { Profitability }\end{array}$ \\
\hline
\end{tabular}

Clustering can point out the existing trend of "tourist accumulation" that can be then influenced by motivating tour operators to spread the number of tourists over the near-by areas of the cluster in preparation of a "one cluster product". In such a cluster product, the aims of sustainability can be managed better. For management, data, both qualitative and quantitative, are of crucial importance (Figure 2). In the cluster analysis presented in this paper, only quantitative data were used. This could be well accompanied with a further, in-depth literature review [45] of the results of a country classification according to their level of tourism growth during the period 2007-2016 [34]. This investigation showed that Visegrad countries were among the LTG cluster (low tourism growth) based on factor analysis. Such results seem to coincide with the better management or regulation of the tourism flows [46].

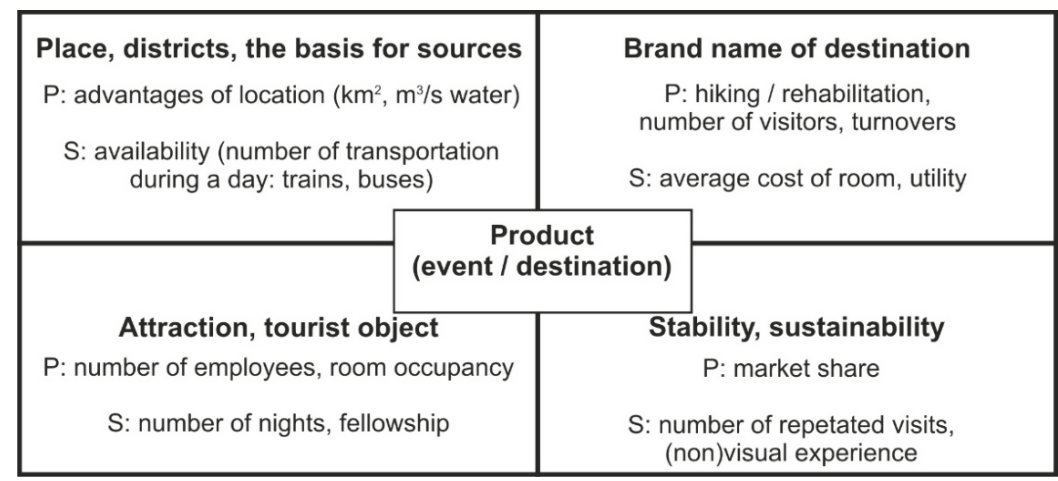

Figure 2. Scheme of general concept towards the "one cluster product" and its criteria for evaluations, for instance in cluster analysis (P: provider of services, S: consumer view).

3. Empirical Aims and Methodology: Disparities Among Regions of Middle and Eastern Europe in the Field of Tourism

There are many different approaches that are applied in the definition of regional disparity. However, in any case, disparity is considered a multi-dimensional problem [47].

In the frame of European Union cohesion, according to the horizontal classification, we distinguish three basic types of disparities: Economic, social and territorial. As territorial indicators, we consider the indicators from the area of environment, transport, health care, science, information society, and tourism.

Some adequate indicators of tourism of regional disparities can be identified in the Eurostat publication Methodological Manual for Tourism Statistics [48]. According to the characteristics of the 
tourism cluster, local development programs consider it to be a local strategy for combating regional disparities and social inequality. Porter [3] emphasizes that tourism does not depend only on the appeal of the main attraction (beaches or historical sites), but also on the comfort and service of hotels, restaurants, souvenir shops, airports, other modes of transport and so on.

In this paper, 54 NUTS 2 regions have been analyzed in order to find the regional disparities from the perspective of selected accommodation tourism indicators. The following countries were included in the study: Czech Republic (8 regions), Slovak Republic (4 regions), Hungary (7 regions), Poland (16 regions), Estonia (1 region), Lithuania (1 region), Latvia (1 region), Slovenia (2 regions), Romania (8 regions) and Bulgaria (6 regions).

\subsection{Data: Indicators of Regional Tourism (by Eurostat)}

The input data for this analysis are indicators obtained from the Eurostat database. This database provides sixteen main categories of data on regional statistics by NUTS classification, but we consider only regional tourism statistics. This category is characterized by a more detailed set of indicators in a given time series. For the purpose of the study, data from the year 2014 were chosen.

The method, how the indicators of tourism statistics are constructed, can be found in the Eurostat publication [48] mentioned above. The main focus of this manual is on explanatory notes on the variables of tourism statistics and their breakdowns.

Considering the position of accommodation statistics within the system of tourism statistics, accommodation (rented or non-rented) is a core tourism subsector even if it is relevant for one part of visitors only (i.e., tourists = overnight visitors). The economic importance of this sector can be seen from the results of some countries where accommodation services accounted for between 15 to $20 \%$ of total internal tourism expenditure. Accommodation statistics is a key part of the system of tourism statistics in the EU and has a long history of data collection.

The scope of observation (or the target population) in accommodation statistics includes all tourist accommodation establishments providing, as a paid service (although the price might be partially or fully subsidized), short-term or short-stay accommodation services.

Tourism capacity/occupancy data is collected by the member states by means of the business survey (in some cases capacity data is available directly from tourism registers).

The indicators of tourism at regional level measured by Eurostat are divided into two main categories: Variables for capacity (including number of (1) establishments, (2) bed places, and (3) bedrooms) and variables for occupancy (including number of (1) nights spent, (2) arrivals of residents and non-residents, (3) occupancy rate of bedrooms, and (4) occupancy rate of bed places).

The indicators mentioned above are further divided by the degree of urbanization, by area (coastal and non-coastal), by type of tourist (resident or non-resident) and by unit (number, the percentage of the total, percentage change over previous period). Some indicators are reported per thousand inhabitants or $\mathrm{km}^{2}$. Therefore, due to our selected regions at the NUTS 2 level, the analysis started with 50 relevant indicators (Table 2). Data were processed using SPSS 19 software.

\subsection{Methods of Regional Disparities Measurement, Grouping the Regions}

The methods of regional disparities measurement are based on an inter-regional comparison, or they are mathematical and statistical methods [49,50], that also include the multivariate statistical methods (method of main components, factor analysis, cluster or discrimination analysis).

To group regions with similar levels of tourism (measured by accommodation statistics), we decided to use one of the multivariate statistical methods-cluster analysis.

The cluster analysis is a statistical method used for the task of grouping a set of objects according to certain, logically selected variables. It is based on the idea of grouping, in some sense, similar objects into the groups, which differ from each other. The object in a specific cluster share many characteristics but are very dissimilar to objects not belonging to the cluster. 
Table 2. Indicators of regional tourism (indicators in italics were used in cluster analysis).

\begin{tabular}{|c|c|}
\hline & Label \\
\hline 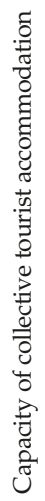 & $\begin{array}{c}\text { Number of establishments-total } \\
\text { Number of establishments - total-PcPP } \\
\text { Number of establishments-cities } \\
\text { Number of establishments - cities-PcPP } \\
\text { Number of establishments—-towns } \\
\text { Number of establishments - towns-PcPP } \\
\text { Number of establishments - rural areas } \\
\text { Number of establishments - rural areas-PcPP } \\
\text { Number of bed-places-total } \\
\text { Number of bed-places-total-PcPP } \\
\text { Number of bed-places-cities } \\
\text { Number of bed-places-cities-PcPP } \\
\text { Number of bed-places-towns } \\
\text { Number of bed-places-towns-PcPP } \\
\text { Number of bed-places-rural } \\
\text { Number of bed-places-rural-PcPP }\end{array}$ \\
\hline 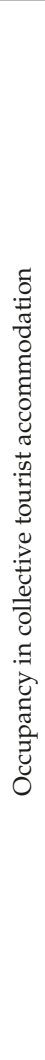 & $\begin{array}{c}\text { Net occupancy rate of bed places } \\
\text { Net occupancy rate of bedrooms } \\
\text { Arrivals of residents } \\
\text { Arrival of residents-PcPP } \\
\text { Arrivals of non-residents } \\
\text { Arrivals of non-residents-PcPP } \\
\text { Arrivals total } \\
\text { Arrivals total-PcPP } \\
\text { Total nights spent by residents-total } \\
\text { Total nights spent by residents-total-PcPP } \\
\text { Total nights spent by residents-cities } \\
\text { Total nights spent by residents-cities-PcPP } \\
\text { Total nights spent by residents-towns } \\
\text { Total nights spent by residents-towns-PcPP } \\
\text { Total nights spent by residents-rural } \\
\text { Total nights spent by residents-rural-PcPP } \\
\text { Total nights spent by non-residents-total } \\
\text { Total nights spent by non-residents-total-PcPP } \\
\text { Total nights spent by non-residents-cities } \\
\text { Total nights spent by non-residents-cities-PcPP } \\
\text { Total nights spent by non-residents-towns } \\
\text { Total nights spent by non-residents-towns-PcPP } \\
\text { Total nights spent by non-residents-rural } \\
\text { Total nights spent by non-residents-rural-PcPP } \\
\text { Nights spent by residents and non-residents-total } \\
\text { Nights spent by residents and non-residents-total-PcPP } \\
\text { Nights spent by residents and non-residents-cities } \\
\text { Nights spent by residents and non-residents-cities-PcPP } \\
\text { Nights spent by residents and non-residents-towns } \\
\text { Nights spent by residents and non-residents-towns-PcPP } \\
\text { Nights spent by residents and non-residents-rural } \\
\text { Nights spent by residents and non-residents-rural-PcPP } \\
\text { Nights spent by residents and non-residents-per thousand inhabitant } \\
\text { Nights spent by residents and non-residents-per km }{ }^{2}\end{array}$ \\
\hline
\end{tabular}

Note: PcPP-percentage change over previous period.

The aim of cluster analysis is to minimize the variability within clusters and maximize the variability between clusters. Unlike other reduction methods, there is no prior knowledge about which element belongs to which cluster [51-54]. The particular steps of the analysis follow: 
1. Correlation matrix-testing of the correlation between variables.

2. The variables have been standardized due to the avoidance of the influence of various units.

3. To create hierarchical agglomeration clustering, the Ward method has been applied.

4. The determination of the best fitting number of the created clusters.

5. The regions were matched to the appropriate number of clusters.

6. The clustering presentation using dendrogram.

For each cluster defined, the calculations of variables' average values were performed.

At first, the correlation of all possible pairs of variables was calculated (using the Pearson Correlation Coefficient). The results showed that there were many pairs of variables with a strong correlation. However, one of the required conditions for the proper analysis is the absence of multi-correlation between variables. To meet the condition of mutually uncorrelated variables, there is an option of providing Principal Component Analysis (PCA) at the beginning. An important condition in PCA is that the number of observations should be at least five times greater than a number of variables [55]. In the beginning, we had 50 variables and only 54 observations (regions). Hence, it was impossible to run PCA. Therefore, we decided to continue the analysis with removing less important variables from the pairs with stronger Pearson correlation. This removal assured that the variables would not be mutually correlated. After that, only 13 variables of tourism (Table 2) remained and were used as input variables for clustering.

The standardization of variables was carried out before the cluster analysis because we opted to remove the influence of the tremendous differences in the variance values that was partly due to various measurement units. The standardized variables were provided in line with the formula of calculation of z-score:

$$
Z_{i j}=\frac{x_{i j}-\overline{x_{j}}}{s_{j}}
$$

where:

$i=1,2, \ldots, n$ ( $n$ is the number of observations),

$j=1,2, \ldots, p$ ( $p$ is the number of variables),

$s j$ is a standard deviation of particular variable,

$\overline{x_{j}}$ is an average value of the particular variable.

The squared Euclidean distance that forms the basis of Ward's clustering method was applied to gauge the distance between observations. The calculation formula for distance is as follows:

$$
d_{i j}^{2}=\sum_{k=1}^{p}\left(X_{i k}-X_{j k}\right)^{2}
$$

where:

$X i k$ denotes the value of the $k t h$ variable for the $i t h$ observation,

$X j k$ denotes the value of the $k t h$ variable for the $j t h$ observation.

To determine the optimum solution of clustering, the hierarchical cluster analysis, specifically Ward's method was used. Referring to this method, it does not rest upon the optimization of distances between clusters, as it is the case in other methods (e.g., nearest neighbor, furthest neighbor, median method, centroid method). Instead of that, it uses that analysis of the variance approach to evaluate the distances between clusters and emphasizes the minimization of the heterogeneity of the clusters. Cluster membership is assessed by calculating the total sum of squared deviations from the mean of a cluster. The criterion for fusion $\Delta C 1$ is that it should be the smallest possible increase in the error sum of squares:

$$
\Delta C_{1}=\frac{n_{h} n_{h}{ }^{\prime}}{n_{h}+n_{h}{ }^{\prime}} \sum_{j=1}^{p}\left(X_{h j}-\bar{X}_{h j}\right)^{2}
$$


where:

$n h$ is the cardinality of cluster $h$,

$X h j$ is a vector of the variable's values of the $j$ th object in the cluster $h$,

$\bar{X}_{h j}$ is the cluster's average.

The advantage of the method is the appearance of the clusters that are less massive (smaller) and relatively alike in terms of frequencies. The method can also be characterized by the tendency of removing the clusters with the least number of observations, which is not the appreciated characteristic of the method.

\section{Results of the Cluster Analysis}

After researching the variables' values for the Prague region, it was found that many variables of this one single region significantly exceed the values of the remaining regions. Because extreme values are not desired in this cluster analysis, this region was excluded from the analysis. After the accomplishment of the analysis, the region of Prague was added to the remaining clusters as a separate cluster consisting of a single region.

The first output from clustering is presented by the proximity matrix. It includes the distances between each pair of regions. The highest distance (this means the highest rate of dissimilarity) was recorded between Polish region PL42_Zachodniopomorskie and two Bulgarian regions: BG32_Severen Tsentralen and BG31_Severozapaden (distance: 13,5 resp. 13,3). The lowest distance (and the highest rate of similarity) was between two Polish regions PL33_Lubelskie and PL31_Swietokrzyskie (distance $=0.85$ ).

The results of each step in the hierarchical clustering process are depicted in Figure 3, where the values of the agglomerative coefficient are shown. These values represent the value of the distance statistics which is the means for forming the clusters. These coefficients helped us to make the decision concerning the number of clusters to choose. The number of clusters stopped with the number satisfying the condition: "Between two agglomerative coefficients are larger distances" (note: In Figure 3, they are shown by the black line). In this analysis, it was estimated at six clusters.

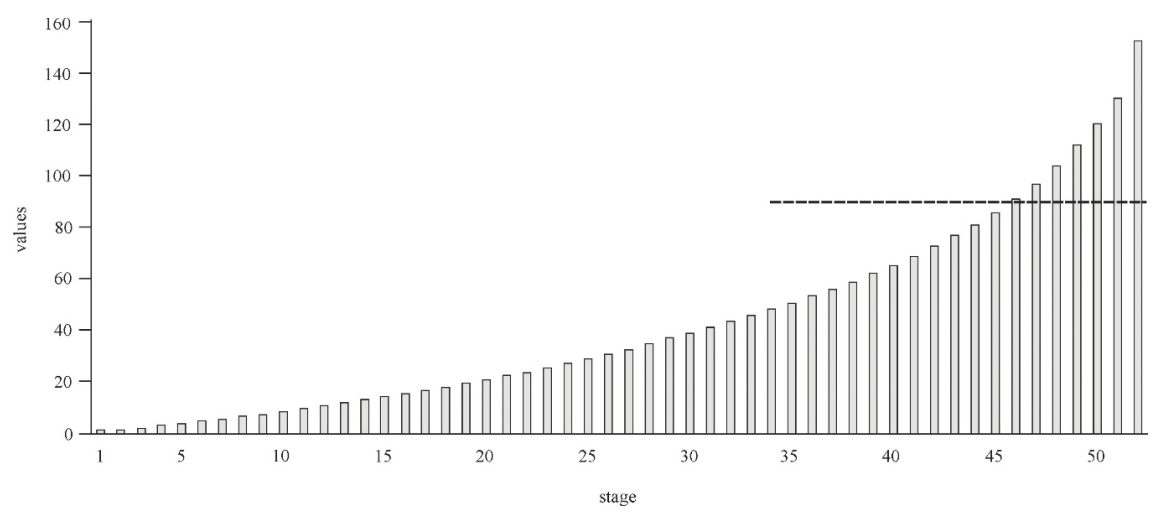

Figure 3. Cluster analysis-agglomeration schedule.

In the graphical presentation of the clusters analysis' results, we observe the joining of particular regions using a dendrogram. The dendrogram is a visual representation of the steps in a hierarchical clustering solution that shows the clusters being combined and the values of the distance coefficients at each step. Connected vertical lines designate joined cases. The dendrogram rescales the actual distances to numbers between 0 and 25, preserving the ratio of the distances between steps. The dendrogram of our clustering (Figure 4) implies (shown by black dotted line) the rising of six clusters. The arisen clusters are shown in the rectangle. 


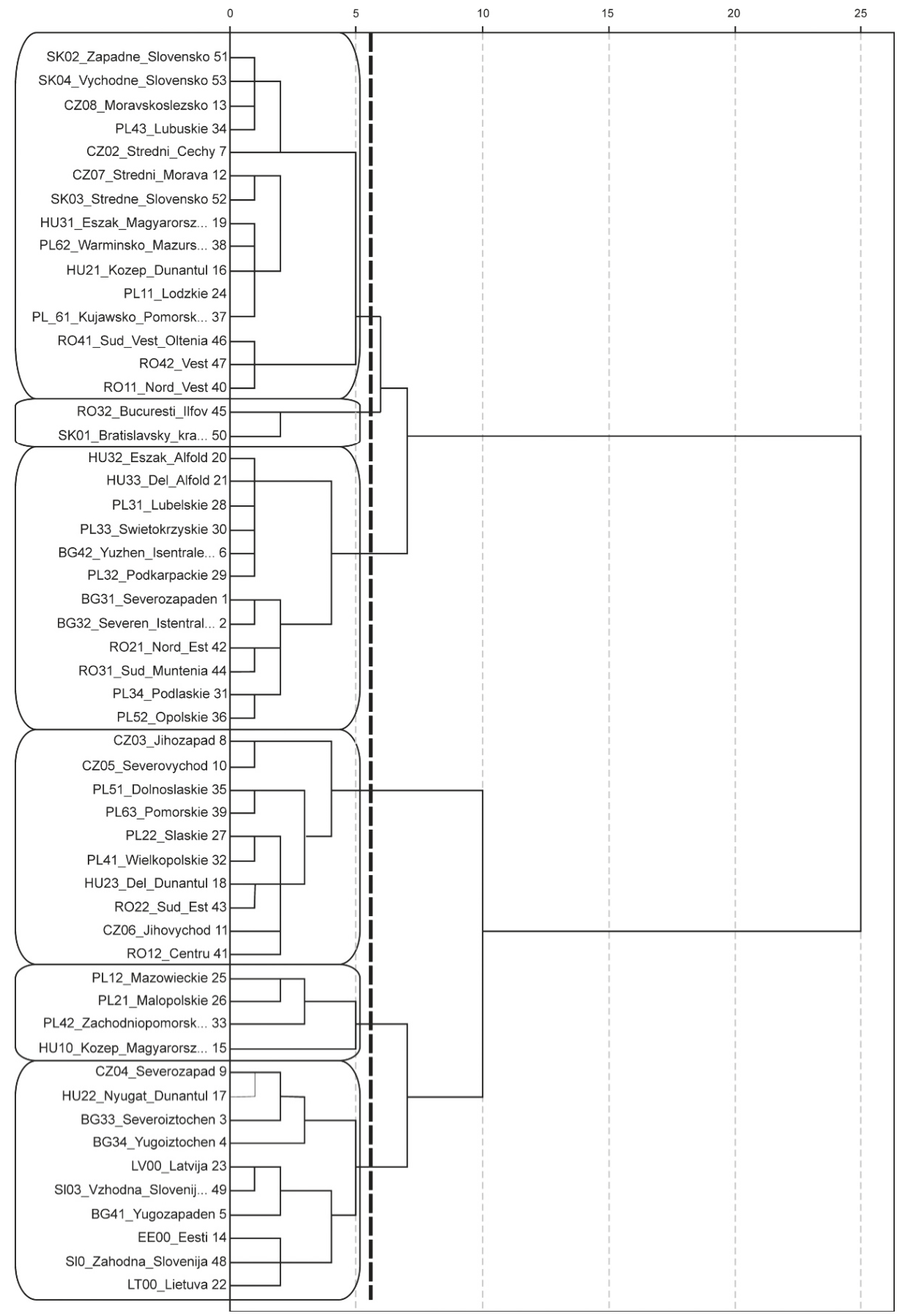

Figure 4. Dendrogram of clustering. 
It is necessary to evaluate the outcome of the cluster analysis regarding the quality of the spread of the individual regions into clusters. At the same time, an appropriate number of the arisen clusters should be assessed. Both matters have already been done in the paragraph above.

The outcome itself does not have a endogenous meaning to the analyst unless it is confronted with the goals of the cluster analysis and with the known facts. The correct quantitative interpretation of the individual clusters by means of the variables' values is, therefore, important. As is the qualitative interpretation with respect to the logical explanations of the particular clusters $[48,50]$. Therefore, to compare among the clusters regarding individual indices their average values were used (Table 3). To the six clusters created in the analysis, the Prague region-a separate cluster-was added for the sake of the comparison.

Table 3. Characteristics of the clusters-the mean values of the variables.

\begin{tabular}{|c|c|c|c|c|c|c|c|}
\hline & \multicolumn{6}{|c|}{ Ward Method } & \multirow[b]{2}{*}{ Prague } \\
\hline & Cluster 1 & Cluster 2 & Cluster 3 & Cluster 4 & Cluster 5 & Cluster 6 & \\
\hline & Mean & Mean & Mean & Mean & Mean & Mean & \\
\hline NE total & 409 & 1068 & 605 & 1270 & 939 & 197 & 757 \\
\hline NBP total & 23008 & 66539 & 40232 & 91786 & 81700 & 24498 & 91613 \\
\hline NBP total (PcPP) & 3,8 & 1,6 & $-2,2$ & 1,3 & 3,1 & 1,6 & $-4,4$ \\
\hline AR-R & 526670 & 748218 & 711372 & 1455388 & 1964992 & 528630 & 780961 \\
\hline AR-NR & 101075 & 1097086 & 180356 & 370612 & 1514119 & 762883 & 5315054 \\
\hline AR total & 627745 & 1845305 & 891728 & 1826000 & 3479111 & 1291513 & 6096015 \\
\hline TN-R total & 1245243 & 1954190 & 1953264 & 3931006 & 5666570 & 1042466 & 1368554 \\
\hline TN-NR total & 224925 & 3525509 & 478193 & 864634 & 3807263 & 1297787 & 13381733 \\
\hline
\end{tabular}

Explanations: NE total: number of establishments-total, NBP total: number of bed-places-total, NBP total (PcPP): number of bed-places-total (percentage change over previous period), NOR-BP: net occupancy rate of bed places, NOR-BR: net occupancy rate of bedrooms, AR-R: arrivals of residents, AR-NR: arrivals of non-residents, AR total: arrivals total, TN-R total: total nights spent by residents- total, TN-NR total: total nights spent by non-residents - total, NS-R-NR total: nights spent by residents and non-residents—-total, NS-R-NR (pTHAB): nights spent by residents and non-residents-per thousand inhabitants, NS-R-NR $\left(\mathrm{pkm}^{2}\right)$ : Nights spent by residents and non-residents-per $\mathrm{km}^{2}$.

Specific numbers in characteristics of the clusters (minimum value, maximum value, the coefficient of variation as the measure of relative variability) are presented in Tables 4 and 5.

Cluster 1 contains 12 regions ( $3 \mathrm{BG}, 2 \mathrm{HU}, 5 \mathrm{PL}, 2 \mathrm{RO}$ ). This is the cluster of regions with the lowest average values of the indicators apart from the highest value of a number of total bed-places (percentage change over previous period) which indicates an increase of 3,8\%.

Cluster 2 contains ten regions-the region with the capital city of Bulgaria and two Bulgarian coastal regions, one Czech region situated between Prague and Germany, three Baltic states and both regions of Slovenia. This cluster has the highest mean value of nights spent by residents and non-residents per thousand inhabitants (3927) and the second highest value of total nights spent by non-residents. In this cluster, the rest of the variables reaches rather higher values.

Cluster 3 is the largest cluster and contains 15 regions ( 3 CZ, 2 HU, 4 PL, 3 RO, 3 SK). This cluster is characterized by the low values of the variables. Among all six arisen clusters, this the only one that shows a decrease in the number of bed-places (percentage change over previous period) which indicates a decline of $2,2 \%$. As for Cluster 3 , it is a relatively homogenous group of regions.

Cluster 4 contains ten regions ( $3 \mathrm{CZ}, 1 \mathrm{HU}, 4 \mathrm{PL}, 2 \mathrm{RO})$. This cluster features the highest mean values of the number of establishment (1270) and the number of bed places (91786), which is higher than the value in Prague (91613). This cluster is also characterized by the second highest value of arrivals of residents and the total nights spent by residents. The regions in this cluster create a homogenous group because every coefficient of variation is lower than $50 \%$. 
Cluster 5 contains one Hungarian region and three Polish regions. In this cluster, the average values of variables are the highest, i.e., second highest within the six arisen clusters. This is because this cluster contains the capital of Hungary (Budapest), the capital of Poland (Warsaw), the region with the Tatra Mountain Range in Poland and one Polish coastal region, which borders with Germany.

Cluster 6 contains two regions-the capital city of Slovakia (Bratislava) and the capital city of Romania (Bucharest). This cluster ranks the best only in the scope of one variable: Nights spent by residents and non-residents-per $\mathrm{km}^{2}$ (1222).

Cluster 7-Prague—is a region on its own (Table 3).

Table 4. Cluster descriptive characteristics of total number of establishments, total number of bed-places, total number of bed-places (percentage change over previous period), net occupancy rate of bed places, net occupancy rate of bedrooms, arrivals of residents, and arrivals of non-residents.

\begin{tabular}{|c|c|c|c|c|c|c|c|c|c|}
\hline & & & \multicolumn{7}{|c|}{ Indicators } \\
\hline & & & NE Total & N-BP Total & N-BP Total (PcPP) & NOR-BP & NOR-BR & AR-R & AR-NR \\
\hline \multirow{24}{*}{ 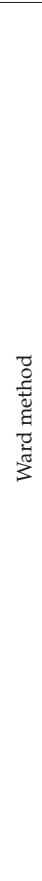 } & \multirow{4}{*}{ Cluster 1} & Mean & 409 & 23008 & 3,8 & 26 & 33 & 526670 & 101075 \\
\hline & & Max & 709 & 51201 & 10 & 31 & 40 & 768159 & 172631 \\
\hline & & Min & 142 & 7913 & $-1,2$ & 17 & 23 & 231813 & 26608 \\
\hline & & $\mathrm{CV}$ & $47 \%$ & $56 \%$ & $x$ & $16 \%$ & $16 \%$ & $36 \%$ & $52 \%$ \\
\hline & \multirow{4}{*}{ Cluster 2} & Mean & 1068 & 66539 & 1,6 & 40 & 50 & 748218 & 1097086 \\
\hline & & Max & 2062 & 128217 & 7,7 & 50 & 68 & 1316696 & 1983315 \\
\hline & & Min & 596 & 39074 & $-6,6$ & 29 & 36 & 461048 & 617558 \\
\hline & & $\mathrm{CV}$ & $52 \%$ & $41 \%$ & $x$ & $14 \%$ & $17 \%$ & $38 \%$ & $45 \%$ \\
\hline & \multirow{4}{*}{ Cluster 3} & Mean & 605 & 40232 & $-2,2$ & 28 & 40 & 711372 & 180356 \\
\hline & & Max & 1064 & 60982 & 2,2 & 32 & 69 & 1022980 & 303587 \\
\hline & & Min & 283 & 18211 & $-9,8$ & 23 & 30 & 426461 & 40719 \\
\hline & & $\mathrm{CV}$ & $35 \%$ & $39 \%$ & $x$ & $9 \%$ & $29 \%$ & $27 \%$ & $38 \%$ \\
\hline & \multirow{4}{*}{ Cluster 4} & Mean & 1270 & 91786 & 1,3 & 29 & 35 & 1455388 & 370612 \\
\hline & & Max & 2235 & 153235 & 5,6 & 37 & 43 & 1906310 & 580736 \\
\hline & & Min & 636 & 42597 & $-4,9$ & 24 & 26 & 883508 & 86717 \\
\hline & & $\mathrm{CV}$ & $43 \%$ & $43 \%$ & $x$ & $14 \%$ & $14 \%$ & $22 \%$ & $44 \%$ \\
\hline & \multirow{4}{*}{ Cluster 5} & Mean & 939 & 81700 & 3,1 & 44 & 55 & 1964992 & 1514119 \\
\hline & & Max & 1418 & 121617 & 5,4 & 46 & 60 & 2702422 & 3157529 \\
\hline & & Min & 476 & 47921 & 1,4 & 42 & 50 & 895617 & 543009 \\
\hline & & $\mathrm{CV}$ & $53 \%$ & $38 \%$ & $x$ & $4 \%$ & $8 \%$ & $43 \%$ & $75 \%$ \\
\hline & \multirow{4}{*}{ Cluster 6} & Mean & 197 & 24498 & 1,6 & 31 & 43 & 528630 & 762883 \\
\hline & & Max & 220 & 28013 & 2,1 & 36 & 53 & 709131 & 921131 \\
\hline & & Min & 173 & 20983 & 1,1 & 26 & 33 & 348128 & 604635 \\
\hline & & $\mathrm{CV}$ & $17 \%$ & $20 \%$ & $x$ & $22 \%$ & $33 \%$ & $48 \%$ & $29 \%$ \\
\hline
\end{tabular}

For explanations, please see Table 3 . 
Table 5. Cluster descriptive characteristics of total arrivals, total nights spent by residents, total nights spent by non-residents, total nights spent by residents and non-residents, nights spent by residents and non-residents (per thousand inhabitants), nights spent by residents and non-residents (per $\mathrm{km}^{2}$ ).

\begin{tabular}{|c|c|c|c|c|c|c|c|c|}
\hline & & & \multicolumn{6}{|c|}{ Indicators } \\
\hline & & & AR Total & TN-R Total & TN-NR Total & NS-R-NR Total & NS-R-NR (pTHAB) & NS-R-NR $\left(\mathrm{pkm}^{2}\right)$ \\
\hline \multirow{24}{*}{ 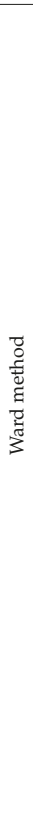 } & \multirow{4}{*}{ Cluster 1} & Mean & 627745 & 1245243 & 224925 & 1470167 & 939 & 76 \\
\hline & & $\operatorname{Max}$ & 924246 & 2319053 & 597848 & 2493552 & 1454 & 140 \\
\hline & & Min & 260184 & 445921 & 56308 & 502229 & 521 & 26 \\
\hline & & $\mathrm{CV}$ & $36 \%$ & $45 \%$ & $73 \%$ & $44 \%$ & $36 \%$ & $47 \%$ \\
\hline & \multirow{4}{*}{ Cluster 2} & Mean & 1845305 & 1954190 & 3525509 & 5479699 & 3927 & 280 \\
\hline & & Max & 3087070 & 3431178 & 6579840 & 8560753 & 8048 & 658 \\
\hline & & Min & 1208553 & 1282484 & 1799696 & 3435008 & 1614 & 64 \\
\hline & & $\mathrm{CV}$ & $35 \%$ & $33 \%$ & $43 \%$ & $27 \%$ & $57 \%$ & $70 \%$ \\
\hline & \multirow{4}{*}{ Cluster 3} & Mean & 891728 & 1953264 & 478193 & 2431457 & 1637 & 173 \\
\hline & & Max & 1192931 & 3100551 & 1004297 & 3449343 & 2821 & 374 \\
\hline & & Min & 483483 & 952851 & 85307 & 1201907 & 755 & 53 \\
\hline & & $\mathrm{CV}$ & $23 \%$ & $30 \%$ & $59 \%$ & $28 \%$ & $41 \%$ & $58 \%$ \\
\hline & \multirow{4}{*}{ Cluster 4} & Mean & 1826000 & 3931006 & 864634 & 4795640 & 2459 & 272 \\
\hline & & $\operatorname{Max}$ & 2416382 & 6023550 & 1382127 & 7093131 & 4200 & 509 \\
\hline & & Min & 1052713 & 2385487 & 324571 & 2979240 & 911 & 105 \\
\hline & & $\mathrm{CV}$ & $23 \%$ & $30 \%$ & $40 \%$ & $29 \%$ & $46 \%$ & $49 \%$ \\
\hline & \multirow{4}{*}{ Cluster 5} & Mean & 3479111 & 5666570 & 3807263 & 9473833 & 3617 & 677 \\
\hline & & Max & 4053146 & 9093763 & 7445571 & 11919404 & 7047 & 1335 \\
\hline & & Min & 2247662 & 1784343 & 2115202 & 6579854 & 1243 & 185 \\
\hline & & $\mathrm{CV}$ & $24 \%$ & $57 \%$ & $64 \%$ & $24 \%$ & $68 \%$ & $71 \%$ \\
\hline & \multirow{4}{*}{ Cluster 6} & Mean & 1291513 & 1042466 & 1297787 & 2340253 & 2216 & 1222 \\
\hline & & Max & 1630262 & 1123459 & 1537443 & 2660902 & 3266 & 1461 \\
\hline & & Min & 952763 & 961473 & 1058131 & 2019604 & 1166 & 984 \\
\hline & & $\mathrm{CV}$ & $37 \%$ & $11 \%$ & $26 \%$ & $19 \%$ & $67 \%$ & $28 \%$ \\
\hline
\end{tabular}

For explanations, please see Table 3 .

\section{Discussion and Concluding Remarks}

The cluster analysis is linked to the factor analysis as characterized previously, in the part on the methodological considerations. Clustering can be ignored in two ways: Disaggregation and aggregation [55]. In that respect, one needs to understand the consequences of such ignoring. It may lead to different results in CFA, such as inflated chi-square statistics or decreased standard errors. Therefore, it is recommended to follow the methodology of multilevel CFA (MCFA).

Even more detailed analysis is then achieved by employing some modeling approaches for analyzing the partially nested data [56]. Similarly, the modeling and visualization of the data may differ using and combining various tools, such as the business intelligence system together with the geographical information system, cartography contours, etc.

This article points out the fusion of regions of Central and Eastern Europe into clusters according to the selected indicators of tourism which Eurostat uses to evaluate tourism. In this regard, for such clusters, as presented in this paper, the definition of the South East England Development Agency (SEEDA) [57] states that "a cluster is a progressive form of business network, which has strong business objectives focusing on improving sales and profits", is more applicable. Data on such clusters, as presented in this paper, can be used in the effective planning and decision-making for the destination management [58] to support the sustainable development of tourism in a specific region. The data can also be used as a relevant base for potential future cooperation between various regions from one cluster to support tourism competitiveness and sustainable development [59-61].

However, the destination management strongly relies on actual data analyzed and composed of several indices in the demand or supply side of the tourism market. The demand (variables for 
occupancy) and supply (variables for capacity) side were presented in both the theoretical and practical point of view applied to the tourism industry. Demand and supply data reflect some of the actual requirements of the destination business, and the related destination business intelligence system (DBIS) [14-16,62]. These data represent inputs to the system. The output of the system is, besides others, clustering as presented in this paper. Within the DBIS, the data used for clustering may also be visualized via a geographical information system tool in order to provide recommendations in the field of decision-making and future planning for both destination managers and stakeholders in a specific destination and thus contribute to the sustainable development of the region.

The link between clustering, as presented in this paper on the example of the East and Central European countries' tourism industry at the NUTS 2 level, and tourism sustainability can be explained via serendipity [63-65]. According to Hom Cary [66] "serendipity in tourism is the effect by which one accidentally stumbles upon something fortunate, especially while looking for something entirely unrelated". However, serendipity [67] or a pilgrimage-like experience in traveling can happen only when potential tourists start to move from place to place, from region to region (e.g., Visegrad-V4 countries), from one cultural space to another. According to the Inglehart map [68], Poland is closer to India, the Czech Republic is closer to Germany and Slovakia to Taiwan and Hungry to Macedonia [68,69]. This supports the idea of clustering based on criteria of importance (e.g., sustainability criteria, number of nights spent or number of tourists, specific indicators given by international companies and/or agencies, e.g., Eurostat, UNWTO, etc.). It changes the traditional view on clusters in tourism $[4,18,25,29,59-61,70]$ and allows one to see new solutions for a specific sector of the economy that tourism undoubtedly is. Bearing in mind that "in most economic activities, it is the product that reaches the consumer, but when it comes to tourism, it is the opposite in that the consumer seeks for tourism services. Because of this characteristic, tourism has a heavy impact on local development" [21]. In this paper, the clusters were identified based on following points

- $\quad$ Place vs. people (variable: numbers of establishments-cities, urban areas, where people look for their touristic utilities), this suggests where the impact on sustainability can be stronger.

- $\quad$ Product vs. people (number of nights spent by non-residents as variable set in the regions), this suggests the strength(cardinality) of the impact on sustainability.

- Participants vs. people (number of bed places) can lead to some estimations of overuse, e.g., of laundry.

However, some limitations of the study should be acknowledged:

1. Results of the study presented in this paper reflect one specific type of territorial unit for statistics as a region within Europe. Recommendations towards specific clusters defined within the study may differ at lower territorial units (NUTS 3). Hence, further study of this issue in different countries or regions all around the world is required to achieve more representative and applicable results.

2. Use of more Eurostat tourism indicators in the cluster analysis may result in more accurate outputs. Potentially, in some cases, it may lead to changes within clusters and/or the number of clusters.

Nevertheless, the presented approach represents a pilot study in this field for mathematical modeling. Further investigation of the possibilities of including complementary data, e.g., on environmental indicators published under the European Union's INSPIRE initiative [71] and European Union's Earth Observation Programme Copernicus [72] is necessary to develop this method at both a theoretical and practical level, as the results may be applicable within the tourism sustainable development European Union wide; and elaborate the use of the European Union's toolkit for sustainable destinations [73].

Author Contributions: Each author (G.K, E.L., L.S., B.K., C.S., M.C., S.K., M.B.) has equally contributed to this publication.

Funding: This work was supported by the Slovak Research and Development Agency under contract no. APVV-14-0797 and the project of the Scientific Grant Agency of the Ministry of Education, Science, Research and Sport of the Slovak Republic and the Slovak Academy of Sciences No. VEGA 1/0515/18. 
Acknowledgments: Authors would like to thank anonymous reviewers for their helpful and constructive comments and suggestions that greatly contributed to improving the final version of this paper.

Conflicts of Interest: The authors declare no conflict of interest. The funders had no role in the design of the study; in the collection, analyses, or interpretation of data; in the writing of the manuscript, or in the decision to publish the results.

\section{References}

1. Charles, V.; Mukesh, K. Satisficing data envelopment analysis: An application to SERVQUAL efficiency. Measurement 2014, 51, 71-80. [CrossRef]

2. Smith, L.J. Tourism Analysis: A Handbook, 2nd ed.; Routledge: London, UK, 1995; 336p, ISBN 978-0582251601.

3. Porter, M.E. The Competitive Advantage of Nations; Free Press: New York, NY, USA, 1990; 875p, ISBN 0029253616.

4. Porter, M.A. On Competition; Harward Business Review Press: Boston, MA, USA, 1998; 485p, ISBN 978-0875847955.

5. Pomering, A.; Noble, G.; Johnson, L.W. Conceptualising a contemporary marketing mix for sustainable tourism. J. Sustain. Tour. 2011, 19, 953-969. [CrossRef]

6. Jesus, C.; Franco, M. Cooperation networks in tourism: A study of hotels and rural tourism establishments in an inland region of Portugal. J. Hosp. Tour. Manag. 2016, 29, 165-175. [CrossRef]

7. Toca Torres, C.E.; Carrillo Rodriguez, J. Ecological Analysis of a Tourism Business Network. Rbgn-Revista Brasileira De Gestao De Negocios 2015, 17, 1044-1063. [CrossRef]

8. Dobson, K.; Boone, S.; Andries, P.; Daou, A. Successfully creating and scaling a sustainable social enterprise model under uncertainty: The case of ViaVia Travellers Cafés. J. Clean. Prod. 2018, 172, 4555-4564. [CrossRef]

9. Asmelash, A.G.; Kumar, S. Assessing progress of tourism sustainability: Developing and validating sustainability indicators. Tour. Manag. 2019, 71, 67-83. [CrossRef]

10. Xiao, H.; Smith, S.L.J. Case studies in tourism research: A state-of-the-art analysis. Tour. Manag. 2006, 27, 738-749. [CrossRef]

11. Hosany, S.; Prayag, G.; Deesilatham, S.; Causevic, S.; Odeh, K. Measuring Tourists' Emotional Experiences: Further Validation of the Destination Emotion Scale. J. Travel Res. 2015, 54, 482-495. [CrossRef]

12. Tong, D.Y.K. International Tourists Interest in Street Vendors Souvenirs: A Descriptive Study. In Proceedings of the 4th International Conference on Tourism Research (4ICTR), Kola Kinabalu, Malaysia, 9-11 December 2014; Othuman Mydin, M.A., Marzuki, A., Eds.; [CrossRef]

13. Fuchs, M.; Abadzhiev, A.; Svensson, B.; Hopken, W.; Lexhagen, M. A knowledge destination framework for tourism sustainability: A business intelligence application from Sweden. Tourism 2013, 61, 121-148.

14. Sidor, C.; Kršák, B.; Štrba, L'. The role of open data on the road to destination business intelligence: Notes on SK NACE I55. In Hotelnictví, Turismus a vzdělávání; Vysoká škola hotelová v Praze: Praha, Czech Republic, 2017; pp. 165-172, ISBN 978-80-87411-99-5.

15. Sidor, C.; Kršák, B.; Štrba, L'. Building up basic tourism geo content for destination business intelligence via open street map file dumps. In The Image and Sustainability of Tourism Destinations. Proceedings of 9th International Tourism Congress; Polytechnic Institute of Leiria: Peniche, Portugal, 2017.

16. Štrba, L'; Kršák, B.; Sidor, C.; Blišt’an, P. Destinations business information systems for smart destinations: The case study of Kosice County. Int. J. Bus. Manag. Stud. 2016, 5, 177-180.

17. Fridgen, J.D. Dimensions of Tourism; AH\&MA Education Institute: East Lansing, MI, USA, 1991; 361p, ISBN 978-0866121040.

18. Ferreira, J.; Estevao, C. Regional competitiveness of a tourism cluster: A conceptual model proposal. Rev. Encontros Científicos Tour. Manag. Stud. 2009, 5, 37-51.

19. Rocha, H. Entrepreneurship and Development: The Role of Clusters. Small Bus. Econ. 2004, 23, 363-400. [CrossRef]

20. Jackson, J.; Murphy, P. Clusters in regional tourism: An Australian case. Ann. Tour. Res. 2006, 33, 1018-1035. [CrossRef]

21. da Cunha, S.K.; da Cunha, J.C. Tourism cluster competitiveness and sustainability: Proposal for a systemic model to measure the impact of tourism on local development. Bar Braz. Adm. Rev. 2005, 2, 47-62. [CrossRef] 
22. Monfort, M.V.M. Competitividad y factores de éxito en la "hotelería de litoral": Experiencia de los destinos turistícos Benidorm y Peniscola. Ph.D. Thesis, Universidad de Valencia, Valencia, Spain, 2000.

23. Beni, M.C. Globalizacao do Turizmo: Megatendencias do Setor e a Realidade Brasileira; Aleph: Sao Paulo, Brazil, 2003; 208p, ISBN 978-8576571087.

24. Final Report on the Expert Group in Enterprise Clusters and Networks. Available online: http://ibr.hi.is/sites/ibr.hi.is/files/FINAL_REPORT_OF_THE_EXPERT_GROUP_ON_ENTERPRISE_ CLUSTERS_AND_NETWORKS.pdf (accessed on 3 January 2019).

25. Kachniewska, M. Towards the Definition of a Tourism Cluster. J. Enterp. Manag. Innov. 2014, 9, 33-56. [CrossRef]

26. Gorynia, M.; Jankowska, B. Koncepcja klastrów jako sposób regulacji zachowań podmiotów gospodarczych. Ekonomista 2007, 3, 311-340.

27. Melisidou, S.; Papageorgiou, A.; Papayiannis, D.; Varvaressos, S. Tourism clusters as a potentially effective tool for local development and sustainability. Rev. Tour. Sci. 2014, 9, 218-232.

28. Fundeanu, D.D. Innovative Regional Cluster, Model of Tourism Development. Procedia Econ. Financ. 2015, 23, 744-749. [CrossRef]

29. Davies, E.; Ellis, P. Porter's competitive advantage of nations: Time for the final judgement? J. Manag. Stud. 2000, 37, 1188-1213. [CrossRef]

30. Kol'veková, G.; Raisová, M. Value-added close-up of Slovak industries regarding the search of sustainability. In CEFE2017 Conference Proceedings; Technical University of Kosice: Kosice, Slovakia, 2017; pp. 403-410.

31. González-Benito, J.; Suárez-González, I. A Study of the Role Played by Manufacturing Strategic Objectives and Capabilities in Understanding the Relationship between Porter's Generic Strategies and Business Performance. Br. J. Manag. 2010, 21, 1027-1043. [CrossRef]

32. Romero, I.; Tejada, P. A multi-level approach to the study of production chains in the tourism sector. Tour. Manag. 2011, 32, 297-306. [CrossRef]

33. Kršák, B.; Kol'veková, G.; Liptáková, E.; Štrba, L'.; Mesároš, P.; Sidor, C.; Mitterpák, M. Meranie efektívnosti v podnikoch ubytovacích služieb. Podn. Rev. 2016, 15, 38-47.

34. Pulido-Fernández, J.I.; Cárdenas-Gacía, P.J.; Espinosa-Pulido, J.A. Does environmental sustainability contribute to tourism growth? An analysis at the country level. J. Clean. Prod. 2019, 213, 309-319. [CrossRef]

35. Dickmann, F. Effectiveness and efficiency of tourism maps in the World Wide Web and their potential for mobile map services. In Map-Based Mobile Services; Springer: Berlin, Germany, 2005; pp. 43-53.

36. Horner, S.; Swarbrooke, J. Consumer Behaviour in Tourism; Routledge: London, UK, 2016; 464p, ISBN 978-1138013391.

37. Schianetz, K.; Kavanagh, L. Sustainability Indicators for Tourism Destinations: A Complex Adaptive Systems Approach Using Systemic Indicator Systems. J. Sustain. Tour. 2008, 16, 601-628. [CrossRef]

38. Roberts, S.; Tribe, J. Sustainability Indicators for Small Tourism Enterprises-An Exploratory Perspective. J. Sustain. Tour. 2008, 16, 575-594. [CrossRef]

39. Manuel-Navarrete, D. Tourism and Sustainability. In Sustainability Science; Heinrichs, H., Martens, P., Michelsen, G., Wiek, A., Eds.; Springer: Dordrecht, The Netherlands, 2016; pp. 283-291.

40. Feranández, J.I.P.; Rivero, M.S. Measuring Tourism Sustainability: Proposal for a Composite Index. Tour. Econ. 2009, 15, 277-296. [CrossRef]

41. Pomering, A.; Johnosn, L.W. Building Sustainability into Services Marketing: Expanding Decision-Making from a Mix to a Matrix. Sustainability 2018, 10, 2992. [CrossRef]

42. Sahebalzamani, S.; Bertella, G. Business Models and Sustainability in Nature Tourism: A Systematic Review of the Literature. Sustainability 2018, 10, 3226. [CrossRef]

43. Higgins-Desbiolles, F. Sustainable tourism: Sustaining tourism or something more? Tour. Manag. Perspect. 2018, 25, 157-160. [CrossRef]

44. Kapera, I. Sustainable tourism development efforts by local governments in Poland. Sustain. Cities Soc. 2018, 40, 581-588. [CrossRef]

45. Morioka, S.N.; Bolis, I.; de Carvalho, M.M. From an ideal dream towards reality analysis: Proposing Sustainable Value Exchange Matrix (SVEM) from systematic literature review on sustainable business models and face validation. J. Clean. Prod. 2018, 178, 76-88. [CrossRef] 
46. Kol’veková, G.; Liptáková, E.; Sidor, C.; Kršák, B. Tourism information flows in destination management. In New Trends in Process Control and Production Management; CRC Press: Leiden, The Netherlands, 2017; pp. 269-274, ISBN 9781138058859.

47. Kutscherauer, A.; Fachinelli, H.; Sucháček, J.; Skokan, K.; Hučka, M.; Tuleja, P.; Tománek, P. Regionální Disparity-Disparity v Regionálním Rozvoji Země, Jejich Pojetí, Identifikace a Hodnocení. Series on Advanced Economic Issues; VŠB-TU Ostrava: Ostrava, Czech Republic, 2010; 250p, ISBN 978-80-248-2335-5.

48. Methodological Manual for Tourism Statistics. Available online: http:/ /ec.europa.eu/eurostat/documents/ 3859598/6454997/KS-GQ-14-013-EN-N.pdf (accessed on 10 November 2017).

49. Loomes, G.; Sugden, R. Regret theory: An alternative theory of rationalchoice under uncertainty. Econ. J. 1982, 92, 805-824. [CrossRef]

50. Pomfret, G. Mountaineering adventure tourists: A conceptual framework for research. Tour. Manag. 2006, 27, 113-123. [CrossRef]

51. Meloun, M.; Militký, J. Statistické Zpracování Experimentálních Dat; East Publishing Praha: Prague, Czech Republic, 1998; 839p, ISBN 978-8072190034.

52. Meloun, M.; Militký, J.; Hill, M. Statistická Analýza Vícerozměrných dat v Př́ikladech; Academia: Prague, Czech Republic, 2012; 756p, ISBN 978-8020020710.

53. ̌ezanková, H.; Húsek, D.; Snášel, V. Shluková Analýza Dat; Professional Publishing: Prague, Czech Republic, 2007; 196p, ISBN 978-80-86946-26-9.

54. Stankovičová, I.; Vojtková, M. Viacrozmerné štatistické Metódy s Aplikáciami; Iura Edition: Bratislava, Slovakia, 2007; 261p, ISBN 978-8080781521.

55. Pornprasertmanit, S.; Lee, J.; Preacher, K.J. Ignoring Clustering in Confirmatory Factor Analysis: Some Consequences for Model Fit and Standardized Parameter Estimates. Multivar. Behav. Res. 2014, 49, 518-543. [CrossRef] [PubMed]

56. Sterba, S.K.; Preacher, K.J.; Forehand, R.; Hardcastle, E.J.; Cole, D.A.; Compas, B.E. Structural Equation Modeling Approaches for Analyzing Partially Nested Data. Multivar. Behav. Res. 2014, 49, 93-118. [CrossRef] [PubMed]

57. South East England Development Agency (SEEDA). SEEDA Cluster Fund-Building your Business for a Better Future. Cluster Fund Brochure \& Call for Proposal; SEEDA: Guilford, UK, 2003.

58. Bhatia, A.K. International Tourism Management; Sterling Publishers Pvt. Ltd.: New Delhi, India, 2001; 539p, ISBN 978-8120724129.

59. Bramwell, B.; Lane, B. Tourism Collaboration and Partnerships: Politics, Practice and Sustainability; Channel View Publications: Clevedon, UK, 2000; 351p, ISBN 9781845413989.

60. Gursoy, D.; Saayman, M.; Sotiriadis, M. (Eds.) Collaboration in Toursim Businesses and Destinations: A Handbook; Emerald Group Publishing Ltd.: Bingley, UK, 2015; 368p, ISBN 9781783508112.

61. Capone, F. Tourist desinations, clusters, and competetiveness: An introduction. In Tourist Clusters, Destinations and Competitiveness: Theoretical Issues and Empirical Evidences; Capone, F., Ed.; Routledge: Abingdon, UK, 2016; pp. 1-12, ISBN 9781317486237.

62. Liptáková, E.; Kol'veková, G.; Štrba, L'.; Kršák, B.; Sidor, C. Statistical indicators of tourism and their use within the Destination Business Intelligence System. In Hotelnictví, Turismus a vzdělávání; Vysoká škola hotelová v Praze: Praha, Czech Republic, 2017; pp. 110-117, ISBN 978-80-87411-99-5.

63. Mody, M.A.; Suess, C.; Letho, X. The accommodation experiencescape: A comparative assessment of hotels and Airbnb. Int. J. Contemp. Hosp. Manag. 2017, 29, 2377-2404. [CrossRef]

64. Blasco, D.; Guia, J.; Prats, L. Emergence of governance in cross-border destinations. Ann. Tour. Res. 2014, 49, 159-173. [CrossRef]

65. Lavadinho, S. Nearness dynamics in the city: Ideas for urban change. Ciudades-Revista Del Instituto Universitatio De Urbanistica De La Universidad De Valladolid 2014, 17, 21-39.

66. Hom Cary, S. The Tourist Moment. Ann. Tour. Res. 2004, 31, 61-67. [CrossRef]

67. Merton, R.K.; Barber, E. The Travels and Adventures of Serendipity: A Study in Sociological Semantics and the Sociology of Science; Princeton University Press: Princeton, NJ, USA, 2011; 352p, ISBN 9781400841523.

68. The WVS Cultural Map of the World. Available online: http://pagines.uab.cat/seangolden/sites/ pagines.uab.cat.seangolden/files/World\%20Values\%20Surveys\%20maps\%2020110606.pdf (accessed on 11 November 2017). 
69. Inglehart, R.; Welzel, C. Changing mass priorities: The link between modernization and democracy. Perspect. Politics 2010, 8, 551-567. [CrossRef]

70. Novelli, M.; Schmitz, B.; Spencer, T. Newtorks, clusters and innovation in tourism, A UK Experience. Tour. Manag. 2006, 27, 1141-1152. [CrossRef]

71. About INSPIRE. Available online: http://inspire.ec.europa.eu/about-inspire/563 (accessed on 16 December 2018).

72. About Copernicus. Available online: https://www.copernicus.eu/en/about-copernicus (accessed on 16 December 2018).

73. The European Commission. The European Tourism Indicator System-Toolkit for Sustainable Destinations; Publications Office of the European Union: Luxembourg, 2013; 60p, ISBN 978-92-79-29339-9.

(C) 2019 by the authors. Licensee MDPI, Basel, Switzerland. This article is an open access article distributed under the terms and conditions of the Creative Commons Attribution (CC BY) license (http://creativecommons.org/licenses/by/4.0/). 
Article

\title{
Economic Valuation of Green Island, Taiwan: A Choice Experiment Method
}

\author{
Han-Shen Chen ${ }^{1,2, *}$ and Chu-Wei Chen ${ }^{3}$ \\ 1 Department of Health Diet and Industry Management, Chung Shan Medical University, No. 110, Sec. 1, \\ Jianguo N. Rd., Taichung City 40201, Taiwan \\ 2 Department of Medical Management, Chung Shan Medical University Hospital, No. 110, Sec. 1, \\ Jianguo N. Rd., Taichung City 40201, Taiwan \\ 3 Department of Applied Economics, National Chung Hsing University, No. 250, Kuo Kuang Rd., \\ Taichung 40227, Taiwan; pat00175@yahoo.com.tw \\ * Correspondence: allen975@csmu.edu.tw; Tel.: +886-4-2473-0022 (ext. 12225)
}

Received: 22 November 2018; Accepted: 10 January 2019; Published: 15 January 2019

\begin{abstract}
The evaluation of ecological security and ecosystem services is now a core issue in the field of natural and environmental resources. Quantifying the economic value of island ecosystem services can inform policy decisions that affect the island and help justify expenditures on ecosystem service improvements. This study investigates the preferences of residents and tourists regarding Green Island and estimates willingness-to-pay (WTP) values for island ecosystem services using a choice experiment. The results indicate significant differences between the preferences of residents and tourists regarding island environmental resources. Therefore, based on the multiple attributes and ecosystem services, this study formulated three assessment schemes: "environmental protection", "recreational development", and "integrated operation and management". Based on our analysis of the problems reflected in the aforementioned valuation models, we recommend that policy makers refer to environmental attribute preferences to create statements or advertisements targeting relevant audiences when planning island development. This paper contributes to the literature by demonstrating how the economic valuation of island ecosystem services can help design and target island conservation policies in order to maximize welfare.
\end{abstract}

Keywords: tourism; sustainability; climate change; choice experiment; islands

\section{Introduction}

Increased demands for tourism and recreational resources, as well as a more holistic understanding of sustainability, have led to the rapid development of island tourism. This, in turn, has given rise to research on island development. This, in turn, has given rise to research by scholars who are concerned about island development [1,2]. For example, Scheyvens and Momsen [3] noted that small, developing islands, because of their economic vulnerability, typically use an expanding tourism industry to stimulate economic development [4,5]. Moreover, Li and Yang [6] suggested that coastal overdevelopment, ecological resource destruction, and pollution are unavoidable consequences of island tourism development. Occupational behaviors also arise-such as occupying land for accommodation and water recreational activities-which greatly destabilize the traditional lifestyles of local communities. Since tourism development also creates restrictions with regard to area coverage, natural resources, fragility, disaster recovery capability, and the economy, tourism and recreational services negatively affect the island's environmental, social, and cultural aspects [7-11].

With $1141 \mathrm{~km}$ of coastline, Taiwan has abundant marine resources. An emerging tourist destination, island tourism in Taiwan is attracted by ecological, historical, and cultural features. In particular, Green Island has rich geological and topographical features (coastal terrains, coral reefs); 
distinctive biological and ecological resources (green sea turtles, flying fish, coconut crabs); and traditional festivals and activities (flying fish festival). Diverse theme-based tours have gradually developed on Green Island, including natural ecology-based tours and relevant experience activities (snorkeling, whale watching, night observation of flying fish). Supported by government policies, island tourism and tribal tourism have become new tourism trends in Taiwan with significant potential for future development. However, tourism growth has also had negative environmental consequences. The construction of coastal embankments can severely damage the coastal environment and destroy biological habitats. Moreover, the introduction of foreign cultures can potentially weaken traditional culture. Given the fragility of island ecosystems, policy makers should develop state land for environmental and cultural protection/conservation while also developing unique ecological and cultural experiences to promote tourism. The development of sightseeing resources must consider sustainable ecological, economic, and social development, while minimizing the impact of recreational activities on the environment. Thus, the adoption of sustainable operating principles and environmental conservation is an important aspect of island tourism development.

Chapin et al. [12] suggested that ecosystem services and biological diversity are important intermediaries between the economic environment and human systems. Further, de Groot et al. [13] argued that in order to value ecosystems, we must first consider ecological, sociocultural, and economic values, and then assess the overall value as a reference for environmental decision-making and management. Barbier et al. [14] estimated the value of ecosystem services such as wetlands, mangroves, coral reefs, seagrass beds, and sandy beaches. Based on changes in land use, Bateman et al. [15] explored the contribution of ecosystem services and ecosystems. Taking four ecological zones in Hangzhou, China, as the research object, Su et al. [16] investigated the effect of landscape pattern and value changes in ecosystem services on urbanization. Maes et al. [17] calculated the value of ecosystem services and used average species richness and species diversity to measure biodiversity.

Due to changes in land-use patterns, the ecosystem functions of natural areas have gradually weakened, and biodiversity has decreased. Ecosystem goods and services provide social benefits such as water supply, recreational activities, and carbon storage [18-20]. Therefore, exploring policies related to changes in land-use patterns, and assessing the benefits of environmental development and protection are important matters of public concern [21]. Given the current situation of Green Island, a complete assessment model for ecosystem services should consider spatial variables such as natural landscape coverage, ecotourism patterns, and land-use patterns. Value functions for assessing ecosystem services should then be constructed and monetized.

Sustainable tourism management is usually conducted in places with high environmental sensitivity, where detailed economic analyses of financial gains vis-à-vis environmental impact are performed prior to developing the area for tourism. Such analyses can support decision making related to the planning, utilization, and sustainable operation of local ecological resources. In the case of Green Island, the conservation efficiency of its eco-environmental resources can only be valued by using non-market goods valuation methods. These methods are classified into two types: revealed preference (RP) and stated preference (SP). In such instances, RP can be used to tease out the values embedded in observed prices. RP directly investigates actual behaviors or results in the target market by using questionnaires. Common RP methods include the traveling cost method (TCM) and the hedonic price method (HPM). Each approach has a different conceptual basis, and can be used to valuate different environmental goods. However, they all share the common feature of using market information or behavior to infer the economic value of an associated non-market impact [22]. TCM is one of the most common methods used in non-market valuation to estimate the recreational values of specific sites [23]. Bertram and Larondelle [24] used TCM to assess the recreational value of forest ruins, while Plant, Rambaldi, and Sipe [25] used HPM to evaluate residents' preferences for tree coverage on urban streets.

The method of stated preference (SP) investigates results that have not yet occurred in the target market to obtain preference data from respondents. SP surveys individual or household preferences 
and, more specifically, willingness to pay (WTP) for changes in the provision of (non-market) goods, which are related to respondents' underlying preferences. Hence, this technique is of particular value when assessing the effects on non-market goods, the value of which cannot be uncovered by RP methods [22]. SP methods include the contingent valuation method (CVM) and the choice experiment method (CEM). Mark and Swait [26] suggested that SP can overcome certain disadvantages of RP-such as insufficient collinearity between variables and the extent of variation-to make the assessment of parameters more explanatory and clearly reflect respondents' true preferences.

CVM has been widely used to evaluate environmental amenities and damage [27-29]; however, it has several biases. For example, respondents may deliberately conceal their true preferences for non-market goods favoring their personal interests, possibly resulting in strategic biases such as the overestimation or underestimation of value. When a separate inquiry is made for goods, or a mixed inquiry is made for goods, the embedding effect will produce a bias between the values estimated. In the designed questionnaire, the explanatory information and alternative options provided for the study objects are insufficient, creating an information effect. Moreover, when the double-bounded dichotomous choice method is adopted, respondents may ignore the question content because of their own subjective views, and tend to give the same answers to all of the questions, thereby producing an acquiescence bias. The bidding game requires setting a starting price for goods, and that price is used as a benchmark for respondents' comments, which could produce a starting point bias [30].

CEM has become one of the main valuation methods for studying preferences for natural resource conservation. It is also an important preference valuation method for valuating non-market goods [31]. In this regard, Liekens et al. [21] noted that CEM assesses the use and non-use values, defines a hypothetical market by using questionnaires to explore public preferences for landscape conservation and natural development, and further reflects WTP for environmental goods (or services). One widely applicable strategy for valuating these services is to conduct an analysis of all of the various factors determining the output of a good, thereby assessing the contribution of the ecosystem services to the production of that good [23].

The most significant difference between CVM and CEM is that the former can only consider the characteristic attributes of natural resources as a whole commodity for separate value analysis; meanwhile, the latter can distinguish and analyze the multiple attributes of natural resources [32]. As CEM can be used to evaluate multiple attributes and levels, different alternative plans can be combined on the basis of important characteristics associated with non-market goods or services, and choice sets are assumed for different scenarios. In this case, respondents can choose appropriate alternative plans according to their preferences, thus avoiding assessment biases [33]. Therefore, CEM can better solve the problem of comparing profit and loss between the multiple attributes of ecosystem services, and it can reveal public preferences for each eco-functional attribute of ecosystem services [34]. Thus, CEM has been widely used for non-market valuation, including species conservation [35-39], wetland recovery [40-44], ecotourism preferences [45-50], tourists' preferences for land, the environmental functions of national parks [21,39-41,51,52], and the exploration of methods for altering specific ecosystem services to affect economic benefits [34,53-58].

Remoundou et al. [59] employed CEM to evaluate the effects of climate change on WTP for the Santander coastal ecosystem. The study attributes included biodiversity, jellyfish blooms, closed beach days, beach size, and annual household expenditures. Mejía and Brandt [49] used CEM to interview tourists visiting the Galapagos Islands about their WTP for protective measures against invasive species. Their attributes included the depth of experience with the islands' ecosystems, length of stay, level of protective measures taken against invasive species, and price of island tourism. They found that tourists visiting the Galapagos Islands highly valued biodiversity and were marginally willing to pay USD 2543 for better protective measures. Schuhmann et al. [60] employed CEM to evaluate the tourist preferences and WTP for coastal attributes in Barbados. Their attributes included price, type of accommodation, beach width, distance from beach, and beach litter. Cazabon-Mannette et al. [61] used CEM and CVM to evaluate the non-use value and non-consumptive value of sea turtles in Tobago. Their attributes 
included price, number of sea turtle sightings, fish diversity (number of species), coral cover, and degree of congestion (number of divers). Xuan et al. [62] used a discrete choice experiment (DCE) to evaluate tourists' WTP for boat tours in the marine-protected area of Vietnam's Nha Trang Bay. Their attributes included coral cover, environmental quality, fishermen's unemployment, and increase in ticket prices. Finally, Peng and Oleson [63] employed DCE to evaluate beach recreationalists' preferences and WTP for improving water quality in Oahu's beaches. Their attributes included water quality, water turbidity, coral cover, fish diversity, and WTP for motor vehicles.

Conditional logit (CL) can be used to estimate the average preferences of tourists from multiple attributes of island tourism and estimate the marginal WTP (MWTP) for these attributes [49,50]. The random parameter logit (RPL) model can reflect the different responses of respondents from different backgrounds toward different attributes. This can be used to examine the heterogeneous preferences of respondents and their WTP for changes in the levels of various attributes (such as folk, cultural, and ecological experiences) [64-66]. To segment a clearer target market, the latent class model (LCM) can segregate respondents into different groups and examine and compare their preferences and group differences (e.g., island tourism preferences, attitudes, and socioeconomic backgrounds) [45]. Based on the aforementioned studies, we can see that the empirical CEM models of CL, RPL, and LCM have been verified for use in the examination and evaluation of multiple attribute preferences for island tourism sites.

These studies show that CEM can be used to construct a multiple attributes utility function for natural resources and the environment to estimate the economic value of goods and services associated with environmental resources. These can include valuation for the conservation and improvement of endangered species populations, service planning and valuation for recreational facilities, and preferences for wetland ecoregion planning. For biodiversity conservation, conservation preferences for different endangered species and the improvement of endangerment levels are the main objectives of species conservation. Establishing a recovery fund system is also an important factor in conservation policies.

In summary, this study assesses the ecosystem service valuation pattern for Green Island. First, the motivation for the study is discussed, and the study objective is proposed. Second, according to the indicators of the ecosystem services of Green Island's ecosystem units, important ecosystem attributes and levels are identified through interviews with relevant experts and researchers, and the attributes and levels of ecological security that were designed into the implementation of the ecological security model are incorporated. Third, CEM is used to construct an ecosystem service assessment utility model. Tourists and residents are categorized into different groups for the questionnaire, and their responses are analyzed to explore differences in WTP for various attributes. Unlike previous studies performed within or outside of Taiwan, this study incorporates the ecological, environmental, and recreational attributes of islands into CEM, and involves the economic benefits of multiple attributes. Finally, based on the results, countermeasures and suggestions are proposed for the sustainable development of the Green Island environment, providing a reference for policy makers to make more efficacious s policies.

\section{Materials and Methods}

\subsection{Description of Green Island}

Green Island, the target area of this study, is located to the southeast of Taiwan island (Figure 1), with a total land area of about $16 \mathrm{~km}^{2}$. Over 3700 people currently live on the island, and its traditional industries are agriculture and fishing. The island has long experienced population decline and aging. Green Island has a great variety of terrain (volcanic island, coastal coral reef); marine ecology; and cultural-historical monuments. In 1995, the Pacific Economic Cooperation Council selected Green Island as an ecotourism development site, suggesting that Green Island should develop into an eco-resort island. Green Island is gradually transforming its local industrial structure to become 
more tourism-focused. According to the Tourism Bureau [67], the number of tourists to Green Island increased from 59,383 in 1991 to 345,622 in 2017, which was a growth rate of $482 \%$. Tourism is now an important industry on the island.

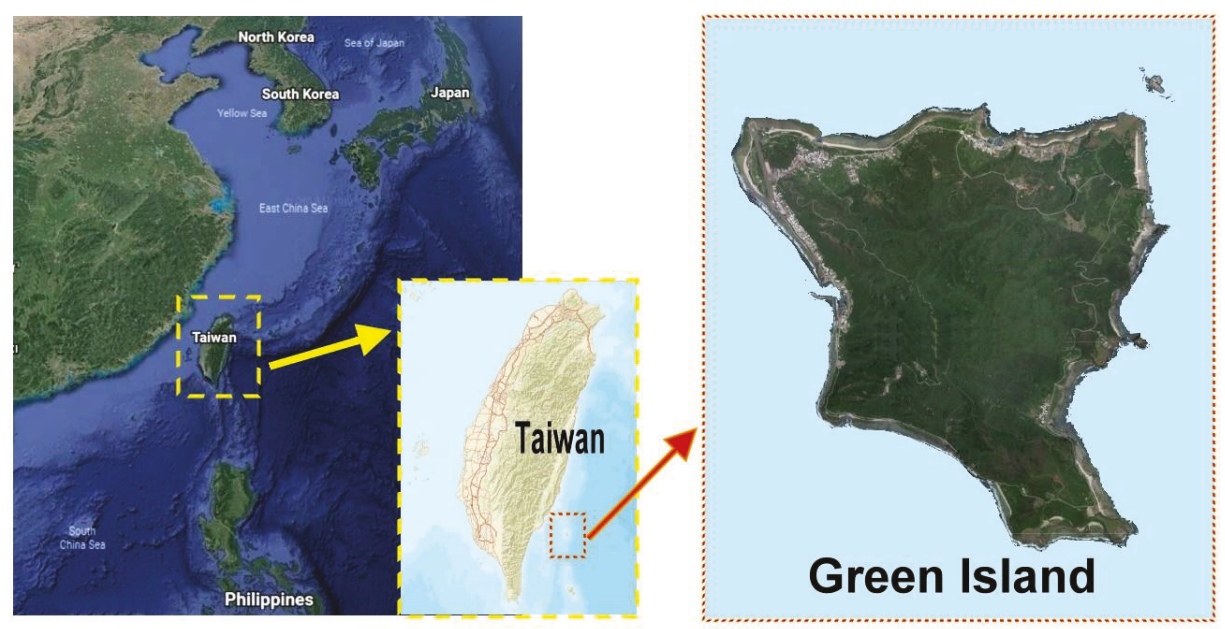

Figure 1. Map of the study area.

Due to the fragility of the island ecosystem, offshore development should focus on environmental conservation and cultural preservation, with special ecological and cultural experiences as the main focus. Therefore, the development of tourism resources must consider sustainable ecological, economic, and social development, while reducing the negative impacts of recreation. It is important to ensure that the tourism industry develops under sustainable management and assists ecosystem conservation. For example, Green Island authorities have been implemented to protect environmental resources and reduce resource losses through the development of low-carbon tourism and intertidal zone ecological conservation, along with other measures. However, some conservation plans remain controversial. Therefore, the motivation for this study stems from important environmental protection issues such as biodiversity and the ecological security level.

\subsection{Construction of a Utility Model for Valuating Ecosystem Services}

\subsubsection{Multiattribute WTP Valuation Model}

CEM was used to construct an ecosystem service assessment utility model for Green Island. An RPL model was used to account for differences between respondents' preferences for attributes in different areas of the island. This model can reflect differences between the preferences of respondents as well as the WTP for different attributes.

CEM is a random utility model that can be used to explore the MWTP for all of the attributes and levels [68]. In the binary model, the utility of the nth respondent is assumed to be determined by the various options the respondent faces $\left(\mathrm{U}_{\mathrm{ni}}\right)$, and these options are used to maximize utility, as shown in Equation (1):

$$
\mathrm{U}_{\mathrm{ni}}=\mathrm{V}_{\mathrm{ni}}+\varepsilon_{\mathrm{ni}},
$$

where $U_{n i}$ represents the attribute of the $n$th respondent facing the ith option, $V_{n i}$ represents the observable part of the utility function, and $\varepsilon_{\mathrm{ni}}$ represents the residual item (i.e., the unobservable part). 
This study explores differences in preferences and WTP between respondents from different social and economic backgrounds, given various attributes and levels. The analysis was conducted using a random parameters logit (RPL) model. The overall utility of the RPL model is as follows:

$$
\mathrm{U}_{\mathrm{ni}}=\mathrm{V}_{\mathrm{ni}}\left(\mathrm{X}_{\mathrm{ni}}, \mathrm{S}_{\mathrm{n}}\right)+\mathrm{I}_{-\mathrm{ni}},
$$

where $V_{n i}$ is the utility coefficient of observable variable $X_{n i}$, and respondent characteristic $S_{n}$ and represents the respondent's preference.

To estimate the relative importance of all of the attributes of the product in terms of value, it is assumed that the degrees of various attributes in the alternative plan remain the same. Then, the marginal change in WTP for the kth attribute can be given by Equation (3):

$$
\mathrm{WTP}=\frac{-\mathrm{I} 2_{\mathrm{k}}}{\mathrm{I} 2_{\mathrm{c}}}
$$

where $\mathrm{I} 2_{\mathrm{k}}$ is the parameter on attribute $\mathrm{k}$, and $\mathrm{I} 2_{\mathrm{c}}$ is the parameter on the payment tool.

\subsubsection{Attribute and Level Assessment Design}

Utilizing previous reports on Green Island along with conducting interviews with experts from various fields, six attributes were selected: land-use pattern, natural landscape coverage, biodiversity, ecotourism model, ecosystem conservation trust fund, and the ecological security level, which was designed in the implementation result of the abovementioned ecological security model, and was also considered an attribute. Table 1 lists the setting and details of these six attributes.

\begin{tabular}{|c|c|c|c|c|}
\hline Attribute & & Level and Current Situation & Ecosystem Service Function & Level Quantity \\
\hline $\begin{array}{l}\text { Land-use pattern } \\
\text { (LUP) }\end{array}$ & $\begin{array}{l}\mathrm{LUP} \pm \\
\mathrm{LUP}+\end{array}$ & $\begin{array}{l}\text { 1. Maintain the current situation } \\
\text { 2. Increase land use (develop or transform } \\
\text { the purposes of the original land) }\end{array}$ & $\begin{array}{l}\text { Supply function: developing } \\
\text { traditional agricultural farming } \\
\text { patterns and transformation to } \\
\text { other land-use purposes }\end{array}$ & 2 \\
\hline $\begin{array}{l}\text { Natural landscape } \\
\text { coverage (NLC) }\end{array}$ & $\begin{array}{l}\mathrm{NLC} \pm \\
\mathrm{NLC}+ \\
\mathrm{NLC}-\end{array}$ & $\begin{array}{l}\text { 1. Maintain the current situation } \\
\text { 2. Increase natural landscape coverage } \\
\text { 3. Reduce natural landscape coverage }\end{array}$ & $\begin{array}{l}\text { Support function: providing an } \\
\text { environment for different species } \\
\text { to inhabit and grow } \\
\text { Cultural function: ecotourism and } \\
\text { existence value }\end{array}$ & 3 \\
\hline Biodiversity (BIO) & $\begin{array}{l}\mathrm{BIO} \pm \\
\mathrm{BIO}+\end{array}$ & $\begin{array}{l}\text { 1. Maintain the current situation } \\
\text { 2. Increase the species recovery plan }\end{array}$ & $\begin{array}{l}\text { Support function: maintaining } \\
\text { biodiversity }\end{array}$ & 2 \\
\hline $\begin{array}{l}\text { Ecotourism model } \\
\text { (EM) }\end{array}$ & $\begin{array}{l}\mathrm{EM} \pm \\
\mathrm{EM}+\end{array}$ & $\begin{array}{l}\text { 1. Maintain the current situation } \\
\text { 2. Carry out an environmental education } \\
\text { program }\end{array}$ & $\begin{array}{l}\text { Cultural function: providing } \\
\text { ecotourism for the public }\end{array}$ & 2 \\
\hline $\begin{array}{l}\text { Ecological security } \\
\text { level (ESL) }\end{array}$ & $\begin{array}{l}\text { ESL } \pm \\
\text { ESL+ } \\
\text { ESL- }\end{array}$ & $\begin{array}{l}\text { 1. Maintain the current situation } \\
\text { 2. Secure status (in which the ecosystem is } \\
\text { not affected and there are few ecological } \\
\text { disasters) } \\
\text { 3. Warning status (in which the ecosystem is } \\
\text { damaged to some extent and ecological } \\
\text { disasters sometimes occur) }\end{array}$ & & 3 \\
\hline $\begin{array}{l}\text { Ecosystem } \\
\text { conservation trust } \\
\text { fund (FUND) }\end{array}$ & FUND & $\begin{array}{l}\text { 1. Free of charge (maintain the current } \\
\text { situation) } \\
\text { 2. NTD250/person/yr } 1 \\
\text { 3. NTD500/person/yr } \\
\text { 4. NTD1000/person/yr }\end{array}$ & & 4 \\
\hline
\end{tabular}

Table 1. Multiple attributes utility assessment indicators for Green Island.

${ }^{1}$ NTD, new Taiwan dollar $(1$ NTD $=0.033$ USD $=0.028$ Euros $)$.

This study constructed a multiple attributes utility assessment model for Green Island, and incorporated the six indicators of the empirical model. The attributes and levels of Green Island were further explored to estimate the MWTP for multiple attributes of Green Island. The results will elucidate the preferences and attitudes of tourists and local residents toward multiple attributes 
of Green Island in order to achieve sustainable management goals, such as tourist experience and resource protection.

\subsection{Preference Selection Combinations for Choice Sets for Green Island Ecosystem Services}

After defining the multiattribute utility assessment indicators and the attributes' various levels for the Green Island ecosystem services (Table 1), the choice experiment (CE) evaluation process was used to further describe the preference selection combinations for choice sets to provide a reference for questionnaire and sampling designs. To understand residents' and tourists' multiattribute preferences for Green Island ecosystem services, a more precise improvement plan and the preference for each attribute level needed to be more clearly defined. The arrangement combinations of the various attributes and their levels produced 288 possible factor combinations $(2 \times 3 \times 2 \times 2 \times 3 \times 4=288)$.

To develop a questionnaire, we used an extensively-used, orthogonal design method (using SPSS), [69]. Using this method, the 288 combinations were reduced to 30 combinations of alternative programs and one status quo alternative. The status quo alternative was included in various choice sets, with each choice including two randomly numbered alternative programs and one status quo alternative. The level of the attribute for the status quo alternative was presented as the current program along with its information. Each questionnaire included the three selected choice sets, and each choice set contained six programs. Thus, there were five versions of the questionnaire. Through the design process and the combination of the aforementioned choice sets, the statistical efficiency of the design of choice sets was improved [45]. Therefore, after deciding on the total number of samples, each respondent randomly selected one questionnaire version for completion.

Each respondent was asked to fill in their answers-that is, select one of the three choice sets (the two alternative programs and one status quo alternative). If the respondent was unable to decide, he or she could select "uncertain;" then, this choice set was considered as a missing value. The various attributes of Green Island ecosystem services and their levels (Table 1), and the content of the choice sets for Green Island preferences (Table 2), were explained to each respondent. This was to help respondents understand the content of the preference attributes of the Green Island ecosystem services before they selected their preferences.

Table 2. Example of a choice set for Green Island preferences and programs.

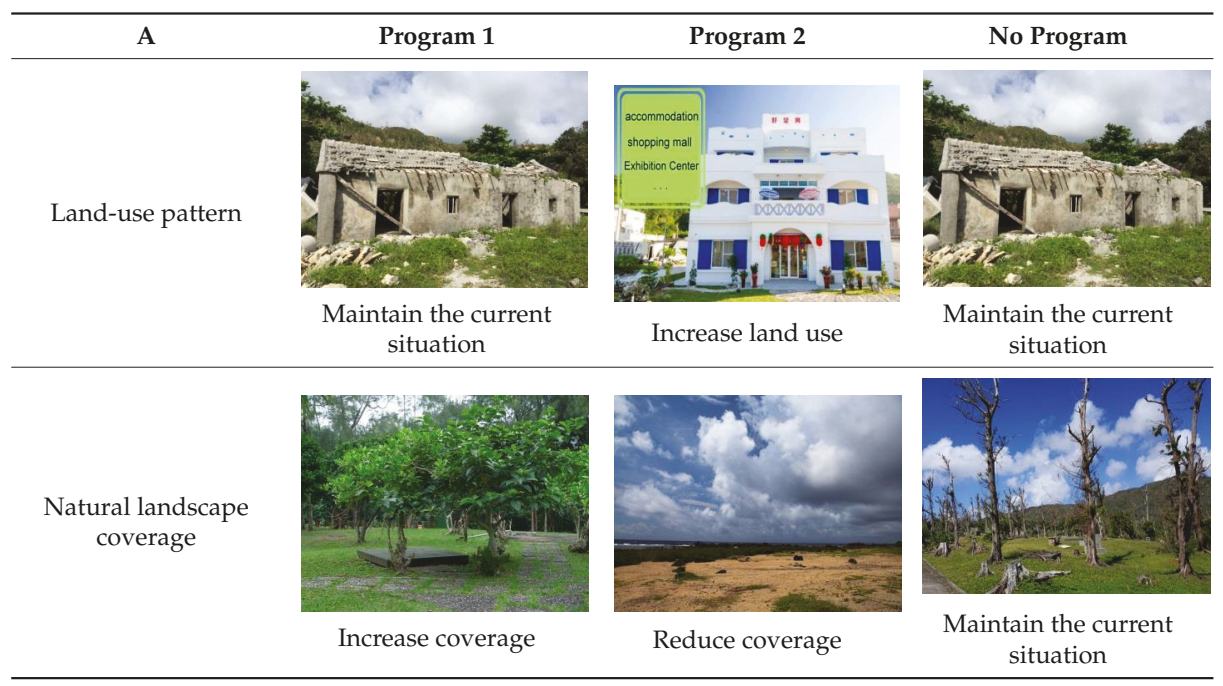


Table 2. Cont.

\begin{tabular}{|c|c|c|c|}
\hline A & Program 1 & Program 2 & No Program \\
\hline \multicolumn{4}{|l|}{ Biodiversity } \\
\hline & $\begin{array}{l}\text { Increase the } \\
\text { speciesrecovery plan }\end{array}$ & $\begin{array}{l}\text { Maintain the current } \\
\text { situation }\end{array}$ & $\begin{array}{c}\text { Maintain the current } \\
\text { situation }\end{array}$ \\
\hline \multicolumn{4}{|l|}{ Ecotourism model } \\
\hline & $\begin{array}{l}\text { Maintain the current } \\
\text { situation }\end{array}$ & $\begin{array}{c}\text { Carry out an } \\
\text { environmental education } \\
\text { program }\end{array}$ & $\begin{array}{l}\text { Maintain the current } \\
\text { situation }\end{array}$ \\
\hline \multicolumn{4}{|l|}{$\begin{array}{c}\text { Ecological security } \\
\text { level }\end{array}$} \\
\hline & Warning status & Secure status & $\begin{array}{c}\text { Maintain the current } \\
\text { situation }\end{array}$ \\
\hline $\begin{array}{l}\text { Ecosystem } \\
\text { conservation trust } \\
\text { fund }\end{array}$ & NTD 500/person/yr & NTD $1000 /$ person/yr & Free of charge \\
\hline $\begin{array}{l}\text { Which policy do you } \\
\text { most prefer? }\end{array}$ & $\square$ & $\square$ & $\square$ \\
\hline
\end{tabular}

\subsection{Survey Design}

Green Island respondents were interviewed in early September 2017 using an initial questionnaire. This questionnaire was then modified based on conservation and management status, expert opinion and advice, and the initial results. Interviews using the final questionnaire were conducted from April to June 2018. A random sampling method and face-to-face interviews were utilized to reduce questionnaire error and help respondents understand the questions. The sampling sites were distributed across the Green Island area, and the respondents were divided into two groups: local residents and tourists. A total of 840 tourists and 420 local residents were interviewed. After incomplete questionnaires were removed, 1021 valid questionnaires remained, representing $81.03 \%$ of the total questionnaires. The respondents comprised 653 tourists and 368 local residents (Table 3).

Of the total sample, 517 respondents (50.64\%) were female; 577 (56.51\%) were single; 444 (43.49\%) were married; $276(42.51 \%)$ were aged $30-39$ years; 267 (26.15\%) were aged $20-29$ years; $562(55.04 \%)$ had a university degree; and 281 (27.52\%) had a high school degree. Further, 407 (39.86\%) earned 20,001-40,000 NTD per month, and 370 (36.24\%) earned 40,001-60,000 NTD per month. 
Table 3. Sociodemographic and economic characteristics of the respondents.

\begin{tabular}{|c|c|c|c|c|c|}
\hline \multicolumn{2}{|c|}{ Description } & \multicolumn{2}{|c|}{ Tourists } & \multicolumn{2}{|c|}{ Local Residents } \\
\hline & & Number & $\%$ & Number & $\%$ \\
\hline \multirow{2}{*}{ Gender } & Male & 317 & 48.55 & 187 & 50.82 \\
\hline & Female & 336 & 51.45 & 181 & 49.18 \\
\hline \multirow{2}{*}{ Marital status } & Single & 371 & 56.81 & 206 & 55.98 \\
\hline & Married & 282 & 43.19 & 162 & 44.02 \\
\hline \multirow{3}{*}{ Education } & High school & 84 & 12.86 & 197 & 53.53 \\
\hline & University & 418 & 64.01 & 144 & 39.13 \\
\hline & Master's & 151 & 23.12 & 27 & 7.34 \\
\hline \multirow{5}{*}{ Age (yr) } & $20-29$ & 229 & 35.07 & 38 & 10.33 \\
\hline & $30-39$ & 328 & 50.23 & 106 & 28.80 \\
\hline & $40-49$ & 74 & 11.33 & 125 & 33.97 \\
\hline & $50-59$ & 19 & 2.91 & 81 & 22.01 \\
\hline & $\geq 60$ & 3 & 0.46 & 18 & 4.89 \\
\hline \multirow{4}{*}{$\begin{array}{c}\text { Monthly } \\
\text { income (NTD) }\end{array}$} & $<20,000$ & 121 & 18.53 & 71 & 19.29 \\
\hline & $20,001-40,000$ & 214 & 32.77 & 193 & 52.45 \\
\hline & $40,001-60,000$ & 282 & 43.19 & 88 & 23.91 \\
\hline & $\geq 60,001$ & 36 & 5.51 & 16 & 4.35 \\
\hline
\end{tabular}

${ }^{1} \mathrm{NTD}$, new Taiwan dollar (1 NTD = 0.033 USD $=0.028$ Euros).

\section{Results}

\subsection{Analysis of Preferences and Benefits of the Green Island Environmental Resource Attributes}

Random parameter logit models were used to analyze tourists' and residents' choice preferences and WTP for Green Island conservation schemes. All of the valuation models passed the goodness-of-fit test and were significantly above the critical value, indicating that the attributes that were selected in this study had sound explanatory capability [70]. Table 4 shows that tourists and local residents had their own preferences for attributes such as "land use", "natural landscape", "biodiversity", "environmental education", and "ecological security level". The RPL model revealed the environmental preferences of each group.

Several factors influenced tourists' environmental preferences (results were significant at the $1 \%$ level). (1) The coefficient of land use was negative and significant, indicating that increasing land-use results in a decrease in tourists' utility level; (2) the coefficient of increasing the natural landscape was positive and significant; (3) the coefficients of increasing biodiversity and environmental education were positive and significant, meaning that the species restoration scheme and the increase in the environmental education scheme could raise tourists' preferences for Green Island ecosystem services; and (4) regarding ecological security, the interviewees showed a significant preference for ecological improvement.

The following factors influenced residents' environmental preferences (results significant at the 1\% level): (1) The coefficient of land use was positive and significant, indicating that developing or changing land-use patterns could raise the utility level for local residents; (2) the coefficient of increasing the natural landscape coverage was positive, meaning that local residents' utility level could rise with an increase in natural landscape coverage; (3) the coefficients of increasing biodiversity and environmental education were positive, demonstrating that the species restoration scheme and the increase in the environmental education scheme could raise residents' preferences for Green Island's ecosystem services; (4) a relationship was found between improving ecological security and preventing ecological damage, indicating that the utility level of local residents increases with improvements in ecological security. 


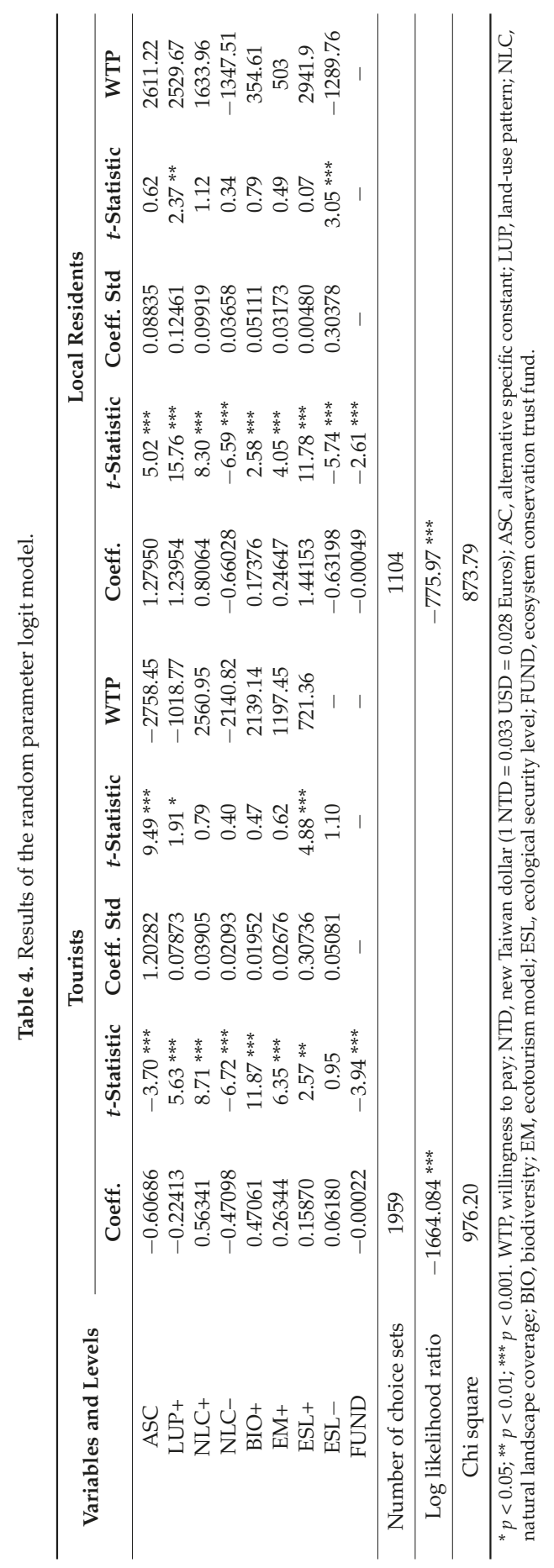


Tourists' WTP was highest for increasing and maintaining the natural landscape (2561 NTD/person/yr), followed by increasing the species restoration scheme (2139 NTD/person/yr), increasing environmental education (1197 NTD/person/yr), reducing changes in land-use patterns (1018 NTD/person/yr), and healthy ecological levels (721 NTD/person/yr). Tourists were also willing to pay an average of $2140 \mathrm{NTD} /$ person/yr to maintain natural landscapes and prevent resulting damage.

Residents' WTP was highest for upgrading ecosystem security to a healthy level (2942 NTD/person/yr), followed by changes in land-use patterns ( $2530 \mathrm{NTD} /$ person/yr), increasing natural landscape coverage (1634 NTD/person/yr), increasing environmental education (503 NTD/person/yr), and the species restoration scheme (355 NTD/person/yr). Additionally, local residents were willing to pay an average of $1348 \mathrm{NTD} /$ person/yr for conservation and planning to prevent damage to natural landscapes, and they were also willing to pay an average of $1290 \mathrm{NTD} /$ person/yr for conservation and planning to prevent damage to ecological security.

\subsection{Difference Analysis of WTP for Resource and Environment Attributes}

Cross-analysis of the resource and environment attributes and the respondents' social variables indicated that tourists had differences in preferences for the two attributes of "increasing land use" and "healthy ecological security level"; meanwhile, local residents had differences in the preference for "damaged ecological security level" (Table 4). In other words, the interviewees had different preferences for environmental protection because of their respective positions. Tables 5 and 6 show the resulting correlations between socioeconomic background and WTP when socioeconomic background is taken into consideration regarding interviewees' WTP for the above attributes.

Table 5. Relationship between socioeconomic background and WTP for increase in land use.

\begin{tabular}{|c|c|c|c|c|c|c|c|c|c|}
\hline \multirow{2}{*}{\multicolumn{2}{|c|}{$\begin{array}{l}\text { Socioeconomic } \\
\text { Characteristics }\end{array}$}} & \multicolumn{4}{|c|}{ Tourists } & \multicolumn{4}{|c|}{ Local Residents } \\
\hline & & \multirow{3}{*}{$\begin{array}{c}\text { Number } \\
371 \\
282\end{array}$} & \multirow{3}{*}{$\begin{array}{c}\text { Mean WTP } \\
\text { (NTD) } \\
-2143.21 \\
-2137.76\end{array}$} & \multicolumn{2}{|c|}{$t$-Statistic F-test } & \multirow{3}{*}{$\begin{array}{c}\text { Number } \\
206 \\
162\end{array}$} & \multirow{3}{*}{$\begin{array}{l}\text { Mean } \\
2541.57 \\
2538.26\end{array}$} & \multirow{3}{*}{$\begin{array}{c}t \text {-Statistic } \\
0.095\end{array}$} & \multirow{3}{*}{$\begin{array}{c}\text { F-Test } \\
-\end{array}$} \\
\hline Marital & Single & & & & & & & & \\
\hline status & Married & & & -0.950 & - & & & & \\
\hline \multirow{3}{*}{ Education } & High school & 84 & -2129.88 & & \multirow{3}{*}{$\begin{array}{c}37.670 \\
* * *\end{array}$} & 197 & 2544.07 & & \multirow{3}{*}{$3.279 * *$} \\
\hline & University & 418 & -2137.71 & - & & 144 & 2534.40 & - & \\
\hline & Master's & 151 & -2201.15 & & & 27 & 2541.62 & & \\
\hline \multirow{5}{*}{ Age (yr) } & $20-29$ & 229 & -2136.27 & \multirow{5}{*}{-} & \multirow{5}{*}{$9.429 * * *$} & 38 & 2539.27 & & \multirow{5}{*}{0.723} \\
\hline & $30-39$ & 328 & -2137.26 & & & 106 & 2541.25 & & \\
\hline & $40-49$ & 74 & -2144.17 & & & 125 & 2536.76 & - & \\
\hline & $50-59$ & 19 & -2233.13 & & & 81 & 2542.07 & & \\
\hline & $\geq 60$ & 3 & -2217.28 & & & 18 & 2549.62 & & \\
\hline \multirow{4}{*}{$\begin{array}{l}\text { Monthly } \\
\text { income } \\
\text { (NTD) }\end{array}$} & $<20,000$ & 121 & -2152.91 & \multirow{4}{*}{ - } & \multirow{4}{*}{$2.856^{* *}$} & 71 & 2551.57 & & \multirow{4}{*}{$5.510^{* * *}$} \\
\hline & $20,001-40,000$ & 214 & -2141.86 & & & 193 & 2538.96 & _ & \\
\hline & $40,001-60,000$ & 282 & -2132.89 & & & 88 & 2531.09 & - & \\
\hline & $\geq 60,001$ & 36 & -2156.76 & & & 16 & 2552.79 & & \\
\hline
\end{tabular}

${ }^{* *} p<0.01 ;{ }^{* * *} p<0.001$. WTP, willingness to pay; NTD, new Taiwan dollar ( 1 NTD $=0.033$ USD $=0.028$ Euros).

Among tourists aged 50-59, highly educated, high-income tourists preferred to reduce changes in land patterns and land use, whereas highly educated, high-income tourists aged 30-39 preferred improvements in the ecological security level. Local residents with lower educational levels and monthly incomes between 20,000-60,000 NTD preferred changes in land patterns to improve land use. Regarding maintaining the ecological level, local residents with high educational levels and high income more actively supported protecting and maintaining ecological security. 
Table 6. Relationship between socioeconomic background and WTP for the healthy ecological security level.

\begin{tabular}{|c|c|c|c|c|c|c|c|c|c|}
\hline \multirow{2}{*}{\multicolumn{2}{|c|}{$\begin{array}{l}\text { Socioeconomic } \\
\text { Characteristic }\end{array}$}} & \multicolumn{4}{|c|}{ Tourists } & \multicolumn{4}{|c|}{ Local Residents } \\
\hline & & \multirow{2}{*}{$\begin{array}{c}\text { Number } \\
371 \\
282\end{array}$} & \multirow{2}{*}{$\begin{array}{c}\text { Mean WTP } \\
514.26 \\
526.19\end{array}$} & \multirow{2}{*}{$\begin{array}{l}t \text {-Statistic } \\
-0.142\end{array}$} & \multirow{2}{*}{$\begin{array}{c}\text { F-test } \\
-\end{array}$} & \multirow{2}{*}{$\begin{array}{c}\text { Number } \\
206 \\
162\end{array}$} & \multirow{2}{*}{$\begin{array}{c}\text { Mean WTP } \\
-1438.60 \\
-1385.77\end{array}$} & \multirow{2}{*}{$\begin{array}{c}t \text {-Statistic } \\
-1.196\end{array}$} & \multirow{2}{*}{$\begin{array}{c}\text { F-Test } \\
-\end{array}$} \\
\hline $\begin{array}{c}\text { Marital } \\
\text { status }\end{array}$ & $\begin{array}{c}\text { Single } \\
\text { Married }\end{array}$ & & & & & & & & \\
\hline Education & $\begin{array}{c}\text { High } \\
\text { school } \\
\text { University } \\
\text { Master's }\end{array}$ & $\begin{array}{c}84 \\
418 \\
151\end{array}$ & $\begin{array}{l}109.57 \\
438.51 \\
631.00\end{array}$ & - & $9.154^{* * *}$ & $\begin{array}{c}197 \\
144 \\
27\end{array}$ & $\begin{array}{l}-1356.24 \\
-1431.75 \\
-1759.11\end{array}$ & - & $\underset{* * *}{11.697}$ \\
\hline Age (yr) & $\begin{array}{c}20-29 \\
30-39 \\
40-49 \\
50-59 \\
\geq 60\end{array}$ & $\begin{array}{c}229 \\
328 \\
74 \\
19 \\
3\end{array}$ & $\begin{array}{l}483.71 \\
655.56 \\
381.40 \\
374.31 \\
281.84\end{array}$ & - & $4.850^{* * *}$ & $\begin{array}{c}38 \\
106 \\
125 \\
81 \\
18\end{array}$ & $\begin{array}{l}-1537.90 \\
-1446.65 \\
-1382.14 \\
-1359.12 \\
-1455.81\end{array}$ & - & 1.558 \\
\hline $\begin{array}{l}\text { Monthly } \\
\text { income } \\
\text { (NTD) }\end{array}$ & $\begin{array}{c}<20,000 \\
20,001-40,000 \\
40,001-60,000 \\
\geq 60,001\end{array}$ & $\begin{array}{c}121 \\
214 \\
282 \\
36\end{array}$ & $\begin{array}{l}338.46 \\
505.03 \\
574.30 \\
783.13\end{array}$ & - & $2.170 *$ & $\begin{array}{c}71 \\
193 \\
88 \\
16\end{array}$ & $\begin{array}{l}-1359.80 \\
-1366.72 \\
-1481.75 \\
-1883.08\end{array}$ & - & $9.156^{* * *}$ \\
\hline
\end{tabular}

${ }^{*} p<0.05 ;{ }^{* * *} p<0.001$. WTP, willingness to pay; NTD, new Taiwan dollar (1 NTD $=0.033$ USD $=0.028$ Euros).

\section{Discussion}

The above analysis shows that tourists and local residents have great differences in their preferences for land use. Tourists hope to reduce land use and development, whereas residents hope for changes in land patterns. Further analysis showed that people who prefer increasing land use belong to groups with lower or higher income levels. Presumably, they want to increase their profits by developing and investing in land patterns.

Previous studies have indicated that residents' support for tourism development is affected by local economic conditions, economic benefits for residents, environmental attitudes, and tourism resources [71-73]. Dodds and Holmes [74] pointed out the differences in environmental conservation attitudes between residents and tourists, which varied according to sex, age, educational level. Robledano et al. [75] pointed out that tourists believed that attributes such as natural landscape, biodiversity, and environmental education are important aspects of the lagoon ecosystem. Stefănica and Butnaru [76] argued that responsibility for the environmental impacts of tourism development-which include the destruction of biodiversity, pollution, global warming, increased waste, and natural resource depletion — should be shared by tourism industry operators and tourists alike.

Considering the differences between tourists' and residents' preferences, this study formulated three assessment schemes based on the six attributes and levels of Green Island's ecosystem services (Table 7): the Environmental Protection Scheme, Recreational Development Scheme, and Integrated Operation and Management Scheme. The Environmental Protection Scheme is based on the attributes of increasing the natural landscape coverage area, increasing biodiversity, and maintaining the ecological security level. The Recreational Development Scheme is based on the attributes of increasing the land use, ecotourism mode, and improving the level of ecological security. The Integrated Operation and Management Scheme is based on the environmental protection and recreational guide, combined with the formulation of the social system. This scheme includes four attributes and levels: increasing the natural landscape coverage area, increasing biodiversity, ecotourism mode, and improving the level of ecological security. Our analysis found that the benefit brought by the Environmental Protection Scheme was 7641 NTD/person/yr. The figures for the Recreational Development Scheme and Integrated Operation and Management Scheme were 6684 NTD/person/yr and $8838 \mathrm{NTD} /$ person/yr, respectively. 
Table 7. WTP for each Green Island ecosystem service management scheme.

\begin{tabular}{cccc}
\hline Policy Attributes & $\begin{array}{c}\text { Environmental } \\
\text { Protection }\end{array}$ & $\begin{array}{c}\text { Recreation } \\
\text { Development }\end{array}$ & $\begin{array}{c}\text { Integrated Operation } \\
\text { and Management }\end{array}$ \\
\hline Land-use pattern & Maintain status quo & Increase land use & Maintain status quo \\
\hline $\begin{array}{c}\text { Natural landscape } \\
\text { coverage }\end{array}$ & Increase coverage & Maintain status quo & Increase coverage \\
\hline Biodiversity & Increase biodiversity & Maintain status quo & Increase biodiversity \\
\hline Ecotourism model & Maintain status quo & $\begin{array}{c}\text { Implement } \\
\text { environmental education }\end{array}$ & $\begin{array}{c}\text { Implement } \\
\text { environmental education }\end{array}$ \\
\hline Ecological security level & Improve security level & Improve security level & Improve security level \\
\hline WTP ${ }^{1}$ (NTD/person/yr) & 7641 & 6684 & 8838 \\
\hline${ }^{1}$ WTP, willingness to pay; NTD, new Taiwan dollar $(1 \mathrm{NTD}=0.033$ USD $=0.028$ Euros).
\end{tabular}

It is clear that the best combination for respondents is to increase natural landscape coverage, increase the species recovery plan, conduct environmental education programs, and secure the status of the ecological security level. These results can help inform future management strategies for eco-environmental impact reduction programs on Green Island.

\section{Conclusions}

Sustainable island tourism development requires the integration of recreation, environment, and management information, which is further considered in the decision making for the development and management of sustainable tourism operations. This study used CE to construct a random utility model for Green Island ecosystem services in Taiwan. To do so, it incorporated various factors into the evaluation model for validation, such as recreation (e.g., ecotourism), environment (e.g., land-use pattern, natural landscape coverage, biodiversity, ecological security), and economic considerations (e.g., ecosystem conservation trust fund).

This study found differences between tourists' and local residents' preferences for ecosystem services. Additionally, in terms of the ecological security attribute, tourists and local residents were willing to make improvements and increase maintenance, and people with high educational levels and incomes showed significantly more willingness than others. We further explored the utility function values of attributes and constructed three hypothetical scenarios for future management to analyze respondents' WTP under different management schemes. To provide a more accurate basis for decision making, we suggested that more consideration should be given to local residents' social views and economic factors before policies and measures are promoted by the policy makers [77].

If Green Island were to implement a pricing system, the economic benefits from the aforementioned programs could be combined with the corresponding operation and management costs, and improvements to service packages and measures could be included. This could be used to plan specific content for Green Island tourism development, which, in turn, could be used as a reference for determining the costs of island tourism packages. Lastly, management units and tour operators should seek to understand tourists' preferences and attitudes in order to propose further operation and management strategies that conform to the concept of island tourism and have more specific and feasible market positioning strategies. This would benefit the sustainable development of tourism on Green Island.

This study has several limitations. If the scope of the study can be expanded in the future, the research framework will be more comprehensive. In view of the conclusions and limitations of this study, we put forward the suggestions outlined below.

This study included only set six environmental resource attributes. However, many other attributes could be included, such as recreational facility maintenance, recreational environment maintenance, and recreational population restrictions. In this way, tourists' and local residents' preferences for environmental attributes could be better understood. 
The questionnaire was distributed by random sampling. In this study, the socioeconomic backgrounds of the interviewees were examined only with respect to sex, educational level, age, and the data obtained. Our sample had an insufficient number of individuals from different groups to represent the overall perceptions of those groups. Whether different types of interviewees have different preferences for environmental resource protection should be further explored. Other survey items could also be added in future studies, such as attitudes toward environmental protection and type of tourism (e.g., historical sites, natural landscapes, local art).

Author Contributions: H.-S.C., the first author, analyzed the data, drafted the manuscript, and acted as corresponding author throughout the submission and revision. C.-W.C. contributed to reviewing and revising the literature.

Funding: This work was supported by the Ministry of Science and Technology (Republic of China, Taiwan) (grant number MOST 106-2410-H-040-014). The funder had no role in the study design; in the collection, analysis, and interpretation of data; in the writing of the report; or in the decision to submit the article for publication.

Conflicts of Interest: The authors have no conflicts of interest to declare.

\section{References}

1. Chen, H.S. The study of the relationship among environmental cognition, attitude, sensitivity, and behavior: The case of an eco-resort island. Int. J. SAFE 2015, 5, 352-358. [CrossRef]

2. Arachchi, R.S.S.W.; Yajid, M.S.A.; Khatibi, A. Ecotourism practices in Sri Lankan eco resorts: A supplier perspective analysis. J. Tour. Hosp. Manag. 2015, 3, 169-180. [CrossRef]

3. Scheyvens, R.; Momsen, J. Tourism in small Island: From vulnerability to strengths. J. Sustain. Tour. 2008, 16, 491-510. [CrossRef]

4. Croes, R.R. A paradigm shift to a new strategy for small island economies: Embracing demand side economics for value enhancement and long term economic stability. Tour. Manag. 2006, 27, 453-465. [CrossRef]

5. Eligh, J.; Welford, E.; Ytterhus, B. Production of sustainable tourism: Concepts and example from Norway. Sustain. Dev. 2002, 10, 223-234. [CrossRef]

6. Li, P.; Yang, G. Ecological footprint study on tourism itinerary products in Shangri-la, Yunnan Province, China. Acta Ecol. Sin. 2007, 27, 2954-2963. [CrossRef]

7. Parolo, G.; Ferrarini, A.; Rossi, G. Optimization of tourism impacts within protected areas by means of genetic algorithms. Ecol. Model. 2009, 220, 1138-1147. [CrossRef]

8. Hannak, J.S.; Kompatscher, S.; Stachowitsch, M.; Herler, J. Snorkelling and trampling in shallow-water fringing reefs: Risk assessment and proposed management strategy. J. Environ. Manag. 2011, 92, 2723-2733. [CrossRef]

9. Burke, L.; Reytar, K.; Spalding, M.D.; Perry, A. Reefs at Risk Revisited; World Resources Institute: Washington, DC, USA, 2012.

10. Chi, Y.; Shi, H.; Wang, X.; Qin, X.; Zheng, W.; Peng, S. Impact factors identification of spatial heterogeneity of herbaceous plant diversity on five southern islands of Miaodao Archipelago in North China. Chin. J. Ocean. Limnol. 2016, 34, 937-951. [CrossRef]

11. Chi, Y.; Shi, H.; Wang, Y.; Guo, Z.; Wang, E. Evaluation on island ecological vulnerability and its spatial heterogeneity. Mar. Pollut. Bull. 2017, 125, 216-241. [CrossRef]

12. Chapin, F.S.; Zavaleta, E.S.; Eviner, V.T.; Naylor, R.L.; Vitousek, P.M.; Reynolds, H.L.; Hooper, D.U.; Lavorel, S.O.; Sala, E.; Hobbie, S.E.; et al. Consequences of changing biodiversity. Nature 2000, 405, 234-242. [CrossRef] [PubMed]

13. de Groot, R.S.; Alkemade, R.; Braat, L.; Hein, L.; Willemen, L. Challenges in integrating the concept of ecosystem services and values in landscape planning, management and decision making. Ecol. Complex. 2010, 7, 260-272. [CrossRef]

14. Barbier, E.B.; Hacker, S.D.; Kennedy, C.; Koch, E.W.; Stier, A.C.; Silliman, B.R. The value of estuarine and coastal ecosystem services. Ecol. Monogr. 2011, 81, 169-193. [CrossRef]

15. Bateman, I.J.; Mace, G.M.; Fezzi, C.; Atkinson, G.; Turner, R.K. Economic Analysis for Ecosystems Assessments. Environ. Res. Econ. 2011, 48, 177-218. [CrossRef] 
16. Su, S.; Zhou, X.; Wan, C.; Li, Y.; Kong, W. Land use changes to cash crop plantations: Crop types, multilevel determinants and policy implications. Land Use Policy 2016, 50, 379-389. [CrossRef]

17. Maes, J.; Paracchini, M.L.; Zulian, G.; Dunbar, M.B.; Alkemade, R. Synergies and trade-offs between ecosystem service supply, biodiversity, and habitat conservation status in Europe. Biol. Conserv. 2012, 155, 1-12. [CrossRef]

18. TEEB. The Economics of Ecosystems and Biodiversity: Ecological and Economic Foundation; Earthscan Publications: Cambridge, UK, 2010.

19. Balmford, A.; Fisher, B.; Green, R.E.; Naidoo, R.; Strassburg, B.; Kerry Turner, R.K.; Rodrigues, A.S.L. Bringing ecosystem services into the Real World: An operational framework for assessing the economic consequences of losing wild nature. Environ. Res. Econ. 2011, 48, 161-175. [CrossRef]

20. Boavida-Portugal, I.; Rocha, J.; Ferreira, C.C. Exploring the impacts of future tourism development on land use/cover changes. Appl. Geogr. 2016, 77, 82-91. [CrossRef]

21. Liekens, I.; Schaafsma, M.; De Nocker, L.; Broekx, S.; Staes, J.; Aertsens, J.; Brouwer, R. Developing a value function for nature development and land use policy in Flanders, Belgium. Land Use Policy 2013, 30, 549-559. [CrossRef]

22. Atkinson, G.; Mourato, S. Cost-Benefit Analysis and the Environment: Recent Developments; OECD: Paris, France, 2006.

23. Hanley, N.; Barbier, E.B.; Barbier, E. Pricing Nature: Cost-Benefit Analysis and Environmental Policy; Edward Elgar Publishing: Glos, UK, 2009.

24. Bertram, C.; Larondelle, N. Going to the woods is going home: Recreational benefits of a larger urban forest site-A travel cost analysis for Berlin, Germany. Ecol. Econ. 2017, 132, 255-263. [CrossRef]

25. Plant, L.; Rambaldi, A.; Sipe, N. Evaluating revealed preferences for street tree cover targets: A business case for collaborative investment in leafier streetscapes in Brisbane, Australia. Ecol. Econ. 2017, 134, 238-249. [CrossRef]

26. Mark, T.L.; Swait, J. Using stated preference and revealed preference modeling to evaluate prescribing decisions. Health Econ. 2004, 13, 563-573. [CrossRef] [PubMed]

27. Almendarez, H.M.; Almendarez, H.L.; Jaramillo, M.G.; Aviles, P.L.; Beltran, M.V.; Hernandez, T.A.; Ortega, R. Economic valuation of water in a natural protected area of an emerging economy: Recommendations for el Vizcaino Biosphere reserve. Interciencia 2013, 38, 245-252.

28. He, J.; Huang, A.; Xuc, L. Spatial heterogeneity and transboundary pollution: A contingent valuation. CV study on the Xijiang River drainage basin in south China. China Econ. Rev. 2015, 36, 101-130. [CrossRef]

29. Perez-Verdin, G.; Sanjurjo-Rivera, E.; Galicia, L.; Hernandez-Diaz, J.C.; Hernandez-Trejo, V.; Marquez-Linares, M.A. Economic valuation of ecosystem services in Mexico: Current status and trends. Ecosyst. Serv. 2016, 21, 6-19. [CrossRef]

30. Choi, A.S.; Ritchie, B.W.; Papandrea, F.; Bennett, J. Economic valuation of cultural heritage sites: A choice modeling approach. Tour. Manag. 2010, 31, 213-220. [CrossRef]

31. Rudd, R.A. National values for reginal aquatic species at risk in Canada. Endanger. Species Res. 2009, 6, $239-249$. [CrossRef]

32. Kinghorn, N.; Willis, K. Estimating visitor preferences for different art gallery layouts using a choice experiment. Museum Manag. Curatorship 2007, 22, 43-58. [CrossRef]

33. Hoyos, D. The state of the art of environmental valuation with discrete choice experiments. Ecol. Econ. 2010, 69, 1595-1603. [CrossRef]

34. Jaung, W.; Putzel, L.; Bull, G.Q.; Guariguata, M.R.; Sumaila, U.R. Estimating demand for certification of forest ecosystemservices: A choiceexperiment with Forest Stewardship Council certificate holders. Ecosyst. Serv. 2016, 22, 193-201. [CrossRef]

35. Boxall, P.C.; Adamowicz, W.L.; Olar, M.; West, G.E.; Cantin, G. Analysis of the economic benefits associated with the recovery of threatened marine mammal species in the Canadian St. Lawrence Estuary. Mar. Policy 2012, 36, 189-197. [CrossRef]

36. Carlos, E.R.; James, R.K.; Layra, P.; William, F.V. An economic valuation of mangrove restoration in Brazil. Ecol. Econ. 2015, 120, 296-302. [CrossRef]

37. Wallmo, K.; Lew, D.K. A comparison of regional and national values for recovering threatened and endangered marine species in the United States. J. Environ. Manag. 2016, 179, 38-46. [CrossRef] [PubMed] 
38. Lee, D.E.; Du Preez, M.D. Determining visitor preferences for rhinoceros conservation management at private, ecotourism game reserves in the Eastern Cape Province, South Africa: A choice modeling experiment. Ecol. Econ. 2016, 130, 106-116. [CrossRef]

39. Lew, D.K.; Wallmo, K. Temporal stability of stated preferences for endangered species protection from choice experiments. Ecol. Econ. 2017, 131, 87-97. [CrossRef]

40. Westerberg, V.H.; Lifran, R.; Olsen, S.B. To restore or not? A valuation of social and ecological functions of the Marais des Baux wetland in Southern France. Ecol. Econ. 2010, 69, 2383-2393. [CrossRef]

41. Guimarães, M.H.; Madureira, L.; Nunes, L.C.; Santos, J.L.; Sousa, C.; Boski, T.; Dentinho, T. Using choice modeling to estimate the effects of environmental improvements on local development: When the purpose modifies the tool. Ecol. Econ. 2014, 108, 79-90. [CrossRef]

42. Richards, D.R.; Warren, P.H.; Moggridge, H.L.; Maltby, L. Spatial variation in the impact of dragonflies and debris on recreational ecosystem services in a floodplain wetland. Ecosyst. Serv. 2015, 15, 113-121. [CrossRef]

43. Dias, V.; Belcher, K. Value and provision of ecosystem services from prairie wetlands: A choice experiment approach. Ecosyst. Serv. 2015, 15, 35-44. [CrossRef]

44. Franzén, F.; Dinnétz, P.; Hammer, M. Factors affecting farmers' willingness to participate in eutrophication mitigation-A case study of preferences for wetland creation in Sweden. Ecol. Econ. 2016, 130, 8-15. [CrossRef]

45. Juutinen, A.; Mitani, Y.; Mäntymaa, E.; Shoji, Y.; Siikamäki, P.; Svento, R. Combining ecological and recreational aspects in national park management: A choice experiment application. Ecol. Econ. 2011, 70, 1231-1239. [CrossRef]

46. Chaminuka, P.; Groeneveld, R.A.; Selomane, A.O.; van Ierland, E.C.V. Tourist preferences for ecotourism in rural communities adjacent to Kruger National Park: A choice experiments approach. Tour. Manag. 2012, 33, 168-176. [CrossRef]

47. Cerda, C.; Ponce, A.; Zappi, M. Using choice experiments to understand public demand for the conservation of nature: A case study in a protected area of Chile. J. Nat. Conserv. 2013, 21, 143-153. [CrossRef]

48. Romão, J.; Neuts, B.; Nijkamp, P.; Shikida, A. Determinants of trip choice, satisfaction and loyalty in an eco-tourism destination: A modelling study on the Shiretoko Peninsula, Japan. Ecol. Econ. 2014, 107, 195-205. [CrossRef]

49. Viteri Mejía, C.V.; Brandt, S. Managing tourism in the Galapagos Islands through price incentives: A choice experiment approach. Ecol. Econ. 2015, 117, 1-11. [CrossRef]

50. Torres, C.; Faccioli, M.; Riera Font, A.R. Waiting or acting now? The effect on willingness-to-pay of delivering inherent uncertainty information in choice experiments. Ecol. Econ. 2017, 131, 231-240. [CrossRef]

51. Ek, K.; Persson, L. Wind farms-Where and how to place them? A choice experiment approach to measure consumer preferences for characteristics of wind farm establishments in Sweden. Ecol. Econ. 2014, 105, 193-203. [CrossRef]

52. León, C.J.; de León, J.; Araña, J.E.; González, M.M. Tourists' preferences for congestion, residents' welfare and the ecosystems in a national park. Ecol. Econ. 2015, 118, 21-29. [CrossRef]

53. Oleson, K.L.L.; Barnes, M.; Brander, L.M.; Oliver, T.A.; van Beek, I.; Zafindrasilivonona, B.; van Beukering, P. Cultural bequest values for ecosystem service flows among indigenous fishers: A discrete choice experiment validated with mixed methods. Ecol. Econ. 2015, 114, 104-116. [CrossRef]

54. Marsh, D.; Phillips, Y. Combining choice analysis with stakeholder consultation to assess management options for New Zealand's Hurunui River. Water. 2015, 7, 1649-1669. [CrossRef]

55. Matthews, Y.; Scarpa, R.; Marsh, D. Using virtual environments to improve the realism of choice experiments: A case study about coastal erosion management. J. Environ. Econ. Manag. 2017, 81, 193-208. [CrossRef]

56. Houessionon, P.; Fonta, W.M.; Bossa, A.Y.; Sanfo, S.; Thiombiano, N.; Zahonogo, P.; Yameogo, T.B.; Balana, B. Economic Valuation of Ecosystem Services from Small-Scale Agricultural Management Interventions in Burkina Faso: A Discrete Choice Experiment Approach. Sustainability 2017, 9, 1672. [CrossRef]

57. Hampson, D.I.; Ferrini, S.; Rigby, D.; Bateman, I.J. River water quality: Who cares, how much and why? Water 2017, 9, 621. [CrossRef]

58. Rai, R.K.; Shyamsundar, P.; Nepal, M.; Bhatta, L.D. Financing watershed services in the foothills of the Himalayas. Water 2018, 10, 965. [CrossRef]

59. Remoundou, K.; Diaz-Simal, P.; Koundouri, P.; Rulleau, B. Valuing climate change mitigation: A choice experiment on a coastal and marine ecosystem. Ecosyst. Serv. 2015, 11, 87-94. [CrossRef] 
60. Schuhmann, P.W.; Bass, B.E.; Casey, J.F.; Gill, D.A. Visitor preferences and willingness to pay for coastal attributes in Barbados. Ocean Coast. Manag. 2016, 134, 240-250. [CrossRef]

61. Cazabon-Mannette, M.; Schuhmann, P.W.; Hailey, A.; Horrocks, J. Estimates of the non-market value of sea turtles in Tobago using stated preference techniques. J. Environ. Manag. 2017, 192, 281-291. [CrossRef]

62. Xuan, B.B.; Sandorf, E.D.; Aanesen, M. Informing management strategies for a reserve: Results from a discrete choice experiment survey. Ocean Coast. Manag. 2017, 145, 35-43. [CrossRef]

63. Peng, M.; Oleson, K.L.L. Beach Recreationalists' willingness to pay and economic implications of coastal water quality problems in Hawaii. Ecol. Econ. 2017, 136, 41-52. [CrossRef]

64. Lyu, S.O. Which accessible travel products are people with disabilities willing to pay more? A choice experiment. Tour. Manag. 2017, 59, 404-412. [CrossRef]

65. Randrianarison, H.; Wätzold, F. Are buyers of forest ecosystem services willing to consider distributional impacts of payments to local suppliers? Results from a choice experiment in Antananarivo, Madagascar. Environ. Conserv. 2017, 44, 74-81. [CrossRef]

66. Fujino, M.; Kuriyama, K.; Yoshida, K. An evaluation of the natural environment ecosystem preservation policies in Japan. J. For. Econ. 2017, 29, 62-67. [CrossRef]

67. Tourism Bureau. 2017 Visitors to Principal Tourist Spots in Taiwan by Month. 2017. Available online: http:/ / admin.taiwan.net.tw/English/index.aspx (accessed on February 15, 2018).

68. Shoyama, K.; Managi, S.; Yamagata, Y. Public preferences for biodiversity conservation and climate-change mitigation: A choice experiment using ecosystem services indicators. Land Use Policy 2013, 34, $282-293$. [CrossRef]

69. Louviere, J.J.; Hensher, D.A.; Swait, J.D. Stated Choice Methods: Analysis and Application; Cambridge University Press: Cambridge, UK, 2000.

70. Gill, J. Bayesian Methods a Social and Behavioral Sciences Approach; CRC Press, Taylor \& Francis Group: Boca Raton, FL, USA, 2015.

71. Dyer, P.; Gursoy, D.; Sharma, B.; Carter, J. Structural modeling of resident perceptions of tourism and associated development on the Sunshine Coast, Australia. Tour. Manag. 2007, 28, 409-422. [CrossRef]

72. Gursoy, D.; Chi, C.G.; Dyer, P. Locals' attitudes toward mass and alternative tourism: The case of Sunshine Coast, Australia. J. Travel Res. 2010, 49, 381-394. [CrossRef]

73. Stylidis, D.; Biran, A.; Sit, J.; Szivas, E.M. Residents' support for tourism development: The role of residents' place image and perceived tourism impacts. Tour. Manag. 2014, 45, 260-274. [CrossRef]

74. Dodds, R.; Holmes, M.R. Education and certification for beach management: Is there a difference between residents versus visitors? Ocean Coast. Manag. 2018, 160, 124-132. [CrossRef]

75. Robledano, F.; Esteve, M.A.; Calvo, J.F.; Martínez-Paz, J.M.; Farinós, P.; Carreño, M.F.; Soto, I.; Avilés, M.; Ballesteros, G.A.; Martínez-Baños, P.; et al. Multi-criteria assessment of a proposed ecotourism, environmental education and research infrastructure in a unique lagoon ecosystem: The Encañizadas del Mar Menor (Murcia, SE Spain). J. Nat. Conserv. 2018, 43, 201-210. [CrossRef]

76. Stefănica, M.; Butnaru, G.I. Research on tourists' perception of the relationship between tourism and environment. Procedia Econ. Finasnc. 2015, 20, 595-600. [CrossRef]

77. Davies, K.K.; Fisher, K.T.; Dickson, M.E.; Thrush, S.F.; Le Heron, R. Improving ecosystem service frameworks to address wicked problems. Ecol. Soc. 2015, 20. [CrossRef]

(C) 2019 by the authors. Licensee MDPI, Basel, Switzerland. This article is an open access article distributed under the terms and conditions of the Creative Commons Attribution (CC BY) license (http:/ / creativecommons.org/licenses/by/4.0/). 
Article

\title{
A Strategic Approach to Sustainable Tourism Development Using the A'WOT Hybrid Method: A Case Study of Zonguldak, Turkey
}

\author{
Nermin Kişi \\ Department of Management and Organization, Çaycuma Vocational School, Zonguldak Bülent Ecevit \\ University, Zonguldak 67900, Turkey; ncelik@beun.edu.tr; Tel.: +90-372-643-6601
}

Received: 27 December 2018; Accepted: 9 February 2019; Published: 13 February 2019

\begin{abstract}
Nowadays, tourism-led economic growth has become a major outcome of the public policy. Researchers have recently begun to address the development of tourism from a perspective that is based on economic, cultural, social, and environmental sustainability. This paper aims at presenting a strategic approach that can help to develop sustainable tourism at touristic destinations. In order to pursue our aim, the A'WOT (AHP-SWOT) hybrid method, developed in combination with SWOT (Strengths, Weaknesses, Opportunities, Threats) analysis and the AHP (Analytic Hierarchy Process) method, was used. SWOT analysis was used to determine the significant strategic factors, and the AHP method was applied to prioritize these factors. The province of Zonguldak, located in Northwest Turkey, was chosen as the research area to suggest tourism strategies that can be sustainable by means of the application of the A'WOT method. Proposed strategies for the research area are related to product diversification and event management, the image of the destination, a sustainable visitor management system, promotion and branding strategies, partnerships, and cooperation. The results illustrate that the dependent economic structure may be broken down with the development of the tourism industry and, therefore, that some strategic initiatives are required to achieve sustainable tourism in the province.
\end{abstract}

Keywords: sustainable tourism; strategic planning; A'WOT; TOWS matrix

\section{Introduction}

As the impact of sustainable development on the world's future is better understood, each industry is encouraged to find a solution for sustainability in its own field. Sustainability puts its "attention on a set of ethical values and principles, which guides action in a responsible and harmonious way, incorporating the environmental and societal consequences of actions, as well as economic goals" [1]. The prefix 'sustainable' is currently being used in various fields, such as tourism, architecture, agriculture, and the development of communities [2]. Thus, sustainability has become one of the most important strategic issues for many industries [3]. For example, the tourism industry, which is one of the world's fastest-growing industries, is now trying to move towards sustainable and responsible practices [4]. Besides this, tourism, which is regarded as an indispensable industry for both economic and social development, may have a positive effect on employment, gross revenue, and production. On the other hand, it may have negative effects on the environment [5]. If tourism is not planned and managed properly, it may cause permanent damage to the physical, social, cultural, and economic environment of a tourist destination [6]. That is why it is important to focus on sustainable tourism as a significant issue. Such reasons as disruption of the ecological balance due to global warming, the loss of social values, and the failure to preserve natural, historical, social, and cultural assets make sustainable tourism a necessity [7]. 
However, in order to achieve a more sustainable form of tourism, there is a need for a more holistic perspective that allows us to consider all of the sectors and resources upon which tourism relies [8]. Furthermore, sustainable tourism has a wide variety of definitions. For instance, sustainable tourism can be defined as "tourism that takes full account of its current and future economic, social, and environmental impacts, addressing the needs of visitors, the industry, the environment, and host communities" [9] (p. 12). In this way, sustainable tourism should ensure an optimal use of environmental resources, respect the socio-cultural characteristics of the local communities, and yet provide socio-economic utility to stakeholders [9]. Similarly, Müller [10] (p. 132) outlined that the objective of sustainable tourism is "to influence economic health, subjective well-being of the locals, unspoiled nature, protection of the resources, healthy culture, and optimum satisfaction of guest requirements". Another definition of sustainable tourism is the one provided by Hunter [11] (p. 851), who defined sustainable tourism as "an adaptive paradigm which legitimizes a variety of approaches according to specific circumstances". According to Niedziolka [12] (p. 160), sustainable tourism is "all forms of activities, management, and development of tourism that preserve natural, economic, and social integrity and guarantee maintenance of natural and cultural resources". The majority of these definitions emphasize that people are responsible for respecting and preserving the economic, environmental, and socio-cultural balances [13-16].

For many years, the sustainable management of tourism has been a challenge for residents and tourists. There has been a radical change in the tourism perceptions of local people, and mass tourism has become a local political issue [17]. This can also be noticed in the emergence of the terms tourism-phobia and overtourism, which have developed from the growing evolution of unsustainable mass-tourism practices. Tourism-phobia describes the social discontentment that has arisen in response to the pressure of tourism [18]. Overtourism is defined by the United Nations World Tourism Organization (UNWTO) [19] (p. 4) as the impact of tourism on a destination that excessively influences the perceived quality of life of the citizens as well as the quality of the visitors' experiences in a negative way. If measures are not taken in terms of sustainability in tourism, environmental problems will be encountered and this will negatively affect both the local population and the number of tourists. In sum, UNWTO [19] (p. 3) states that "tourism will only be sustainable if developed and managed considering both visitors and local communities". As can be seen, the protection of natural, historical, and cultural resources and long-term sustainability in tourism are becoming important for all countries. Therefore, a systematic approach is needed in the design of sustainable tourism development planning.

The main purpose of this study is to present a strategic approach that can contribute to the sustainability of tourism at touristic destinations. In order to achieve this purpose, the A'WOT (AHP-SWOT) hybrid method was used in this study. The province of Zonguldak in the West Black Sea Region of Turkey was chosen as a case study. Hence, the sub-purpose of this study is to propose sustainable tourism strategies for Zonguldak using the A'WOT method. To achieve this sub-purpose, both the internal and external factors affecting the tourism industry in Zonguldak were determined in advance, and the priorities of these factors were also calculated. The strategy proposals for sustainable tourism in Zonguldak were formulated by using the TOWS (Threats, Opportunities, Weaknesses, Strengths) matrix together with the region-specific vision statement and the main sustainable tourism goals. The outcome may also have implications for the implementation of future policy for the stakeholders in the region. Moreover, the findings within this study may also be applicable to other destinations where sustainable tourism can be developed.

\section{Literature Review}

Numerous authors have discussed sustainable tourism as a topic [20-22]. However, a relatively lower number of studies have focused on the development of strategies for sustainable tourism. It will be useful to provide a brief review of the literature on sustainable tourism development strategies from the standpoint of the purpose of this study. 
Different regions have been subject to studies related to sustainable tourism development strategies. Using the benchmarking method, Helmy [23] evaluated the Egyptian tourist planning mechanism from the sustainability perspective. He demonstrated that the tourist planning system lacks sustainable tourism development programmes and more cooperative efforts were necessary for the Egyptian tourist planning mechanism in order to achieve sustainability in tourism. Font and Serra [24] improved sustainable tourism marketing strategies in Barcelona. They emphasized the criteria of sustainability, such as minimizing the negative environmental and social impacts, reducing the carbon footprint of transport, normalizing the behavior of the visitors, reducing touristic overcrowding, compensating for the negative impacts caused by tourism, serving the destination, and serving the needs of the city. Grytsiuk et al. [25] built a strategy for the sustainable development of tourism in the Carpathian region of Ukraine under the conditions brought about by modern global changes. The basis of the sustainable development tourism strategy was to enhance the life quality of the inhabitants of the Carpathians. They also emphasized the formulation of an organizational development management mechanism of tourist destinations and the construction of an effective model of cooperation between government, business, and society. Another example is the one offered by Cortez [26], who presented the strategies that were adopted by the Government of the State of Bolivia to improve sustainable tourism. She highlighted that sustainable tourism development was linked to the community's self-actualization and requires planning. Mondal [27] determined that the present tourism activities in Bangladesh are unsustainable and analyzed a way to attain a sustainable tourism industry in Bangladesh using the Strengths, Weaknesses, Opportunities, Threats (SWOT) analysis and a TOWS matrix. To develop a sustainable tourism industry, he suggested several strategies, such as ensuring the security of tourists, planning for sustainable economic profits, more environmental regulations, notifying people about sustainable tourism, and the development of the required infrastructure. He also implied that the findings of the study would help tourism stakeholders to analyze present problems of tourism. Feili et al. [28] used the SWOT approach and fuzzy logic to find sustainable tourism development strategies in Iran. Their strategies included planning the progress of transportation in the region, informing people about tourism developers' activities in the media, providing accommodation for overnight and long stays, using professional managers in various tourist places, and implementing plans related to ecotourism. Rezapouraghdam and Esmaeili [29] evaluated SWOT for sustainable desert-tourism development in Khara Desert, Iran. They tried to provide a holistic sustainable strategic planning methodology for tourism authorities and practitioners in Iran. They concluded that if desert-tourism drew enough attention from tourism authorities, it would be seen as having a great potential for contributing to the economy, the prosperity, and the sustainable development of the environmental societies in Iran. They stressed that the most important step to be taken was to prepare a sustainable management master plan for the region. Sulistyadi et al. [30] used the SWOT analysis and a quantitative strategic planning matrix to build a sustainable tourism development model in their study and applied this model to the Thousand Islands Tourism Area, Jakarta. As a result, they summarized their tourism development strategies as strengthening the commitment of the stakeholder, increasing the role and capabilities of the local communities, re-enforcing the principles of sustainable tourism, and developing responsible tourism marketing. They also highlighted that the role of destination management organizations leads the applied tourism development strategy model.

The United Nations Educational, Scientific and Cultural Organization (UNESCO) [31] is also counted among the institutions that use SWOT in order to present sustainable tourism strategies for better management and long-term planning on core issues in Bali, Indonesia. The resulting strategy included a shared vision, strategic objectives, and an action plan to be implemented by stakeholders. Paunovic and Jovanovic [32] mentioned in their study that sustainable tourism was based on a holistic approach and a knowledge-based platform; thereby, all forms and approaches of tourism should be considered. They suggested a holistic approach for improving sustainable mountain tourism and collected the data through interviews with individuals for the development of sustainable tourism 
in the German Alps. Indicators of sustainable tourism, cross-border cooperation, and stakeholder participation emerged as important themes for the practice of sustainable tourism. Stoddard et al. [33] suggested that tourism development organizations should adopt a triple-bottom-line framework, which includes economic, environmental, and social sustainability strategies to enhance sustainability. They pointed out that the triple-bottom-line framework could improve the strategic decision-making of tourism development organizations. Neto [34] focused on giving higher priority to the participation of the community and the reduction of poverty in developing countries for the development of sustainable tourism. According to him, the emphasis should be placed on a pro-poor tourism approach all over the world. He determined four major policy recommendations that could contribute to the expansion of the pro-poor tourism approach in developing countries. These policies were poverty alleviation at the center of national strategies, more opportunities for the poor to make use of tourism benefits and partnerships, and role of the international community. Reichel and Uriely [35] presented a conceptual strategic approach for sustainable tourism development in the Israeli Negev Desert. This approach was based on the assumption that developments in tourist demand associated with postmodern tourism are persistent. They combined cultural heritage and nature-oriented themes with simulated attractions in their study. Nowacki et al. [36] evaluated tourism development strategies in Poland, pointing towards strategic planning, the involvement of the stakeholders within the process, and sustainable development principles. They signified that there were real problems with implementing the principles of sustainable tourism in Poland and these policies must put into practice. Besides this, they emphasized that sustainable development must be understood by all stakeholders. To develop sustainable tourism in the Cameron Highlands of Malaysia, Aminu et al. [37] presented an approach based on the Analytic Network Process (ANP) and a Geographic Information System (GIS). They have demonstrated that the integration of ANP and GIS is useful in that it provides analytical tools for spatial planning with regards to sustainable tourism. Tsaur and Wang [38] evaluated sustainable tourism development using the Analytic Hierarchy Process (AHP) and Fuzzy Set Theory and illustrated how it could be implemented in the Green Island in Taiwan. These authors highlighted that the development of tourism could be beneficial for the economy but harmful for the environment and, therefore, a well-designed plan for tourism development was necessary. They also pointed out that tourism authorities have to pay more attention to the protection of the environment and tourism business has to be operated with an ecological consideration.

Several authors have specifically sought to develop sustainable tourism strategies for national parks. For example, Goodwin [39] explored the opportunities for local economic development through tourism at the Komodo, Keoladeo, Gonarezhou, and Puerto Princesa National Parks, and concluded his study with a list of actions. These actions were related to non-capital-intensive enterprises, tourism based on local skills and technology, enclave practices, partnerships between public and private sectors, institutions, and revenue-sharing policies. Cottrell and Cutumisu [40] focused on the analysis of two national parks in Sweden and Romania and examined planning authority and other tourism stakeholders' perceptions of a sustainable tourism development strategy with in-depth interviews. Candrea and Bouriaud [41] assessed the benefits of and threats to sustainable tourism development in Romania's Piatra Craiului National Park using a stakeholder analysis. They identified the main challenges that tourism brings to the protected area in Piatra Craiului via interviews with local stakeholders and revealed the necessity of implementing sustainable tourism strategies in this park. The ecotourism practice was identified as the best solution to solve the problem of sustainable tourism development in this park. The authors also recommended three main policies for sustainable tourism: systematic planning, a private-public partnership, and local authorities and protected area administration. Garcia-Melon et al. [42] proposed strategies with regard to the local, social, and natural environment for the coastal national parks of Venezuela using the ANP technique to help managers make decisions about the sustainability of national parks by taking experts' and stakeholders' opinions into account. They stressed that ANP was a suitable tool for assessing sustainable tourism development strategies. Reihanian et al. [43] addressed the question of whether the current tourism activities in 
the Boujagh National Park of Iran comply with the sustainability requirements or not. They used SWOT analysis and a TOWS matrix to identify the required management strategies so as to develop the tourism in the park.

The literature section includes sustainable tourism strategies that have been developed in different regions and national parks by making use of a variety of techniques and approaches, such as SWOT, the ANP, a GIS, the AHP, fuzzy logic, benchmarking, a quantitative strategic planning matrix, a TOWS matrix, and interviews. In these studies, sustainable tourism strategies can be generally categorized into three groups: economic, social, and environmental. Some authors have made attempts to evaluate present tourism planning of the regions and have suggested new strategies for a sustainable form of tourism. In addition to developing a strategy, several authors have also emphasized the significant role of stakeholders and experts in the development of sustainable tourism and the necessity of a systematic planning or a holistic approach.

In this study, a strategic approach for sustainable tourism development is presented by means of an integration of SWOT analysis and the AHP method to help managers make decisions about regional sustainable tourism. The province of Zonguldak, which is located in the West Black Sea Region of Turkey, is discussed as a destination area. In this context, SWOT factors were first determined through expert opinions. After that, these factors were prioritized via the AHP method. Finally, regional sustainable tourism development strategies are presented by means of the TOWS matrix in accordance with the region-specific vision statement and the main sustainable tourism goals.

\section{Materials and Methods}

\subsection{The Research Area}

Turkey, which has a high potential for tourism development and offers different types of tourism, is among the top 10 countries in international tourist arrivals and among the top 17 countries in international tourism receipts [44]. However, as a result of mass-tourism activities in Turkey, we face a mass concentration at Mediterranean and Aegean coastal areas, a distorted urban development, a lack of infrastructure, and also environmental problems [45]. In addition, the rapid growth of the tourism industry has transformed tourism trends and policies. The current trends in tourism show that tourists seek more interaction, more exploration of other cultures, more experience, more emotional connections, and more authenticity [46]. Turkey has various natural, cultural, and historical resources, and it is known as a major center of attraction for foreign tourists. In recent years, Turkey has shifted to special interest types of tourism by adopting a sustainable approach to tourism and by distributing tourism activities throughout the year. In particular, the West Black Sea Region of Turkey is suitable for the development of special interest tourism. The climate and nature of the West Black Sea Region will also increase the preference rate of the region in the future. The coasts of this region make it suitable for coastal tourism, and its forests, plateaus, caves, canyons, and waterfalls make it appropriate for ecotourism. Additionally, it is also suitable for cultural tourism thanks to its ancient cities (Filyos Tios, Karabuk-Hadrianapolis, etc.), its examples of civil architecture (Safranbolu houses, Bartin houses, etc.), and its cultural items and local values (Devrek walking sticks, wire breaking, etc.) [47].

In this study, the province of Zonguldak, located in the West Black Sea region of Turkey, was chosen as the research area. This decision was influenced by the fact that the preferences of tourists for special interest tourism will increase the demand for tourism in this region. Moreover, improper tourism policy practices can damage natural and cultural resources. Given the density of tourism activities throughout Turkey, the city of Zonguldak is among the cities that have not attracted the attention of natural tourism planners and tourism organizations so far. Zonguldak also offers a wide range of natural formations, such as caves, forests, and mountain pastures, which have not been considered for tourism activities yet. Within the 2014-2023 vision of the West Black Sea Region Plan [48], Zonguldak has been considered "to be a region that has broken the dependent economic structure and improved the quality of life". The three main principles for achieving this vision are multi-sectoralism, 
participation, and sustainable development, and the two main axes for development are "sustainable social development" and "sectoral diversity supported by innovation and entrepreneurship". This raises the following questions for the research area: Is it possible to evaluate the tourism industry in terms of sectoral diversity? What is the current status of the tourism industry? What are the most important internal and external factors affecting the tourism industry? Which strategies can be developed for sustainable tourism? The case study tries to find answers to these questions. The region is well-known for being rich in hard coal, its underground resources, and its iron and steel industry. Although the industrial activities in the region are still predominantly based on the mining and iron and steel industries, the employment rates have begun to decline due to the difficulties experienced in mining. This has made unemployment the biggest problem of the region, and the cause of unemployment is mainly the failure to achieve sectoral diversity. That is why it is of vital importance to change the economic structure in the region, of which development currently rests on the mining, iron, and steel industries. It is also crucial to create new employment areas in other sectors that are starting to take off within the region. The sectors that can play a critical role in the economic and social development of the region are machinery manufacturing, the ship industry, the auto supplier industry, and the tourism industry [48]. The region has the potential to be an important tourist attraction, especially in terms of special interest tourism types. Within the scope of the West Black Sea Corridor project, which was presented by the Ministry of Culture and Tourism [45], the diversification and development of tourism was established as the priority area [48]. This decision can be implemented in the province of Zonguldak by considering the following elements.

In the region, the demographic characteristics of the urban and rural areas are very close to each other. In 2018, the population of Zonguldak was 599,698, of which $49.58 \%$ are male and $50.42 \%$ are female [49]. Fifty-two percent (52\%) of Zonguldak is covered with forests and it is rich in natural attractions, which provide its inhabitants with the opportunity for hunting. The coastline and beaches along the Black Sea, the caves, and the flora, which remain green throughout the year, can also be counted among the natural resources of the province. There are plenty of places in Zonguldak with great potential for trekking, photo safaris, angling, and hunting activities. Besides this, Zonguldak is one of the leading cities in Turkey for cave formations, and nearly all of the caves in Zonguldak are open to the public. In addition, mining, weaving, embroidery, and woodworking are region-specific activities [50]. The city is well-known for coal mining, since it has the country's largest coal reserves. In this context, the Zonguldak Mining Museum, the first mining museum in Turkey, has been exhibiting the tools and materials that are used in mining activities. The region is particularly rich in terms of natural tourism resources, and there are several tourism types in Zonguldak that can still be developed, such as tableland tourism, botanical tourism, butterfly observing, cycling tourism, trekking, rafting, cave tourism, and cultural tourism [51]. Zonguldak has been known as an industrial city since the first years of the Republic, with tourism largely overlooked until now. It is believed that the reason why tourism is ignored not a lack of potential, but rather a lack of entrepreneurship, infrastructure, and services [48].

\subsection{Methods}

In this study, the A'WOT method and a TOWS matrix were employed to suggest sustainable tourism strategies for the tourism industry in Zonguldak province, Turkey. The key strategic factors were determined by means of SWOT analysis; the decision hierarchy was built through the AHP; the priorities of SWOT factors and groups were calculated via AHP; and the strategies were developed using a TOWS matrix by integrating the region-specific vision statement and the main sustainable tourism goals. The flow diagram of the method is shown as in Figure 1. 


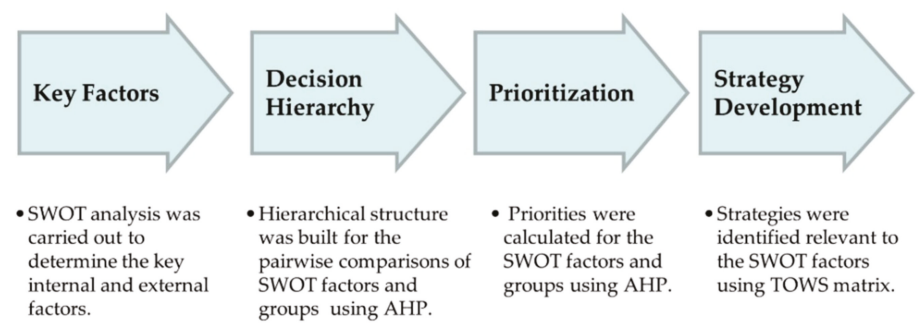

Figure 1. The flow diagram of the applied method. SWOT, Strengths, Weaknesses, Opportunities, Threats; AHP, Analytic Hierarchy Process; TOWS, Threats, Opportunities, Weaknesses, Strengths.

\subsubsection{The A'WOT Method}

The A'WOT method, which combines the AHP and SWOT analysis [52], is an appropriate method for situations of strategic planning. The idea while using a hybrid method is to evaluate SWOT factors and determine their intensities. The steps of the A'WOT method are listed below [53]:

- a SWOT analysis is carried out;

- $\quad$ pair-wise comparisons between SWOT factors are carried out within every SWOT group using AHP;

- $\quad$ pair-wise comparisons are made between the four SWOT groups using AHP; and

- the results are utilized in the strategy formulation and in the evaluation process.

SWOT analysis is also an early stage of the strategic planning process that helps planners define their strategies and make decisions on the allocation of resources in pursuing those strategies. Problem structuring is a significant stage of the strategy formulation. It means that strategic proposals are closely based on the selected factors. In this case, determining internal and external factors is critical. SWOT analysis is "an effective means for analyzing internal and external environments. The analysis involves systematic thinking and comprehensive diagnosis of factors relating to a new product, technology, management, or planning" [54]. SWOT analysis provides us with knowledge regarding the situation and allows us to design procedures that may be deemed necessary for thinking in a strategic way [55]. Hence, it is a significant tool within situation analysis and it can also be used to collect essential strategic information on decision-making from various resources [56]. However, the importance of SWOT factors is not analytically identified and evaluated in conventional SWOT analysis [54,57]. Conventional SWOT analysis only supplies the basic framework for analyzing the decision-making process.

The aim of $\mathrm{A}^{\prime} \mathrm{WOT}$ is "to improve the quantitative information basis of strategic planning processes". To address a prioritization, selection, or evaluation problem, the AHP method, which is the most popular technique for individual and group decision-making, can be utilized. The advantages of using the AHP in the SWOT analysis are the quantitative testing of SWOT factors and the inclusion of decision-making preferences for planning [58]. The AHP enables decision-makers to assign a relative priority to each factor through pair-wise comparison and assists in carrying out the SWOT analysis more analytically [52-54,59]. In the AHP, verbal expressions are given for providing a pair-wise comparison to decision-makers, and the reciprocal matrices are formed by converting linguistic labels into numerical values [60]. After the hierarchical structure is formed, pairwise judgments are assigned based on the nine-point scale shown in Table 1 to determine the relative importance of the factors. 
Table 1. Saaty's scale of relative importance [61].

\begin{tabular}{cc}
\hline Intensity of Relative Importance & Definition \\
\hline 1 & Equal importance \\
3 & Moderate importance of one over another \\
5 & Essential or strong importance \\
7 & Very strong importance \\
9 & Extreme importance \\
$2,4,6,8$ & Intermediate values between the two adjacent judgments \\
\hline
\end{tabular}

The questionnaire, which consists of pairwise judgments, can be applied by face-to-face interviewing to "maximize the response rate and ensure that the AHP component was clearly understood by respondents" [62]. While selecting decision-makers, their knowledge, years of experience, and level of gain in society are important, not the sample size [63]. The notion of a single decision-maker or team approach can be used to solve the problem. The geometric mean is the correct way of averaging data for the team approach [64]. In making judgments, people cannot estimate the values precisely. Thus, the AHP allows for inconsistency [65]. After making all the pair-wise comparisons, the Consistency Ratio (CR) is determined for each comparison matrix. If it does not exceed 0.10 , the CR is acceptable and a decision is made based on normalized values [66]. If the consistency ratio is found to exceed the limit, decision-makers should revise the pair-wise comparisons [67]. Finally, AHP represents the relative importance or priorities of the decision elements at each particular level [68,69]. These are utilized in the strategy formulation and in the evaluation process.

The A'WOT method has been widely used by different authors in different areas, such as forestry [52,53,70], agriculture [54], manufacturing [57], education [71], health services [72], energy [73], maritime [74], cultural industry [75], and tourism [76-81]. Kajanus et al. [76] have proposed a pioneering initiative in the field of tourism by means of the application of the A'WOT method. They centered the investigation of the present state of tourism in the regions of Yla-Savo in Finland and Kassel in Germany and suggested that alternative strategies could be defined in the next step of the planning process. Then, the A'WOT method was used to develop strategies for types of tourism, such as rural tourism [77], ecotourism [78,81], cruise tourism [79], and mountain tourism [80]. In this study, the A'WOT method has been used to develop strategies in the field of sustainable tourism.

\subsubsection{The TOWS Matrix}

The ultimate goal of a strategic planning process is "to develop and adopt a strategy resulting in a good fit between internal and external factors" [52]. After calculating the priorities of SWOT factors with the AHP, strategies can be developed in accordance with information obtained from this comparison. In the strategy development stage, the TOWS matrix, which is generally employed to assist information analysis in the process of systematizing strategic choices [82], can be used for this purpose. At this stage, strategy alternatives are presented taking into account the internal and external factors derived from the SWOT analysis. Table 2 shows the TOWS matrix suggested by Weihrich [83].

Table 2. The TOWS strategic alternatives matrix [83].

\begin{tabular}{ccc}
\hline & Internal Strengths (S) & Internal Weaknesses (W) \\
\hline External & SO: "Maxi-Maxi" Strategies & WO: "Mini-Maxi" Strategies \\
Opportunities (O) & Strategies that use to strengths to & Strategies that minimize weaknesses \\
& maximize opportunities & by taking advantage of opportunities \\
ST: "Maxi-Mini" Strategies & WT: "Mini-Mini" Strategies \\
External Threats (T) & Strategies that use strengths to & Strategies that minimize weakness \\
& minimize threats & and avoid threats
\end{tabular}

SO, strength-opportunity; ST, strength-threats; WO, weaknesses-opportunities; WT, weaknesses-threats. 
The TOWS matrix identifies four alternative strategy groups: Strength-Opportunity (SO), Strength-Threats (ST), Weaknesses-Opportunities (WO), and Weaknesses-Threats (WT). These strategies are derived by maximizing the strengths and opportunities as well as minimizing the weaknesses and threats. SO strategies aim at maximizing both strengths and opportunities, while ST strategies are based on the strengths that can deal with threats in the environment. WT strategies are created by minimizing both weaknesses and threats, while WO strategies attempt to minimize the weaknesses and to maximize the opportunities [83].

\section{Results and Discussion}

\subsection{SWOT Analysis of the Tourism Industry in Zonguldak}

In this study, the strategy development process in the tourism industry is presented analytically by utilizing the A'WOT hybrid method. The province of Zonguldak in West Black Sea Region of Turkey was selected as the case study and is discussed step-by-step. The first step of the case was to determine expert groups from different backgrounds. The expert groups consisted of managers of tourism and culture organizations, travel agency owners, hotel managers, local managers, and academics. The relevant factors of the internal environment (strengths and weaknesses) and external environment (opportunities and threats) were determined by selected experts working in the tourism industry as shown in Table 3.

Table 3. The SWOT Matrix for the tourism industry in Zonguldak.

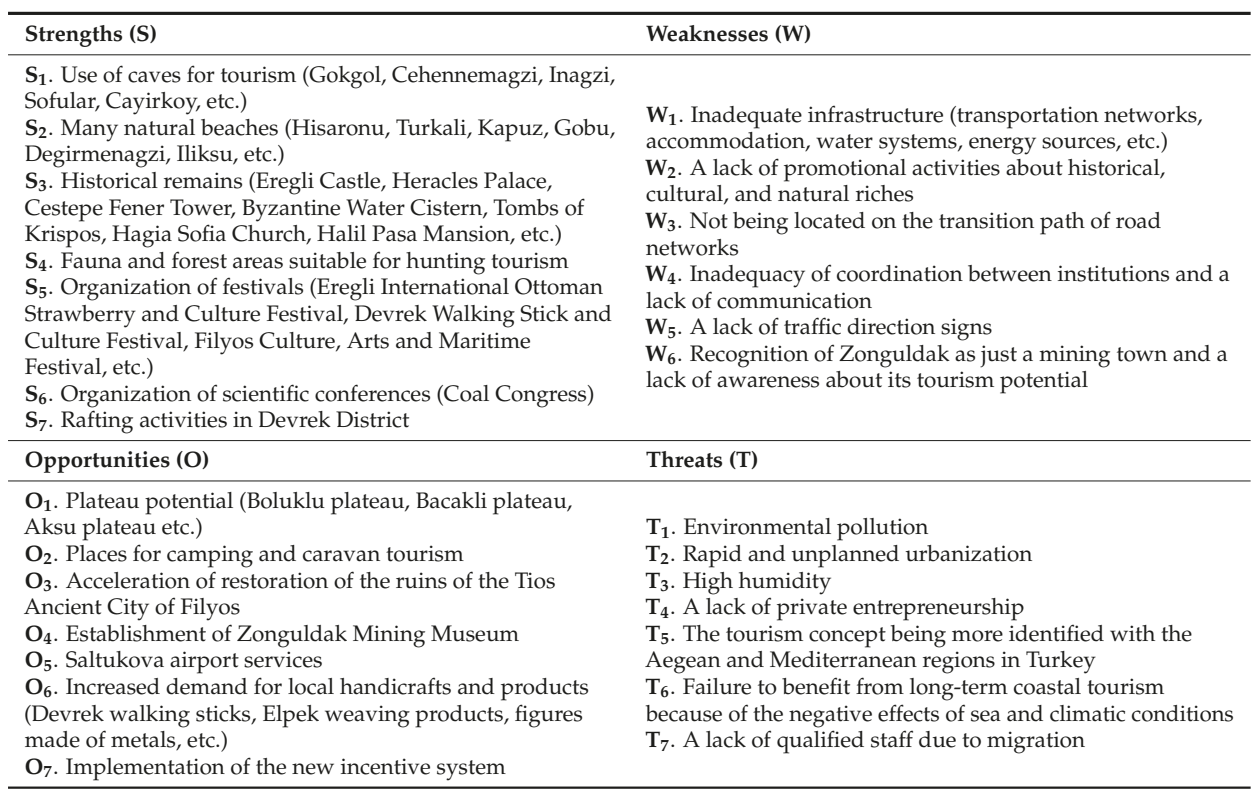

Source: Constructed by the author.

\subsection{Building the Hierarchical Structure}

In this step, the decision hierarchy was built for the pair-wise comparisons of SWOT factors and groups. There are three levels in the hierarchical structure (Figure 2). The first level (ultimate goal) is to develop regional sustainable tourism strategies. The second level (criteria) is the SWOT groups, and the third level (sub-criteria) is the SWOT factors. 




Figure 2. The hierarchical structure of sustainable tourism development for Zonguldak.

\subsection{Prioritization of SWOT Factors and Groups}

After constructing the decision hierarchy, the importance degrees of SWOT factors and groups were specified by experts. In this step, pair-wise comparisons were made and a questionnaire form consisting of 27 questions was prepared. Experts were interviewed face-to-face, and judgments were taken in the form of paired comparisons on the questionnaire. The questionnaire forms were conducted with experts closely related to the tourism industry in Zonguldak. Experts were selected by considering their expertise and experiences of working in the tourism industry. Ten participants from different backgrounds (one manager of tourism and culture organizations, one travel agency owner, three hotel managers, two local managers from municipal and provincial administrations, and three tourism academics) completed the questionnaire. While the tourism academics had at least a master's degree, the other participants of the expert group had more than 10 years of experience in their fields. To reach the group consensus, geometric means of expert opinions were used. The geometric means of all responses for each pair-wise comparison were analyzed using the Super Decisions (Version 2.8) software package. Furthermore, the consistency ratio (CR) was calculated for each comparison matrix and was found to be less than 0.10 . Priorities of related factors are illustrated in Table 4 .

Table 4. The priorities of criteria and subcriteria.

\begin{tabular}{|c|c|c|c|c|c|c|c|}
\hline Criteria & $\begin{array}{c}\text { Priorities } \\
\text { for Level } 2\end{array}$ & Subcriteria & $\begin{array}{l}\text { Priorities } \\
\text { for Level } 3\end{array}$ & Criteria & $\begin{array}{c}\text { Priorities } \\
\text { for Level } 2\end{array}$ & Subcriteria & $\begin{array}{c}\text { Priorities } \\
\text { for Level } 3\end{array}$ \\
\hline \multirow{7}{*}{$\mathrm{S}$} & \multirow{7}{*}{0.25} & $S_{1}$ & 0.4258 & \multirow{7}{*}{ W } & \multirow{7}{*}{0.25} & $\mathrm{~W}_{1}$ & 0.3165 \\
\hline & & $\mathrm{S}_{2}$ & 0.0653 & & & $\mathrm{~W}_{2}$ & 0.2943 \\
\hline & & $\mathrm{S}_{3}$ & 0.0505 & & & $\mathrm{~W}_{3}$ & 0.0933 \\
\hline & & $\mathrm{S}_{4}$ & 0.1362 & & & $\mathrm{~W}_{4}$ & 0.0688 \\
\hline & & $\mathrm{S}_{5}$ & 0.0963 & & & $\mathrm{~W}_{5}$ & 0.0387 \\
\hline & & $\mathrm{S}_{6}$ & 0.1136 & & & $\mathrm{~W}_{6}$ & 0.1885 \\
\hline & & $\mathrm{S}_{7}$ & 0.1125 & & & & \\
\hline \multirow{7}{*}{$\mathrm{O}$} & \multirow{7}{*}{0.25} & $\mathrm{O}_{1}$ & 0.0510 & \multirow{7}{*}{$\mathrm{T}$} & \multirow{7}{*}{0.25} & $\mathrm{~T}_{1}$ & 0.2997 \\
\hline & & $\mathrm{O}_{2}$ & 0.0469 & & & $\mathrm{~T}_{2}$ & 0.1898 \\
\hline & & $\mathrm{O}_{3}$ & 0.1837 & & & $\mathrm{~T}_{3}$ & 0.0314 \\
\hline & & $\mathrm{O}_{4}$ & 0.1350 & & & $\mathrm{~T}_{4}$ & 0.1594 \\
\hline & & $\mathrm{O}_{5}$ & 0.3183 & & & $\mathrm{~T}_{5}$ & 0.0859 \\
\hline & & $\mathrm{O}_{6}$ & 0.1146 & & & $\mathrm{~T}_{6}$ & 0.1748 \\
\hline & & $\mathrm{O}_{7}$ & 0.1504 & & & $\mathrm{~T}_{7}$ & 0.0591 \\
\hline
\end{tabular}

According to Table 4, it was determined that the greatest strengths of the province in terms of tourism were the potential for cave tourism (0.4258) and the fauna and forest areas suitable for hunting tourism (0.1362). Zonguldak is known as one of Turkey's richest regions in terms of cave formations. The region has a rugged topography and is rich in flora, which make it possible for various wild animals to shelter. There are wild animals, including bears, pigs, wolves, foxes, mountain goats, wild ducks, wild pigeons, and partridges, for hunting in the forest areas in the Devrek, Gokcebey, and Eregli districts. Managing the natural heritage values of a region is an important tool in sustainable tourism 
planning [84]. In this regard, cave tourism and hunting tourism are vital. While cave tourism improves the social and economic well-being of the local community and the protection of the environment [85], hunting tourism creates a synergy between eco, rural, and sports tourism, and stands out as a special tourism offer based on sustainability [86]. Therefore, these strengths will be among the most effective assets in the development of the sustainable tourism potential of the province.

Moreover, the opportunities of the province will facilitate the development of sustainable tourism on their own. The most important opportunity offered by the environment that should be used is the Saltukova Airport (0.3183). Airports increase the perceived quality in a tourist destination [87] and play a crucial role for the development of tourism. It is expected that Saltukova Airport will contribute to re-enliven tourism activities in the region. The second important opportunity is the restoration the ruins of the Tios Ancient City of Filyos (0.1837). The investigation of the Tios Ancient City, the first and only excavated ancient city on Turkey's Black Sea coast, is of great importance in terms of cultural tourism. As a result of the excavation activity, it is estimated that a large city will be revealed with its roads, forum, baths, religious buildings, houses, storehouses, shops, and graves.

Despite its strengths and opportunities, there are also weaknesses and threats for the province. The most important weakness of the province is its inadequate infrastructure (0.3165). This infrastructure forms an integral part of the tourism package and includes a high number of services, such as transportation networks, accommodation, water systems, and energy resources, which are necessary to meet the needs of tourists [88]. The quality of the infrastructure is an important indicator of the competitiveness and development level of a region in tourism. The second most important weakness is the lack of promotional activities dealing with historical, cultural, and natural riches (0.2943). The promotion of destinations has a great impact on the international tourism market. Image and branding in the tourism industry are regarded as important factors in gaining competitive power. This weakness should be eliminated as soon as possible, since promotion is seen as an effective tool for sustaining the target marketing activities as well as attracting tourists [89].

Environmental pollution (0.2997) and unplanned urbanization (0.1898) are the main environmental threats that can affect the tourism industry. To minimize environmental impacts, the authorities should act within the context of environmental sustainability while implementing activities for tourism development.

\subsection{Strategy Development}

In the previous studies suggesting sustainable tourism strategies in different regions, several authors used only SWOT analysis to develop sustainable tourism strategies [29,31,43], while others used SWOT analysis along with other methods, such as the TOWS matrix [27], fuzzy logic and the TOWS matrix [28], and a quantitative strategic planning matrix [30]. For example, Aminu et al. [37] and Garcia-Melon et al. [42] proposed sustainable strategies using the ANP technique. Tsaur and Wang [38] proposed an evaluation procedure for sustainable tourism development by the AHP and Fuzzy Set Theory. In this study, a strategic approach for the sustainable tourism development of touristic destinations was presented by means of the application of the A'WOT method and the TOWS matrix in accordance with the region-specific vision statement and main sustainable tourism goals. The region-specific vision statement for a sustainable tourism strategy in Zonguldak province was identified as "to ensure long-term and healthy development of the tourism industry by distributing tourism activities more widely in Zonguldak" based on the Tourism Strategy of Turkey: 2023 Report [45] and on the definition of sustainable tourism $[9,10,19]$ as found in the literature. Accordingly, the main Sustainable Tourism Goals (STGs) for Zonguldak were determined as follows [9,24]:

STG1. Providing a high-quality experience to visitors

STG2. Providing economic benefits to host communities

STG3. Minimizing environmental impacts and protecting the authenticity of the province 
To be able to achieve sustainable tourism goals, effective strategies should be developed and implemented in cooperation with all relevant stakeholders, authorities, and institutions. During the development of tourism strategies, priorities of criteria and subcriteria should be taken into account in addition to the vision statement and the main STGs. Strategies related to the sustainable tourism goals need to be evaluated from a holistic perspective to achieve the maximum benefit from sustainable tourism. According to the internal and external factors in the matrix of SWOT, strategy proposals were formulated with experts' guidance by means of the TOWS matrix for sustainable tourism in Zonguldak as shown in Table 5 .

Table 5. The strategy formulation using the TOWS matrix.

\begin{tabular}{|c|c|c|c|c|}
\hline & STG & Strengths & STG & Weaknesses \\
\hline Opportunities & STG1-STG2 & $\begin{array}{l}\text { SO Strategies } \\
\text { Support product diversification } \\
\text { and event management (S1, S2, } \\
\text { S3, S4, S5, S6, S7, O1, O2, O3, O4, } \\
\text { O5, O6, O7) } \\
\text { - } \quad \begin{array}{l}\text { Guidance of destination } \\
\text { management organizations } \\
\text { for organizing national and } \\
\text { international events }\end{array} \\
\text { - } \quad \begin{array}{l}\text { Reward best practices } \\
\text { within tourism types }\end{array} \\
\text { - } \begin{array}{l}\text { Promote the development } \\
\text { of traditional handicrafts }\end{array}\end{array}$ & STG1-STG3 &  \\
\hline Threats & STG1-STG3 & $\begin{array}{l}\text { ST Strategies } \\
\text { Ensure a sustainable visitor } \\
\text { management system that } \\
\text { minimizes environmental impacts } \\
\text { (S1, S2, S3, S4, S5, S6, S7, T1, T4, } \\
\text { T5, T6, T7) } \\
\text { - } \quad \text { Distribute tourism } \\
\text { activities throughout the } \\
\text { year without changing the } \\
\text { identity and culture of } \\
\text { the city } \\
\text { Initiate activities to increase } \\
\text { tourism entrepreneurship } \\
\text { awareness of the society by } \\
\text { considering optimal use of } \\
\text { environmental resources } \\
\text { Training on sustainable } \\
\text { tourism for relevant } \\
\text { stakeholdersReduce and } \\
\text { recycle waste } \\
\text { Reduce and recycle waste }\end{array}$ & STG1-STG2-STG3 & $\begin{array}{l}\text { WT Strategies } \\
\text { Initiate effective promotion and } \\
\text { branding strategies (W2, T5) } \\
\text { - } \quad \begin{array}{l}\text { Advertise of destination } \\
\text { in the country } \\
\text { and abroad }\end{array} \\
\text { Establish partnerships and } \\
\text { cooperation (W4, T4) } \\
\text { - } \quad \begin{array}{l}\text { Organize permanent } \\
\text { programs for a } \\
\text { public-private partnership } \\
\text { - } \\
\text { Strengthen linkages } \\
\text { between tourism and } \\
\text { other regional } \\
\text { industrial sectors } \\
\text { Empower local } \\
\text { authorities in the } \\
\text { implementation of } \\
\text { sustainable principles }\end{array}\end{array}$ \\
\hline
\end{tabular}

Source: Constructed by the author. STG, sustainable tourism goal.

Support product diversification and event management: The success of sustainable tourism development depends on using policies of diversification and specialization wisely [90]. In addition, event tourism attempts to derive a benefit from events to attract tourists to visit [91]. Therefore, the proposed product diversification and event management programs within the scope of this study could be organized by means of a public-private partnership to provide a high-quality experience to visitors (STG1). Besides this, destination management organizations could be the guide for organizing national and international events. In previous studies, Sulistyadi et al. [30] and Klimek [92] also pointed out the role of destination management organizations in the implementation of sustainable tourism. In the context of the diversity of tourism products, the competitiveness of tourism relies on the sustainable use of resources in natural ecosystems [90]. Hence, in particular, the caves, which are the strongest assets of the city (0.4258), must be protected, be used in a sustainable way, and achieve availability today and in the future. Nevertheless, the suitable fauna and forest areas for hunting tourism (0.1362), rafting activities (0.1125), natural beaches (0.0653), historical remains (0.0505), 
the organization of scientific conferences (0.1136), and festivals (0.0963) are the other factors that can be evaluated within the scope of product diversity and event management. Thanks to tourism diversification, seasonality, which has negative environmental, economic, social, and cultural impacts on sustainable tourism destinations, can be prevented [93]. As a result, tourism activities can spread throughout the year by increasing the number of tourist visits during low periods [94]. Thus, a management system that provides for the sustainable use of resources and prevents overtourism in the future will be in operation. Sustainable tourism not only benefits from the visitor but also the maximization of benefits from the host communities [13]. Similarly, Tsaur and Wang [38] also claimed that tourism development could be beneficial for the economy. To provide economic benefits to the host communities (STG2), incentive-based and conscious entrepreneurial approaches should be developed. For instance, best practices within tourism types, such as tableland tourism, botanical tourism, butterfly observing, cycling tourism, trekking, rafting, cave tourism, and cultural tourism, can be rewarded. As special interest tourism types promote more balanced growth in accordance with local environmental and socio-cultural concerns, it is increasingly recognized as the key to sustainable development [95]. In addition to this, handicrafts also affect sustainable tourism development [96]. The increased demand for traditional handicrafts (0.1146) will affect the province in terms of both economic and socio-cultural development.

Enhance the image of the destination: Another topic related to sustainable tourism destinations is the destination's image, which is the main factor in achieving effective marketing for the destination [97]. The inclusion of Zonguldak in tour programs, the modernization of the infrastructure, and the protection of value-added products and services are among the main topics to help enhance the image of the destination and, therefore, to provide a high-quality experience to the visitors (STG1). Tourism infrastructure development activities should be carried out with sustainable environmental management practices that minimize environmental impacts (STG3). This is in line with prior studies, in which Mondal [27] suggested the development of the required infrastructure and more environmental regulation for sustainable tourism. Both the inclusion of Zonguldak in tour programs and tourism infrastructure play an important role in the tourism industry as it affects the level of visitor satisfaction. Moreover, it is known that high-value-added products and services in the tourism sector and sustainable use of natural and cultural resources increase competitiveness [98]. Mining, weaving, embroidery, and woodworking are among the value-added activities of the region. In addition, the establishment of the Zonguldak Mining Museum (0.1350), which is considered to be a part of the cultural heritage, is among the factors that can enhance the image of the destination.

Ensure a sustainable visitor management system that minimizes environmental impacts: One of the ways to ensure sustainable visitor management and provide a high-quality experience to visitors (STG1) is to distribute tourism activities throughout the year. For this purpose, it may be suggested to increase the touristic initiatives and to enrich the touristic experiences with different types of special interest tourism without changing the identity and culture of the city. Tsaur and Wang [38] emphasized that tourism development could be harmful to the environment. The other sustainability practice for tourism development is to minimize environmental impacts [16]. The two most important threats to the province are, as stated above, environmental pollution (0.2997) and rapid, unplanned urbanization (0.1898). To minimize the negative impacts on the environment and protect the authenticity of the province (STG3), the authorities should act within the context of environmental sustainability and promote actions that do not change the identity and culture of the city, while planning and implementing activities for tourism development. At this point, training on sustainable tourism for relevant stakeholders, reducing waste, and encouraging recycling are among the important issues to be considered.

Initiate effective promotion and branding strategies: In the constantly changing tourism market, it has become difficult for a destination to be competitive on the global level [99]. A sustainable tourism marketing strategy can bring a competitive advantage to a touristic destination [100]. The practices for sustainable tourism destinations to support the destination brand and image are based on advertising 
the destination in the country and abroad. "A lack of promotional activities" (0.2943) is among the weaknesses of the province. This weakness can be eliminated by developing effective promotion and brand strategies. For example, Grytsiuk et al. [25] and Cortez [26] also suggested promotion strategies for sustainable tourism in their study. These strategies, complementary to other sustainable tourism strategies, will benefit from both the visitors (STG1) and the host communities (STG2).

Establish partnerships and cooperation: Another important dimension for the development of sustainable tourism is related to partnerships and cooperation, which have been seen as an effective way to support initiatives in tourism development [101]. To achieve sustainable tourism goals, stakeholders play a significant role in both strategy evaluation and at an implementation stage. In other studies, Paunovic and Jovanovic [32] and Nowacki et al. [36] also emphasized that the participation of stakeholders must be ensured in the practice of sustainable tourism. Establishing permanent programs for a public-private partnership, strengthening links between tourism and other regional industrial sectors, and strengthening local governments toward the implementation of sustainable principles are the main actions to be taken to ensure cooperation. In their research on sustainable tourism strategies, Goodwin [39] and Candrea and Bouriaud [41] have also proposed partnerships between public and private sectors. Moreover, Grytsiuk et al. [25] pointed out the formation of an effective model of cooperation between government, business, and society. Similarly, Sulistyadi et al. [30] summarized their tourism development strategies as strengthening the commitment of the stakeholder and increasing the role and capabilities of the local communities. Considering the possible strategies developed, it can be inferred that sustainable tourism development requires the participation of all of the relevant stakeholders.

\section{Conclusions}

The need for the sustainable development of tourism has become a current issue due to the rapid growth of the tourism industry worldwide and the adverse effects of tourism on the social structure, natural resources, and cultural values. As a matter of fact, sustainable tourism allows us to minimize the environmental impact and to maximize the socio-economic advantages of tourist destinations [102]. In other words, sustainability is meant to consider both the development and preservation of the tourism industry [103]. For this reason, tourism activities need to be planned, managed, and monitored carefully using a long-term sustainable approach [104]. In this study, a strategic approach for the sustainable tourism development of destinations was presented by means of the application of the A'WOT method. The primary advantages of this study's method are to present an integrated perspective that can help in the design of a strategic planning process and to strengthen the quantitative side of strategic planning. The province of Zonguldak, located in the West Black Sea Region of Turkey, was chosen as the research area to propose sustainable tourism strategies. Zonguldak province has the potential to be a suitable destination for the development of special interest tourism types with its cultural richness, forests, plateaus, caves, and natural beauties created by a combination of blue and green colors. Besides this, it can be concluded that, despite its many weaknesses and environmental threats, Zonguldak bears a tourism potential that should be managed in a sustainable way with strategic approaches. It should be considered that, on the one hand, the "support product diversification and event management" strategies proposed in this study would particularly help to develop tourism as an economic diversification tool by breaking the dependent structure of the province. On the other hand, it would "ensure a sustainable visitor management system that minimizes environmental impacts" and "enhance the image of the destination", which would increase in the number of tourists and indirectly help to solve the problem of overtourism in popular tourist destinations.

These regional strategies, suggested within the framework of an analytical approach, can lead to the design of sustainable tourism development planning. This study contributes to a theoretical approach by reviewing the literature on sustainable tourism development strategies and by reflecting on the current situation of the tourism industry of Zonguldak with the A'WOT method. This method 
supports decision-makers in the decision-making process by providing a flow diagram that consists of the basic stages of identifying SWOT factors, establishing a decision hierarchy, prioritizing SWOT factors and groups, and developing a strategy using the TOWS matrix. Thereby, from a practical perspective, it supplies a systematic approach for decision-makers in the implementation of sustainable tourism strategies and the production of feasible solutions for the tourism industry. The use of this step-by-step decision-making process can promote a guiding role for tourism stakeholders, such as national and local government, tourism enterprises, local communities, and educational institutions. The original aspects of this study are the use of the strategic approach, which consists of the A'WOT method, the TOWS matrix, a region-specific vision statement, and the main sustainable tourism goals, in sustainable tourism development and the application of the method in Zonguldak. Furthermore, the analytical structure used in this study can be applied to other similar destinations. This structure can be used in further studies related to sustainability by integrating other multicriteria decision-making methods.

Funding: This research received no external funding.

Acknowledgments: The authors would like to thank the experts for their valuable contributions.

Conflicts of Interest: The authors declare no conflict of interest.

\section{References}

1. Font, X.; Mccabe, S. Sustainability and Marketing in Tourism: Its Contexts, Paradoxes, Approaches, Challenges and Potential. J. Sustain. Tour. 2017, 25, 869-883. [CrossRef]

2. Butcher, J. What Meaning for Sustainability? The Politics of 'Good Development'. J. Policy Res. Tour. Leis. Events 2017, 9, 216-218. [CrossRef]

3. Fiskel, J. Sustainability and Resilience: Towards a System Approach. Sustain. Sci. Pract. Policy 2006, 2, 1-8. [CrossRef]

4. Font, X.; Tapper, R.; Cochrane, J. Competitive Strategy in a Global Industry: Tourism. Handb. Bus. Strategy 2006, 7, 51-55. [CrossRef]

5. Fossati, A.; Panella, G. Tourism and Sustainable Economic Development; Kluwer Academic Publishers: New York, NY, USA, 2000; ISBN 978-1-4613-6940-0.

6. Dwyer, L.; Edwards, D. Sustainable Tourism Planning. In Understanding the Sustainable Development of Tourism; Liburd, J.J., Edwards, D., Eds.; Goodfellow Publishers: Woodeaton, UK, 2010; pp. 19-44, ISBN 978-1-906884-13-0.

7. Selvi, M.S.; Şahin, S. Yerel Yönetimler Perspektifinden Sürdürülebilir Turizm: Batı Karadeniz Bölgesi Örneği. IJSES 2012, 2, 23-36.

8. Dodds, R. Sustainable Tourism and Policy Implementation: Lessons from the Case of Calvia, Spain. Curr. Issues Tour. 2007, 10, 296-322. [CrossRef]

9. UNEP/WTO. Making Tourism More Sustainable: A Guide for Policy Makers; United Nations Environment Programme/World Tourism Organisation: Paris, France; Madrid, Spain, 2005.

10. Müller, H. The Thorny Path to Sustainable Tourism Development. J. Sustain. Tour. 1994, 2, 131-136. [CrossRef]

11. Hunter, C. Sustainable tourism as an adaptive paradigm. Ann. Tour. Res. 1997, 24, 850-867. [CrossRef]

12. Niedziolka, I. Sustainable Tourism Development. Reg. Form. Dev. Stud. 2012, 8, 157-166.

13. Creaco, S.; Querini, G. The Role of Tourism in Sustainable Economic Development. Presented at the 43rd Congress of the European Regional Science Association, Jyvaskyla, Finland, 27-30 August 2003.

14. Muhanna, E. Sustainable Tourism Development and Environmental Management for Developing Countries. Probl. Perspect. Manag. 2006, 4, 14-30.

15. Richins, H. Environmental, Cultural, Economic and Socio-Community Sustainability: A Framework for Sustainable Tourism in Resort Destinations. Environ. Dev. Sustain. 2009, 11, 785-800. [CrossRef]

16. Patterson, C. Sustainable Tourism: Business Development, Operations, and Management; Human Kinetics: Champaign, IL, USA, 2016; ISBN 978-1-4504-6003-3. 
17. Goodwin, H. The Challenge of Overtourism. Responsible Tourism Partnership Working Paper 4. 1-19, October 2017. Available online: http://haroldgoodwin.info/pubs/RTP \T1 textquoteleftWP4Overtourism01 \T1 \textquoteright2017.pdf (accessed on 20 October 2018).

18. Milano, C. Overtourism and Tourismphobia: Global Trends and Local Contexts; Technical Report; Ostelea School of Tourism \& Hospitality: Barcelona, Spain, 2017.

19. UNWTO. 'Overtourism'? Understanding and Managing Urban Tourism Growth beyond Perceptions. Available online: https:/ / www.e-unwto.org/doi/pdf/10.18111/9789284420070 (accessed on 25 October 2018).

20. Zolfani, S.H.; Sedaghat, M.; Maknoon, R.; Zavadskas, E.K. Sustainable Tourism: A Comprehensive Literature Review on Frameworks and Applications. Econ. Ekon. Istraz. 2015, 28, 1-30. [CrossRef]

21. Bramwell, B.; Higham, J.; Lane, B.; Miller, G. Twenty Five Years of Sustainable Tourism and the Journal of Sustainable Tourism: Looking Back and Moving Forward. J. Sustain. Tour. 2017, 25, 1-9. [CrossRef]

22. Dodds, R.; Butler, R. Barriers to Implementing Sustainable Tourism Policy in Mass Tourism Destinations. Tour. Int. Multidiscip. J. Tour. 2010, 5, 35-53.

23. Helmy, E. Towards Integration of Sustainability into Tourism Planning in Developing Countries: Egypt as a Case Study. Curr. Issues Tour. 2004, 7, 478-501. [CrossRef]

24. Font, X.; Serra, J. Bases for the Implementation of Tourist Marketing for a Sustainable Destination: The Case of Barcelona. Tourism 2020 Strategic Plan. 2017. Available online: https:/ /ajuntament.barcelona.cat/turisme/sites/default/files/bases_for_the_implementation_of_ tourist_marketing_for_a_sustainable_dest_0.pdf (accessed on 18 October 2018).

25. Grytsiuk, M.; Grytsiuk, P.; Gryciuk, Y. Building a Sustainable Tourism Development Strategy in the Carpathian Region of Ukraine. Sci. Pap. Sil. Univ. Technol. Organ. Manag. Ser. 2017, 35-50. [CrossRef]

26. Cortez, S.L. Strategies for the Development of Sustainable Tourism in the Amazon Rainforest of Bolivia. Worldw. Hosp. Tour. Themes 2010, 2, 136-143. [CrossRef]

27. Mondal, M.S.H. SWOT Analysis and Strategies to Develop Sustainable Tourism in Bangladesh. UTMS J. Econ. 2017, 8, 159-167.

28. Feili, H.; Qomi, M.; Sheibani, S.; Azmoun, G. SWOT Analysis for Sustainable Tourism Development Strategies Using Fuzzy Logic. Presented at the 3rd International Conference of Science \& Engineering in the Technology Era, Copenhagen, Denmark, 30 November 2017.

29. Rezapouraghdam, H.; Esmaeili, B. Sustainable Desert-Tourism Development Strategies in Khara, Iran: A Swot Analysis Approach. In Proceedings of the 7th Advances in Hospitality \& Tourism Marketing \& Management Conference, Eastern Mediterranean University, Famagusta, North Cyprus, 10-15 July 2017.

30. Sulistyadi, Y.; Eddyono, F.; Hasibuan, B. Model of Sustainable Tourism Development Strategy of the Thousand Islands Tourism Area-Jakarta. J. Econ. Manag. Trade 2017, 19, 1-17. [CrossRef]

31. UNESCO. Cultural Landscape of Bali Province: The Subak System as a Manifestation of the Tri Hita Karana Philosophy. 2012. Available online: https://whc.unesco.org/document/157465 (accessed on 27 September 2018).

32. Paunovic, I.; Jovanovic, V. Implementation of Sustainable Tourism in the German Alps: A Case Study. Sustainability 2017, 9, 226. [CrossRef]

33. Stoddard, J.E.; Pollard, C.E.; Evans, M.R. The Triple Bottom Line: A Framework for Sustainable Tourism Development. Int. J. Hosp. Tour. Adm. 2012, 13, 233-258. [CrossRef]

34. Neto, F. A New Approach to Sustainable Tourism Development: Moving Beyond Environmental Protection. Nat. Resour. Forum 2003, 27, 212-222. [CrossRef]

35. Reichel, A.; Uriely, N. Sustainable Tourism Development in the Israeli Negev Desert: An Integrative Approach. J. Park Recreat. Adm. 2003, 21, 14-29.

36. Nowacki, M.; Kowalczyk-Aniol, J.; Krolikowska, K.; Pstrocka-Rak, M.; Awedyk, M. Strategic Planning for Sustainable Tourism Development in Poland. Int. J. Sustain. Dev. World 2018, 25, 562-567. [CrossRef]

37. Aminu, M.; Matori, A.N.; Yusof, K.W.; Malakahmad, A.; Zainol, R.B. Analytic Network Process (ANP)-Based Spatial Decision Support System (SDSS) for Sustainable Tourism Planning in Cameron Highlands, Malaysia. Arab. J. Geosci. 2017, 10, 1-20. [CrossRef]

38. Tsaur, S.-H.; Wang, C.-H. The Evaluation of Sustainable Tourism Development by Analytic Hierarchy Process and Fuzzy Set Theory: An Empirical Study on the Green Island in Taiwan. Asia Pac. J. Tour. Res. 2007, 12, 127-144. [CrossRef] 
39. Goodwin, H. Local Community Involvement in Tourism around National Parks: Opportunities and Constraints. Curr. Issues Tour. 2002, 5, 338-360. [CrossRef]

40. Cottrell, S.P.; Cutumisu, N. Sustainable Tourism Development Strategy in WWF Pan Parks: Case of a Swedish and Romanian National Park. Scand. J. Hosp. Tour. 2006, 6, 150-167. [CrossRef]

41. Candrea, A.N.; Bouriaud, L. A Stakeholders' Analysis of Potential Sustainable Tourism Development Strategies in Piatra Craiului National Park. Ann. Res. 2009, 52, 191-198.

42. Garcia-Melon, M.; Gomez-Navarro, T.; Acuna-Dutra, S. An ANP Approach to Assess the Sustainability of Tourist Strategies for the Coastal National Parks of Venezuela. Technol. Econ. Dev. Econ. 2010, 16, 672-689. [CrossRef]

43. Reihanian, A.; Mahmood, N.Z.B.; Kahrom, E.; Hin, T.W. Sustainable Tourism Development Strategy by SWOT Analysis: Boujagh National Park, Iran. Tour. Manag. Perspect. 2012, 4, 223-228. [CrossRef]

44. UNWTO. Tourism Highlights. 2017. Available online: http://people.unica.it/carlamassidda/files/2017/06/ UNWTO_Tourism-Highlights_2017.pdf (accessed on 2 August 2018).

45. Ministry of Culture and Tourism. Turkey's Tourism Strategy 2023 and Activity Plan for Tourism Strategy of Turkey 2007-2013. Available online: http://www.kultur.gov.tr/Eklenti/43537, turkeytourismstrategy2023pdf.pdf?0\&_tag1=796689BB12A540BE0672E65E48D10C07D6DAE291 (accessed on 20 October 2018).

46. Miedema, P.; Winchenbach, A. The Dilemma of Fair Shares in Township Tourism- A Case Study from Port Elizabeth. In Progress in Responsible Tourism; Goodwin, H., Font, X., Eds.; Goodfellow Publishers: Woodeaton, UK, 2015; pp. 4-16. ISBN 978-1-910158-03-6.

47. West Black Sea Development Agency. West Black Sea Region (Zonguldak-Karabuk, Bartin) Regional Plan; West Black Sea Development Agency: Zonguldak, Turkey, 2010; Available online: http://bakkakutuphane. org/upload/dokumandosya/BatY-Karadeniz-Bolgesi-2010---2013-Bolge-PlanY-13.02.2015.14.50.30.pdf (accessed on 2 August 2018).

48. West Black Sea Development Agency. West Black Sea Region (Zonguldak- Karabuk, Bartin) 2014-2023 Regional Plan Volume 1 Analysis of the Current Situation. 2013. Available online: http:/ / bakkakutuphane.org/upload/dokumandosya/2014-2023-bati-karadeniz-bolge-plani-cilt1mevcut_durum_analizi_1_2.pdf (accessed on 28 August 2018).

49. TURKSTAT. Statistics by Theme: Population and Demography. Available online: https://biruni.tuik.gov.tr/ medas / ?kn=95\&locale=en (accessed on 13 February 2019).

50. Zonguldak Provincial Directorate of Culture and Tourism. Zonguldak Presentation Book. 2014. Available online: http:/ / bakkakutuphane.org/upload/dokumandosya/zonguldak-brosur.pdf (accessed on 28 August 2018).

51. West Black Sea Development Agency. West Black Sea Region (Zonguldak- Karabuk, Bartin) 2014-2023 Regional Plan Volume 2 Growth Axis, Priority and Precaution. 2013. Available online: http:/ / bakkakutuphane.org/upload/dokumandosya/2014-2023-bati-karadeniz-bolge-plani-cilt2gelisme_ekseni_oncelik_ve_tedbirler_mt.pdf (accessed on 28 August 2018).

52. Kangas, J.; Pesonen, M.; Kurttila, M.; Kajanus, M. A'WOT: Integrating the AHP with SWOT Analysis. In Proceedings of the 6th ISAHP, Berne, Switzerland, 2-4 August 2001.

53. Kurttila, M.; Pesonen, M.; Kangas, J.; Kajanus, M. Utilizing the Analytical Hierarchy Process (AHP) in SWOT Analysis-A Hybrid Method and Its Application to a Forest-Certification Case. For. Policy Econ. 2000, 1, 41-52. [CrossRef]

54. Shrestha, R.K.; Alavalapati, J.R.R.; Kalmbacher, R.S. Exploring the Potential for Silvopasture Adoption in South-Central Florida: An Application of SWOT-AHP Method. Agric. Syst. 2004, 81, 185-199. [CrossRef]

55. Lozano, M.; Valles, J. An Analysis of the Implementation of an Environmental Management System in a Local Public Administration. J. Environ. Manag. 2007, 82, 495-511. [CrossRef] [PubMed]

56. Pahl, N.; Richter, A. SWOT Analysis-Idea, Methodology and a Practical Approach; Grin Verlag: Norderstedt, Germany, 2007; ISBN 978-3-640-30303-8.

57. Shinno, H.; Yoshioka, H.; Marpaung, S.; Hachiga, S. Quantitative SWOT Analysis on Global Competitiveness of Machine Tool Industry. J. Eng. Des. 2006, 17, 251-258. [CrossRef]

58. Oreski, D. Strategy Development by Using SWOT-AHP. TEM J. 2012, 1, 283-291. 
59. Leskinen, L.A.; Leskinen, P.; Kurttila, M.; Kangas, J.; Kajanus, M. Adapting Modern Strategic Decision Support Tools in the Participatory Strategy Process-A Case Study of a Forest Research Station. For. Policy Econ. 2004, 8, 1-12. [CrossRef]

60. Yuen, K.K.F. Analytic Hierarchy Prioritization Process in the AHP Application Development: A Prioritization Operator Selection Approach. Appl. Soft Comput. 2009, 10, 975-989. [CrossRef]

61. Saaty, T.L. How to Make a Decision: The Analytic Hierarchy Process. Eur. J. Oper. Res. 1990, 48, 9-26. [CrossRef]

62. Morgan, R.; Lesueur, M.; Henichart, L.-M. Fisheries Diversification: A Case Study of French and English Fishers in the Channel. In Social Issues in Sustainable Fisheries Management; Urquhart, J., Acott, T.G., Symes, D., Zhao, M., Eds.; Mare Publication Series; Springer: Dordrecht, The Netherlands; Heidelberg, Germany; New York, NY, USA; London, UK, 2014; pp. 165-182. ISBN 978-94-007-7910-5.

63. Saaty, T.L.; Özdemir, M.S. How Many Judges Should There Be in a Group? Ann. Data Sci. 2015, 1, 359-368. [CrossRef]

64. Bodin, L.; Gass, S.I. On Teaching the Analytic Hierarchy Process. Comput. Oper. Res. 2003, 30, 1487-1497. [CrossRef]

65. Saaty, T.L. Decision-making with the AHP: Why is the Principal Eigenvector Necessary. Eur. J. Oper. Res. 2003, 145, 85-91. [CrossRef]

66. Sharma, M. Multi Attribute Decision Making Techniques. Int. J. Res. Manag. Sci. Technol. 2013, 1, 49-51.

67. Ho, W. Integrated Analytic Hierarchy Process and Its Applications-A Literature Review. Eur. J. Oper. Res. 2008, 186, 211-228. [CrossRef]

68. Srdjevic, B. Combining Different Prioritization Methods in the Analytic Hierarchy Process Synthesis. Comput. Oper. Res. 2005, 32, 1897-1919. [CrossRef]

69. Huang, Y.; Bian, L.A. Bayesian Network and Analytic Hierarchy Process Based Personalized Recommendations for Tourist Attractions over the Internet. Expert Syst. Appl. 2009, 36, 933-943. [CrossRef]

70. Pesonen, M.; Ahola, J.; Kurttila, M.; Kajanus, M.; Kangas, J. Applying A’WOT to Forest Industry Investment Strategies: Case Study of a Finnish Company in North America. In The Analytic Hierarchy Process in Natural Resource and Environmental Decision Making; Schmoldt, D., Kangas, J., Mendoza, G.A., Pesonen, M., Eds.; Springer: Dordrecht, The Netherlands, 2001; Volume 3, pp. 187-199. ISBN 978-90-481-5735-8.

71. Nastase, C.; Kajanus, M. The Role of the Universities in a Regional Innovation System-A Comparative A'WOT Analysis. Amfiteatru Econ. 2008, 10, 219-224.

72. Osuna, E.E.; Aranda, A. Combining Swot and Ahp Techniques for Strategic Planning. In Proceedings of the ISAHP 2007, Vina del Mar, Chile, 2-6 August 2007.

73. Wota, A.K.; Wozniak, A. The Application of the SWOT and AHP Methods for the Assessment of Region's Strategic Position in the Aspect of Wind Energy. Agric. Eng. 2015, 19, 129-138. [CrossRef]

74. Akyuz, E.; Celik, M. Using of A'wot to Design an Enhanced Planned Maintenance System (E-Pms) on-Board Ship. Brodogradnja 2017, 68, 61-75. [CrossRef]

75. Fan, T.; Xue, D.Q. Sustainable Development of Cultural Industry in Shaanxi Province of Northwest China: A SWOT and AHP Analysis. Sustainability 2018, 10, 2830. [CrossRef]

76. Kajanus, M.; Kangas, J.; Kurttila, M. The Use of Value Focused Thinking and the A'WOT Hybrid Method in Tourism Management. Tour. Manag. 2004, 25, 499-506. [CrossRef]

77. Fabac, R.; Zver, I. Applying the Modified Swot-Ahp Method to the Tourism of Gornje Medimurje. Tour. Hosp. Manag. 2011, 17, 201-215.

78. Akbulak, C.; Cengiz, T. Determining Ecotourism Strategies Using A'WOT Hybrid Method: Case Study of Troia Historical National Park, Çanakkale, Turkey. Int. J. Sustain. Dev. World 2014, 21, 380-388. [CrossRef]

79. Kim, M.; Boo, C.-S.; Kim, J.-T.; Kang, S.-Y.; Yang, H.-S. Analysis on Development Strategy Alternatives of Jeju Cruise Tourism Industry. J. Fish. Mar. Sci. Educ. 2014, 26, 838-845. [CrossRef]

80. Nikolic, D.; Spasic, J.; Zivkovic, Z.; Djordjevic, P.; Mihajlovic, I.; Kangas, J. SWOT-AHP model for Prioritization of Strategies of the Resort Stara Planina. Serb. J. Manag. 2015, 10, 141-150. [CrossRef]

81. Bianco, S.; Marciano, C. Using an Hybrid AHP-SWOT Method to Build Participatory Ecotourism Development Strategies: The Case Study of the Cupe Valley Natural Reserve in Southern Italy. In New Metropolitan Perspectives; Calabro, F., Della Spina, L., Bevilacqua, C., Eds.; Springer: Cham, Switzerland, 2019; Volume 101, pp. 327-336. ISBN 978-3-319-92101-3. 
82. Pesic, D.; Pesic, A.; Ivkovic, S.; Apostolovic, D. Fuzzification of the 'Tows' Strategic Concept: A Case Study of the Magneti Marelli Branch in the Serbian Automotive Industry. S. Afr. J. Ind. Eng. 2015, 26, 203-217. [CrossRef]

83. Weihrich, H. The TOWS Matrix-A Tool for Situational Analysis. Long Range Plan. 1982, 15, 54-66. [CrossRef]

84. Asia Pacific Economic Cooperation (APEC). Report to APEC on the International Workshop: Advancing Sustainable Tourism at Cultural and Natural Heritage Sites (Mogao Caves World Heritage Site, China, 26-29 September 2009); APEC Tourism Working Group: Singapore, 2010.

85. Okonkwo, E.E.; Afoma, E.; Martha, I. Cave Tourism and its Implications to Tourism Development in Nigeria: A Case Study of Agu-Owuru Cave in Ezeagu. Int. J. Res. Tour. Hosp. 2017, 3, 16-24. [CrossRef]

86. Milojica, V.; Drpic, D.; Nakovski, D. Developing Hunting Tourism-A New Perspective of Achieving Competitiveness of Rural Croatia. Presented at the 3rd International Scientific Symposium Economy of Eastern Croatia-Vision and Growth, Osijek, Croatia, 22-24 May 2014.

87. Martin-Cejas, R.R. Tourism Service Quality Begins at the Airport. Tour. Manag. 2006, 27, 874-877. [CrossRef]

88. Seetanah, B.; Juwaheer, T.D.; Lamport, M.J.; Rojid, S.; Sannassee, R.V.; Subadar Agathee, U. Does Infrastructure Matter in Tourism Development? Univ. Maurit. Res. J. 2011, 17, 89-108. [CrossRef]

89. Mulec, I. Promotion as a Tool in Sustaining the Destination Marketing Activities. Turizam 2009, 14, 13-21. [CrossRef]

90. Weidenfeld, A. Tourism Diversification and Its Implications for Smart Specialisation. Sustainability 2018, 10, 319. [CrossRef]

91. Higgins-Desbiolles, F. Event Tourism and Event Imposition: A Critical Case Study from Kangaroo Island, South Australia. Tour. Manag. 2018, 64, 73-86. [CrossRef]

92. Klimek, K. Destination Management Organisations and their Shift to Sustainable Tourism Development. Eur. J. Tour. Hosp. Recreat. 2013, 4, 27-47.

93. Martin, J.M.M.; Aguilera, J.D.D.J.; Moreno, V.M. Impacts of Seasonality on Environmental Sustainability in the Tourism Sector Based on Destination Type: An Application to Spain's Andalusia Region. Tour. Econ. 2014, 20, 123-142. [CrossRef]

94. Lee, C.; Bergin-Seers, S.; Galloway, G.; O’Mahony, B.; McMurray, A. Seasonality in the Tourism Industry: Impacts and Strategies; Technical Report; Sustainable Tourism Cooperative Research Centre: Gold Coast, Australia, 2008; ISBN 9781920965518.

95. Ioannides, D. A Flawed Implementation of Sustainable Tourism: The Experience of Akamas, Cyprus. Tour. Manag. 1995, 16, 583-592. [CrossRef]

96. Zargham, H. Sustainable Tourism Development and Handicrafts in the Developing World. Trans. Ecol. Environ. 2007, 102, 111-117.

97. Liu, Y.Y. Destination Images for Marketing Sustainable Tourism Destinations. Econ. Bus. 2017, 11, 520-525.

98. Romao, J.; Guerreiro, J.; Rodrigues, P.M.M. Territory and Sustainable Tourism Development: A Space-Time Analysis on European Regions. Region 2017, 4, 1-17. [CrossRef]

99. Golja, T.; Nizic, M.K. Corporate Social Responsibility in Tourism-The Most Popular Tourism Destinations in Croatia: Comparative Analysis. Management 2010, 15, 107-121.

100. Kiralova, A. Sustainable Tourism Marketing Strategy: Competitive Advantage of Destination. In Emerging Innovative Marketing Strategies in the Tourism Industry; Ray, N., Ed.; IGI Global: Hershey, PA, USA, 2015; pp. 54-81. ISBN 9781466687004.

101. Graci, S. Collaboration and Partnership Development for Sustainable Tourism. Tour. Geogr. 2013, 15, $25-42$. [CrossRef]

102. Vidishcheva, E.V.; Bryukhanova, G.D. Analyses of the Sustainable Tourism Development Factors: The Example of Sochi-City. J. Advocacy Res. Educ. 2017, 4, 172-180.

103. Wang, Y.; Xia, Z.; Chen, W. Aesthetic Values in Sustainable Tourism Development: A Case Study in Zhangjiajie National Park of Wuling Yuan, China. J. China Tour. Res. 2008, 4, 205-218. [CrossRef]

104. UNESCO. Sustainable Tourism Development in UNESCO Designated Sites in South-Eastern Europe; Ecological Tourism in Europe: Bonn, Germany, 2009; pp. 1-43.

(C) 2019 by the author. Licensee MDPI, Basel, Switzerland. This article is an open access article distributed under the terms and conditions of the Creative Commons Attribution (CC BY) license (http:/ / creativecommons.org/licenses/by/4.0/). 
Article

\title{
Agritourism-A Sustainable Development Factor for Improving the 'Health' of Rural Settlements. Case Study Apuseni Mountains Area
}

\author{
Ramona Ciolac ${ }^{1}$, Tabita Adamov ${ }^{1, *}$, Tiberiu Iancu ${ }^{1}$, Gabriela Popescu ${ }^{1}$, Ramona Lile ${ }^{2}$, \\ Ciprian Rujescu ${ }^{1}$ and Diana Marin ${ }^{1}$ \\ 1 Faculty of Management and Rural Tourism, Banat's University of Agricultural Sciences and Veterinary \\ Medicine "King Michael I of Romania", Calea Aradului no.119, 300645 Timisoara, Romania; \\ ramonamarianaciolac@usab-tm.ro (R.C.); tiberiuiancu@usab-tm.ro (T.I.); gabrielapopescu@usab-tm.ro (G.P.); \\ rujescu@usab-tm.ro (C.R.); dianamarin@usab-tm.ro (D.M.) \\ 2 Faculty of Economics, Aurel Vlaicu University, Bd. Revolutiei no.77, 310130 Arad, Romania; \\ ramona.lile@uav.ro
}

Received: 22 January 2019; Accepted: 27 February 2019; Published: 9 March 2019

\begin{abstract}
Agritourism is a complex activity, a chance maybe today to ensure both human health and the "health" of the environment and rural settlements in order to achieve a most wanted desideratum, the sustainability of the rural environment. The idea of this paper starts from the trend of the current period, meaning the strong emphasis on natural, organic, bio, in all human activities, health and environment, in a word, sustainability. The necessity of implementing the sustainability of activities, health and environment in rural areas, taking into account the agritourism field, was a subject pursued in the study, taking as area of study the mountainous rural environment, the reason of this choice deriving from the fact that the mountain area offers great opportunities for agritourism development, the practice of which is even necessary in the current period. The sustainability of agritourism on rural health and environment cannot be dissociated from the economic, social and cultural life of the community in which it manifests itself, and has a multiplier effect on all the domains with which it interacts. So the purpose of the paper is to follow the development of the agritourism field and, based on some present information, to make a future forecast for some specific indicators, to highlight the representative aspects related to the development and capitalization of guesthouses from a rural mountain environment through agritourism and to come up with a forecast for future transformations that need to take place in the studied area in order to support the sustainable development of the human environment through agritourism.
\end{abstract}

Keywords: agritourism; sustainable development; the "health" of rural settlements; Apuseni mountains; forecast through a logistic model

\section{Introduction}

Most European countries, and beyond, have to see rural development as a chance to fight poverty, to ensure the sustainability $[1,2]$ of the rural environment, so each industry is encouraged to find a solution for sustainability in its own field [3]. Sustainability puts its accent on values and principles, which have as their main purpose to guide actions, in a responsible and harmonious way, taking into consideration the environmental and societal consequences, as well as economic purposes [4].

Agritourism is an activity that links the economic, social and environmental components of sustainability, strongly related to local communities and their attitudes towards tourism [5], so one of the solutions for rural areas can undoubtedly be agritourism. Agritourism can be seen as an innovative and diversifying strategy for farms, [6] including recreational and leisure activities for tourists, with 
many economic and non-economic benefits for farmers, visitors and communities [7], with a significant emphasis on natural, organic, bio aspects, in any part of human activities, health and the environment, in a word on sustainability $[8,9]$. In practical terms, agritourism is a complex activity, which is directly connected with other local activities [10]. In a rural locality, tourism cannot be dissociated from the economic, social and cultural life of the community in which it manifests itself. In European countries, agritourism has become a priority in the last decades of this century, in local development policies now and in the future, and this type of tourism is being based on three coordinates: space, people and products that are in a close correlation, unable to exist without each other. Agritourism can support new directions in rural sustainable development, with specific effects on the environment, agricultural heritage, or economic growth [11,12].

As a tourism offer, agritourism appeared in Europe around the 1960s. The popularity of rural and mountainous areas, in particular, [13] as a possibility to spend a second holiday [14] has increased in most countries [14]. Therefore, in European countries agritourism is not a new phenomenon, what is new is the expansion of it in recent years justified by concerns related to a high quality of life, and of course sustainability. Every offer of agritourism varies in Europe. The real agritourism offer is relatively rare, $[11,15]$ so there are countries with specific agritourism offer (such as Italy, Austria, Switzerland, Germany, Denmark, Spain, the Netherlands, Belgium), or with a mixed offer of rural tourism and agritourism (France, Ireland, Portugal).

As mentioned, the notion "sustainable" is used in various fields, agritourism being one, so sustainability has become one of the most important strategic issues for many rural areas. [3] Most studies have shown that tourism combined with rural resources and traditional products would be an important "tool" for revitalizing rural, mountainous areas [16-22]. Modern patterns of rural development highlight that a rational and planned exploitation of agricultural resources together with the valorization of cultural and naturalistic heritage of rural areas, or simply said, the right leverage to assure sustainable growth of rural settlements, are through agritourism [23].

In fact, the connection between agritourism and sustainability is very well identified in the Italian National Law, [24] in which the eight sustainable objectives of agritourism to support rural area are mentioned: stop rural outmigration by keeping farmers on the land, improving the use of both natural and built rural resources; enhancement of environmental conservation and management; promotion of "typical" rural products; support for rural traditions and cultural initiatives; development of agricultural areas; development of youth and social tourism; and enhancement of the relationship between city and countryside [25].

The idea of sustainable development through agritourism activity in the Apuseni Mountains area is supported by the high potential for tourism activities, (the degree of urbanization is below $30 \%$, meaning large areas that are still rural), and we consider it to be one of the viable solutions for this area. Other studies are based on this statement, studies which reveal the fact that the little settlements here are in decline in the face of limited employment opportunities and poor services, and very important for the "health" of this area is the emphasis on private farming and the expansion of some new activities that are attractive to young people, such as agritourism $[17,22]$.

\section{Literature Review}

The sustainability of agritourism on the "health" of rural environment derives from the fact that this activity cannot be dissociated from the economic, social and cultural life of the community. Between tourism and environment there is a close relationship based on: the environmental elements considered to be tourist attractions; facilities and tourism infrastructure; and the impacts generated by tourism development and tourist use on the environment and settlements [26]. The link between agritourism and the sustainability of rural settlements derives from the definition of this activity. Agritourism (see Table 1) is as a form of rural tourism [13] a hospitality activity, performed by agricultural entrepreneurs and their families, that first of all, must remain connected to farming activities (which involves production activities, activities of processing agricultural products in the 
household and their marketing), [24], and complementary to developing tourism activities, that completes the income from agricultural activity [27]. We conclude that there is a sustainable activity for agricultural activities and for stopping migration.

Table 1. Agritourism as a tourism offer.

\begin{tabular}{|c|c|c|}
\hline $\begin{array}{l}\text { Criteria for Defining } \\
\text { Agritourism }\end{array}$ & The Elements of Definition & Benefits for Those Involved in Developing this Activity \\
\hline \multirow{4}{*}{$\begin{array}{l}\text { Definition of agritourism from the } \\
\text { perspective of agricultural activity }\end{array}$} & \multirow{4}{*}{$\begin{array}{l}\text { unites elements of two complex } \\
\text { sectors-agriculture and tourism } \\
\text { can play a significant role in } \\
\text { supporting many agricultural } \\
\text { enterprises }\end{array}$} & \multirow{6}{*}{$\begin{array}{l}\text { Advantages for farmers } \\
\text { (1) development of new market niches } \\
\text { (2) increasing interest for agricultural local products } \\
\text { (3) the opportunity to maintain/use agricultural land } \\
\text { (4) creating jobs at the family level } \\
\text { (5) increasing the sustainability of } \\
\text { agricultural businesses }\end{array}$} \\
\hline & & \\
\hline & & \\
\hline & & \\
\hline \multirow{4}{*}{$\begin{array}{l}\text { Definition of agritourism from the } \\
\text { perspective of the development of } \\
\text { rural communities }\end{array}$} & \multirow{4}{*}{$\begin{array}{l}\text { source of the growth and } \\
\text { diversification of the rural } \\
\text { economy } \\
\text { diversification to maintain the } \\
\text { viability of agricultural businesses }\end{array}$} & \\
\hline & & \\
\hline & & \multirow{2}{*}{$\begin{array}{l}\text { Benefits for communities } \\
\text { (6) creating new jobs }\end{array}$} \\
\hline & & \\
\hline \multirow{6}{*}{$\begin{array}{l}\text { Defining agritourism as a } \\
\text { stand-alone component }\end{array}$} & \multirow{6}{*}{$\begin{array}{l}\text { economic activity within an } \\
\text { agricultural holding/farm or food } \\
\text { industry enterprise } \\
\text { carried out in order to produce } \\
\text { visitors' advantages and } \\
\text { satisfaction } \\
\text { carried out in order to generate } \\
\text { additional income for the farmer }\end{array}$} & expansion of local market \\
\hline & & (8) attracting other businesses and small industries \\
\hline & & Benefits for tourism industry \\
\hline & & (9) diversifying the mix of tourist products \\
\hline & & (10) positioning, as a rarity, of agritourism communities \\
\hline & & \\
\hline
\end{tabular}

Source: Authors' processing by various bibliographic sources (processing after 7,9,13,27,28).

Therefore, agritourism implies the existence of two main activities: agricultural and tourism activities, which assume three elements specific to any tourist product with some particularities in this case: accommodation, food and entertainment [28], and of these peculiarities of the tourist product rural settlements may have a chance to win:

- The first element of the agritourism product is accommodation. The farmer has the possibility to obtain additional income from renting the surplus of rooms existing in the farm. The agritourism accommodation service is thus intertwined with the main activity of the farmer (agriculture), but without interfering with it.

- The second element of the agritourism product is food. Through food, the farmer has the possibility of direct capitalization of agricultural production, being a direct relationship between the person who offers the services (the farmer and his family) and the one who requests them (the tourist). Another peculiarity of food in agritourism is the fact that it is based on the traditional cuisine of the place and prepared with products from their own household, or from the area/region, thus supporting both the agritourism farm and the area it is part of.

- The third element of the agritourism product is tourist entertainment. In the case of agritourism, the tourist entertainment is based on traditional activities in the farm or household where the tourist can actively or passively participate.

The preservation of a rural world, with everything that is significant, can take into account the initiation and development of this form of tourism. The meeting between the rural area, a particularly fragile environment, and the dynamism imposed by the tourism phenomenon poses the risk of restructuring. However, agritourism must become an alternative to the problems of rural settlement, so in this context it may take three forms (see Figure 1). 


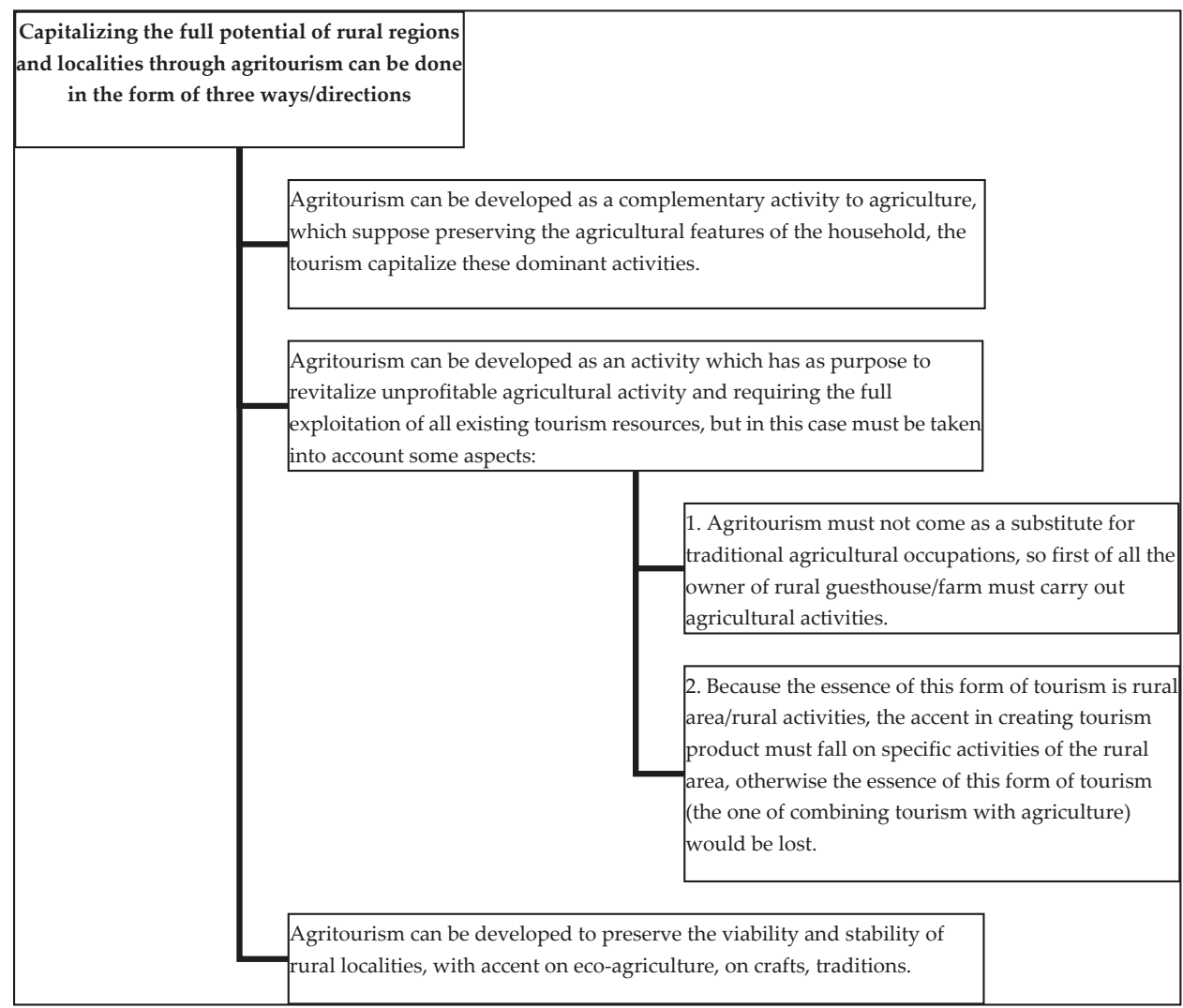

Figure 1. Capitalizing the full potential of rural regions and localities through agritourism (processing after $6,9,10,14,27)$.

The impact of agritourism on quality of life standards is significant in terms of profit, in many ways, [29], so the rural areas where agritourism will be practiced will become the places where all elements of local sustainable development will be assembled [5,30]. There will appear an interest in improving the infrastructure, of creating a spiritual life of rural localities, strategic objectives may be achieved regarding the human factor, technical endowments and heritage conservation [31-33]. So in order to support these statements, illustrated in Figure 2, we have briefly reviewed some examples of good practices, focusing on community approach and territorial cohesion in rural areas. 




Figure 2. The importance of agritourism sustainable development for rural settlements [5,30-32].

Maintaining agricultural activity is a major challenge for European rural areas. The decline of local economies affects the environment, landscapes and other economic sectors, especially tourism and social life. Agritourism can be a way of diversifying rural economies in rural areas and can provide alternative incomes for the population of these areas, through the quality and authenticity of traditional products, which represent the identity of popular localities, and attract consumers, saturated by the homogeneity of the same products. However, the quality of local products has a special role to play in influencing and securing agritourism [19]. Therefore, the focus should be on strong partnerships, to ensure mixing/blending of cultural activities, cultural heritage, gastronomy, agriculture. There are some practical examples from different countries, where this blending was made possible through some projects in which, through the approach or benefits of the projects, the beneficial consequences mentioned in Figure 2 or others express the link between agritourism and sustainability:

- The Province of Belluno, Italy, has developed a new approach regarding the development of mountainous territory, involving different economic sectors. "Routes to mountain aromas" was a project linking tour operators with local agricultural products from the territory. The tourist package developed includes local agricultural products, the environment and landscapes, crafts and culture, traditions, the aim being to bring together various productive sectors such as farmers, craftsmen, tourists and cultural activities through a multi-sectorial approach, supporting social cohesion by linking territorial tourism activities, encouraging the use of local products [19].

- $\quad$ The "Rural Tourism District" is another innovative project applied in the Valle del Crocchio Local Action Group from Italy. The project demonstrates innovation and forward thinking because it anticipated regional regulation regarding rural districts at a time when no other area had thought 
about it. The project itself focuses on community approach and territorial cohesion in rural areas through an integrated package of activities that have developed the quality of infrastructure for agritourism in the region and connects: the tourist accommodation structures with agriculture; local cooperatives; cultural attractions such as museums and architectural sites and recreational activities such as pedestrianized road networks [20].

- The project "Grandmother's House", from GA Pomoottoriry LAG, Finland, was the idea of a local who focused on the country's lifestyle, and the economic and ecological benefits were taken into account, the project being implemented by local authorities in order to capitalize natural and anthropogenic resources in the region and encourage migration in this region, given the economic benefits generated by the growth of housing development. The repopulation of this rural area was one of the priorities of the LAG, at the same time as economic development strategy, coupled with the stimulation of tourism and other service sectors [20].

- $\quad$ "Intelligent Village of the Future (Ruhtinansalmi)" from Finland, in this case, the proposed activity of the project takes place in an active and innovative but isolated village in the northeastern part of Finland. As in many isolated areas of Europe, the village faces a population decline, the effect of an economy based on agriculture that has become unprofitable for the population. This project has been developed to improve the situation of the community as this project proposes the development of infrastructure and services to attract people from all over the world or from other countries to live, work or spend a holiday in the area. The aims of this project were: to provide fast internet in the village; to develop methods of obtaining bio energy; to renovate and equip the adult education center from locality; to develop sites for promoting the area (both in German and English); to test activities such as adventure tourism; to map the properties and to promote them for sale or rent; to place tourist information signs in areas where they do not exist [21].

- The "Spa center on a farm built in 1645 " from The Netherlands is another example of community approach and territorial cohesion. One of the features that make this project different is the high level of cooperation with local and regional entrepreneurs for the supply of beverages or food [21].

Agritourism, more than any other field of activity, is dependent on the environment, representing its "raw material", the object and field of activity and the development of tourism, being its framework support, or the bearer of its resources. Tourism is carried out in the environment, and the environment and its quality can favor or disadvantage tourism activities [34]. Some principles can be mentioned in the case of agritourism in order for it to be sustainable tourism: [35] economic development, social development and environmental protection.

There are also many benefits for the tourists willing to practice this activity (see Table 2).

World Tourism Organization statistics show that forms of tourism in rural area are increasing. Specialists believe that rural communities will be more successful in the future in caring out agritourism activities for several reasons [36]:

- $\quad$ in Europe, the aging population leads to an increase in the number of elderly tourists attracted by this form of tourism;

- $\quad$ to increase interest in environmental and health issues;

- those from urban area have short vacations, so they want destinations that are easy to find and affordable from a financial point of view;

- to increase the number of those who want a quiet tourist area in an unpolluted environment. 
Table 2. Possible elements to offer through agritourism to potential tourists.

\begin{tabular}{|c|c|}
\hline $\begin{array}{l}\text { What Does the Agritourism } \\
\text { Consumer Want? }\end{array}$ & What Can be Offered Through Agritourism? \\
\hline Quiet & $\begin{array}{ll}\text { - } & \text { location away from the noise sources } \\
\text { - } & \text { respect for privacy }\end{array}$ \\
\hline Healthy food & $\begin{array}{l}\text { - } \quad \text { products obtained in their own household } \\
\text { - } \quad \text { specific culinary tradition }\end{array}$ \\
\hline Relax in an active way & $\begin{array}{ll}\text { - } & \text { climate of relaxation } \\
\text { - } & \text { alternatives to spending leisure time }\end{array}$ \\
\hline Return to nature & $\begin{array}{l}\text { - } \quad \text { location as close as possible to the vegetation areas } \\
\text { - } \quad \text { knowledge of the area's natural resources }\end{array}$ \\
\hline Knowledge of the rural area & $\begin{array}{l}\text { - } \quad \text { access to traditions, folk costumes, customs } \\
\text { - } \quad \text { practicing specific rural handicrafts, such as weaving, pottery, etc. } \\
\text { - } \quad \text { participation at some specific local holidays }\end{array}$ \\
\hline Environmental refuge & $\begin{array}{l}\text { - } \quad \text { location away from the sources of pollution } \\
\text { - } \quad \text { biological food }\end{array}$ \\
\hline $\begin{array}{l}\text { Participation in the life of the } \\
\text { rural community }\end{array}$ & $\begin{array}{l}\text { - } \quad \text { proximity between tourist and host } \\
\text { - } \quad \text { discussions on rural issues and how to deal with them }\end{array}$ \\
\hline
\end{tabular}

Source: Authors' processing by various bibliographic sources $[7,8,14,28,30]$.

\section{The Aim of the Paper}

This paper has as its purpose to highlight the importance of agritourism for improving the "health" of the environment and rural settlements, through sustainable capitalization of the full potential of rural regions and localities. The first sub-purpose is to explain the meaning and reason why agritourism must become an alternative to the problems of rural area, in order to achieve the main desideratum, the sustainability of this environment, taking in consideration its principles and benefits. The second sub-purpose of the paper is to underline the evolution of the current situation of Romanian agritourism guesthouses and to complete a future forecast by using a logistic model. For the third sub-purpose of the paper we chose the Apuseni Mountains, as a concrete area of research, and here we have applied a questionnaire to reveal aspects related to: the surface of the farm and the existence of specialized training, the development and capitalization of households through agritourism, the motivation of tourists to practice agritourism in the area, the desire for cooperation of the owners of agritourism structures to improve the agritourism product. Based on the statistical information existing for the Apuseni Mountains area, a series of future forecasts were made, using the same logistic model as the national level, and the results obtained support the sustainability of this area of activity for this rural area.

\section{Materials and Methods}

The methodological approach of this paper involved a combination of "desk research" methods (collecting information from secondary sources, already existing) with the collection of primary information through quantitative studies and discussions (interviews/questionnaires). The main advantage of the research is represented by the series analysis of 8 years, so the data were analyzed for a recent and relevant period for agritourism development, as well as the analysis of a representative 
tourist area (7\% of the country's surface). Specifically, the main activities specific to the research carried out in this study are:

- $\quad$ Office research (identifying and evaluating the information sources, collecting and analyzing secondary information, preparing the theoretical framework).

- Foundation and achievement of some quantitative research (interviews/questionnaires for accommodation spaces from the Apuseni Mountains), centralization, analysis and interpretation of data resulting from the two primary researches and inclusion of conclusions in the final report.

- The questionnaire used in this paper covered two parts:

- identification of information on the respondents' characteristics and the degree of socio-economic development of the area;

- $\quad$ focus on the agritourism field itself.

The questionnaire was conducted through a face-to-face interview, and was addressed directly to the owners of agritourism structures. In order to achieve the proposed objectives, a questionnaire was designed, and subsequently applied in the six counties constituent of the Apuseni Mountains. Questionnaires were applied to each county, the areas being chosen for their representativeness for agritourism activity, and the number of questionnaires applied being directly correlated with the number of households approved for agritourism.

The dynamics of the number of agritourism guesthouses, meaning the net index using the agritourist accommodation capacity, was studied by using a logistic model NATE = $\left(1 / u+b_{0} \cdot b_{1}{ }^{Y}\right)^{-1}$, respectively IAA $=\left(1 / u+b_{0} \cdot b_{1}{ }^{Y}\right)^{-1}$, motivated by the fact that such series have a capped evolution. The dynamics of the occupied population in agritourism has been studied as a function of the number of such guesthouses found in the area studied at a particular moment in time using the hyperbola POA $=b_{0}+b_{1} /$ NATE.

Statistical calculations were performed using the SPSS system in the case of determining the regression functions and correlation coefficients. For graphical representations Wolfram Alpha or Microsoft Excel applications were used. The notions of tabular calculation were achieved by using Microsoft Excel.

The motivation of choosing the area of the Apuseni Mountains, as area of this study derives from the desire to bring this area into the spotlight. We support the above statement by the fact that the area is part of the category of rural areas with great tourist potential that can offer a wide variety of tourist products to tourists. The surface of the Apuseni Mountains region (see Figure 3) represents 7\% of Romania and is extended across six counties: Alba, Arad, Bihor, Cluj, Hunedoara and Salaj. The degree of urbanization is low, about $30 \%$, which is an excellent condition for rural tourism. As a human habitat, the area groups 16 towns, 1253 villages, the characteristic element being the absolute dominance of small villages and towns, namely 348 villages have under 100 inhabitants, of which 42 villages have fewer than 20 people [37].

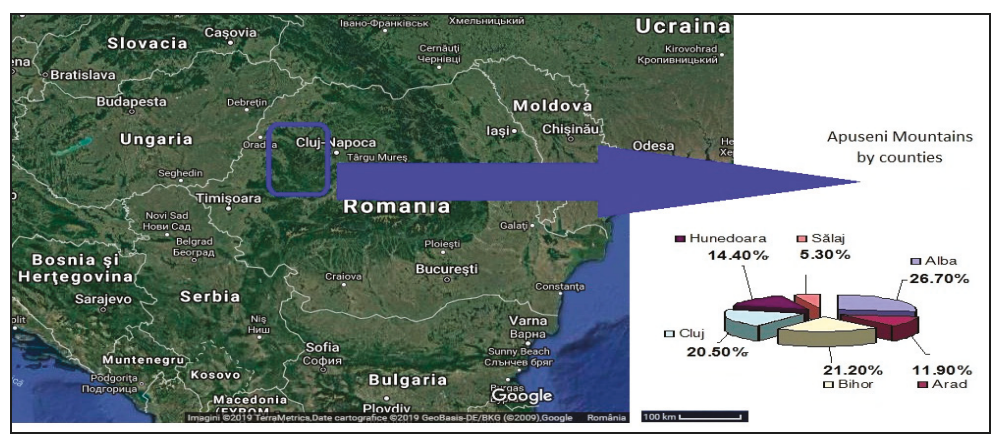

Figure 3. Apuseni Mountains area, (adapted from [38]). 
The tourist areas from Apuseni Mountains are grouped, from geographical point of view, in 15 areas, each having certain specific features, being characterized through certain forms of the tourism that it is possible to develop, taking into consideration the main resources existent in each area: Vadul Crisului area and Crisul Repede area, Meziad area, Padis-Cetatile Ponorului area, Aleul Valley area, Valea Iadului-Stana de Vale area, the karst area of the Vascau-Izbuc Calugari, the area of Baisoara Mountain, Gilau-Tarnita area, Belis-Fantanele area, Ighiu Valley area, Ampoi Valley area, the Codru-Moma mountain area, the depression area of Gurahont-Halmagiu, Geoagiu Valley, Aries Valley area.

\section{Results}

\subsection{Agritourism in Romania. Current Situation and Future Forecasts}

At Romania's level, according to the national statistics found in the National Institute of Statistics, [39], there are 2556 agritourism accommodation structures (see Table 3-current situation) with 44,499 accommodation places in year 2017 (a certain evolution being recorded here, from 20,208 places in 2010, and 30,480 places in 2014), concentrated in the areas of Bran-Moeciu, Apuseni, Maramures, Bucovina, and the Danube Delta. The Romanian economy has known numerous changes in the period after 1989 up until today. Also the year 2007, relevant to the integration of Romania into the European Union (EU), represents a distinct point in the study of the dynamics of evolution of some statistical-economic indicators. More precisely, a number of factors that were, before these years, very limited compared to the values observed in the old EU member states, recently have become important developments, but it will probably be necessary to wait a long time before they reach the natural saturation period [40].

Table 3. Agritourism in Romania. Current situation and future forecasts.

\begin{tabular}{|c|c|c|c|c|c|c|c|c|c|c|}
\hline & \multicolumn{8}{|c|}{ Current Situation } & \multicolumn{2}{|c|}{ Future Forecasts } \\
\hline & 2010 & 2011 & 2012 & 2013 & 2014 & 2015 & 2016 & 2017 & 2020 & 2030 \\
\hline $\begin{array}{l}\text { No. of agritourism } \\
\text { guesthouses } \\
\text { (number) (NATE) }\end{array}$ & 1354 & 1210 & 1569 & 1598 & 1665 & 1918 & 2028 & 2556 & 3236 & 7113 \\
\hline $\begin{array}{l}\text { Index of net using the } \\
\text { agritourism accommodation } \\
\text { capacity (\%) (IAA) }\end{array}$ & 12.4 & 13.8 & 13.2 & 12.6 & 13.2 & 15.1 & 15.5 & 15.7 & 17.8 & 23.2 \\
\hline $\begin{array}{c}\text { Population occupied in } \\
\text { agritourism (persons) (POA) }\end{array}$ & 4372 & 4327 & 4672 & 4520 & 4756 & 4830 & 4912 & 4978 & 5072 & 5409 \\
\hline
\end{tabular}

Such an evolution (see Table 3-future forecast) can be described using a logistic model [41,42]. with a statistically assured correlation coefficient, $r=0.947$ at sig. $<0.001$. Thus, for the year 2020 the function determined indicates the value $\mathrm{NATE}_{2030}=3236$ respectively for the year 2030 being NATE$_{2030}=7113$ agritourism guesthouses.

The net index using the agritourism accommodation capacity was described by the logistic function, whose expression we have determined as being (see Table 3-future forecast):

$$
\mathrm{IAA}=\left(1 / 50+4.6 \cdot 10^{37} \cdot 0.9564^{\mathrm{Y}}\right)^{-1}
$$

having $\mathrm{r}=0.835$ at sig. $=0.01$. For the year 2020, the function indicates the value $\mathrm{IAA}_{2020}=17.8$ respectively $\mathrm{IAA}_{2030}=23.2$ for the year 2030 .

The dynamics of the occupied population in agritourism was established as a function, depending of the number of guesthouses at the time, using the function (Figure 3):

$$
\mathrm{POA}=5690.94-2 \cdot 10^{6} / \mathrm{NATE}
$$


having $\mathrm{r}=0.957$ at sig. $<0.001$. For the year 2020, the function indicates a population occupied in agritourism in a number of $\mathrm{POA}_{2020}=5072$ respectively of $\mathrm{POA}_{2030}=5409$ people in year 2030.

As a comparison, Italy and Austria, especially in the mountain area, have more than 2.5 million accommodation places and host more than 50 million tourists annually. This is in conditions, in which the mountain is the main attraction, but Romania has a mountain area of over 70,000 square kilometers, and Italy and Austria have just over 50,000 square kilometers. To get deeper, the average annual occupancy degree of the guesthouses of Romania is half (25-30 days) compared to the two countries where it reaches 60 days. That means hundreds of millions of euros each year [43].

\subsection{Specific Features of the Agritourist Activity from the Apuseni Mountains Area}

Over time in the Apuseni Mountains, the rural specificity of the region has directly determined and influenced the specific way of life of this area. The socio-economic problems of the Apuseni Mountains area are related to the high degree of dispersal in the territory of human settlements, which determines major deficiencies in the provision of technical and public infrastructure, as well as the negative dynamics of the population caused by the high level of emigration and demographic aging. The complexity of agritourism activity for the area in question is supported, firstly, by the fact that the Apuseni Mountains include six counties and three development regions, the solution of the various problems regarding the development of the area embraces a large number of institutions, or the correlation of measures and actions that will be undertaken in each region will have to extend beyond the administrative boundaries of the regions. This is because the processes and phenomenon have zonal features that do not stop at the arbitrary border of the regions and the characteristics of such a tourist development program for the Apuseni Mountains region involves simultaneous marketing and financing programs.

If we were to undertake a diagnosis of the tourist activity of the area, we could conclude that many disparities are registered according to some studies in the field. [16-18,22,44,45] (see Table 4):

- The natural tourism potential, meaning the geographical conditions, specific to the area, represents strong points when we speak about the agritourism sector of this area.

- The anthropic potential can contribute to the increase of income and to attracting young people to the rural area, taking into account the agritourism activities. This statement is based on the fact that a large part of the area's localities are very good at preserving traditions. The rural area has not lost its originality, from its attractive side, but has supported the preservation of the identity of settlements, culture, and traditions.

- $\quad$ Another positive aspect is the fact that lately we became aware of the existence of a great tourist potential and the area begun to be promoted, but still quite shy.

- The total accommodation capacity of the Apuseni Mountains area represents about $9.74 \%$ of the accommodation capacity at the national level. 
Table 4. The main disparities of the Apuseni Mountains area-brief SWOT (Strengths, Weaknesses, Opportunities, Threats) analysis.

\begin{tabular}{|c|c|}
\hline Weakness/Threats & Strong Points/Opportunities \\
\hline $\begin{array}{l}\text { The tourist potential of the area is exploited only in a } \\
\text { small extent (12 hotels, classified with one or two } \\
\text { stars, } 20 \text { villas, classified with one-four stars, } 6 \text { motels } \\
\text { classified with one or two stars, } 16 \text { cottages, classified } \\
\text { with one-three stars, } 3 \text { holiday villages, located in: } \\
\text { Boga, Fantanele, Vartop, } 202 \text { households / agritourism } \\
\text { guesthouses). } \\
\text { Absence of public services (water, canal, thermal } \\
\text { energy) at the level of rural localities. } \\
\text { The general access infrastructure is one of the major } \\
\text { weaknesses (low degree of road equipment, } \\
\text { underdevelopment of the utility distribution } \\
\text { network, places that are not yet electrified). } \\
\text { Labor force (high share of unemployed, dependence } \\
\text { of the workforce on mining enterprises, migration of } \\
\text { the population and village disappearance). } \\
\text { Tourist potential is not capitalized: lack of local } \\
\text { brands and tourist products, lack of specialized } \\
\text { training, lack of guidance to tourist areas, the } \\
\text { existence of a poorly diversified offer. } \\
\text { Poor cooperation at local level. }\end{array}$ & $\begin{array}{l}\text { Favorable areas to agritourism: Aries area, } \\
\text { Belis-Fantanele areas, Buntesti, Pietroasa, } \\
\text { Budureasa areas, Gurahont-Halmagiu areas, } \\
\text { Gurahont-Halmagiu areas, that can contribute } \\
\text { to the increase of income and attracting young } \\
\text { people to the rural area. } \\
\text { Lately it has learned about the idea of a great } \\
\text { tourist potential and has begun to be promoted. } \\
\text { Components of the possible agritourist product } \\
\text { (relief resources and those with rural features, } \\
\text { gastronomical elements, the existence of } \\
\text { traditions, customs, folklore and } \\
\text { local architecture. } \\
\text { The economy is predominantly agrarian, but } \\
\text { the income from agriculture is quite low, and } \\
\text { the territorial services are use below standard, } \\
\text { which requires a reorientation towards those } \\
\text { activities that can capitalize the } \\
\text { existing resources. }\end{array}$ \\
\hline
\end{tabular}

Source: Authors' opinions, based on previous researches [16-18,22,44,45].

However, as observed above, with all the great potential, there are many negative elements that influence the development of agritourism in the studied area:

- $\quad$ Absence of public services (water, canal, thermal energy) at the level of rural localities;

- The general access infrastructure is one of the major weaknesses, which has a long way to go to improve up to the national average quality level and still very much to be comparable to the infrastructure of tourist areas of the West, if such an evolution of localities in the area is desired;

- $\quad$ Non-exploitation of the agritourism potential, the causes being multiple:

- $\quad$ agritourism is practiced more in a spontaneous form rather than an organized form, following the motto "the tourist finds the agritourist farm and it is not the farm that attracts the tourists". This is one of the reasons that demonstrate the need to organize this form of tourism with the involvement of the authorities and the local community, so it will be economically viable for both.

- the owners of tourist locations have entrepreneurial skills, in general, and less specialized knowledge in the field of tourism and management skills in this field;

- tourist locations have a low occupancy degree compared to the potential;

- $\quad$ services offered to tourism consumers are not very diversified (accommodation and meals).

However, in years to come, the Apuseni Mountains must be perceived, not only as a geographical individuality, but also as an individuality from economic or tourism point of view. Therefore, according to some studies, a reconsideration of the area's economy is necessary and it requires a reorientation towards those activities that can capitalize on the existing resources. In recent years, all counties from Apuseni Mountains have documented their main guidelines for future development by focusing on local tourism, of which agritourism has a very large share, but, in the future, a series of measures are needed for a re-launching solution for the rural areas, such as: the need to modernize tourist offers by developing regional products; raising workforce qualification; improving service quality; improving public-private collaboration and partnership; the qualitative and quantitative increase of tourism promotion $[22,44,46,47]$. 
4.3. Identifying Representative Aspects Related to the Development and Capitalization of Households from the Apuseni Mountains Area through Agritourism

A large number of Apuseni Mountains localities are very good at preserving traditions. (see Figure 4). If traditions and customs areas are added to mountain natural resources and specific traditional products, $[5,22,45,48]$ a valuable tourist product emerges, which could contribute to the increase of income and to attracting young people to the rural area $[17,18]$. The rural settlements, which have a remarkable historical, natural and cultural potential and have developed the necessary tourist infrastructure (guesthouses/agritourism farms) have entered in the tourist circuit.

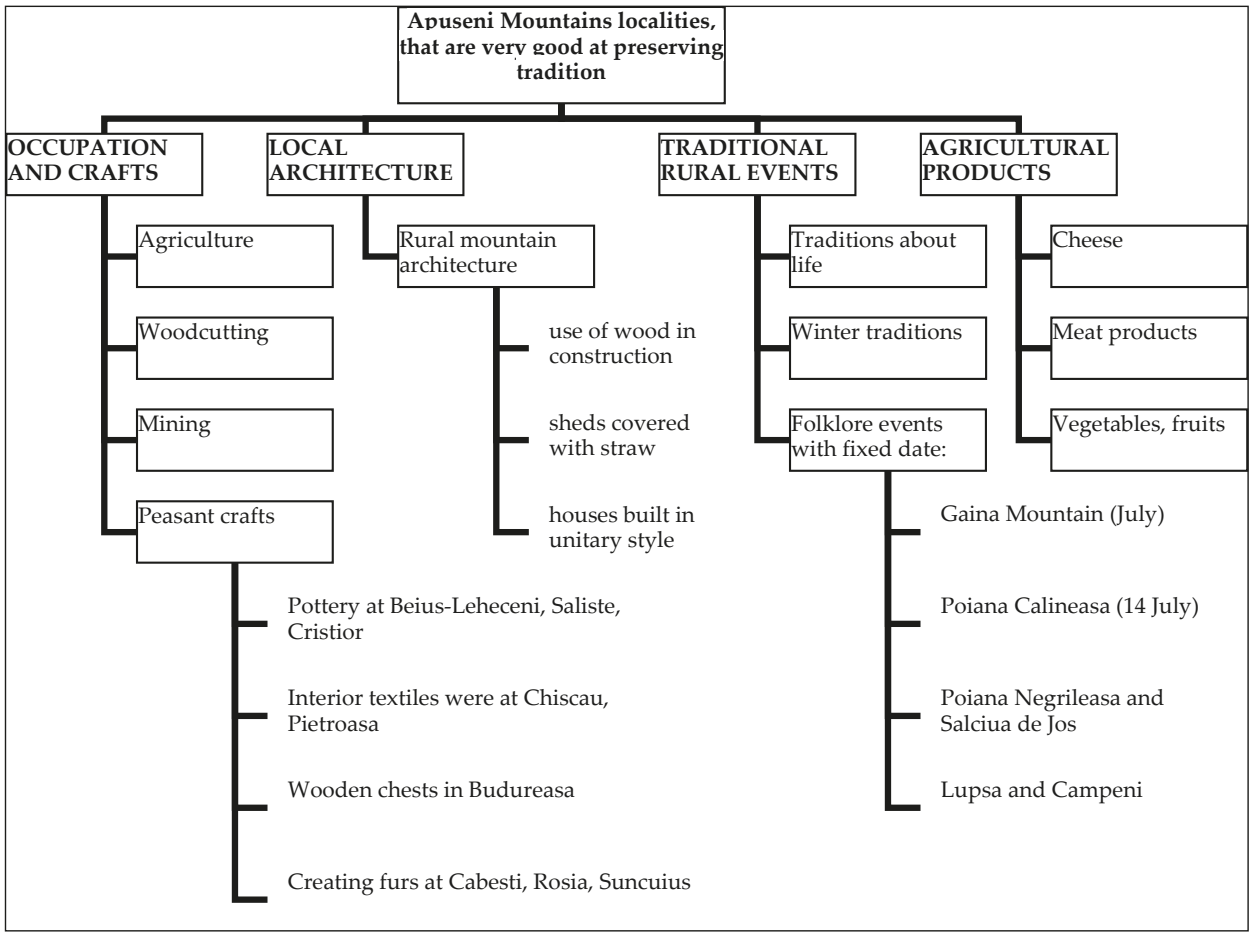

Figure 4. Apuseni Mountains localities, that are very good at preserving tradition $[17,18]$.

The agritourism guesthouses (see Table 5) are unequally distributed in the counties constituent of Apuseni Mountains and starting from this premise, the questionnaires that we applied were different in number.

Table 5. Distribution by counties of the guesthouses questioned.

\begin{tabular}{cccccc}
\hline Cluj County & Bihor County & Alba County & Arad County & Salaj County & Hunedoara County \\
\hline 60 guesthouses & 44 & 48 & 7 & 23 & 20 \\
\hline
\end{tabular}

Thus, in order to pursue the purpose of the paper, to underline the evolution of the current situation of the current situation of the agro-tourism guesthouses in Romania and for future forecasting through a logistic model, specifically on the Apuseni Mountains, we have used a questionnaire that was conducted through a face-to-face interview, and addressed directly to the owners of agritourism structures. The samples were selected by taking into consideration their representativeness for agritourism activity (to practice booth agriculture and tourism), their geographic position, their 
economic representativeness. The number of questionnaires applied was directly correlated with the number of households approved for agritourism from the area, and then statistical calculations were performed in SPSS.

The items included in the questionnaire, ten in number, are grouped in the following categories:

- $\quad$ finding information about the characteristics of respondents;

- finding aspects related to the surface of the farm and the existence/inexistence of a specialized training;

- $\quad$ finding aspects related to the development and capitalization of households in the area analyzed through agritourism;

- $\quad$ finding aspects related to the motivation of tourists to practice agritourism in the area/agritourism guesthouses under analysis;

- finding aspects about the willingness to cooperate, in order to improve the agritourism product, from the owners of the agritourism structures.

Characteristics of respondents. A number of 202 owners of agritourist households/guesthouses from the chosen area have been chosen, namely from the Apuseni Mountains area, their distribution on counties, showing a representative share for Cluj County (29.70), followed by Alba County (23.76\%), Bihor County (21.78\%). (see Table 6).

Table 6. Grouping the respondents from Apuseni Mountains area by counties and sex.

\begin{tabular}{|c|c|c|c|c|c|}
\hline $\begin{array}{c}\text { Sex } \\
\text { Studied Area }\end{array}$ & Measure Unit & Men & Woman & No. & $\%$ \\
\hline Alba County & $\begin{array}{c}\text { No. } \\
\%\end{array}$ & $\begin{array}{c}32 \\
66.66\end{array}$ & $\begin{array}{c}16 \\
33.33\end{array}$ & 48 & 23.76 \\
\hline Bihor County & $\begin{array}{c}\text { No. } \\
\%\end{array}$ & $\begin{array}{c}23 \\
52.27\end{array}$ & $\begin{array}{c}21 \\
47.72\end{array}$ & 44 & 21.78 \\
\hline Cluj County & $\begin{array}{c}\text { No. } \\
\%\end{array}$ & $\begin{array}{c}42 \\
70.00\end{array}$ & $\begin{array}{c}18 \\
30.00\end{array}$ & 60 & 29.70 \\
\hline Hunedoara County & $\begin{array}{c}\text { No. } \\
\%\end{array}$ & $\begin{array}{c}13 \\
65.00\end{array}$ & $\begin{array}{c}7 \\
35.00\end{array}$ & 20 & 9.90 \\
\hline Arad County & $\begin{array}{c}\text { No. } \\
\%\end{array}$ & $\begin{array}{c}3 \\
42.85\end{array}$ & $\begin{array}{c}4 \\
57.14\end{array}$ & 7 & 3.46 \\
\hline Salaj County & No. & 15 & 8 & 23 & 11.38 \\
\hline
\end{tabular}

The lowest share of the number of persons interviewed is attributed to Arad County (3.46\%). Their distribution by gender is as follows: 128 men, representing $63.36 \%$ from the total and 74 women, respectively $36.63 \%$ from the total of those interviewed.

Aspects related to the surface of the farm and the existence/non-existence of specialized training among owners of agritourism households. Because agritourism activity is conditioned by agricultural activity, the existence of the farm was an aspect pursued by us in the questionnaire. Thus, from the 202 agritourist guesthouses surveyed, (see Table 7) within the six counties, a large proportion of farms have a small size farm between 5 and 10 hectares. 
Table 7. Aspects related to the surface of the farm and the existence/inexistence of specialized training.

\begin{tabular}{|c|c|c|c|c|c|c|}
\hline \multirow[t]{2}{*}{ Studied Area } & \multirow{2}{*}{$\begin{array}{c}\text { Measure } \\
\text { Unit }\end{array}$} & \multicolumn{2}{|c|}{$\begin{array}{l}\text { Existence/Non-existence of } \\
\text { Some Specialized Training }\end{array}$} & \multicolumn{3}{|c|}{$\begin{array}{l}\text { Agricultural Area of the Farm } \\
\text { (Ha) }\end{array}$} \\
\hline & & Yes & No & $5.00-10.00$ & $10.00-20.00$ & $20.00-30.00$ \\
\hline Alba County & $\begin{array}{c}\text { No. } \\
\%\end{array}$ & $\begin{array}{c}19 \\
39.58\end{array}$ & $\begin{array}{c}29 \\
60.41\end{array}$ & 41 & 7 & - \\
\hline Bihor County & $\begin{array}{l}\text { No. } \\
\%\end{array}$ & $\begin{array}{c}17 \\
38.63\end{array}$ & $\begin{array}{c}27 \\
61.36\end{array}$ & 36 & 8 & - \\
\hline Cluj County & $\begin{array}{l}\text { No. } \\
\%\end{array}$ & $\begin{array}{c}34 \\
56.66\end{array}$ & $\begin{array}{c}26 \\
43.33\end{array}$ & 42 & 12 & 6 \\
\hline Hunedoara County & $\begin{array}{l}\text { No. } \\
\%\end{array}$ & $\begin{array}{c}7 \\
35.00\end{array}$ & $\begin{array}{c}13 \\
65.00\end{array}$ & 14 & 4 & 2 \\
\hline Arad County & $\begin{array}{c}\text { No. } \\
\%\end{array}$ & $\begin{array}{c}3 \\
42.85\end{array}$ & $\begin{array}{c}4 \\
57.14\end{array}$ & 4 & 2 & 1 \\
\hline Salaj County & $\begin{array}{l}\text { No. } \\
\%\end{array}$ & $\begin{array}{c}10 \\
43.47\end{array}$ & $\begin{array}{c}13 \\
56.52\end{array}$ & 16 & 7 & - \\
\hline
\end{tabular}

On the other hand there is a small number of agritourism guesthouses on farms between 20 and 30 hectares. The existence/non-existence of specialized training among agritourist households is also a representative aspect to be followed, and following the data processed in Table 4 and comparing it to other studies [48] within the area, we see an improvement in the last few years. Despite the training situation in the area studied, in five counties of six, the number of Apuseni Mountains has improved, and the number of agro-tourism guesthouses that do not have specialized training is higher than the number of those who work in the field of agritourism.

Aspects related to development and capitalization of households in the area analyzed through agritourism. Essential elements of agritourism activity, but also some of the main attraction points for tourists, practicing craft activities with the involvement of tourists, or the capitalization of products from their own farm through agritourism were also on the list of aspects we pursued in this paper. The extent to which agritourism represented or not a growth opportunity for their own household, or in other words, the degree of awareness of the beneficial aspects of agritourism activity by those who carry it. (see Table 8), has also been determined.

Table 8. Development and capitalization of households from the area analyzed through agritourism.

\begin{tabular}{|c|c|c|c|c|c|c|c|}
\hline \multirow[t]{2}{*}{$\begin{array}{c}\text { Studied } \\
\text { Area }\end{array}$} & \multirow[t]{2}{*}{$\begin{array}{c}\text { Measure } \\
\text { Unit }\end{array}$} & \multicolumn{2}{|c|}{$\begin{array}{l}\text { Capitalization of } \\
\text { Product from Own } \\
\text { Farm Through } \\
\text { Agritourism (1) }\end{array}$} & \multicolumn{2}{|c|}{$\begin{array}{c}\text { Practicing Craft Activities } \\
\text { with the Involvement of } \\
\text { Tourists (2) }\end{array}$} & \multicolumn{2}{|c|}{$\begin{array}{l}\text { Agritourism } \\
\text { Represented or not a } \\
\text { Growth Chance for } \\
\text { Own Household (3) }\end{array}$} \\
\hline & & Yes & No & Yes & No & Yes & No \\
\hline Alba & No. & 29 & 19 & 23 & 25 & 43 & 5 \\
\hline County & $\%$ & 60.41 & 39.58 & 47.91 & 52.08 & 89.58 & 10.41 \\
\hline Bihor & No. & 25 & 19 & 21 & 23 & 36 & 8 \\
\hline County & $\%$ & 56.81 & 43.18 & 47.72 & 52.27 & 81.81 & 18.18 \\
\hline Cluj & No. & 48 & 12 & 38 & 22 & 53 & 7 \\
\hline County & $\%$ & 80.00 & 20.00 & 63.33 & 36.66 & 88.33 & 11.66 \\
\hline Hunedoara & No. & 13 & 7 & 9 & 11 & 14 & 6 \\
\hline County & $\%$ & 65.00 & 35.00 & 45.00 & 55.00 & 70.00 & 30.00 \\
\hline Arad & No. & 7 & - & 2 & 5 & 4 & 3 \\
\hline County & $\%$ & 100.00 & - & 28.57 & 71.42 & 57.14 & 42.85 \\
\hline Salaj & No. & 18 & 5 & 12 & 11 & 17 & 6 \\
\hline County & $\%$ & 78.26 & 21.73 & 52.17 & 47.82 & 73.91 & 26.08 \\
\hline
\end{tabular}

It can be noticed that, in the analyzed area, (see Table 8, (1)) for the first aspect subjected to analysis, the capitalization of the products from the farm through agritourism, a favorable trend is registered or an essential condition of agritourism activity (that of the production of a part of the products capitalized through tourism). In all six counties, the majority share tends towards the capitalization of products from their own farm through agritourism. Among the products capitalized through agritourism 
activities are: livestock products, vegetables, fruits, many obtained under biological conditions, fishery products, wine products.

The second aspect analyzed, (see Table 8, (2)) practicing craft activities with the involvement of the tourists, registered a positive trend, mostly at the level of Cluj and Salaj counties, but also a negative one at the level of Alba, Bihor, Arad, Hunedoara counties. The evolution is a favorable one as this statement is based on the fact that 5-7 years ago the share of those who did not value the capitalization of the traditional crafts through agritourism within this area was much higher. The craft activities practiced in the guesthouses questioned are: various woodworking, picking forest fruits in the guesthouses from Alba County; weaving, sewing folk costumes, wood processing, picking forest fruits in the guesthouses from Cluj County; zootechnical activities (sheep, cows) specific to mountain areas, specific culinary activities, weaving/sewing in the guesthouses from Bihor County; techniques of making wine, agritourism occupations, hunting, fishing in guest houses from Arad County.

Although agritourism is practiced more in a spontaneous rather than in an organized form in the studied area, the owners of tourist locations have entrepreneurial skills in general, and less specialized knowledge in tourism and management fields; the tourist locations have a low occupancy degree compared to their potential; and services offered to tourists are diversified to a limited extent. Agritourism represented a chance that for their own households to grow in the overwhelming opinion of those interviewed, (see Table 8, (3)).

Through the capitalization of the local resources and products by combining two activities, the agricultural activity as a core activity and the tourism activity as complementary activity, the profitability of agritourism is high, being in fact a chance for alternative income for rural areas with those in the mountain area. The practice of agritourism promotes the idea of combining economic interests in community development, the conservation of nature, and in other words, it ensures the sustainable development of the area. The entrepreneurs in the area can have a successful model for capitalizing the tourist potential of the area and for supplementing farm incomes through the possibility of adding a modest income from tourism activities.

Aspects related to the motivation of tourists to practice agritourism in the area/agritourism guesthouses under analysis. From this point of view, it was intended to identify the motivation for which the tourists chose the guesthouses in the Apuseni Mountains/agrotourism and three major aspects were considered (see Table 9):

- $\quad$ Special tourist resources specific to the Apuseni Mountains area;

- Quality-price ratio;

- The products/services offered by the agritourism guesthouses from the area.

Table 9. The motivation of tourists to practice agritourism in the area/agritourism guesthouses from Apuseni Mountains.

\begin{tabular}{|c|c|c|c|c|c|c|}
\hline \multirow{2}{*}{ Studied Area } & \multicolumn{2}{|c|}{ Special Tourist Resources } & \multicolumn{2}{|c|}{ Quality-Price Report } & \multicolumn{2}{|c|}{ Products/Services Offered } \\
\hline & No. & $\%$ & No. & $\%$ & No. & $\%$ \\
\hline Alba County & 22 & 45.83 & 14 & 29.16 & 12 & 25.00 \\
\hline Bihor County & 15 & 34.09 & 13 & 29.54 & 16 & 36.36 \\
\hline Cluj County & 23 & 38.33 & 18 & 30.00 & 19 & 31.66 \\
\hline Hunedoara County & 12 & 60.00 & - & - & 8 & 40.00 \\
\hline Arad County & - & - & 5 & 71.42 & 2 & 28.57 \\
\hline Salaj County & 3 & 13.04 & 11 & 47.82 & 9 & 39.13 \\
\hline
\end{tabular}

We have obtained this information through the questionnaire, questioning the owners of agritourism guesthouses. The conclusions reveal the fact that, from the experience of agritourism farm owners, tourists are attracted by the exceptional tourist resource, at a higher share, by the quality-price report on the second place and then by the products offered. Although the aspect of the diversification 
of tourism products and services offered is still to be worked on, it is apparently one of the attractive elements to tourists in the area.

The Apuseni Mountains area is valuable in terms of the existence of traditional resources and products that can be exploited by agritourism, and there are agritourism structures that attract tourists throughout the year (both in summer and winter). In conclusion, agritourism is a lever for local development, but we still have to solve a number of problems that this area is currently facing.

Aspects related to the identification of the desire to collaborate in order to improve the agritourism products from the owners of the agritourism structures. In recent years, all counties in the Apuseni Mountains have documented their main directions regarding future development, focusing on local tourism, within which agritourism has a huge share.

For agritourism to be truly a solution for the economic recovery of rural areas in the future, a series of measures are needed, such as: the modernization of tourist offers; creating some tourist products that highlight the "brand" of the area; collaboration between those involved in the implementation of this activity and the application of public-private partnerships would be just a few examples (see Table 10). The research made shows that the owners of agritourism guesthouses identify as future actions the increase of agritourism product quality/branding (in a large percent in Bihor County and Alba County, and in a small percent in Arad County form example) and, secondly, it is necessary to create tourism programs that focus on the life of the farm (Arad County having for this aspect the largest percent, the explanation deriving from the fact that here agritourism is at the beginning of development compared to the other counties). Regarding the third direction for improving the agritourism product, counties Salaj, Hunedoara, Bihor and Cluj consider opportune to focus on promotion and distribution.

Table 10. Identifying the desire to collaborate in order to improve the agritourism product.

\begin{tabular}{|c|c|c|c|c|c|c|}
\hline \multirow[b]{2}{*}{ The Studied Area } & \multirow[b]{2}{*}{$\begin{array}{l}\text { Measure } \\
\text { Unit }\end{array}$} & \multicolumn{2}{|c|}{ Desire for Collaboration } & \multicolumn{3}{|c|}{ Directions for Improving Agritourism Produc } \\
\hline & & Yes & No & $\begin{array}{c}\text { Increasing } \\
\text { Quality }\end{array}$ & $\begin{array}{l}\text { Focusing on } \\
\text { Life on the } \\
\text { Farm }\end{array}$ & $\begin{array}{l}\text { Focusing on } \\
\text { Promotion and } \\
\text { Distribution }\end{array}$ \\
\hline \multirow{2}{*}{ Alba County } & No. & 33 & 15 & 31 & 13 & 4 \\
\hline & $\%$ & 68.75 & 31.25 & 64.58 & 27.08 & 8.33 \\
\hline \multirow{2}{*}{ Cluj County } & No. & 46 & 14 & 37 & 13 & 10 \\
\hline & $\%$ & 76.66 & 23.33 & 61.66 & 21.66 & 16.66 \\
\hline \multirow{2}{*}{ Hunedoara County } & No. & 11 & 9 & 9 & 7 & 4 \\
\hline & $\%$ & 55.00 & 45.00 & 45.00 & 35.00 & 20.00 \\
\hline \multirow{2}{*}{ Arad County } & No. & 6 & 1 & 3 & 3 & 1 \\
\hline & $\%$ & 85.71 & 14.28 & 42.85 & 42.85 & 14.28 \\
\hline
\end{tabular}

\subsection{Current Situation and Future Forecasts Regarding Agritourism from the Apuseni Mountains Area}

For future forecasts concerning agritourism in the Apuseni Mountains area, a special tourist resource, the quality-price report must be taken into account, as well as a focus on the products and services offered (see Table 9). Also, from the identification of representative aspects related to the development and capitalization of households in the Apuseni Mountains area through agritourism, it is concluded that agritourism entrepreneurs capitalize products and craft activities with the involvement of tourists from their own farms through agritourism, an aspect which, in most part, represents a chance for their own household to grow (see Table 8). In this way entrepreneurs are becoming aware of the opportunity of agritourism as an activity, identifying the desire to collaborate (see Table 10), the need to increase the agritourism product quality through some tourism programs with an emphasis on increasing quality, a focus on the life on the farm, and strong and sustained promotion (see Table 10).

Starting from the existing and the forecast situation (see Table 11), we have considered that such an analysis at the level of the analyzed area is appropriate. Just as at the national level, in 
the Apuseni Mountains region there has been an upward trend, during the analyzed period, in the number of agritourist accommodation structures; in other words, an increased interest from the agritourism entrepreneurs. Although there is an increase during the analyzed period, if in 2010 the number of agritourism units from the Apuseni Mountains represented $11.37 \%$ from the total number of agritourism guesthouses at a national level (see Table 11), in 2017 the Apuseni Mountains held a share of $9.74 \%$ of the total number of agritourism guesthouses existing at the national level, for the following reasons: the increase of the number of structures at the national level, the poor infrastructure of the area, the low financial motivation of the human resources from the area, or the preference of the consumers for other tourist areas. Also, in the net index using agritourism, the accommodation capacity follows an upward trend, reaching $15.6 \%$ in 2017 . With regard to the population occupied in agritourism, the trend is growing, but the growth is less visible. (see Table 12).

Table 11. The current situation of the distribution of agritourism guesthouses from the Apuseni Mountains area, by counties.

\begin{tabular}{|c|c|c|c|c|c|c|c|c|c|}
\hline \multirow{3}{*}{$\begin{array}{l}\text { Types of tourist } \\
\text { Accommodation } \\
\text { Structures }\end{array}$} & \multirow{3}{*}{ County } & \multicolumn{8}{|c|}{ Years } \\
\hline & & 2010 & 2011 & 2012 & 2013 & 2014 & 2015 & 2016 & 2017 \\
\hline & & \multicolumn{8}{|c|}{ UM: Number of Units } \\
\hline \multirow{6}{*}{ guesthouses } & Alba & 29 & 45 & 50 & 49 & 56 & 59 & 60 & 75 \\
\hline & Arad & 13 & 8 & 13 & 14 & 11 & 12 & 12 & 9 \\
\hline & Hunedoara & 11 & 7 & 7 & 7 & 6 & 8 & 9 & 20 \\
\hline & Bihor & 5 & 1 & 8 & 13 & 14 & 18 & 23 & 44 \\
\hline & Cluj & 90 & 54 & 63 & 50 & 40 & 36 & 38 & 77 \\
\hline & Salaj & 6 & 6 & 9 & 9 & 12 & 16 & 19 & 24 \\
\hline \multicolumn{2}{|c|}{$\begin{array}{l}\text { Total agritourism guesthouses from } \\
\text { Apuseni Mountains }\end{array}$} & 154 & 121 & 150 & 142 & 139 & 149 & 161 & 249 \\
\hline \multicolumn{2}{|c|}{$\begin{array}{l}\text { No. of agritourism guesthouses at } \\
\text { national level }\end{array}$} & 1354 & 1210 & 1569 & 1598 & 1665 & 1918 & 2028 & 2556 \\
\hline
\end{tabular}

Source: processing according to data from the National Institute of Statistics, http:/ / statistici.insse.ro, consulted in 6 May 2018, and other administrative data [39].

Table 12. Current situation and future forecasts regarding some agritourism indicators from the Apuseni Mountains area.

\begin{tabular}{|c|c|c|c|c|c|c|c|c|c|c|}
\hline & \multicolumn{8}{|c|}{ Current Situation } & \multicolumn{2}{|c|}{$\begin{array}{c}\text { Future } \\
\text { Forecasts }\end{array}$} \\
\hline & 2010 & 2011 & 2012 & 2013 & 2014 & 2015 & 2016 & 2017 & 2020 & 2030 \\
\hline $\begin{array}{l}\text { No. of agritourism } \\
\text { guesthouses } \\
\text { (number) (NATE) }\end{array}$ & 154 & 121 & 150 & 142 & 139 & 149 & 161 & 249 & 261 & 560 \\
\hline $\begin{array}{l}\text { Index of net using the } \\
\text { agritourism accommodation } \\
\text { capacity (\%) (IAA) }\end{array}$ & 10.2 & 11.4 & 13.5 & 12.6 & 12.9 & 14.3 & 15.4 & 15.6 & 18.6 & 26.7 \\
\hline $\begin{array}{l}\text { Population occupied in } \\
\text { agritourism (persons) (POA) }\end{array}$ & 413 & 373 & 422 & 457 & 466 & 481 & 493 & 517 & 540 & 601 \\
\hline
\end{tabular}

Source: processing according to data from the National Institute of Statistics, http:/ / statistici.insse.ro, consulted on 6 May 2018, and other administrative data [39].

The number of agritourism guesthouses in the Apuseni Mountains was established in the form of the logistic evolutionary model (Figure 5):

$$
\mathrm{NATE}=\left(1 / 2500+8 \cdot 10^{76} \cdot 0.9135^{\mathrm{Y}}\right)^{-1}
$$

with a statistically assured correlation coefficient $r=0.797$ at sig. $=0.03$. For the year 2020, the determined function indicates the value of $\mathrm{NATE}_{2020}=261$ respectively for the year 2030, $\mathrm{NATE}_{2030}=$ 560 agritourism guesthouses. 


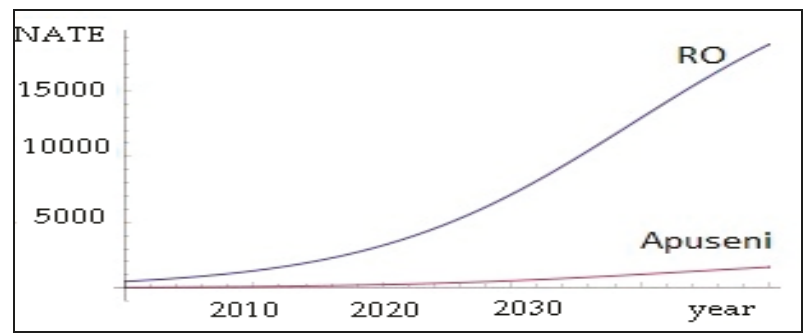

Figure 5. Graphical representation of the functional model for the number of agritourism establishments (NATE).

The net index using the agritourism accommodation capacity evolves after the logistic expression as being (Figure 6):

$$
\mathrm{IAA}=\left(1 / 50+7.8 \cdot 10^{55} \cdot 0.9637^{\mathrm{Y}}\right)^{-1}
$$

having $\mathrm{r}=0.910$ at sig. $=0.004$. For the year 2020, the function indicates $\mathrm{IAA}_{2020}=18.6$ and $\mathrm{IAA}_{2030}=26.7$ respectively for the year 2030 .

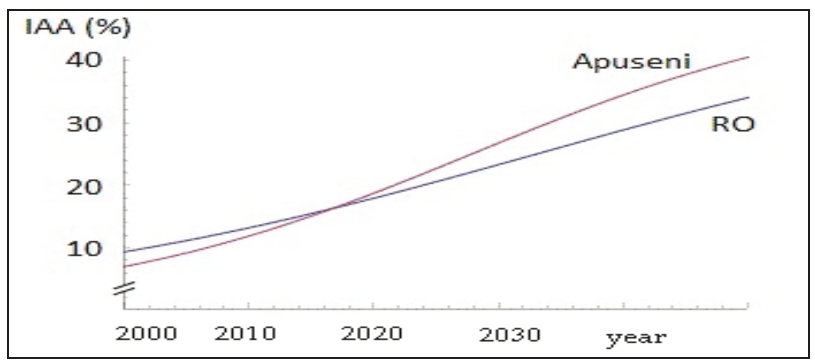

Figure 6. Graphical representation of the functional model for the net index using the agritourism accommodation capacity (\%) (IAA).

The population occupied in agritourism has been established in the same way, as a function of the number of boarding houses, using the function (Figure 7):

$$
\mathrm{POA}=654.825-29818 / \mathrm{NATE}
$$

having $\mathrm{r}=0.808$ at sig. $=0.028$. For the year 2020, the function indicates a population occupied in agritourism in a number of $\mathrm{POA}_{2020}=540$; respectively, in the year 2030 we predict that the number of people employed in agritourism would be $\mathrm{POA}_{2030}=601$.

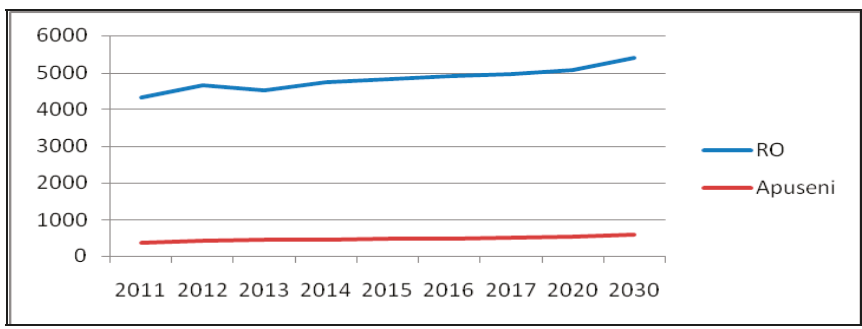

Figure 7. Graphical representation of the annual evolution of population occupied in agritourism (POA). 


\section{Discussion}

Starting from the current situation and following the forecasts made, it was found that the forecast situation is satisfactory, the area being one with high tourist potential. Consequently, the premise of this scientific paper, in the sense that the people have become aware of the existence of great tourist potential, is supported by the statement that the total accommodation capacity of the Apuseni Mountains area is about $74 \%$ of accommodation capacity at national level, with good expectations in the future. Given the fact that the area confronts many disparities, described in Table 4, it can be stated that agritourism activity has the potential for development, being a particularly valuable one, which somewhat supports the sustainability of this field of activity for rural area of Apuseni Mountains, through many benefits [49,50]:

- It ensures unaltered preservation of rural structures and the ways of living, customs and traditions, in a word of a traditional culture made available to tourists. This form of tourism is a multifunctional activity, representing more than just a stay at a peasant guesthouse. In general, the interest in natural and rational nutrition represents a factor of attraction that is increasingly manifested by tourists from developed countries. Due to the relatively small size of the companies involved (most of them family business), agritourism is able to satisfy the demands of tourists for quality, intimacy and originality, and the flexibility of purchased services ensures their adaptability to individual needs.

- Diversification and, in conclusion, a certain stabilization of the local economy, with the possibility of creating some business opportunities [51,52] and through them the emergence of new jobs.

- the superior capitalization of the natural and anthropic valences of rural settlements from the area studied through agritourism, the accent being placed on maintaining attractive traditional components at the same time with the increasing the requirements of modern, competitive tourism; co-participation and co-hosting of tourist-host and host-receptor, which are defining elements.

- Positive evolutions among tourists-that come in contact with other mentalities, customs, with another way of organizing life, as well as among hosts who might learn about a series of characteristics of the environment and the places from where tourists come from. Thus, through the exchange of information, the rural world comes out of isolation, and it protects its cultural dimension, viability and stability through tourism.

Nowadays, the growth of global tourism has caused a significant interest in research focused on the impact of the tourism on environment and community, specifically on agritourism structures. $[53,54]$ The development of agritourism $[55,56]$, in the studied area, will lead to a sustainable economic development of rural localities. From the forecasts, we can gather that there will be positive influences on the environment, agriculture, transport, construction, processing and food-processing industries, and services from various fields. The development of rural entrepreneurship, in the agritourism field, based on managerial knowledge and non-polluting technologies, in harmony with the principles of sustainable development, can certainly become a profitable activity for the inhabitants of the Apuseni Mountains, ensuring them a decent living and a job.

Therefore, entrepreneurs from the area can, through agritourism activity, develop a successful model in order to capitalize the tourist potential of the area, and to supplement the income from agricultural holdings through the opportunity of adding a modest income from tourism activities. Such a proposal aims at an approach focused on that area, which capitalizes the advantages of the region: agriculture, tourism and recreational activities.

\section{Conclusions}

The reason for choosing the Apuseni Mountains area derives from the fact that it has high agritourism potential, so the desire to highlight this area is justified. We support the above affirmation 
by the fact that the area takes part of the rural areas with special tourist potential, at the European level, which can offer to tourists a variety of tourism products.

This paper has as its purpose to highlight some aspects regarding the importance of the necessity of implementing the sustainability of the agritourism field, with benefits for rural settlements, taking as an area of study the mountainous rural environment of the Apuseni Mountains. During the study, we drew some conclusions that have been demonstrated in the paper:

- At present, the combination between sustainable rural development and tourism facilities represent a "must have", so a particular importance is given to agritourism, both in the specialized literature and in practice. The rural settlements where agritourism will be practiced will become places where all elements of local sustainable development will be assembled, and become a possible alternative to the problems of agriculture and the "health" of the rural environment, the development of agritourism, related to the evolution of agriculture, takes many forms and brings many benefits also for tourists that are willing to practice this activity if some principles are respected, these aspects are underlined in Figure 1, Figure 2, Table 1, Table 2.

- In order to underline the evolution of the current situation of Romanian agritourism guesthouses and to make future forecasts, a logistic model, according to Table 2, was used. We can conclude that, regarding this purpose at the Romanian level, there are 2556 agritourism accommodation structures (see Table 3-current situation) with 44,499 accommodation places in year 2017, concentrated in different geographic areas of the country and using a logistic model; the result is that in 2030 these structures will be NATE $2030=7113$ agritourism guesthouses (see Table 3-future forecasts).

- $\quad$ One of the sub-purposes was to achieve a concrete study on the Apuseni Mountains by using a questionnaire so it can highlight the aspects related to: information about the characteristics of respondents; the surface of the farm and the existence of specialized training; the development and capitalization of households in the area analyzed through agritourism; the motivation of tourists to practice agritourism in the area under analysis; and the identification of the desire to collaborate in order to improve the agritourism product from the owners of agritourism structures. Therefore, we can conclude that, regarding the capitalization of the products from the farm through agritourism, a favorable trend is registered (Table 8). Regarding the capitalization of craft activities through tourism with the involvement of tourists, this registered a positive trend mostly at the level of Cluj and Salaj counties, but also a negative one at the level of Alba, Bihor, Arad, Hunedoara counties (Table 8). The owners of tourist locations have entrepreneurial skills, in general, and less specialized knowledge in tourism and management fields (Table 7). From the experience of agritourism farm owners, the tourists are attracted by the boarding house/area, due to the exceptional tourist resources and the quality-price report (Table 9). The research shows that the owners of agritourism guesthouses identify as future actions the increase of agritourism product quality/branding and, secondly, that it is necessary to create tourism programs that focus on the life of the farm. (Table 10).

- For the Apuseni Mountains area, some future forecasts were made by using a logistic model, and it was found that the forecast situation is a positive and satisfactory one; so the first indicator analyzed, NATE, will increase to 261 agritourism guesthouses in 2030, the second indicator, IAA, will also have a satisfactory evolution to $18.6 \%$ in 2013 , and the third indicator POA, will also rise to 540 persons occupied in agritourism in 2030, according to the results from Table 12.

The time series for 2010-2017 indicate a significant increase regarding the indicators studied (IAA, NATE, POA). This aspect is largely due to the European/national support and funding programs that have been intensively carried out during this period, but also to a tendency to change the opinions of the population, especially young people. This is also evidenced by the increase in employment (IAA), which is noticeably higher in the Apuseni Mountains compared to Romania (Romania's IAA shows an increase of $26.61 \%$ in the period 2010-2017 while at the level of the Apuseni Mountains, 
the IAA shows an increase of 52.94\%). This difference was observed against the background of a relatively similar growth in the number of units: NATE increased by $88.77 \%$ at the level of the whole country and at the level of the Apuseni Mountains only by $61.68 \%$, but also a significant increase. Also the growth rate of the occupied population (POA) is higher in the Apuseni Mountains, the increase observed in this period being $25.18 \%$, while in Romania the growth was $13.86 \%$. These details clearly show the sustainability of an improved attitude of the population in terms of options regarding such non-tourist activities, which does not exhaust resources and preserves the environment. Moreover, the local population growth trend in these areas (POA) indicates with great certainty the possibility of professional reconversion of people who not long ago were undertaking other activities in the sense of being able to carry out activities that support and induce sustainability.

From the previous points in the paper, we have concluded that, regarding the specific peculiarities of agritourism activity from the Apuseni Mountains area, during recent years it developed great tourism potential, which has gradually begun to be used through agritourism structures to attract tourists throughout the year. Given the fact that the area is confronted with many disparities, described in Table 4, the statement that agritourism supports the sustainability of this mountainous rural area through many benefits, expressed in the text, is real. The transformations that need to take place in the rural area to support the connection between sustainable development and agritourism, in our opinion, are:

- $\quad$ raising the level of civilization and comfort of the boarding houses, in accordance with their originality and diversity.

- change of mentality, by giving up a way of thinking synthesized by the phrase "this is fine, too", and understanding the exigencies and necessity of professionalism and performance in carrying out agritourism activities. As generous as the supply of certain components is, it does not necessarily prove to be profitable unless it manifests itself in a system that integrates all the factors that define the agritourism product (accommodation, tourist movement, animation, various activities, services, courtesy, exemplary cleanliness, attention to detail, etc.).

- the development of entrepreneurial spirit among the "natives". Agritourism can only be developed under conditions of risk assumption, by those from rural households with the development of human health and the "health" of the environment, and through this achieve the main desideratum — the sustainability of the rural environment.

Obviously, it is not easy for transformations to take place in the studied area, especially because of the large territorial extension, but in the long term agritourism can support the emergence of horizons in the sustainable development of rural settlements, at least for the analyzed area.

Author Contributions: All authors have contributed to the study and writing of this research. R.C. and T.I., conceived the overall idea of the research; C.R. performed the calculations; T.A., G.P. and D.M. analyzed the data and R.L. drew the main conclusions. In conclusion, all authors have the same rights on the paper.

Funding: The publication of this paper is supported through the project "Assuring Excellence in RDI Activities within the USAMVBT" Code 35PFE.

Acknowledgments: This paper is published within the project "Assuring Excellence in RDI Activities within the USAMVBT" Code 35PFE, submitted in Competition Program 1-Development of the National Research and Development System, Subprogram 1.2-Institutional Performance, Institutional Development Projects-Excellence Funding Projects in RDI.

Conflicts of Interest: The authors declare no conflict of interest.

\section{References}

1. Bungau, S.; Suciu, R.; Bumbu, A.; Cioca, G.; Tit, D.M. Study on hospital waste management in medical rehabilitation clinical hospital, Baile Felix. J. Environ. Prot. Ecol. 2015, 16, 980-987.

2. Torretta, V.; Rada, E.C.; Ragazzi, M.; Trulli, E.; Istrate, I.A.; Cioca, L.I. Treatment and disposal of tyres: Two EU approaches. A review. Waste Manag. 2015, 45, 152-160. [CrossRef] [PubMed] 
3. Kişi, N.A. Strategic approach to sustainable tourism development using the a'wot hybrid method: A case study of Zonguldak, Turkey. Sustainability 2019, 11, 964. [CrossRef]

4. Font, X.; Mccabe, S. Sustainability and marketing in tourism: Its contexts, paradoxes, approaches, challenges and potential. J. Sustain. Tour. 2017, 25, 869-883. [CrossRef]

5. Muresan, I.C.; Oroian, C.F.; Harun, R.; Arion, F.H.; Porutiu, A.; Chiciudean, G.O.; Todea, A.; Lile, R. Local residents' attitude toward sustainable rural tourism development. Sustainability 2016, 8, 100. [CrossRef]

6. Tinsley, R.; Lynch, P. Small tourism business networks and destination development. Intl. J. Hosp. Manag. 2001, 20, 367-378. [CrossRef]

7. Tew, C.; Barbieri, C. The perceived benefits of agritourism: The provider's perspective. Tour. Manag. 2012, 33, 215-224. [CrossRef]

8. Bramwell, B. Rural tourism and sustainable rural tourism. J. Sustain. Tour. 1994, 2, 1-6. [CrossRef]

9. Turnock, D. Sustainable rural tourism in Romanian Carpatians. Geogr. J. 1999, 165, 192-199. [CrossRef]

10. Călina, A.; Călina, J.; Iancu, T. Research regarding the implementation, development and impact of Agritourism on Romania's rural areas between 1990 and 2015. Environ. Eng. Manag. J. 2017, 16, 157-168. [CrossRef]

11. Bonnin, C.; Cauet, J.M. L' Évaluation de l' Entreprise en Hotellerie-Restauration; Editura BPI: Paris, France, 1991.

12. Ciolac, R.; Iancu, T.; Rujescu, C.; Milin, A.; Merce, I.; Marin, D.; Dincu, A.M.; Stanciu, S.O. Agro-tourism in European Mountain Areas. Rural Dev. Proc. 2013, 6, 80-85.

13. Lane, B. What is rural tourism? J. Sustain. Tour. 1994, 2, 7-21. [CrossRef]

14. Ghereş, M. Agroturism, de la Tradiţie la Ofertă Comercială; Editura Risoprint: Cluj-Napoca, Romania, 2003.

15. Bausch, T. Le Tourisme et l' Environnement en Europe; Office dest Publications Officielles des Communautes Europeennes: Luxemburg, 1995.

16. Rey, R. European Context and the Crisis State from Romanian Agriculture and Mountain Rural Area, Out of the Volume Rural World-Today and Tomorrow-Coord.acad; Cristian Hera; Editura Academiei Române: Bucureşti, Romania, 2006.

17. Abrudan, I.; Turnock, D.A. Rural development strategy for the Apuseni Mountains, Romania. GeoJournal 1998, 46, 319-336. [CrossRef]

18. Ciolac, R.; Csosz, I.; Bogdan, N. Brief description of the agritourism potential of Western Mountains area and identification of the main traditional products possible sold through agrotourism. Agrobuletin 2012, 12, 148-154.

19. Euromontana. Către dezvoltarea integrată a zonelor montane și recunoașterea acestora în cadrul politicii agricole comune. Modelarea noului spațiu european. In Proceedings of the Euromontana Conference, Piatra Neamt, Romania, 4-6 October 2007.

20. Comisia Europeană. O Selecție a Celor Mai Bune Practici Leader+; Comisia Europeană: Brussels, Belgium, 2009.

21. RNDR. Bune Practici, 2014, No. 4 Anul II, USR, Departamentul Publicaţii MADR. Available online: http:/ / madr.ro (accessed on 16 February 2019).

22. Vaetisi, S. Rural Tourism in the Apuseni Mountains, Romania. An anthropological research on using natural and cultural resources in developing tourism in a poor region. In Tourists and Tourism; Abhijeet Publications: New Delhi, India, 2006.

23. Ammirato, S.; Felicetti, A. The Agritourism as a Means of Sustainable Development for Rural Communities: A Research from the Field. Int. J. Interdiscip. Environ. Stud. 2014, 8, 17-29. [CrossRef]

24. Legge Quadro Nazionale n. 730/1985 sull'Agriturismo art.1, pubblicata nella G.U. $n .295$ del 16 dicembre. 1985. art.1. Available online: https://www.tuttocamere.it/files/agricol/1985_730.pdf (accessed on 7 March 2019).

25. Sonnino, R. For a 'Piece of Bread'? interpreting sustainable development through agritourism in southern Tuscany. J. Eur. Soc. Rural Sociol. 2004, 44, 285-300. [CrossRef]

26. Karabati, S.; Dogan, E.; Pinar, M.; Celik, M.L. Socio-Economic Effects of Agri-Tourism on Local Communities in Turkey: The Case of Aglasun. Intl. J. Hosp. Tour. Adm. 2009, 10, 129-142. [CrossRef]

27. Garcia, H.B. Marketing în Turism Rural; Editura Irecson: Bucureşti, Romania, 2003.

28. Brezuleanu, S.; Brad, I. Consideraţii privind activităţile agroturistice din landul Baden-Wurttemberg, Germania. Lucr. şt. USAMV Iaşi. Seria Agronomie. 2001, vol. 44. Available online: http://www. uaiasi.ro/revagrois/PDF/pdf_2001_fdf99a5620d83e128992e72b54a04713.pdf (accessed on 7 March 2019). 
29. Marin, D. Study on the economic impact of tourism and of agrotourism on local communities. Res. J. Agric. Sci. 2015, 47, 160-163.

30. Iorio, M.; Corsale, A. Rural tourism and livelihood strategies in Romania. J. Rural Stud. 2010, 26, $152-162$. [CrossRef]

31. Ciurea, I.V. Şi colaboratorii. Organizarea activităţilor economico-sociale în sistem agroturistic a localităţilor montane de pe Valea Oituzului, judeţul Bacău. Lucrări ştiinţifice seria Agronomie Universitatea Agronomică Iaşi 1995, 38.

32. Buciuman, E. Economia Turismului Rural şi Agroturismului; Editura ProTransilvania: Alba-Iulia, Romania, 1999.

33. Nistoreanu, P. Turismul Rural-o Afacere Mică cu Perspective Mari; Editura Didactică şi Pedagogică: Bucureşti, Romania, 1999.

34. Istrate, I.; Bran, F.; Roşu, A. Economia Turismului şi Mediul Înconjurător; Editura Economică: Bucureşti, Romania, 1996.

35. Rusu, S. Turism Rural şi Agroturism; Editura Mirton: Timişoara, Romania, 2007.

36. Condratov, I. Priorităţi ale turismului rural românesc. Revista de Turism 2006, 1, 48-51.

37. Ciolac, R.; Rujescu, C.; Constantinescu, S.; Adamov, T.; Dragoi, M.; Lile, R. Management of a tourist village establishment in mountainous area through analysis of costs and incomes. Sustainability 2017, 9, 875. [CrossRef]

38. Google Maps. Available online: https://www.google.com/maps (accessed on 10 November 2004).

39. National Institute of Statistics. Available online: http:/ / statistici.insse.ro (accessed on 6 May 2018).

40. Feher, A.; Goșa, V.; Raicov, M.; Haranguș, D.; Condea, B.V. Convergence of Romanian and Europe Union agriculture-evolution and prospective assessment. Land Use Policy 2017, 67, 670-678. [CrossRef]

41. Kwasnicki, W. Logistic growth of the global economy and competitiveness of nations. Technol. Forecast. Soc. Chang. 2013, 80, 50-76. [CrossRef]

42. Stoleriu, I. Matematici Financiare; Universitatea A.I. Cuza: Iaşi, Romania, 2015.

43. Bussines Cover. Available online: https://www.businesscover.ro/romania-si-tentativa-de-agroturism/ (accessed on 12 March 2018).

44. Bran, P.; Bran, F.; Roşca, I.; Manea, G.; David, O.; Costică, I.; Iorgulescu, A. Componenta Ecologică a Strategiei de Dezvoltare Economică a Zonei Munţilor Apuseni: Studiu de caz Roşia Montană; Editura A.S.E.: Bucureşti, Romania, 2003.

45. Constantin, V.; Kantor, C.M.; Surd, V. An analysis of the Apuseni Mountains settlements development based on synthetic indicators. J. Environ. Res. Prot. 2015, 12, 6-17.

46. Constantin, V.; Surd, V.; Kantor, C.M. Vision and Strategic Objectives for Sustainable Development of the Apuseni Mountains Mining Settlements. Geogr. Pannonica 2014, 18, 82-88. [CrossRef]

47. Buza, M.; Dimen, L.; Pop, G.; Turnock, D. Environmental protection in the Apuseni Mountains: The role of Environmental Non-Governmental Organisations (ENGOs). GeoJournal 2001, 55, 631-653. [CrossRef]

48. Ciolac, R.; Csosz, I.; Petroman, C.; Petroman, I.; Iancu, T.; Martin, S.; Marin, D.; Dincu, A.-M. Research regarding agro-tourism stage in Apuseni Mountains area and capitalize of traditional products through this. Sci. Pap. Anim. Sci. Biotechnol. 2013, 45, 366-371.

49. Giannakis, E. The role of rural tourism on the development of rural areas: The case of Cyprus Elias. Rom. J. Reg. Sci. 2014, 8, 38-53.

50. Garau, C. Perspectives on cultural and sustainable tourism in a smart region: The case study of Marmilla in Sardinia (Italy). Sustainability 2015, 7, 6412-6434. [CrossRef]

51. Getz, D.; Page, J.S. The Business of rural Tourism International Perspectives; International Thompson Publishing Company: Toronto, ON, Canada, 1997.

52. Evans, N. Strategic Management for Tourism, Hospitality and Events; Routledge: New York, NY, USA, 2015.

53. Cioca, L.I.; Giurea, R.; Precazzini, I.; Ragazzi, M.; Achim, M.I.; Schiavon, M.; Rada, E.C. Agro-Tourism and Ranking. In Proceedings of the AIP Conference Proceedings, Karnataka, India, 10-11 August 2018; Volume 1968.

54. Cioca, L.I.; Giurea, R.; Moise, I.A.; Precazzini, I.; Ragazzi, M.; Rada, E.C. Local environmental impact of wood combustion in agro-tourism structures. In Proceedings of the 8th International Conference on Energy and Environment (CIEM), Bucharest, Romania, 19-20 October 2017; pp. 120-123. 
55. Panyik, E.; Costa, C.; Rátz, T. Implementing integrated rural tourism: An event-based approach. Tour. Manag. 2011, 32, 1352-1363. [CrossRef]

56. Polo-Peña, A.I.; Frías-Jamilena, D.; Rodríguez-Molina, M.A. The perceived value of the rural tourism stay and its effect on rural tourist behaviour. J. Sustain. Tour. 2012, 20, 1045-1065. [CrossRef]

(C) 2019 by the authors. Licensee MDPI, Basel, Switzerland. This article is an open access article distributed under the terms and conditions of the Creative Commons Attribution (CC BY) license (http:/ / creativecommons.org/licenses/by/4.0/). 
Article

\title{
Estimating the Impact of Air Pollution on Inbound Tourism in China: An Analysis Based on Regression Discontinuity Design
}

\author{
Daxin Dong, Xiaowei $\mathrm{Xu}$ * and Yat Fung Wong \\ School of Business Administration, Southwestern University of Finance and Economics, Chengdu 611130, China; \\ dongdaxinedu@126.com (D.D.); hyf@swufe.edu.cn (Y.F.W.) \\ * Correspondence: xiaoweix@swufe.edu.cn
}

Received: 6 March 2019; Accepted: 15 March 2019; Published: 20 March 2019

\begin{abstract}
Prior studies have suggested the existence of a reverse causality relationship between air quality and tourism development: while air quality influences tourism, dynamic segments of the tourism industry (e.g., cruising, airline, foodservice) have impacts on air quality. This reverse causality hinders a precise estimate on the effect of air pollution on tourism development within a conventional econometric framework, since the variable of air pollution is endogenous. This study estimates the impact of air pollution on the inbound tourism industry in China, by controlling for endogeneity based on a regression discontinuity design (RDD). The estimate is derived from a quasi-experiment generated by China's Huai River Policy, which subsidizes coal for winter heating in northern Chinese cities. By analyzing data from 274 Chinese cities during the period 2009-2012, it is found that air pollution significantly reduces the international inbound tourism: an increase of $\mathrm{PM}_{10}$ (particulate matter smaller than $10 \mu \mathrm{m}$ ) by $0.1 \mathrm{mg} / \mathrm{m}^{3}$ will cause a decline in the tourism receipts-to-local gross domestic product (GDP) ratio by 0.45 percentage points. This study also highlights the importance of controlling for endogeneity, since the detrimental impact of air pollution would otherwise be considerably underestimated. This study further demonstrates that, although air pollution is positively correlated with the average expenditure of each tourist, it substantially depresses the number of inbound tourists. The results imply that air quality could potentially influence inbound tourists' city destination choices. However, it is interesting to note that travelers in air polluted cities in China tend to spend more money.
\end{abstract}

Keywords: air pollution; inbound tourism; China, $\mathrm{PM}_{10}$; regression discontinuity design

\section{Introduction}

Sustainability is rooted in environmentalism, and it has been regarded as a fundamental concept for tourism development [1]. A balance among environmental, economic, and social sustainability, the three main pillars of sustainability, is the key to achieving sustainable tourism development [2]. Since tourism has become one of the largest-growing economic sectors in the world, policy makers should shift their focus from the quantity of economic growth to the quality of growth, which could be determined by natural environmental performance. The impact of environmental factors (e.g., nice weather, personal safety, unpolluted environment, standards of hygiene of the destination) on the tourism industry cannot be overlooked, as they influence customers' destination choices [3,4], travel experiences [5], as well as tourist aesthetic judgement [6]. Moreover, pollution becomes a major health concern. For instance, 4.2 million deaths every year are linked to outdoor air pollution exposure [7]. However, it is noticed that the impact of environmental quality on tourism development has been examined less extensively than the impact of tourism on environmental quality. 
Since 2014, air quality improvement has been regarded as a top priority for sustainable development by the United Nations Environment Assembly [8]. According to AirVisual [9], the top 10 polluted cities were dominated by India, Pakistan and China in 2018. It was reported that India's toxic air caused 1.24 million deaths in 2017 [10], and prompted visitors to defer or cancel their trips to destinations such as Delhi, Agra and Varanasi [11]. In Pakistan, air pollution led to an increase in asthma and other respiratory diseases [12]. China's problems with severe air pollution have also received worldwide attention in recent years. Haze, a serious health threat, has become one of the most disastrous weather events in China [13]. According to the Wall Street Journal [14], foreign visitors to Beijing, China suddenly declined by roughly 50\% in the first three quarters of 2013. One of the main factors for the decline might be the city's notorious air pollution, as hyped by foreign media, which increases foreign visitors' perceptions of environmental risks in China.

Although the number of tourists inbound for China in 2017 reached 139 million, this only represented a $0.8 \%$ increase compared to last year. Dai Bin, the president of the China Tourism Academy, regarded environmental concerns as being one of the potential reasons for deterring international tourists [15]. It is implied that inbound tourism in China should be improved by adhering to the overarching goal of achieving sustainable tourism development. To provide additional evidence on the negative impact that air quality might have on inbound tourism in China, quantitative analyses are needed.

With the aim of providing a more precise estimation on the effects of air pollution, this study carefully considers the following points: (1) the development of tourism might, reversely, affect environmental quality. This is confirmed by some existing studies that have discussed the influence of the tourism industry on pollution. The existence of reverse causality hinders a precise estimate on the effect of air pollution on tourism development within a conventional econometric framework, as air pollution is an endogenous variable. This issue should be dealt with in econometric regressions. (2) This study takes into account the effect of China's Huai River Policy, which subsidizes coal for winter heating to people living in northern Chinese cities. Given that this policy has led to a dramatically higher degree of air pollution in northern China than that in southern China [16], a discontinuous distribution of air pollution around the north-south boundary could be observed. In this situation, regression discontinuity design (RDD) is regarded as a powerful method for dealing with the endogeneity of the air pollution variable, while identifying a causal effect from air quality to tourism development. (3) Given that the distribution of tourism resources is highly uneven in different districts in China, the representativeness of the sample used in analysis should be noted. Existing studies in literature have either investigated the circumstances at aggregate levels such as country- and province-levels, or have focused on some hot tourism destinations such as Beijing and Shanghai. If the study subject is the whole country or the provinces, the findings may be driven by circumstances in districts with large tourism scales. If only the hot tourism destination cities are considered, many cities would be ignored, even though they probably have distinct characteristics. Differently, this study analyzes China's city-level data instead of its national- or province-level data. Our sample consists of 274 cities, covering over $80 \%$ of the districts of China. (4) This study inspects the impacts of air quality on three tourism indicators: inbound tourism receipts, the number of arrivals, and the expenditure per tourist. These three variables are all crucial indicators in tourism analysis. This study attempts to provide a comprehensive understanding on how air quality influences the tourism industry.

This study contributes to the body of literature in two aspects. First, since this study addresses explicitly the endogeneity issue in the regressions, it probably provides a more accurate estimate on the damage of air pollution on China' inbound tourism. According to the estimates of this study, if $\mathrm{PM}_{10}$ (particulate matter smaller than $10 \mu \mathrm{m}$ ) density increases by $0.1 \mathrm{mg} / \mathrm{m}^{3}$, the tourism receipts-to-local gross domestic product (GDP) ratio will decline by 0.45 percentage points, implying a reduction of 567 million RMB (approximately 80 million USD) in tourism receipts; the tourist arrivals-to-local population ratio will reduce by 4.6 percentage points, implying a reduction of 0.19 million tourists. The estimates of this study demonstrate that pollution's negative impact will 
be substantially underestimated if the endogeneity is not mitigated. Second, this study is the first attempt to analyze the impact of air pollution on tourism over a wide sample of Chinese cities. The sample covers 274 cities, containing over $80 \%$ of Chinese cities. This sample includes not only a set of well-known cities with high levels of tourism development, but also many promising cities which currently have medium or small scales of tourism industries. Therefore, the empirical findings of this study reflect the general situations in China.

The rest of this paper is organized as follows. Section 2 presents a literature review on the interaction between air pollution and tourism. Section 3 illustrates the significant discontinuity of air pollution and tourism variables around the north-south boundary of China. Section 4 demonstrates the empirical model and the data used in the regressions. The estimate results are discussed in Section 5. Discussions are then presented in Section 6. Finally, Section 7 provides the conclusions, limitations of this study, and recommendations for future research.

\section{Literature Review}

This literature review section examines the bilateral causality between environmental quality and tourism development, with a special focus on air pollution issues.

\subsection{The Relationship between Environment and Tourism}

Numerous studies have investigated the impact of tourism growth on local economic development $[17,18]$. It has been acknowledged that tourism, especially in less developed countries, is regarded as a generator of economic benefits including improvements in employment, incomes and exports $[19,20]$. Since tourism development depends greatly on climatic and natural resources such as rivers, lakes, and landscape [21], tourism industry practitioners should optimize the use of the environmental resources to promote economic growth and alleviate poverty.

In recent decades, tourism was no longer a luxury good, but widely enjoyed by the general public. It is noticed that individuals' perceptions of tourism-environment relationship have changed due to tourism's potential impact on the natural environment such as noise pollution, water pollution, air pollution, biodiversity loss and coastal degradation [22-24]. The multiple segments of the tourism industry could also induce negative environmental impacts. For instance, tourism transport cruise ship emission could cause air pollution [25], and the hotel sector increases environmental burden due to its high level of energy and water consumption [26]. A recent report indicates that worldwide tourism industry accounts for $8 \%$ of global $\mathrm{CO}_{2}$ emissions from 2009 to 2013 [27]. Increasing attention has been paid to the appropriate handling of the relationship between tourism and the environment rather than speeding up the tourism resources' exploitation and utilization.

In addition to the aforementioned studies highlighting the tourism-influenced environmental disturbances, a number of studies have indicated the impact of environment on tourism industry, especially for international tourism [28]. The rationale behind is that changes in climate or weather conditions could influence the demand for tourism. Poor environmental conditions in the destination country could reduce inbound travelers' visit intentions, while poor environmental conditions in the place of origin could serve as a push motivator for outbound travelers [29].

\subsection{The Impact of Air Pollution on Tourism}

Air pollution not only harms the health of tourists, but also reduces air visibility, which directly influences tourists' travel experiences. Therefore, good air quality is indispensable for tourism sustainability. As an increasing number of people are now aware of daily levels of air pollution, scholars have started to investigate the impact of air pollution on tourism, and they have found that haze-related air pollution significantly reduces a country's inbound tourism [30]. In recent years, China has been suffering from a serious air pollution problem, which has received worldwide attention since 2013. Beijing, the capital of China, once reached a $\mathrm{PM}_{2.5}$ (particulate matter smaller than $2.5 \mu \mathrm{m}$ ) concentration value that was around 40 times the World Health Organization's maximum 
guideline [31]. Tourists' perceptions of haze pollution alter the tourism seasonality in Beijing [4]. Since then, China's air pollution issues have become the focus of some studies examining the relationship between air pollution and tourism.

From a micro-level perspective, Becken et al. [32] conducted a survey on US and Australian residents, and found that their perceived air quality risk in China has a significant negative impact on destination image and visit intention. Similarly, Peng and Xiao [33] examined the impact of smog in the air on the domestic travel demand to Beijing, and found a significant indirect impact of travel risk perception on avoidance tendency, mediated by travel dissatisfaction and negative destination image.

Evidence on the negative impacts of air pollution on tourism have also been found from macro-level analyses. Deng et al. [34] report that industrial waste gas emissions in provinces of China have a significant negative effect, both directly on the local inbound tourism industry, and indirectly via a spillover effect on other provinces. Using Google Trends search results, $\mathrm{Xu}$ and Reed [35] reported that the people's high degree of concerns about the pollution in China resulted in lower inbound tourism. In a study for 24 Chinese cities, Zhou et al. [36] reported that if the value of the air pollution index increased by $1 \%$ over the last month, the number of inbound tourist arrivals in the current month would decline by $0.25 \%$. Other researchers have reported similar findings, with a focus on one specific city or scenic spot in China, including the Sun Moon Lake Scenic Area in Taiwan [37] and Shanghai [38].

These aforementioned studies all support the claim that air pollution harms tourism development. However, it is noticed that previous studies failed to take into account the endogeneity of air pollution resulting from reverse causality, which might result in either an overestimation or an underestimation of the results. More specifically, in the case that the development of the tourism industry mitigates air pollution, an OLS (Ordinary Least Squares) estimate with tourism development as the dependent variable and pollution as the explanatory variable, may report a spurious negative coefficient. This causes an overestimate on the effect of air pollution. On the contrary, in the case that tourism development increases pollution emissions, an OLS estimate on the air pollution's impact tends to underrate the real magnitude. The previous literature indicates that these two different circumstances are both possible.

\subsection{The Impact of Tourism on Air Pollution}

Tourism, often referred to as the non-smoking industry, has now posed potential threats to natural resources in the world. Belsoy et al. [39] summarized that the negative environmental impacts of tourism include the disruption of ecological life systems, air, water and noise pollution, and pressure on land resources. According to a recent study on the carbon footprint of global tourism, the tourism industry is responsible for $8 \%$ of global greenhouse gas emissions [27]. Several scholars also reported that tourism expansion exacerbates pollution. For instance, Azam et al. [40] reported a positive effect from tourists' arrivals on $\mathrm{CO}_{2}$ emission in Malaysia. Similar findings are reported for some other countries, including Turkey [41], Cyprus [42], and 35 Organization for Economic Co-operation and Development (OECD) countries [43]. Lu et al. [44] found that the growth of domestic tourism earnings in Qingyang City, Gansu, China increases the local discharge of garbage; and air pollutants discharged from waste disposal have become an air pollution source [45]. Based on a study in the Mallorca area of Spain, Saenz-de Miera and Rosselló [24] found that a 1\% increase in tourist numbers was related to a $0.45 \%$ increase in $\mathrm{PM}_{10}$ concentration levels.

Meanwhile, there were actually some contradictory findings suggesting that the development of tourism may mitigate air pollution. For example, Azam et al. [40] observed a negative effect of tourism on $\mathrm{CO}_{2}$ emissions in Thailand and Singapore, which was consistent with studies on EU countries [46,47] and Singapore [48]. A regional panel analysis in China showed that tourism has a negative impact on $\mathrm{CO}_{2}$ emissions in eastern China [49]. Ahmad et al. [2] further reported that the impact of tourism on environmental quality varies across different provinces. Specifically, a negative 
impact was found in the Ningxia, Qinghai, Gansu, and Shaanxi provinces, while a positive impact was found in Xinjiang.

In a nutshell, the literature shows that tourism and air pollution may have bilateral interactions. It is thus necessary to consider the potential endogeneity of air pollution when estimating its impact on the tourism industry.

\section{The Discontinuous Distribution of Air Pollution and Tourism in China}

This section demonstrates the discontinuous distribution of air pollution and tourism development around the north-south boundary of China. The relevant stylized facts will serve as a foundation for the further analyses in this paper.

\subsection{The Discontinuous Distribution of Air Pollution}

The line formed by Huai River and Qinling Mountains, at around latitude $33^{\circ} \mathrm{N}$, is the geographic boundary between northern and southern China. Due to budgetary limitations, since the planned economy period, the central government has implemented distinct policies for winter indoor heating in these two regions [16]. In most northern cities, the government subsidizes coal for winter indoor heating against the cold. This is called the "Huai River Policy". In contrast, in the south, this policy is not prevalent. Since the use of coals generates substantial emissions, the air quality in the northern cities is worse than that in the south, ceteris paribus. This phenomenon was already confirmed in the literature. For example, Almond et al. [16] showed that the degree of air pollution has a considerable leap from the south to the north side of the Huai River-Qinling Mountains. Chen et al. [50] and Ebenstein et al. [51] utilized this discontinuity to estimate the impact of air pollution on health. Huang and Lanz [52] used this to evaluate impacts on wage and house price.

Figure 1 demonstrates the discontinuous distribution of air pollution in 274 Chinese cities located at different degrees of latitude. We use the $\mathrm{PM}_{10}$ concentration as the indicator of air pollution. From the graph, we observe that the degree of air pollution has a strong relationship with the latitudes of the cities. In southern China, the air pollution increases along with the latitude. Around the north-south boundary, latitude $33^{\circ} \mathrm{N}$, annual average $\mathrm{PM}_{10}$ density has an apparent jump, from around $0.08 \mathrm{mg} / \mathrm{m}^{3}$ to nearly $0.1 \mathrm{mg} / \mathrm{m}^{3}$. This occurs as the result of the Huai River Policy. After this leap, air quality is stable for some degrees of latitude. Finally, when the latitude becomes larger and larger, the level of air pollution declines.

We also formally utilize a regression discontinuity design to test the effect of the Huai River Policy on $\mathrm{PM}_{10}$ density. (Th details about the data and sample are documented in Section 4) We use the following empirical model of a sharp RDD:

$$
\operatorname{PM10}_{i}=\alpha_{0}+\alpha_{1} \text { North }_{i}+\eta F\left(\text { Latitude }_{i}\right)+v_{i}
$$

where $P M 10_{i}$ is the density of the $\mathrm{PM}_{10}$ concentration in city $i$; North $h_{i}$ is a dummy variable indicating whether the city is located in north China, and thus, covered by Huai River Policy (=1 if in the north, and $=0$ otherwise); Latitude $e_{i}$ is the degree of latitude; $v_{i}$ is the error term. Within the RDD framework, $P M 10_{i}$ is the outcome variable; and $F\left(\right.$ Latitude $\left._{i}\right)$ represents the polynomial terms of the running variable Latitude $_{i}$. We are interested in the average treatment effect (ATE) of the policy, which is measured by the coefficient $\alpha_{1}$. The model is estimated by a local polynomial regression. We first use a second-order polynomial, and allow different bandwidths at the two sides of the policy cutoff boundary, to obtain our baseline estimate. The point estimate, which confirms a statistically significant impact at the $10 \%$ significance level, is shown in the first row of column (a) in Table 1. The Huai River Policy raised $\mathrm{PM}_{10}$ by $0.018 \mathrm{mg} / \mathrm{m}^{3}$. To check the robustness, in column (b), we add the logarithm of GDP and population as additional covariates, and, in column (c), we use a third-order polynomial function and restrict using the same bandwidths on both sides of the policy boundary. Our finding holds. 


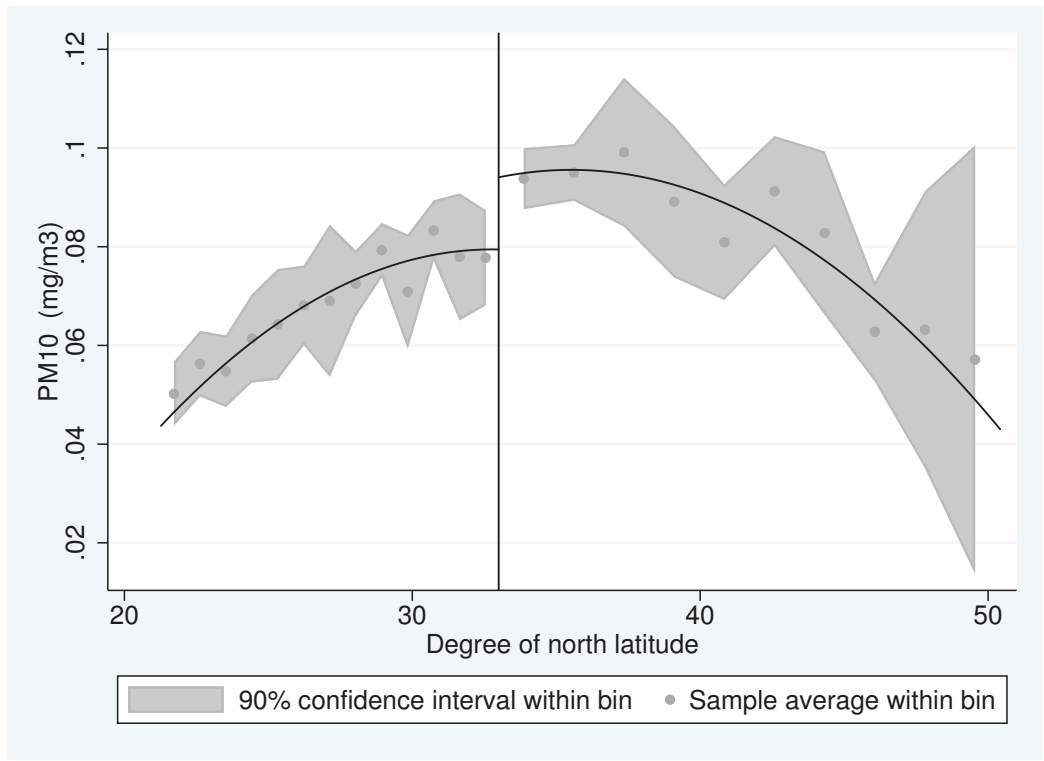

Figure 1. Annual average $\mathrm{PM}_{10}$ concentrations of Chinese cities in different latitudes. Note: The gray points represent the annual average $\mathrm{PM}_{10}$ concentrations across a set of cities grouped in bins according to the degrees of latitude. The gray shadowed area demonstrates the $90 \%$ confidence interval for each bin. The bins were constructed through a data-driven procedure based on the mean squared error (MSE)-optimal bandwidth selector. The vertical line in the middle of the figure indicates the position of latitude $33^{\circ} \mathrm{N}$. The plotted curves report the fitted values from a regression of $\mathrm{PM}_{10}$ concentration on a second-order polynomial in latitude, estimated separately on each side of the north-south boundary.

Table 1. Regression discontinuity estimates of the impacts of the Huai River Policy.

\begin{tabular}{lccc}
\hline Outcome Variable & (a) & (b) & (c) \\
\hline$P M_{10}$ & $0.018^{*}$ & $0.012^{*}$ & $0.022^{*}$ \\
& $(0.011)$ & $(0.007)$ & $(0.013)$ \\
Tourism receipts & $-0.338^{* * *}$ & $-0.304^{* * *}$ & $-0.192^{*}$ \\
& $(0.128)$ & $(0.112)$ & $(0.098)$ \\
Tourist arrivals & $-3.968^{* *}$ & $-3.226^{*}$ & -1.963 \\
& $(1.695)$ & $(1.747)$ & $(1.361)$ \\
\hline Observations & 274 & 274 & 274 \\
Polynomial type & 2 nd order & 2nd order & 3rd order \\
Same bandwidths in both sides & No & No & Yes \\
Additional covariates & No & Yes & No \\
\hline
\end{tabular}

Note: (1) Statistical significance: ${ }^{*} p<0.1 ;{ }^{* *} p<0.05$; ${ }^{* * *} p<0.01$. Standard errors are in parentheses. (2) This table presents the regression discontinuity estimates of the impacts of the Huai River policy on three outcome variables: $\mathrm{PM}_{10}$ concentration $\left(\mathrm{mg} / \mathrm{m}^{3}\right)$, the ratio of inbound tourism receipts to local GDP (\%), and the ratio of inbound tourist arrivals to the local population (\%). (3) Column (a) gives the baseline result; column (b) adds the logarithm GDP and the population as additional covariates; column (c) uses a third-order polynomial function and restricts using the same bandwidths at both sides of the policy boundary.

\subsection{The Discontinuous Distribution of Tourism}

Now, we move to inspect the relationship between tourism and latitude. Figure 2 shows the distribution of receipts from inbound tourism as a ratio to local GDP. Similar to what we can read from Figure 1, this graph shows at least two important points. First, the tourism revenue has a strong relationship with latitude. Second, there is an obvious discontinuity around the latitude $33^{\circ} \mathrm{N}$. Particularly, the tourism receipts-to-GDP ratio suddenly drops when moving from the south to the 
north. This abrupt negative change of tourism revenue is in contrast to the sudden positive change of $\mathrm{PM}_{10}$ displayed in Figure 1. Thus, it is reasonable to conjecture that tourism revenue has a negative correlation with air pollution.

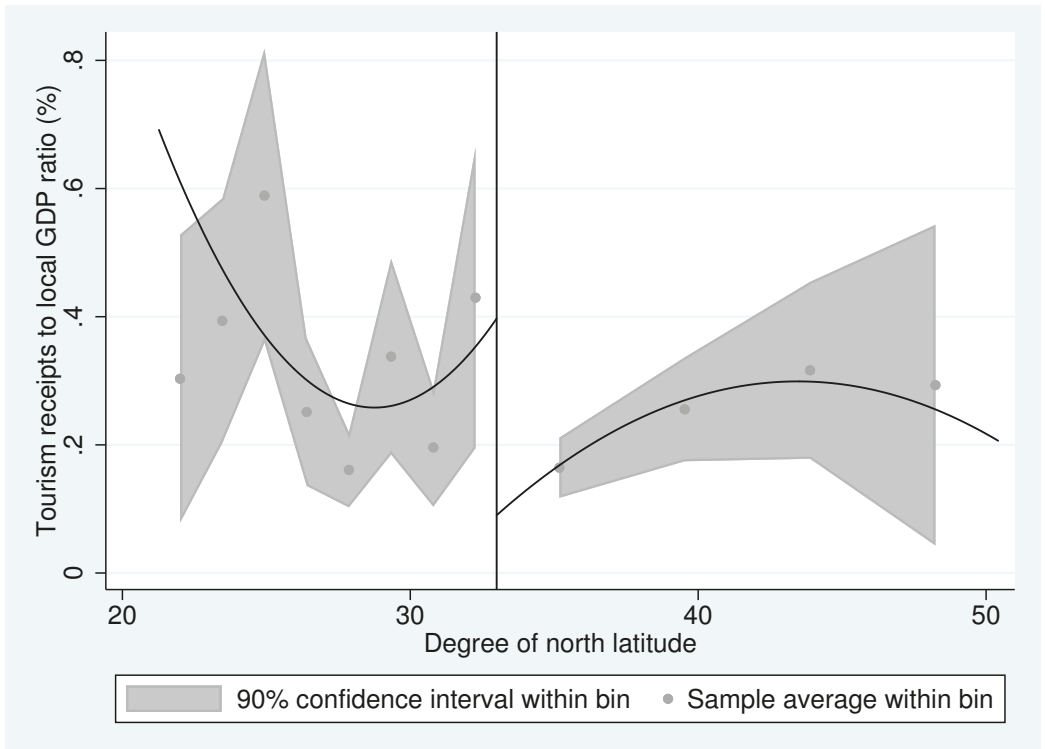

Figure 2. Annual average inbound tourism receipts-to-local GDP ratios of Chinese cities in different latitudes. Note: The gray points represent the annual average inbound tourism receipts-to-local GDP ratios across a set of cities grouped in bins according to the degrees of latitude. The gray shadowed area demonstrates the $90 \%$ confidence interval for each bin. The bins were constructed through a data-driven procedure based on the mean squared error (MSE)-optimal bandwidth selector. The vertical line in the middle of the figure indicates the position of latitude $33^{\circ} \mathrm{N}$. The plotted curves report the fitted values from a regression of the tourism receipts-to-local GDP ratio on a second-order polynomial in latitude, estimated separately on each side of the north-south boundary.

Figure 3 shows the relationship between the latitude and the ratio of inbound tourist arrivals to the local population. The distribution of the tourist arrivals-to-population ratio was similar to that of tourism revenue, as shown in Figure 2. It is especially notable that there is substantial discontinuity around the north-south boundary. Compared to the situation of $\mathrm{PM}_{10}$ demonstrated in Figure 1, we guess that tourist amount is negatively correlated with air pollution.

Besides the visual observation of the sudden drop of tourism around the north-south boundary, we also use a regression discontinuity design to examine the effects of the Huai River policy. The estimates rely on Equation (1), with the outcome variables of tourism receipts and tourist arrivals. As documented in the second and third rows of column (a) in Table 1, our baseline RD estimates show that Huai River Policy resulted in significant drops in tourism receipts and tourist arrivals at the $1 \%$ and $5 \%$ significance levels, respectively. The results are robust if we add additional covariates, or change the polynomial type and the bandwidth, as shown in columns (b) and (c) of Table 1. The finding that Huai River Policy had significant impacts on tourism generates a strong implication. Since this policy was designed only for winter-heating purpose, it has no direct link to tourism. Taking into account that we had already confirmed the crucial influence of the Huai River Policy on $\mathrm{PM}_{10}$ concentration, we can reasonably believe that the impact of the policy on tourism is through the channel of air pollution. 
This implies that a dummy variable, indicating whether a city is covered by the Huai River Policy, can work as the instrument variable for air pollution to help identify pollution's impacts on tourism.

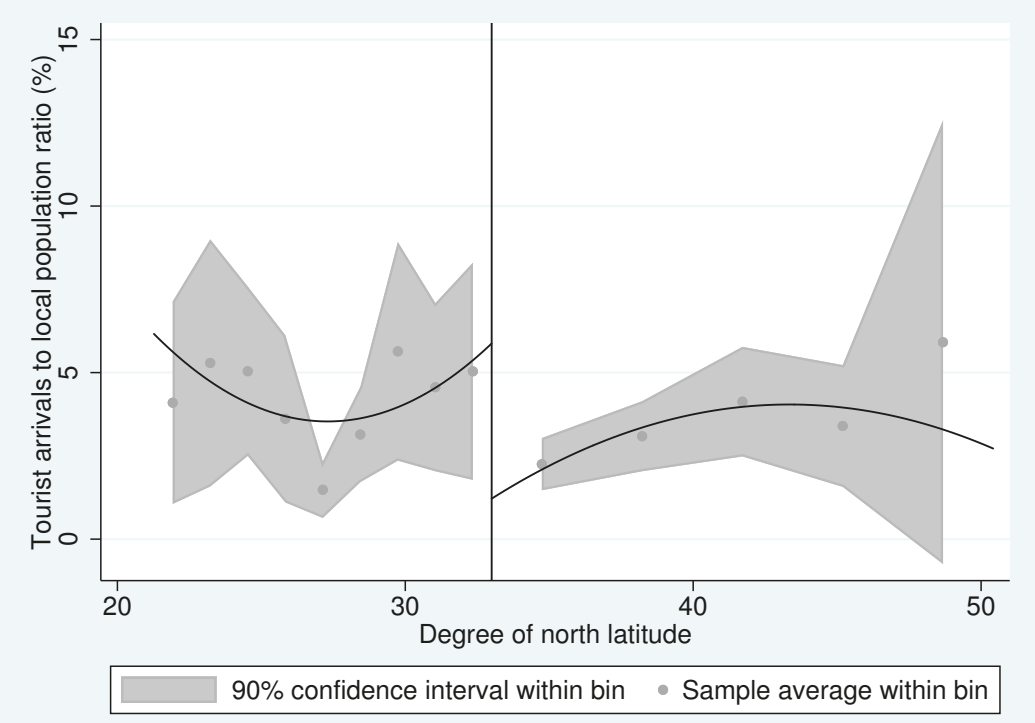

Figure 3. Annual average inbound tourist arrivals-to-local population ratios of Chinese cities in different latitudes. Note: The gray points represent the annual average inbound tourist arrivals-to-local population ratios across a set of cities grouped in bins according to the degrees of latitude. The gray shadowed area demonstrates the $90 \%$ confidence interval for each bin. The bins were constructed through a data-driven procedure based on the mean squared error (MSE)-optimal bandwidth selector. The vertical line in the middle of the figure indicates the position of latitude $33^{\circ} \mathrm{N}$. The plotted curves report the fitted values from a regression of tourist arrivals-to-local population ratio on a second-order polynomial in latitude, estimated separately on each side of the north-south boundary.

\section{Empirical Model and Data}

In this section, we explain the econometric model and the data used in our empirical analyses.

\subsection{Empirical Model}

In order to estimate the impact of air pollution on tourism development, a linear model is established as follows:

$$
\text { Tourism }_{i}=\beta_{0}+\beta_{1} P M 10_{i}+\theta^{\prime} X_{i}+\varepsilon_{i},
$$

where the dependent variable Tourism $_{i}$ is an indicator of tourism development in city $i$. We primarily consider Receipts ${ }_{i}$, the ratio of inbound tourism receipts to local GDP. We use this relative value of tourism revenue to GDP, rather than an absolute value of revenue volume because we want to measure the degree of tourism development in each city, rather than its scale. Besides the index of tourism revenue, later we will also investigate its extensive and intensive margins separately. The indicator for the extensive margin is Tourist $_{i}$, which is the number of inbound tourist arrivals as a ratio to local population. The indicator for the intensive margin is Expenditure $_{i}$, which is the average expenditure of each tourist. The core explanatory variable of interest in our analyses is the level of air pollution. We use $P M 10_{i}$, density of $\mathrm{PM}_{10}$ concentration, to measure air pollution. Ebenstein et al. [51] showed there was significant damage from $\mathrm{PM}_{10}$ concentrations in Chinese cities on the health of the residents. Furthermore, as one of the most important components of TSP (Total Suspended 
Particulates), $\mathrm{PM}_{10}$ substantially lowers the air visibility. Thus, $\mathrm{PM}_{10}$ is a crucial indicator for air pollution (In the robustness analysis section, we will additionally test the validity of our findings using another two indices: $A Q I_{i}$, the Air Quality Index; and $P M 2.5_{i}$, the density of $\left.\mathrm{PM}_{2.5}\right) . X_{i}$ is a vector of control variables including: the number of $5 \mathrm{~A}$ - and $4 \mathrm{~A}-$-rated scenic spots $\left(\right.$ Scenic $\left._{i}\right)$, the number of star-rated hotels $\left(\right.$ Hotel $\left._{i}\right)$, the density of the transportation infrastructure (Transport ${ }_{i}$ ), industrial structure $\left(\right.$ Structure $\left._{i}\right)$, government size (GovSize $\left.e_{i}\right)$, and the GDP per capita $\left(G D P p c_{i}\right) . \varepsilon_{i}$ represents the error term.

As discussed in the Introduction and Literature Review, air pollution is probably endogenous because tourism may have impacts on environmental quality. An estimate on the coefficient $\beta_{1}$ without dealing with endogeneity potentially introduces bias. To mitigate endogeneity, we use a 2SLS-IV (two-stage least squares-instrumental variable) approach based on the discontinuous distribution of air pollution and tourism in China, as already analyzed in Section 3. Previously, we have used RDD to confirm the significant impacts of the Huai River Policy on both pollution and tourism variables. Since the design purpose of the policy had nothing to do with the local tourism industry, the policy's impact on tourism should be indirect and works via some mediating variables. If the policy only influences tourism through its impacts on pollution, it is valid to treat Equation (1) as the first stage equation in a 2 SLS regression. To simplify, we employ a parametric version of Equation (1). Specifically, in the 2SLS our first stage regression is:

$$
P M 10_{i}=\gamma_{0}+\gamma_{1} \text { North }_{i}+\gamma_{2} \text { Latitude }_{i}+\gamma_{3} \text { Latitude }_{i}^{2}+u_{i},
$$

where $\mathrm{North}_{i}$ is a dummy variable indicating whether the city is located in northern China $(=1$ if in the north, and $=0$ otherwise); Latitude $_{i}$ is the degree of latitude; Latitude $e_{i}^{2}$ is the square of latitude; $u_{i}$ is error term. After Equation (3) is estimated, the fitted value of $\mathrm{PM}_{10}$ density is used to replace $P M 10_{i}$ in Equation (2). This constructs the second-stage regression. Similar 2SLS models, which utilize the nonlinear relationship between air pollution and latitude with the existence of the Huai River Policy, have been exploited in Chen et al. [50], Ebenstein et al. [51], and Huang and Lanz [52]. Chen et al. [50] and Ebenstein et al. [51] evaluated the impact of air pollution on health. Huang and Lanz [52] investigated its impacts on wage and house prices.

Table 2 gives detailed definitions of all the variables used in our regressions.

Table 2. List of variables used in the regressions.

\begin{tabular}{ll}
\hline Variable & Definition \\
\hline Dependent variables \\
\hline Receipts & Receipts from the inbound tourism industry, as a ratio to local GDP (\%) \\
\hline Tourist & Number of inbound tourist arrivals, as a ratio to the local population (\%) \\
\hline Expenditure & $\begin{array}{l}\text { Average expenditure of each inbound tourist (\$1000), equaling the total tourism receipts } \\
\text { divided by tourist arrivals }\end{array}$ \\
\hline Core explanatory variables of interest \\
\hline PM10 & $\begin{array}{l}\text { Density of PM } \\
\left(\mathrm{mg} / \mathrm{m}^{3}\right)\end{array}$ \\
\hline $\begin{array}{l}\text { AQI (used for } \\
\text { robustness check) }\end{array}$ & $\begin{array}{l}\text { Air quality index, calculated according to the Technical Regulation on Ambient Air } \\
\text { Quality Index }(\mathrm{HJ} \text { 633-2012) published by China's Ministry of Environmental Protection }\end{array}$ \\
\hline $\begin{array}{l}\text { PM2.5 (used for } \\
\text { robustness check) }\end{array}$ & $\begin{array}{l}\text { Density of PM } \mathrm{P}_{2.5} \text { (particulate matter smaller than } 2.5 \mu \mathrm{m} \text { ) concentration in the air } \\
\left(\mathrm{mg} / \mathrm{m}^{3}\right)\end{array}$ \\
\hline
\end{tabular}


Table 2. Cont.

\begin{tabular}{|c|c|}
\hline Variable & Definition \\
\hline \multicolumn{2}{|c|}{ Control variables } \\
\hline Scenic & $\begin{array}{l}\text { Number of } 5 \mathrm{~A} \text { - and } 4 \mathrm{~A} \text {-rated scenic spots, divided by the local population (since a } \\
5 \mathrm{~A}-\text { rated spot is usually considered to be much more attractive, one } 5 \mathrm{~A} \text { spot is regarded } \\
\text { as equal to three } 4 \mathrm{~A} \text { spots) }\end{array}$ \\
\hline Hotel & $\begin{array}{l}\text { Number of star-rated hotels, divided by the local population (we use the average value } \\
\text { during } 2000 \text { and } 2003 \text {, to deal with the concern that the number of hotels in the current } \\
\text { period is affected by contemporary tourism development) }\end{array}$ \\
\hline Transport & Density of transportation infrastructure, proxied by the road length $(\mathrm{km})$ per area $\left(\mathrm{km}^{2}\right)$ \\
\hline Structure & $\begin{array}{l}\text { Industrial structure, proxied by the ratio of the service sector GDP to the industrial } \\
\text { sector GDP }\end{array}$ \\
\hline GovSize & Government size, measured by the ratio of fiscal spending to local GDP \\
\hline$G D P p c$ & $\begin{array}{l}\text { Logarithm of GDP per capita (RMB, at the constant price in 2000) (we use the average } \\
\text { value during } 2000 \text { and } 2003 \text {, to deal with the concern that the overall economic growth in } \\
\text { the current period is affected by contemporary tourism development) }\end{array}$ \\
\hline \multicolumn{2}{|c|}{ Variables for the first stage regression in 2SLS } \\
\hline North & $\begin{array}{l}\text { Dummy variable indicating the city location ( }=1 \text { if the city is located in north China, } \\
=0 \text { otherwise) }\end{array}$ \\
\hline Latitude & Latitude of the city center \\
\hline
\end{tabular}

\subsection{Data}

We collect data for approximately 300 prefecture-level administrative districts in China (For convenience, we will refer to "cities" as including these administrative districts). This initial sample is highly representative since it covers around $90 \%$ of the area of China. The sample period spans over four years, between 2009 and 2012. We use the annual average over these four years to avoid disturbances at the business cycle frequency. We extract the data of $\mathrm{PM}_{10}$ density from a series of yearly published reports- "The Report on the State of the Environment of China". The reports, written by China's Ministry of Environmental Protection (MEP), provide official data about the environmental quality in different areas of China. The reason why we choose the period 2009-2012 is that MEP released a relatively complete $\mathrm{PM}_{10}$ dataset, which covers approximately 300 cities in China, during this four-year period. In the robustness checks, we will also use the measures of $A Q I$ and $\mathrm{PM}_{2.5}$ concentration to inspect our findings. $A Q I$ is calculated according to the method in the MEP's Technical Regulation on Ambient Air Quality Index (HJ 633-2012), using the data of $\mathrm{PM}_{10}, \mathrm{SO}_{2}$, and $\mathrm{NO}_{2}$ documented in MEP's report series. The data of $\mathrm{PM}_{2.5}$ is from NASA's Global Annual $\mathrm{PM}_{2.5}$ Grids data $[53,54]$. (Here, we clarify several important points about the $A Q I$ and $\mathrm{PM}_{2.5}$ indictors. (1) Following Huang and Lanz [52], we use the data of $\mathrm{PM}_{10}, \mathrm{SO}_{2}$, and $\mathrm{NO}_{2}$ to calculate the value of $A Q I$. Strictly speaking, we should also take into account the values of $\mathrm{CO}, \mathrm{O}_{3}$ and $\mathrm{PM}_{2.5}$, according to the standard of the MEP's Technical Regulation on Ambient Air Quality Index (HJ 633-2012). However, the Report on the State of the Environment of China only presents the data for the former three pollutants. Because of this data availability issue, the latter three pollutants are not considered in our calculations. The detailed index construction method is discussed in HJ 633-2012 and Huang and Lanz [52]. (2) The data provided by MEP is based on direct measurements in different local observation stations. Thus, MEP's data can accurately reflect the degree of air pollution of each city. The $\mathrm{PM}_{2.5}$ data provided by NASA comes from the remote sensing measurement of space satellites. The measurement error is relatively larger, compared to the data from local observation stations. Thus, our baseline regressions utilize MEP's data, while NASA's data is used for robustness checks. (3) In our sample, the Pearson correlation coefficient between $A Q I$ and $\mathrm{PM}_{10}$ is 0.986 , and the correlation between $\mathrm{PM}_{2.5}$ and $\mathrm{PM}_{10}$ is 0.178 . Given our sample size, $A Q I$ and $\mathrm{PM}_{2.5}$ are both positively correlated 
with $\mathrm{PM}_{10}$ at the $1 \%$ statistical significance level. Our later robustness checks will also make it clear that our empirical findings hold no matter which air pollution index is used. In other words, we have no concerns about the selection of the pollution indicators because our analyses are not sensitive to that.) The latitude data is from NGCC, the National Geomatics Center of China. The variables of tourism and other control variables are from the China Statistical Yearbook for Regional Economy in the corresponding years.

There are several special cities within our sample. We regard them as outliers. For example, every year, a very large volume of travelers from Hong Kong and Macao visit Shenzhen and Zhuhai cities for the purposes of shopping, and visiting relatives or friends, as these cities are mutually adjacent. A similar phenomenon also occurs in some border cities. In Chinese inbound tourism statistics, those travelers who usually arrive and leave within one day are all recorded as inbound tourists. Obviously, those visitors are different from "inbound tourists" in a general sense, and, thus, should be cleaned out from our sample. To get rid of the outliers, we delete cities with values of Receipts ${ }_{i}$ Tourist $_{i}$, or Expenditure $_{i}$ within the top $5 \%$ of the initial sample. Finally, we obtain a sample of 274 cities, covering over $80 \%$ of the area of China. Table 3 gives the summary statistics of the variables.

Table 3. Summary statistics.

\begin{tabular}{lcccc}
\hline Variable & Mean & SD & Min & Max \\
\hline Receipts & 0.281 & 0.369 & 0 & 1.814 \\
Tourist & 3.706 & 5.263 & 0.003 & 30.798 \\
Expenditure & 0.383 & 0.179 & 0.062 & 0.948 \\
\hline PM10 & 0.079 & 0.026 & 0.026 & 0.276 \\
AQI & 0.064 & 0.013 & 0.028 & 0.162 \\
PM2.5 & 0.034 & 0.016 & 0.003 & 0.073 \\
\hline Scenic & 4.396 & 4.199 & 0 & 25 \\
Hotel & 0.071 & 0.067 & 0.005 & 0.412 \\
Transport & 0.912 & 0.484 & 0.029 & 2.054 \\
Structure & 0.761 & 0.347 & 0.125 & 2.692 \\
GovSize & 0.199 & 0.146 & 0.048 & 1.112 \\
GDPpc & 8.797 & 0.613 & 7.329 & 10.721 \\
\hline North & 0.496 & 0.501 & 0 & 1 \\
Latitude & 33.433 & 6.757 & 21.27 & 50.42 \\
\hline
\end{tabular}

\section{Results}

In this section, we report our estimation results. Section 5.1 discusses the estimated impact of air pollution on inbound tourism receipts. Section 5.2 discusses the impact on tourist arrivals. In Section 5.3, we evaluate the effect on expenditure per tourist. We find that air pollution significantly reduces tourism revenue and tourist amount, but it positively correlates with the expenditure per tourist. Our estimates indicate that the deprivation of air quality has different effects on the extensive and intensive margins of tourism: pollution incurs some potential tourists to give up travel plans, but it raises the expenditure of tourists who ultimately arrive at China. The overall effect of air pollution on Chinese inbound tourism development is detrimental.

\subsection{The Impact of Air Pollution on Tourism Receipts}

In order to evaluate air pollution's impact on tourism revenue, the inbound tourism receipts-tolocal GDP ratio $\left(\right.$ Receipts $_{i}$ ) works as the dependent variable in Equation (2). For the purpose of comparison, we first report the OLS estimate in column (a) of Table 4. The result shows a significant negative effect of $\mathrm{PM}_{10}$ concentration on tourism revenue. Regarding the control variables, we find that the amount of scenic spots $\left(\right.$ Scenic $\left._{i}\right)$, amount of hotels $\left(\right.$ Hotel $\left._{i}\right)$, road density $\left(\right.$ Transport $\left._{i}\right)$, and the relative size of the service sector $\left(\right.$ Structure $_{i}$ ) all have significant positive correlations with tourism receipts. The estimated coefficients of these control variables are consistent with previous literature. 
In addition, we detect a positive correlation between the government size (GovSize $\left.e_{i}\right)$ and the tourism revenue, probably because Chinese local governments play crucial roles in the economic development and the transformation of industrial structure. The coefficient of GDP per capita $\left(G D P p c_{i}\right)$ is positive, but not statistically significant.

Since air pollution is possibly endogenous, the OLS estimate reported in column (a) may have considerable bias. In order to mitigate the endogeneity, we now exploit the 2SLS-IV approach. The estimates and the associated test statistics from 2SLS are displayed in column (b) of Table 4. The Durbin $\chi^{2}$ statistic and the $\mathrm{Wu}-\mathrm{Hausman} F$ statistic are 7.005 and 6.952, respectively. These two statistics are both significant at the $1 \%$ level, rejecting the null hypothesis that $\mathrm{PM}_{10}$ is exogenous. This endorses the necessity for using the IV approach to mitigate endogeneity. The Hansen $J$ statistic is 0.742 , which does not reject the joint null hypothesis that our instruments are valid instruments, i.e., uncorrelated with the error term, and that the excluded instruments from the estimated equation are correctly excluded. This indicates that our selection of instrument variables is suitable. The estimated coefficient shows that, after controlling for the endogeneity, air pollution indeed significantly reduces inbound tourism receipts. It is especially notable that the coefficient of $\mathrm{PM}_{10}$ in column (b) is -4.477 . Its magnitude is substantially larger than that of -1.408 , the estimated coefficient in column (a). This makes it clear that, if we fail to consider endogeneity, air pollution's damage on China's inbound tourism would be significantly underestimated.

Our finding is not only statistically significant, but also economically significant. According to our 2SLS estimate, if $\mathrm{PM}_{10}$ density increases by $0.1 \mathrm{mg} / \mathrm{m}^{3}$, the tourism receipts-to-local GDP ratio will decline by 0.45 percentage points. In our sample, the average GDP of the cities is around 126 billion $\mathrm{RMB}$, and a decline of 0.45 percentage points means a reduction of 567 million RMB (approximately 80 million USD). This is a huge loss.

Table 4. Impact of air pollution on tourism receipts.

\begin{tabular}{|c|c|c|c|c|c|c|}
\hline \multirow{3}{*}{ Variable } & \multirow[b]{2}{*}{ OLS } & \multirow[b]{2}{*}{ IV } & \multicolumn{4}{|c|}{ Robustness Check } \\
\hline & & & $\begin{array}{l}\text { IV } \\
\text { (LIML) }\end{array}$ & $\begin{array}{l}\text { IV } \\
\text { (GMM) }\end{array}$ & $\begin{array}{l}\text { IV } \\
\text { (Use AQI) }\end{array}$ & $\begin{array}{l}\text { IV } \\
\text { (Use } \mathrm{PM}_{2.5} \text { ) }\end{array}$ \\
\hline & (a) & (b) & (c) & (d) & (e) & (f) \\
\hline PM10 & $-1.408 *$ & $-4.477^{* *}$ & $-4.504^{* *}$ & $-3.995^{* *}$ & & \\
\hline$A Q I$ & & & & & $-8.556^{* *}$ & \\
\hline PM2.5 & & & & & & $-29.686 * *$ \\
\hline Scenic & $0.019^{* * *}$ & $0.019^{* * *}$ & $0.019^{* * *}$ & $0.020^{* * *}$ & $0.019^{* * *}$ & $0.024^{* * *}$ \\
\hline Hotel & $2.089 * * *$ & $1.826^{* * *}$ & $1.823^{* * *}$ & $1.845^{* * *}$ & $1.795^{* * *}$ & 0.713 \\
\hline Transport & $0.091 *$ & 0.114 ** & $0.114^{* *}$ & $0.116^{* *}$ & $0.107^{* *}$ & 0.780 ** \\
\hline Structure & $0.160^{* *}$ & $0.219^{* * *}$ & $0.220^{* * *}$ & $0.208^{* * *}$ & $0.220^{* * *}$ & $0.154 *$ \\
\hline GovSize & $0.560 * *$ & $0.635^{* *}$ & $0.635^{* *}$ & $0.641 * *$ & $0.599 * *$ & 0.314 \\
\hline$G D P p c$ & 0.061 & 0.105 & 0.105 & 0.104 & 0.102 & 0.121 \\
\hline Constant & -0.691 & -0.899 & -0.901 & $-0.932 *$ & -0.668 & -0.832 \\
\hline Observations & 274 & 274 & 274 & 274 & 274 & 274 \\
\hline $\operatorname{Adj}-R^{2}$ & 0.322 & 0.28 & 0.28 & 0.292 & 0.283 & -0.194 \\
\hline Durbin $\chi^{2}$ stat. & - & $7.005^{* * *}$ & - & - & $7.116^{* * *}$ & $8.566^{* * *}$ \\
\hline Wu-Hausman F stat. & - & $6.952 * * *$ & - & - & $7.006^{* * *}$ & $8.552 * * *$ \\
\hline Hansen $J$ stat. & - & 0.742 & 0.741 & 0.742 & 0.486 & 0.601 \\
\hline
\end{tabular}

To validate our finding, we conduct several robustness checks for our 2SLS estimate. In columns (c) and (d), we report the results using LIML-IV (Limited Information Maximum Likelihood-IV) and GMM-IV (Generalized Method of Moments-IV), respectively. We find that the coefficients demonstrated in column (b) do not have large changes. In other words, our results are reliable. Furthermore, we address the concern that $\mathrm{PM}_{10}$ is perhaps not the most crucial indicator for air pollution, when the tourists make their decisions. We reestimate Equation (2) by using another two 
indices of air pollution. In column (e), we use $A Q I$; in column (f), we use $\mathrm{PM}_{2.5}$ concentration. Our previous finding still holds: air pollution significantly decreases tourism revenue.

The variation of tourism receipts may be caused by variations in two dimensions: the extensive margin, namely, the number of tourists; and the intensive margin, namely, the average expenditure of each traveler. In the next two subsections, we analyze these two margins.

\subsection{The Impact of Air Pollution on Tourist Arrivals}

Now, we investigate the impact of air pollution on the number of inbound travelers. We use the ratio of inbound tourist arrivals to the local population $\left(\right.$ Tourist $\left._{i}\right)$ as the dependent variable, to estimate Equation (2). The estimate results in Table 5 show a significant negative effect of air pollution on the tourist amount. The coefficient of $\mathrm{PM}_{10}$ reported in column (b) indicates that the tourist arrivals-to-local population ratio will reduce by 4.6 percentage points, if the $\mathrm{PM}_{10}$ density rises by $0.1 \mathrm{mg} / \mathrm{m}^{3}$. Among our sample cities, the average population is 4.1 million. Thus, a decline of 4.6 percentage points means a reduction of 0.19 million tourists. In columns (c)-(f), we demonstrate the results of the robustness checks. Clearly, we have a robust finding: air pollution incurs many potential tourists to give up their plans to visit China.

If we incorrectly ignore the endogeneity of air pollution, the damage would be substantially underestimated. Column (a) displays the result of the OLS estimate, which only reports a value of -20.776 for the coefficient of $\mathrm{PM}_{10}$. This value is less than half of -46.066 , the estimated coefficient by the 2SLS-IV approach documented in column (b).

Table 5. Impact of air pollution on tourist arrivals.

\begin{tabular}{|c|c|c|c|c|c|c|}
\hline \multirow{3}{*}{ Variable } & \multirow[b]{2}{*}{ OLS } & \multirow[b]{2}{*}{ IV } & \multicolumn{4}{|c|}{ Robustness check } \\
\hline & & & $\begin{array}{l}\text { IV } \\
\text { (LIML) }\end{array}$ & $\begin{array}{l}\text { IV } \\
\text { (GMM) }\end{array}$ & $\begin{array}{l}\text { IV } \\
\text { (Use AQI) }\end{array}$ & $\begin{array}{l}\text { IV } \\
\text { (Use } \mathrm{PM}_{2.5} \text { ) }\end{array}$ \\
\hline & (a) & (b) & (c) & (d) & (e) & (f) \\
\hline PM10 & $-20.776^{* * *}$ & $-46.066^{*}$ & -46.094 * & $-44.488^{* *}$ & & \\
\hline$A Q I$ & & & & & $-86.828 *$ & \\
\hline$P \widetilde{M} 2.5$ & & & & & & $-302.464 *$ \\
\hline Scenic & $0.278^{* * *}$ & $0.280 * * *$ & $0.280^{* * *}$ & $0.277^{* * *}$ & $0.280^{* * *}$ & $0.328^{* * *}$ \\
\hline Hotel & $35.860 * * *$ & $33.688^{* * *}$ & $33.686^{* * *}$ & $33.822 * * *$ & $33.434^{* * *}$ & 22.388 * \\
\hline Transport & $1.713^{* *}$ & $1.895^{* * *}$ & $1.895^{* * *}$ & $1.960 * * *$ & $1.821^{* * *}$ & $8.680 *$ \\
\hline Structure & $1.694 * *$ & $2.180 * *$ & $2.181 * *$ & $2.161 * *$ & $2.172 * *$ & 1.503 * \\
\hline GovSize & $4.179 * *$ & 4.800 ** & $4.800^{* *}$ & $4.806^{* *}$ & 4.424 ** & 1.522 \\
\hline$G D P p c$ & $2.013 * *$ & $2.378 * *$ & $2.378^{* *}$ & $2.358 * *$ & $2.343 * *$ & $2.539 * *$ \\
\hline Constant & $-19.809^{* * *}$ & $-21.526^{* * *}$ & $-21.528^{* * *}$ & $-21.530^{* * *}$ & $-19.137^{* *}$ & $-20.809^{* *}$ \\
\hline Observations & 274 & 274 & 274 & 274 & 274 & 274 \\
\hline $\operatorname{Adj}-R^{2}$ & 0.493 & 0.479 & 0.479 & 0.481 & 0.476 & 0.227 \\
\hline Durbin $\chi^{2}$ stat. & - & $3.132 *$ & - & - & 3.535 * & $5.742 * *$ \\
\hline Wu-Hausman F stat. & - & $3.064 *$ & - & - & 3.464 * & $5.672 * *$ \\
\hline Hansen $J$ stat. & - & 0.047 & 0.047 & 0.047 & 0.05 & 0.254 \\
\hline
\end{tabular}

Statistical significance: ${ }^{*} p<0.1 ;{ }^{* *} p<0.05 ;{ }^{* * *} p<0.01$.

\subsection{The Impact of Air Pollution on Expenditure per Tourist}

In this subsection, we consider whether air pollution affects the expenditure of a typical tourist. The average expenditure of each tourist (Expenditure $e_{i}$ ) is used as dependent variable in Equation (2). Previously, when we estimated the influence of air pollution on tourism receipts (Receipts $s_{i}$ ) and tourist amount (Tourist $t_{i}$ ), we used the instrumental variables regarding the discontinuous distribution of $\mathrm{PM}_{10}$ to mitigate endogeneity. This time, however, when we regress Expenditure ${ }_{i}$ on $P M 10_{i}$, we find that the statistic tests do not reject the null hypothesis of exogeneity. This enables us to use OLS directly. Our estimates are reported in Table 6. Our results show a strong positive correlation 
between pollution and tourism expenditure per capita. According to the coefficient in column (a), if the $\mathrm{PM}_{10}$ concentration rises by $0.1 \mathrm{mg} / \mathrm{m}^{3}$, the average expenditure per tourist will expand by 77.1 USD. The positive impact of air pollution on tourism expenditure does not necessarily imply that the tourists are willing to consume more in cities with more severe pollution. Instead, the reason is plausibly unpleasant: for example, air pollution may encumber the transportation system such that tourists need to increase transportation costs; additionally, tourists may have additional health care expenses because pollution increases the health risk. Therefore, in the long term, the positive impact of air pollution on tourism expenditure probably hurts the development of tourism by lowering tourists' experiences and the reputations of travel destinations. In columns (b) and (c), we make estimations by using $A Q I$ and $\mathrm{PM}_{2.5}$ as dependent variables, respectively. The results confirm the finding in column (a). Among the control variables, the hotel amount $\left(\mathrm{Hotel}_{i}\right)$ has a significant negative correlation to tourism expenditure, perhaps because a larger number of hotels indicates strong competition and lower average prices in the hotel industry; the coefficient of the relative share of service sector $\left(\right.$ Structure $_{i}$ ) is significantly positive, as tourists' expenditure is majorly aimed towards the consumption on services, and not of industrial products; local GDP per capita $\left(G D P p c_{i}\right)$ has a significant positive coefficient, since the price level is usually higher in a city with a higher GDP per capita. The estimated coefficients of other control variables, Scenic ${ }_{i}$, Transport ${ }_{i}$, GovSize $_{i}$, are not statistically significant.

Our empirical analyses have found that air pollution reduces tourist arrivals, but it increases the average expenditure per tourist. The relative importances of these two effects determine the net effect of air pollution on tourism receipts. We can illustrate this via a simple example. Considering an "average" city with the initial Tourist $t_{i}$ value being at its mean level, 0.03706 , and Expenditure ${ }_{i}$ being at its mean level, $383 \mathrm{USD}$, if $\mathrm{PM}_{10}$ increases by $0.01 \mathrm{mg} / \mathrm{m}^{3}$, according to the estimated coefficients in column (b) of Tables 5 and 6, Tourist ${ }_{i}$ will decline by 0.0046 - a reduction of $12.4 \%$, and Expenditure $i$ will rise by 7.71 USD-an increase of $2 \%$. Obviously, the relative magnitude of air pollution's negative impact on tourist arrivals exceeds that of pollution's positive impact on the tourism expenditure per capita. In consequence, the aggregate effect of pollution on tourism revenue is negative.

Table 6. Impact of air pollution on expenditure per tourist.

\begin{tabular}{|c|c|c|c|}
\hline \multirow{3}{*}{ Variable } & \multirow[b]{2}{*}{ OLS } & \multicolumn{2}{|c|}{ Robustness Check } \\
\hline & & $\begin{array}{l}\text { OLS } \\
\text { (Use AQI) }\end{array}$ & $\begin{array}{l}\text { OLS } \\
\left(\text { Use } \mathrm{PM}_{2.5} \text { ) }\right.\end{array}$ \\
\hline & (a) & (b) & (c) \\
\hline PM10 & $0.771 *$ & & \\
\hline$A Q I$ & & $1.579 * *$ & \\
\hline PM2.5 & & & $2.100 *$ \\
\hline Scenic & 0.003 & 0.003 & 0.003 \\
\hline Hotel & $-0.453^{* *}$ & $-0.443^{* *}$ & $-0.413^{* *}$ \\
\hline Transport & 0.005 & 0.006 & -0.038 \\
\hline Structure & $0.063 *$ & $0.062 *$ & 0.076 ** \\
\hline GovSize & 0.08 & 0.085 & 0.114 \\
\hline$G D P p c$ & $0.159^{* * *}$ & $0.158^{* * *}$ & $0.164^{* * *}$ \\
\hline Constant & $-1.125^{* * *}$ & $-1.164^{* * *}$ & $-1.160 * * *$ \\
\hline Observations & 274 & 274 & 274 \\
\hline $\operatorname{Adj}-R^{2}$ & 0.243 & 0.244 & 0.245 \\
\hline
\end{tabular}

\section{Discussion}

This study quantifies the influence of air pollution on the Chinese inbound tourism industry. It is found that air pollution significantly reduces tourism revenue and the number of international tourist arrivals, which is qualitatively consistent with the previous study results such as Deng et al. [34], Zhou et al. [36], Xu and Reed [38]. Some potential tourists might give up their travel 
plans to China when they are aware of China's haze problem. It is suggested that tourism policy makers should roll out more environmental policies for tackling air pollution in China. In addition, they should make more efforts to promote tourism and culture in China worldwide to overcome travelers' fear of air pollution. In addition, due to the fact that air pollution is closely related to climate change on a global scale $[55,56]$, air pollution in China could be a potential consequence of global climate change issue. Therefore, the findings of this study tend to raise public awareness of climate change and call for more sustainable tourism practices to preserve a healthy environment.

While the findings in this study emphasize the importance of good air quality for sustainable tourism, which is claimed by the existing literature, this study provides quantitatively novel insights. This study provides supplementary inputs to the view of Holden [57] that the tourism-environment relationship should be understood as being reciprocal. It is noted that air quality and tourism development have simultaneous impacts on each other. The existence of this bilateral causality results in the endogeneity of the regressor, which impedes a precise estimate for the impact of air pollution on tourism. If we fail to control for this issue, the impact may be either underestimated or overestimated. In this article, we take advantage of the quasi-experiment derived by the coal-based winter indoor heating policy in northern Chinese cities, to use the regression discontinuity design to quantify the influence of air pollution on Chinese inbound tourism. By analyzing data from 274 Chinese cities during the period of 2009-2012, it is found that an increase of $\mathrm{PM}_{10}$ by $0.1 \mathrm{mg} / \mathrm{m}^{3}$ will cause a decline of the tourism receipts-to-local GDP ratio by 0.45 percentage points, and a shrinkage of the tourist arrivals-to-local population ratio by 4.6 percentage points. Failing to consider the endogeneity results in substantial underestimates: the OLS estimates merely report a reduction of 0.14 percentage points in tourism receipts, and 2.1 percentage points in tourism arrivals, respectively.

Additionally, it is interesting to find that air pollution increases the international tourists' average expenditure, which has not been reported in prior studies. The potential reason for this might be that tourists who ultimately make their decision to visit China are likely to have longer trips because haze impedes transportation. Based on retail therapy, it is also possible that travelers tend to make purchases to lessen their negative emotions (e.g., depression, anxiety) that are evoked by the severe haze-fog [58].

\section{Conclusions, Limitations and Future Research}

In conclusion, the overall effect of air pollution on Chinese inbound tourism development is detrimental. This study highlights the importance of good air quality for sustainable tourism, and demonstrates that the magnitude of regression coefficients is plausibly much larger than what has been estimated before.

Like any other studies, this study is bound by certain limitations. First, this study does not capture the air pollution trends in the most recent years, since the $\mathrm{PM}_{10}$ data for a wide set of Chinese cities released so far only covers the period from 2009 to 2012 . The work could be improved if more data becomes available in the future. Second, while this study focuses on air pollution, it should be considered that other types of pollution (e.g., water pollution, noise pollution) might also affect tourism. If the alternative types of pollution could be measured precisely at the city level, a comprehensive evaluation on the impact of pollution on tourism would be promising.

Future research may explore the mechanisms underlying the relationship between air pollution and tourism expenditure at the micro-level. In light of the study of Wang et al. [29], who examined the effect of air pollution in the place of origin on outbound tourism demand by utilizing transaction data from a leading online travel agent (OTA) in China, it is also interesting to verify their results by using the data derived from MEP. Additionally, future studies could examine the role of China's air pollution control policies in the relationship between environment and tourism industry. The insights of this study can also be extended to assess the circumstances in other countries, especially those densely populated developing countries like India, Indonesia and Pakistan. 
Author Contributions: Conceptualization and Funding Acquisition, D.D. and X.X.; Methodology, Data Curation, Formal Analysis, and Original Draft Preparation, D.D.; Literature Review, and Review and Editing, X.X.; Software, Validation, and Supervision, Y.F.W.

Funding: This research was funded by the Fundamental Research Funds for the Central Universities (Grant Nos. JBK1801039 and JBK1809054).

Acknowledgments: The authors are grateful to the editors and three anonymous referees for their comments and suggestions.

Conflicts of Interest: The authors declare no conflict of interest.

\section{References}

1. Liu, Z. Sustainable Tourism Development: A Critique. J. Sustain. Tour. 2003, 11, 459-475. [CrossRef]

2. Ahmad, F.; Draz, U.M.; Su, L.; Ozturk, I.; Rauf, A. Tourism and Environmental Pollution: Evidence from the One Belt One Road Provinces of Western China. Sustainability 2018, 10, 3520. [CrossRef]

3. Mutinda, R.; Mayaka, M. Application of destination choice model: Factors influencing domestic tourists destination choice among residents of Nairobi, Kenya. Tour. Manag. 2012, 33, 1593-1597. [CrossRef]

4. Zhang, A.; Zhong, L.; Xu, Y.; Wang, H.; Dang, L. Tourists' Perception of Haze Pollution and the Potential Impacts on Travel: Reshaping the Features of Tourism Seasonality in Beijing, China. Sustainability 2015, 7, 2397-2414. [CrossRef]

5. Becken, S.; Wilson, J. The impacts of weather on tourist travel. Tour. Geogr. 2013, 15, 620-639. [CrossRef]

6. Kirillova, K.; Fu, X.; Lehto, X.; Cai, L. What makes a destination beautiful? Dimensions of tourist aesthetic judgment. Tour. Manag. 2014, 42, 282-293. [CrossRef]

7. World Health Organization. Ambient Air Pollution: Health Impacts. 2019. Available online: https: //www.who.int/airpollution/ambient/health-impacts/en/ (accessed on 1 March 2019).

8. Melamed, M.L.; Schmale, J.; von Schneidemesser, E. Sustainable policy-Key considerations for air quality and climate change. Curr. Opin. Environ. Sustain. 2016, 23, 85-91. [CrossRef]

9. AirVisual. World Most Polluted Cities $2018\left(\mathrm{PM}_{2.5}\right)$. 2019. Available online: https:/ /www.airvisual.com/ world-most-polluted-cities (accessed on 1 March 2019).

10. Reuters. India's Polluted Air Claimed 1.24 Million Lives in 2017: Study. 2018. Available online: https: / / www.reuters.com/article/us-india-pollution-lancet/indias-polluted-air-claimed-1-24-m illion-lives-in-2017-study-idUSKBN1O51T8 (accessed on 1 March 2019).

11. Parklin, B. Toxic Smog Threatens to Suffocate India's Tourism Industry. Financial Times, 18 January 2019.

12. Khan, M.Z. The Growing Problem of Air Pollution in Pakistan. 2017. Available online: https://thewire.in/e nvironment/growing-problem-pollution-pakistan (accessed on 1 March 2019).

13. Li, M.; Zhang, L. Haze in China: Current and future challenges. Environ. Pollut. 2014, 189, 85-86. [CrossRef]

14. Wall Street Journal. Pollution Halves Visitors to Beijing. 2013. Available online: https://blogs.wsj.com/chin arealtime/2013/10/31/beijing-air-pollution-drives-50-drop-in-visitors/ (accessed on 1 March 2019).

15. Cheng, S. Inbound Tourism Still Rising. 2018. Available online: http://www.chinadaily.com.cn/a/201805 /23/WS5b04bdc4a3103f6866ee9ff2.html (accessed on 1 March 2019).

16. Almond, D.; Chen, Y.; Greenstone, M.; Li, H. Winter Heating or Clean Air? Unintended Impacts of China's Huai River Policy. Am. Econ. Rev. 2009, 99, 184-190. [CrossRef]

17. Lee, C.C.; Chang, C.P. Tourism development and economic growth: A closer look at panels. Tour. Manag. 2008, 29, 180-192. [CrossRef]

18. Oh, C.O. The contribution of tourism development to economic growth in the Korean economy. Tour. Manag. 2005, 26, 39-44. [CrossRef]

19. Akama, J.S.; Kieti, D. Tourism and Socio-economic Development in Developing Countries: A Case Study of Mombasa Resort in Kenya. J. Sustain. Tour. 2007, 15, 735-748. [CrossRef]

20. Durbarry, R. Tourism and Economic Growth: The Case of Mauritius. Tour. Econ. 2004, 10, 389-401. [CrossRef]

21. Gössling, S.; Hall, C.M. Uncertainties in Predicting Tourist Flows Under Scenarios of Climate Change. Clim. Chang. 2006, 79, 163-173. [CrossRef]

22. Kavallinis, I.; Pizam, A. The Environmental Impacts of Tourism-Whose Responsibility Is It Anyway? The Case Study of Mykonos. J. Travel Res. 1994, 33, 26-32. [CrossRef] 
23. Kuo, N.W.; Chen, P.H. Quantifying energy use, carbon dioxide emission, and other environmental loads from island tourism based on a life cycle assessment approach. J. Clean. Prod. 2009, 17, 1324-1330. [CrossRef]

24. Saenz-de Miera, O.; Rosselló, J. Modeling tourism impacts on air pollution: The case study of PM10 in Mallorca. Tour. Manag. 2014, 40, 273-281. [CrossRef]

25. Eckhardt, S.; Hermansen, O.; Grythe, H.; Fiebig, M.; Stebel, K.; Cassiani, M.; Baecklund, A.; Stohl, A. The influence of cruise ship emissions on air pollution in Svalbard-A harbinger of a more polluted Arctic? Atmos. Chem. Phys. 2013, 13, 8401-8409. [CrossRef]

26. Fraj, E.; Matute, J.; Melero, I. Environmental strategies and organizational competitiveness in the hotel industry: The role of learning and innovation as determinants of environmental success. Tour. Manag. 2015, 46, 30-42. [CrossRef]

27. Lenzen, M.; Sun, Y.Y.; Faturay, F.; Ting, Y.P.; Geschke, A.; Malik, A. The carbon footprint of global tourism. Nat. Clim. Chang. 2018, 8, 522-528. [CrossRef]

28. Sajjad, F.; Noreen, U.; Zaman, K. Climate change and air pollution jointly creating nightmare for tourism industry. Environ. Sci. Pollut. Res. 2014, 21, 12403-12418. [CrossRef] [PubMed]

29. Wang, L.; Fang, B.; Law, R. Effect of air quality in the place of origin on outbound tourism demand: Disposable income as a moderator. Tour. Manag. 2018, 68, 152-161. [CrossRef]

30. Anaman, K.A.; Looi, C.N. Economic Impact of Haze-Related Air Pollution on the Tourism Industry in Brunei Darussalam. Econ. Anal. Policy 2000, 30, 133-143. [CrossRef]

31. BBC News. China Pollution: First Ever Red Alert in Effect in Beijing. 2015. Available online: https: //www.bbc.com/news/world-asia-china-35026363 (accessed on 1 March 2019).

32. Becken, S.; Jin, X.; Zhang, C.; Gao, J. Urban air pollution in China: destination image and risk perceptions. J. Sustain. Tour. 2017, 25, 130-147. [CrossRef]

33. Peng, J.; Xiao, H. How does smog influence domestic tourism in China? A case study of Beijing. Asia Pac. J. Tour. Res. 2018, 23, 1115-1128. [CrossRef]

34. Deng, T.; Li, X.; Ma, M. Evaluating impact of air pollution on China's inbound tourism industry: A spatial econometric approach. Asia Pac. J. Tour. Res. 2017, 22, 771-780. [CrossRef]

35. Xu, X.; Reed, M. Perceived pollution and inbound tourism in China. Tour. Manag. Perspect. 2017, 21, $109-112$. [CrossRef]

36. Zhou, B.; Qu, H.; Du, X.; Yang, B.; Liu, F. Air Quality and Inbound Tourism in China. Tour. Anal. 2018, 23, 159-164. [CrossRef]

37. Chen, C.M.; Lin, Y.L.; Hsu, C.L. Does air pollution drive away tourists? A case study of the Sun Moon Lake National Scenic Area, Taiwan. Transp. Res. Part D Transp. Environ. 2017, 53, 398-402. [CrossRef]

38. Xu, X.; Reed, M. Perceived pollution and inbound tourism for Shanghai: A panel VAR approach. Curr. Issues Tour. 2019, 22, 601-614. [CrossRef]

39. Belsoy, J.; Korir, J.; Yego, J. Environmental Impacts of Tourism in Protected Areas. J. Environ. Earth Sci. 2012, 2, 64-73.

40. Azam, M.; Alam, M.M.; Hafeez, M.H. Effect of tourism on environmental pollution: Further evidence from Malaysia, Singapore and Thailand. J. Clean. Prod. 2018, 190, 330-338. [CrossRef]

41. Katircioğlu, S.T. International tourism, energy consumption, and environmental pollution: The case of Turkey. Renew. Sustain. Energy Rev. 2014, 36, 180-187. [CrossRef]

42. Katircioğlu, S.T.; Feridun, M.; Kilinc, C. Estimating tourism-induced energy consumption and $\mathrm{CO}_{2}$ emissions: The case of Cyprus. Renew. Sustain. Energy Rev. 2014, 29, 634-640. [CrossRef]

43. Wang, M.C.; Wang, C.S. Tourism, the environment, and energy policies. Tour. Econ. 2018, 24, 821-838. [CrossRef]

44. Lu, C.; Pang, M.; Yang, J.; Wang, D. Research on Interactions between the Economy and Environment in Tourism Development: Case of Qingyang, China. Sustainability 2018, 10, 4033. [CrossRef]

45. Tian, H.; Gao, J.; Hao, J.; Lu, L.; Zhu, C.; Qiu, P. Atmospheric pollution problems and control proposals associated with solid waste management in China: A review. J. Hazard. Mater. 2013, 252-253, 142-154. [CrossRef]

46. Dogan, E.; Aslan, A. Exploring the relationship among $\mathrm{CO}_{2}$ emissions, real GDP, energy consumption and tourism in the EU and candidate countries: Evidence from panel models robust to heterogeneity and cross-sectional dependence. Renew. Sustain. Energy Rev. 2017, 77, 239-245. [CrossRef] 
47. Lee, J.W.; Brahmasrene, T. Investigating the influence of tourism on economic growth and carbon emissions: Evidence from panel analysis of the European Union. Tour. Manag. 2013, 38, 69-76. [CrossRef]

48. Katircioğlu, S.T. Testing the tourism-induced EKC hypothesis: The case of Singapore. Econ. Model. 2014, 41, 383-391. [CrossRef]

49. Zhang, L.; Gao, J. Exploring the effects of international tourism on China's economic growth, energy consumption and environmental pollution: Evidence from a regional panel analysis. Renew. Sustain. Energy Rev. 2016, 53, 225-234. [CrossRef]

50. Chen, Y.; Ebenstein, A.; Greenstone, M.; Li, H. Evidence on the impact of sustained exposure to air pollution on life expectancy from China's Huai River policy. Proc. Natl. Acad. Sci. USA 2013, 110, 12936-12941. [CrossRef] [PubMed]

51. Ebenstein, A.; Fan, M.; Greenstone, M.; He, G.; Zhou, M. New evidence on the impact of sustained exposure to air pollution on life expectancy from China's Huai River Policy. Proc. Natl. Acad. Sci. USA 2017, 114, 10384-10389. [CrossRef]

52. Huang, X.; Lanz, B. The Value of Air Quality in Chinese Cities: Evidence from Labor and Property Market Outcomes. Environ. Resour. Econ. 2018, 71, 849-874. [CrossRef]

53. Van Donkelaar, A.; Martin, R.V.; Brauer, M.; Hsu, N.C.; Kahn, R.A.; Levy, R.C.; Lyapustin, A.; Sayer, A.M.; Winker, D.M. Global Estimates of Fine Particulate Matter Using a Combined Geophysical-Statistical Method with Information from Satellites. Environ. Sci. Technol. 2016, 50, 3762-3772. [CrossRef] [PubMed]

54. Van Donkelaar, A.; Martin, R.V.; Brauer, M.; Hsu, N.C.; Kahn, R.A.; Levy, R.C.; Lyapustin, A.; Sayer, A.M.; Winker, D.M. Global Annual PM 2.5 Grids from MODIS, MISR and SeaWiFS Aerosol Optical Depth (AOD) with GWR, 1998-2016; Columbia University: New York, NY, USA, 2018; doi:10.7927/H4ZK5DQS.

55. Gössling, S. Global environmental consequences of tourism. Glob. Environ. Chang. 2002, 12, $283-302$. [CrossRef]

56. Scott, D.; Gössling, S.; Hall, C.M. International tourism and climate change. Wiley Interdiscip. Rev. Clim. Chang. 2012, 3, 213-232. [CrossRef]

57. Holden, A. The environment-tourism nexus: Influence of market ethics. Ann. Tour. Res. 2009, 36, 373-389. [CrossRef]

58. Wu, L.; Yang, F. Influence of Haze-Fog on Consumers' Desire for Money. Open J. Soc. Sci. 2019, 7, 190-208. [CrossRef]

(C) 2019 by the authors. Licensee MDPI, Basel, Switzerland. This article is an open access article distributed under the terms and conditions of the Creative Commons Attribution (CC BY) license (http:/ / creativecommons.org/licenses/by/4.0/). 


\title{
Community-Based Tourism as a Sustainable Direction in Destination Development: An Empirical Examination of Visitor Behaviors
}

\author{
Heesup Han ${ }^{1}$, Taeyeon Eom ${ }^{1}$, Amr Al-Ansi ${ }^{1}$, Hyungseo Bobby Ryu ${ }^{2}$ and Wansoo Kim ${ }^{3, *}$ \\ 1 College of Hospitality and Tourism Management, Sejong University, 98 Gunja-Dong, Gwanjin-Gu, \\ Seoul 143-747, Korea; heesup.han@gmail.com (H.H.); ken.eom2@gmail.com (T.E.); \\ amralansi1@gmail.com (A.A.-A.) \\ 2 School of Hospitality and Tourism Management, Kyungsung University, 309 Suyoungro, Nam-Gu, \\ Busan 48434, Korea; bobbyryu414@hanmail.net \\ 3 Department of Tourism Management, Dong-A University 1 Bumin-dong (2 Ga), Seo-gu, Busan 49236, Korea \\ * Correspondence: warooo@dau.ac.kr; Tel.: +82-10-2409-3583
}

Received: 14 April 2019; Accepted: 16 May 2019; Published: 20 May 2019

\begin{abstract}
Community-based tourism is an emerging form of sustainable tourism. Community-based tourism often brings various financial/non-financial benefits to local communities and maximizes sustainability at the local level. The present study was designed to uncover the role of community-based tourism performance in elucidating travelers' post-purchase decision-making process for sustainable destination products by considering the moderating effect of sense of belonging. A quantitative approach was adopted for the achievement of the research objective. A field survey conducted at community-based tourism destinations was utilized for data collection. The acceptable level of the measurement quality was demonstrated. The results of the structural equation modeling provided empirical evidence that community-based tourism performance significantly affects the formation of travelers' post-purchase intentions. In addition, the adequacy of the higher-order structure of community-based tourism performance was identified. The community-based tourism performance and intention relationship was also moderated by sense of belonging. With a lack of empirical research about community-based tourism, the findings of this research significantly add to the existing body of knowledge in sustainable tourism.
\end{abstract}

Keywords: community-based tourism; local community; sustainable tourism; destination development; sense of belonging; pro-social/pro-environmental behavior

\section{Introduction}

For the past few decades, sustainable development has increasingly become a vital issue at every tourism destination [1-3]. Likewise, sustainable tourism as a form of pro-social/pro-environmental traveling behavior has received increasing attention from destination researchers/practitioners as well as visitors [4,5]. Many destinations and tourism companies in the destinations have launched a variety of sustainable initiatives for preserving nature, conserving natural/local resources, protecting cultural authenticity, and achieving socio-economic benefits $[2,3,6]$.

Community-based tourism an essential approach to tourism, efficiently and strongly supporting sustainability at the community/local level [7,8]. The successful development of the community-based tourism makes important contributions to bringing diverse benefits to the local destination (e.g., boosting quality job creations, inducing local economic development, helping eco-friendly tourism development, enabling community empowerment, and preserving the traditional value of the local community) [8-10]. In addition, travelers of the community-based tourism destinations are encouraged to engage in practicing pro-social/pro-environmental tourism behaviors in an active manner [5,11]. 
It is acceptable that community-based tourism is increasingly recognized as a crucial issue in the sustainable tourism context $[9,12]$. However, little research has assessed the community-based tourism performance of a destination. In addition, although visitors' behavior is indisputably a core of tourism destination development [1,2,5], to the best of our knowledge, no empirical research has yet investigated how such community-based tourism performance affects visitors' pro-social behaviors for sustainable destination products. Moreover, the significance of sense of belonging in explicating traveler purchase behaviors as a moderator has been frequently stressed by scholars in destination management $[13,14]$. Yet, the possible moderating influence of the sense of belonging on travelers' sustainable intention formation is seldom assessed.

Filling this gap, the present research attempted to explore the clear role of the performance of community-based tourism and its dimensions in explicating visitor post-purchase decision-making process by considering the moderating impact of sense of belonging. In particular, this research aimed to (1) examine the effect of community-based tourism performance on behavioral intentions (i.e., revisit intention and word-of-mouth intention), (2) discover the adequacy of the higher-order structure of community-based tourism performance and its function within the hypothesized conceptual framework, and (3) explore the moderating impact of sense of belonging. The study findings highlighted certain significant contributions for academician and industry. It asserted the essential role of the sense of belonging in moderating the community-based tourism performance and traveler's behavior intention. This result extends the present conceptualization and identification of it to cover a wider range of tourism forms. It also provided in-depth consideration to the industry developers and DMO's to improve creating more tourism elements (i.e., tangible, intangible) that increases the linkage between local communities, tourists, and a place. The subsequent parts include the literature review, methodology, and result sections. In addition, a discussion and implications section are presented.

\section{Literature Review}

\subsection{Community-Based Tourism Performance and Its Role}

Sustainable tourism is one of the most important topics in the global tourism industry. Sustainability is often regarded as competitiveness in tourism destinations as travelers are increasingly aware of the pro-social/pro-environmental/conservation issues. Community-based tourism is an important type of sustainable tourism. Although the knowledge about community-based tourism has not been thus far sufficiently uncovered, several studies exist that have examined this sustainable form of tourism and its characteristics (e.g., [15-17]). According to Mayaka et al. [17] and Jones [18], the core of community-based tourism is the development of the community through tourism where its value extends beyond economy development. Although the relationship between community development and tourism in the community has been debated, it has been suggested that community-based tourism brings diverse positive outcomes (e.g., socio-economic development, local community ownership, human resource development, community strength and unity, community empowerment, ecological contribution/conservation), leading to the sustainable development of the local community $[15-17,19,20]$.

Community-based tourism covers a variety of aspects of local culture: entertainment, people, natural environment, superstructure, food, products, accommodations [2,15,17,18,20-22]. Previous studies indicated that these factors are also essential attributes of a tourism destination $[15,20,21,23]$. Undoubtedly, maximizing the performance of these attributes contributes to eliciting travelers' positive post-purchase behaviors for tourism destinations [2,23]. Bitner et al. [24] indicated that performance refers to customers' perception/appraisal about the outcomes obtained through experiencing/consuming product attributes. Likewise, community-based tourism performance in the present research indicates travelers' perceived outcomes obtained from the experiences with community-based tourism attributes at the destination.

Customers often form post-purchase intentions and engage in repurchase or recommendation behaviors based on their appraisal of product/service performance [24,25]. A number of studies 
in consumer behavior and tourism found the link between product performance and behavioral intentions [13,23-26]. In the retail sector, Chang et al. [26] found that the excellent performance of product attributes elicits patrons' positive evaluation of their product experiences and influences their favorable post-purchase decisions/behaviors. In the cruise sector, Chua et al. [13] assessed the effect of cruise tourism performance. Their finding revealed that customers repeat purchase and word-of-mouth intentions increase based on the performance of the cruise tourism product and its attributes. Consistently, in their empirical examination of tourists' behaviors at a tourism destination, Han et al. [23] found that tourists' perceived performance of destination attributes significantly increases their intention to revisit and recommend the destination. The findings of these studies supported Bitner et al.'s [24] and Oliver's [25] assertion regarding the positive link between product performance and behavioral intentions. Based on this evidence, we developed the following hypotheses:

Hypothesis 1. Community-based tourism performance has a positive and significant influence on revisit intention.

Hypothesis 2. Community-based tourism performance has a positive and significant influence on word-of-mouth intention.

\subsection{Behavioral Intentions}

Despite the various existing definitions on behavioral intentions, it is generally agreed that it is one's readiness/likelihood for a particular behavior [25,27]. In other words, it is an individual intention/perception toward using or consume a particular product or service. The term "behavioral intentions" is one of the most significant concepts in marketing and consumer behavior as customers' behavioral intentions for a product/service likely result in actual purchase/consumption behaviors [25]. Ajzen [27] and Perugini and Bagozzi [28] asserted that one's behavioral intentions are the most proximal and salient determinant of his/her actual behaviors. According to them, triggering the predictors of behavioral intentions is therefore the effective means of inducing the related behaviors due to the sturdy intention-behavior linkage. Behavioral intentions in consumer behavior indicate patrons' likelihood (or subjective probability) that they will engage in a given action $[25,28]$. Scholars in diverse contexts agree that the repurchase and recommendation intentions are the two major constituents of behavioral intentions $[23,25,27,29]$. These intentions are also described as revisit and word-of-mouth intentions. Overall, in the present study, behavioral intentions refer to travelers' willingness or perceived likelihood of engaging in revisit and word-of-mouth behaviors for the community-based tourism destination.

\subsection{Sense of Belonging and Its Role}

It is described as a critical psychological dimension that consists of a sophisticated interaction between people and a place to build up the person's/community sentiment [30,31]. A sense of belonging, alternatively termed "involvement" [14], is regarded as an essential concept in the community-based tourism sector [17]. While sense of belonging is an attitudinal/psychological term, its scope also encompasses engagement/attachment [32,33]. One can feel a sense of belonging to a both a person or place [34]. Unarguably, travelers' sense of belonging to a certain destination contributes to community development [17]. A sense of belonging as a concept with multiple facets is often described as the bonding between a traveler and his/her important place [35]. Giuliani [32] indicated that the major aspect of sense of belonging is emotional connection between two parties (e.g., traveler and place). When a visitor strongly feels a sense of belonging to a certain destination, he/she is likely to feel an emotional bonding with the destination and to be attached to the destination [36-38].

Strengthening customers' sense of belonging is widely believed to influence their post-purchase decision formation and behaviors [14,36,37]. In the tourism sector, Hyun and Han [37] examined the role of sense of belonging. Their empirical finding indicated that travelers' sense of belonging to a product significantly affects their intention generation process. More recently, in their research about patrons' 
decision-making process, Han and Hyun [14] uncovered that the relationships among motivations, satisfaction, and loyalty intentions become stronger when patrons' feel a strong sense of belonging. In their empirical study, loyalty intentions were evaluated with repeat purchase and word-of-mouth intentions. Consistently, in the cultural tourism sector, Hung et al. [36] also demonstrated that on-site involvement in activities in a cultural tourism destination (on-site belonging to the activities) includes a significant influence on travelers' intention formation for the destination. These empirical studies discussed above supported the moderating nature of sense of belonging in a traveler's post-purchase decision-making process. Therefore, the following hypotheses were developed:

Hypothesis 3a. Sense of belonging significantly moderates the relationship between community-based tourism performance and revisit intention.

Hypothesis $3 \mathbf{b}$. Sense of belonging significantly moderates the relationship between community-based tourism performance and word-of-mouth intention.

\section{Methods}

\subsection{Measures and Questionnaire Development}

To evaluate study variables, existing validated measurement items were adopted form the extant literature $[13,14,25,27,39-43]$. Multiple items and seven-point Likert type scale were used ("Strongly disagree" $=1-$ "Strongly agree" $=7$ ). In particular, a total of three items were utilized to measure local culture (e.g., "I had the opportunity to experience various local ways of life."). (See Appendix A). We used three items for the evaluation of local entertainments (e.g., "I participated in unique activities at the CBT destination that I cannot usually experience in everyday life."). A total of three items for local people (e.g., "Local people at the CBT destination were friendly/kind.") was used. We utilized three items for the assessment of local natural environment (e.g., "The natural environment at the CBT destination was appealing."). We used two items to evaluate local superstructure (e.g., "The architecture at the CBT destination was unique."). A total of three items for local food and dishes (e.g., "I experienced good quality of local dishes in restaurants at the CBT destination.") were utilized.

In addition, we used two items for the assessment of local products (e.g., "In the CBT destination, I experienced a variety of products/brands in local shops."). A total of three items for local accommodations (e.g., "I experienced good quality of local life in the place of accommodation at the CBT destination.") was used. Moreover, we utilized three items for the evaluation of sense of belonging (e.g., "I felt a strong sense of belonging to the CBT destination and its settings/facilities."). Furthermore, we used two items for the assessment of revisit intention (e.g., "I will make an effort to experience the CBT destination again in the near future.") and two items for the evaluation of word-of-mouth intention (e.g., "I encourage my friends and relatives to experience the CBT destination."). The draft version of the survey questionnaire comprised these measures and questions for socio-demographic information. The questionnaire was pre-tested with tourism academics. After slight modification, it was also reviewed and finalized by academic experts.

\subsection{Data Collection Procedure and Samples}

In the present research, a nonprobability convenience sampling method was used. The field survey was conducted at famous community-based tourism sites in South Korea such as Bukchon Hanok Village, Ewha Mural Village, Seorae Village, Achasan Mountain Ecological Park, Seoul Forest Park, and Jeonju Hanok Village. Surveyors approached the actual visitors of the aforementioned places and invited them to participate in the survey. Particularly, representative CBT destinations in Korea were introduced first and then tourists were asked to mark on a region of CBT destinations that they had previously visited in the questionnaire. Each region was presented with various representative 
CBT destinations, which were reviewed by two academics and professionals in the field of hospitality and tourism. During this process, only respondents who had previously visited CBT destinations were selected for the survey participation. After filling out the questionnaire, the participants returned the completed questionnaire onsite. The surveyors checked if there is any missing response. Through this process, a total of 428 usable responses were gathered. These cases were utilized for data analysis.

Among 428 respondents, $64.3 \%$ were female travelers, and $35.7 \%$ were male travelers. About $52.3 \%$ reported that they were four-year college graduates, followed by high school graduates or less (29.7\%), two-year college graduates (11.7\%), and graduate degree holders (6.3\%). Regarding the participants' age, about $59.1 \%$ indicated that their age is less than 30 years old, followed by between $30-39$ years old (18.7\%), 50-59 years old (12.1\%), 40-49 years old $(7.7 \%)$, and 60 years old or more $(2.3 \%)$. In terms of the duration of the stay, about $49.8 \%$ reported one day trip, followed by two days (25.9\%), three days $(16.6 \%)$, five days or more $(4.2 \%)$, and four days (3.5\%). When the participants' travel purpose was asked, about $68.0 \%$ indicated for relaxation, followed by nature/well-being $(18.0 \%)$, enjoyment/pleasure $(6.5 \%)$, socializing $(3.3 \%)$, study $(1.6 \%)$, other $(1.4 \%)$, and business $(1.2 \%)$.

\section{Results}

\subsection{Data Quality Testing}

A measurement model was generated by using a confirmatory factor analysis. Results showed that the model contained a satisfactory level of goodness-of-fit statistics $\left(\chi^{2}=620.694, \mathrm{df}=322, \chi^{2} / \mathrm{df}=1.928\right.$, $p<0.001, \mathrm{RMSEA}=0.047, \mathrm{CFI}=0.959, \mathrm{IFI}=0.919, \mathrm{TLI}=0.948$ ). All loading values (standardized) were significant $(p<0.01)$. In addition, internal consistency of the multiple-item measures was evident in that composite reliability values ranged from 0.748 to 0.897 (see Table 1). These values were all above Hair et al.'s [44] recommended threshold of 0.700 . Next, convergent validity was estimated. Our result showed that average variance extracted values were all above Hair et al.'s [44] recommended threshold of 0.500 . This, convergent validity was evident. As shown in Table 1 , the average variance extracted values were greater than the between-construct correlations (squared). This provided evidence of discriminant validity. 


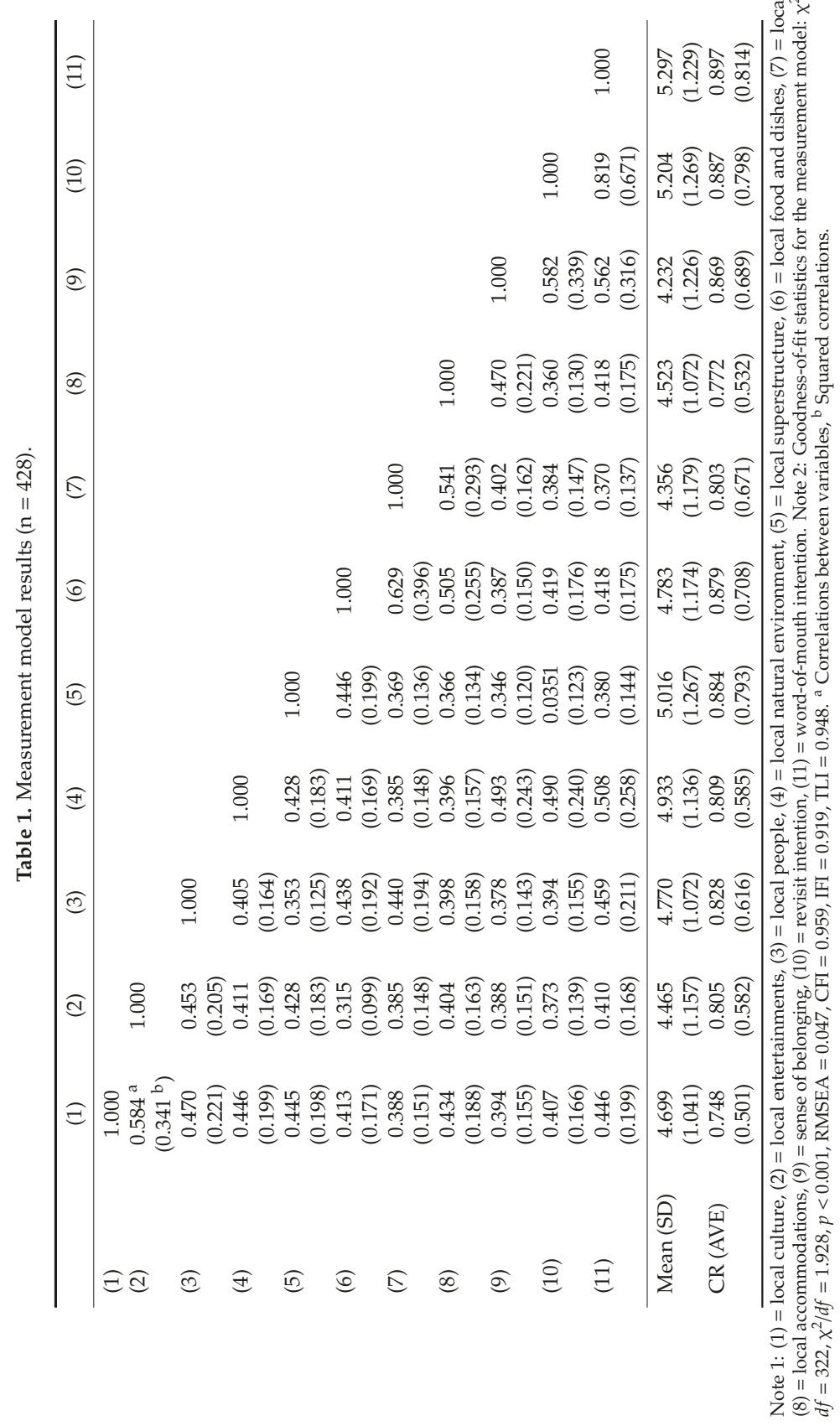




\subsection{Evaluation of the Higher-Order Framework and Modeling Comparison}

Structural equation modeling was conducted. The maximum likelihood estimation approach was utilized. Results showed that the model had a satisfactory level of goodness-of-fit statistics $\left(\chi^{2}=912.632\right.$, $\left.\mathrm{df}=289, p<0.001, \chi^{2} / \mathrm{df}=3.158, \mathrm{RMSEA}=0.071, \mathrm{CFI}=0.901, \mathrm{IFI}=0.902, \mathrm{TLI}=0.889\right)$. The details regarding the structural equation modeling results are shown in Figure 1 and Table 2. Our result revealed that the higher-order latent factor is significantly and positively related to eight first-order constructs ( 1 = local culture, 2 = local entertainments, $3=$ local people, $4=$ local natural environment, 5 = local superstructure, $6=$ local food and dishes, $7=$ local products, $8=$ local accommodations). The coefficients were 0.746 ( 1 = local culture), 0.662 ( 2 = local entertainments), 0.683 ( 3 = local people), 0.742 ( 4 = local natural environment), 0.624 ( $5=$ local superstructure), 0.687 ( $6=$ local food and dishes), $0.713(7=$ local products $)$, and $0.703(8=$ local accommodations $)$. Moreover, all associations were significant at $p<0.01$. While the goodness-of-fit statistics of the first-order model $\left(\chi^{2}=548.556\right.$, $\mathrm{df}=255, p<0.001, \chi^{2} / \mathrm{df}=2.151$, RMSEA $=0.052, \mathrm{CFI}=0.954$, IFI $=0.954$, TLI $\left.=0.941\right)$ were slightly better than the higher-order model, no independent variable among eight factors had a significant direct influence on revisit intention and word-of-mouth intention $(p<0.05)$. This finding demonstrated the adequacy of the higher-order framework of community-based tourism performance. The higher-order latent variable sufficiently account for the eight first-order factors of local culture $\left(R^{2}=0.557\right)$, local entertainments $\left(R^{2}=0.438\right)$, local people $\left(R^{2}=0.466\right)$, local natural environment $\left(R^{2}=0.550\right)$, local superstructure $\left(R^{2}=0.390\right)$, local food and dishes $\left(R^{2}=0.472\right)$, local products $\left(R^{2}=0.508\right)$, and local accommodations $\left(R^{2}=0.495\right)$. 


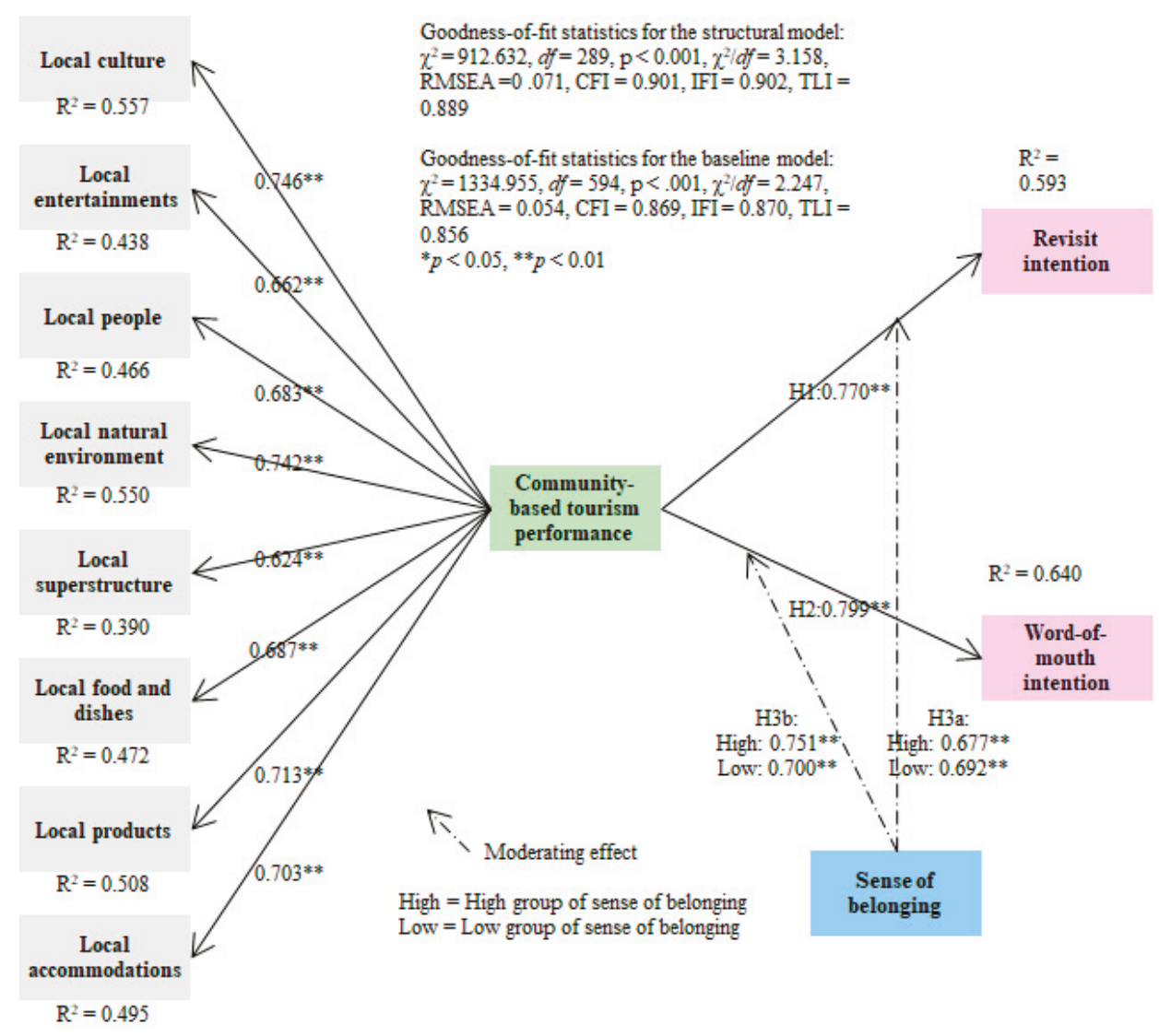

Figure 1. Results of the structural equation modeling $(n=428)$.

Table 2. Structural model assessment and hypotheses testing $(n=428)$

\begin{tabular}{lllll}
\hline \multicolumn{1}{c}{ Independent Variable } & & Dependent Variable & Standardized Estimate & $t$-Value \\
\hline H1 Community-based tourism performance & $\rightarrow$ & Revisit intention & 0.770 & $11.037^{* *}$ \\
H2 Community-based tourism performance & $\rightarrow$ & Word-of-mouth intention & 0.799 & $10.899^{* *}$ \\
\hline Goodness-of-fit statistics for the structural model: & Total variance explained $\left(\mathrm{R}^{2}\right):$ & \\
$\chi^{2}=912.632, d f=289, p<0.001, \chi^{2} / d f=3.158$, & $\mathrm{R}^{2}$ for revisit intention $=0.593$ & \\
RMSEA $=0.071, \mathrm{CFI}=0.901, \mathrm{IFI}=0.902$, & $\mathrm{R}^{2}$ for word-of-mouth intention $=0.640$ \\
TLI $=0.889$ & ${ }^{*} p<0.05,{ }^{* *} p<0.01$ & \\
\hline
\end{tabular}

\subsection{Test for the Hypothesized Relationships}

The proposed effect of community-based tourism performance on behavioral intentions was evaluated. As reported in Figure 1 and Table 2, our results showed that community-based tourism performance exerted a significant influence on revisit intention $(\beta=0.770, p<0.01)$ and word-of-mouth intention $(\beta=0.799, p<0.01)$. Therefore, Hypotheses 1 and 2 were supported. About $59.3 \%$ of the total variance in revisit intention and about $64.0 \%$ of the variance in word-of-mouth intention was accounted for by the higher-order framework of community-based tourism performance, respectively. This result implies that boosting the community-based tourism performance is an essential requisite for the attainment of travelers' strong intentions to revisit the community-based tourism destination and recommend the place to others 


\subsection{Test for Metric Invariance}

The hypothesized moderating influence of sense of belonging was tested using a test for metric invariance. First, the responses were divided into high and low groups of sense of belonging by employing a K-means cluster analytical technique. The K-means findings determined a high group, which included 269 cases whereas the low group included 159 cases. A baseline model encompassing these high and low sense-of-belonging groups was then generated. As reported in Table 3 and Figure 1, the model contained an acceptable level of the goodness-of-fit statistics $\left(\chi^{2}=1334.955, \mathrm{df}=594, p<0.001, \chi^{2} / \mathrm{df}=2.247, \mathrm{RMSEA}=0.054, \mathrm{CFI}=0.869, \mathrm{IFI}=0.870, \mathrm{TLI}=0.856\right)$. Next, we made a comparison between the baseline model and nested models using a chi-square test. Within the nested models, a particular path of interest was restricted to be equal between high and low sense-of-belonging groups. As reported in Table 3, our result showed that the linkage between community-based tourism performance and revisit intention was not significantly difference across high and low sense-of-belonging groups $\left(\Delta \chi^{2}[1]=3.791, p>0.05\right)$. Therefore, Hypothesis 3a was not supported. However, as expected, the linkage between community-based tourism performance and word-of-mouth intention differed significantly between high and low groups $\left(\Delta \chi^{2}[1]=4.268\right.$, $p<0.05)$. This result supported Hypothesis $3 \mathrm{~b}$. That is, sense of belonging significantly moderated the path from community-based tourism performance to word-of-mouth intention.

Table 3. Structural invariance model results

\begin{tabular}{|c|c|c|c|c|c|c|}
\hline \multirow[t]{2}{*}{ Paths } & \multicolumn{2}{|c|}{$\begin{array}{l}\text { High Group of Sense } \\
\text { of Belonging }(n=269)\end{array}$} & \multicolumn{2}{|c|}{$\begin{array}{l}\text { Low Group of Sense } \\
\text { of Belonging }(n=159)\end{array}$} & \multirow{2}{*}{$\begin{array}{l}\text { Baseline Model } \\
\text { (Freely Estimated) }\end{array}$} & \multirow{2}{*}{$\begin{array}{l}\text { Nested Model } \\
\text { (Constrained to Be Equal) }\end{array}$} \\
\hline & Coefficients & $t$-Values & Coefficients & $t$-Values & & \\
\hline $\begin{array}{l}\text { CBT perf. } \rightarrow \\
\text { Revisit intention }\end{array}$ & 0.677 & 8.003 ** & 0.692 & 5.990 ** & $\chi^{2}(594)=1334.955$ & $\chi^{2}(595)=1338.746^{a}$ \\
\hline $\begin{array}{l}\text { CBT perf. } \rightarrow \\
\text { WOM intention }\end{array}$ & 0.751 & 6.139 ** & 0.700 & $7.787 * *$ & $\chi^{2}(594)=1334.955$ & $\chi^{2}(595)=1339.223^{b}$ \\
\hline \multicolumn{4}{|c|}{$\begin{array}{l}\text { Chi-square difference test: } \\
\text { a } \Delta \chi^{2}(1)=3.791, p>0.05 \text { (insignificant) (H3a was not supported) } \\
\text { b } \Delta \chi^{2}(1)=4.268, p<0.05 \text { (significant) (H3b was supported) }\end{array}$} & \multicolumn{3}{|c|}{$\begin{array}{l}\text { Goodness-of-fit statistics for the baseline model: } \\
\chi^{2}=1334.955, d f=594, p<0.001, \chi^{2} / d f=2.247, \text { RMSEA }=0.054, \\
\text { CFI }=0.869, \text { IFI }=0.870, \text { TLI }=0.856 \\
{ }^{*} p<0.05,{ }^{* *} p<0.01\end{array}$} \\
\hline
\end{tabular}

\section{Discussion}

This research provides a strong theorization related to travelers' perceptions of community-based tourism performance in explicating their post-purchase decision formation. The present research was one of the few studies that considers the moderating influence of sense of belonging on such decision-making process in the sustainable tourism sector. Findings of the present study help comprehend the community-based tourism advancement and its role better, which ultimately leads to achieving the intentions to revisit the community-based tourism destination and to spread positive word-of-mouth for the destination. In addition, the study provides a clearer understanding of the critical function of the sense of belonging and its active role in the formation of behavioral intentions as a moderator. Given that boosting visitors' favorable post-purchase decisions/behaviors is one of the essential requisites for the successful sustainable destination development under the competitive market environment, the study finding is of utmost importance in helping community-based tourism practitioners develop the means of increasing the retention rate and enhancing the diverse forms of recommendation behaviors.

A specific valuable and important point regarding the framework of community-based tourism performance is its higher-order structure. It was apparent that the eight first-order variables $(1=$ local culture, 2 = local entertainments, $3=$ local people, $4=$ local natural environment, $5=$ local superstructure, $6=$ local food and dishes, $7=$ local products, $8=$ local accommodations) significantly belong to one higher-order concept of community-based tourism performance. The higher-order global factor sufficiently extracted the commonality underlying the first-order variables. From a theoretical point of view, this result enriched the community-based tourism literature by providing a hierarchical 
approach, which clearly captures the performance of community-based tourism. This result helps destination researchers more concisely theorize such an intricate concept in the community-based tourism context. From a practical point of view, the strength of the relationships between the global latent factor and the eight first-order factors was all high. In addition, the explanatory power of the higher-order factor for each first-order variable was strong. Hence, dealing with and enhancing the performance of local culture, local entertainments, local people, local natural environment, local superstructure, local food, local products, and local accommodations are crucial to fulfill the vital aspects of visitors' needs and wants when traveling to a community-based tourism destination.

It has been recognized that community-based tourism is ultimately an efficient means of increasing the sustainability of the socio-ecosystem, reviving local traditions, conserving natural resources, reducing poverty, and exhibiting/respecting local culture in the community [15,22]. Beyond these contributions of community-based tourism, the present research successfully linked it to traveler post-purchase decisions. Indeed, our empirical result supported the significant linkage between community-based tourism performance and behavioral intentions. The effective ways of enhancing the number of visitors in a community-based tourism destination is weakly known. Utilizing the quantitative approach, this research successfully demonstrated that community-based tourism performance and its attributes are critical sources for destination practitioners when inventing efficient tactics about how to retain visitors and eliciting their positive word-of-mouth activities about the destination.

It was revealed that travelers' sense of belonging to a community-based tourism destination moderates the relationship between community-based tourism performance and word-of-mouth intention. In particular, the association was stronger in the high sense of belonging group $(\beta=0.751$, $p<0.01$ ) than in the low group $\beta=0.700, p<0.01$ ). This result implies that travelers' perception of community-based tourism performance more likely results in word-of-mouth intention when their sense-of-belonging level for the destination is high. Our finding provides important theoretical information that the magnitude of the relationship strength between community-based tourism performance and intention relationship is determined on the basis of sense-of-belonging level. In order to obtain a deeper understanding of the role of sense of belonging, tourism academics should recognize its moderating nature. Regarding the practical aspect, our result offered crucial insights. The finding informed practitioners in the community-based tourism destination that they should make various efforts to strengthen the affective bonding between the destination and its visitors. As evidenced in this study, at a similar perception level regarding the performance of the community-based tourism destination, travelers more actively engage in diverse forms of word-of-mouth behaviors especially when they feel strongly connected to the destination.

As intensively studied by Álvarez-García, Durán-Sánchez, and del Río-Rama [45], a tremendous number of studies on community-based tourism has been gradually increased in the past few years. This notable concerns by a few scholars is related to the focal role of community-based tourism to enhance the quality of life for the local community [45]. Nonetheless, it is quite axiomatic that it would be difficult for any business to be sustained without consistent purchase of consumers. Such a concept is also applied to various range of tourism and sustainable development. In this sense, a study that comprehends the revisit and word-of-mouth intentions can be significant. Communities should consider the tourists' behaviors to sustain the community benefits through the profit of tourists or mutual benefits. In other words, endeavors to understand the tourists who visit their communities need to be vigorous in order to support the core goal the community tourism initiatives.

Finally, one particular interesting result from data collection is that about $70 \%$ of respondents declared that their travel purposes were for relaxation. This concentrated outcome may represent the characteristic of Korean tourists who visit CBT places. As known, South Korea's working environment is extremely stressful. Average working hours and suicide rate in South Korea have been frequently ranked first or second among OECD nations [46,47]. In this regard, Korean tourists may have deep desires to have relaxation time even though they had visited a CBT destination to experience a local social environment away from home. Besides, lots of Korean CBT destinations are located in rural areas which has highly 
motivated Korean local authorities to develop rural places as CBT destinations on purpose. For instance, TourDure is the government support program of CBT initiative in Korea. Most of the TourDure programs and products are in rural areas in which are good places to relax in nature. Given that general Korean people have lots of stress due to hard working conditions, living mostly in metropolitan areas (about half population), most of the tourists might desire to have a good rest during their vacation for CBT. In this sense, organizations or markers for CBT in Korea may consider relaxation as a marketing strategy and plan in order to meet visitors' needs

\section{Conclusions}

Sustainable tourism is a steadily growing phenomenon in the global tourism industry. Community-based tourism is one of the core facets of sustainable tourism development in destinations. Moving beyond the extant conceptualization, the present research was an important attempt to build a framework linking the higher-order structure of community-based tourism comprising eight first-order factors and behavioral intentions by taking into account the moderating impact of a sense of belonging. In closing, taking us one step further toward comprehending the role of these concepts, the proposed theorization was wholly supported. This study had several limitations that provide insightful points for future studies. First, while most correlations are under the problematic level, several inter-correlations are somewhat high. This implies that the results of this study are not entirely away from the multi-collinearity issue. For future research, a more thorough measurement design is highly recommended. Researchers also might investigate such measurements design using different analytical methods such as SEM using partial least square [48]. Second, previous studies in sustainable tourism asserted the importance of some mediators that clearly explained travelers' sustainable decision-making process and behaviors (e.g., satisfaction, emotions, commitment) $[1,40,49]$. Yet, the present research did not include such crucial mediators that possibly maximize the effect of independent variables on the outcome variables. Future scholars are advised to extend the proposed conceptual framework by incorporating such mediators. This effort would help to increase the prediction power of the proposed model and provide a valuable explanation for travelers' behavioral intentions in sustainable tourism development.

Author Contributions: Conceptualization, T.E.; Data curation, W.K.; Funding acquisition, W.K.; Investigation, A.A.A.; Methodology, T.E.; Project administration, W.K.; Software, A.A.A.; Visualization, H.R.; Writing- original draft, H.H.; Writing - review \& editing, H.R.

Funding: This work was supported by the Dong-A University research fund.

Conflicts of Interest: The authors declare no conflict of interest.

\section{Appendix A}

\section{Local culture}

- I had the opportunity to experience various local ways of life.

- I think that programs offered at the CBT destination were rich in history for the locals.

- The chance to try/experience local foods/beverages in the CBT destination was sufficient (e.g., makgeolli, pajeon).

Local entertainments

- I participated in unique activities at the CBT destination that I cannot usually experience in everyday life

- There were interesting, special events at the CBT destination.

- At the CBT destination, I joined festivals and events that I was interested in.

Local people

- $\quad$ Local people at the CBT destination were friendly/kind.

- Local people at the CBT destination showed a good willingness to help me/us.

- Local people at the CBT destination showed a good willingness to share information about the destination/history/culture. 
Local natural environment

- The natural environment at the CBT destination was appealing.

- The CBT destination was well preserved.

- The landscape at the CBT destination was awe-inspiring.

Local superstructure

- $\quad$ The architecture at the CBT destination was unique.

- The buildings at the CBT destination were interesting.

Local food and dishes

- $\quad$ At the CBT destination, the quality of foods/services in the restaurants was good.

- I experienced a good quality of local dishes in restaurants at the CBT destination.

- I experienced a variety of dishes/brands in the local restaurants at the CBT destination.

Local product

- I experienced a guaranteed quality of products/services in shopping centers at the CBT destination.

- At the CBT destination, the quality of local products in shopping centers was nice.

- In the CBT destination, I experienced a variety of products/brands in local shops.

Local accommodation

- I experienced a guaranteed quality of accommodation at the CBT destination.

- At the CBT destination. I didn't experience a high quality of nature in the place of accommodation.

- I experienced a good quality of local life in the place of accommodation at the CBT destination.

Revisit intention

- I will make an effort to experience the CBT destination again in the near future.

- I plan to experience the CBT destination again in the near future.

Word-of-mouth intention

- I encourage my friends and relatives to experience the CBT destination.

- If someone is looking for a tour program, I generally advise him/her to experience the CBT destination.

Sense of belonging

- I felt a strong sense of belonging to the CBT destination and its settings/facilities. I experienced a good quality of local dishes in restaurants at the CBT destination.

- I was very attached to the CBT destination.

- $\quad$ The CBT destination meant a lot to me.

\section{References}

1. Hwang, J.; Choi, J. An investigation of passengers' psychological benefits from green brands in an environmentally friendly airline context: The moderating role of gender. Sustainability 2018, 10, 80. [CrossRef]

2. Kiatkawsin, K.; Han, H. Young travelers' intention to behavior pro-environmentally: Merging the value-belief-norm theory and the expectancy theory. Tour. Manag. 2017, 59, 76-88. [CrossRef]

3. Nilnoppakun, A.; Ampavat, K. Is Pai a sustainable tourism destination? Procedia Econ. Financ. 2016, 39, 262-269. [CrossRef]

4. Melissen, F.; Cavagnaro, E.; Damen, M.; Düweke, A. Is the hotel industry prepared to face the challenge of sustainable development? J. Vac. Mark. 2015, 22, 227-238. [CrossRef]

5. Meng, B.; Han, H. Effect of environmental perceptions on bicycle travelers' decision-making process: Developing an extended model of goal-directed behavior. Asia Pac. J. Tour. Res. 2016, 21, 1184-1197. [CrossRef]

6. Boley, B.B.; McGehee, N.G.; Hammett, A.L.T. Importance-performance analysis (IPA) of sustainable tourism initiatives: The resident perspective. Tour. Manag. 2017, 58, 66-77. [CrossRef] 
7. Dodds, R.; Ali, A.; Galaski, K. Mobilizing knowledge: Determining key elements for success and pitfalls in developing community-based tourism. Curr. Iss. Tour. 2018, 21, 1547-1568. [CrossRef]

8. Lemelin, R.H.; Koster, R.; Youroukos, N. Tangible and intangible indicators of successful aboriginal tourism initiatives: A case study of two successful aboriginal tourism lodges in Northern Canada. Tour. Manag. 2015, 47, 318-328. [CrossRef]

9. Lee, T.H.; Jan, F.H.; Tseng, C.H.; Lin, Y.F. Segmentation by recreation experience in island-based tourism: A case study of Taiwan's Liuqiu island. J. Sustain. Tour. 2018, 26, 362-378. [CrossRef]

10. Tolkach, D.; King, B. Strengthening community-based tourism in a new resource-based island nation: Why and how? Tour. Manag. 2015, 48, 386-398. [CrossRef]

11. Tyrväinen, L.; Uusitalo, M.; Silvennoinen, H.; Hasu, E. Towards sustainable growth in nature-based tourism destinations: Clients' views of land use options in Finnish Lapland. Landsc. Urb. Plan. 2014, 122, 1-15. [CrossRef]

12. Sakata, H.; Prideaux, B. An alternative approach to community-based ecotourism: A bottom-up locally initiated non-monetised project in Papua New Guinea. J. Sustain. Tour. 2013, 21, 880-899. [CrossRef]

13. Chua, B.; Lee, S.; Han, H. Consequences of cruise line involvement: A comparison of first-time and repeat passengers. Int. J. Contemp. Hosp. Manag. 2017, 29, 1658-1683. [CrossRef]

14. Han, H.; Hyun, S. Role of motivations for luxury cruise traveling, satisfaction, and involvement in building traveler loyalty. Int. J. Hosp. Manag. 2018, 70, 75-84. [CrossRef]

15. Lee, T.H.; Jan, F.-H. Can community-based tourism contribute to sustainable development? Evidence from residents' perceptions of the sustainability. Tour. Manag. 2019, 70, 368-380. [CrossRef]

16. Lee, T.H.; Jan, F.H.; Yang, C.C. Conceptualizing and measuring environmentally responsible behaviors from the perspective of community-based tourists. Tour. Manag. 2013, 36, 454-468. [CrossRef]

17. Mayaka, M.; Croy, W.G.; Cox, J.W. A dimensional approach to community-based tourism: Recognising and differentiating form and context. Ann. Tour. Res. 2019, 74, 177-190. [CrossRef]

18. Jones, S. Community-based ecotourism: The significance of social capital. Ann. Tour. Res. 2005, 32, $303-324$. [CrossRef]

19. Mottiar, Z.; Boluk, K.; Kline, C. The roles of social entrepreneurs in rural destination development. Ann. Tour. Res. 2018, 68, 77-88. [CrossRef]

20. Mtapuri, O.; Giampiccoli, A. Interrogating the role of the state and nonstate actors in community-based tourism ventures: Toward a model for spreading the benefits to the wider community. S. Afr. Geogr. J. 2013, 95, 1-15. [CrossRef]

21. Simpson, M.C. Community benefit tourism initiatives: A conceptual oxymoron? Tour. Manag. 2008, 29, 1-18. [CrossRef]

22. Wearing, S.L.; Wearing, M.; McDonald, M. Understanding local power and interactional processes in sustainable tourism: Exploring village-tour operator relations on the kokoda track, Papua New Guinea. J. Sustain. Tour. 2010, 18,61-76. [CrossRef]

23. Han, H.; Al-Ansi, A.; Olya, H.G.T.; Kim, W. Exploring halal-friendly destination attributes in South Korea: Perceptions and behaviors of Muslim travelers toward a non-Muslim destination. Tour. Manag. 2019, 71, 151-164. [CrossRef]

24. Bitner, M.J.; Boons, B.H.; Tetreault, M.S. The service encounter: Diagnosing favorable and unfavorable incidents. J. Mark. 1990, 54, 71-84. [CrossRef]

25. Oliver, R.L. Satisfaction: A Behavioral Perspective on the Consumer, 2nd ed.; McGraw-Hill: New York, NY, USA, 2010.

26. Chang, E.; Burns, L.D.; Francis, S.K. Gender differences in the dimensional structure of apparel shopping satisfaction among Korean consumers: The role of hedonic shopping value. Cloth. Text. Res. J. 2004, 22, 185-199. [CrossRef]

27. Ajzen, I. The theory of planned behavior. Organ. Behav. Hum. Dec. 1991, 50, 179-211. [CrossRef]

28. Perugini, M.; Bagozzi, R.P. The role of desires and anticipated emotions in goal-directed behaviors: Broadening and deepening the theory of planned behavior. Brit. J. Sol. Psychol. 2001, 40, 79-98. [CrossRef]

29. Choo, H.; Ahn, K.; Petrick, J.F. An integrated model of festival revisit intentions: Theory of planned behavior and festival quality/satisfaction. Int. J. Contemp. Hosp. Manag. 2016, 28, 818-838. [CrossRef]

30. Pretty, G.H.; Chipuer, H.M.; Bramston, P. Sense of place amongst adolescents and adults in two rural Australian towns: The discriminating features of place attachment, sense of community and place dependence in relation to place identity. J. Environ. Psychol. 2003, 23, 273-287. [CrossRef] 
31. Tsai, C.T. Memorable tourist experiences and place attachment when consuming local food. Int. J. Tour. Res. 2016, 18, 536-548. [CrossRef]

32. Giuliani, M.V. Theory of attachment and place attachment. In Psychological Theories of Environmental Issues; Bonnes, M., Lee, T., Bonaiuto, M., Eds.; Ashgate: Aldershot, UK, 2003; pp. 137-170.

33. Lee, C.C. Predicting tourist attachment to destinations. Ann. Tour. Res. 2001, 28, 229-232. [CrossRef]

34. Scannell, L.; Gifford, R. Defining place attachment: A tripartite organizing framework. J. Environ. Psychol. 2010, 30, 1-10. [CrossRef]

35. Scannell, L.; Gifford, R. The relations between natural and civic place attachment and pro-environmental behavior. J. Environ. Psychol. 2010, 30, 289-297. [CrossRef]

36. Hung, K.-P.; Peng, N.; Chen, A. Incorporating on-site activity involvement and sense of belonging into the Mehrabian-Russell model-The experiential value of cultural tourism. Tour. Manag. Perspect. 2019, 30, 43-52. [CrossRef]

37. Hyun, S.S.; Han, H. Luxury cruise travelers: Other customer perceptions. J. Travel. Res. 2015, 54, $107-121$. [CrossRef]

38. Tsai, S.-P. Love and satisfaction driver persistent stickiness: Investigating international tourist hotel brands. Int. J. Tour. Res. 2014, 16, 565-577. [CrossRef]

39. Byun, J.; Jang, S. "To compare or not to compare?": Comparative appeals in destination advertising of ski resorts. J. Destin. Mark. Manag. 2018, 10, 143-151. [CrossRef]

40. Cheng, T.M.C.; Wu, H.; Huang, L.M. The influence of place attachment on the relationship between destination attractiveness and environmentally responsible behavior for island tourism in Penghu, Taiwan. J. Sustain. Tour. 2013, 21, 1166-1187. [CrossRef]

41. Hwang, J.; Lee, J. Relationships among Senior Tourists' Perceptions of Tour Guides' Professional Competencies, Rapport, Satisfaction with the Guide Service, Tour Satisfaction, and Word of Mouth. J. Travel. Res. 2018. [CrossRef]

42. Moon, H.; Han, H. Destination attributes influencing Chinese travelers' perceptions of experience quality and intentions for island tourism: A case of Jeju Island. Tour. Manag. Perspect. 2018, 28, 71-82. [CrossRef]

43. Smaldone, D.; Harris, C.; Sanyal, N. The role of time in developing place meanings. J. Leis. Res. 2008, 40, 479-504. [CrossRef]

44. Hair, J.F.; Black, W.C.; Babin, B.J.; Anderson, R.E. Multivariate Data Analysis, 7th ed.; Prentice-Hall: Upper Saddle River, NJ, USA, 2010; pp. 600-638.

45. Álvarez-García, J.; Durán-Sánchez, A.; del Río-Rama, M. Scientific coverage in community-based tourism: Sustainable tourism and strategy for social development. Sustainability 2018, 10, 1158. [CrossRef]

46. Organisation for Economic Co-Operation and Development. Hours Worked (Indicator). Available online: https://www.oecd-ilibrary.org/employment/hours-worked/indicator/english_47be1c78-en (accessed on 15 May 2019).

47. Organisation for Economic Co-Operation and Development. Suicide Rates (Indicator). Available online: https://www. oecd-ilibrary.org/social-issues-migration-health/suicide-rates/indicator/english_a82f3459-en (accessed on 15 May 2019).

48. Al-Ansi, A.; Olya, H.G.; Han, H. Effect of general risk on trust, satisfaction, and recommendation intention for halal food. Int. J. Hosp. Manag. 2018. [CrossRef]

49. Zhang, Y.; Wang, L. Influence of sustainable development by tourists' place emotion: Analysis of the multiply mediating effect of attitude. Sustainability 2019, 11, 1384. [CrossRef]

(C) 2019 by the authors. Licensee MDPI, Basel, Switzerland. This article is an open access article distributed under the terms and conditions of the Creative Commons Attribution (CC BY) license (http://creativecommons.org/licenses/by/4.0/). 
Article

\title{
Assessing Tourists' Preferences of Negative Externalities of Environmental Management Programs: A Case Study on Invasive Species in Shei-Pa National Park, Taiwan
}

\author{
Tzu-Ming Liu ${ }^{1, *}$ and Chia-Mei Tien ${ }^{2}$ \\ 1 Graduate Institute of Marine Affairs, National Sun Yat-sen University, Kaohsiung 80424, Taiwan \\ 2 Marketing and Sales Department, Queena Plaza Hotel Tainan, Tainan 71081, Taiwan; clara@queenaplaza.com \\ * Correspondence: liutm.tw@gmail.com
}

Received: 9 May 2019; Accepted: 20 May 2019; Published: 24 May 2019

\begin{abstract}
This study uses discrete choice experiments to evaluate and reduce the environmental impact of negative externalities of managing invasive alien species (IAS), such as "ecological shock", "health risk", "waiting time" "tour range" and "prevention and control fee", on the support of IAS prevention and control. We used data from Taiwan's Shei-Pa National Park and its visitors for the case study and obtained 602 valid questionnaires. The results indicate that visitors consider that each unit of externality of IAS prevention and control measures significantly reduces their utility, and the magnitude equals the estimated value of externality. However, although negative externalities are inevitable, the support for IAS prevention and control measures could be maximized by adjusting the types and proportions of negative externalities. For example, visitors are willing to sacrifice up to $1.41 \%$ of the tour range in exchange for a $1 \%$ reduction in ecological shock. This study summarizes the negative externalities of IAS prevention and control measures and proposes to adjust the combination of negative externalities to reduce the shocks of those IAS prevention and control measures on the public, so as to increase the public support for IAS policies and increase the sustainability of tourism.
\end{abstract}

Keywords: discrete choice experiments; invasive species control; tourists' preferences; two stage on-site sampling; negative externalities

\section{Introduction}

National parks (NPs) not only bear the important responsibility of protecting key eco-environments and landscapes but also must meet the needs of public sightseeing and recreation. The various sustainability objectives of NPs are occasionally compatible but may also conflict with one another [1]. Such conflicts are particularly obvious in the prevention and control of invasive alien species (IASs). Because IASs can spread by attaching themselves to the human body, clothing, vehicles, and recreational equipment, the greater that the number of tourists who visit NPs is, the greater the probability that the NPs will be impacted and the higher the severity of the impact [2-6]. Once it enters an NP, an IAS may change the characteristics of the park ecosystem, compete with local species for food, cause local species to disappear, and change the landscape. This problem worsens with the increase in the number of NP tourists. IAS prevention and control is therefore regarded as the largest challenge facing NP management $[7,8]$.

The impact of IASs on sustainability of NPs has been documented. For example, the cinnamon fungus caused a large area of forest blight in Brisbane Ranges NP in Australia and a decrease in its vegetation coverage rate [9]. The mile-a-minute weed reduced the plant richness of the Chitwan NP in Nepal [10]. The Burmese python caused a significant reduction in the number of mammals and birds 
in Everglades NP [11]. IASs not only severely damage the ecology and landscape of NPs, they also harm other IASs. For example, in America's Hawaii Volcanoes National Park, the firebush gradually replaced the endemic plant ohia [12] while promoting the expansion of the leafhopper population, another IAS [13], and the subsequent apoptosis of native plants. These cases show that IASs pose a serious threat to the precious biodiversity of NPs and change the original landscape. Therefore, many NPs seek to actively controlled and manage IASs $[14,15]$. However, these NPs often find themselves in a unique dilemma in regard to preventing and controlling IASs.

The first challenge to NPs in the prevention and control of IASs is that the prevention and control measures often endanger other species and the ecology in NPs. The Booderee NP's approach to controlling the bitou bush reduced the number of bird species in the park [16]. Capitol Reef NP's efforts to control the codling moth also reduced alfalfa leafcutting bee's nectar, which in turn threatened several species of endangered plants in the park [17]. Measures taken by Queensland Conservation Reserve to control para grass resulted in a decrease in the abundance of amphibians and reptiles, such as skinks and frogs, in the park [18]. Antioch Dunes National Wildlife Refuge applied chemical agents to inhibit ripgut brome only to drastically reduce the hatchability of Lange's metalmark butterfly, an internationally endangered species [19]. Therefore, in preventing and controlling IASs, NPs must understand potential side effects (i.e., negative externalities) and choose the most appropriate approach [18].

Sightseeing and recreational activities are another challenge to NPs in preventing and controlling IASs. This challenge originates in the fact that tourists are a medium of IAS proliferation. Thus, IAS prevention measures can impinge on tourist sightseeing and recreation activities. Therefore, NP business management confronts conflicting objectives: providing sightseeing opportunities and preventing IAS proliferation. Many studies confirm that tourists contribute to IAS proliferation. Lonsdale and Lane [20] investigated IASs attached to tourist vehicles in Kakadu NP. They collected 1960 seeds from 304 vehicles and found that one vehicle alone carried 789 seeds belonging to 15 plants. Research by Whinam, et al. [21] on tourists at the Macquarie Island Nature Reserve produced similar findings. An investigation of the clothing, belongings, and travel equipment of 64 visitors found 981 seeds belonging to 15 families and 90 plants. The cited studies confirm that tourists are a medium by which IASs enter NPs. Therefore, the more tourists that there are, the higher the risk of NPs being impacted by IASs. In terms of managing the IAS impact, NPs face two conflicting management objectives: reducing IAS risk and maintaining normal sightseeing and recreational activities.

Preventing and controlling IASs can negatively impact tourists in many ways. For example, the ecological impact of IAS prevention and control can reduce the quality of tourist recreation [22]. Chemicals used to prevent and control IASs are harmful to tourist health [23]. Closing controlled areas reduces the available recreational area. An IAS inspection prior to entrance into the park delays tourists. All these examples represent negative externalities of IAS prevention and control. Such externalities decrease tourist recreational satisfaction with NPs, which pressures NPs managers to adopt corrective measures $[24,25]$. However, if an NP repeatedly modifies its IAS prevention and control strategy in response to tourist complaints, it may compromise the efficiency of the strategy and aggravate the IAS problem. Therefore, when planning measures to prevent and control IASs, NPs must carefully consider any negative externalities and tourist comments on such externalities. Currently, there is a lack of research on the preferences of NPs tourists regarding the negative externalities associated with IAS prevention and control. A detailed analysis of NP tourist preferences regarding the negative externalities of NP IAS prevention and control would help NPs evaluate tourist responses to the trade-offs between the externalities and the tourists' willing-to-pay price. Then, based on the trade-offs and the willing-to-pay price, prevention and control measures could be designed that have the least impact on tourists (which represents the tourists' first preference). With the help of such an analysis, NPs could avoid the conflict between tourist recreational demands and IAS prevention and control.

To close the previously noted research gap, this study investigates the trade-offs between NP tourists and the externalities of IAS prevention and control measures. Taiwan's Shei-Pa National 
Park is chosen as the research focus. The following section explains the measures adopted to prevent and control IASs and generalizes the externalities of the measures for use in an attributes-of-choice experiment. This study's most important contribution is its focus on the negative externalities of IAS prevention and control measures. The results of this study reflect our effort to consider both the need for NPs to prevent and control IASs and their dependence of the support of NP tourists.

\section{Overview of Shei-Pa NP, Taiwan}

Shei-Pa NP is a mountain-type NP features glacial landforms, ice-age relict species, unique landscapes and aboriginal culture. There is an ice-age relict species called the Formosan land-locked salmon (Oncorhynchus masou formosanus), an endemic subspecies of Taiwan, which proves the impacts of the glaciation process and the uplifting of mountain ranges on Taiwan. It is a miraculous and major discovery of biogeography. The main peak of Snow Mountain, a height of $3886 \mathrm{~m}$, is the highest point in the NP and the second-highest peak in Taiwan. Mount Dabajian, $3492 \mathrm{~m}$ above sea level, has a sharp and steep shape and is surrounded by rugged terrain and cliffs. It is the core area of the Atayal native tribe and the birthplace of the ancestors of the Saisiyat native tribe. Those fragile and rare ecological and cultural features of Shei-Pa NP attract a large number of visitors. How to balance conservation demands and recreational impacts is a major challenge in the management of Shei-Pa NP, and the IAS issue is a top priority.

The management office of the Shei-Pa NP once investigated the IAS in the park. The research found a total of 65 species of invasive plants, which could be categorized into 21 families and 48 genera, accounting for about a quarter of invasive plants in Taiwan. In terms of the proportion of IAS to native plants of Taiwan, the percentage for Shei-Pa NP was 20\%, much higher than the $6 \%$ for the rest of Taiwan. As visitors and hikers come and go, these IAS plants are likely to invade precious and rare habitats. For example, IAS plants have already spread to the Formosan land-locked salmon's habitat, where they have become dominant plants, which could impact the recovery of this endangered species. Exotic wildcats in the area prey on the protected green-backed tit (Parus monticolus), plumbeous water redstart (Phoenicurus fuliginosus) and Formosan shrew (Episoriculus fumidus). The exotic red-billed blue magpie (Urocissa erythrorhyncha) is observed to nest and feed together with the blue magpie (Urocissa caerulea), an endemic species in Taiwan. This behavior indicates that the two might hybridize, causing genetic pollution problems. These phenomena reflect the problem that IAS are invading Shei-Pa NP, which should be taken seriously.

\section{Data and Methodology}

\subsection{Negative Externalities of IAS Prevention and Control Measures and Questionnaire Design, Attributes and Levels}

To study the public preference for negative externalities of IAS prevention and control using the choice experiment method, the first step is to develop the attributes and levels of the questionnaires. In terms of the topic of negative externalities of IAS prevention and control, items to be considered include the target species to be prevented and controlled, control methods applicable to the target species, the characteristics of the ecosystem of the target species, cost, side effects and so on. The actual prevention and control plan is the result of multi-party assessment and is highly professional and technical. As far as surveys for public opinions are concerned, such information must be presented. However, it is impossible to present all the information combinations in the questionnaires. Moreover, the public likely cannot fully understand professional and technical information. Information combination, along with professional and technical issues, pose the most difficult obstacles to this research.

Professional and technical information should be assessed by professionals, but the opinions of the public should not be neglected. Therefore, we rely on both literature review and focus groups to arrive at a solution. We arranged three focus group discussions. Each time, there were six people, of whom two are IAS prevention and control professionals and the other four are not. With reference to 
the IUCN's top 100 IAS directory, we collect and summarize the target species, control and prevention methods applicable to target species, characteristics of the ecosystem of the target species, cost, and side effects as materials for the discussion of focus groups. The conclusions of the focus groups include the following: (1) conducting research on each target species one by one is too slow and not affordable; (2) the prevention and control measures are highly professional and technical, making them difficult for the public to understand, and they should be evaluated and planned by professionals; and (3) what the public is concerned about is the impact of those prevention and control measures. It is therefore recommended to assess the externalities of the control and prevention measures, rather than evaluating specific target species (e.g., RIFA) or specific methods of control (e.g., pesticides).

Based on the results of the focus groups and literature review, and considering the characteristics of the Shei-Pa NP, we summarize four negative externalities (or the so-called attributes in the choice experiment method) of the IAS prevention and control measures for visitors of NPs, including "the intensity of the impact of the prevention and control on the ecosystem", "recreational or visiting range reduced by those measures", "the possibility that visitors' health is negatively affected by the measures", and "waiting time of visitors caused by the implementation of the measures". We also determine the intensity of the four externalities (the so-called levels in the choice experiment method). Below are the explanations of the content and meaning of those attributes and levels.

1. The intensity of the impact of the prevention and control on the ecosystem (ecological shocks)

Biodiversity is an important factor that attracts visitors to NPs [22]. However, IAS prevention and control measures could cause serious negative impacts on the biodiversity of the treated areas, therefore reducing the utility of visitors in recreational activities. For a sense of the impact of IAS prevention and control measures on NPs' ecosystem, see the case studies of Booderee NP [16], Capitol Reef NP [17], the Queensland conservation reserve [18], and the Antioch Dunes National Wildlife Refuge [19]. Among those, Stark et al. (2012) estimated that the impact of IAS measures on the number of affected groups reached 30\%. According to the research of Stark, et al. [19], and based on the suggestion of Ryan, et al. [26] that each level of the attribute should be $15 \%$ higher or lower than the baseline value or the previous level, we divide the intensity of the impact of the prevention and control on ecosystem to five levels at $0 \%, 15 \%, 30 \%, 45 \%$, and $60 \%$.

2. Recreational or visiting range reduced by those measures (tour range)

IAS prevention and control measures would affect the range of visitors' activities. For example, after applying chemicals in the IAS prevention areas, the areas would be closed to prevent visitors from coming into contact with those chemicals. When using manual labor and chain saws, the affected areas should be closed for the work. Tourist activities are often prohibited around the monitored facilities to avoid interference. However, there might be antagonism toward partial closure of some NP areas [27]. Therefore, limitation of the scope of visitors' recreational activities caused by the implementation of the prevention and control measure of IAS is also one of the externalities of those measures. This attribute is expressed as the percentage of reduced recreational or visiting range and is set at $0 \%, 20 \%, 40 \%, 60 \%$ and $80 \%$.

3. The possibility that visitors' health is negatively affected by the measures (health risk)

IAS prevention and control measures include the use of chemicals, but chemical agents could affect human health and cause diseases [23]. Using chemical methods for prevention and control in recreational areas might affect the health of visitors, which is one of the negative externalities of prevention and control measures. Currently, there is no relevant literature that provides specific and empirical data on the level of negative impacts of IAS chemical prevention and control on visitors' health. We assume probability values of each level at $0 \%, 30 \%, 60 \%$ and $90 \%$.

4. Waiting time of visitors caused by the implementation of the measures (waiting time) 
Because visitors cherish travel time [28], delay or waiting time would reduce their utility. Therefore, when the implementation of IAS prevention and control measures in NPs causes delay, it becomes an externality of IAS prevention and control measures. According to LeDoux and Martin [29], those measures would cost each visitor approximately 15-20 min. This research sets the attribute of levels of visitors' waiting time at $0,20,40$ and $60 \mathrm{~min}$.

To assess the willingness to pay for the various attributes of the externalities of the IAS prevention and control measures, we establish the attribute of "additional and special fee for prevention and control collected at the entrance of attractions or parks".

5. Additional and special fee for prevention and control collected at the entrance of attractions or parks (prevention and control fee)

Based on the research of Adams, et al. [30] on Florida residents' willingness to pay for access to state parks, the fee levels are set at 40 NTD, 80 NTD, 120 NTD, 160 NTD, and 200 NTD, with a 120 NTD baseline.

After determining the attributes and levels, we use the orthogonal design methods to generate alternatives and obtain a total of 25 alternatives. Then, we divide these 25 alternatives into groups of 5 , and each group is called a scenario. Furthermore, to avoid the condition in which none of the 5 alternatives are accepted by respondents but they are required to make a choice, we add a "status $q u o^{\prime \prime}$ option to each scenario [31]. Thus, each questionnaire has 5 scenarios and each scenario has 6 alternatives.

\subsection{Econometrics Analysis}

We use the random utility maximization model to analyze the data. In this model, the utility of respondent when choosing alternative $i$ could be represented by the following formula:

$$
U_{i n}=V_{i n}+\varepsilon_{i n}, \forall i \in C_{n}
$$

$U_{i n}$ is the utility of respondent $n$ with alternative $i$, and $C_{n}$ is the set of all available choices to respondent $n$. Because actual utility of the respondent could not be observed, we use $V_{\text {in }}$ to represent observable items and a random variable $\varepsilon_{\text {in }}$ for unobservable items. If $\varepsilon_{\text {in }}$ is i.i.d. with type 1 extreme value distribution (i.e., McFadden's conditional logit model), the probability of respondent $n$ choosing alternative $i$ could be represented by Formula (2):

$$
P_{\text {in }}=\frac{\exp \left(\mu V_{i n}\right)}{\sum_{j \in \mathrm{C}} \exp \left(\mu V_{j n}\right)}
$$

In addition, we establish the linear function with the attribute of $V_{\text {in }}$ as in Formula (3):

$$
V_{\text {in }}=A S C_{i}+\beta_{1} X_{i 1} \ldots+\beta_{K} X_{i K}
$$

$\beta_{K}$ is the coefficient of attribute $K . X_{i K}$ represents attribute $K$ of alternative $i$ chosen by the respondent. Alternative-specific constant (ASC) is an indicator variable, showing whether the corresponding option is selected or not. Its estimated value shows the function that other attributes could not represent or the utility of the "status quo" [32]. If ASC is positive, it means that respondent prefers "status quo" to any other alternatives. Choosing another alternative would lower utility; therefore, the respondent chooses "status quo" and vice versa.

With the above assumptions, the marginal rate of substitution of each pair of attributes is represented by Formula (4):

$$
\operatorname{MRS}_{S K}=-\frac{\beta_{K}}{\beta_{S}}
$$

If the price attribute is $\beta_{S}$, the estimation of Formula (4) is the willingness to pay for $\beta_{K}$. 
This research conducted a questionnaire survey in Shei-Pa NP from March to November 2014. We used two-stage sampling to select the time and respondents of the survey. First, a stratified random sampling method was used to choose the survey time, and then, the systematic sampling method was used to obtain the samples. In this research, 4 survey months were randomly selected out of 12, specifically, March, July, August, and November. Then, the date of the survey was randomly selected for each month. On the day of the survey, we selected a number, sorted as the date of the day, between 0 and 9, from the random number table. On the same day, the visitor who passed the questionnaire distribution point in the order of the selected number became the first respondent. After that, three was used as the sampling unit, i.e., every third person who passed the questionnaire distribution point would be the next respondent. By randomly selecting the survey time and the initial respondent, we obtained the samples required by random sampling. A total of 692 people were surveyed, and 81 refused, making the rate of rejection $8.54 \%$. In the end, a total of 611 questionnaires were recovered. Among them, 9 were invalid, and 602 were valid, making the effective return ratio $98.5 \%$. Each respondent was required to answer questions regarding 5 scenarios. However, some of them did not complete all the scenarios, reducing the number of analyzable scenarios to 2998.

\section{Results}

The estimates of all attribute parameters are negative and statistically significant (Table 1), indicating that visitors believe that the externalities of IAS prevention and control measures significantly reduce their utility. The more the utility falls, the more difficult it is for the corresponding IAS prevention and control measure to get visitors' support. Using Formula (4), we calculate the willingness to pay of visitors for the negative externalities of IAS prevention and control measures (Table 1). The least preferred side effects are "ecological shock", followed by "health risk", "waiting time", and "tour range", and the last is the "prevention and control fee". These results reveal that the antipathy caused per unit of "ecological shock" is higher than that for any other types of externalities per unit. The utility of "none of the above" is -1.8732 , indicating that visitors believe that the utility of IAS prevention and control is higher than not having such prevention and control. These results respond to research purposes (1) and (4). Specifically, the public's willingness to pay for the IAS prevention and control measures is positive. Negative externalities of IAS prevention and control reduce the welfare of the public and reduce the support for IAS prevention and control measures. However, the proportion of various negative externalities could be adjusted following the results related to research purposes (2) and (3). Although negative externalities are unavoidable, visitors' support of IAS prevention and control measures could still be maximized.

MWTP was calculated based on parameter estimates of Equation (4).

Detailed parameter estimates of various externalities and willingness to pay are as below. "Ecological shock" is estimated to be -0.014 , indicating that it would reduce visitors' utility. Conversely, when ecological shock declines by $1 \%$, visitors' welfare would increase by 9.3 NTD. In other words, visitors are willing to pay 9.3 NTD to reduce $1 \%$ of ecological shock. "Tour range" is -0.0099 , showing that reduced visiting range would lower visitors' utility. In terms of willingness to pay, a $1 \%$ reduction of visiting range caused by prevention and control equals an increase in visitors' welfare of 6.6 NTD. The estimate for "health risk" is -0.0109 , indicating that the impact of prevention and control on the health of visitors would reduce their utility. A decline of $1 \%$ of health risk from prevention and control would increase visitors' welfare by 7.3 NTD. The value for waiting time is -0.0107 , meaning that waiting would reduce visitors' utility. Saving 1 min of waiting time could increase visitors' welfare by 7.1 NTD. The estimate for "prevention and control fee" is -0.0015 , which is smaller than those of other attributes and indicates that visitors are less inclined to other negative externalities caused by IAS prevention and control and are willing to pay to reduce these negative externalities. 
Table 1. Estimation results.

\begin{tabular}{|c|c|c|}
\hline Attributes & Coefficient & MWTP \\
\hline ASC & $\begin{array}{c}-1.8732 \text { *** } \\
0.0846\end{array}$ & \\
\hline Ecological Shocks & $\begin{array}{c}-0.014^{* * *} \\
0.00107\end{array}$ & -9.3 \\
\hline Tour Range & $\begin{array}{c}-0.0099^{* *} \\
0.00082\end{array}$ & -6.6 \\
\hline Health Risk & $\begin{array}{c}-0.0109^{* * *} \\
0.0007\end{array}$ & -7.3 \\
\hline Waiting Time & $\begin{array}{c}-0.0107^{* * *} \\
0.00104\end{array}$ & -7.1 \\
\hline Prevention and Control Fee & $\begin{array}{c}-0.0015 \text { * } \\
0.0004\end{array}$ & \\
\hline Observations & 2998 & \\
\hline Log-Likelihood & -5034 & \\
\hline AIC & 10,080 & \\
\hline
\end{tabular}

These results provide detailed guidelines for improving visitors' acceptance of IAS prevention and control. For example, estimates for "ecological shock" and "tour range" are -0.014 and -0.0099 , respectively, showing that visitors are more willing to exchange reduced recreational range for lower ecological shock. Specifically, visitors are willing to sacrifice up to $1.41 \%$ tour range for a $1 \%$ reduction in ecological shock. Therefore, if limiting the tour range could help the NP management carry out IAS prevention and control measures more easily and use methods with less ecological shock, visitors would still support the measures even if their tour range is reduced.

The estimate for "health risk" is -0.0109 , which has a 1-to-1 ratio with "tour range". This result shows that visitors are willing to sacrifice recreational area to reduce the likelihood of health risks. They are willing to sacrifice up to $1.1 \%$ of tour range for a 1\% decline in health risk. Expanding the quarantine area could reduce visitors' contact with materials used for IAS prevention and control and avoid any harms to them. The larger the restricted area, the lower the health risk. From the perspective of visitors, the acceptable scope of quarantine could not be expanded indefinitely or even up to the closure of NP. It all depends on the potential health risk. They are willing to accept at most a $1.1 \%$ reduction in recreational area for a $1 \%$ drop in health risk.

The absolute value of the estimate of "ecological shock" is higher than that of "health risk", showing that visitors are more concerned about the ecological impact of IAS prevention and control than about their own health. The ratio of the two is 1.28 , indicating that visitors could accept a higher risk to health, but they are willing to take up to $1.28 \%$ more health risk to reduce $1 \%$ of ecological impact in the face of an IAS prevention and control measure with lower ecological shock.

The estimate of "waiting time" is similar to "health risk". Its ratio (trade-off) with other externalities of IAS prevention and control measures is also similar to that of "health risk", and so is the interpretation of the meaning of the estimates.

\section{Discussion}

The results show that there are negative externalities associated with IAS prevention and control measures, which are unwanted because they reduce the utility of the public. However, though negative externalities are unavoidable, visitors' support of IAS prevention and control measures could still be maximized by adjusting the proportions of various types of negative externalities. 
The conclusion of this research agrees with previous literature that IAS prevention and control is supported by the research results. The study of Rolfe and Windle (2014) on the willingness to pay of residents of Brisbane, Australia for RIFA prevention found a negative ASC, indicating that respondents were prone to choosing IAS prevention and control. That result is similar to our ASC estimate. Adams et al. (2011) studied Florida residents' willingness to pay for accessing state parks and concluded that each visitor was willing to pay an average of $\$ 5.41$ to reduce the coverage of exotic invasive plants. The estimate of biodiversity was positive, which meant that the decline in biodiversity caused by IAS prevention and control would decrease visitors' utility. Their result conforms to our negative estimate of "ecological shock". Our estimate of "tour range" is negative, indicating that limiting visitors' recreational area for IAS prevention would reduce their utility. This result is in line with the conclusion of Beville et al. (2012) that closing recreational fishing areas would lower utility.

This research also proposes several elements that have not been studied by previous research but are more in line with the needs of NPs for the prevention and control of IAS. We obtain visitors' preference for various negative externalities of IAS prevention and control measures and their willingness to pay to avoid those externalities. Based on those results, NPs could analyze whether IAS prevention and control conform to visitors' trade-offs of various negative externalities so that they may choose the plan that maximizes visitors' welfare. Our results are more specific, more in line with the needs of NPs in the actual planning of IAS prevention and control measures and consider the utility of visitors of NPs.

This study finds that respondents prefer IAS prevention and control, low ecological impact and no reduction in tour range. Those findings agree with the conclusions of the studies by Rolfe and Windle (2014), Adams et al. (2011), and Beville et al. (2012). However, this study goes further by exploring the trade-offs of those variables. Specifically, visitors would like to exchange a $1.4 \%$ reduction in tour range for a $1 \%$ decrease in ecological impact. Compared with previous research, these findings better answer the needs of the actual planning of IAS prevention and control. NPs preserve important ecological and cultural landscapes and are popular tourist attractions. However, IAS seriously interrupt the operations and management of NPs and create a unique dilemma. To solve this problem, this paper proposes two approaches, a focus on the externalities of IAS prevention and control and the evaluation of the public's trade-offs of various externalities in IAS prevention and control. The first advocates that the NPs' management must carefully consider the externalities of the prevention and control measures before making any choices. From the perspective of visitors, the second evaluates visitors' trade-offs of various negative externalities associated with the measures, so as to provide a basis for NPs to make decisions and choose the IAS prevention and control measures that have least impact on visitors (maximum utility) and are most supported by visitors.

\section{Conclusions and Policy Suggestions}

This paper uses the choice experiment method to study the preference of visitors of NPs for negative externalities in IAS prevention and control measures and selects visitors to Shei-Pa NP as the research objects. The topic of this research is the negative externalities of IAS prevention and control measures, which have not yet been fully discussed by academia. Moreover, there is scarcely any research on the public preference (trade-off) for those negative externalities. Therefore, the research topic of this paper is highly innovative. Our research uses a stratified random sampling method to decide the time of the onsite questionnaire survey. By combining random selection of the first and the last samples and systematic sampling in the onsite survey, we increase the randomness of respondents' chances of being selected. Because those methods are rarely used, they could serve as a reference for other onsite survey research studies.

The study shows that visitors prefer IAS prevention and control more so than not. They care most about the measures' impact on ecological environment, followed by personal health risk, waiting time and, finally, reduced recreational area. The estimate of ASC tells us whether visitors support IAS prevention and control measures. A negative ASC indicates that the utility of choosing "none of the above" is lower than that of any prevention and control measure. Thus, we could conclude that 
visitors prefer the prevention and control of IAS. In terms of visitors' willingness to pay for negative externalities of IAS prevention and control measures, they are willing to pay 9.3 NTD for a $1 \%$ reduction in ecological shock, 7.3 NTD for a 1\% decrease in health risk, 7.1 NTD for 1 min less waiting time, and 6.6 NTD for a $1 \%$ reduction in tour range. Decreasing any negative externalities of IAS prevention and control measures could improve visitors' welfare. Prevention and control measures that conform to the trade-off relationship between various externalities are those that could maximize visitors' welfare.

This study contributes to both empirical application and academic research. Although it is a case study of Taiwan's Shei-Pa NP, its findings are consistent with previous studies, meaning that the findings of this research are generalizable and can serve as reference for other NPs that are planning IAS prevention and control. Additionally, the methods used in this study, such as trade-off relations between various negative externalities of IAS prevention and control measures, are not seen in previous research but could better address the needs of IAS prevention and control. The onsite random sampling method could provide reference for other studies using onsite surveys to improve the randomness of sampling and the efficiency of statistical analysis.

Although the research objects of this study are Taiwan's Shei-Pa NP and its visitors, its findings could provide reference for other areas that are under IAS prevention and control. Attributes used in this study are not unique or exclusive to the Taiwan Shei-Pa NP. Instead, they are collected and summarized from case studies and research findings around the world. They are common in various settings of daily life, such as parks, green spaces, campuses, lakes and streams in many countries. When taking IAS prevention and control measures in those living areas, at least one or even several attributes discussed in this paper would be involved. Of course, the estimates and trade-off relations should vary with cultural, social, economic, environmental differences in various countries and the characteristics of areas under prevention and control, but there are no obvious differences in the types of attributes. While carrying out IAS prevention and control, these areas could use the attributes in this paper to estimate the parameters or borrow the estimates of this paper to evaluate the IAS prevention and control measures that cause the least negative externalities to the public, so as to gain public support for IAS prevention and control measures. Major contributions of this paper to the research and practice of ecological conservation are summarizing the negative externalities of IAS prevention and control measures; putting forward an empirical approach to evaluate the public's willingness to pay for IAS prevention and control measures and for negative externalities of the measures; exploring the public's trade-offs of various negative externalities of IAS prevention and control measures; and proposing to reduce the impact of negative externalities on the public by adjusting the combination of those externalities, so as to improve public support for IAS policy and sustainability of NPs.

Author Contributions: Conceptualization, T.-M.L. and C.-M.T.; Methodology, T.-M.L.; Software, T.-M.L.; Validation, T.-M.L. and C.-M.T.; Formal Analysis, T.-M.L.; Investigation, C.-M.T.; Resources, T.-M.L.; Data Curation, C.-M.T.; Writing-Original Draft Preparation, C.-M.T.; Writing—Review \& Editing, T.-M.L.; Visualization, C.-M.T.; Supervision, T.-M.L.; Project Administration, T.-M.L.; Funding Acquisition, T.-M.L.

Funding: This research was funded by Ministry of Science and Technology, Taiwan, grant number NSC 101-2621-M-002-032, NSC 102-2621-M-002-027, Most 103-2621-M-002-019, and Most 105-2119-M-110-012.

Conflicts of Interest: The authors declare that they have no conflict of interest.

\section{References}

1. Eagles, P.F.; McCool, S.F.; Haynes, C.D.; Phillips, A. Sustainable Tourism in Protected Areas: Guidelines for Planning and Management; IUCN Gland: Gland, Switzerland, 2002; Volume 8.

2. Mount, A.; Pickering, C.M. Testing the capacity of clothing to act as a vector for non-native seed in protected areas. J. Environ. Manag. 2009, 91, 168-179. [CrossRef]

3. Perrings, C. Mitigation and adaptation strategies for the control of biological invasions. Ecol. Econ. 2005, 52, 315-325. [CrossRef]

4. Liu, T.-M.; Yang, W.-C. Using choice experiments to inform management of black-faced spoonbill reserve in Taiwan. Cogent Soc. Sci. 2019, 5, 1611984. [CrossRef] 
5. Balmford, A.; Green, J.M.; Anderson, M.; Beresford, J.; Huang, C.; Naidoo, R.; Walpole, M.; Manica, A. Walk on the wild side: Estimating the global magnitude of visits to protected areas. PLoS Biol. 2015, 13, e1002074. [CrossRef]

6. Liu, T.-M. Testing on-site sampling correction in discrete choice experiments. Tour. Manag. 2017, 60, $439-441$. [CrossRef]

7. Lee, C.E. Evolutionary genetics of invasive species. Trends Ecol. Evol. 2002, 17, 386-391. [CrossRef]

8. Thomas, M.B.; Reid, A.M. Are exotic natural enemies an effective way of controlling invasive plants? Trends Ecol. Evol. 2007, 22, 447-453. [CrossRef]

9. Boon, P.I.; Fluker, M.; Wilson, N. A ten-year study of the effectiveness of an educative programme in ensuring the ecological sustainability of recreational activities in the Brisbane Ranges National Park, South-eastern Australia. J. Sustain. Tour. 2008, 16, 681-697. [CrossRef]

10. Shrestha, B.K.; Dangol, D.R. Impact of Mikania micrantha HBK invasion on diversity and abundance of plant species of Chitwan National Park, Nepal. J. Inst. Sci. Technol. 2014, 19, 30-36. [CrossRef]

11. Dove, C.J.; Snow, R.W.; Rochford, M.R.; Mazzotti, F.J. Birds consumed by the invasive Burmese python (Python molurus bivittatus) in Everglades National Park, Florida, USA. Wilson J. Ornithol. 2011, 123, 126-131. [CrossRef]

12. Walker, L.R.; Vitousek, P.M. An invader alters germination and growth of native dominant tree in Hawai'i. Ecology 1991, 72, 1449-1455. [CrossRef]

13. Lenz, L.; Taylor, J.A. The influence of an invasive tree species (Myrica faya) on the abundance of an alien insect (Sophonia rufofascia) in Hawai'i Volcanoes National Park. Biol. Conserv. 2001, 102, 301-307. [CrossRef]

14. Mukwada, G.; Chingombe, W.; Taru, P. Strifes of the frontier: An assessment of Acacia mearnsii related park-community conflicts in the Golden Gate Highlands National Park, South Africa. J. Integr. Environ. Sci. 2016, 13, 37-54. [CrossRef]

15. Salinas, R.A.; Stiver, W.H.; Corn, J.L.; Lenhart, S.; Collins, C.; Madden, M.; Vercauteren, K.C.; Schmit, B.B.; Kasari, E.; ODOI, A.; et al. An individual-based model for feral hogs in Great Smoky Mountains National Park. Nat. Resour. Model. 2015, 28, 18-36. [CrossRef]

16. Catford, J.; Lindenmayer, D.; Hobbs, R. Non-target impacts of weed control on birds, mammals and reptiles. Ecosphere 2017. [CrossRef]

17. Alston, D.G.; Tepedino, V.J.; Bradley, B.A.; Toler, T.R.; Griswold, T.L.; Messinger, S.M. Effects of the insecticide phosmet on solitary bee foraging and nesting in orchards of Capitol Reef National Park, Utah. Environ. Entomol. 2007, 36, 811-816. [CrossRef] [PubMed]

18. Bower, D.S.; Valentine, L.E.; Grice, A.C.; Hodgson, L.; Schwarzkopf, L. A trade-off in conservation: Weed management decreases the abundance of common reptile and frog species while restoring an invaded floodplain. Biol. Conserv. 2014, 179, 123-128. [CrossRef]

19. Stark, J.D.; Chen, X.D.; Johnson, C.S. Effects of herbicides on Behr's metalmark butterfly, a surrogate species for the endangered butterfly, Lange's metalmark. Environ. Pollut. 2012, 164, 24-27. [CrossRef]

20. Lonsdale, W.; Lane, A. Tourist vehicles as vectors of weed seeds in Kakadu National Park, Northern Australia. Biol. Conserv. 1994, 69, 277-283. [CrossRef]

21. Whinam, J.; Chilcott, N.; Bergstrom, D. Subantarctic hitchhikers: Expeditioners as vectors for the introduction of alien organisms. Biol. Conserv. 2005, 121, 207-219. [CrossRef]

22. Corona, P.; Chirici, G.; McRoberts, R.E.; Winter, S.; Barbati, A. Contribution of large-scale forest inventories to biodiversity assessment and monitoring. For. Ecol. Manag. 2011, 262, 2061-2069. [CrossRef]

23. Ip, K.K.; Liang, Y.; Lin, L.; Wu, H.; Xue, J.; Qiu, J.-W. Biological control of invasive apple snails by two species of carp: Effects on non-target species matter. Biol. Control 2014, 71, 16-22. [CrossRef]

24. Clark, S.G.; Vernon, M.E. Governance challenges in joint inter-jurisdictional management: The Grand Teton National Park, Wyoming, elk case. Environ. Manag. 2015, 56, 286-299. [CrossRef]

25. Saayman, M.; Martín, J.C.; Román, C. There is no fuzziness when it comes to measuring service quality in national parks. Tour. Econ. 2016, 22, 1207-1224. [CrossRef]

26. Ryan, M.; Gerard, K.; Amaya-Amaya, M. Using Discrete Choice Experiments to Value Health and Health Care; Springer Science \& Business Media: Berlin, Germany, 2007; Volume 11.

27. Gundersen, V.; Mehmetoglu, M.; Vistad, O.I.; Andersen, O. Linking visitor motivation with attitude towards management restrictions on use in a national park. J. Outdoor Recreat. Tour. 2015, 9, 77-86. [CrossRef] 
28. Zhang, H.; Zhang, J.; Kuwano, M. An integrated model of tourists' time use and expenditure behaviour with self-selection based on a fully nested Archimedean copula function. Tour. Manag. 2012, 33, 1562-1573. [CrossRef]

29. LeDoux, C.B.; Martin, D.K. Proposed BMPs for Invasive Plant Mitigation during Timber Harvesting Operations; USDA Forest Service: Washington, DC, USA, 2013.

30. Adams, D.C.; Bwenge, A.N.; Lee, D.J.; Larkin, S.L.; Alavalapati, J.R. Public preferences for controlling upland invasive plants in state parks: Application of a choice model. For. Policy Econ. 2011, 13, 465-472. [CrossRef]

31. Hanley, N.; Mourato, S.; Wright, R.E. Choice modelling approaches: A superior alternative for environmental valuatioin? J. Econ. Surv. 2001, 15, 435-462. [CrossRef]

32. Hoyos, D. The state of the art of environmental valuation with discrete choice experiments. Ecol. Econ. 2010, 69, 1595-1603. [CrossRef]

(C) 2019 by the authors. Licensee MDPI, Basel, Switzerland. This article is an open access article distributed under the terms and conditions of the Creative Commons Attribution (CC BY) license (http://creativecommons.org/licenses/by/4.0/). 


\title{
Determinants of Behavioral Intentions in the Context of Sport Tourism with the Aim of Sustaining Sporting Destinations
}

\author{
Yunduk Jeong ${ }^{1}$, Suk-Kyu Kim ${ }^{2}$ and Jae-Gu Yu ${ }^{3, *}$ \\ 1 Department of Sport Management, Kyonggi University, Suwon 16277, Korea; fcgangwon@nate.com \\ 2 Department of Sports Science, Dongguk University, Gyeongju 38066, Korea; skkim2018@dongguk.ac.kr \\ 3 Department of Sport Industry, Chungang University, Anseong 17546, Korea \\ * Correspondence: unlisted@cau.ac.kr
}

Received: 25 April 2019; Accepted: 29 May 2019; Published: 31 May 2019

\begin{abstract}
This study was undertaken to examine structural relationships between event quality, tourist satisfaction, place attachment, and behavioral intentions with emphasis on the mediating effects of tourist satisfaction and place attachment on relations between event quality and behavioral intentions in the context of a small-scale recurring sporting event. Responses obtained from 350 attendees were collected and analyzed. Results showed positive impacts of (a) event quality, tourist satisfaction and place attachment on behavioral intentions, (b) event quality and tourist satisfaction on place attachment, and (c) event quality on tourist satisfaction, and demonstrated (d) tourist satisfaction and place attachment partially mediate relationships between event quality and behavioral intentions and that (e) place attachment partially mediates the relationship between tourist satisfaction and behavioral intentions.
\end{abstract}

Keywords: event quality; tourist satisfaction; place attachment; behavioral intentions; sport tourism; sporting event

\section{Introduction}

Intense competition between countries and regions in the tourism industry has resulted in focus on behavioral intentions, such as intention to recommend and revisit, being viewed as a prime concern of tourism destinations and their marketing organizations [1,2]. In particular, since the number of people using the Internet has dramatically increased, intention to recommend has become increasingly important as tourists can easily disseminate frank opinions, experiences, and knowledge of visited destinations worldwide through social media using, for example, personal blogs, Facebook, YouTube, and Instagram [3]. Thus, it is critical that destination managers consider behavioral intentions a priority for future success.

Destination marketing organizations should attempt to develop effective and attractive tourism marketing strategies to arouse potential tourists' interests and persuade tourists to visit to a destination [4]. The majority of scholars suggest hosting sporting events provides tourists, especially sports fans, an array of enjoyable and memorable experiences [5]. Sporting events are referred to as hedonic services that offer many tangible and intangible benefits to host countries and regions [6]. Notably, it has been reported small-scale sporting events can attract many domestic tourists and improve destination image almost as effectively as mega sporting events [5]. For this reason, small local communities not able to host large-scale sporting events should consider small-scale recurring sporting events a cost-effective means of attracting tourists.

Given that behavioral intentions are important for sustainable destination management in the context of tourism, destination managers should understand how tourists' behavioral intentions are 
formed. Increasing numbers of researchers have concluded tourist satisfaction is probably a key factor of behavioral intentions [7], and it is widely acknowledged that customer satisfaction is crucial for assessing the success of marketing strategies. For this reason, research during the past two decades has focused on this concept and explored its antecedents and consequences [8]. Additionally, the link between place attachment and behavioral intentions is viewed as being of considerable importance in tourism marketing literature [9]. The notion of place attachment has received increasing attention from destination marketers over recent years because the concept represents emotional bonds between tourists and places they have visited and is regarded as a definitive tourism marketing strength [10] that might induce behavioral intentions like loyalty.

Although a number of studies have provided a necessary foundation for sport tourism studies, they have three major limitations. First, few published studies have identified positive relationships between event quality and destination-related variables (e.g., place attachment) or outcome variables (e.g., behavioral intentions). In other words, despite the importance of event quality in the context of attracting sport tourists [11], scant empirical work has been conducted to address whether quality has direct consequences. Thus, the present study sought to expand current theorizations by examining the mutual relationships between event quality, tourist satisfaction, place attachment, and behavioral intentions in response to recent requests from sport tourism researchers to provide more exhaustive analyses.

Second, although prior studies have been conducted to expand understanding of tourist satisfaction, they largely ignored the mediating effects of place attachment on relations between tourist satisfaction and behavioral intentions. Rather, most researchers focused on the direct link between tourist satisfaction and behavioral intentions and overlooked the possibility that place attachment mediates relations between tourist satisfaction and behavioral intentions [2]. Based on existing research on direct effects between these three variables, tourists would seem to be likely to consider 'place attachment' an important component of the path between tourist satisfaction and behavioral intentions. In the present study, to promote theory development, we investigated the mediating effect of tourist satisfaction on the relation between event quality and behavioral intentions, and that of place attachment on the relation between event quality and behavioral intentions. Naturally, the four conditions proposed by Baron and Kenny's [12] were satisfied to establish the validities of mediating effects.

Third, in a sport and tourism context, the majority of studies have focused on large-scale sporting events such as the Olympic Games, the FIFA (Fédération Internationale de Football Association) World Cup, the European Football Championships, and the Asian Games. However, small-scale recurring sporting events have not been well studied. Wong and Tang [5] found small-scale sporting events receive relatively little attention in sport or event tourism literature and argued that such events could lead to loyalty. Hence, it would appear studies on small-scale recurring sporting events add a new perspective to sport tourism literature.

Accordingly, the current study sought to explore mutual relationships between event quality, tourist satisfaction, place attachment, and behavioral intentions collectively and systematically and to place emphasis on their mediating effects at a small-scale recurring sporting event.

\section{Theoretical Background, Research Hypotheses, and Model}

\subsection{Information about Gyeongju City}

Gyeongju is a city near the southeastern coast of mainland South Korea and in 2017 had a population of 257,903 [13]. The city was the capital of the 1000-year-long Silla dynasty, an ancient kingdom, which later governed the Korean peninsula [14]. Thanks to the rich cultural and historical heritage of this dynasty, Gyeongju is known as 'The museum without walls' and has more tombs, temples, rock carvings, pagodas, cultural artifacts, and Buddhist statuaries than any other location in South Korea [15]. In 2000, UNESCO (The United Nations Educational, Scientific and Cultural Organization) designated The Gyeongju Historic Area, which contains the ruins of temples and palaces, 
outdoor pagodas and statuary, reliefs, Buddhist art, and the Yangdong Folk Village (a traditional clan village dating back to the Joseon dynasty (added in 2010)), a World Cultural Heritage Site [16].

Gyeongju is one of the most popular tourist destinations for international and domestic visitors, especially among those interested in the cultural heritage of the Silla dynasty and the architecture of the Joseon Dynasty [17]. In addition, Gyeongju has placed emphasis on sporting events, especially marathon events, which allow the city to promote its rich tangible cultural heritage via through TV broadcasts [18]. The Gyeongju International Marathon is held annually and attracts around 20,000 spectators and participants [19], and local authorities are hopeful that those visiting the event will recommend it to others and revisit, and thus, promote Gyeongju as a sporting destination [18].

\subsection{Event Quality}

Undoubtedly, event quality is a crucial topic in sport tourism research and service quality is one of its most important components [11]. Service quality has received much attention in recent years and is recognized as a critical factor because of the influence it has on the psychological and behavioral responses of tourists [20]. Service quality is defined as "a customer's overall impression of the relative inferiority/superiority of an organization and its services" [21]. Based on existing literature, the current study defines event quality as spectator/participant overall judgement regarding the value of an event attribute. In the context of sport tourism, some studies have defined four dimensions of event quality, that is, game quality, interaction quality, outcome quality, and physical environment quality [11]. According to Jin et al. [11], game quality represents spectators' impressions about the quality of the game, interaction quality 'the performance of managing staff and volunteers responsible for delivering services,' outcome quality "the link between consumers' perceptions of gains received from interactions with the service provider," and physical environment quality is the spectators' evaluations of the qualities of physical facilities. Therefore, in the current study, event quality consisted of 12 items representing game quality, interaction quality, outcome quality, and physical environment quality.

\subsection{Tourist Satisfaction}

Tourist satisfaction has been widely shown to be one of the most substantial factors of future success, and much has been published on the topic. The theory of tourist satisfaction is rooted in the marketing literature and according to Oliver [22], "satisfaction is defined as pleasurable fulfillment, that is, the consumer senses that consumption fulfilled some need, desire, goal, or so forth, and that this fulfillment is pleasurable." Some marketing researchers proposed the 'expectancy disconfirmation model', which compares initial expectations and perceived performance after consumption and determines the final state of satisfaction [23]. In other words, if a customer perceives he/she has received more value than expected, he/she is satisfied. Some have suggested the cognitive-affective model, which is regarded as being more insightful because consumer perceived satisfaction is more likely to arise spontaneously by cognitive and affective processing [24]. According to Yoon and Uysal [25], tourist satisfaction can be measured using multiple items, and based on previous studies, Lee [26] proposed three travel satisfaction items—overall satisfaction, satisfaction versus expectation, and satisfaction—based on considerations of invested time and effort. The present study used this scale to measure tourist satisfaction.

A vast amount of the marketing literature is dedicated to the direct relationship between service quality and customer satisfaction [27], and in the context of tourism, some studies have shown that service quality and satisfaction are related [28]. Existing research suggests that if tourists highly value a product or service provided at a sporting event, they are more likely to have a high level of satisfaction. Thrane [29] examined possible links between service quality (festival quality), overall satisfaction, and intention to recommend and concluded service quality is a predictor of satisfaction. Yoon, Lee, and Lee [30] also empirically tested relationships between festival quality, visitor satisfaction, and loyalty using a structural approach and demonstrated that improving festival quality can become a 
fundamental strategic metric for building tourist satisfaction. Their findings suggested event quality is related to tourist satisfaction. Accordingly, the current study proposed the following hypothesis.

H1: Event quality influences tourist satisfaction.

\subsection{Place Attachment}

Place attachment has received much attention in tourism, environmental psychology, and environmental education literature [31]. The word attachment represents affect and the word place represents the environmental setting to which people have strong attachments [9]. According to Morgan [32], place attachment may be defined as "an affective bond to a particular geographical area and to the meaning attributed to that bond." In other words, place attachment is commonly conceptualized as an overall connectedness or bond between a person and a location. In many studies, place attachment has been dichotomized into place identity and place dependence. Place identity refers to "the symbolic importance of a place as a repository for emotions and relationships that give meaning and purpose to life" [33], and place dependence reflects "how well a setting serves goal achievement given an existing range of alternatives" [34].

In the context of hospitality management, empirical evidence shows that event quality is influenced by place attachment. Alexandris, Kouthouris, and Meligdis [35] tested the effect of service quality (physical environment quality, interaction quality, and outcome quality) on place attachment on 264 recreational skiers and showed that physical environment quality and interaction quality play central roles in engendering place attachment. Baek, Ryu, and Chae [36] held the view event quality leads to place attachment. They examined the impact of festival quality on visitor place attachment and behavioral intention and concluded that festival quality is critical for stimulating place attachment. Given the direct impact reported in some studies, it was expected that event quality would positively impact place attachment.

H2: Event quality influences place attachment.

In line with the development theory of place attachment [32], Hosany et al. [33] acknowledged a link between tourist satisfaction and place attachment. They developed a model based on the development theory of place attachment that provided some useful evidence on the positive effect of tourist satisfaction on place attachment. Su, Cheng, and Huang [37] empirically demonstrated tourist satisfaction is related to place identity and place dependence, and Zenker and Rütter [38] emphasized that satisfaction with a city is a direct antecedent of attachment to the city. Considering previous studies, it seems reasonable to assume that tourist satisfaction positively influences place attachment.

H3: Tourist satisfaction influences place attachment.

\subsection{Behavioral Intention}

Behavioral intention has long constituted an important domain of research in interdisciplinary studies. The concept can be depicted as a tourists' intention to revisit based on past memorable experiences at a destination and to engage in word-of-mouth [39]. Most researchers have long regarded behavioral intention as one of the most reliable sources of information regarding potential tourists [40]. Lee and Han [41] ascertained behavioral intention can decrease negative recognition and perceived risk of destination, which indicates behavioral intention should be considered when evaluating the success of an event.

The link between event quality and behavioral intention might be explained by a study conducted by Jin et al. [11]. They proposed a conceptual model that included event quality, perceived value, destination image, and behavioral intention, and concluded event quality leads to behavioral intention. Likewise, Moon, Ko, Connaughton, and Lee [42] examined theoretical relationships between service quality at a sporting event, perceived value, destination image, and behavioral intention, and revealed 
that service quality significantly influenced behavioral intention. The results of these previous studies hint at a relationship between event quality and behavioral intention, and thus, the current study felt confident enough to postulate a relationship between event quality and behavioral intention.

\section{H4: Event quality influences behavioral intentions.}

The symbolic relationship between satisfaction and behavioral intentions is a frequent topic in interdisciplinary studies [43], and it is generally believed tourist satisfaction leads to behavioral intention. Chen et al. [2] provided supportive evidence for this link and examined relationships between experience quality, perceived value, satisfaction, and behavioral intention for heritage tourists. Their findings revealed that the more satisfied tourists are with experiences, the more likely they are to revisit and recommend the destination to others. Hutchinson, Lai, and Wang [44] reinforced the link between tourist satisfaction and behavioral intentions. An integrative model that explored relationships between quality, value, equity, satisfaction, and behavioral intentions was developed and tested using golf supporters, and it was concluded tourist satisfaction is a strong predictor of behavioral intentions. Therefore, the current study adopted the following hypothesis regarding the impact of tourist satisfaction on behavioral intentions.

\section{H5: Tourist satisfaction influences behavioral intentions.}

The relationship between place attachment and behavioral intention has received renewed attention during the past few years. For example, a tourism study by Lee et al. [9] presented evidence showing that place attachment is related to behavioral intention. They examined the relations between place attachment (place identity and place dependence), festival satisfaction, and loyalty (word-of-mouth, revisit intentions, and destination preference), and detected a significant, positive relationship between place identity and revisit intentions, and between place dependence and word-of-mouth. Loureiro [45] explored the relationship between experience economy, place attachment, and behavioral intentions in the context of rural tourism and maintained place attachment acts as an antecedent of behavioral intentions. Accordingly, it seems reasonable to suggest place attachment affects behavioral intention.

\section{H6: Place attachment influences behavioral intentions.}

With respect to the mediating effect of tourist satisfaction between event quality and behavioral intentions, Lee, Graefe, and Burns [7] demonstrated that satisfaction plays a mediating role between service quality and behavioral intentions. In terms of the mediating effect of place attachment between event quality and behavioral intentions, Alexandris, Kouthouris, and Meligdis [38] indicated that service quality is a key driver of place attachment, which in turn affects consumers' loyalty like behavioral intentions. Also, Jin et al.'s [11] study showed that event quality has a direct effect on behavioral intentions. Regarding the mediating effect of place attachment between tourist satisfaction and behavioral intentions, according to Lee, et al. [9] study, satisfaction indirectly affects word-of-mouth (WOM) via place dependence, and revisit intention via place identity/social bonding of place attachment. Also, existing studies reported satisfaction is a direct antecedent of behavioral intentions [44]. These results strongly support the intervening role of place attachment. Accordingly, the current study proposes the following three hypotheses:

H7: Tourist satisfaction mediates the relationship between event quality and behavioral intentions.

H8: Place attachment mediates the relationship between event quality and behavioral intentions.

H9: Place attachment mediates the relationship between tourist satisfaction and behavioral intentions.

Based on previous studies, the current study proposes the following conceptual model (Figure 1). 


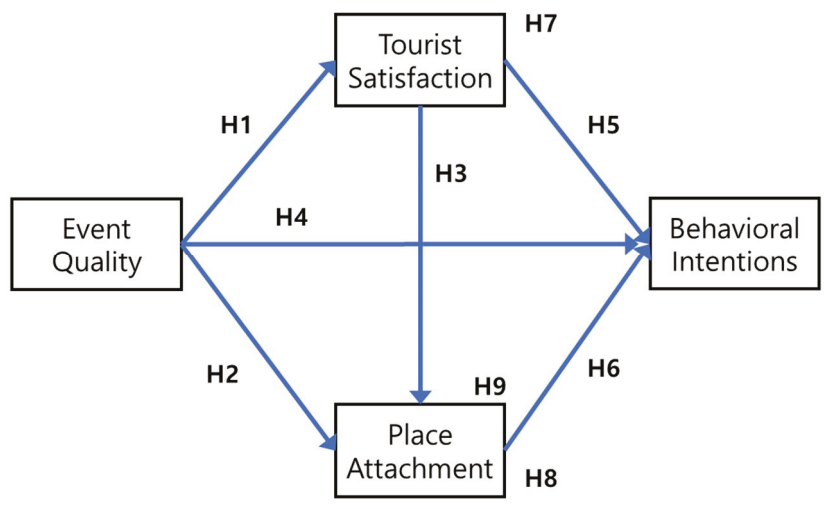

Figure 1. The conceptual model.

\subsection{What is Sport Tourism and How It Divides?}

Sport tourism has resurged in the past few years as it makes an important contribution to local economy such as improving destination image and attracting a flow of visitors [46]. In fact, many local governments in South Korea view sport tourism as one of the most critical driving forces of tourism success, and strive to host sport events. According to Gibson's [47] study, sport tourism can be described as leisure-based travel that takes individuals temporarily away from their mundane life to participate in or watch a sporting event or to venerate a sporting heritage. Therefore, the author suggests that sport tourism can be described as three main behaviors: participating, watching, and visiting/venerating. Based on this view, there is explicit consensus among sport tourism researchers that sport tourism is divided into three categories: event sport tourism, active sport tourism, and nostalgia sport tourism [47]. Event sport tourism depicts tourists passively engage in a sporting event as spectators whose main purpose of travel is to cheer for their country and favorite star players or to spend time with family members, friends, and social groups [48]. As such, many countries and regions increasingly consider mega sporting events such as Olympic Games and World Championships as a core component of the destination marketing strategy [6]. Active sport tourism describes tourists actively engage in a sporting event as participants in order to improve mental and physical health, relieve the stress, and meet personal goals [49] (Figure 2). Nostalgia sport tourism represents tourists visit famous sporting venues such as stadiums and museums of the mega sporting events and professional teams [47].

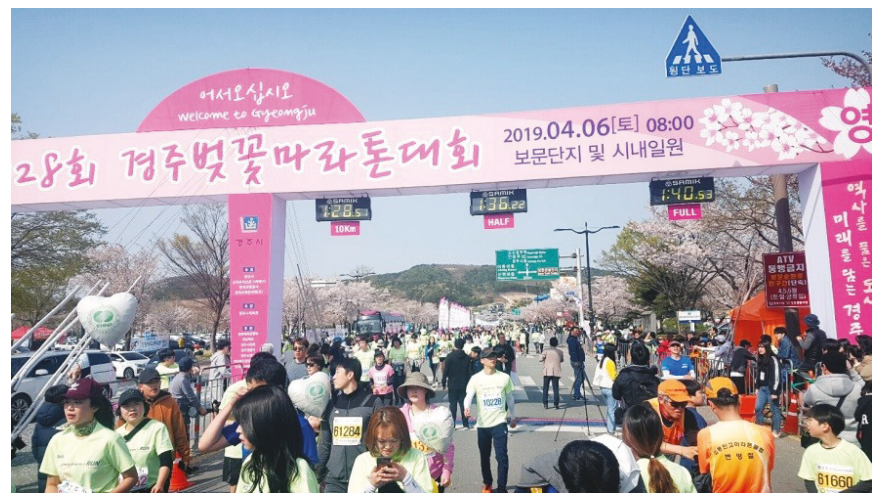

Figure 2. Active sport tourism. 


\section{Method}

\subsection{Data Collection}

Data for the current study was collected from spectators and participants that attended the 2018 International Marathon in Gyeonju City. To collect a representative sample, the authors and two trained research assistants administered a face-to-face, questionnaire-based survey on 21 October 2018. Using a convenient sampling procedure, 400 people were approached to take part in in the survey. No-one was solicited to participate. Finally, 375 questionnaires were completed, but 25 were subsequently eliminated due nonanswered questions. The remaining 350 satisfactorily completed questionnaires were analyzed. The sample was almost equally split between makes (64\%) and females (36\%). The majority were aged between 40 and 49 years $(40.3 \%, n=141)$, university educated $(44.3 \%, n=155)$, married $(68.6 \%, n=240)$, and earned $\$ 40,000-59,999(21.7 \%, n=76)$ per annum.

\subsection{Measures}

The survey instrument was developed based on the study objectives and a literature review. A seven-point Likert scale, anchored on unimportant and extremely important (scored as 1 and 7 , respectively) was used. The survey questionnaire addressed five domains: (a) event quality, (b) tourist satisfaction, (c) place attachment, (d) behavioral intention, and (e) demographic information. Event quality was assessed using 12 items (3 items addressed game quality, 3 interaction quality, 3 outcome quality, and 3 physical environment quality); these items were adapted from those used by Jin et al. [11] and by Jae Ko, Zhang, Cattani, and Pastore [50]. Tourist satisfaction was assessed using 3 items derived from Yoon et al. [25]. Place attachment was assessed using 6 items (3 items addressed place identity and 3 place dependence), and these items were adapted from Hosany et al. [33] and Williams and Vaske [51]. Behavioral intention was assessed using 6 items (3 items addressed intention to recommend and 3 intention to revisit), and these items were adapted from Hosany et al. [33], Žabkar, Brenčič and Dmitrović [52], and Lam and Hsu [53]. To ensure face validity, three experts with theoretical knowledge were invited to examine the survey items.

\subsection{Validity and Reliability}

The nine-factor (game quality, interaction quality, outcome quality, physical environment quality, tourist satisfaction, place identity, place dependence, and intention to recommend and intention to revisit) confirmatory factor analysis (CFA) model used had a total of 288 degrees of freedom. The measurement model indicated reasonable fit with data $\left(x^{2} / d f=2.531, \mathrm{NFI}=0.923, \mathrm{RFI}=0.907\right.$, $\mathrm{TLI}=0.941, \mathrm{SRMR}=0.046$ and $\mathrm{RMSEA}=0.066$ ). All model fit indices were within recommended thresholds [54] (Table 1).

Construct validity was assessed using convergent and discriminant validities. To evaluate convergent validity, we calculated factor loadings, construct reliability $(C R)$, and average variance extracted (AVE). All factor loading values were $<0.5$ and significant $(p<0.001)$ (Table 1$)$. CR values all exceeded the recommended value of 0.7 (range from 0.827 to 0.914 ) and AVE values all exceeded the minimum requirement of 0.5 (range 0.615 to 0.780 ). Therefore, convergent validity was satisfactory (Table 1).

If all the items in the structural equation model are used as observed variables, the complexity of the model increase, which may cause problems such as the size of the sample, the model fit indices, and the significance of the parameter estimation [55]. When there are too many items, the number of items should be adjusted through item parceling [56]. Item parceling is a method of parceling using average when analysis is difficult in the structural equation model due to the large number of observable variables and has become increasingly popular in various area such as education, psychology, and marketing in recent years [56]. To utilize item parceling, convergent validities regarding the three observable variables of game quality, interaction quality, outcome quality, physical environment 
quality, place identity, place dependence, intention to recommend, and intention to revisit should be satisfactory.

Table 1. Confirmatory factor analysis (CFA) results for measurement model.

\begin{tabular}{|c|c|c|c|c|}
\hline Scale Items & $\beta$ & CR & AVE & Cronbach \\
\hline \multicolumn{5}{|l|}{ Game quality } \\
\hline It is exciting to watch skillful players & 0.736 & & & \\
\hline Skill performance of players is excellent & 0.763 & 0.827 & 0.615 & 0.783 \\
\hline Information about this evet is easy to obtain & 0.750 & & & \\
\hline \multicolumn{5}{|l|}{ Interaction quality } \\
\hline The demeanor of the staff is pleasant & 0.841 & & & \\
\hline I enjoy being with the other spectators & 0.888 & 0.862 & 0.676 & 0.860 \\
\hline Spectators follow the regulations & 0.733 & & & \\
\hline \multicolumn{5}{|l|}{ Outcome quality } \\
\hline I view the outcome of this event favorably & 0.864 & & & \\
\hline I really enjoy the social interaction at this event & 0.831 & 0.863 & 0.677 & 0.895 \\
\hline I spend quality time with my friend/family at this event & 0.884 & & & \\
\hline \multicolumn{5}{|c|}{ Physical environment quality } \\
\hline The facility is clean and well maintained & 0.852 & & & \\
\hline I am impressed with the design of the facility & 0.891 & 0.880 & 0.709 & 0.904 \\
\hline The facility is safe & 0.876 & & & \\
\hline \multicolumn{5}{|l|}{ Tourist satisfaction } \\
\hline Gyeongju is better than I expected & 0.866 & & & \\
\hline It is worth visiting Gyeongju & 0.914 & 0.870 & 0.691 & 0.918 \\
\hline Overall, I am satisfied with holidaying in Gyeongju & 0.893 & & & \\
\hline \multicolumn{5}{|l|}{ Place identity } \\
\hline Gyeongju is a very special destination to me & 0.894 & & & \\
\hline I feel very attached to Gyeongiu & 0.909 & 0.870 & 0.691 & 0.910 \\
\hline Holidaying in Gyeongju means a lot to me & 0.845 & & & \\
\hline \multicolumn{5}{|l|}{ Place dependence } \\
\hline GJ is the best for what I like to do on holidays & 0.816 & & & \\
\hline I would not substitute GJ with any other places & 0.884 & 0.849 & 0.654 & 0.784 \\
\hline I got more satisfaction out of holidaying in GJ than others & 0.736 & & & \\
\hline \multicolumn{5}{|l|}{ Intention to recommend } \\
\hline I will recommend Gyeongju to other people & 0.930 & & & \\
\hline I will say positive things about Gyeongju to other people & 0.960 & 0.903 & 0.756 & 0.955 \\
\hline I will encourage friends and relatives to visit Gyeongju & 0.920 & & & \\
\hline \multicolumn{5}{|l|}{ Intention to revisit } \\
\hline If had to decide again I would choose GJ again & 0.970 & & & \\
\hline I want to visit Gyeongju & 0.922 & 0.914 & 0.780 & 0.956 \\
\hline I intend to visit Gyeongju in next 12 months & 0.918 & & & \\
\hline $\mathrm{x}^{2} / d f=2.531, \mathrm{NFI}=0.923, \mathrm{RFI}=0.907, \mathrm{TLI}=0.941, \mathrm{SI}$ & $\mathrm{D}$ & 6 & 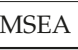 & $=0.066$ \\
\hline
\end{tabular}

To evaluate convergent validities, we confirmed factor loadings, CR and AVE whose values all exceeded the recommended values (Table 1). Since the convergent validities concerning all observable variables was satisfactory, these variables were parceled as event quality, place attachment, and behavioral intentions, respectively. In other word, each subfactor of event quality, place attachment, and behavioral intentions turned into four, two, and two observable variables, respectively. 
To evaluate discriminant validity, we compared the square root of AVE for each construct with correlations between pairs of latent variables [57]. Since it was difficult to verify all latent variables, the pair with the highest correlation was selected and verified. The highest correlation found was 0.729 (between tourist satisfaction and behavioral intentions) (See Table 2) and its square value $(0.729)^{2}$ was 0.531. AVE for tourist satisfaction was 0.692 and AVE for behavioral intentions was similar at 0.670. Since AVE values were all greater than the square value (0.531), discriminant validity was satisfactory.

Reliability estimates (Cronbach's alpha) for game quality, interaction quality, outcome quality, physical environment quality, tourist satisfaction, place identity, place dependence, intention to recommend, and intention to revisit were above the recommended threshold of 0.7 (range from 0.783 to 0.956 ), indicating measures were reliable (Table 1 ).

Table 2. Correlations between constructs.

\begin{tabular}{ccccc}
\hline Constructs & $\mathbf{1}$ & $\mathbf{2}$ & $\mathbf{3}$ & $\mathbf{4}$ \\
\hline Event quality & 1 & & & \\
Tourist satisfaction & $0.686^{* *}$ & 1 & & \\
Place attachment & $0.415^{* *}$ & $0.596^{* *}$ & 1 & \\
Behavioral intentions & $0.606^{* *}$ & $0.729^{* *}$ & $0.621^{* *}$ & 1 \\
\hline & $* * p<0.01$. & & &
\end{tabular}

\section{Results}

Overall, the structural equation modeling (SEM) achieved acceptable fit $\left(x^{2}=0.103 .093, d f=38\right.$, $x^{2} / d f=2.713, p<0.001$ ). The absolute fit index (Goodness of Fit Index $=0.951$, Standardized Root Mean Residual $=0.031$, Adjusted Goodness of Fix Index $=0.915$ and Root Mean Error of Approximation $=0.07$ ), and incremental fit index (Normed Fit Index $=0.968$ and Relative Fit Index $=0.954$ ) were satisfactory.

Table 3. Structural parameter estimates.

\begin{tabular}{|c|c|c|c|c|}
\hline Hypothesis & Path & Coefficient & $t$-value & Results \\
\hline 1 & Event quality $\rightarrow$ tourist satisfaction & 0.736 & $13.775^{* * *}$ & Accepted \\
\hline 2 & Event quality $\rightarrow$ place attachment & 0.112 & $2.063 *$ & Accepted \\
\hline 3 & Tourist satisfaction $\rightarrow$ place attachment & 0.647 & $11.224^{* * *}$ & Accepted \\
\hline 4 & Event quality $\rightarrow$ behavioral intentions & 0.143 & $2.690^{* *}$ & Accepted \\
\hline 5 & Tourist satisfaction $\rightarrow$ behavioral intentions & 0.436 & $5.461^{* * *}$ & Accepted \\
\hline 6 & Place attachment $\rightarrow$ behavioral intentions & 0.420 & $5.150 * * *$ & Accepted \\
\hline
\end{tabular}

The estimates of structural coefficients (paths) provided the basis for testing the proposed hypotheses. As shown in Table 3, event quality had a significantly positive effect on tourist satisfaction $(0.736, p<0.001)$ and place attachment $(0.112, p<0.05)$, which offers supportive evidence for hypotheses 1 and 2 . The path coefficient from tourist satisfaction to place attachment was positive and statistically significant $(0.647, p<0.001)$, supporting hypothesis 3 . Hypothesis 4 was also supported, as event quality significantly and positively influenced behavioral intentions $(0.143, p<0.01)$. Tourist satisfaction and place attachment were found to influence behavioral intentions directly $(0.436$ and 0.420 , respectively, $p<0.001$ ), which supported hypotheses 5 and 6 .

As shown in Table 4, the mediating effect of tourist satisfaction on the relation between event quality and behavioral intentions was found to be statistically significant. In other words, tourist satisfaction showed a partial mediating effect, which supported hypothesis 7. Furthermore, the mediating effect of place attachment on the relation between event quality and behavioral intentions was found to be statistically significant. In other words, place attachment showed a partial mediating 
effect, which supported hypothesis 8 . The mediating effect of place attachment on the relation between tourist satisfaction and behavioral intentions was found to be statistically significant, that is, place attachment showed a partial mediating effect, which supported hypothesis 9 .

Table 4. Mediating effects of tourist satisfaction and place attachment.

\begin{tabular}{cccccc}
\hline \multicolumn{1}{c}{ Path } & & Coefficient & S.E. & $\begin{array}{c}\text { 95\% CI } \\
\text { (Bias-corrected) }\end{array}$ & $p$ \\
\hline Event quality $\rightarrow$ Tourist & Indirect effect & 0.406 & 0.042 & $0.328 \sim 0.468$ & 0.004 \\
satisfaction $\rightarrow$ Behavioral & Direct effect & 0.200 & 0.069 & $0.093 \sim 0.308$ & 0.006 \\
intentions & Total effect & 0.606 & 0.052 & $0.517 \sim 0.693$ & 0.003 \\
\hline Event quality $\rightarrow$ Place & Indirect effect & 0.185 & 0.113 & $0.056 \sim 0.392$ & 0.008 \\
attachment $\rightarrow$ Behavioral & Direct effect & 0.421 & 0.125 & $0.213 \sim 0.598$ & 0.001 \\
intentions & Total effect & 0.606 & 0.052 & $0.517 \sim 0.693$ & 0.003 \\
\hline Tourist satisfaction $\rightarrow$ Place & Indirect effect & 0.172 & 0.129 & $0.047 \sim 0.413$ & 0.011 \\
attachment $\rightarrow$ Behavioral & Direct effect & 0.557 & 0.139 & $0.304 \sim 0.712$ & 0.001 \\
intentions & Total effect & 0.729 & 0.032 & $0.673 \sim 0.776$ & 0.003 \\
\hline
\end{tabular}

As shown in Table 4, the mediating effect of tourist satisfaction on the relation between event quality and behavioral intentions was found to be statistically significant. In other words, tourist satisfaction showed a partial mediating effect, which supported hypothesis 7. Furthermore, the mediating effect of place attachment on the relation between event quality and behavioral intentions was found to be statistically significant. In other words, place attachment showed a partial mediating effect, which supported hypothesis 8 . The mediating effect of place attachment on the relation between tourist satisfaction and behavioral intentions was found to be statistically significant, that is, place attachment showed a partial mediating effect, which supported hypothesis 9 .

\section{Discussion and Conclusions}

The main objective of this study was to investigate integrated model positive relationships between event quality, tourist satisfaction, place attachment, and behavioral intentions with emphasis on the mediating effects of tourist satisfaction and place attachment at a small-scale recurring sporting event. The proposed model allows the identification of relationships between (1) event quality and tourist satisfaction, (2) event quality and place attachment, (3) tourist satisfaction and place attachment, (4) event quality and behavioral intentions, (5) tourist satisfaction and behavioral intentions, and (6) place attachment and behavioral intentions, and showed (7) tourist satisfaction and place attachment had partial mediating effects on the relation between event quality and behavioral intentions, and that (8) place attachment partial mediated the relation between tourist satisfaction and behavioral intentions.

From a theoretical point of view, this study provides several contributions to research in marketing, tourism, hospitality, and sport management. First, this study is a response to recent calls to researchers to consider event quality as an antecedent that influences outcome variables such as tourist satisfaction, place attachment, and behavioral [11,42]. In other words, our findings demonstrate the merit of including event quality in studies aimed at better understanding and predicting tourist behaviors, whereas previous studies have almost exclusively considered destination image and tourist satisfaction as determinants of behavioral intentions [40,58]. Furthermore, no previous study has explored structural relationships between event quality, tourist satisfaction, place attachment, and behavioral intentions. Furthermore, our study delineates four dimensions (game quality, interaction quality, outcome quality, and physical environment quality) and suggests 12 items that can be used to accurately reflect the characteristics of sporting event quality [11].

Second, this study sheds new light on the link between tourist satisfaction and place attachment. In fact, the relationship between tourist satisfaction and place attachment is the subject of debate. Some researchers insist satisfaction be conceptualized as antecedent of place attachment [59], whereas 
others argue that satisfaction be conceptualized as an outcome of place attachment [60]. Based on a comprehensive analysis by Morgan [32] on place attachment, Hosany et al. [33] held the view that tourist satisfaction is an antecedent of place attachment. Likewise, Lee et al. [9] found "to a greater extent, satisfied visitors become attached to a community due to attributes and features that support their experience-related needs." Thus, the consensus appears to be that tourist satisfaction is an antecedent of place attachment.

Third, this study heeds the call of Loureiro [45] by seeking to understand the role of place attachment in a tourist behavioral model. More specifically, Loureiro emphasized place attachment is central to the understanding of behavioral intentions and urged further investigation be conducted on the relationship. In this respect, the present study creates a link between place attachment and behavioral intentions by showing that an affective bond with the destination, based on past meaningful and memorable experiences, may lead to an intention to engage in word-of-mouth communications and revisit. Also, we tested the relationship between place attachment and behavioral intentions, and found place attachment is an important predictor of behavioral intentions among sport tourists, which is in accord with previous studies $[9,61]$.

Fourth, this study contributes to tourism studies by examining the mediating effects of tourist satisfaction and place attachment on the relation between event quality and behavioral intentions. Our results highlight the need to include event quality, tourist satisfaction, and place attachment in models aimed at determining sport tourists' intentions to recommend and revisit a destination. Notably, our findings demonstrate tourist satisfaction partially mediates place attachment. The relations found in the present study make an important contribution to the sport tourism literature because they reveal that while event quality plays a pivotal role in nurturing behavioral intentions, tourist satisfaction and place attachment also play key roles by strengthening behavioral intentions. Furthermore, they indicate intention to recommend and revisit can be developed through tourist satisfaction and place attachment as well as by event quality.

Fifth, the study also revealed place attachment mediated the relationship between tourist satisfaction and behavioral intentions. In particular, although the proposed model was grounded in extant literature, the present study is the first to incorporate place attachment as a mediator of the relation between satisfaction and behavioral intentions. Furthermore, the results obtained show place attachment has a partial mediating effect and confirm that tourist satisfaction indirectly influences behavioral intentions via place attachment. Previous studies have overlooked the mediating role of place attachment on the path from tourist satisfaction to behavioral intentions. By exploring the mediating effect of place attachment, the present study helps to address a gap in current tourism marketing literature and represents an important step toward understanding tourist psychology and behavior.

From a practical point view, the results of the present study provide meaningful guidelines to destination marketers in the context of sporting tourism destinations. First of all, they demonstrate that strengthening the quality of an event should be considered a priority by destination marketers. Our findings demonstrate that event quality has a positive effect on tourist satisfaction, place attachment, and behavioral intentions, and should encourage destination marketers to make strenuous efforts to improve the four latent dimensions of event quality (i.e., game quality, interaction quality, outcome quality, and physical environment quality) to meet the needs and desires of sporting tourists.

To improve game quality, event organizers should endeavor to attract talented and competent players to participate. It is intuitively assumed that if competent players are involved, tourists' interests in the event will be increased. To enhance interaction quality, volunteers and staff should be trained and educated well, because acts of kindness can have considerable positive impacts on tourists [33], whereas displays of a negative demeanor or inhospitality result in negative attitudes toward the destination and event. To develop physical environment quality, destination managers should increase safety-orientated security and maintain the cleanliness of facilities. Constant efforts are required to develop positive perceptions of environment quality and to ensure the success of 
sporting events. In addition, the current study suggests hosting events offer excellent educational opportunities for vocational college and university students, especially those majoring in marketing, tourism, hospitality, or sport management. Students could participate as volunteers to help and communicate with visitors. Such efforts would contribute to the development of event quality and help create positive behavioral intentions.

Several limitations of this study warrant consideration. First, the cohort was composed individuals visiting the venue for the first-time and repeat visitors, which may differ in terms of travel characteristics, travel motivations, and post-trip evaluations [33]. The current study suggests this aspect be explored in the future research by multigroup analysis. Second, the proposed model includes only a handful of constructs, and thus, to more fully understand sport tourist psychology and behaviors, we suggest additional antecedents (e.g., emotional experience, destination image, and motivation) of tourist satisfaction and behavioral intentions be included in future studies. Third, relations between tourist satisfaction and place attachment were investigated to determine the path between event quality and behavioral intentions, and there is a possibility that other variables such as perceived value and brand image also have mediating effects. These variables should also be addressed to provide a more comprehensive framework.

Author Contributions: Conceptualization, Y.J. and S.K.; Methodology, Y.J. and J.Y.; Software, Y.J. and J.Y.; Validation, J.Y. and S.K.; Formal Analysis, Y.J.; Investigation, S.K.; Resources, Y.J.; Data Curation, S.K.; Writing-Original Draft Preparation, Y.J.; Writing-Review and Editing, Y.J. and S.K.; Visualization, J.Y.; Supervision, J.Y.; Project Administration, S.K.; Funding Acquisition, J.Y.

Funding: This research received no external funding.

Conflicts of Interest: The authors declare no conflicts of interest.

\section{References}

1. Chuang, L.M.; Chen, P.C.; Chen, Y.Y. The determinant factors of travelers' choices for pro-environment behavioral intention-integration theory of planned behavior, unified theory of acceptance, and use of technology 2 and sustainability values. Sustainability 2018, 10, 1869. [CrossRef]

2. Chen, C.F.; Chen, F.S. Experience quality, perceived value, satisfaction and behavioral intentions for heritage tourists. Tour. Manag. 2010, 31, 29-35. [CrossRef]

3. Munar, A.M.; Jacobsen, J.K. Motivations for sharing tourism experiences through social media. Tour. Manag. 2014, 43, 46-54. [CrossRef]

4. Xu, Z.; Zhang, H.; Zhang, C.; Xu, M.; Dong, N. Exploring the role of emotion in the relationship between museum image and tourists' behavioral intention: The case of three museums in Xi'an. Sustainability 2019, 11, 559. [CrossRef]

5. Wong, I.A.; Tang, S.L. Linking travel motivation and loyalty in sporting events: The mediating roles of event involvement and experience, and the moderating role of spectator type. J. Travel Tour. Mark. 2016, 33, 63-84. [CrossRef]

6. Fourie, J.; Santana-Gallego, M. The impact of mega-sport events on tourist arrivals. Tour. Manag. 2011, 32, 1364-1370. [CrossRef]

7. Lee, J.; Graefe, A.R.; Burns, R.C. Service quality, satisfaction, and behavioral intention among forest visitors. J. Travel Tour. Mark. 2004, 17, 73-82. [CrossRef]

8. Del Bosque, I.R.; San Martín, H. Tourist satisfaction a cognitive-affective model. Ann. Tour. Res. 2008, 35, 551-573. [CrossRef]

9. Lee, J.; Kyle, G.; Scott, D. The mediating effect of place attachment on the relationship between festival satisfaction and loyalty to the festival hosting destination. J. Travel. Res. 2012, 51, 754-767. [CrossRef]

10. Tsai, S.P. Place attachment and tourism marketing: Investigating international tourists in Singapore. Int. J. Tour. Res. 2012, 14, 139-152. [CrossRef]

11. Jin, N.; Lee, H.; Lee, S. Event quality, perceived value, destination image, and behavioral intention of sports events: The case of the IAAF World Championship, Daegu, 2011. Asia Pac. J. Tour. Res. 2013, 1, 849-864. [CrossRef] 
12. Baron, R.M.; Kenny, D.A. The moderator-mediator variable distinction in social psychological research: Conceptual, strategic, and statistical considerations. J. Personal. Soc. Psychol. 1986, 51, 1173-1182. [CrossRef]

13. Lee, S.W. The Population of Gyeongju Decreased by 1549 Compared to Last Year. Gjnews, 11 January 2018. Available online: http://www.gjnews.com/default/index_view_page.php?part_idx=4\&idx=56759 (accessed on 10 March 2019).

14. Yoo, B.C. Gyeongju, You Can Ride a Bike and Feel the Past, Present, and Future. Seoul ilbo, 14 May 2018. Available online: http://www.seoulilbo.com/news/articleView.html?idxno=315331 (accessed on 11 March 2019).

15. Jang, S.J. Gyeongju is the Museum without Walls. Gyeongbuk ilbo, 10 May 2018. Available online: http: //www.kbsm.net/default/index_view_page.php?part_idx=213\&idx=206343 (accessed on 13 March 2019).

16. Lee, P.H. Gyongju is the City with the Largest Number of World Heritage Sites in South Korea. Gjnews, 2 November 2017. Available online: http://www.gjnews.com/default/index_view_page.php?part_idx=442\& idx=55783 (accessed on 13 March 2019).

17. Lee, J.H.; Lee, S.B.; Kim, D.H. Satisfaction evaluation of urban tourism attributes in Gyeongju city using revised IPA: Focused on Gyeongju MICE foreign participants in 2016. Aca. Soc. Eve. Con. 2018, 14, 163-178.

18. Kim, S.J. Influence of regional marathon race on regional community. Korean Soc. Leisure Sci. 2014, 5, 1-10.

19. Lee, S.P. Gyeongju City is Going to Attract Tourists in the Fall. Daegu ilbo, 11 October 2017. Available online: http://www.idaegu.co.kr/news/articleView.html?idxno=233970 (accessed on 19 March 2019).

20. Theodorakis, N.D.; Kaplanidou, K.; Karabaxoglou, I. Effect of event service quality and satisfaction on happiness among runners of a recurring sport event. Leisure Sci. 2015, 37, 87-107. [CrossRef]

21. Bitner, M.J.; Hubbert, A.R. Encounter Satisfaction Versus Overall Satisfaction versus Quality. In Service Quality: New Directions in Theory and Practice; Sage Publications, Inc.: London, UK, 1994; Volume 34, pp. 72-94.

22. Oliver, R.L. Whence consumer loyalty? J. Mark. 1999, 63, 33-44. [CrossRef]

23. Oliver, R.L. A cognitive model of the antecedents and consequences of satisfaction decisions. J. Mar. Res. 1980, 17, 460-469. [CrossRef]

24. Huang, S.; Weiler, B.; Assaker, G. Effects of interpretive guiding outcomes on tourist satisfaction and behavioral intention. J. Travel Res. 2015, 54, 344-358. [CrossRef]

25. Yoon, Y.; Uysal, M. An examination of the effects of motivation and satisfaction on destination loyalty: A structural model. Tour. Manag. 2015, 26, 45-56. [CrossRef]

26. Lee, C.K.; Yoon, Y.S.; Lee, S.K. Investigating the relationships among perceived value, satisfaction, and recommendations: The case of the Korean DMZ. Tour. Manag. 2007, 28, 204-214. [CrossRef]

27. Spreng, R.A.; Mackoy, R.D. An empirical examination of a model of perceived service quality and satisfaction. J. Retail. 1996, 72, 201-214. [CrossRef]

28. Oh, H. Service quality, customer satisfaction, and customer value: A holistic perspective. Int. J. Hosp. Manag. 1999, 18, 67-82. [CrossRef]

29. Thrane, C. Music quality, satisfaction, and behavioral intentions within a jazz festival context. Event. Manag. 2002, 7, 143-150. [CrossRef]

30. Yoon, Y.S.; Lee, J.S.; Lee, C.K. Measuring festival quality and value affecting visitors' satisfaction and loyalty using a structural approach. Int. J. Hosp. Manag. 2010, 29, 335-342. [CrossRef]

31. Kirkup, N.; Sutherland, M. Exploring the relationships between motivation, attachment and loyalty within sport event tourism. Curr. Issue Tour. 2017, 20, 7-14. [CrossRef]

32. Morgan, P. Towards a developmental theory of place attachment. J. Environ. Psychol. 2010, 30, 11-22. [CrossRef]

33. Hosany, S.; Prayag, G.; Van Der Veen, R.; Huang, S.; Deesilatham, S. Mediating effects of place attachment and satisfaction on the relationship between tourists' emotions and intention to recommend. J. Travel Res. 2017, 56, 1079-1093. [CrossRef]

34. Jorgensen, B.S.; Stedman, R.C. Sense of place as an attitude: Lakeshore owners attitudes toward their properties. J. Environ. Psychol. 2001, 21, 233-248. [CrossRef]

35. Alexandris, K.; Kouthouris, C.; Meligdis, A. Increasing customers' loyalty in a skiing resort: The contribution of place attachment and service quality. Int. J. Contemp. Hosp. Manag. 2006, 18, 414-425. [CrossRef]

36. Baek, G.M.; Ryu, S.Y.; Chae, Y.S. The impact of festival quality on visitor's place attachment and behavioral intention -Focused on the visitors of 2016 Hoengseong hanu festival. Aca. Soc. Eve. Con. 2017, 13, 19-32. 
37. Su, H.J.; Cheng, K.F.; Huang, H.H. Empirical study of destination loyalty and its antecedent: The perspective of place attachment. Serv. Ind. J. 2011, 31, 2721-2739. [CrossRef]

38. Zenker, S.; Rütter, N. Is satisfaction the key? The role of citizen satisfaction, place attachment and place brand attitude on positive citizenship behavior. Cities 2014, 38, 11-17. [CrossRef]

39. Wallin Andreassen, T.; Lindestad, B. Customer loyalty and complex services: The impact of corporate image on quality, customer satisfaction and loyalty for customers with varying degrees of service expertise. Int. J. Serv. Ind. Manag. 1998, 9, 7-23. [CrossRef]

40. Chi, C.G.Q.; Qu, H. Examining the structural relationships of destination image, tourist satisfaction and destination loyalty: An integrated approach. Tour. Manag. 2008, 29, 624-636. [CrossRef]

41. Lee, D.S.; Han, H.S. A study on the behavior intention of festival visitors by using theory of planned behavior: Focusing on moderation effect of perceived risk. Tour. Res. 2016, 41, 205-225.

42. Moon, K.S.; Ko, Y.J.; Connaughton, D.P.; Lee, J.H. A mediating role of destination image in the relationship between event quality, perceived value, and behavioral intention. J. Sport Tour. 2013, 18, 49-66. [CrossRef]

43. Park, E.; Lee, S.; Kwon, S.; del Pobil, A. Determinants of behavioral intention to use South Korean airline services: Effects of service quality and corporate social responsibility. Sustainability 2015, 7, 12106-12121. [CrossRef]

44. Hutchinson, J.; Lai, F.; Wang, Y. Understanding the relationships of quality, value, equity, satisfaction, and behavioral intentions among golf travelers. Tour. Manag. 2009, 30, 298-308. [CrossRef]

45. Loureiro, S.M.C. The role of the rural tourism experience economy in place attachment and behavioral intentions. Int. J. Hosp. Manag. 2014, 40, 1-9. [CrossRef]

46. Deery, M.; Jago, L. The management of sport tourism. Sport Soc. 2005, 8, 378-389. [CrossRef]

47. Gibson, H.J. Sport tourism: A critical analysis of research. Sport. Manag. Rev. 1998, 1, 45-76. [CrossRef]

48. Kwon, W.; Min, S.; Park, S.I. Causal chains of spectator motives and service factors leading to subjective well-being: Evidence from the World Championships Athletics. Korea Soc. Wellness 2014, 9, 1-15.

49. Yang, G.; Kang, J.H. The effect of sports event participating determinants on satisfaction and behavior intention. J. Sport Leisure Stud. 2001, 43, 473-483.

50. Jae Ko, Y.; Zhang, J.; Cattani, K.; Pastore, D. Assessment of event quality in major spectator sports. Manag. Serv. Qual. Int. Jour. 2011, 21, 304-322. [CrossRef]

51. Williams, D.R.; Vaske, J.J. The measurement of place attachment: Validity and generalizability of a psychometric approach. For. Sci. 2003, 49, 830-840.

52. Žabkar, V.; Brenčič, M.M.; Dmitrović, T. Modelling perceived quality, visitor satisfaction and behavioural intentions at the destination level. Tour. Manag. 2010, 31, 537-546. [CrossRef]

53. Lam, T.; Hsu, C.H. Predicting behavioral intention of choosing a travel destination. Tour. Manag. 2006, 27, 589-599. [CrossRef]

54. Browne, M.W.; Cudeck, R. Alternative Ways of Assessing Model Fit, Sage Focus ed.; Sage: Thousand Oaks, CA, USA, 1993; Volume 154, p. 136.

55. Woo, J.P. Understanding of Structural Equation Modeling; Hannarae: Seoul, Korea, 2014; pp. 329-332.

56. Bandalos, D.L.; Finney, S.J. Item Parceling Issues in Structural Equation Modeling. In Advanced Structural Equation Modeling: New Developments and Techniques; Lawrence Erlbaum Associates: Mahwah, NJ, USA, 2001; pp. 269-296.

57. Gefen, D.; Straub, D. A practical guide to factorial validity using PLS-Graph: Tutorial and annotated example. Commun. Assoc. Inf. Syst. 2005, 16, 91-109. [CrossRef]

58. Wang, C.Y.; Hsu, M.K. The relationships of destination image, satisfaction, and behavioral intentions: An integrated model. J. Travel Tour. Mark. 2010, 27, 829-843. [CrossRef]

59. Chen, C.F.; Phou, S. A closer look at destination: Image, personality, relationship and loyalty. Tour. Manag. 2013, 36, 269-278. [CrossRef] 
60. Veasna, S.; Wu, W.Y.; Huang, C.H. The impact of destination source credibility on destination satisfaction: The mediating effects of destination attachment and destination image. Tour. Manag. 2013, 36, 511-526. [CrossRef]

61. Kil, N.; Holland, S.M.; Stein, T.V.; Ko, Y.J. Place attachment as a mediator of the relationship between nature-based recreation benefits and future visit intentions. J. Sustain. Tour. 2012, 20, 603-626. [CrossRef]

(C) 2019 by the authors. Licensee MDPI, Basel, Switzerland. This article is an open access article distributed under the terms and conditions of the Creative Commons Attribution (CC BY) license (http://creativecommons.org/licenses/by/4.0/). 


\title{
Adopters versus Non-Adopters of the Green Key Ecolabel in the Dutch Accommodation Sector
}

\author{
Eelco Buunk ${ }^{1}$ and Edwin van der Werf ${ }^{2, *}$ \\ 1 KplusV, P.O. Box 60055, 6800 JB Arnhem, The Netherlands \\ 2 Environmental Economics and Natural Resources Group, Wageningen University, P.O. Box 8130, \\ 6700 EW Wageningen, The Netherlands \\ * Correspondence: edwin.vanderwerf@wur.nl; Tel.: +31-3174-83318
}

Received: 3 May 2019; Accepted: 24 June 2019; Published: 28 June 2019

\begin{abstract}
Accommodation providers such as hotels, campsites, and holiday villages can use ecolabels to show their green credentials to potential customers. Whereas there is extensive literature on ecolabel adoption in the Hotel and Bed and Breakfast (B \& B) sector, no such research exists for other accommodation sectors. In this paper, we present the results of statistical analyses of survey data from firms in the Dutch accommodation sector (including hotels, campsites, and group accommodations) with and without the Green Key ecolabel, which is a third-party certified international label for the tourist and leisure sector. We obtain insights into the motivations for adopting (or not), analyze the characteristics of firms with and without the label, and get an indication of the perceived impact of ecolabel adoption on costs and profits. We find that previously found results for hotels and B \& Bs do not always apply to other subsectors of the accommodation sector. We also find that obtaining the label required a limited investment for almost half of the sample, and resulted in cost reductions for more than half of the responding firms.
\end{abstract}

Keywords: ecolabel; sustainable tourism; certification; hotel management; campsites; ecolabel adoption

\section{Introduction}

Accommodation providers, such as hotels and campsites, impact the environment in various ways, including water and energy use, impact on the landscape, and disposal of waste and wastewater [1-3]. While companies in the accommodation sector increasingly voluntarily implement sustainable business practices, such 'green' production processes may be more costly than conventional ones [4-8]. Furthermore, since green goods are credence goods [9], consumers are not able to recognize environmental attributes when purchasing the product. Ecolabels can help reduce this information asymmetry. When a firm applies for a third-party certified ecolabel, a verifying body assesses the firm. If it passes the test, the firm receives a label that allows it to communicate to customers that it is green according to the standards set by the labeling organization [10,11]. Hence, ecolabels reduce consumers' costs for searching for information about product characteristics [12]. Although green products may be more costly to produce, green customers may be willing to pay a price premium over the price of 'brown' conventionally produced goods (e.g., [13,14]). If adopting firms turn from the provision of brown goods to green goods or if consumers switch from brown to green goods after observing an ecolabel, ecolabels may help reduce environmental impacts. Ecolabels are, as a (voluntary) policy instrument, especially relevant for sectors that are subject to little environmental regulation from public authorities, such as the tourism sector [15]. Buckley ([4], pp. 187-192) provides a great description of the rise and development of ecolabels in tourism.

The aims of this paper are (1) to assess the motivations for firms in the Dutch accommodation sector (not) to adopt an ecolabel; (2) to assess how labeled firms perceive the effect of adoption of the Green 
Key label on profits and costs, and what investments were required; and (3) to analyze the differences between firms with and without the ecolabel in terms of firm characteristics, market conditions, and perceptions of ecolabels. We present results from survey data on the motivation of firms in the Dutch accommodation sector to adopt or not to adopt the Green Key ecolabel and analyze the characteristics of firms that did (not) adopt the label. The Green Key ecolabel is a third-party certified international label that is used in the tourist and leisure sector to show that companies make more effort than required by law to be environmentally sustainable. We contribute to the existing literature on ecolabel adoption in the accommodation sector in three ways. First, while the existing literature focuses on hotels and Bed and Breakfasts (B \& Bs, e.g., [5,12,16]), our study is the first to analyze ecolabel adoption by campsites and holiday villages as well. Second, most of the literature on ecolabels in the accommodation sector uses qualitative methods and small samples (e.g., $[5,8,16])$, or only studies labeled [17] or unlabeled firms [18]. We present statistical evidence based on survey data from more than 200 firms and analyze how firms with and without the label differ in the Dutch accommodation sector at large as well as in each of the subsectors. We not only present results from statistical tests for the distribution of the variables, but also analyze whether results from these tests still hold in multiple regression analyses. Third, we present initial quantitative evidence on the perceived impacts of ecolabel adoption on costs and profits.

The case study of our analysis is the Green Key ecolabel, which is an international label that is used in the tourist and leisure sector to show that companies make more effort than required by law to be environmentally sustainable [19]. The Green Key label is issued by a non-profit non-governmental organization, and can be adopted voluntarily. Green Key International started as a Danish initiative in 1994 and was adopted by the Foundation for Environmental Education (FEE) in 2002, making it an internationally recognized label $[20,21]$. The Dutch branch of Green Key has its origin in the 'Milieubarometer' (Environmental Barometer). This label started in 1998 as an initiative from businesses in the recreational and tourist industry. In 2003, a European cooperative started between different labels, resulting in the merger of these labels. In 2007, the name 'Milieubarometer' changed to 'Green Key'. With this change, the international Green Key guidelines replaced the original guidelines, but because the Milieubarometer had stricter guidelines than Green Key, the Dutch Green Key guidelines were adapted to these. Hence, the Dutch branch of Green Key has different, stricter, standards than the international ones. Guests should be unaware of the environmental measures taken, in the sense that comfort levels should not be negatively affected.

The entrance fee is $€ 195$, which covers the costs of verification. The annual fee depends on annual turnover; the maximum rate is $€ 725$ for companies with a turnover of at least $€ 1.2$ million. Verification is done by a third party: Groen Belicht. The criteria and standards comprise 13 categories, such as water, waste, and energy [22]. The requirements for each category differ per subsector, e.g., hotels and campsites have different requirements within the same category. There are obligatory norms for obtaining the label, which is indicated as the 'Bronze' label, that include water-saving norms for showers and toilets, bans on single-service packages, and serving coffee and tea from sustainable brands. In addition, there are 'Silver' and 'Gold' labels. If a firm meets at least $52 \%$ of the optional norms, it can obtain the 'Gold' label. Optional norms range from the use of ecolabeled cleaning products to installation of Combined Heat and Power units for electricity and heat generation. In this paper, we do not differentiate between the different categories.

We focused on firms in the accommodation sector as defined by SBI-code I-55 of the Dutch Chamber of Commerce. We focus our study on the subsectors hotels, conference centres, campsites, holiday villages, group accommodations, natural campsites, mini campsites, and B \& Bs, and excluded about 50 companies from subsectors as diverse as 'restaurants', 'public swimming and indoor halls', 'passenger transport by boat', and 'outdoor sports' that are clearly distinct from the accommodation sector. Holiday villages consist of a few dozen up to a few hundred houses with one or more bedrooms, and typically cater to families and offer swimming and dining facilities. For our analysis, 'hotel' and 'B \& B' were combined into one group, as were 'campsite', 'natural campsite', and 'mini-campsite' 
(into 'Campsite'), as were 'holiday villages' and 'group accommodations' (into 'Holiday villages and group accommodations'). The group 'Conference centres' largely consists of conference centres and other activity centers (music and theatre). Some hotels that were classified in the first group offer conference rooms as well.

We find that results for the hotel and B \& B sector are not necessarily representative for the accommodation sector as a whole. For example, we find that labeled hotels and B \& Bs are larger than their unlabeled counterparts, but we find mixed results for campsites and holiday villages. Whereas statistical tests show that labeled firms tend to agree more than unlabeled firms with the statement that consumers are confident that the information conveyed by ecolabels is reliable, this result disappears in all of our multiple regression models. Regarding profits and costs: while more than half of responding firms with a Green Key label reported a reduction in variable costs after adoption of the label, only $26 \%$ reported an increase in profits. Interestingly, almost $40 \%$ of responding firms had to make investments of $€ 500$ or less to obtain the label.

The remainder of this paper is organized as follows. In the next section, we present a survey of the literature and key items of our survey. In Section 3, we introduce the Green Key ecolabel and describe the sampling and data collection procedures. In Section 4, we first present results on the motivations of firms for adopting the Green Key label and present reported changes in profits and the costs of labeled firms. We then analyze characteristics of firms with and without the label for the Dutch accommodation sector as a whole and for the various subsectors. We also use a probit model to test whether these results still hold in a multiple regression model of ecolabel adoption and assess how the probability of being labeled is affected by firm characteristics. In Section 5, we discuss our results, and we conclude in Section 6.

\section{Literature and Key Survey Items}

In this section, we review the literature on the adoption of ecolabels in the accommodation sector to identify the key variables needed in our empirical assessment of ecolabel adoption in the Dutch accommodation sector. Since the literature on ecolabels is rather limited, we also include literature on the adoption of environmental management systems (EMSs). We follow Ayuso ([23], p. 209) and define an EMS as having the aim to "manage the environmental performance of the company and improve it continuously according to a planned strategy", whereas the aim of an ecolabel is to "ensure the environmental performance of the company with regard to certain aspects, and offer the corresponding information to the consumer". Hence, ecolabels are more consumer-oriented than EMSs.

\subsection{Motivations for Adoption}

Economic theory suggests that eco-label adoption allows 'green' producers to demand a higher price than their 'brown' competitors, which is needed because of the higher costs of production when using sustainable production processes [24]. However, Rivera [12] did not find evidence that the hotels that participate in the Costa Rican Certification for Sustainable Tourism program were able to demand higher prices. Indeed, possession of an ecolabel does not seem to lead to increased sales for hotels and B \& Bs [12,16]. Motivations for an ecolabel can largely be grouped into two categories: business benefits and green philosophy. Tzschentke et al. [8] interviewed 30 owner-managers of small hotels and B \& Bs that were members of the Green Tourism Business Scheme (GTBS), and found that the decision to join the GTBS was based on "the prospect of commercial benefits, the knowledge that joining required little or no change to current practices, and the fact that the principles of the scheme were ones the owner-manager endorsed" (p. 120). Based on interviews with 30 managing directors of Spanish hotels, Ayuso [15] found that hotels that adopt an ecolabel have a history of environmental practices, and do not have to make big investments to get certified. Duglio et al. [17] found that personal awareness of the sustainability issue and improving the corporate image were the main motivation for adoption of the European ecolabel by Italian accommodation establishments. Dunk et al. [5] asked 109 members and former members of the GTBS in Scotland about their reasons and expectations for joining. Allowing 
for multiple answers, $63 \%$ gave 'green philosophy and practice' as a reason for joining. With $58 \%$, the group indicating 'business benefits' as one of the reasons was not much smaller.

The literature on EMSs confirms the (mixed) results for ecolabels. Implementation of an EMS seems to lead to cost savings rather than cost increases in the hotel sector, often with little investment. Geerts [6] found that 17 out of 21 interviewed managers of London hotels had implemented sustainable business practices to save costs, whereas less than half of the respondents implemented them for environmental motivations. Ayuso [15] found that envisioned cost savings are one of the main motivations for initiating environmental practices (including both ecolabels and EMSs), yet more than half of the respondents also mentioned personal awareness, and EMS adoption is rather motivated by a feeling of getting recognized for the efforts by a third party.

Garay and Font [25] found that economic motivations are only secondary to altruistic reasons such as environmental protection in their analysis of (mostly small) hotels in Catalunya. Ayuso [15] found that an EMS does not seem to lead to increased sales for hotels and B \& Bs.

Adoption of an ecolabel usually comes with certification costs. In addition to the monetary costs of certification, assessment by the certification agency is a time-consuming process. These costs can induce managers not to adopt the ecolabel, despite meeting the label's standards [15].

In the survey, we asked respondents about their motivation (not) to adopt an ecolabel. We also asked certified firms about the investments they had to make and the resulting cost savings and change in profits.

\subsection{Differences in Characteristics of Firms with and without an Environmental Management Tool}

The tourism literature suggests that firms (in this literature: hotels and B \& Bs) with an EMS can differ from their uncertified competitors along various dimensions. Obtaining certification is a costly and time-consuming process that may be too costly for small firms $[6,23,26]$. Larger firms may have higher awareness and more resources to undertake the process of implementation and adoption $[6,27,28]$. Segarra-Oña et al. [7] found that hotels in Spain with an ISO 14001 certificate are generally larger than hotels without. Since hotels that belong to a chain can use a central management unit for the certification process, having multiple establishments may matter [23,29,30]. Ayuso [15] found that the involvement of hotel management and staff is a critical factor for the implementation of an EMS in Spanish hotels, which suggests that the larger the number of employees, or the larger the number of organisational layers in the firm, the harder it becomes to implement an EMS.

In addition to size, age might be a firm characteristic that is relevant for ecolabel adoption: younger firms may be more willing to adopt new business practices than older firms. Indeed, based on the sustainable entrepreneurship literature, Hockerts and Wüstenhagen ([31], p. 481) argued that "in the early stages of an industry's transformation towards sustainability, it is typically small firms and new entrants that stimulate disruptive sustainability innovation".

Segarra-Oña et al. [7] reported that the share of Spanish hotels with ISO14001 certification is higher for rural hotels than for city hotels.

As noted above, green philosophy can be a motivation to adopt an ecolabel or EMS. Sampaio et al. [16] found that the environmental preferences of the owners or managers matter for the adoption of the GTBS label, while Ayuso [23] found the same for the adoption of environmental practices (including both ecolabels and EMSs).

We asked our respondents about the age of their firm, its size, whether it had multiple establishments, its location (rural or urban), and to what extent sustainability is important for their company.

\subsection{Market Conditions}

The adoption of an ecolabel allows a firm to differentiate itself from its competitors. The opportunity for a firm to do so will depend on the characteristics of the market in which it operates. Geerts [6] interviewed 21 managers of hotels in London that had joined a certification scheme (although not 
necessarily one that is third-party certified) and concluded that price, location, and quality appeared to be more important for guests when booking a hotel than certifications. Hence, we asked respondents to what extent they think that customers value sustainability, and whether firms in the sector compete on price, quality, or green image.

Ecolabel adoption can be viewed as the diffusion of a new technology in a sector, which is a gradual process [32]. Firms would like to have information about the new technology before adopting it, and can acquire this information from early adopters in their sector. As a consequence, adoption might differ between subsectors (hotels, holiday villages, campsites), also because of differences in sector-specific characteristics (including technologies and costs to meet the requirements of the label) and regulation. A firm's probability to be certified will also be affected by the behavior of their competitors [33]. Therefore, we asked firms in which subsector they operate, to what extent they agree with the statement "many competitors have an ecolabel", and for an estimate of the percentage of competitors with an ecolabel.

\subsection{Perceptions of Ecolabels}

Ecolabels can signal to consumers that the labeled firm uses 'green' production technologies and allow their holders to show to customers that their environmental efforts are real and genuine rather than 'greenwash'. Chen and Chang [34] analyzed the relation between greenwash and consumers' green trust in electronics products in Taiwan, and found that greenwash is positively related to consumer confusion. Consumer attitudes toward ecolabels matter, as an ecolabel should be understood and trusted by consumers $[11,35,36]$. Hence, adopting firms may be more confident that consumers trust ecolabels than unlabeled competitors. Still, several studies reported that hotel managers argue that customers are unfamiliar with or sceptical toward certification schemes, possibly because there are so many of them $[18,37,38]$. We asked respondents to what extent they agree with the statement, "Consumers are confident that the information conveyed by ecolabels is reliable". We also asked respondents to what extent they agree with the statement "Consumers understand the meaning of ecolabels".

Following the same reasoning, firms' trust in the label is equally important. Firms will only invest in costly certification if they think that the label successfully separates sustainable from unsustainable firms: the higher the perceived accuracy of the certification procedure, the fewer unsustainable firms will apply and pay for certification [24]. Therefore, we asked firms about their perceptions of the assessment of ecolabeled firms.

\section{Research Questions, Case Study, Sampling, and Data Collection}

\subsection{Research Questions and Hypotheses}

The aim of the paper is to analyze differences between firms in the Dutch accommodation sector that did and did not adopt the Green Key ecolabel. To that purpose, we formulated the following research questions: (1) What are the motivations for firms in the Dutch accommodation sector (not) to adopt an ecolabel? (2) How do labeled firms perceive the effect of adoption of the Green Key label on profits and costs, and what investments were required? (3) What are the differences between firms with and without the ecolabel in terms of firm characteristics, market conditions, and perceptions of ecolabels? Regarding the latter, we have the following hypotheses based on the discussion of the literature in Section 2:

- $\quad$ a positive correlation between firm size and ecolabel adoption;

- a negative correlation between age and ecolabel adoption;

- a positive correlation between being located in a rural area and ecolabel adoption;

- $\quad$ a positive correlation between firms' views on sustainability and ecolabel adoption;

- a positive correlation between firms' views on consumers valuation of sustainability and ecolabel adoption; 
- a positive correlation between the (perceived) number of labeled competitors and ecolabel adoption;

- a positive correlation between firms' views on consumers perceptions about ecolabels and ecolabel adoption;

- and a positive correlation between firms' own perceptions of ecolabels and ecolabel adoption.

\subsection{Sampling and Data Collection}

A list of all the Dutch Green Key labeled companies can be found on the website of Green Key Netherlands [39]. We first contacted companies with multiple references (e.g., hotels belonging to a chain) to check whether it was centrally decided to adopt the label or if they had decided to adopt it independently. Our final list—of Green Key labeled firms that had either independently adopted the Green Key label or adopted it through the chain's central management-consisted of 270 firms. The unlabeled companies were selected from the website of the Dutch Chamber of Commerce [40]. A database was created, including all the companies within the accommodation sector in the Netherlands (SBI-code I-55), except for the about 50 firms mentioned above. Additionally, the following characteristics were selected: the results had to be business enterprises that were still economically active and were the main office within that enterprise. This resulted in 6622 different potential observations, which were arranged by their Chamber of Commerce registration number. From this list, 650 unique random numbers were drawn, and the corresponding firms were selected. When a firm either had a Green Key label or did not have an email address, the next firm on the list was selected. For each selected unlabeled firm, it was checked whether it was part of a franchise organization or chain.

The final database consisted of 918 companies, of which 270 had a Green Key ecolabel and 648 did not. All the firms were approached via email for an online survey, for which we used the web-based tool Qualtrics. After one week, a first reminder was sent to each firm that had not completed the questionnaire by then, and another week later, a second reminder was sent. In total, 206 unique respondents started the questionnaire and at least indicated whether they had a Green Key label, of which 89 had the Green Key label and 117 had no ecolabel. Unfortunately, not all the questionnaires were fully completed, and hence, the number of observations differs per variable. More information on the questions used in the survey and the number of responses per question can be found in Appendix A.

We tested whether our sample of responding firms is representative for the sample of the firms that we contacted using the sector in which the firm operated and the province where the firm is located (the only variables for which we have information for both samples). We were not able to reject the null hypothesis ( $5 \%$ significance level) that the proportions in the sample of responding firms were equal to the proportions in the sample of firms contacted, for both the labeled and unlabeled firms.

The questionnaire included questions covering the key variables identified in the literature (see Section 2). Descriptive statistics can be found in Table A1 in Appendix A.

\section{Results}

\subsection{Motivations for Adopting or Not Adopting}

We asked firms for their main motivation for (not) adopting the Green Key ecolabel. Respondents could only mention one reason. As can be seen in Table 1, the two main reasons for labeled firms to adopt the Green Key label were "better for the environment" and "good for the image of the company". Interestingly, "it increases profits" was mentioned only once, and differentiation from competitors was also mentioned far less often than the first two reasons. 
Table 1. Frequency distribution of reasons for Green Key labeled firms for adopting the label.

\begin{tabular}{cc}
\hline Reason for Being Labeled & Frequency \\
\hline Better for the environment & 23 \\
Good for the image of the company & 23 \\
To differentiate within the sector & 9 \\
It increases profits & 1 \\
The competition has a label as well & 1 \\
Other & 13 \\
Missing & 19 \\
Total & 70 \\
\hline
\end{tabular}

We not only asked labeled firms for their motivations to adopt an ecolabel; we also asked unlabeled firms why they had not adopted an ecolabel. Table 2 shows that almost one-third of responding firms did not deem it necessary to have an ecolabel in order to be sustainable. A large group of firms mentioned costs as a reason not to adopt an ecolabel: 20 firms indicated that the investments to be made in order to comply with the standards would be too large, while eight firms indicated that certification costs are too high. Only two firms thought that their variable costs would increase after adoption of the label. A lack of demand for environmentally sustainable services was mentioned by nine firms.

Table 2. Frequency distribution of reasons for unlabeled firms for not adopting an ecolabel.

\begin{tabular}{cc}
\hline Reason for Not Being Labeled & Frequency \\
\hline It is not necessary to have an ecolabel in order to be sustainable & 32 \\
The investments that have to be made in order to comply with the standards are too large & 20 \\
There is not enough demand for environmentally sustainable services in my sector & 9 \\
The certification costs are too high & 8 \\
The variable costs would increase & 2 \\
I can ask a lower price than my competitors & 1 \\
Other & 26 \\
Missing & 19 \\
Total & 98 \\
\hline
\end{tabular}

\subsection{Labeled Firms: Profits and Costs}

We found that, of the 68 Green Key labeled firms that responded to the question of whether their profits had increased due to adoption of the ecolabel, $26 \%$ stated that their company had become more profitable after adoption, but only $4 \%$ reported that they were able to increase their price. This suggests that the profit increase resulted from a decrease in costs. Indeed, while $10 \%$ of responding labeled firms reported an increase in variable costs after adoption of the label, 58\% reported a decrease in variable costs $(\mathrm{N}=71)$. Of the 43 firms reporting a percentage change in variable costs after adoption of the label, five reported an increase, and 15 reported a decrease. The mean change in variable costs was $-3.2 \%$ (t-stat. -2.55 ), where we excluded one observation where a $100 \%$ reduction was reported, which we deemed unrealistic. Of the 18 labeled companies reporting an increase in profits, 15 stated that this was due to lower variable costs, whereas three reported that this was due to a higher price.

In our sample, of all the labeled firms that reported on fixed adjustment costs $(\mathrm{N}=56), 18 \%$ reported zero adjustment cost, and $21 \%$ reported positive investment costs of $€ 500$ or less. Still, mean investment costs were $€ 17.634$, the median was $€ 3.000$ and the maximum reported investment was $€ 350.000$, suggesting that while a substantial fraction of firms that adopted the Green Key ecolabel had zero or little adjustment costs to fulfill the criteria, this is not a general rule for adopting firms. 


\subsection{Differences between Labeled and Unlabeled Firms}

In this section, we present the results of statistical tests in which we compared firms with the Green Key ecolabel against firms without an ecolabel. Depending on the structure of the underlying data, we reported results for Mann-Whitney, Fisher's exact, and Pearson's Chi-squared tests.

\subsubsection{Firm Characteristics}

We asked firms with and without the Green Key ecolabel about the size of their firm, and did so for various dimensions: number of full-time equivalent (FTE) employees, revenues (in five categories, ranging from less than $€ 100,000$ to more than $€ 5,000,000$ ), and whether the firm had multiple establishments. The results in Table 3 show that for all three variables, the null hypothesis (either equal distribution for labeled and unlabeled firms or that the proxy for size is independent of being labeled) is rejected. Inspection of the relative frequency distributions shows that in all cases, the distribution for labeled firms is shifted to the right. Labeled firms tend to have more employees (the mean is $21.3 \mathrm{FTE}$ for firms with the Green Key label and 3.7 for unlabeled firms), and more revenues than unlabeled firms. This suggests that larger firms are more able to bear the monetary and non-monetary costs of ecolabel adoption than smaller firms. Labeled firms also tend to have more establishments than unlabeled firms (means: 1.35 and 1.03 respectively). Labeled firms are also older (means: 36 and 26 years, respectively).

Table 3. Labeled vs. unlabeled firms: firm characteristics. FTE: full-time equivalent.

\begin{tabular}{cccc}
\hline Variable & Hypothesis & Test Result & N \\
\hline Employees (FTE) & Same distribution labeled and unlabeled firms & $\mathrm{z}=4.33^{* * *}$ & 97 \\
\hline Revenues (five categories) & Revenues independent of being labeled & $p=0.00^{* * *}$ & 119 \\
\hline Multiple establishments & Having multiple establishments independent of & $p=0.02^{* *}$ & 206 \\
\hline Age & Same distribution labeled and unlabeled firms & $\mathrm{z}=2.48^{* *}$ & 204 \\
\hline $\begin{array}{c}\text { Sustainability important for } \\
\text { company (five categories) }\end{array}$ & Response to statement in-dependent of being labeled & $p=0.00^{* * *}$ & 151 \\
\hline Urban & Urban yes/no independent of being labeled & $p=0.02^{* *}$ & 191 \\
\hline & $* / * * * * *$ indicates statistically significant at the 10/5/1\% level. & &
\end{tabular}

We asked respondents to what extent (five-point Likert scale, ranging from 'Strongly agree' to 'Strongly disagree') they agreed with the statement '[company name] has the opinion that sustainability is important'. Labeled firms tended to agree more strongly with this statement than firms without a label. Unfortunately, we could not assess whether this was a reason for adoption, or this was a result of adoption (for example, through increased environmental awareness).

The final firm characteristic concerns the location of the firm for firms with only one establishment $(\mathrm{N}=191)$. Firms with the Green Key ecolabel tend to be more often located in urban areas than unlabeled firms.

Table 4 shows the results by subsector. Hotels and B \& Bs with the Green Key label tend to be larger than unlabeled competitors along all the dimensions. In all the subsectors, labeled companies tend to have more revenues than unlabeled firms. Labeled holiday villages and group accommodations also tend to have more employees. The number of establishments appears to be larger for labeled firms only in the Hotel and B \& B sector. 
Table 4. Labeled vs. unlabeled firms: firm characteristics by subsector.

\begin{tabular}{ccccc}
\hline Variable & Hotels and B \& Bs & Campsites & $\begin{array}{c}\text { Holiday Villages and } \\
\text { Group Accommodations }\end{array}$ & $\begin{array}{c}\text { Conference } \\
\text { Centers }\end{array}$ \\
\hline Employees (FTE) & $\mathrm{z}=3.39^{* * *}(36)$ & $\mathrm{z}=1.29(32)$ & $\mathrm{z}=1.85^{*}(15)$ & $\mathrm{z}=1.61(13)$ \\
\hline $\begin{array}{c}\text { Revenues (five } \\
\text { categories) }\end{array}$ & $p=0.01^{* * *}(43)$ & $p=0.08^{*}(42)$ & $p=0.03^{* *}(19)$ & $p=0.02^{* *}(15)$ \\
\hline $\begin{array}{c}\text { Number of } \\
\text { establishments }\end{array}$ & $p=0.01^{* * *}(76)$ & $p=0.39(62)$ & $p=0.56(36)$ & $p=0.69(31)$ \\
\hline Age & $\mathrm{z}=0.84^{(75)}$ & $\mathrm{z}=2.17^{* *}(62)$ & $\mathrm{z}=1.98^{* *}(36)$ & $\mathrm{z}=2.03^{* *}(30)$ \\
\hline $\begin{array}{c}\text { Sustainability } \\
\text { important for company } \\
\text { (five categories) }\end{array}$ & $p=0.00^{* * *}(57)$ & $p=0.04^{* *}(46)$ & $p=0.07^{*}(25)$ & $p=0.40(22)$ \\
\hline Urban & $p=0.02^{* *}(68)$ & $-{ }^{a}(61)$ & $-{ }^{a}(35)$ & $p=0.13(26)$ \\
\hline
\end{tabular}

$* / * * * * *$ indicates statistically significant at the $10 / 5 / 1 \%$ level. Number of observations in parentheses. ${ }^{a}$ All the campsites and holiday villages and group accommodations reported to be located in a rural environment.

Interestingly, the age distribution of firms does not differ for labeled and unlabeled hotels and B \& Bs, while labeled firms tend to be older in all the other subsectors.

Whereas labeled and unlabeled conference centers do not seem to differ in their response to the statement '[company name] is of the opinion that sustainability is important', labeled firms in the other subsectors tend to agree more strongly with this statement than unlabeled firms. It should be noted that the number of observations is smallest for the former group.

Labeled hotels and B \& Bs were more likely to be located in urban areas than their unlabeled competitors. Zero campsites, holiday villages, and group accommodations (both labeled and unlabeled) were located in urban areas.

\subsubsection{Market Conditions}

Market conditions may affect the willingness of a firm to adopt an ecolabel. We asked firms to what extent they agree with the statement 'Customers value sustainability', using a five-point Likert scale. As shown in Table 5, firms with the Green Key ecolabel tended to agree more strongly with the statement than unlabeled firms.

Table 5. Labeled vs. unlabeled firms: Market conditions.

\begin{tabular}{cccc}
\hline Variable & Hypothesis & Test Result & N \\
\hline $\begin{array}{c}\text { Customers value sustainability (five } \\
\text { categories) }\end{array}$ & $\begin{array}{c}\text { Response to statement } \\
\text { independent of being labeled }\end{array}$ & $p=0.02 * *$ & 149 \\
\hline Competition focuses on price & $\begin{array}{c}\text { Same distribution labeled and } \\
\text { unlabeled firms }\end{array}$ & $p=0.28$ & 150 \\
\hline Competition focuses on green image & $\begin{array}{c}\text { Same distribution labeled and } \\
\text { unlabeled firms }\end{array}$ & $p=0.52$ & 150 \\
\hline $\begin{array}{c}\text { Many competitors have an ecolabel } \\
\text { (five categories) }\end{array}$ & $\begin{array}{c}\text { Response to statement } \\
\text { independent of being labeled }\end{array}$ & $p=0.00 * * *$ & 148 \\
\hline $\begin{array}{c}\text { Percentage of competitors that have } \\
\text { an ecolabel }\end{array}$ & $\begin{array}{c}\text { Same distribution of labeled } \\
\text { and unlabeled firms }\end{array}$ & $\mathrm{z}=6.43^{* * *}$ & 122 \\
\hline ****** indicates statistically significant at the 10/5/1\% level. &
\end{tabular}

Next, we asked respondents about the main item of competition in the sector: price, quality, green image, or 'other'. There was not a statistically significant difference between the two groups of firms for any of the items. Interestingly, even though it does not seem that labeled firms operate in an environment in which competition focuses on having a green image, labeled firms tended to agree 
more strongly with the statement 'Many of my competitors have an ecolabel' than unlabeled firms, and they tend to report a higher number for the percentage of competitors that has an ecolabel.

Table 6 presents the results on market conditions by subsector. At the subsector level, the result that labeled firms tended to agree more strongly with the statement that customers value sustainability was only confirmed for hotels and B \& Bs. This was probably partly driven by the small sample sizes for the other subsectors. The absence of a statistically significant difference in the perception of the focus point of competition also shows up at the level of the subsectors.

Table 6. Labeled vs. unlabeled firms: market conditions by subsector.

\begin{tabular}{|c|c|c|c|c|}
\hline Variable & Hotels and B \& Bs & Campsites & $\begin{array}{l}\text { Holiday Villages and } \\
\text { Group Accommodations }\end{array}$ & $\begin{array}{l}\text { Conference } \\
\text { Centres }\end{array}$ \\
\hline $\begin{array}{l}\text { Customers value } \\
\text { sustainability } \\
\text { (five categories) }\end{array}$ & $p=0.10 *(57)$ & $p=0.79(47)$ & $p=1.00(25)$ & $p=0.58(19)$ \\
\hline $\begin{array}{l}\text { Competition focuses } \\
\text { on price }\end{array}$ & $p=0.45(56)$ & $p=0.29(47)$ & $p=0.30(24)$ & $p=0.37(22)$ \\
\hline $\begin{array}{c}\text { Competition focuses on } \\
\text { green image }\end{array}$ & $p=0.71(56)$ & $p=0.36(47)$ & $p=0.54(24)$ & $p=0.82(22)$ \\
\hline $\begin{array}{l}\text { Many competitors have an } \\
\text { ecolabel (five categories) }\end{array}$ & $p=0.00^{* * *}(53)$ & $p=0.08 *(47)$ & $p=0.42(25)$ & $p=0.02 * *(22)$ \\
\hline $\begin{array}{l}\text { Percentage of competitors } \\
\text { that have an ecolabel }\end{array}$ & $z=3.59 * * *(45)$ & $z=1.22(36)$ & $z=3.05^{* * *}(21)$ & $\mathrm{z}=2.71^{* * *}(20)$ \\
\hline
\end{tabular}

$* / * * * *$ indicates statistically significant at the $10 / 5 / 1 \%$ level. Number of observations in parentheses.

In all the subsectors except for holiday villages and group accommodations, labeled firms tended to agree more strongly with the statement that many competitors have an ecolabel than unlabeled firms. However, when it comes to the reported number of competitors with an ecolabel, campsites were the only sector in which labeled firms did not report a statistically significant higher number for the percentage of competitors that had an ecolabel than unlabeled firms.

\subsubsection{Perceptions of Ecolabels}

The results in Table 7 show that the two groups of firms did not differ in their response to the statement 'Consumers understand the meaning of ecolabels'. Interestingly, not a single firm responded 'strongly agree', and for both groups of firms, a large share responded with 'disagree' or 'strongly disagree'. Firms with the Green Key ecolabel tended to agree more strongly with the statement 'Consumers are confident that the information conveyed by ecolabels is reliable' than unlabeled firms. It should be noted that the opinion of labeled firms may have been formed after adoption of the Green Key label.

Table 7. Labeled vs. unlabeled firms: perceptions of ecolabels.

\begin{tabular}{cccc}
\hline Variable & Hypothesis & Test Result & N \\
\hline $\begin{array}{c}\text { Consumers understand the meaning } \\
\text { of ecolabels (five categories) }\end{array}$ & $\begin{array}{c}\text { Response to statement } \\
\text { independent of being labeled }\end{array}$ & $p=0.29$ & 145 \\
\hline $\begin{array}{c}\text { Consumers are confident that the } \\
\text { information conveyed by ecolabels } \\
\text { is reliable (five categories) }\end{array}$ & $\begin{array}{c}\text { Response to statement } \\
\text { independent of being labeled }\end{array}$ & $p=0.07 *$ & 146 \\
\hline $\begin{array}{c}\text { There is sufficient assessment of } \\
\text { compliance of labeled firms with } \\
\text { ecolabel's rules (five categories) }\end{array}$ & $\begin{array}{c}\text { Response to statement } \\
\text { independent of being labeled }\end{array}$ & $p=0.00^{* * *}$ & 147 \\
\hline & &
\end{tabular}


Green firms may be more willing to adopt an ecolabel when they trust its assessment procedure, while brown firms may be less likely to adopt a label when there is sufficient assessment of compliance. Green Key-labeled firms tended to agree more strongly with the statement 'There is sufficient assessment of compliance of labeled firms with ecolabel's rules' than unlabeled firms. However, whether this was already the case before adoption, or labeled firms became confident due to their experience with the Green Key assessment procedure is not clear.

When we analyzed the responses at the level of subsectors (Table 8), some interesting results appeared. Hotels and B \& Bs seemed to be the only sector in which labeled firms tended to agree more strongly with the statement that consumers are confident that the information conveyed by ecolabels is reliable. While for the 'Holiday villages and group accommodations' and 'Conference center' groups, this may have been caused by the relatively small subsamples, the result for Campsites was rather striking, as not only was the sample rather large, the p-value of the Fisher Exact test was also very high. Whereas two unlabeled firms strongly agreed with the statement, zero labeled firms did.

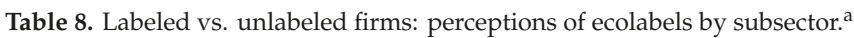

\begin{tabular}{cccc}
\hline Variable & Hotels and B \& Bs & Campsites & $\begin{array}{c}\text { Holiday Villages and } \\
\text { Group Accommodations }\end{array}$ \\
\hline $\begin{array}{c}\text { Consumers are confident } \\
\text { that the information } \\
\text { conveyed by ecolabels is } \\
\text { reliable (five categories) }\end{array}$ & $p=0.05 *(54)$ & $p=0.80(45)$ & $p=0.33(25)$ \\
\hline $\begin{array}{l}\text { Consumers understand the } \\
\text { meaning of ecolabels (five } \\
\text { categories) }\end{array}$ & $p=0.36(52)$ & $p=0.54(47)$ & $p=0.75(25)$ \\
\hline $\begin{array}{l}\text { There is sufficient } \\
\text { assessment of compliance of } \\
\text { labeled firms with ecolabel's } \\
\text { rules (five categories) }\end{array}$ & $p=0.00 * * *(54)$ & $p=0.00 * * *(46)$ & $p=0.21(21)$ \\
\hline$* * * * *$ indicates statistically significant at the $10 / 5 / 1 \%$ level. Number of observations in parentheses.
\end{tabular}

Table 7 shows that there was no statistically significant difference between the responses of the two groups to the statement 'Consumers understand the meaning of ecolabels'. This result was also found for each of the subsectors.

The result that labeled firms tend to agree more strongly with the statement 'There is sufficient assessment of compliance of labeled firms with ecolabel's rules' than unlabeled firms seems to hold for all of the subsectors except for the conference centres. The non-significance for conference centres can be explained by the sample size: only four unlabeled conference centres responded to this statement.

\subsection{Econometric Analysis}

The previous section presented the results of one-way statistical tests. In this section, we present results of a multiple regression analysis. We use probit and logit models to analyze which variables affect the likelihood of having adopted the Green Key ecolabel. The dependent variable takes a value of one if the firm adopted the Green Key ecolabel and the value of zero if it had not (we excluded the dummy variable for location in an urban as opposed to rural area, since this question was only asked to firms with a single establishment). The independent variables included are those that showed statistically significant differences between labeled and unlabeled firms in the one-way statistical analyses above. For firm characteristics, these are age, size (one of the reported proxies), sector, and whether the respondent (strongly) agreed with the statement that sustainability was important for the company, were we used the natural logarithm of $(1+$ age $)$ to decrease the skewness of the data and avoid having to take the logarithm of zero. We have not reported the results for size in terms of number of FTE, since the number of observations was too low for the regression results to be meaningful. For market conditions, we included one of two proxies for the number of competitors that had an 
ecolabel: a dummy equal to one when the respondent strongly disagreed with the statement that many competitors had an ecolabel, or the reported percentage of competitors that had an ecolabel. Here we used "(strongly) disagree" because "(strongly) agree" has zero respondents without the Green Key label. We use the natural logarithm of $(1+$ reported percentage) for the percentage of competitors with an ecolabel to decrease the skewness of the data and avoid having to take the logarithm of zero. In addition we included a dummy variable that was equal to one when the respondent (strongly) agreed with the statement that customers valued sustainability. For the perceptions of ecolabels (of firms and of customers), we included a dummy variable that was equal to one when the respondent (strongly) agreed with the statement that there was sufficient assessment of compliance of labeled firms, and a dummy that was equal to one when the respondent (strongly) agreed with the belief that customers were confident that the information conveyed by ecolabels was reliable.

To facilitate interpretation of the regression results, Table 9 reports marginal effects (average marginal effects over all the observations), which were calculated based on the results from the probit and logit estimations, instead of coefficients from the regressions. Column (1) presents results for a probit model. The probability of having adopted the Green Key label was 0.367 higher for firms with multiple establishments (a proxy for firm size) than for firms with a single establishment, controlling for all of the covariates. The marginal effect for age shows that a $10 \%$ increase in age increases the probability of having adopted the Green Key label by 7\%. Firms in the sectors Hotels and B \& Bs, Campsites, and Holiday villages and group accommodations had a probability of being labeled that was about 0.3 lower than the Conference centers sector. We could not reject the null hypothesis that the probability was identical for the former three sectors $(p=0.75)$. Regarding variables that describe market conditions: firms that (strongly) disagreed with the statement that many competitors had an ecolabel were $20 \%$ less likely to adopt the Green Key label than firms that were neutral toward the statement or (strongly) agreed, and firms that (strongly) agreed with the statement that sustainability was important for their company were 39\% more likely to have adopted the label than their peers. Perceptions of customers' attitudes toward ecolabels did not seem to be correlated with the probability of having adopted the Green Key label, whereas having (strongly) agreed with the statement that labeled firms were sufficiently assessed was positively correlated with ecolabel adoption (probability of having adopted was 0.4 higher).

In columns (2)-(4), we report the results of sensitivity analyses. In column (2), we present results for a logit regression model instead of a probit model. The results were nearly identical. The results in column (3) are based on a probit model with four revenue categories as proxies for size rather than a dummy for having multiple establishments (note that this regression has fewer observations). The reference group has revenues of less than $€ 100,000$. Larger firms were $19-26 \%$ more likely to have adopted the Green Key label. While the probability of adoption for the largest firms cannot be statistically distinguished from that of the smallest firms, it also did not differ statistically from the firms with revenues ranging from 0.5 to 1.5 million euros. All the other results were close to those in column (1), except for one: the probability of adoption for Campsites did not differ statistically from that of the Conference centres sector. For the results in column (4), we replaced the dummy for strongly disagreeing with the statement that many competitors had an ecolabel by the logarithm of the reported percentage of competitors that had an ecolabel. A $10 \%$ increase in the perceived percentage of labeled competitors increased the probability of adoption by $6.6 \%$, which confirmed that perceptions of competitors having a label were positively correlated with the probability of having adopted the Green Key label. All the other results were close to those in column (1), except for a positive correlation between (strongly) agreeing with the statement that consumers valued sustainability and Green Key adoption, which was statistically significant. Finally, in column (5), we present results for a regression without potentially endogenous independent variables. Again, size and age were positively correlated with adoption, and the Conference centres sector had a higher probability of adoption than the other sectors. In addition, the firms that (strongly) disagreed with the statement that many competitors had an eco-label were less likely to have adopted the Green Key label, as in the other regressions. 
Table 9. Marginal effects from probit and logit regressions.

\begin{tabular}{|c|c|c|c|c|c|}
\hline $\begin{array}{c}\text { Dependent: Has Green Key } \\
\text { label }(\text { Yes }=1)\end{array}$ & (1) & (2) & (3) & (4) & (5) \\
\hline & Probit & Logit & Probit & Probit & Probit \\
\hline Multiple & $\begin{array}{l}0.367^{* * *} \\
(0.05)\end{array}$ & $\begin{array}{c}0.366^{* * *} \\
(0.05)\end{array}$ & & $\begin{array}{c}0.314^{* * *} \\
(0.06)\end{array}$ & $\begin{array}{c}0.412 * * * \\
(0.13)\end{array}$ \\
\hline Age & $\begin{array}{l}0.072 * * \\
(0.03)\end{array}$ & $\begin{array}{c}0.071 * * \\
(0.03)\end{array}$ & $\begin{array}{l}0.061 * \\
(0.03)\end{array}$ & $\begin{array}{c}0.081^{* * *} \\
(0.03)\end{array}$ & $\begin{array}{c}0.097^{* * *} \\
(0.04)\end{array}$ \\
\hline $\begin{array}{l}\text { Hotel and } \\
\text { B \& B }\end{array}$ & $\begin{array}{c}-0.282^{* * *} \\
(0.09)\end{array}$ & $\begin{array}{c}-0.290 \text { ** } \\
(0.12)\end{array}$ & $\begin{array}{c}-0.236^{* *} \\
(0.11)\end{array}$ & $\begin{array}{c}-0.268^{* *} \\
(0.12)\end{array}$ & $\begin{array}{c}-0.451^{* * *} \\
(0.11)\end{array}$ \\
\hline Campsite & $\begin{array}{c}-0.320 * * * \\
(0.09)\end{array}$ & $\begin{array}{c}-0.330^{* * *} \\
(0.12)\end{array}$ & $\begin{array}{c}-0.169 \\
(0.12)\end{array}$ & $\begin{array}{c}-0.367^{* * *} \\
(0.11)\end{array}$ & $\begin{array}{c}-0.363^{* * * *} \\
(0.11)\end{array}$ \\
\hline $\begin{array}{l}\text { Holiday vill. } \\
\text { and group acc. }\end{array}$ & $\begin{array}{c}-0.338^{* * * *} \\
(0.10)\end{array}$ & $\begin{array}{c}-0.336^{* * *} \\
(0.13)\end{array}$ & $\begin{array}{c}-0.213 * \\
(0.12)\end{array}$ & $\begin{array}{c}-0.328^{* * *} \\
(0.12)\end{array}$ & $\begin{array}{c}-0.322 * * * \\
(0.12)\end{array}$ \\
\hline Disagr. Many & $-0.197^{* * *}$ & $-0.188^{* * *}$ & $-0.230^{* * *}$ & & $-0.268^{* * *}$ \\
\hline labelled Competitors & $(0.06)$ & $(0.06)$ & $(0.06)$ & & $(0.08)$ \\
\hline $\begin{array}{l}\text { Sustainability } \\
\text { important }\end{array}$ & $\begin{array}{c}0.388^{* * *} \\
(0.05)\end{array}$ & $\begin{array}{c}0.392 * * * \\
(0.05)\end{array}$ & $\begin{array}{c}0.358^{* * * *} \\
(0.06)\end{array}$ & $\begin{array}{l}0.401^{* * * *} \\
(0.05)\end{array}$ & \\
\hline Cons. value & 0.057 & 0.053 & 0.058 & $0.112^{* *}$ & \\
\hline sustainability & $(0.05)$ & $(0.05)$ & $(0.06)$ & $(0.05)$ & \\
\hline Consumers & 0.008 & 0.013 & 0.042 & 0.013 & \\
\hline confident & $(0.05)$ & $(0.06)$ & $(0.07)$ & $(0.06)$ & \\
\hline Firms & $0.402 * * *$ & $0.399^{* * *}$ & $0.368^{* * *}$ & $0.319^{* * *}$ & \\
\hline assessed & $(0.06)$ & $(0.06)$ & $(0.06)$ & $(0.06)$ & \\
\hline Revenue & & & $0.187^{* *}$ & & \\
\hline $100-500 \mathrm{~K}$ & & & $(0.08)$ & & \\
\hline Revenue & & & $0.255^{* * *}$ & & \\
\hline $500-1500 \mathrm{~K}$ & & & $(0.09)$ & & \\
\hline Revenue & & & 0.185 & & \\
\hline$>1500 \mathrm{~K}$ & & & $(0.12)$ & & \\
\hline $\begin{array}{l}\% \text { competitors } \\
\text { with label }\end{array}$ & & & & $\begin{array}{c}0.066^{* * *} \\
(0.02)\end{array}$ & \\
\hline Log-likelih. & -40.449 & -40.825 & -30.517 & -29.087 & -75.008 \\
\hline $\mathrm{Chi}^{2}$ & 75.538 & 59.181 & 81.286 & 71.241 & 39.33 \\
\hline Pseudo- $R^{2}$ & 0.574 & 0.570 & 0.599 & 0.633 & 0.251 \\
\hline N & 138 & 138 & 111 & 115 & 146 \\
\hline
\end{tabular}

${ }^{*} p<0.1,{ }^{* *} p<0.05,{ }^{* * *} p<0.01$; Huber-White robust standard errors in parentheses. Model statistics from underlying probit/logit model.

\section{Discussion}

To our knowledge, the results from the literature on ecolabels mostly focus on motivations and perceptions rather than firm characteristics, market conditions, and perceptions of ecolabels. Consequently, most references in this section refer to the EMS literature.

We find that labeled hotels and B \& Bs are larger than their unlabeled counterparts, which is in line with findings by Segarra-Oña et al. [7] for the ISO14001 adoption by Spanish hotels. However, our results are mixed for the other subsectors, where labeled firms tended to be larger in terms of revenues, but not in terms of the number of establishments, and only labeled holiday villages and group accommodations were larger than their unlabeled competitors in terms of employees. Although the sustainable entrepreneurship literature [31] suggests that smaller and younger firms stimulate disruptive sustainability innovation, we found that firms with the Green Key label were not smaller, and tended to be older. This might be due to the low innovative character of the sustainable measures that are necessary to obtain the label, such as water and energy reduction and offering sustainable food and beverages. Labeled firms tend to have more establishments than unlabeled firms, which is in line with the findings of Álvarez Gil et al. [29] and Ayuso [23] for EMSs. Ayuso [23] found that staff involvement is critical for the implementation of an EMS in hotels, which suggests that smaller 
hotels are more likely to adopt sustainable business practices. Our result that labeled hotels are larger than their unlabeled competitors suggests that either larger firms are able to involve their staff, or staff involvement is less important than previously thought (perhaps because being well-organized is more important than the involvement of individual staff members).

We find that labeled hotels and B \& Bs are more likely to be located in urban areas than their unlabeled competitors. This is contrary to the findings of Segarra-Oña et al. [7] for ISO14001 adoption by hotels.

The two groups of firms did not differ in their response to the statement 'Consumers understand the meaning of ecolabels'. Interestingly, not a single firm responded 'strongly agree', and for both groups of firms, a large share responded 'disagree' or 'strongly disagree'. This is in line with earlier findings that consumers are unfamiliar with or sceptical toward certification schemes $[6,15]$. Hotels and B \& Bs seemed to be the only sector in which labeled firms tended to agree more strongly with the statement that consumers are confident that the information conveyed by ecolabels is reliable. Again, this result shows that whereas most of the research on ecolabel adoption in the tourism sector focuses on the Hotel and B \& B sector, the results for this sector are not necessarily representative for other subsectors of the accommodation sector.

Multiple regression analysis confirmed the results of the statistical tests for most of the variables. However, the correlation between adoption and firms' perceptions of consumers' opinions on sustainability and reliability of ecolabels largely disappeared in the regression analysis.

\section{Conclusions}

The economics literature on ecolabel adoption hypothesizes that using green production technologies leads to higher production costs and requires a higher price. The tourism literature-often using small samples of firms that are not randomly selected-finds that ecolabel adoption tends to lead to lower costs. Using a large, randomly selected sample of firms confirms the results from the tourism literature: labeled firms on average faced a reduction in costs, but did not increase their price.

The tourism literature on ecolabel adoption focuses on the Hotel and B \& B sector. We extended this by including campsites and group accommodations. Our results for hotels and B \& Bs only partially confirmed the findings from the literature. In addition, we found that the results for this subsector of the accommodation sector are not representative for other subsectors: campsites, holiday villages and group accommodations, and conference centers. We found that hotels and B \& Bs with the Green Key label tended to be larger than unlabeled competitors. Labeled companies in all the subsectors of the accommodation sector tended to have more revenues and, apart from Campsites, more employees (in FTE). Labeled hotels and B \& Bs also tended to have more establishments than unlabeled competitors. These results suggest that economies of scale (for example, resulting in the availability of monetary and non-monetary resources, or being able to apply the same assessment procedure to multiple establishments) matter for ecolabel adoption. While the age distribution of firms in the Hotel and B \& B sector did not seem to differ for labeled and unlabeled firms, labeled firms in the other subsectors tended to be older than unlabeled firms. Labeled firms reported a higher number for the percentage of competitors with an ecolabel than unlabeled firms did. However, it does not seem that labeled firms operate in a business environment in which competition focuses on having a 'green image'.

Adoption of the Green Key label and implementing sustainable business practices led to a reduction in costs for $58 \%$ or respondents with an average cost reduction of $3.2 \%$. Furthermore, almost $40 \%$ of respondents indicated that they had to make investments of $€ 500$ or less to meet the Green Key requirements. Green Key offers potential adopters the opportunity of opening a test account for a free self-assessment so that firms can get an impression of the efforts to be made to obtain the label. To expand the adoption of its label, Green Key could communicate the opportunity for a free self-assessment and that fulfilling the criteria can lead to permanent cost savings, possibly at relatively low investment costs, more clearly to potential adopters. 
A limitation of this study is that we cannot assess causality. For example, Green Key-labeled firms tended to agree more strongly with the statement 'There is sufficient assessment of compliance of labeled firms with ecolabel's rules' than unlabeled firms. However, whether this was already the case before adoption, or labeled firms became confident due to their experience with the Green Key assessment procedure, cannot be assessed with our data. Another limitation is that not all the surveys were fully completed. Response rates were lower for questions toward the end of the survey, which probably had less to do with fatigue (the median completion time was $7 \mathrm{~min}$ ) and more with the questions at the end being the more sensitive ones (e.g., on profits and turnover). Indeed, in an earlier pilot of the survey, these questions were at the start of the survey, and companies were very reluctant to participate in the survey at all.

In this paper, we focused on ecolabel adoption. Obviously, adoption of the label does not necessarily imply that labeled firms improved their environmental outcomes to comply with the label's standards. As noted, firms may decide to adopt the label because they were already compliant with its standards. Therefore, the question of the label's effects on environmental outcomes is an interesting path for future research. Another interesting question is whether the presence of labeled competitors induces firms to implement sustainable business practices without adopting the label, thereby possibly reducing costs without having to spend money on certification and annual fees. Third, while we found evidence for a profit increase and a cost decrease after adoption, and most respondents were not able to increase their price, we did not assess changes in turnover and occupancy rates. Finally, the potential role of ecolabels in the sharing economy would be interesting to assess. Can ecolabels be expanded to private apartments such that they can be advertised on sharing websites such as AirBnB, and what would be the costs and benefits for the suppliers, customers, and local communities?

Author Contributions: Formal analysis, E.B.; Investigation, E.B. and E.v.d.W.; Methodology, E.B. and E.v.d.W.; Writing—original draft, E.v.d.W.; Writing—review and editing, E.B. and E.v.d.W.

Funding: This research received no external funding.

Acknowledgments: We thank Erik van Dijk, managing director of Green Key Netherlands, for providing us with additional information on Green Key's requirements and implementation, and Mohammed B. Degnet for useful comments on an earlier draft.

Conflicts of Interest: The authors declare no conflict of interest.

\section{Appendix A Survey Response and Descriptive Statistics}

Section 3.2 provides a brief description of our sample. Here, we provide some more details.

As noted in Section 3.2, 206 unique respondents started the questionnaire and at least indicated whether they had the Green Key label. Table A1 shows the response rate (column N) per variable. Note that many variables are categorical variables (e.g., province and Likert-scale questions with the scale ranging from 1 , 'strongly agree', to 5 , 'strongly disagree').

The first block in Table A1 shows the response rate to the questions that we used to check our sample: the province in which the firm is located (see Section 3.2), the sector in which it operates (see Section 3.2), whether it is familiar with the Green Key ecolabel, whether the firm has an ecolabel, and if so, which ecolabel. All the firms that had an ecolabel had the Green Key ecolabel and were familiar with it.

The second block of variables contained the reasons (not) to adopt an ecolabel. See Section 4.1 of the main text.

The third block presents response rates and descriptive statistics for the variables used in Section 4.2. Note that these questions only apply to firms that possess the Green Key ecolabel, i.e., the sample could not be larger than 89 . Since these questions refer to the firm's finances, respondents were reluctant to respond to these questions. Only 57 firms were willing to indicate the size of their investment to obtain the label, and only 71 firms were willing to indicate whether their variable costs increased, decreased, or had stayed the same after adoption. Of these, 25 firms were willing to assign a (non-zero) value to 
the percentage change in variable costs. Of the 89 labeled firms, 69 were willing to indicate whether they had become more profitable after adoption and whether they had been able to ask a higher price.

The final block of variables in Table A1 presents the descriptive statistics of the variables used in the statistical and econometric analyses of Sections 4.3 and 4.4 .

The median time used to complete the survey was $7 \mathrm{~min}$. Since some respondents took a break during the survey, the average time was $31 \mathrm{~min}$. The response rate was lower for questions toward the end of the survey. Overall, $13 \%$ of contacted firms completed the survey, and $22 \%$ indicated at least whether they had an ecolabel and some additional information. While the $22 \%$ response rate was lower than average for unannounced online surveys of managers [41], lower response rates for questions toward the end of the survey were not [42] Response rates were lower for questions toward the end of the survey, which probably had less to do with fatigue (given the median completion time of $7 \mathrm{~min}$ ) and more with the questions at the end being the more sensitive ones (e.g., on profits and turnover). Indeed, in an earlier pilot of the survey, these questions were at the start of the survey, and companies were very reluctant to participate in the survey at all.

Table A1. Descriptive statistics.

\begin{tabular}{|c|c|c|c|c|c|}
\hline & $\mathbf{N}$ & Mean & $\begin{array}{l}\text { Std. } \\
\text { Dev. }\end{array}$ & Min. & Max. \\
\hline Province & 193 & 6.91 & 3.39 & 1 & 12 \\
\hline Sector & 205 & 4.33 & 2.84 & 1 & 9 \\
\hline Know Green Key (Y/N) & 206 & 0.65 & 0.48 & 0 & 1 \\
\hline Has ecolabel $(\mathrm{Y} / \mathrm{N})$ & 206 & 0.43 & 0.49 & 0 & 1 \\
\hline Which ecolabel (GK/other) & 89 & 1.00 & 0.00 & 0 & 1 \\
\hline Reason label & 70 & 2.61 & 1.81 & 1 & 6 \\
\hline Reason no label & 98 & 4.79 & 2.16 & 1 & 7 \\
\hline Investment $(€)$ & 57 & 17,324 & 52,006 & 0 & 350,000 \\
\hline Variable costs up/down/same & 71 & 2.17 & 0.58 & 1 & 3 \\
\hline Variable costs up $(\%)$ & 5 & 10.00 & 3.53 & 5.00 & 15.00 \\
\hline Variable costs down (\%) & 20 & 14.40 & 21.27 & 0.00 & 100.00 \\
\hline More profitable $(\mathrm{Y} / \mathrm{N})$ & 69 & 1.74 & 0.44 & 1 & 2 \\
\hline Higher price $(\mathrm{Y} / \mathrm{N})$ & 69 & 1.96 & 0.20 & 1 & 2 \\
\hline Employees (FTE, log) & 97 & 1.51 & 1.28 & 0.00 & 5.44 \\
\hline Revenue (5 categories) & 119 & 2.08 & 1.19 & 1 & 5 \\
\hline Multiple (Y/N) & 206 & 0.07 & 0.26 & 0 & 1 \\
\hline Age (years, log) & 206 & 3.01 & 1.02 & 0.00 & 5.17 \\
\hline Sustainability important for company ( 5 categories) & 151 & 1.86 & 0.76 & 1 & 4 \\
\hline Urban $(\mathrm{Y} / \mathrm{N})$ & 191 & 0.16 & 0.36 & 0 & 1 \\
\hline Consumers value sustainability ( 5 categories) & 150 & 2.85 & 0.78 & 1 & 5 \\
\hline Competition_point (4 cat) & 151 & 2.01 & 1.06 & 1 & 4 \\
\hline Many competitors have ecolabel (5 categories) & 149 & 3.44 & 0.98 & 1 & 5 \\
\hline Percentage competitors with label (\%) & 122 & 23.62 & 27.51 & 0.00 & 100.00 \\
\hline Consumers understand (5 categories) & 146 & 3.41 & 0.78 & 2 & 5 \\
\hline Consumers confident ( 5 categories) & 147 & 2.31 & 0.68 & 1 & 5 \\
\hline Assessment of compliance (5 categories) & 148 & 2.55 & 0.75 & 1 & 5 \\
\hline
\end{tabular}

\section{References}

1. Hindle, R.; Swift, J.; Bennett, A.; Macdonald, B.; Denman, J.; Denman, R.; Somper, C. Mapping of Evidence and Trends in Sustainable Tourism; SQW Consulting: London, UK, 2007.

2. Hunter, C.; Shaw, J. The ecological footprint as a key indicator of sustainable tourism. Tour. Manag. 2007, 28, 46-57. [CrossRef]

3. Gössling, S.; Peeters, P. Assessing tourism's global environmental impact 1900-2050. J. Sustain. Tour. 2015, 23, 639-659. [CrossRef]

4. Buckley, R. Tourism ecolabels. Ann. Tour. Res. 2002, 29, 183-208. [CrossRef] 
5. Dunk, R.M.; Gillespie, S.A.; MacLeod, D. Participation and retention in a green tourism certification scheme. J. Sustain. Tour. 2016, 24, 1585-1603. [CrossRef]

6. Geerts, W. Environmental certification schemes: Hotel managers' views and perceptions. Int. J. Hosp. Manag. 2014, 39, 87-96. [CrossRef]

7. Segarra-Oña, M.; Peiró-Signes, Á.; Verma, R.; Miret-Pastor, L. Does environmental certification help the economic performance of hotels? Evidence from the Spanish hotel industry. Cornell Hosp. Q. 2012, 53, 242-256. [CrossRef]

8. Tzschentke, N.; Kirk, D.; Lynch, P.A. Reasons for going green in serviced accommodation establishments. Int. J. Contemp. Hosp. Manag. 2004, 16, 116-124. [CrossRef]

9. Darby, M.R.; Karni, E. Free competition and the optimal amount of fraud. J. Law Econ. 1973, 16, 67-88. [CrossRef]

10. Font, X. Environmental certification in tourism and hospitality: Progress, process and prospects. Tour. Manag. 2002, 23, 197-205. [CrossRef]

11. Iraldo, F.; Barberio, M. Drivers, barriers and benefits of the EU Ecolabel in European companies' perception. Sustainability 2017, 9, 751. [CrossRef]

12. Rivera, J. Assessing a voluntary environmental initiative in the developing world: The Costa Rican Certification for Sustainable Tourism. Policy Sci. 2002, 35, 333-360. [CrossRef]

13. Bjørner, T.B.; Hansen, L.G.; Russell, C.S. Environmental labeling and consumers' choice-An empirical analysis of the effect of the Nordic Swan. J. Environ. Econ. Manag. 2004, 47, 411-434. [CrossRef]

14. Cason, T.N.; Gangadharan, L. Environmental labeling and incomplete consumer information in laboratory markets. J. Environ. Econ. Manag. 2001, 43, 113-134. [CrossRef]

15. Ayuso, S. Comparing voluntary policy instruments for sustainable tourism: The experience of the Spanish hotel sector. J. Sustain. Tour. 2007, 15, 144-159. [CrossRef]

16. Sampaio, A.R.; Thomas, R.; Font, X. Small business management and environmental engagement. J. Sustain. Tour. 2012, 20, 179-193. [CrossRef]

17. Duglio, S.; Ivanov, S.; Magliano, S.; Ivanova, M. Motivation, costs and benefits of the adoption of the European Ecolabel in the tourism sector: An exploratory study of Italian accommodation establishments. Izv. J. Varna Univ. Econ. 2017, 61, 83-95.

18. Barbulescu, A.; Moraru, A.-D.; Duhnea, C. Ecolabelling in the Romanian seaside hotel industry-Marketing considerations, financial constraints, perspectives. Sustainability 2019, 11, 265. [CrossRef]

19. Green Key. Available online: http://www.greenkey.nl (accessed on 17 February 2019).

20. Green Key. Available online: http://www.greenkey.global/history (accessed on 17 February 2019).

21. Plüss, C.; Zotz, A.; Monshausen, A.; Kühhas, C. Sustainability in Tourism. A Guide through the Label Jungle. Available online: https:/destinet.eu/who-who/civil-society-ngos/ecotrans/publications/guide-through-labeljungle-1/ (accessed on 17 May 2019).

22. Green Key. Available online: http://www.greenkey.nl/l/library/download/106681 (accessed on 6 March 2014).

23. Ayuso, S. Adoption of voluntary environmental tools for sustainable tourism: Analyzing the experience of Spanish hotels. Corp. Soc. Responsib. Environ. Manag. 2006, 13, 207-220. [CrossRef]

24. Mason, C.F. The economics of eco-labeling: Theory and empirical implications. Int. Rev. Environ. Resour. Econ. 2012, 6, 341-372. [CrossRef]

25. Garay, L.; Font, X. Doing good to do well? Corporate social responsibility reasons, practices and impacts in small and medium accommodation enterprises. Int. J. Hosp. Manag. 2012, 31, 329-337. [CrossRef]

26. Vernon, J.; Essex, S.; Pinder, D.; Curry, K. The "greening" of tourism micro-businesses: Outcomes of focus group investigations in South East Cornwall. Bus. Strategy Environ. 2003, 12, 49-69. [CrossRef]

27. Ateljevic, J. Small tourism firms and management practices in New Zealand: The centre stage macro region. Tour. Manag. 2007, 28, 307-316. [CrossRef]

28. Brammer, S.; Hoejmose, S.; Marchant, K. Environmental management in SMEs in the UK: Practices, pressures and perceived benefits. Bus. Strategy Environ. 2012, 21, 423-434. [CrossRef]

29. Álvarez Gil, M.J.; Burgos Jiménez, J.; Céspedes Lorente, J.J. An analysis of environmental management, organizational context and performance of Spanish hotels. Omega Int. J. Manag. Sci. 2001, 29, 457-471. [CrossRef]

30. Carmona, E.; Céspedes, J.; De Burgos, J. Environmental strategies in Spanish hotels: Contextual factors and performance. Serv. Ind. J. 2004, 24, 101-130. [CrossRef] 
31. Hockerts, K.; Wüstenhagen, R. Greening Goliaths versus emerging Davids—Theorizing about the role of incumbents and new entrants in sustainable entrepreneurship. J. Bus. Ventur. 2010, 25, 481-492. [CrossRef]

32. Griliches, Z. Hybrid corn: An exploration in the economics of technical change. Econometrica 1957, 48, 501-522. [CrossRef]

33. Sipic, T. Eco-labelling of marine recreation services: The case of Blue Flag price premium in Croatia. J. Ecotour. 2017, 16, 1-23. [CrossRef]

34. Chen, Y.S.; Chang, C.H. Greenwash and green trust: The mediation effect of green consumer confusion and green perceived risk. J. Bus. Ethics 2013, 114, 489-500. [CrossRef]

35. Gössling, S.; Buckley, R. Carbon labels in tourism: Persuasive communication? J. Clean. Prod. 2016, 111, 358-369.

36. Mufidah, I.; Jiang, B.C.; Lin, S.-C.; Chin, J.; Puspa Rachmaniati, Y.; Fadil Persada, S. Understanding the consumers' behavior intention in using green ecolabel product through pro-environmental planned behavior model in developing and developed regions: Lessons learned from Taiwan and Indonesia. Sustainability 2018, 10, 1423. [CrossRef]

37. Duglio, S.; Beltramo, R. Quality assessment in the Italian mountain huts. Eur. J. Tour. Res. 2014, 8, $115-142$.

38. Font, X.; Sanabria, R.; Skinner, E. Sustainable tourism and ecotourism certification: Raising standards and benefits. J. Ecotour. 2003, 2, 213-218. [CrossRef]

39. Green Key. Available online: http://www.greenkey.nl/locaties (accessed on 12 February 2014).

40. Kamer van Koophandel. Available online: http://www.kvk.nl (accessed on 12 February 2014).

41. Cycyota, C.S.; Harrison, D.A. What (not) to expect when surveying executives: A meta-analysis of top manager response rates and techniques over time. Organ. Res. Methods 2006, 9, 133-160. [CrossRef]

42. Flynn, A. e-Surveying and respondent behaviour: Insights from the public procurement field. Electron. J. Bus. Res. Methods 2018, 16, 38-53.

(C) 2019 by the authors. Licensee MDPI, Basel, Switzerland. This article is an open access article distributed under the terms and conditions of the Creative Commons Attribution (CC BY) license (http://creativecommons.org/licenses/by/4.0/). 


\title{
Electricity Forecasting Improvement in a Destination Using Tourism Indicators
}

\author{
Oscar Trull $^{1, *}$, Angel Peiró-Signes ${ }^{2}$ and J. Carlos García-Díaz ${ }^{1}$ \\ 1 Departamento de Estadística e Investigación Operativa Aplicadas y Calidad, \\ Universitat Politècnica de València, E46022 Valencia, Spain \\ 2 Departamento de Dirección y Organización de Empresas, Universitat Politècnica de València, \\ E46022 Valencia, Spain \\ * Correspondence: otrull@eio.upv.es
}

Received: 25 April 2019; Accepted: 28 June 2019; Published: 3 July 2019

\begin{abstract}
The forecast of electricity consumption plays a fundamental role in the environmental impact of a tourist destination. Poor forecasting, under certain circumstances, can lead to huge economic losses and air pollution, as prediction errors usually have a large impact on the utilisation of fossil fuel-generation plants. Due to the seasonality of tourism, consumption in areas where the industry represents a big part of the economic activity follows a different pattern than in areas with a more regular economic distribution. The high economic impact and seasonality of the tourist activity suggests the use of variables specific to it to improve the electricity demand forecast. This article presents a Holt-Winters model with a tourism indicator to improve the effectiveness on the electricity demand forecast in the Balearic Islands (Spain). Results indicate that the presented model improves the accuracy of the prediction by $0.3 \%$. We recommend the use of this type of model and indicator in tourist destinations where tourism accounts for a substantial amount of the Gross Domestic Product (GDP), we can control a significant amount of the flow of tourists and the electrical balance is controlled mainly by fossil fuel power plants.
\end{abstract}

Keywords: electricity; tourism; time series; forecasting

\section{Introduction}

Tourism is growing worldwide, as is its environmental impact on tourist destinations. Evaluating the impact of tourism goes further than evaluating the economic facet; it must also take into account both its environmental and social dimensions [1,2]. Among the environmental dimensions, positive and negative impacts on biodiversity, erosion and physical damage, pollution, resources or landscape change have been reported [3]. The extent and nature of the environmental impact of tourism is related to the magnitude of the development and the volume of visitors, but also to the spatial and temporal concentration of tourism activities [4]. Thus, accurate forecasting of visitors allows to allocate the appropriate resources benefiting the sustainable development of tourism destinations [5]. Specifically, in the Balearic Islands, one of the main resources to manage is electricity. The vast majority of services require it to function, and have great economic and environmental impact.

Electricity demand management is a key factor-its development and use are increasing, both in terms of production and distribution. The efficiency of managing such resources has a big economic impact, as electricity powers a large amount of devices of any kind used. Energy cannot be stored in large quantities; rather, it must be produced on demand. Losses are generated when there is a mismatch between production and consumption. As energy is produced based on consumption prediction, reducing losses necessitates improving demand forecasts. A better prediction model will improve electricity production management. 
The main objective of this paper is to present a new short-term prediction model for energy consumption that incorporates tourism indicators as a predictor. More precisely, we propose a new model that improves consumption prediction in an area where the tourism industry accounts for a big amount of the Gross Domestic Product (GDP), the Balearic Islands. Following Bakhat and Roselló [6], we incorporated Daily Human Pressure Indicator (DHPI). DHPI considers the variation on the population due to the increase or decrease of tourists. We hypothesised that the variation of the population in the tourism area is impacting the amount of electric energy consumed while other factors, such as temperature, remain constant. Therefore, introducing DHPI in a prediction model will improve significantly the energy consumption prediction.

The paper is structured as follows: in Section 2, we review the literature concerning the worked topics, in Section 3, we study the electrical demand in the Balearic Islands, and the associated emissions; in Section 4, we introduce the new model including a touristic indicator; in Section 5 we analyse the results and discuss them. Section 6 reflects on the conclusions and limitations of the study.

\section{Literature Review}

Research into the environmental impact of the tourism industry [7-9] has been focused primarily on determining the impact of transportation utilisation subserving it. Indeed, air transportation alone is believed to account for more than $60 \%$ of this impact. Scott et al. [10-12] analysed the tourism impact on Climate Change and Paris Agreement effects for the tourism industry.

Becken and Simmons [13] and Gössling [14,15] have described the potential environmental damage caused by tourism activities. Tourism impact on emissions has been reported by several authors (Meng et al. [16], Lee y Brahmasrene [17] Paramati et al. [18]). Specifically, tourism contributes approximately $5 \%$ to the global emissions of $\mathrm{CO}_{2}$ [19]. Important here is the increasing concern across countries about global warming, as is impacted by the latter. Such concerns extend to the energetic impact of tourism activities $[20,21]$ as the industry represents one of the greatest energy consumers $[7,13,15,22-25]$, especially in the European Union where travel and tourism represents the highest contributor to the GDP and visitors' exports [26].

Studies have also paid attention to the hospitality industry ([16] Becken et al. [23,27]), a subsegment of tourism, as a primary energy consumer. World Tourism Organization and the United Nations Environment Programme estimated that accommodation accounts for $21 \%$ of tourism's total greenhouse gas emissions [26].

Despite these worrisome indicators, the broadscale energy consumption and environmental pollution caused by tourism have not declined since the 1990s [10,11,28-31]. Pablo-Romero et al. [32], in fact, found an increasingly positive relationship between electricity consumption of the hospitality sector and overnight stays, and Katircioglu et al. [29] reported a positive relationship between tourist arrivals and energy consumption. Consequently, they recommended energy-efficiency measures, such as the adoption of renewable energy systems and the development of energy management capabilities. Moreover, the electricity consumption elasticity values of the hospitality sector (with respect to tourist overnight stays) have the highest values in touristic areas, indicating that for the same overnight stays the impact on electricity consumption is higher in these areas and, thus negatively affecting sustainability [33]. Other researchers $[31,34,35]$ have indicated that provision of quality hotel service can produce increases in energy consumption.

The increase of tourism in certain areas is expected to increase the environmental impact on tourist destinations. Several initiatives have recently been undertaken by destination stakeholders to reduce its negative effects. These actions have focused mainly on governments setting environmental policy measures, setting objectives and providing financial support to reduce their carbon footprint [36] and tourism companies reducing energy and water consumption [37,38]. Following this line, there is still room for improvement within the actual technological system. More precisely, improving energy consumption prediction is able to reduce the environmental impact of energy utilisation and, at the same time, lower its overall cost. 
Production management is also affected by generation units. Generation units are distributed between the available electrical production technologies that enable the electricity source to control the amount of production. Lags between demand and production turn out to be harmful to the environment, as they typically cause a higher use of fossil fuel-generation plants. When this occurs, carbon dioxide production from electricity production is increased, as is the cost of the energy. Hobbs [39] pointed out that a $1 \%$ prediction improvement can save thousands, even millions of dollars. More precisely, Hong [40] estimated that a $1 \%$ improvement in the short-term demand forecasting in an electrical system (based on 1GW peak demand) can save approximately $\$ 600,000$ per year. Unfortunately, there is a research gap related to the evaluation of the environmental impact of this prediction inefficiency. However, using the Balearic Islands (Spain) consumption and emissions data from Red Eléctrica de España (Transmission system operator in Spain), we estimated that a $2 \%$ prediction error might be generating $1 \mathrm{~T} \mathrm{CO}_{2}$ /hour additional emissions.

\section{Data}

\subsection{Electricity Demand and Their Emissions}

Electricity management is a key factor in the Balearic Islands. Resources are limited, and a full power supply to citizens and industries must be ensured. The responsibility of this electricity distribution, as well as the operational planning of the production units and demand forecasting, is the responsibility of the Transmission System Operator (TSO). For that reason, Red Eléctrica de España (REE), the unique TSO in Spain, is always endeavouring to improve forecasting models to obtain more accurate predictions. REE continuously provides electricity demand in the Balearic Islands through the website www.ree.es. The overall electricity demand, forecasts and emissions can be obtained for each Island separately. They are provided in intervals of $10 \mathrm{~min}$. In this paper, we developed the research model using an hourly resolution; this information was therefore cropped. We used available data from May 2013 to October 2015. Figure 1 shows the hourly electricity demand in Mallorca. Menorca's demand provided similar results, but different from the peninsula.

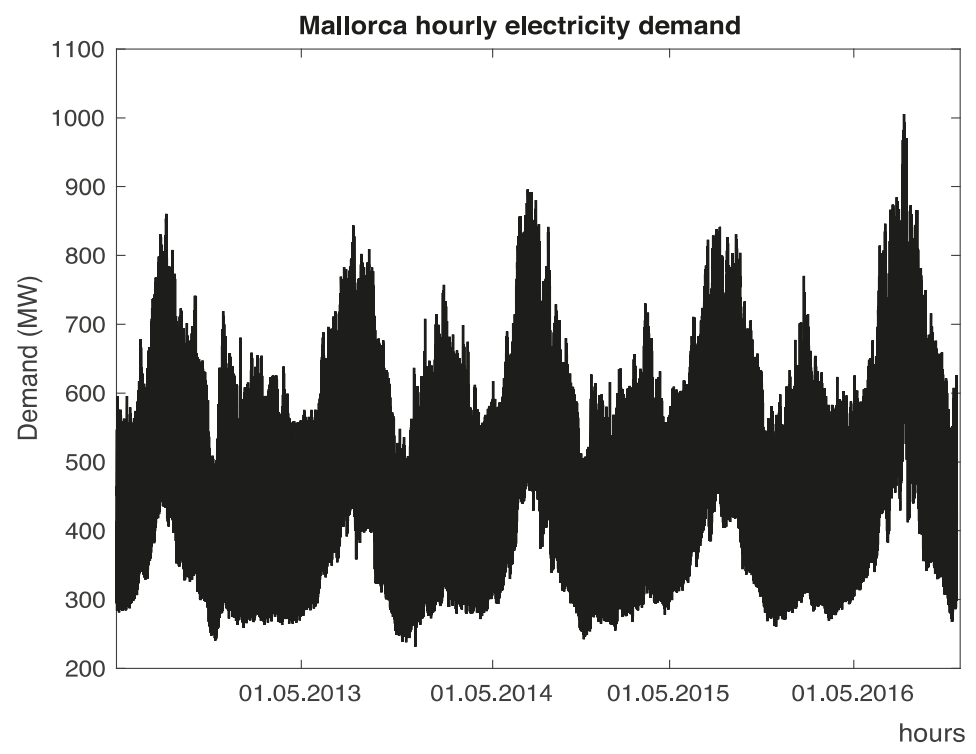

Figure 1. Hourly electricity demand in Mallorca. 
The series shows effects that are highly influenced by the seasons, with maximum peaks occurring in summer and at the Easter holiday. This seasonality is mainly caused by tourism activity, as it is the main economic driver of the region. A comparison of the Islands' Gross Domestic Product (GDP) and that of Spain, provided by Instituto Nacional e Estadística (INE) and Exceltur (main tourism non-profit group formed by 28 leading Spanish tourist groups), is shown in Figure 2. This accounts for the direct, indirect and induced effect on the GDP [41]. It can be easily shown how the tourism activity reaches up to $45 \%$ of the GDP in the Islands, whereas in Spain it only reaches $11 \%$. In addition, the figure shows an increasing trend of this activity in the GDP from 2010. Thus, the more people coming into the Islands, the more consumption of electricity, as explained in the introduction.

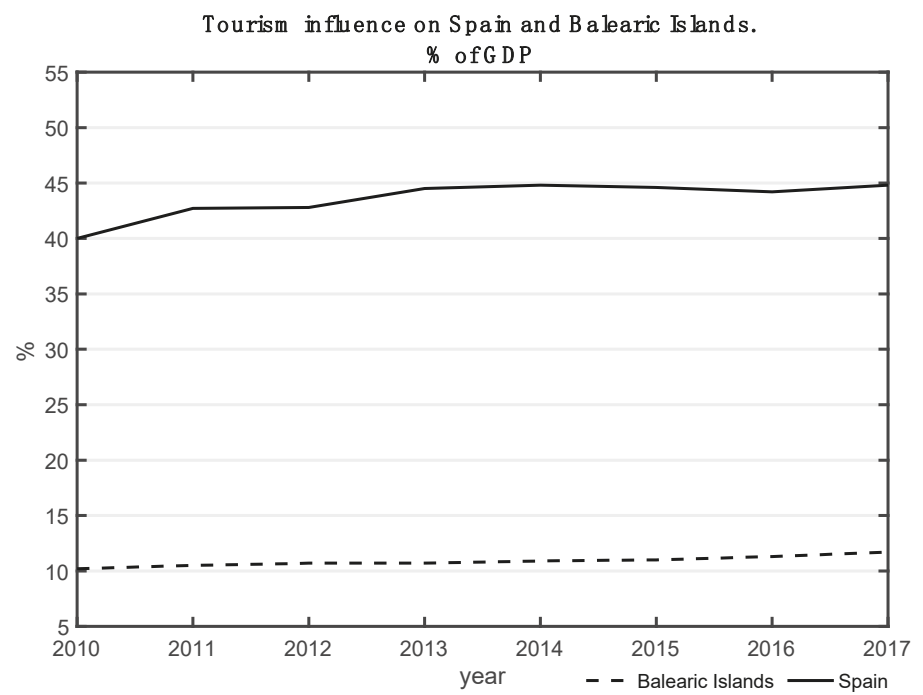

Figure 2. Tourism Gross Domestic Product (GDP) in the Balearic Islands against Spain's. Source: Own elaboration based on Incotur's and Exceltur's information.

Herce [42] analysed the economy in the Balearic Islands, as well as its electricity generation. He highlighted how between 1990 and 2005, $\mathrm{CO}_{2}$ emissions increased to $62.2 \%$. This increase was due to the power usage of fossil fuel stations (which reached up to $97 \%$ of the produced energy in the Islands). The "Plan Director Sectorial Energético de la Illes Balears" [43], a sectorial energetic plan, promoted the construction of an interconnexion cable between the peninsula and the archipelago, as well as integration of renewables within the energy-generation system. However, as shown in Figure 3, the evolution of emissions is not yet under control. Emissions of $\mathrm{CO}_{2}$ are increasing as overall demand grows. However, more importantly, the emission factor (in $\mathrm{T} \mathrm{CO}_{2} / \mathrm{MWh}$ ) is also increasing (although its slope is less steep). The factor, altogether, reflects a worsening in the emissions objectives.

Figure 4 elucidates some of the primary factors causing emissions to continue their upward climb. Coal power stations represent half of the electrical generation. They are generally used as the main source, although other alternatives with less negative environmental impact are available. Renewables have a low generation ratio and, despite the green-focused policies, the ratio is still about $5 \%$. The way to reduce this trend is to make greater investments in renewable energies [44]. In addition, a more useful and accurate electricity demand forecast would help to program the generation units (thereby enabling a change in the ratio of energy sources in favour of those that are renewable $[45,46])$. 


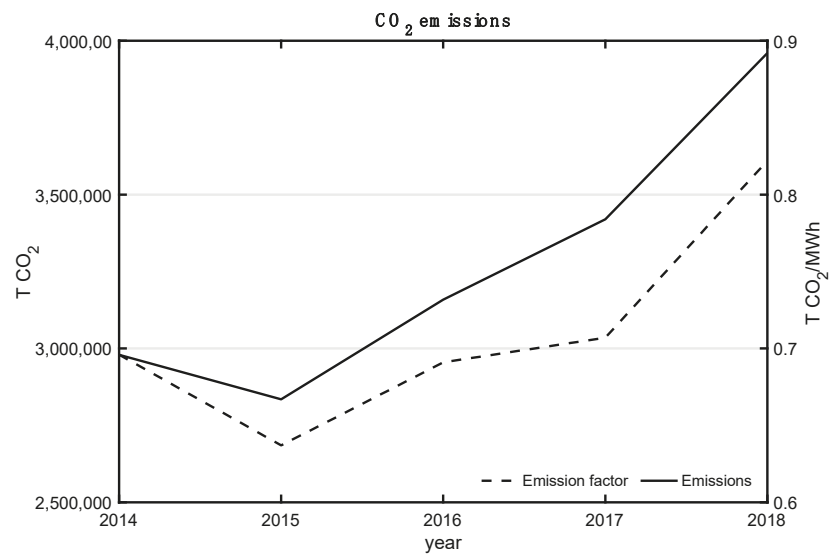

Figure 3. Evolution of the $\mathrm{CO}_{2}$ emissions in the Balearic Islands due to power generation. The emissions factor is measured as a weight of emissions per MWh, right axis.



Figure 4. Distribution of the electricity generation in the Balearic Islands.

The evolution of emissions and electricity demand shown in the previous figures reveal that the increasing trend is directly related to economic growth, and in particular to tourism activity. This is not an isolated case. Pfenninger and Keirstead [47] analysed several scenarios combining all kinds of energy sources in the UK. They concluded that there is no clear direction to be taken. There are still many constraints making fossil fuel power plants a source that needs to be exploited.

\subsection{Daily Human Presure Indicator (DHPI)}

Figure 5 shows data regarding arrivals and departures to and from the Islands, through both airand seaports. It can be seen that tourist arrivals by ship and airplane exceed 20,000,000 passengers. The plot shows an increasing trend, due in part to local government policies $[48,49]$. Tourism can be expected to remain the main economic activity in the Island in the ensuing years. 


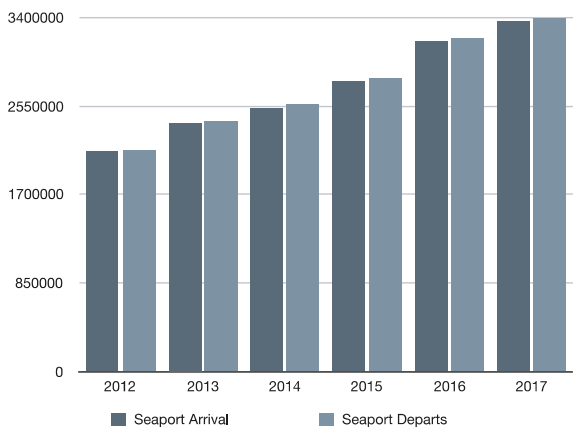

(a)

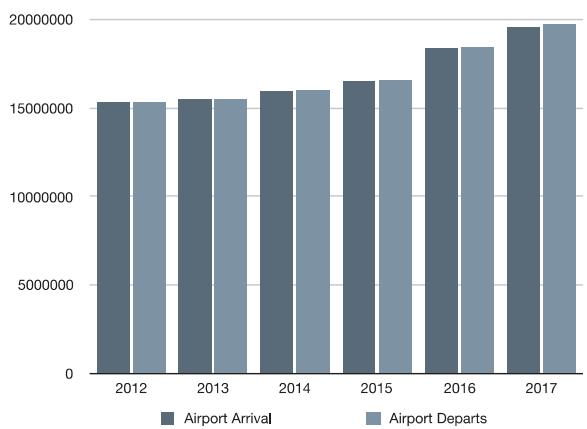

(b)

Figure 5. Balance of arrivals and departures to/from Balearic Islands. (a) seaport data; (b) airport data. Source: IBSTAT.

However, these data cannot be directly integrated into a model. Both variables are dependent and cannot be worked separately. Nevertheless, the Institut d'Estadística de les Illes Balears (IBSTAT) publishes annual data regarding visitors to the Islands, obtained from data provided by the Balearic government (through an indicator named Daily Human Pressure Indicator; DHPI). This indicator measures the quantity of people in the Islands each day, incorporating tourists' movements in the data. Riera and Mateu [50] explain how this indicator has been designed and the data are collected. The DHPI is defined according to a formula wherein (1),

$$
\mathrm{DHPI}_{D}=\mathrm{POP}_{a}+\sum_{d=1}^{D}\left(A_{d a}-D_{d a}+w_{d a} D_{a}\right)
$$

where $a$ refers to the year of analysis; $D$ refers to the day of analysis. $P O P_{a}$ stands for the population on 1 January of the year $a ; A_{d a}$ represents the total arrivals (per sea and airport) to the Islands, whereas $D_{d a}$ represents the departures. $D_{a}$ is the result of the difference between the year $a$ and the year $a+1$. Finally, $w_{d a}$ is considered the probability of making an error while estimating the arrivals. Figure 6 shows the evolution on $\mathrm{DHPI}_{D}$ within the years 1997 to 2017 for the main Islands Mallorca and Menorca.

The DHPI shows a high seasonal behaviour, with maximum peaks during summer, as the tourism in Balearic Islands is closely related to weather conditions [48]. An in-depth analysis of the indicator can reveal that the seasonality of electrical demand and DHPI are closely related. This point permits the DHPI to be integrated as part of an electricity demand model.

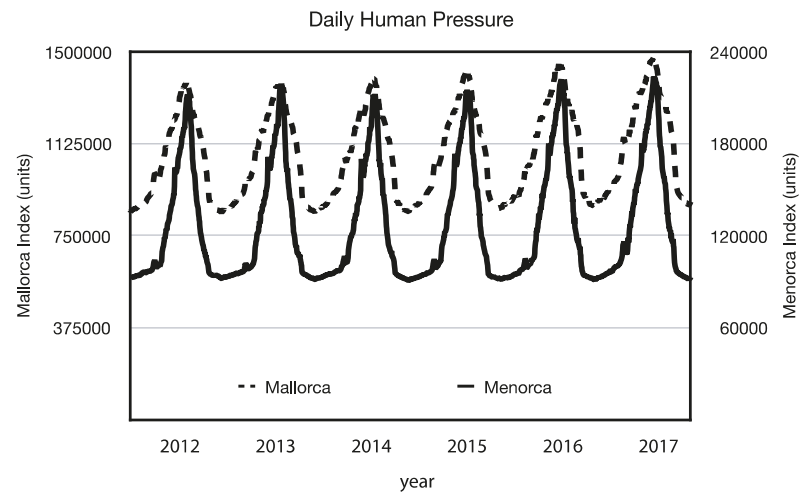

Figure 6. Daily human pressure index in Mallorca and Menorca. Source: IBESTAT. 


\section{Model Development}

Most TSOs use time series to model the behaviour of the electricity demand and price. This kind of tools have turned out to be very powerful as they provide very accurate predictions, although sometimes they are complex. Time series use the observed data in the past to fit a model, and later predict new values. Weron [51] gathers the state of the art of the techniques used for this purpose [52]. This author organises the forecasting methods in statistical methods, artificial intelligence and others. For the first group, representative methods are ARIMA models, exponential smoothing, including Holt-Winters methods, state space models and AR-models. The second group includes neural networks and support vector machines. Some other naïve methods are also available; however, their use is minor. TSOs usually develop their own models as a combination of all the former. In Spain, REE uses its own model in which 24 hourly subsets are forecasted each hour, and there is a daily forecast for medium-term purposes $[53,54]$. This model is based on the decomposition, for each hour of demand, in basic load (where trend and seasonality are included) and load modifiers due to special days or climatic factors. The basic load is adjusted to an ARIMA time series model, while the modifiers are dummy variables. Usually, TSOs do not publish their own forecasting models; they use a combination of several time series techniques, as described by Suganthi [55]. Electricité de France developed its own model based on regression models and Fourier decomposition of the seasonality [56,57], whereas TERNA (Italy's TSO) uses a model more similar to REE's [58,59].

This paper focuses on Holt-Winters' methods, as they are very efficient in electricity demand forecasting, due to their simplicity and accuracy on time series with a strong seasonal effect [60].

\subsection{Basic Holt-Winters Methods}

The Holt-Winters exponential smoothing methods (HW) were introduced by P.R Winters [61] in the 1960s. These methods consist of several smoothing equations, which model the level, trend and seasonal components in the observed data. A final equation uses the information of smoothing equations to provide forecasts, and thus, it is named forecasting equation. In all models, there is at least one level equation. The other equations can be avoided if no trend or no seasonality is considered. Equations (2)-(5) show the Holt-Winters model.

$$
\begin{gathered}
L_{t}=\alpha\left(\frac{X_{t}}{I_{t-s}}\right)+(1-\alpha)\left(L_{t-1}+T_{t-1}\right) \\
T_{t}=\gamma\left(L_{t}-L_{t-1}\right)+(1-\gamma) T_{t-1} \\
I_{t}=\delta\left(\frac{X_{t}}{L_{t} I_{t-s}}\right)+(1-\delta) I_{t-s} \\
\hat{X}_{t+k}=\left(L_{t}+k T_{t}\right) I_{t-s+k}+\varphi_{A R}^{k} \varepsilon_{t}
\end{gathered}
$$

where $L_{t}$ is the level equation with a smoothing parameter $\alpha, T_{t}$ stands for the trend equation, with smoothing parameter $\gamma$ and $I_{t}$ is the seasonal indices of cycle length $s$ and smoothing parameter $\delta . X_{t}$ is the observed data whereas $\hat{X}_{t+k}$ is the k-ahead predictions; $\varphi_{A R}^{k}$ is the adjustment factor related to the first autocorrelation error $\left(\varepsilon_{t}\right)$. Gardner et al. [62] and latterly Taylor [63] include a damping factor in the trend. Williams and Miller [64] propose a new model in which interventions are modelled as level adjustments. The most important evolution is introduced by J.W. Taylor by including the double [65] and triple seasonal [66] Holt-Winters (HWT), and an adjustment using the first autocorrelation error (AR1), that improves the forecasts [67]. Trull et al. use discrete-interval moving seasonalities to model Easter holidays [68].

The equations in the model can be combined using different methods: additive and multiplicative. The previous methods used an additive method for trends, while seasonal indices were included using a multiplicative one. García-Díaz and Trull [69] generalise these methods to n seasonalities and apply them using three factors followed by the seasonal cycle length. The first factor stands for the 
trend method, the second for the seasonal method, and the third describes whether the model has been adjusted with AR1. Table 1 summarises all possible combinations. As an example, a $24 \mathrm{~h}$-length multiplicative trend, multiplicative seasonality including AR1 adjustment will expressed as $\mathrm{MMC}_{24}$.

Table 1. Summary of Holt-Winters (HWT) method combinations.

\begin{tabular}{ccccccc}
\hline \multirow{2}{*}{ Seasonality } & None & Additive & Multip. & None & Additive & Multip. \\
\cline { 2 - 7 } & & Normal & & \multicolumn{3}{c}{ AR(1) Adjusted } \\
\hline None & NNL & NAL & NML & NNC & NAC & NMC \\
Additive & ANL & AAL & AML & ANC & AAC & AMC \\
Damped Additive & dNL & dAL & dML & dNC & dAC & dMC \\
Multiplicative & MNL & MAL & DML & MNC & MAC & MMC \\
Damped Multiplicative & DNL & DML & DML & DMC & DAC & DMC \\
\hline
\end{tabular}

The parameters are obtained through an optimisation algorithm, by minimising the error of a one-step-ahead forecast compared to observed values. The Holt-Winters methods are recursive; it is thus mandatory to obtain at the beginning the initial values of each model. The level was obtained as the moving average of the first two cycles. The trend was calculated by averaging the difference between the first and the second cycle. The seasonal indices were obtained by dividing each value of the first cycle by moving average. The minimisation algorithm is then launched, with the smoothing parameters bounded between 0 and 1 . The root of the mean of the squared error (RMSE) is used to measure the error. RMSE is defined in Equation (6).

$$
\text { RMSE }=\sqrt{\frac{1}{m} \sum_{t=1}^{m}\left(\hat{X}_{t}-X_{t}\right)^{2}}
$$

where $m$ is the number of observed values in the time series used to fit the model.

\subsection{New Holt-Winters with the DHPI Model}

The first autocorrelation error obtained during the model fit, as a result of the optimisation, reflects the variability of the series itself, but also could be related to another exogenous variable. The addition of the AR1 adjustment improves the forecasting accuracy, but some information could be lost. The innovation proposed in this paper consists in splitting this error into two components: one due to the effect of the variability by tourism indicators and the other due to the variability of the series itself. It is possible to perform this action because, as explained in the introductory section, the energy use of the Balearic Islands is highly related to tourism; it is also geographically aisled.

The air temperature is an exogenous variable that is commonly integrated into the model(s) used [70], but, for very short-term forecasting, it is not necessary. The demand itself captures the temperature transitions [71]. Only abrupt changes in the climate conditions could have influence on the model; however, the temperature in Balearic Islands is relatively smooth and thus can be considered constant. In the same way, GDP is a variable that must be kept out of the model. While it may have influence in the long term [72], it is not possible to include it in the model. The series correspond to the aggregate demand of all energy of the islands, and not only that related to tourism. However, the fact that tourism has such a high percentage of GDP means that demand must be associated with tourism components, such as the DHPI, contrary to other places where the weight of tourism is not so high, and its effect is diluted among other sectors. A good sample is the peninsula, where the industrial sector exerts its influence.

The procedure to integrate the indicator in the model was as follows: First, we obtained a simple Holt-Winters model for the DHPI without AR1 adjustment, as the error will be used in the main model. 
We used the Holt-Winters model for DHPI because the time series shows a high seasonal component and is proportional to the demand model. The DHPI model is described by Equations (7)-(10).

$$
\begin{gathered}
L_{t}^{D H P I}=\alpha_{D I P H}\left(\frac{D H P I_{t}}{I_{t-s}^{D H P I}}\right)+\left(1-\alpha_{D H P I}\right)\left(L_{t-1}^{D H P I}+T_{t-1}^{D H P I}\right) \\
T_{t}^{D H P I}=\gamma_{D H P I}\left(L_{t}^{D H P I}-L_{t-1}^{D H P I}\right)+\left(1-\gamma_{D H P I}\right) T_{t-1}^{D H P I} \\
I_{t}^{D H P I}=\delta_{\text {DHPI }}\left(\frac{X_{t}^{D H P I}}{L_{t}^{D H P I} I_{t-s}^{D H P I}}\right)+\left(1-\delta_{\mathrm{DHPI}}\right) I_{t-s}^{D H P I} \\
\hat{X}^{D H P I}{ }_{t+k}=\left(L_{t}^{D H P I}+k T_{t}^{D H P I}\right) I_{t-s+k}^{\mathrm{DHPI}}
\end{gathered}
$$

where $L_{t}^{D H P I}, T_{t}^{D H P I}$ and $I_{t}^{D H P I}$ are the equations for level, trend and seasonal indices with smoothing parameters $\alpha_{D I P H}, \gamma_{D H P I}$ and $\delta_{D H P I}$ for the DIPH. $\hat{X}_{t+k}^{D H P I}$ are the k-ahead prediction values for DHPI. The error made by the forecasts of (10) is a very important information. The model defined by (2)-(5) does not react to forecasts produced by (10) because that information is latent in the model. However, a big difference between the forecast of (10) and DHPI means a special situation, that the model (2)-(5) cannot adequately describe or account for. We tried using covariates, as explained by Bermúdez [73], but the results were not positive. The way to relate mismatches in the both forecasting equations_-demand and DHPI—is through a linear combination, as shown in (11).

$$
\hat{X}_{t+k}=\left(L_{t}+k T_{t}\right) I_{t-s+k}+\varphi_{A R}^{k}\left[\varepsilon_{t}-\rho\left(\hat{X}_{t+k}^{D H P I}-D H P I_{t+k}\right)\right]
$$

Here, $\rho$ is the relation factor between both models. The complete model is thus expressed as in Equations (12)-(19).

$$
\begin{gathered}
L_{t}=\alpha\left(\frac{X_{t}}{I_{t-s}}\right)+(1-\alpha)\left(L_{t-1}+T_{t-1}\right) \\
T_{t}=\gamma\left(L_{t}-L_{t-1}\right)+(1-\gamma) T_{t-1} \\
I_{t}=\delta\left(\frac{X_{t}}{L_{t} I_{t-s}}\right)+(1-\delta) I_{t-s} \\
L_{t}^{D H P I}=\alpha_{D I P H}\left(\frac{D H P I_{t}}{I_{t-s}^{D H P I}}\right)+\left(1-\alpha_{D H P I}\right)\left(L_{t-1}^{D H P I}+T_{t-1}^{D H P I}\right) \\
T_{t}^{D H P I}=\gamma_{D H P I}\left(L_{t}^{D H P I}-L_{t-1}^{D H P I}\right)+\left(1-\gamma_{D H P I}\right) T_{t-1}^{D H P I} \\
I_{t}^{D H P I}=\delta_{\text {DHPI }}\left(\frac{X_{t}^{D H P I}}{L_{t}^{D H P I} I_{t-s}^{D H P I}}\right)+\left(1-\delta_{\text {DHPI }}^{D H} I_{t-s}^{D H P I}\right. \\
\hat{X}^{D H P I}{ }_{t+k}=\left(L_{t}^{D H P I}+k T_{t}^{D H P I}\right) I_{t-s+k}^{\mathrm{DHPI}} \\
\hat{X}_{t+k}=\left(L_{t}+k T_{t}\right) I_{t-s+k}+\varphi_{A R}^{k}\left[\varepsilon_{t}-\rho\left(\hat{X}^{D H P I}{ }_{t+k}-D H P I_{t+k}\right)\right]
\end{gathered}
$$

In order to exploit the model, variables should match on the resolution. Electricity demand is provided hourly, while DHPI is daily. This discrepancy is solved by using 24 hourly models for electricity demand, one for each hour, that share the same DHPI. That is, we used 24-h models to forecast every day.

\section{Results}

In order to check the effectiveness of the new proposed model, we tested all methods in Table 1. An analysis was carried out, in which the forecasts for the electricity demand for Mallorca and Menorca were validated. We split the available data into two subsets: we used $90 \%$ of the observed values to fit 
the models and obtain the parameters, and the rest to perform an out-of-sample validation, making forecasts and comparing with real values.

To obtain the new parameter $\rho$, we tested two different methods, as it was not clear which one could be more efficient:

1. two-step process, where both models were fit separately to obtain the parameters. Then, parameters were combined to obtain $\rho$.

2. The DHPI was initially fit, as the electricity demand model requires its error. After obtaining DHPI parameters and error, the complete model is simultaneously adjusted, including $\rho$.

The forecast accuracy for m-ahead forecasts was measured using the Mean Average Percentage Error (MAPE) defined in (20).

$$
\text { MAPE }=\frac{1}{m} \sum_{t=1}^{m}\left|\frac{X_{t}-\hat{X}_{t}}{X_{t}}\right| \cdot 100
$$

The validation process of the method consists in making forecasts for a specific horizon, and comparing them with the real data obtained a posteriori during a period. This period is chosen according to whether it is sufficiently representative [74,75]. We used a forecast horizon of $24 \mathrm{~h}$ (typical for the short-term forecasting) during a period of 7 days, as tourists' average stay in the Island is about 8 days (source: IBESTAT). The analysis compared the MAPE obtained using the basic model against the new proposal. The average improvement obtained for Mallorca and Menorca is summarized in Table 2. Although all methods in Table 1 were tested, only the most relevant are shown in Table 2. The new proposal outperforms the basic model as it reduces MAPE. The best results are obtained in Mallorca, as the tourist population is much bigger in Mallorca, as is its influence on the results. Additionally, we decided to apply for further analysis the all-in-one method as it outperformed the two-step one.

Table 2. Forecast comparison of the new proposal against the standard method. Average reduction of the hourly MAPE\% for 7-days-ahead forecasts in Mallorca and Menorca.

\begin{tabular}{ccccc}
\hline \multicolumn{3}{c}{ Mallorca } & Menorca & \\
\hline & 2-STEP & ALL-IN-ONE & 2-STEP & ALL-IN-ONE \\
\hline AMC & -0.06 & -0.12 & -0.03 & -0.02 \\
AAC & -0.05 & -0.10 & -0.03 & -0.03 \\
NAC & -0.05 & -0.09 & -0.03 & -0.03 \\
NMC & -0.06 & -0.11 & -0.03 & -0.03 \\
\hline
\end{tabular}

Based on the former results, we focused the analysis on the Mallorca electricity demand, and we built Table 3. It shows an hourly split of the MAPE improvement against the basic model. The main improvements are produced during the central hours of the day. These results might be indicating the relation between the energy consumption and tourists' activity. Our results indicate that the proposed model can reach an improvement of $0.3 \%$ in MAPE. This results in an estimated reduction of $200 \mathrm{~kg}$ $\mathrm{CO}_{2}$ /hour.

Figure 7 shows a comparison chart for a random day between the demand forecasts given by the regular HW model and the proposed new model. It is appreciated as the new proposal outperforms the results, and approaches the real demand. This graph shows how the introduction of the DHPI acts in the model, bringing the forecast closer to the real demand compared to the regular model. In any case, it is a random example, and at other times the result may be different, although on average the improvements indicated in Table 3 will be obtained. 
Table 3. Hourly MAPE reduction in the electricity forecasting for Mallorca. A comparison among the selected models.

\begin{tabular}{ccccc}
\hline Hour & AMC & AAC & NAC & NMC \\
\hline 1 & 0.0 & 0.0 & 0.0 & 0.0 \\
2 & -0.1 & 0.0 & 0.0 & 0.0 \\
3 & 0.0 & 0.0 & 0.0 & 0.0 \\
4 & 0.0 & 0.0 & 0.0 & 0.0 \\
5 & 0.0 & 0.0 & 0.0 & 0.0 \\
6 & 0.0 & 0.0 & 0.0 & 0.0 \\
7 & -0.1 & -0.1 & -0.1 & -0.1 \\
8 & -0.3 & -0.2 & -0.2 & -0.3 \\
9 & -0.2 & -0.2 & -0.2 & -0.2 \\
10 & -0.1 & -0.1 & -0.1 & -0.1 \\
11 & -0.1 & -0.1 & -0.1 & -0.1 \\
12 & -0.2 & -0.1 & -0.1 & -0.2 \\
13 & -0.1 & -0.1 & -0.1 & -0.1 \\
14 & -0.1 & -0.1 & -0.1 & -0.1 \\
15 & -0.1 & -0.1 & -0.1 & -0.1 \\
16 & -0.2 & -0.2 & -0.2 & -0.2 \\
17 & -0.2 & -0.2 & -0.2 & -0.2 \\
18 & -0.3 & -0.2 & -0.2 & -0.2 \\
19 & -0.2 & -0.2 & -0.2 & -0.2 \\
20 & -0.2 & -0.2 & -0.2 & -0.2 \\
21 & -0.2 & -0.2 & -0.2 & -0.2 \\
22 & -0.1 & -0.1 & -0.1 & -0.1 \\
23 & 0.0 & 0.0 & 0.0 & 0.0 \\
24 & -0.1 & -0.2 & 0.0 & 0.0 \\
\hline
\end{tabular}

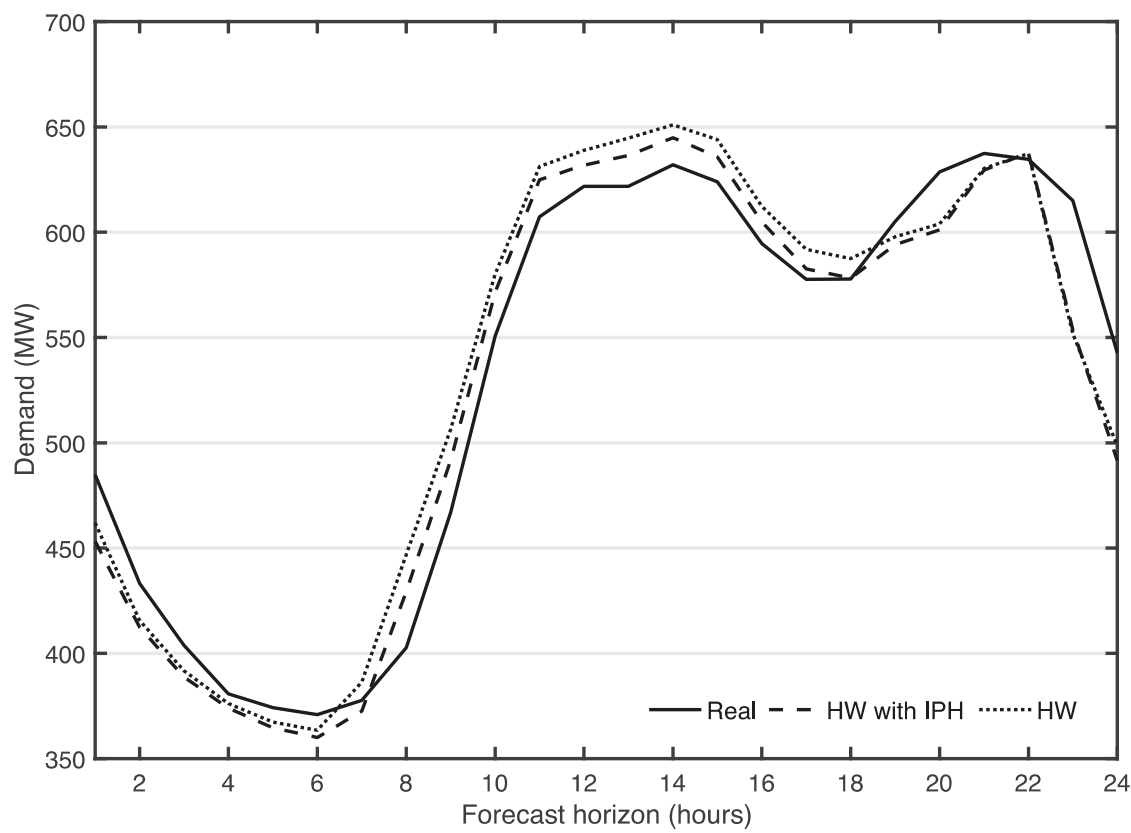

Figure 7. Comparison of one-day-ahead forecasts using the HW method and the new proposed HW-IPH, against the real consumption. 


\section{Conclusions and Limitations}

Tourism has been a powerful tool for local destination development, however social concern about its environmental impact is raising questions about the overall benefits of touristic activities at a local level [76]. The associated environmental costs related to the tourism industry have a broad scope that needs specific approaches [3].

In this paper, we work on the reduction of the environmental impact due to the electricity consumption. More specifically, we focus on electricity demand forecast. The aim of electricity prediction improvement is to reduce the economic and environmental impact caused by forecast errors on electricity demand. Particularly, the environmental impact due to the generation of greenhouse gases has been continuously increasing, despite the policies carried out to increase renewable energies [19]. This effect, in the electricity system, is caused mainly by the generation structure. The generation system uses coal and diesel power plants to adapt to the demand. Demand errors increase the production of these power plants and consequently, the pollution.

We followed Cardenas and Roselló [5], introducing the Daily Human Pressure Indicator, which relates the arrivals and departures of passengers on a daily basis. Previous findings about the relation of energy consumption with tourism pressure [29,32], a higher electricity consumption elasticity in touristic areas [32] and the greater portion of the total electricity consumption due to tourism activities suggested the use of tourism indicators to improve the electricity forecast in tourism areas. Then, the introduction of DHPI makes sense in a context where tourism-related activities represent a large portion of the local GDP. We analyse the demand and its relationship with tourism in the Balearic Islands where tourism accounts for up to $45 \%$ of the GDP. Data indicates that electricity demand time series are highly affected by the tourist variation. Thus, we developed a new model using DHPI to improve forecasts. We present a new electric demand forecast model using the Holt-Winters model. We checked the effectiveness of the new model using the data provided by REE and IBESTAT. The results indicated that the model improves demand predictions up to $0.3 \%$ in MAPE. This improvement would allow the TSO plan and supply a larger amount of the electricity from sustainable sources and its impact would be equivalent to a reduction in $\mathrm{CO}_{2}$ emissions of around $200 \mathrm{Kg} / \mathrm{hour}$.

Our study contributes to uncover the benefits of using relevant indicators related to the dominant economic activity in an area to improve the electricity consumption forecast. The results have relevant implications to TSO providers and policy makers. TSO providers might improve the electric consumption forecast at a local level with data sources outside the electricity sector. Policy makers might encourage the data exchange between public institutions and TSO to improve the forecast and reduce the environmental impact. Moreover, policy makers might use information from electricity consumption and tourism activity to evaluate the impact of environmental policies and actions taken in a touristic area.

The analysis of this model has been limited to the Balearic Islands, in which tourism accounts for a large portion of the GDP and DHPI is easily associated with the electricity demand as it is calculated by the human arrival to and departure from the islands by sea or by air. The use of these indicators in other tourist destinations might be limited by the number of these visitors accessing the area by other means, such as car or train. However, this might be an interesting path for specific destinations where tourist flow is easily controlled and the electrical balance is controlled by fossil fuel power plants. Future research will have to verify this model in other similar tourist destinations, such as the Canary Islands, to strengthen our conclusions.

Author Contributions: Conceptualization, O.T. and A.P.-S.; Formal analysis, O.T. and J.C.G.-D.; Investigation, O.T.; Methodology, O.T.; Software, O.T.; Writing—original draft, O.T. and A.P.-S.; Writing—review and editing, O.T., A.P.-S. and J.C.G.-D.

Funding: This research received no external funding.

Acknowledgments: The authors would like to thank the editor and the four anonymous referees for their thorough comments and suggestions. We would also like to thank Institut d'Estadística de les Illes Balears (IBESTAT) for providing DHPI data. 
Conflicts of Interest: The authors declare no conflict of interest.

\section{References}

1. Gray, R.; Bebbington, J. Accounting for the Environment; Sage Publications: London, UK, 2001; ISBN 9780761971368.

2. Rubio Gil, M.Á.; Mazón Martínez, T. El capital social como factor coadyuvante de los procesos de desarrollo turístico y socioeconómico de los destinos de interior [Social capital as a contributory factor in the tourism and socioeconomic development processes of interior destinations]. Pap. Tur. 2009, 45, 41-55.

3. Mason, P. Tourism Impacts, Planning and Management, 3rd ed.; Routledge: London, UK, 2015; ISBN 9781315781068.

4. Archer, B.; Cooper, C.; Ruhanen, L. The positive and negative impacts of tourism. In Global Tourism; Elsevier Science: Burlington, MA, USA, 2005; pp. 79-102.

5. Zhang, M.; Li, J.; Pan, B.; Zhang, G. Weekly hotel occupancy forecasting of a tourism destination. Sustainability 2018, 10, 4351. [CrossRef]

6. Bakhat, M.; Rosselló, J. Estimation of tourism-induced electricity consumption: The case study of Balearics Islands, Spain. Energy Econ. 2011, 33, 437-444. [CrossRef]

7. Gössling, S. Sustainable Tourism Development in Developing Countries: Some Aspects of Energy Use. J. Sustain. Tour. 2000, 8, 410-425. [CrossRef]

8. Gössling, S.; Hall, M. An Introduction to Tourism and Global Environmental Change. In Tourism and Global Environmental Change; Routledge: London, UK, 2006; pp. 15-48, ISBN 9780203011911.

9. Peeters, P.; Schouten, F. Reducing the Ecological Footprint of Inbound Tourism and Transport to Amsterdam. J. Sustain. Tour. 2006, 14, 157-171. [CrossRef]

10. Scott, D.; Hall, C.M.; Gössling, S. A report on the Paris Climate Change Agreement and its implications for tourism: Why we will always have Paris. J. Sustain. Tour. 2016, 24, 933-948. [CrossRef]

11. Scott, D.; Hall, C.M.; Gössling, S. A review of the IPCC Fifth Assessment and implications for tourism sector climate resilience and decarbonization. J. Sustain. Tour. 2016, 24, 8-30. [CrossRef]

12. Scott, D.; Gössling, S.; Hall, C.M.; Peeters, P. Can tourism be part of the decarbonized global economy? The costs and risks of alternate carbon reduction policy pathways. J. Sustain. Tour. 2016, 24, 52-72. [CrossRef]

13. Becken, S.; Simmons, D.G. Understanding energy consumption patterns of tourist attractions and activities in New Zealand. Tour. Manag. 2002, 23, 343-354. [CrossRef]

14. Gössling, S. Global environmental consequences of tourism. Glob. Environ. Chang. 2002, 12, $283-302$. [CrossRef]

15. Gössling, S.; Hansson, C.B.; Hörstmeier, O.; Saggel, S. Ecological footprint analysis as a tool to assess tourism sustainability. Ecol. Econ. 2002, 43, 199-211. [CrossRef]

16. Meng, W.; Xu, L.; Hu, B.; Zhou, J.; Wang, Z. Quantifying direct and indirect carbon dioxide emissions of the Chinese tourism industry. J. Clean. Prod. 2016, 126, 586-594. [CrossRef]

17. Lee, J.; Brahmasrene, T. Investigating the influence of tourism on economic growth and carbon emissions: Evidence from panel analysis of the European Union. Tour. Manag. 2013, 38, 69-76. [CrossRef]

18. Paramati, S.R.; Alam, M.S.; Chen, C.-F. The Effects of Tourism on Economic Growth and $\mathrm{CO}_{2}$ Emissions: A Comparison between Developed and Developing Economies. J. Travel Res. 2017, 56, 712-724. [CrossRef]

19. Rutty, M.; Gössling, S.; Scott, D.; Hall, C.M. The Global Effects and Impacts of Tourism. In The Routledge Handbook of Tourism and Sustainability; Routledge: Abingdon, UK, 2015.

20. Cárdenas, V.; Rosselló, J. Análisis económico de los impactos del cambio climático en el turismo: Estado de la cuestión [Economic analysis of the impacts of climate change on tourism: State of the art]. Ekonomiaz Revista vasca de Economía 2008, 67, 262-283.

21. Fortuny, M.; Soler, R.; Cánovas, C.; Sánchez, A. Technical approach for a sustainable tourism development. Case study in the Balearic Islands. J. Clean. Prod. 2008, 16, 860-869. [CrossRef]

22. Becken, S. Analysing international tourist flows to estimate energy use associated with air travel. J. Sustain. Tour. 2002, 10, 114-131. [CrossRef]

23. Becken, S.; Simmons, D.G.; Frampton, C. Energy use associated with different travel choices. Tour. Manag. 2003, 24, 267-277. [CrossRef]

24. Becken, S. Tourism and Transport in New Zealand: Implications for Energy Use. 2001, pp. 1-34. Available online: https://core.ac.uk/download/pdf/35459093.pdf (accessed on 21 January 2019). 
25. Tabatchnaia-Tamirisa, N.; Loke, M.K.; Leung, P.; Tucker, K.A. Energy and tourism in Hawaii. Ann. Tour. Res. 1997, 24, 390-401. [CrossRef]

26. World Tourism Organization and the United Nations Environment Programme (Ed.) Climate Change and Tourism-Responding to Global Challenges; World Tourism Organization and the United Nations Environment Programme: Madrid, Spain, 2008; ISBN 9789284412341.

27. Becken, S.; Frampton, C.; Simmons, D. Energy consumption patterns in the accommodation sector-The New Zealand case. Ecol. Econ. 2001, 39, 371-386. [CrossRef]

28. Katircioglu, S.T. International tourism, energy consumption, and environmental pollution: The case of Turkey. Renew. Sustain. Energy Rev. 2014, 36, 180-187. [CrossRef]

29. Katircioglu, S.T.; Feridun, M.; Kilinc, C. Estimating tourism-induced energy consumption and $\mathrm{CO}_{2}$ emissions: The case of Cyprus. Renew. Sustain. Energy Rev. 2014, 29, 634-640. [CrossRef]

30. Zaman, K.; Shahbaz, M.; Loganathan, N.; Raza, S.A. Tourism development, energy consumption and Environmental Kuznets Curve: Trivariate analysis in the panel of developed and developing countries. Tour. Manag. 2016, 54, 275-283. [CrossRef]

31. Tsai, K.T.; Lin, T.P.; Hwang, R.L.; Huang, Y.J. Carbon dioxide emissions generated by energy consumption of hotels and homestay facilities in Taiwan. Tour. Manag. 2014, 42, 13-21. [CrossRef]

32. Pablo-Romero, M.d.P.; Pozo-Barajas, R.; Sánchez-Rivas, J. Relationships between tourism and hospitality sector electricity consumption in Spanish Provinces (1999-2013). Sustainability 2017, 9, 480.

33. Pablo-Romero, M.P.; Sánchez-Braza, A.; Sánchez-Rivas, J. Relationships between hotel and restaurant electricity consumption and tourism in 11 European Union countries. Sustainability 2017, 9, 2109. [CrossRef]

34. Wang, J.C. A study on the energy performance of school buildings in Taiwan. Energy Build. 2016, 133, 810-822. [CrossRef]

35. Warnken, J.; Bradley, M.; Guilding, C. Eco-resorts vs. mainstream accommodation providers: An investigation of the viability of benchmarking environmental performance. Tour. Manag. 2005, 26, 367-379. [CrossRef]

36. Financing Europe's Low Carbon, Climate Resilient Future. Available online: https://www.eea.europa.eu/ themes/climate/financing-europe2019s-low-carbon-climate (accessed on 12 May 2019).

37. Pace, L.A. How do tourism firms innovate for sustainable energy consumption? A capabilities perspective on the adoption of energy efficiency in tourism accommodation establishments. J. Clean. Prod. 2016, 111, 409-420. [CrossRef]

38. Sozer, H. Improving energy efficiency through the design of the building envelope. Build. Environ. 2010, 45, 2581-2593. [CrossRef]

39. Hobbs, B.F. Analysis of the value for unit commitment of improved load forecasts. IEEE Trans. Power Syst. 1999, 14, 1342-1348. [CrossRef]

40. Hong, T. Crystal Ball Lessons in Predictive Analytics. Energybiz 2015, 12, 35-37.

41. Polo, C.; Valle, E. Un análisis estructural de la economía balear [A structural analysis of the Balearic economy]. Estadística Española 2007, 49, 227-257.

42. Herce, J.A. La economía de Illes Balears: Diagnóstico estratégico [The Economy of Illes Balears: Strategic Diagnosis]; SE La Caixa: Barcelona, Spain, 2008.

43. BOIB. Aprobación Definitiva de la Revisión del Plan Director Sectorial Energético de las Illes Balears. [Final Approval of the Revision of the Sectorial Energy Management Plan of the Balearic Island]; Consejería de Comercio, Industriay Energía: Mallorca, Spain, 2005; pp. 46-53.

44. Bilan, Y.; Streimikiene, D.; Vasylieva, T.; Lyulyov, O.; Pimonenko, T.; Pavlyk, A.; Bilan, Y.; Streimikiene, D.; Vasylieva, T.; Lyulyov, O.; et al. Linking between Renewable Energy, $\mathrm{CO}_{2}$ Emissions, and Economic Growth: Challenges for Candidates and Potential Candidates for the EU Membership. Sustainability 2019, 11, 1528. [CrossRef]

45. Morales, J.M.; Conejo, A.J.; Madsen, H.; Pinson, P.; Zugno, M. Integrating Renewables in Electricity Markets: Operational Problems; Springer: New York, NY, USA, 2013; ISBN 9781461494119.

46. Sioshansi, F. Evolution of Global Electricity Markets: New Paradigms, New Challenges, New Approaches; Elsevier Science \& Technology: Amsterdam, The Netherlands, 2013; ISBN 9780123979063.

47. Pfenninger, S.; Keirstead, J. Renewables, nuclear, or fossil fuels? Scenarios for Great Britain's power system considering costs, emissions and energy security. Appl. Energy 2015, 152, 83-93. [CrossRef]

48. Aguiló, E.; Alegre, J.; Sard, M. The persistence of the sun and sand tourism model. Tour. Manag. 2005, 26, 219-231. [CrossRef] 
49. Manera, C. El creixement de l'economia turística a les Illes [The growth of the tourist economy in the Islands]. Recerques 2009, 59, 151-192.

50. Riera Font, A.; Mateu Sbert, J. Aproximación al volumen de turismo residencial en la Comunidad Autónoma de las Illes Balears a partir del cómputo de la carga demográfica real [Approximation to the volume of residential tourism in the Autonomous Community of the Balearic Islands from the calculation of the real demographic burden]. Estud. Turísticos 2007, 174, 59-71.

51. Weron, R. Modeling and Forecasting Electricity Loads and Prices: A Statistical Approach; John Wiley \& Sons: Chichester, UK, 2006; ISBN 978-0-470-05753-7.

52. Weron, R. Electricity price forecasting: A review of the state-of-the-art with a look into the future. Int. J. Forecast. 2014, 30, 1030-1081. [CrossRef]

53. Cancelo, J.R.; Espasa, A.; Grafe, R. Forecasting the electricity load from one day to one week ahead for the Spanish system operator. Int. J. Forecast. 2008, 24, 588-602. [CrossRef]

54. López, M.; Valero, S.; Senabre, C.; Gabaldón, A. Analysis of the Influence of Meteorological Variables on Real-Time Short-Term Load Forecasting in Balearic Islands. In Proceedings of the 2017 11th IEEE International Conference on Compatibility, Power Electronics and Power Engineering, CPE-POWERENG 2017, Cadiz, Spain, 4-6 April 2017; Institute of Electrical and Electronics Engineers Inc.: Cádiz, Spain, 2017; pp. 10-15.

55. Suganthi, L.; Samuel, A.A. Energy models for demand forecasting-A review. Renew. Sustain. Energy Rev. 2012, 16, 1223-1240. [CrossRef]

56. Bruhns, A.; Deurveilher, G.; Roy, J. A non-linear regression model for mid-term load forecasting and improvements in seasonality. In Proceedings of the PSCC'05, Liège, Belgium, 22-26 August 2005; pp. 22-26.

57. Pierrot, A.; Goude, Y. Short-Term Electricity Load Forecasting With Generalized Additive Models. In Proceedings of the 16th Intelligent System Applications to Power Systems Conference (ISAP), Hersonisso, Greece, 25-28 September 2011.

58. Bianco, V.; Manca, O.; Nardini, S. Electricity consumption forecasting in Italy using linear regression models. Energy 2009, 34, 1413-1421. [CrossRef]

59. De Felice, M.; Alessandri, A.; Ruti, P.M. Electricity demand forecasting over Italy: Potential benefits using numerical weather prediction models. Electr. Power Syst. Res. 2013, 104, 71-79. [CrossRef]

60. Taylor, J.W. An evaluation of methods for very short-term load forecasting using minute-by-minute British data. Int. J. Forecast. 2008, 24, 645-658. [CrossRef]

61. Winters, P.R. Forecasting sales by exponentially weighted moving averages. Management 1960, 6, 324-342.

62. Gardner, E.S.; McKenzie, E., Jr.; McKenzie, E. Forecasting Trends in Time Series. Manag. Sci. 1985, 31, 1237-1246. [CrossRef]

63. Taylor, J.W. Exponential smoothing with a damped multiplicative trend. Int. J. Forecast. 2003, 19, 715-725. [CrossRef]

64. Williams, D.W.; Miller, D. Level-adjusted exponential smoothing for modeling planned discontinuities. Int. J. Forecast. 1999, 15, 273-289. [CrossRef]

65. Taylor, J.W. Short-term electricity demand forecasting using double seasonal exponential smoothing. J. Oper. Res. Soc. 2003, 54, 799-805. [CrossRef]

66. Taylor, J.W. Triple seasonal methods for short-term electricity demand forecasting. Eur. J. Oper. Res. 2010, 204, 139-152. [CrossRef]

67. Gardner, E.S., Jr. Exponential smoothing: The state of the art, part II. Int. J. Forecast. 2006, 22, 637-666. [CrossRef]

68. Trull, Ó.; García-Díaz, J.C.; Troncoso, A.; Trull, Ó.; García-Díaz, J.C.; Troncoso, A. Application of Discrete-Interval Moving Seasonalities to Spanish Electricity Demand Forecasting during Easter. Energies 2019, 12, 1083. [CrossRef]

69. García-Díaz, J.C.; Trull, Ó. Competitive Models for the Spanish Short-Term Electricity Demand Forecasting. In Time Series Analysis and Forecasting: Selected Contributions from the ITISE Conference; Rojas, I., Pomares, H., Eds.; Springer International Publishing: Cham, Germany, 2016; pp. 217-231. ISBN 978-3-319-28725-6.

70. Pardo, A.; Meneu, V.; Valor, E. Temperature and seasonality influences on Spanish electricity load. Energy Econ. 2002, 24, 55-70. [CrossRef]

71. Taylor, J.W.; McSharry, P.E. Short-term load forecasting methods: An evaluation based on european data. Power Syst. IEEE Trans. 2007, 22, 2213-2219. [CrossRef] 
72. Pérez-García, J.; Moral-Carcedo, J. Analysis and long term forecasting of electricity demand trough a decomposition model: A case study for Spain. Energy 2016, 97, 127-143. [CrossRef]

73. Bermúdez, J.D. Exponential smoothing with covariates applied to electricity demand forecast. Eur. J. Ind. Eng. 2013, 7, 333-349. [CrossRef]

74. Hyndman, R.J.; Athanasopoulos, G. Forecasting: Principles and Practice; OTexts: Melbourne, Australia, 2018; ISBN 978-0-9875071-1-2.

75. Bergmeir, C.; Hyndman, R.J.; Koo, B. A Note on the Validity of Cross-Validation for Evaluating Autoregressive Time Series Prediction. Comput. Stat. Data Anal. 2018, 120, 70-83. [CrossRef]

76. Almeida García, F.; Balbuena Vázquez, A.; Rafael, C.M. Resident's attitudes towards the impacts of tourism. Tour. Manag. Perspect. 2015, 13, 33-40. [CrossRef]

(C) 2019 by the authors. Licensee MDPI, Basel, Switzerland. This article is an open access article distributed under the terms and conditions of the Creative Commons Attribution (CC BY) license (http://creativecommons.org/licenses/by/4.0/). 
Article

\title{
Evaluating Sustainable Purchasing Processes in the Hotel Industry
}

\author{
Manuel-Francisco Morales-Contreras ${ }^{1, *}$, Paloma Bilbao-Calabuig ${ }^{1}$, Carmen Meneses-Falcón ${ }^{2}$ \\ and Victoria Labajo-González ${ }^{3}$ \\ 1 Department of Management, Universidad Pontificia Comillas, ICADE, 28015 Madrid, Spain \\ 2 Department of Sociology and Social Work, Universidad Pontificia Comillas, CIHS, 28049 Madrid, Spain \\ 3 Department of Marketing, Universidad Pontificia Comillas, ICADE, 28015 Madrid, Spain \\ * Correspondence: mfcontreras@comillas.edu
}

Received: 30 June 2019; Accepted: 2 August 2019; Published: 7 August 2019

\begin{abstract}
Managing sustainability along the supply chain has gained significant relevance in recent years, in both academic and business environments. The aim of this research paper is to describe and evaluate the degree of implementation of sustainable purchasing (SP) in the supply chain of the hotel sector in Spain, as well as to identify the main drivers and barriers to effective implementation. This is done from the double perspective of hotel chains and suppliers (industrial laundries). An exploratory and inductive qualitative methodology has been adopted, consisting of (a) observation; (b) collection, review, and analysis of primary sources; and (c) in-depth interviews with 15 managers of hotel chains and suppliers. This triangulation of data sources provides validity and credibility to the results and reduces any potential bias. Evidence is found to support that SP is at an early stage of implementation in the hotel sector in Spain, with big differences among companies. The results suggest that the main drivers and barriers to effective implementation are final customers, governments, market conditions, management commitment, and conflicts in customer/supplier interests. The authors propose a new classification of companies based on the size, type, and degree of implementation of SP.
\end{abstract}

Keywords: sustainability; purchasing; supply chain; qualitative methodology; hotel industry

\section{Introduction}

The concept of sustainability has gained great relevance in recent years, in both academic and business environments. The World Commission on Environment and Development [1] (p. 8) defined sustainability as "development that meets the needs of the present without compromising the ability of future generations to meet their own needs." Sustainability management implies that companies should consider the impact of their actions not only on economic aspects, but also on environmental and social ones [2]. All stakeholders (clients, governments, organizations, workers, communities, suppliers, etc.) are increasingly exerting pressure on companies to put in place policies that ensure compliance with sustainability objectives from these three perspectives. Having good or bad performance in these aspects has a very significant impact on the image of the company and might bring relevant consequences.

However, compliance with sustainability criteria should not be considered solely within the company itself, but must go beyond its boundaries, throughout the entire supply chain in which it operates. It is not enough for a company to comply within social and environmental fields; its suppliers must also comply with it, since if the management of its suppliers is not adequate, the company's reputation might be damaged to a large extent, and its level of performance might also be impacted $[3,4]$. In recent years there have been cases in which this has occurred with companies such as Mattel, Nike, and Dell [5-8]. 
Therefore, it is the responsibility of companies to ensure that they manage their supply chain in a sustainable way. Despite the fact that sustainability is increasingly emerging in companies' supply chain practices, especially in multinational enterprises [9-12], corporate initiatives to implement sustainable purchasing (SP) are still scarce, disordered, and not well anchored on strong motivations to exert sustainable behaviors and to disclose trustworthy and accurate information about them $[13,14]$. Moreover, the extent of deployment and integration of these policies differs significantly depending on the business sector and the type of company [15]. Stakeholders increasingly have higher expectations for companies to adopt effective SP policies towards all suppliers with whom they work [16]. There is still a great distance between the society and community expectations and reality, and this occurs both in private and public corporations [10].

Sustainability in supply chain management (SSCM) has not been addressed in a holistic and comprehensive way. First, attention has been paid mainly to environmental issues, leaving wide room to attempts aimed at understanding the social side of supply chain sustainability [16-18]. Second, most studies adopt an instrumental - "what-do-I-earn-if-I-act-sustainable" —approach limiting the understanding of SSCM to cause-effect and reactive-to-compliance understandings $[16,19,20]$. And third, research has focused mainly on the sustainability of downstream supply chain; consequently, upstream sustainable practices remain insufficiently addressed [19,21,22].

Thus, there is a need to strengthen and reorient research on SCM sustainability [16,23-26], and in particular, the purchasing function, which has a greater environmental bias [10,25,27-29]. In part, this bias is due to the different emphasis required by the environmental dimension, focused on the product and all stages of its life, and the social dimension, with greater emphasis on the supplier and the conditions around the production process $[10,25]$.

Top management appears to be one of the most relevant drivers of the implementation of the purchasing function, so it is necessary to better and more thoroughly define the exact role to be played by top management. On the one hand, managers might send a clear message of responsibility to the organization and thus motivate responsible purchasing practices. According to Espino-Rodríguez [30], "the application of operations policies and practices has a short-term effect on non-financial performance, measured as the satisfaction of stakeholders (customers, tour operators, and employees), and a possible long-term effect on financial performance (e.g., return on assets, profit margins, occupancy)" in the hotel industry in Spain. On the other hand, managers might not authorize expenditures for, or investment in, responsible purchases, thus saving funds for future projects. As research has found that cost is the main barrier, these behaviors can simply be a sign of the low priority given to the role of responsible purchasing by senior management [4].

This is also applicable to the tourism sector in Spain, and more specifically to the hotel industry, one of the sectors with a high impact on the country's economy, whose companies, as in any other industry, are called to be responsible. When assessing the way in which they address sustainability, we can see that the situation is less developed than that of other sectors: There is some activity from both the academic and business practice points of view, with the aim of implementing sustainability aspects and policies in large companies in the sector. However, most of them focus more on the environmental aspect (new designs of facilities, energy efficiency, and waste management, primarily). There are some non-academic publications and editions of documents issued by companies, sectoral associations, consultancies, or other groups of interest. Examples of this type of document could be their codes of conduct, annual company reports, or sustainability reports, and specific initiatives that lead to recognition awards by the sector, etc. In the last sectoral meetings, several initiatives were presented and seminars were developed to raise awareness of the need to address the concept of sustainability as a strategic pillar. These initiatives are led by some companies, associations, the administration, and specific organizations, and in general they are more oriented toward environmental aspects. Examples of this type of document could be national tourism plans, those derived from programs and sessions at international fairs such as FITUR (Feria Internacional de Turismo, Madrid, Spain), or initiatives by the World Tourism Organization. 
Regarding the responsible management of the supply chain in this sector and, particularly, incorporating sustainability within the purchasing function, it is noted that activities and literature are scarce and in their earliest stages, from both the academic and non-academic point of view.

The objective of this research paper is to describe and evaluate the degree of implementation of SP in the supply chain of the hotel sector in Spain. This is done from the double perspectives of customers (hotel chains) and suppliers (industrial laundries). More specifically, the purpose of this paper is threefold: First, to evaluate how companies in this sector follow the proposed models and frameworks from the literature; second, to identify the main drivers and barriers to effective implementation; and third, to determine whether a taxonomy of companies with different purchasing categories can be proposed based on previous findings.

An exploratory and inductive qualitative methodology was followed, consisting of (a) observation; (b) collection, review, and analysis of primary sources; and (c) in-depth interviews. In-depth interviews were conducted with 15 managers of client and supplier companies (hotel chains and industrial laundries), providing the authors with a reliable view of what is happening in this sector. The information obtained through observation and primary sources was completed, confirmed, and consolidated. This triangulation of data sources provided validity and credibility to the results and reduced any potential bias.

Evidence has been found to support that SP is at an early stage of implementation in the hotel sector in Spain, with big differences among companies. The results suggest that the main drivers of, and barriers to, effective implementation are final customers, governments, market conditions, management commitment, and conflicts in customer/supplier interests. The same factors may act as drivers or enablers when they help or support effective implementation, or as barriers when they hinder it or make it difficult. The authors propose a new classification of companies based on the size and type of corporation and degree of implementation of SP. This study also proposes an implementation model, as well as a list of initiatives and proposals for industry managers and policy makers.

The paper has been organized as follows: Section 1 is the introduction; Section 2 refers to the literature review; Section 3 describes the methodology and materials; Section 4 presents the results; Section 5 is the discussion.

\section{Literature Review}

One of the main research concerns in tourism has been customers' sensitivity toward sustainability as a development driver of the industry [31-36]. However, many studies have revealed that the industry is reacting slowly to this need despite the growing global relevance of sustainability in business [37-39]. Explanations for this can be found in a "lack of collective leadership amongst tourism's stakeholders" and in the so-called environmental paradox of the industry: Whereas natural resources are key characteristics of tourist destinations, such resources are at the same time sacrificed to satisfy a growing demand [39].

The large amount of studies published on sustainability in the hotel industry reveals a wide variety of approaches and matters of research in this field [40]. Previous works have mainly addressed the design of more ecological and efficient hotels, the reduction of water and energy consumption, technological innovations to improve sustainability, and progress in workforce management. Consumers' satisfaction with hotels' sustainable practices is another concern that has received much attention [41-46].

Other works have addressed the role of management systems for sustainability [47] and, particularly, the aspect related to "reporting practices" [48,49]. De Grosbois [50] analyzed the methods and scope of corporate social responsibility (CSR), reporting on 150 of the world's leading hotel chains. He pointed out that, although many of them reported their commitment to and objectives for aspects of environmental and social sustainability, few detailed specific initiatives were developed or results achieved. Regarding environmental practices, reporting on EMS-i.e., corporate policies, assessments, plans, and actions directed to define the company relationship with the natural environment-has gained significant weight in the promotion of more sustainable supply chain practices since it can lead 
to gain international accreditation of best practices. Such accreditation is granted if EMSs actually comply with the International Organization for Standardization (ISO) 14,001 and 14,040 standards, or with the European Eco Management and Audit Scheme (EMAS) standard [11,51,52]. Research has shown that, compared to manufacturing companies, service ones—such as hotels-are more confident in the benefits of having environmentally accredited supply chain practices [11].

Looking specifically at the case of the Spanish hotel industry, the work of Molina- Azorín et al. [53] offers an empirical analysis of the impact of sustainability practices on firm performance, highlighting how the environmental management of hotels can reduce their costs and increase their returns. In this sense, on the one hand, they identify, through regression analysis, those practices with the greatest impact on a series of variables related to performance. On the other hand, through a cluster analysis, they identify three groups of hotels (proactive, basic, and reactive) based on their proactivity in environmental management practices, showing significant differences in performance between them. "Environmentally proactive" refers to hotels with the most developed environmental strategies, including higher-category hotels usually affiliated with a hotel chain. The second group, basic, includes hotels with a basic environmental commitment. It is the largest group, and is characterized by its three-star, independent, above-average sized hotels. The third group, reactive hotels, have a low environmental commitment, usually three-star, independent, small hotels. Eco-labels are strong indicators of the environmental practices of companies, they help build an image in consumers' minds and to prevent confusion about the actual company environmental behavior [54]. In the hotel industry, the European eco-label requires the compliance with a number of provisions and conditions, some of them referring particularly to holding a green supply chain: The use of eco-labelled products in their service supply; integrated environmental values in the operations management, and initiatives for reducing the use of energy and the creation of waste. Like environmental regulatory standards, the use of eco-labels promotes environmental practices since they are perceived by hotels to be accompanied by economic benefits, competitive and commercial [55].

Rodriguez-Anton et al. [47] analyzed the use of sustainability management systems in the Spanish hotel industry, looking empirically at their existence as well as their scope, sequence of implementation, and possible integration of different standard management systems.

Despite some notable efforts to crystallize and systematize conceptual frameworks for sustainability in the hotel sector (first by Clarke [56], and recent studies [38,40,57,58]), this apparent richness and dynamism that characterizes the academic literature includes weaknesses, such as a fragmentary nature and the lack of a coherent structure or clear framework of analysis, and the need for consensus on priorities for future research agendas [40], the identification of more consistent methodological approaches, and the development of appropriate measurement scales [58].

On the other hand, in relation to the hotel sector, more scholars have pointed out that academic research should integrate the three aspects of sustainability (economic, social, and environmental) with a holistic approach [3,50], in addition to developing a deeper understanding of sustainability specifically related to SCM [59-63]. In this sense, it is worth highlighting the work of Zhang et al. [64], who present a review of the literature related to SCM in the context of tourism, as well as the work of Xu and Gursoy [65], who present a conceptual framework for sustainable hospitality SCM and start a discussion about the impact on customers' satisfaction, loyalty, and willingness to pay extra. They present "five critical aspects including the actions, motivators and inhibitors, company characteristics, the evaluation approaches, and the impacts." Sustainable hospitality SCM can be defined as "the management of material, products, services, and cooperation and coordination among organizations in the hospitality supply chain to achieve three objectives of sustainable development: environmental, social, and economic sustainability" [65].

Carter and Jennings [66] proposed a new concept, purchasing social responsibility, along with its specific activities and drivers, developed through a review of the CSR and related purchasing and SCM literature and an integration of extant findings from in-depth interviews with supply chain managers. Hollos et al. [67] examined the effects of sustainable supplier cooperation on firm performance. Through 
an empirical study based on a survey in Western European countries, they conclude that sustainable supplier cooperation has generally positive effects on firm performance across the three dimensions of sustainability. However, only environmentally friendly practices have positive and significant effects on economic performance.

In this same direction, but with empirical research specifically focused on the European hotel industry, Kassinis et al. [68] explored, through a structural equation model, the nature of the relationship between environmental management practices on the "external portion of the service profit chain" and performance. Particularly, they show that the use of environmental practices in service companies is positively related to performance through the mediating effect of greater consumer satisfaction and loyalty.

The literature includes some efforts to offer a frame of general validity for managers on the dimensions and motivational factors of responsible supply [66], or for the understanding of trans-sectoral models of sustainable SCM, and propose schemes of general application [25,69-72]. These frameworks or models can be of a different nature, depending on whether they: (i) Refer globally to sustainable SCM or focus more on the purchasing function; (ii) can refer to a specific aspect within this function or to the implementation process; or (iii) identify the factors that influence an adequate implementation or not. However, each author identifies different stages and key success factors for an adequate SP implementation process. Mamic [23], for example, indicates that the common elements of these integrated models generally cover the following four areas: (a) Development of a vision; (b) understanding of that vision by employees and suppliers; (c) implementation; and (d) monitoring, feedback, and improvements.

In addition, none is conceived or presented as a decision model for the company that allows weighing advantages and disadvantages of alternatives or their adaptation to different business contexts and strategies. Nor is there a model that combines stages with obstacles to, and drivers of, each stage or that describes the influence of different stakeholders in each stage. However, Maloni and Brown [5] consider that each sector or industry has sufficiently significant peculiarities to require the development of independent sector studies that adapt the risks, priorities, and management models specific to each industry. Additionally, we find that the literature has scarcely examined the relationship of SP with the size of the company: Fassin [73] warns that studies tend to focus on the relationship between transnational corporations and their suppliers in less developed countries; thus, these studies pay little attention to the role and particularities of small and medium enterprises.

The literature related to different models or theoretical frameworks on SP implementation processes has been reviewed $[3,7,23,25,27-29,66,67,69-72,74-86]$. A summary of the findings is presented in Table 1, with details about (1) scope (P for purchasing function, SCM for supply chain management); (2) whether it is a real implementation model, with all stages clearly identified and described; (3) whether it identifies factors (drivers and barriers) for implementation; (4) whether it is just focused on one stage (e.g., supplier assessment or implementation of code of conduct); (5) whether it is a decision tool; and (6) whether it refers to a specific sector $(S)$ or a geographic area $(\mathrm{G})$.

Table 1. Summary of sustainable purchasing (SP) implementation models from the literature.

\begin{tabular}{|c|c|c|c|c|c|c|c|c|}
\hline Authors & Date & Description & 1 & 2 & 3 & 4 & 5 & 6 \\
\hline Carter and Jennings & 2004 & Purchasing role in CSR & $\mathrm{P}$ & & $\checkmark$ & & & \\
\hline Mamic & 2005 & Global SCM & SCM & & $\checkmark$ & $\checkmark$ & & $S$ \\
\hline Teuscher et al. & 2006 & Framework for sustainability in SCM & SCM & & $\checkmark$ & & & \\
\hline Vermeulen and Ras & 2006 & $\begin{array}{l}\text { The Challenge of Greening Global } \\
\text { Product Chains: Meeting Both Ends }\end{array}$ & SCM & & $\checkmark$ & & & $\mathrm{S}, \mathrm{G}$ \\
\hline Svensson & 2007 & $\begin{array}{l}\text { Conceptual framework and empirical } \\
\text { example }\end{array}$ & SCM & & $\checkmark$ & & & $S$ \\
\hline Carter and Rogers & 2008 & Framework for sustainability in SCM & SCM & & $\checkmark$ & & & \\
\hline Seuring and Müller & 2008 & $\begin{array}{c}\text { Theoretical framework for } \\
\text { sustainability in SCM }\end{array}$ & SCM & & $\checkmark$ & & & \\
\hline
\end{tabular}


Table 1. Cont.

\begin{tabular}{|c|c|c|c|c|c|c|c|c|}
\hline Authors & Date & Description & 1 & 2 & 3 & 4 & 5 & 6 \\
\hline Vurro et al. & 2009 & $\begin{array}{l}\text { Model classification according to } \\
\text { network determinants }\end{array}$ & SCM & & & & & \\
\hline Björklund & 2010 & Benchmark tool for CSR in purchasing & $\mathrm{P}$ & $\boldsymbol{v}$ & $\boldsymbol{\nu}$ & & $\boldsymbol{\nu}$ & G \\
\hline Hietbrink et al. & 2010 & CSR in purchasing function & $P$ & & $\checkmark$ & & & \\
\hline Leire and Mont & 2010 & $\begin{array}{l}\text { Implementation model for socially } \\
\text { responsible purchasing }\end{array}$ & $\mathrm{P}$ & $\checkmark$ & $\checkmark$ & & $\checkmark$ & G \\
\hline Dai and Blackhurst & 2012 & $\begin{array}{c}\text { Four-phase AHP-QFD approach for } \\
\text { supplier assessment }\end{array}$ & $\mathrm{P}$ & & $\checkmark$ & $\checkmark$ & $\checkmark$ & \\
\hline Wolf & 2011 & $\begin{array}{l}\text { Integration of sustainable SCM in } \\
\text { German manufacturing industry }\end{array}$ & SCM & & $\checkmark$ & $\checkmark$ & & S, G \\
\hline $\begin{array}{l}\text { Giménez and } \\
\text { Tachizawa }\end{array}$ & 2012 & Extending sustainability to suppliers & SCM & & $\checkmark$ & $\checkmark$ & & \\
\hline Perry and Towers & 2013 & $\begin{array}{l}\text { Conceptual framework for } \\
\text { implementation of SCM }\end{array}$ & $\mathrm{SCM}$ & & $\checkmark$ & $\checkmark$ & & S, G \\
\hline Vargas and Moreno & 2013 & Efficient and SP management & $\mathrm{P}$ & & $\checkmark$ & & & G \\
\hline Azadnia et al. & 2015 & $\begin{array}{c}\text { Sustainable supplier selection and } \\
\text { order lot-sizing }\end{array}$ & $P$ & & $\checkmark$ & $\checkmark$ & $\boldsymbol{v}$ & \\
\hline Atkin and Gergin & 2016 & $\begin{array}{l}\text { Mathematical modeling of sustainable } \\
\text { procurement strategies }\end{array}$ & $P$ & & $\checkmark$ & $\checkmark$ & 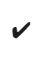 & \\
\hline Prier et al. & 2016 & $\begin{array}{c}\text { Practices on sustainable public } \\
\text { purchases }\end{array}$ & $P$ & & $\checkmark$ & $\checkmark$ & & S \\
\hline Carbone et al & 2012 & $\begin{array}{l}\text { Diffusion of sustainable SCM toward a } \\
\text { conceptual framework }\end{array}$ & SCM & & $\checkmark$ & & & \\
\hline Hollos et al. & 2012 & $\begin{array}{l}\text { Examining whether sustainable } \\
\text { supplier cooperation affects } \\
\text { performance }\end{array}$ & $\mathrm{P}$ & & $\checkmark$ & & & G \\
\hline Kirce and Seifert & 2015 & $\begin{array}{l}\text { Dynamic capabilities in sustainable } \\
\text { SCM theoretical framework }\end{array}$ & SCM & & $\checkmark$ & & & $S$ \\
\hline Ahmad et al. & 2017 & $\begin{array}{l}\text { Integrative framework for sustainable } \\
\text { SCM practices in the oil and gas } \\
\text { industry }\end{array}$ & $\mathrm{SCM}$ & $\checkmark$ & $\checkmark$ & & & S \\
\hline Tavana et al. & 2017 & $\begin{array}{l}\text { Hybrid goal programming and } \\
\text { dynamic data envelopment framework }\end{array}$ & SCM & & & $\checkmark$ & $\checkmark$ & $S, G$ \\
\hline Abduh et al. & 2018 & $\begin{array}{l}\text { Development methodology for } \\
\text { sustainable procurement of } \\
\text { construction works in Indonesia }\end{array}$ & SCM & & $\checkmark$ & & & $S, G$ \\
\hline Prasad et al. & 2018 & $\begin{array}{l}\text { Analyzing the critical success factors } \\
\text { for implementation of sustainable } \\
\text { SCM: Indian case study }\end{array}$ & SCM & & $\checkmark$ & & & $S, G$ \\
\hline
\end{tabular}

Notes: 1. Scope: Purchasing function (P), supply chain management (SCM); 2. Real implementation model, with all stages clearly identified and described; 3 . Identifies factors (drivers and barriers) for implementation; 4 . Just focused on one stage (e.g., supplier assessment or implementation of code of conduct); 5 . Decision tool; 6 . Specific sector $(S)$, or geographic area $(G)$.

We note that most of the proposed models refer to sustainable SCM generically, without going into detail on the topic of purchasing management, which is the subject of this study. Likewise, the vast majority of the models try to define a general framework, in which proposals are made on the level of interrelationships of various stakeholders and actors in the supply chain and relationship strategies between them. Only two studies $[25,76]$ tried to develop an SP implementation model in which each and every one of the stages for the complete implementation process is presented in a clear and detailed manner, identifying the key decisions of each stage and the success factors. The other models provide very interesting ideas and proposals, and a framework for carrying them out, but they do not take these ideas to all stages of the buying process. Some models refer to the purchasing function, but they focus on a very specific aspect or phase within the SP process. For instance, one model focuses on the development and implementation of codes of conduct; another mathematical model proposes measurement to assess the degree of sustainability of suppliers (so they serve as a tool for decision making on supplier selection). Some refer to specific sectors (manufacturing, textiles, food, footwear, public administration, etc.), or to certain geographical areas in which companies operate (Asia, South Africa, Germany, United States, Colombia, etc.). 
Of all the references studied, Leire and Mont [25] propose the most complete model of implementation of the SP function, based on secondary and empirical sources, including interviews with different organizations, which allowed them to validate their conclusions. We chose this model as a basis for our study because it responds more directly to the set of objectives, with a clear focus on the practical implementation of sustainability in purchasing, describing each stage and phase, identifying the responsibilities in these stages and the factors that influence them for adequate implementation. The model is presented as a tool that can help in decision making and is applicable to any sector. The rest of the studied references are not discarded, but they provide good inputs, ideas, and proposals that complement the use of this model. These contributions were used in the preparation of the interview script.

The model of Leire and Mont [25] of implementation of the SP function is based on a process consisting of five stages: (i) Developing internal policies; (ii) setting purchasing criteria; (iii) applying assurance practices; (iv) managing supplier relations; and (v) building internal SP capacity. This model details all the phases in the SP implementation process and how they are connected to each other. It begins with developing internal policies within the organization itself. From there, purchasing criteria are established, particularly the sustainability criteria that must be incorporated in the purchasing process. This is the starting point for the selection of suppliers and the application of control practices and monitoring of suppliers. The relationships with suppliers should not be based solely on monitoring and controlling certain performance indicators; it is essential to take into account other aspects in the management of the relationship. Finally, the model proposes the development of internal capacity for SP management.

Most of the frameworks or models discussed above make good proposals regarding the factors that most influence adequate SP implementation, identifying the drivers that favour its implementation as well as the obstacles or barriers that make it difficult $[3,7,10,23,25,27-29,46,66,67,69-72,74,76-83,85,86]$. Drivers are classified as internal factors (within the buying company) or external factors (outside the buying company). In the same manner, barriers are classified as internal barriers (within the buying company) or two kinds of external barriers (outside the buying company, and for suppliers). Tables 2 and 3 present a summary of all of them.

Table 2. Drivers of SP implementation.

\begin{tabular}{|c|c|}
\hline References & Drivers of Implementation \\
\hline $\begin{array}{c}{[3,7,10,23,25,27-} \\
29,46,66,67,69 \\
71,72,76,77,79 \\
82,83,85,86]\end{array}$ & $\begin{array}{l}\text { Internal factors within the buying company } \\
\text { - } \quad \text { Risk mitigation, and therefore cost reduction. } \\
\text { - } \quad \text { Vision of the organization, policy, or code of conduct. } \\
\text { - } \quad \text { Protection of the brand image. } \\
\text { - } \quad \text { Search for suppliers that share the same values as the organization. } \\
\text { - } \quad \text { Providing workers with an adequate environment. } \\
\text { - } \quad \text { Individual values of purchasing department employees. } \\
\text { - } \quad \text { For public organizations: Preserving the good name of the region or country. } \\
\text { - } \quad \text { Size and organizational culture of the company. }\end{array}$ \\
\hline $\begin{array}{c}{[3,10,23,25,29,46} \\
66,69,71,72,76- \\
83,85,86]\end{array}$ & $\begin{array}{l}\text { External factors outside the buying company } \\
\text { - } \quad \text { Expectations of stakeholders, especially nongovernmental organizations (NGOs) and media. } \\
\text { - } \quad \text { Public opinion. } \\
\text { - } \quad \text { Maintiance with regulations by the government and public administrations. } \\
\text { - } \quad \text { Market and final consumers require more good records on SP practices. } \\
\text { - } \quad \text { External evaluations and ratios. } \\
\text { - } \quad \text { Need to report sustainability issues. } \\
\text { - For public organizations: Political vision in the region or country. } \\
\text { - } \quad \text { For public organizations: Decisions of politicians. } \\
\text { - Generalized practices in the sector and between competitors. } \\
\text { - } \quad \text { Differentiating element with respect to the competition. } \\
\text { - Involvement of third parties that support the implementation process. }\end{array}$ \\
\hline
\end{tabular}


Table 3. Barriers to SP implementation.

\begin{tabular}{|c|c|}
\hline References & Barriers of Implementation \\
\hline $\begin{array}{c}{[3,7,10,23,25,} \\
66,67,72,74, \\
76,79,80]\end{array}$ & $\begin{array}{l}\text { Internal barriers for the buying company } \\
\text { - } \quad \text { Lack of information on how to develop or implement SP policies. } \\
\text { - } \quad \text { Lack of commitment from senior management, especially in the implementation phases. } \\
\text { - } \quad \text { Seed to justify the activity and its cost based on the benefits it brings to the company. } \\
\text { - } \quad \text { Lack of material and resources for staff training due to the specificity of sector/company. } \\
\text { - } \quad \text { Organizational inertia. }\end{array}$ \\
\hline $\begin{array}{c}{[3,10,23,25,} \\
28,72,74,76, \\
79,83]\end{array}$ & $\begin{array}{l}\text { External barriers for the buying company } \\
\text { - High cost of supplier audits. } \\
\text { - } \quad \text { Qualification of audit teams: Low-quality risk due to growing competition between audit } \\
\text { - } \quad \text { Difficulty in establishing cooperative and long-term relationships with suppliers. } \\
\text { - Lack of understanding of the importance of social aspects by suppliers, as well as duplicity of } \\
\text { "accounting books" and deception. } \\
\text { - } \quad \text { Difficulty in influencing beyond level } 1 \text { of suppliers and high cost of changing suppliers; } \\
\text { - } \quad \text { Emplex supply chains, with several levels of subcontracting that are difficult to control. } \\
\text { - } \quad \text { Lack of clear legislation for clients on how to integrate social aspects into the supply chain. } \\
\text { - } \quad \text { Continuons of suppliers with a low level of automation (more labor-intensive operations). } \\
\text { - Difficulty in verifying the veracity of the responses of suppliers. } \\
\text { - Difficulty in verifying the implementation of action plans carried out by suppliers. } \\
\text { - } \quad \text { Institutional barriers in international trade. } \\
\text { - } \quad \text { Doubts about the economic situation when making investments. }\end{array}$ \\
\hline $\begin{array}{c}{[3,10,25,66,} \\
69,70,72,74, \\
76,79]\end{array}$ & $\begin{array}{l}\text { External barriers for suppliers } \\
\text { - Customer practices with urgent orders and increasingly shorter delivery times facilitate } \\
\text { - } \quad \text { Rorse working conditions and lack of attention to safety issues. } \\
\text { - Lack of legislation and its reinforcement for suppliers in one or several countries. } \\
\text { - Conflict between high levels of performance in sustainability criteria and increasingly } \\
\text { reduced margins in products and services. } \\
\text { - } \quad \text { iefficulties in influencing beyond level } 1 \text { of suppliers; complex supply chains, with several } \\
\text { levels of subcontracting that are difficult to control. } \\
\text { - Time dedicated to preparing audits and inspections. } \\
\text { Trust in relationships. }\end{array}$ \\
\hline
\end{tabular}

\section{Materials and Methods}

An exploratory and inductive qualitative methodology was used, aimed at theory building. It consisted of (a) observation; (b) collection, review, and analysis of secondary sources; and (c) in-depth interviews. This approach is particularly useful when the research needs to answer "how" and "why" questions [87]. Interviews are "a highly efficient way to gather rich, empirical data, especially when the phenomenon of interest is highly episodic and infrequent" [88], as well as in circumstances when (i) there is little documentation; (ii) it is unclear and unstructured, making it difficult to compare and interpret; (iii) the information is only provided from the perspective of the client, not its suppliers; and (iv) it is difficult to contrast whether what is said in the documents corresponds to the reality of what is actually done [89]. The combination of data collection techniques provided validity and reliability to the results and helped to reduce any potential bias.

Observations were based on documented experiences by one of the authors during close to two years working in this industry. Observation and analysis of secondary sources (documents from company websites, industry reports, congress, etc.) showed that information about sustainable business practices is incomplete, scarce, unclear, and hardly comparable. Sustainability issues are 
delicate and sensitive, so formal business documents tend to avoid being specific about the company position, initiatives, commitments, and/or future plans. The in-depth interview is a methodology that helps to collect precise and detailed qualitative information and is used when the research problem cannot be completely observed due to ethical or complex issues [90]. We conducted individual in-depth interviews with interlocutors from hotel chains and their suppliers. We then carried out an in-depth category and interpretative analysis of our interviewees' responses.

First, an interview script (see a script summary in Appendix A) based on the literature review was prepared, but issues were reformulated in a language suitable for our interlocutors to understand. The script begins with an introduction to the research project and some general questions about the business context of the company, and then deepens into questions about the implementation of SP policies. The questions are fundamentally based on concepts extracted from the model of Leire and Mont [25], although they also use as reference the rest of the models described in Table 1 in the previous section. Some of the questions were formulated in a very precise way, looking for a concrete answer, and some were done in a more open way in order to encourage the interlocutor to respond more freely. Depending on the interview, new questions could arise to clarify and specify some of the answers.

When determining the number of people to interview, the principle of theoretical saturation was taken into account, which says that the so-called theoretical saturation point is reached when the information collected is enough in relation to the research objectives [91]. For a population under study that is homogeneous, made up of experts in the field of study, and the objectives are well defined, Guest et al. [92] suggest that a sample of 6 interviews is enough to achieve information saturation. A sample of 7 client-type companies (hotel chains) and 6 supplier-type companies (industrial laundries) was determined, for 13 companies in total, but there were 15 interviews. We interviewed 2 managers at 2 of the companies (one hotel chain and one supplier). The reasons for this were that they were both big companies (+300 sites, $+20,000$ employees), so they have different departments and management positions with knowledge and expertise that could bring very interesting and complimentary inputs to our research (operations vs. sales; corporate sustainability vs. procurement). They were also available and open to share these different views with us.

The selection of companies to interview was carried out in the following way:

- Client companies (hotel chains): We classified the hotel chains into 3 groups (large, medium, and small) based on their size (number of hotels and rooms). Based on Loeda [93], we listed and ordered the hotel groups based on size, and we determined that large group includes the largest 15 hotel chains (representing 30.5\% of hotels and 32.8\% of rooms in Spain); medium group includes the next 59 hotel chains (representing 33.3\% of hotels and 36.2\% of rooms in Spain); and finally small group includes the remaining hotel chains (representing $36.2 \%$ of hotels and $31.0 \%$ of rooms in Spain). Three companies from the large group and two from the medium and small groups were selected according to the following criteria: Recognized companies within the group, with central offices located in the central zone of Spain, and accessible to the management team. In general, all the large hotel chains have centralized procurement departments (CPD), but only some medium and small chains have CPD.

- Supplier companies (industrial laundries): Industrial laundries were selected as supplier for this research because their activity is directly related to the three aspects of sustainability: (a) Their activity has a clear impact on the quality and service that the hotel chains provide to their guests (economic aspect); (b) industrial laundries are labour intensive (social aspect); (c) their production processes require the use and consumption of big quantities of water, energy, chemical products, gas, material (linen), etc. (environmental aspect). A classification of industrial laundries was carried out for 3 groups based on their size and geographical scope of activity. Small companies are not the object of this study. Three medium and large companies were selected.

The interlocutors were carefully selected according to the following criteria: Hierarchical responsibility in the company, ability to make decisions in relations between client and supplier, 
experience in the workplace and the industry, and experience and responsibility in the field of sustainability. In the hotel chains, the profiles that met these requirements were purchasing managers, operations managers, and managers in charge of sustainability. In the supplier companies, the profiles that met these requirements were factory managers, commercial directors, and managers.

Some considerations were evaluated in order to guarantee the quality of the information obtained in the interviews, such as their preparation and duration, the selection of the interviewers, the date, the place, and the recording process. The interviews were digitally recorded, with a second recorder as backup. The recording was completed with notes during the interview by the interviewer. This is convenient not only to record the subject's voice, but also to observe the various reactions that occur throughout the interview [94].

The quality of the information obtained in the interviews depends on the collaboration of the interviewees, which entails "serious ethical obligations towards them" [94-96]. That is why informed consent, confidentiality, and consequence documents were prepared and signed, guaranteeing that the information from the interview: (i) Would not be disseminated to third parties; (ii) would only be part of the study in question; and (iii) would be included in this paper in such a way that no data, names, or numbers could help to identify the interviewee or the company.

A methodological field journal was kept, with the aim of recording the process of contact with interlocutors, the conversations that took place before the interviews, the introductory stages, and aspects related to the detailed observation during the interview or during other informal meetings. The purpose of this double recording was to perform a compared analysis with the recorded conversation during the interview session, in order to clarify certain nuances or circumstances. Once the interviews were carried out, they were transcribed within a period not exceeding $48 \mathrm{~h}$. Transcription truthfulness and quality were guaranteed by a second person, who double-checked that the text corresponded authentically with the recordings.

Then, we proceeded to the coding of the transcribed interviews. This consisted of extracting the concepts from the original data and developing them in terms of their properties and dimensions [97], and this was carried out with the support of NVivo software. Initially, coding of the interviews followed a deductive approach: An interview script was elaborated from the research objectives and the theoretical framework, first categories were extracted from it, and the coding process was started (see Figure 1 for categories of analysis). From the transcripts, we continued the coding process, this time inductively: Based on a careful and precise reading of the interviews and the data obtained from them, definitive categories emerged. During this process, the contents were labelled, concepts were identified, and ideas were written down, so they could be used (if considered) to improve the script for the following interviews when rethinking new topics [97]. This codification process was completed with the reading of the field journal, from which ideas, nuances, and interpretations were also extracted that reinforced or questioned the information obtained, providing more solidity to our work.

Once all the resources and interviews were coded, we proceeded to a deep categorical and interpretative discourse and content analysis phase, aimed at interpretation. Discourse analysis was focused on analyzing the words and discourse used by the informants. The words used, the frequency of their use, and their relation to key concepts were studied, always bearing in mind the context of the conversation and the interviewee's profile. NVivo software helped us build cloud marks of word frequency, statistics, and data tables. See Figure 2 for an example of a word frequency cloud mark for hotel chains. 


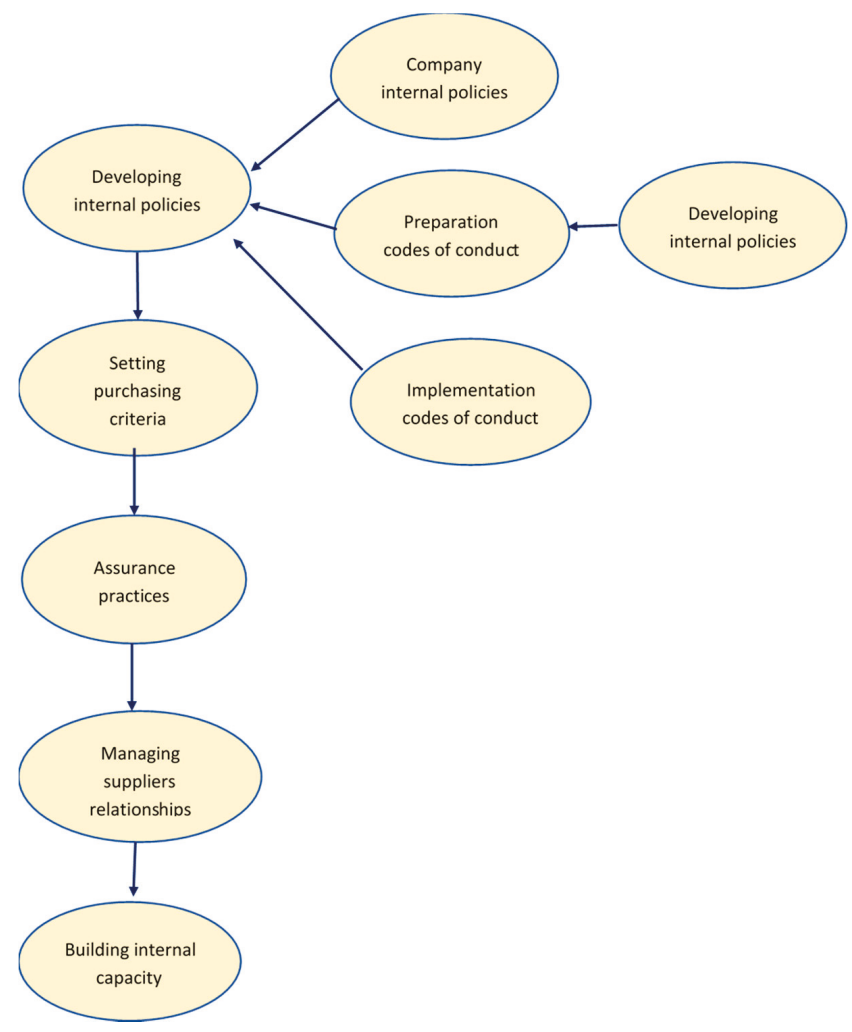

Figure 1. Categories of analysis.

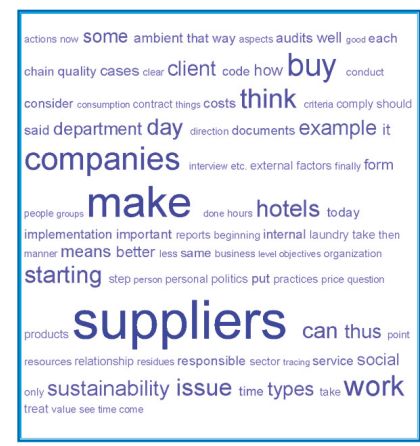

Figure 2. Word frequency cloud mark for hotel chains.

Next, we proceeded to content analysis of the coded categories. For each category, the coded content was evaluated, comparing some interviews with others, information from hotel chains and suppliers, and different segments. Findings were obtained by detecting patterns to the extent that the information was repeated (saturation was achieved) or there were divergences in the discourse. From all this, relationships between the categories and elements were extracted, providing results that helped us to respond to the research objectives. See Figures 3 and 4 for an example of the relationship of categories with each of the resources (interviews). 


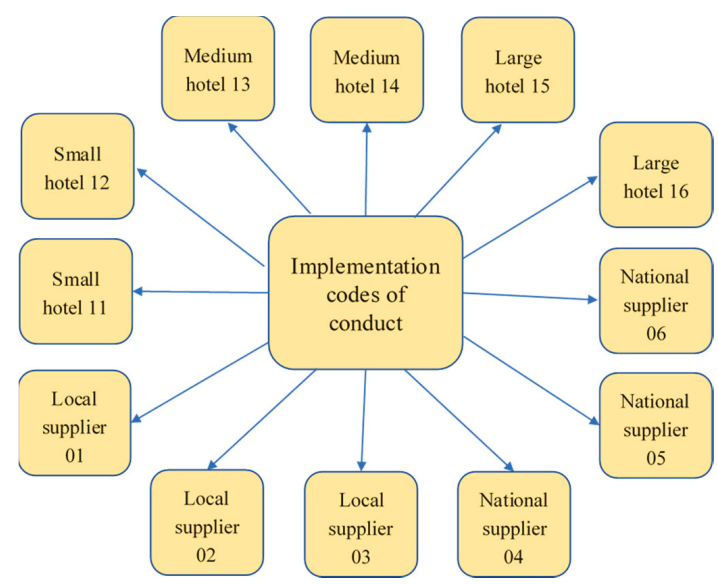

Figure 3. Relationship of categories with resources (interviews). Implementation of codes of conduct.

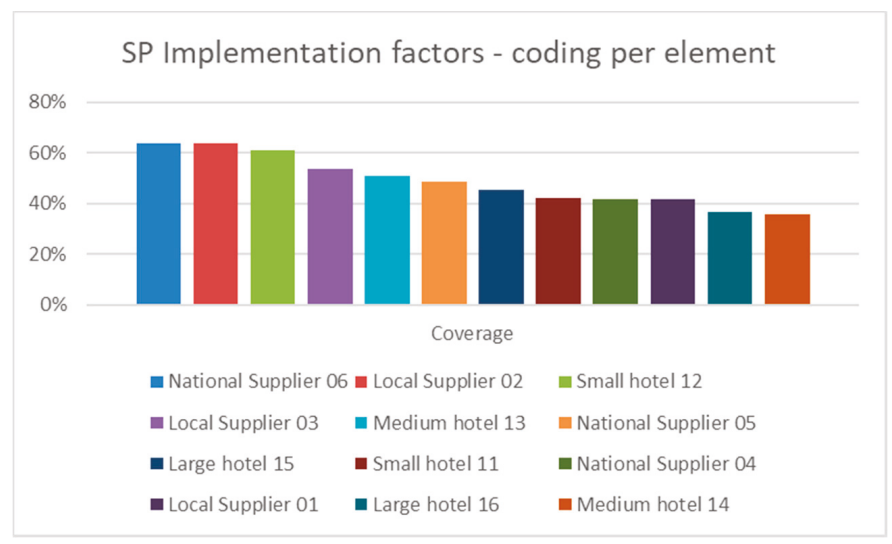

Figure 4. Relationship of categories with resources (interviews). Implementation factors-coding per element.

\section{Results}

In this section we present the findings or results of our research. The results are organized in two main subsections: (i) First, an evaluation of how companies in this sector follow the proposed models and frameworks from the literature; and (ii) second, findings on the identification of main drivers and barriers to effective implementation. It is important to mention that the semi-structured interview has been proven to be the best, if not the only, methodology to obtain the results that we present in this section. Some of the companies in this study do not have a website, and the ones with a website do not publish all information about sustainability practices. Their initiatives in SCM, and particularly SP, are not published and accessible. Surveys could have provided answers to some questions, but we considered that the depth, details, and nuances of the information that we were looking for could only be achieved through interviews with managers, experts in the hotel industry [87-90]. 


\subsection{Evaluation of SP Practices}

This section discusses the evaluation of the degree of implementation of SP in the supply chain of the hotel sector in Spain. It is done from the double perspectives of customers (hotel chains) and suppliers (industrial laundries).

In the literature review section, we identified different models for sustainability implementation in the purchasing function (see Table 1), and concluded that Leire and Mont's [25] model is the most complete and adequate, as it details all implementation stages. The findings from interviews confirm that the implementation of SP in the hotel industry follows this model, singularly five stages: (i) Developing internal policies; (ii) setting purchasing criteria; (iii) applying assurance practices; (iv) managing supplier relations; and (v) building internal capacity.

Interviewees also mentioned that this model could be completed by incorporating the following ideas:

(i) An initial stage, before stage 1, with a strong commitment from the top management of the hotel companies.

(ii) An internal review at the end of each stage, with the aim of verifying, confirming, and validating completion of the stage before moving forward in the implementation process.

(iii) The supplier point of view, meaning that in some stages, feedback from suppliers should be considered as a check or validating point.

Once the model was validated, we proceeded to assess how the hotel companies had implemented it. The results that we obtained vary depending on the different types of hotel chains.

In large hotel chains, sustainability awareness and the commitment of the company's top management appear to be high, which is why they have developed initiatives internally. Once these initiatives were implemented within their organization, they were transferred to their suppliers. Large hotel chains have documented and formalized procurement processes, with a CPD at their headquarters. We account for initiatives in all five stages of Leire and Mont's [25] model, although some missing points were detected: (i) Not all initiatives proposed by that model have been launched; (ii) some initiatives have been launched but not completed or have not been effectively implemented; and (iii) there are initiatives launched in all five stages, but none of the stages have been fully completed.

Currently we can say that large hotel chains are in a phase close to maturity according to the model of Leire and Mont [25], that is, with initiatives in all stages.

Table 4 shows some quotes from interviews with large hotel chain managers on sustainability implementation in the purchasing function.

We obtained different findings for medium-sized hotel chains, depending on whether they have CPD or not. In general, all of them have defined purchasing procedures, although not completely documented and formalized.

In medium-sized hotel chains with CPD, sustainability awareness and the commitment of the company's top management are moderate. Internal policies on sustainability are vague, so they are vague when transferred to suppliers. We account for initiatives in some stages of Leire and Mont's [25] model (usually stages 1 and 2, none having been fully completed), and they are still far from carrying them to all stages. Some of these initiatives have been launched but not completed or have not been effectively implemented. Currently we can say that medium-sized hotel chains are in a phase close to introduction according to the model of Leire and Mont [25], that is, with initiatives only in one or two stages. Table 5 shows some quotes from interviews with medium-size hotel chain managers (with CPD) about sustainability implementation in the purchasing function. 
Table 4. Quotes from interviewees: Large hotel chain managers.

\begin{tabular}{l} 
"The commitment to sustainability comes from top management here in Spain, who leads and promotes all the \\
policies and activities carried out here, and this commitment reaches all employees. But, being a multinational \\
company, all this comes to us from the headquarters, where it has been implemented for many years." \\
"The company owns a very well-defined code of conduct. Part of an implication of the top management of the \\
company, with a very specific mission and values." \\
"These codes of conduct have been generated by our company in Spain, in the quality department, which is \\
responsible for this, but they are based on the models that have been implemented internationally from the \\
headquarters." \\
"Top management is totally involved. Every document, corporate memory, code of conduct is preceded by a \\
total commitment by senior management." \\
"We have a very well-defined code of conduct. It starts with an implication of the top management of the \\
company, with a very specific mission and values and the following sections: (a) Scope, application and \\
compliance; (b) ethical and responsible behavior (general principles and commitment to stakeholders); (c) \\
application procedure: advice and procedure to report complaints of the code of conduct; d) validity." \\
\hline "There is a large department of corporate purchasing that leads these activities towards suppliers. In matters \\
of sustainability, it works in coordination with the department of sustainability and the environment, to the \\
extent that purchasing requests it." \\
"The code of conduct of the company has section with a code of conduct code of suppliers, to which they must \\
adhere." \\
"Adhesion to the code of conduct. The code of conduct forms part of the approval contract of the purchasing \\
department since 2012. It includes an acceptance clause as an exclusion criterion in the selection phase of \\
suppliers. They need to be qualified to participate in the following phases of the contest. Last year, 173 codes \\
were signed, reaching the cumulative figure of $1391 . "$ \\
"Purchasing management is responsible for the implementation." \\
"The signing of the code of conduct is done during the approval process. A supplier is not approved if it has \\
not signed the code." \\
\hline
\end{tabular}

Table 5. Quotes from interviewees: Medium-size hotel chain managers (with CPD).

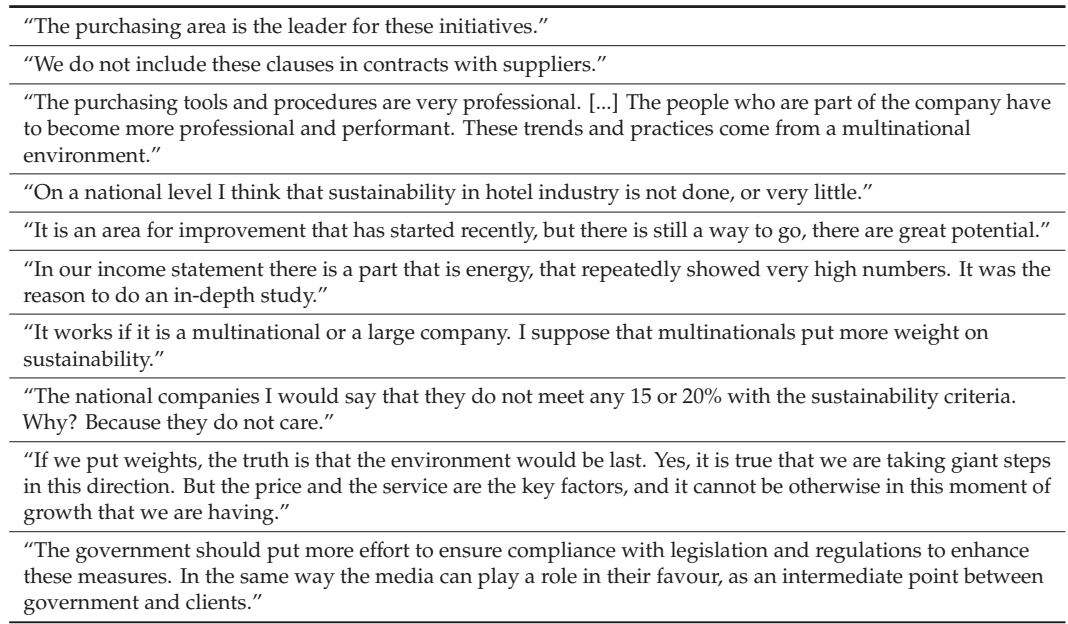

Medium-sized hotel chains without CPD and small hotel chains present a similar approach to sustainability. In general, all of them have defined purchasing procedures, although not completely documented and formalized. None of them show any awareness or commitment from their top management to sustainability issues. The process of implementing some initiatives according to the model of Leire and Mont [25] has not begun within the companies themselves. Thus, if they do not believe in it and do not do it, they consider that they should not take any initiative on sustainability implementation with their suppliers. Tables 6 and 7 show some quotes from interviews with medium-size hotel chain managers (without CPD) and small hotel chain managers about sustainability implementation in the purchasing function. 
Table 6. Quotes from interviewees: Medium-size hotel chain managers (without CPD).

\begin{tabular}{l}
\hline "Small and medium-sized companies have little interest in sustainability." \\
"Any hotel chain has significantly reduced the headcount, and apart from reducing the headcount, they have \\
given more obligations to the remaining workers. Then, people do not have time." \\
\hline "What is clear today is that companies look more at the economic part than at the sustainability one." \\
"The priority is cost reduction, without a doubt. It cannot be otherwise in the hotel sector in which we find \\
ourselves and given the situation of general crisis and our exponential growth in these years." \\
"If this approach (to be certified in sustainability) arose here in a steering committee, the answer would \\
probably be that there are other priorities." \\
"In the hotel sector the issue of certification is not as important." \\
"It is not the same to be a national company as an international one. The multinational companies are forced to \\
follow internal regulations different from the national ones." \\
"This commitment requires in some way time, and time is money." \\
"I do not believe that today the client is properly educated on this issue of sustainability. Yes, it is true that \\
there are people who are involved and committed, but on the total of society this percentage is still low. Maybe \\
if they were, it could be a sales argument. But they are not yet." \\
"They do not do it because they surely do not have the requirement from their clients." \\
"In Spain I think that sustainability culture is not yet spread, and if in future it may be, I think that it will come \\
from the outside. This is how I see this sustainability issue."
\end{tabular}

Table 7. Quotes from interviewees: Small hotel chain managers.


"If at the same time that we reduce costs, less waste is generated, then it would be great. But the trigger I think is the cost."

"It takes time from my staff. And all this has a cost."

"At a business level, what counts is the revenue and the results. Results are the main goal, comply with the budget, obtain the expected profit. The rest is not as high priority."

"The shareholders, of course, are not aware. They only think about the results, the profit.

"If this crisis had never happened, the pressure for the result would surely be less intense, and I do not doubt that we would have evolved towards a more sustainable society. But now the criterion is the economic one."

"Sometimes the application of regulations is necessary to change things and raise awareness."

"We do not have support from the administration. There is a lack of resources, as information, containers for recycling, available and accessible disposal points, etc."

"Companies would surely implement sustainability if they felt more pressure from the administration."

"I do not think that customers demand sustainability at hotels. If they did, we would study the business case to analyze the profitability. I mean, if the number of customers grows significantly by being sustainable, then we would do it."

"Sustainability is not a priority for us. Which is the main reason? The lack of space, the costs and dedication times, that we do not have. I am convinced that sustainability is not a priority for the hotel industry."

"We do not have codes of conduct for sustainability. We do not have them internally, so we cannot ask the suppliers to comply with and sign them. I do not think that they exist in the hotel industry."

"It is not our responsibility as a customer to make sure that our suppliers comply with sustainability or legal issues. It is their responsibility, as well as the administration responsibility." 


\subsection{Drivers and Barriers for an Effective SP Implementation}

This research also identified the main factors that may influence the proper and effective implementation of sustainability in purchasing policies in the hotel sector. These factors could be drivers, facilitators, or catalysts insofar as they can help, facilitate, or promote these initiatives (positive approach). On the other hand, these same factors could also become barriers, obstacles, or limitations to the extent that they can hinder, slow, or prevent these initiatives (negative approach). For instance, the factor "commitment of the hotel chain management" could be:

(i) A driver (positive approach): If the manager is committed, he/she will act as helper, facilitator, or promoter to support the implementation of these initiatives.

(ii) A barrier (negative approach): If the manager is not committed, he/she will not support the implementation of these initiatives, becoming an obstacle, even stopping any related proposal.

A thorough analysis of all the interviews provides us with a list of factors, all previously identified in the literature (see Tables 2 and 3). Factors have been classified into three groups:

(i) Internal factors (within hotel chains), relating solely to management and decisions within the scope of the chain.

(ii) Internal factors (in the relationship between hotel chains and suppliers), relating to management and decisions around the relationship between hotel chains and suppliers.

(iii) External factors (in the hospitality sector), relating to aspects of agents in the hospitality sector outside the relationship between hotel chains and their suppliers.

The most relevant factors are:

Internal factors (within hotel chains):

- Awareness and commitment of the hotel chain management.

- Economic or cost factor for the implementation of these practices.

- $\quad$ Risk reduction and brand image and trying to enhance visibility.

Internal factors (in the relationship between hotel chains and suppliers):

- Conflicts between hotel chains and suppliers on requirements to meet sustainability criteria and with a situation of increasingly lower prices and margins, or with operational criteria (product quality, service, delivery times).

External factors (in the hospitality sector):

Demand: Final consumers who request compliance with sustainability.

Requirements of regulations, governments, and public administrations.

- Market situation in terms of demand, prices, and margins.

Likewise, other factors were identified by the interviewees, but they were rated or considered as less important. They refer to issues related to facility or installation design, lack of space, the cultural and multinational nature of companies, lack of knowledge, and growth and expansion of the hotel chain. Some interviewees described these secondary factors more as excuses than real factors, as they thought the main issue was a lack of commitment from the hotel chain management.

\section{Discussion and Conclusions}

The objective of this research paper was to describe and evaluate the degree of implementation of SP in the supply chain of the hotel sector in Spain from the double perspectives of customers (hotel chains) and suppliers (industrial laundries).

As a first step, we evaluated how companies in this sector follow the proposed models and frameworks in the literature. In Table 1, we presented a summary of the main models and frameworks 
from the literature. After a thorough analysis and as a result of our field work, we concluded that Leire and Mont's [25] model is the most adequate for SP implementation. We chose this model as a basis for our study because it has a clear focus on the practical implementation of sustainability purchasing in terms of (i) describing each stage and phase; (ii) identifying the responsibilities in these stages; (iii) identifying the factors that influence an adequate implementation; (iv) presenting a tool for decision making; and (v) being applicable to any sector. During the interviews, new ideas and proposals arose with the aim of completing this model. These proposals refer to incorporating new activities in the model; as: (i) An initial stage, about a strong commitment from the top management of the hotel companies; (ii) an internal verification and validation review at the end of each stage; and; (iii) feedback from suppliers as a check or validating point.

We detected a general lack of awareness of, or commitment to, incorporating sustainability within the purchasing function in SCM in the hotel sector. One reason could be that the study was carried out in the years after a big economical and financial crisis (2014-2019), so the economic factor is predominant in company decisions versus other aspects such as social or environmental.

Previous sections showed that we obtained different results depending of the type of hotel chain. Molina-Azorín et al. [53] proposed a classification of hotels based on a cluster analysis of how proactive/reactive they were about their environmental policies. This taxonomy cannot be strictly applicable to our study, as we consider a wider scope of analysis in two ways: (i) We analyze sustainability, which includes environmental, economic, and social aspects; and (ii) we study how it is implemented in the purchasing function, and not within the hotel company. Thus, a taxonomy of companies with different purchasing categories is proposed based on our findings in previous sections (see Table 8).

Table 8. Hotel chain classification related to the degree of implementation of SP.

\begin{tabular}{cccc}
\hline Classification & Purchasing Processes & Model Stages & Hotel Chains \\
\hline Advanced & Formalized & $1,2,3,4,5$ & Large \\
Elementary & Defined & 1,2 & Medium (with CPD) \\
Passive & Defined & None & Medium (without CPD) \\
& & & Small \\
\hline
\end{tabular}

"Advanced" refers to the group of large hotel chains with documented and formalized purchasing processes and implemented initiatives in SP at all five stages of Leire and Mont's [25] model, although we discussed that the implementation level is not complete in general.

"Elementary" refers to the group of medium hotel chains with defined purchasing processes and CPD. They have partially implemented initiatives in SP stages 1 and 2 of Leire and Mont's [25] model.

"Passive" refers to the group of medium hotel chains with defined purchasing processes and no CPD. They have not implemented any SP initiatives.

This research also identifies the main factors that may influence the proper and effective implementation of sustainability in purchasing policies in the hotel sector. These factors could act as drivers or barriers, and we grouped them into three types: (i) Internal factors (within hotel chains); internal factors (in the relationship between hotel chains and suppliers); and external factors (in the hospitality sector). Carefully analyzing these factors, we can conclude, on the one hand, that they are all part of what the literature identified (see Tables 2 and 3). Although the literature identified other factors, we must admit that our interlocutors did not consider them relevant. On the other hand, the literature exposes factors classified into two large groups, drivers and barriers; instead, our research allows us to conclude that the same factors that could act as drivers could also act as barriers depending on the way they are applied, as explained previously.

We can conclude that several of the factors refer to the potential conflict that could arise between the three aspects of sustainability (economic, environmental, and social) insofar as a hotel chain does not want to renounce consideration of the economic aspect in favour of the environmental and social 
aspects. This can be seen in the factors that deal with costs and investments, prices and margins, quality and service. Another group of factors is related to the commitment to, and awareness of, sustainability, both by the management of hotel chains (whose initiative and leadership are necessary for the implementation of these practices), and by governments, customers, and markets, which, each in its scope, may motivate companies and require them to comply with sustainability criteria themselves and in their purchase from suppliers.

This paper is of practical and social interest, and offers managerial implications, as the results of this study provide meaningful guidelines for different stakeholders (users, customers, suppliers, society, governments, employees, etc.). From a practical point view, we would like to propose some recommendations and initiatives in the direction of supporting the drivers or factors for effective implementation of SP in the hotel industry.

First, we suggest continuing to promote consciousness and commitment from society in general, and hotel guests and customers, in particular. This could be achieved with communication and awareness programs by governments, entities, agencies, or media. Lessons learned from more developed countries could be brought to this topic. When individual customers are committed, they will demand it from hotel chains. Corporate and group customers commitment towards sustainability is also very important, and as they manage high volumes in terms of sales for the hotel chains, they can exert higher power to them oriented towards demanding the implementation of sustainable practices within the hotels and SP practices towards their suppliers.

Second, the implication of the government must also be manifested in other directions, such as: (i) Launching initiatives with the aim of standardizing, simplifying, and clarifying the different regulations that concern aspects of sustainability; (ii) putting in place mechanisms of pressure to ensure that these regulations and laws are respected; and (iii) providing support and resources for hotel chains (such as glass hoods, containers, delivery points, and nearby waste collection).

Third, support should be provided to raise the consciousness of, and commitment by, hotel chain management. The above-mentioned recommendations could help, in the same way that other results from this paper could help them understand that sustainability practices in SCM are a means to achieve competitive advantage rather than a cost conflict issue. Redesigning processes and contract relations in SCM should be a strategic decision.

This research is bound by certain limitations, as are many other studies. First, we limited our interviews to 15 , which was enough for our research purposes, but could be extended in future research, and even supported by a survey. This could reach a wider population and different management profiles that could help researchers obtain more data and information, and richer results with the aim of evaluating the applicability of the proposed SP model. This could also be done by different typologies of hotels (for instance, rural, holidays, city hotels), and tests of the applicability of the proposed SP model could be carried out in each of these typologies.

Second, we limited our study to a very specific geographical area (Spain) and period (2014-2019). By extending the research to other geographical areas researchers could have the opportunity to assess how SP is implemented in the hospitality industry in different societies with different levels of consciousness compared to Spanish society. It would also be a good opportunity to evaluate the applicability of the proposed SP model.

Third, we focused on one specific type of supplier, industrial laundries, with a clear impact in the three dimensions of sustainability, but this could restrict the applicability of results. Therefore, research could be extended to other suppliers (for instance, room cleaning companies, maintenance companies, etc.) with different operational contexts and constraints. For instance, room cleaning companies are also labour intensive and deal with environmental issues (use of chemical products) but in a different manner than industrial laundries (less water and energy consumption, as an example).

Fourth, research could also be extended to other members within the supply chain (for instance, tier 2 or tier 3 suppliers). It could be interesting to assess how SP practices are implemented in tier 
2 and tier 3 suppliers, evaluating the different roles of the hotel chains and the tier 1 suppliers, and testing the applicability of the proposed SP model.

Fifth, we consider that the lack of certified or labelled hotels in our analysis may be a limitation. It would also be interesting to carry out a comparative analysis of certified or labelled hotels versus non-certified hotels with the aim of evaluating sustainability policies, how they have been implemented towards their suppliers, as well as the applicability of the SP model in both contexts.

Author Contributions: Conceptualization and literature review, M.-F.M.-C.; P.B.-C.; C.M.-F.; V.L.-C.; Methodology, M.-F.M.-C.; P.B.-C.; C.M.-F. Software, M.-F.M.-C.; C.M.-F. Data curation, M.-F.M.-C.; P.B.-C.; C.M.-F.; Writing-Original draft preparation, M.-F.M.-C.; P.B.-C.; V.L.-C. Writing-Review and editing, M.-F.M.-C.

Funding: This research received no external funding.

Conflicts of Interest: The authors declare no conflict of interest.

\section{Appendix A}

\section{Interview Script Summary}

The interview script consists on more than 50 questions and sub-questions based on literature review. It has been summarized to present the main topics.

Introduction

Research Project introduction.

Questions related to Sustainability definitions, individual and business approaches.

Questions related to sustainability applications within the interviewed company, as well as about the real consciousness of the corporation.

The Development of Internal Policies on Sustainability

Internal policies on sustainability (social, environmental) within the organization: codes of conduct, guidelines for the proper use of resources, waste management, social issues, etc.

Questions related to the training and sensitization of personnel: number and type of initiatives, trainers, etc.

Purchasing Codes of Conduct

Purchasing codes of conduct elaboration. Who? How? Responsibilities, documents, objectives, qualitative/quantitative, management commitment.

Purchasing codes of conduct implementation. Who? Responsibilities. How? Communication to suppliers, documents.

Definition of purchasing criteria (social, environmental, economic). Contracts. Same criteria for all suppliers?

Aplication of Control Practices for Suppliers

Practices to monitor supplier performance (operational, quality, service, social, environmental).

Auditing to suppliers. Who? How? Responsibilities, documents, goals, key performance indicators (qualitative/quantitative), own procedures and methodologies or standard, etc.

Same criteria/format for all suppliers?

Ranking for evaluation of suppliers.

Internal/external auditors.

Management of Relationship with Suppliers

Supplier selection criteria. Prioritize.

Who? How? Responsibilities, documents, procedures.

Environmental and social indicators?

Lack of compliance/Contingency plans/Continuous improvement plans.

Team work and collaboration versus top-down relationship. 
Sustainability Internal Capacity Development

Best practices in sustainability as an individual responsibility for the supplier versus as a joint responsibility.

Formal plans to expand sustainability practices in future (more suppliers, more codes of conduct, better performance, training, best practices sharing, etc.).

Capabilities: Who? How? Responsibilities, documents, procedures, tools, external support.

Integration with business management.

Drivers and Barriers for an Effective Implementation of Sustainable Purchasing

Drivers/enablers identification. Justification.

Barriers identification. Justification.

\section{References}

1. World Commission on Environment and Development (WCED). Our Common Future, World Commission on Environment and Development; Oxford University Press: Oxford, UK, 1987; p. 8.

2. Elkington, J. Cannibals with Forks: The Triple Bottom Line of the 21st Century; New Society: Stoney Creek, CT, USA, 1998.

3. Seuring, S.; Müller, M. From a literature review to a conceptual framework for sustainable supply chain management. J. Clean. Prod. 2008, 16, 1699-1710. [CrossRef]

4. Hoejmose, S.U.; Adrien-Kirby, A.J. Socially and environmentally responsible procurement: A literature review and future research agenda of a managerial issue in the 21st century. J. Purch. Supply Manag. 2012, 18, 232-242. [CrossRef]

5. Maloni, M.J.; Brown, M.E. Corporate social responsibility in the supply chain: An application in the food Industry. J. Bus. Ethics 2006, 68, 35-52. [CrossRef]

6. Story, L.; Barboza, D. Mattel Recalls 19 Million Toys Sent from China. The New York Times, 2007. Available online: http://www.nytimes.com/2007/08/15/business/worldbusiness/15imports.html?pagewanted=all\&_r=0 (accessed on 29 January 2015).

7. Giménez, C.; Tachizawa, E.M. Extending sustainability to suppliers: A systematic literature review. Supply Chain Manag. Int. J. 2012, 17, 531-543. [CrossRef]

8. Danwatch. Case Story Exploitation and Miserable Conditions Are Routine Dell Suppliers. 2013. Available online: https://www.danwatch.dk/en/articles/case-story-exploitation-and-miserable-conditions-are-routinedells-suppliers/270 (accessed on 2 February 2015).

9. Bowen, F.E.; Cousins, P.D.; Lamming, R.C.; Faruk, A.C. The role of supply management capabilities in green supply. Prod. Operat. Manag. 2001, 110, 174-189. [CrossRef]

10. Mont, O.; Leire, C. Socially responsible purchasing in the supply chain: Drivers and barriers in sweden. Soc. Responsib. J. 2009, 5, 388-407. [CrossRef]

11. Chiarini, A. Strategies for developing an environmentally sustainable supply chain: Differences between manufacturing and service sectors. Bus. Strategy Environ. 2014, 23, 493-504. [CrossRef]

12. Wua, Z.; Jiab, F. Toward a theory of supply chain fields-Understanding the institutional process of supply chain localization. J. Operat. Manag. 2018, 58-59, 27-41. [CrossRef]

13. Chkanikova, O. Sustainable purchasing in food retailing: Interorganizational relationship management to green product supply. Bus. Strat. Environ. 2016, 25, 478-494. [CrossRef]

14. Kim, Y.H.; Davis, G.F. Challenges for global supply chain sustainability: Evidence from conflict minerals reports. Acad. Manag. J. 2016, 59, 1896-1916. [CrossRef]

15. Murray, J.J. When you get what you bargained for-But don't. Purchaising 2003, 132, 26.

16. Montabon, F.; Pagell, M.; Wu, Z. Making sustainability sustainable. J. Supply Chain Manag. 2016, 52, 11-27. [CrossRef]

17. George, G.; Howard-Grenville, J.; Joshi, A.; Tihanyi, L. Understanding and tackling societal grand challenges through management research. Acad. Manag. J. 2016, 59, 1880-1895. [CrossRef]

18. Tang, C.S. Socially responsible supply chains in emerging markets: Some research opportunities. J. Operat. Manag. 2018, 57, 1-10. [CrossRef] 
19. Villena, V.H.; Gioia, D.A. On the riskiness of lower-tier suppliers: Managing sustainability in supply networks. J. Operat. Manag. 2018, 64, 65-87. [CrossRef]

20. Xiao, C.; Wilhelm, M.; Vaart, T.; Donk, D.P. Inside the buying firm: Exploring responses to paradoxical tensions in sustainable supply chain management. J. Supply Chain Manag. 2019, 55, 3-20. [CrossRef]

21. Foerstl, K.; Azadegan, A.; Leppelt, T.; Hartmann, E. Drivers of supplier sustainability: Moving beyond compliance to commitment. J. Supply Chain Manag. 2015, 51, 67-92. [CrossRef]

22. Goebel, P.; Reuter, C.; Pibernik, R.; Sichtmann, C.; Bals, L. Purchasing managers' willingness to pay for attributes that constitute sustainability. J. Operat. Manag. 2018, 62, 44-58. [CrossRef]

23. Mamic, I. Managing global supply chain: The sports footwear, apparel and retail sectors. J. Bus. Ethics 2005, 59, 81-100. [CrossRef]

24. Pedersen, E.R.; Andersen, M. Safeguarding corporate social responsibility (CSR) in global supply chains: how codes of conduct are managed in buyer-supplier relationships. J. Public Aff. 2006, 6, 228-240. [CrossRef]

25. Leire, C.; Mont, O. The implementation of socially responsible purchasing. Corp. Soc. Responsib. Environ. Manag. 2010, 17, 27-39. [CrossRef]

26. Park-Poaps, H.; Rees, K. Stakeholder Forces of Socially Responsible Supply Chain Management Orientation. J. Bus. Ethics 2010, 92, 305-322. [CrossRef]

27. Azadnia, A.H.; Saman, M.Z.M.; Wong, K.Y. Sustainable supplier selection and order lot-sizing: An integrated multi-objective decision-making process. Int. J. Prod. Res. 2015, 53, 383-408. [CrossRef]

28. Aktin, T.; Gergin, Z. Mathematical modelling of sustainable procurement strategies: three case studies. J. Clean. Prod. 2016, 113, 767-780. [CrossRef]

29. Prier, E.; Schwerin, E.; McCue, C.P. Implementation of sustainable public procurement practices and policies: A sorting framework. J. Public Procure. 2016, 16, 312-346. [CrossRef]

30. Espino-Rodríguez, T.F.; Gil-Padilla, A. The structural and infrastructural decisions of operations management in the hotel sector and their impact on organizational performance. Tour. Hosp. Res. 2015, 15, 3-18. [CrossRef]

31. Figuerola, M.; Rubio, J.M.; Gallego, E.; Navarro, J.; Pérez, L.; Moncada, P. Los Sectores de la Hostelería en 2012; Fundación de Hostelería de España: Pozuelo de Alarcón, Spain, 2012.

32. Marín-Lozano, O. Informe del Sector Turístico; Banca March: Palma de Mallorca, Spain, 2012.

33. Cabrini, L. GSTC Destinations Community Conference. Destinations, Tourism and Sustainability. Available online: https://www.gstcouncil.org/gstc-destinations-community-barcelona-summit/?lang=es (accessed on 1 January 2019).

34. Pfahl, S.; Cabrini, L.; Haxton, P.; Ruggles-Brisle, O. Cómo acelerar el cambio hacia pautas de consumo y producción sostenibles en el sector turístico. In Proceedings of the Conference at Jornadas de FITURGREEN 2015: VI Foro Sostenibilidad y Turismo ITH-OMT, Fitur, Madrid, Spain, 28-30 January 2015.

35. UNEP. Sustainable Tourism Programme. 2015. Available online: http://www.unep.org/10YFP/tourism (accessed on 2 February 2015).

36. Deloitte. Managing Changes in an Unsettled Economic Climate Tourism and Hospitality Trends. 2017. Available online: https:/www2.deloitte.com/content/dam/Deloitte/cn/Documents/international-businesssupport/deloitte-cn-ibs-france-hospitality-and-tourism-trends-en-2017.pdf (accessed on 1 January 2019).

37. Cavagnaro, E.; Gehrels, S.A. Sweet and sour grapes: Implementing sustainability in the hospitality industry-A case study. J. Culinary Sci. Technol. 2009, 7, 181-195. [CrossRef]

38. Van Rheede, A.; Blomme, R.J. Sustainable practices in hospitality: A research framework. In Advances in Hospitality and Leisure; Chen, J.S., Ed.; Advances in Hospitality and Leisure; Emerald Group Publishing Limited: Bingley, UK, 2012; Volume 8, pp. 257-271.

39. Williams, P.; Ponsford, I.F. Confronting tourism's environmental paradox: Transitioning for sustainable tourism. Futures 2009, 41, 396-404. [CrossRef]

40. Peter, J.; Hillier, D.; Comfort, D. Sustainability in the hospitality industry: Some personal reflections on corporate challenges and research agendas. Int. J. Contemp. Hosp. Manag. 2016, 28, 3667.

41. Prud'homme, B.; Raymond, L. Sustainable development practices in the hospitality industry: An empirical study of their impact on customer satisfaction and intentions. Int. J. Hosp. Manag. 2013, 34, 116-126. [CrossRef]

42. Manaktola, K.; Jauhan, V. Exploring consumer attitudes and behaviour towards green practices in the lodgings industry in India. Int. J. Contemp. Hosp. Manag. 2007, 19, 365-377. [CrossRef] 
43. Sigala, M. Customer involvement in sustainable supply chain management: A research framework and implications in tourism. Cornell Hosp. Q. 2014, 55, 76-88. [CrossRef]

44. Sirakaya-Turk, E.; Baloglu, S.; Mercado, H.U. The efficacy of sustainability values in predicting travelers' choices for sustainable hospitality businesses. Cornell Hosp. Q. 2014, 55, 115-126. [CrossRef]

45. Sloan, P.; Legrand, W.; Chen, J.S. Factors influencing German hoteliers' attitudes toward environmental management. In Advances in Hospitality and Leisure; Emerald Group Publishing Limited: Bingley, UK, 2005; pp. 179-188.

46. Zhang, J.J.; Joglekar, N.; Verma, R. Pushing the frontier of sustainable service operations management: Evidence from US hospitality industry. J. Serv. Manag. 2012, 23, 377-399. [CrossRef]

47. Rodríguez-Antón, J.M.; del Mar Alonso-Almeida, M.; Celemín, M.S.; Rubio, L. Use of different sustainability management systems in the hospitality industry. The case of Spanish hotels. J. Clean. Prod. 2012, 22, 76-84. [CrossRef]

48. Bonilla-Priego, M.J.; Font, X.; del Rosario, P.O. Corporate sustainability reporting index and baseline data for the cruise industry. Tour. Manag. 2014, 44, 149-160. [CrossRef]

49. Pérez, A.; Rodríguez-del-Bosque, I. Sustainable development and stakeholders: A renew proposal for the implementation and measurement of sustainability in hospitality companies. Knowl. Process Manag. 2014, 21, 198-205. [CrossRef]

50. De Grosbois, D. Corporate social responsibility reporting by the global hotel industry: commitments, initiatives and performance. Int. J. Hosp. Manag. 2012, 31, 896-905. [CrossRef]

51. Darnall, N.; Jolley, G.J.; Handfield, R. Environmental management systems and green supply chain management: Complements for sustainability? Bus. Strategy Environ. 2008, 17, 30-45. [CrossRef]

52. Testa, F.; Iraldo, F; Daddi, T. The effectiveness of EMAS as a management tool: A key role for the internalization of environmental practices. Organ. Environ. 2018, 31, 48-69. [CrossRef]

53. Molina-Azorín, J.F.; Claver-Cortés, E.; Pereira-Moliner, J.; Tarí, J.J. Environmental practices and firm performance: An empirical analysis in the Spanish hotel industry. J. Clean. Prod. 2009, 17, 516-524. [CrossRef]

54. Gosselt, J.F.; van Rompay, T.; Haske, L. Won't get fooled again: The effects of internal and external CSR ECO-labeling. J. Bus. Ethics 2019, 155, 413-424. [CrossRef]

55. Mirela, T.A. Quality milestones of the sustainable tourism. Ann. Univ. Oradea Econ. Sci. Ser. 2014, 23, 175-184.

56. Clarke, J. A framework of approaches to sustainable tourism. J. Sustain. Tour. 1997, 5, 224-235. [CrossRef]

57. Aragón-Correa, J.A.; Martin-Tapia, I.; de la Torre-Ruiz, J. Sustainability issues and hospitality and tourism firms' strategies: Analytical review and future directions. Int. J. Contemp. Hosp. Manag. 2015, 27, 498-522. [CrossRef]

58. Myung, E.; McClaren, A.; Li, L. Environmentally related research in scholarly hospitality journals: Current status and future opportunities. Int. J. Hosp. Manag. 2012, 31, 1264-1275. [CrossRef]

59. Ashby, A.; Leat, M.; Hudson Smith, M. Making connections: A review of supply chain management and sustainability literature. Supply Chain Manag. Int. J. 2011, 17, 497-516. [CrossRef]

60. Budeanu, A. Environmental supply chain management in tourism: The case of large tour operators. J. Clean. Prod. 2009, 17, 1385-1392.

61. Font, X.; Tapper, R.; Schwartz, K.; Kornilaki, M. Sustainable supply chain management in tourism. Bus. Strat. Environ. 2008, 17, 260-271. [CrossRef]

62. Hassini, E.; Surti, C.; Searcy, C. A literature review and a case study of sustainable supply chains with a focus on metrics. Int. J. Prod. Econ. 2012, 140, 69-82. [CrossRef]

63. Sigala, M. A supply chain management approach for investigating the role of tour operators on sustainable tourism: The case of TUI. J. Clean. Prod. 2008, 16, 1589-1599. [CrossRef]

64. Zhang, X.; Song, H.; Huang, G.Q. Tourism supply chain management: A new research agenda. Tour. Manag. 2009, 30, 345-358. [CrossRef]

65. Xu, X.; Gursoy, D. A conceptual framework of sustainable hospitality supply chain management. J. Hosp. Mark. Manag. 2015, 24, 229-259. [CrossRef]

66. Carter, C.R.; Jennings, M.M. The role of purchasing in corporate social responsibility: A structural equation analysis. J. Bus. Logist. 2004, 25, 145-170. [CrossRef] 
67. Hollos, D.; Blome, C.; Foerstl, K. Does sustainable supplier co-operation affect performance? Examining implications for the triple bottom line. Int. J. Prod. Res. 2012, 50, 2968-2986. [CrossRef]

68. Kassinis, G.; Soteriou, A. Greening the service profit chain: The impact of environmental management practices. Prod. Operat. Manag. 2003, 12, 386-403. [CrossRef]

69. Teuscher, P.; Grüninger, B.; Ferdinand, N. Risk management in sustainable supply chain management (SSCM): Lessons learnt from the case of GMO-free soybeans. Corp. Soc. Responsib. Environ. Manag. 2006, 13, 1-10. [CrossRef]

70. Svensson, G. Aspects of sustainable supply chain management (SSCM): Conceptual framework and empirical example. Supply Chain Manag. Int. J. 2007, 12, 262-306. [CrossRef]

71. Carter, C.R.; Rogers, D.S. A framework of sustainable supply chain management: Moving toward new theory. Int. J. Phys. Distrib. Logist. Manag. 2008, 38, 360-387. [CrossRef]

72. Wolf, J. Sustainable supply chain management integration: A qualitative analysis of the German manufacturing industry. J. Bus. Ethics 2011, 102, 221-235. [CrossRef]

73. Fassin, Y. SMEs and the fallacy of formalizing CSR. Bus. Ethics Eur. Rev. 2008, 17, 364-378. [CrossRef]

74. Vermeulen, W.J.V.; Ras, P. The challenge of greening global product chains: Meeting both ends. Sustain. Dev. 2006, 14, 245-256. [CrossRef]

75. Vurro, C.; Russo, A.; Perrini, F. Shaping sustainable value chains: Network determinants of supply chain governance models. J. Bus. Ethics 2009, 90, 607-621. [CrossRef]

76. Björklund, M. Benchmarking tool for improved corporate social responsibility in purchasing. Benchmarking Int. J. 2010, 17, 340-362. [CrossRef]

77. Hietbrink, J.J.C.; Berens, G.; Rekom, J.V. Corporate social responsibility in a business purchasing context: The role of CSR type and supplier product share size. Corp. Reput. Rev. 2010, 13, 284-300. [CrossRef]

78. Dai, J.; Blackhurst, J. A four-phase AHP-QFD approach for supplier assessment: A sustainability perspective. Int. J. Prod. Res. 2012, 50, 5474-5490. [CrossRef]

79. Perry, P.; Towers, N. Conceptual framework development CSR implementation in fashion supply chains. Int. J. Phys. Distrib. Logist. Manag. 2013, 43, 478-500. [CrossRef]

80. Vargas Moreno, O. Management of efficient and sustainable purchasing: Model for the supply chain and to break paradigms. Punto de Vista 2014, V, 41-54.

81. Carbone, V.; Moatti, V.; Wood, C.H. Diffusion of SSCM towards a conceptual framework 2012. Supply Chain Forum Int. J. 2012, 13. [CrossRef]

82. Kirce, M.; Seifert, R.W. Dynamic capabilities in SSCM A theoretical framework, 2015. Supply Chain Forum Int. J. 2015, 16. [CrossRef]

83. Ahmad, N.K.W.; de Brito, M.P.; Rezaei, J.; Tavasszy, L.A. An integrative framework for sustainable supply chain management practices in the oil and gas industry. J. Environ. Plan. Manag. 2017, 60, 577-601. [CrossRef]

84. Tavana, M.; Shabanpour, H.; Yousefi, S.; Farzipoor Saen, R. A hybrid goal programming and dynamic data envelopment analysis framework for sustainable supplier evaluation. Neural Comput. Appl. 2016, 28, 3683-3696. [CrossRef]

85. Abduh, M.; Wirahadikusumah, R.D.; Messah, Y. Framework development methodology for sustainable procurement of construction works in Indonesia. In Proceedings of the International Conference on Civil, Offshore \& Environmental Engineering 2018 (ICCOEE 2018), Kuala Lumpur, Malaysia, 13-15 August 2018.

86. Prasad, D.S.; Pradhan, R.P.; Gaurav, K.; Chatterjee, P.P.; Kaur, I.; Dash, S.; Nayak, S. Analysing the critical success factors for implementation of sustainable supply chain management: An Indian case study. Decision 2018, 45, 3-25. [CrossRef]

87. Yin, R.K. Case Study Research: Design and Methods, 5th ed.; SAGE Publications: London, UK, 2014.

88. Eisenhardt, K.M.; Graebner, M.E. Theory building from cases: Opportunities and challenges. Acad. Manag. J. 2007, 50, 25-32. [CrossRef]

89. Roca, M.; Ayuso, S. La RSC en la Cadena de Suministro de las 50 Mayores Empresas en España. Available online: https://www.compromisorse.com/upload/estudios/000/243/RSC-cadena-de-suministro.pdf (accessed on 1 January 2019).

90. Hernández Sampieri, R.; Fernández Collado, C.; Baptista Lucio, P. Metodología de la Investigación, 5th ed.; McGraw-Hill Interamericana: Mexico City, Mexico, 2010; ISBN 978-607-15-0291-9.

91. Glaser, B.; Strauss, A.L. The Discovery of Grounded Theory; Aldine: Chicago, IL, USA, 1967.

92. Guest, G.; Bunce, A.; Johnson, L. How many interviews are enough? Field Methods 2006, 18, 59-82. [CrossRef] 
93. Loeda, R. Grupos Hoteleros en España: Preparándose para tiempos mejores. In Alimarket: Hoteles y Restauración: Hostelmarket; Publicaciones Alimarket: Madrid, Spain, 2014; pp. 30-50.

94. Vallés, M. Entrevistas Cualitativas. Cuadernos Metodológicos; CIS: Madrid, Spain, 2002.

95. Rubin, H.J.; Rubin, L. Qualitative Interviewing. The Art of Hearing Data; Sage: London, UK, 1995.

96. Kvale, S. Interviews. An Introduction to Qualitative Research Interviewing; Sage: London, UK, 1996.

97. Corbin, J.; Strauss, A. Basics of Qualitative Research; Sage: Thousand Oaks, CA, USA, 2008.

(C) 2019 by the authors. Licensee MDPI, Basel, Switzerland. This article is an open access article distributed under the terms and conditions of the Creative Commons Attribution (CC BY) license (http://creativecommons.org/licenses/by/4.0/). 
Article

\title{
Semantic Icons: A Sentiment Analysis as a Contribution to Sustainable Tourism
}

\author{
Juan Pablo Vázquez Loaiza ${ }^{1, *}$, Antonio Pérez-Torres ${ }^{1}$ and Karol Marylin Díaz Contreras ${ }^{2}$ \\ 1 Grupo de Investigación de la Gestión de las Mipymes, Universidad Politécnica Salesiana, \\ Cuenca 010102, Ecuador \\ 2 Salesian Language Institute, Universidad Politécnica Salesiana, Cuenca 010102, Ecuador \\ * Correspondence: jvazquez@ups.edu.ec
}

Received: 29 June 2019; Accepted: 10 August 2019; Published: 27 August 2019

\begin{abstract}
The construction of this research was developed to reflect the way information and communication technologies (ICT) have transformed the tourist distribution channel. This phenomenon has caused, in the first place, the direct interaction between tourists and tourism operators and, second, the appearance of real virtual intermediation actors, a situation that disadvantages the activity of traditional travel agencies and causes immersions in reintermediation processes at risk of compromising its permanence in the market. On the other hand, in a sustainable tourism context, this work represents an opportunity for intermediation agencies in terms of a value management practice as they can develop sustainable promotion processes that promote, for example, the protection of the territory, the conservation of resources, and cultural rescue. Therefore, according to travel agencies, to directly influence the distribution chain, we verified this work to demonstrate the use of digital language as a benefit in the design of sustainable tourism products. Thus, from the methodological discipline of discourse analysis, we created sets of words with semantic content that were valued through the sentiment scales of the Facebook social media network. The results showed that digital promotion favors airline companies and hostels more than a sustainable tourism environment as such. Finally, from the study of probability and density equations, predictive models were used to configure linguistic icons in promoting sustainable tourism.
\end{abstract}

Keywords: semantic analysis; ICT; essential marketing; tourism and sustainability; value and tourism

\section{Introduction}

The gradual growth of tourism can be represented by an annual average of $4 \%$ during the last eight years, which represents a displacement of over 393 million people [1], indicating an opportunity for impulsive tourist activities. It can also favor the progress of countries as it also provides positive impacts to their economy. However, it can also present negative repercussions regarding the protection of the environment due to the development and abrasion of their resources [2,3]. This issue, seen from the perspective of sustainable tourism, must be managed together with the generation of employment and wealth; the conservation of culture and patrimony, social inclusion, and respect to diversity; the efficiency of resources; and the fight against poverty [4].

A great number of researchers have addressed these problems by motivating and proposing the promotion of tourist destinations by distinguishing different aspects. For example, the synergy between faith and religion as a cultural essence for the delineation of strategies [5-7]; the awareness of animal protection that regards them as elements that improve tourism and the economic potential of a place [8-11]; the handcrafting and agricultural impulse [12,13], along with ancestral practices [14,15] as a revitalizing economic alternative in rural areas; the development of gastronomy entrepreneurships as culture value; and the fight against poverty $[16,17]$. 
However, according to an ontological dimension, a tourist destination has to be studied beyond these aspects, and even include psychological and emotional factors due to the fact that sustainable tourism is seen as the result of development, is understood as a response of the actors' needs-travelers and the local community—and their long term projection capacity [18]. All these factors are a necessity for the adoption of marketing strategies [19]. Furthermore, this approach can be consolidated with an approximation of evaluation through economic, environmental, socio-cultural, institutional, and infrastructure indicators [20-22]. Although, according to all stakeholders, there exist some other factors that must be analyzed, but have been minimized, such as the phenomenon of 'overtourism', where some democratic terms need to be integrated into the rights of people [23].

In this research, we describe the theoretical bases and orientations of interest as we try to create a model of social responsibility. Besides, we examine the necessity of generating a conscience in travelers toward respect for the territory, as intermediation agencies are responsible for the promotion of activities both inside and outside its boundaries [24]. Additionally, in the value chain model, the distribution of tourist offerings constitutes a facilitator between tourism operators and tourists, and becomes an important link to spread, drive, and ensure the sustainability of tourist destinations [25]. Furthermore, it has met with resilient arguments to face de-intermediation in the development of social responsibility [26].

The aims are to sustain the structure of tourism intermediation [27] and adapt to the transformations produced by the interference of information and communication technologies (ICT), that some researchers $[28,29]$ have addressed, such as:

1. The increase of the operators and their capacity to establish a vertical and direct relationship with the tourist, thus avoiding intermediation;

2. The necessity of personalization processes undertaken by the intermediaries, thus recovering power and position in the channel;

3. The effectiveness of the construction of products that respond to the tourists' needs; and

4. A transformation in the activity of the final consumer, who demands the implementation of co-creation processes.

Additionally, to maintain sustainability, an evaluation must be made for corporative management to ensure satisfaction among all the interested parties, resource management [30], the reduction of the process, and the integration of the micro, small, and medium businesses to the quality objectives [31] such as quality of service, cost reduction, consistency, and information security.

Thus, to exploit the use of ICT, and give value to the management of tourism intermediation, this research was constructed as a follow-up study of previous work. This defined a technological ecosystem, where the models of business-to-business and business-to-consumers would work on a dynamic of intelligence and internal management based on interaction and knowledge [31]. The intention is that, from an innovation attempt, a logical sequential flow of identification, capture, creation, and diffusion of knowledge that contemplates touristic horizons regarding accessibility, accommodation, attractions, and services is adapted [32]. In addition, instituting it simultaneously as a tool for the value chain to facilitate the management and integration of the actors [33].

It must also be extended not only as a simple solution of optimization but as a contribution to gathering relevant information for decision-making and the definition of strategies. For instance, the information regarding the determination of content associated with travelers and their relationship with the existing attractions within the touristic space [34]. Thus, the aim is to try not to reach a critical status where the traveler wastes their traveling experience by seeing themselves embedded by the excessive use of technology, obtaining, in this way, a false perception and satisfaction, and causing isolation of the individual or becoming a case of e-lienation [35] due to loss of authenticity [36-38] and the intra-personal authenticity destroyed by the technophilia [39].

As a practice of social manifestation, consequences are spread through social networks, becoming significant input for marketing studies and merchandising planning, and should be managed through 
the adoption of technology [40]. In this research, social and environmental variables were an important alternative contribution within the 'triple bottom line' (Guidance framework for measuring business objectives that considers economic, environmental and social aspects [41]) [42]. In this way, sustainability is not only provided by the business, but also accomplishes different precepts of the administration and preservation of resources for future generations, attending to the need for sustainability for the development of society [42].

Hence, the actions that the business must perform through social networks must consider an implicit benefit for the travelers; in addition, the interaction and immediacy of response can be formalized as they are features that affect the brand attitude and corporate confidence [43]. Furthermore, they are configured in hedonist forms for tourists and associated to use the channel and income for the business [44]. In addition, they indicate that in the context of tourism, a large volume of information prevails that is dependent on effective communication [45]. In this research, acculturation manifestations are represented [46] as derived from the social impact exteriorized through stress factors, adaptation processes, and negative emotions $[47,48]$ as well as integration and polarization facilitators, which transform the society and create new consumption opportunities [49].

Therefore, to discover and understand the meaning of the digital social expressions that go beyond simple words, this research is attached to the horizon of discourse analysis (DA), as the comprehension of the social dictions of natural language and their meanings are promoters of a real construction of the society [50,51]. Moreover, as described in [52], it helps to establish a logical inferential structure for accessing knowledge as a contribution to Aristotle's logic, so that language analysis explains the nature of the environment and facilitates the detection of requirements [53]. Arguments of special interest for this work try to offer an opportunity of applied investigation and practical contribution to innovation in intermediary tourism agencies.

Likewise, the importance of lexicon and discourse, according to [54], favors facing the control that it exercises on any society, as demonstrated in the investigation conducted in [55]. This fact was intended to be transformed with this investigation, ensuring that control favors intermediary agencies as a conciliating entity between supply and demand. It is then important to delve into the semantics to discover the relationships that, from the inspection of the 'corpus', facilitate the configuration of new statements of values adapted to a reality [56], that are elaborated and guided by cognitive structures [57] that define the linguistic signs as the representation of a tourist's object of interest. Therefore, to benefit the results in this research, and according to [58], which acknowledges the contribution of DA to the analysis of conflicts in economic, political, anthropological, and psychological environments, it is expected to be the pragmatic basis of a new approach into the paradigm of sustainable tourism.

Additionally, it is important to discover if digital social expressions represent, in some measure, the desires, beliefs, and values of a society and the tourist environment. They must respond, from a cognitive line to an enforceable action from prior planning that understands that the textual and contextual structure allows for the formulation of the message in the receptor, giving them a fast and convenient meaning [59]. However, their subjectivity must be registered in the subjectivity of the social context-understood as the tourist environment in this study—and discourse [60]. All of this is to recognize the 'systems of dispositions', which are latent in the environment and the social structure [61], so that it can reaffirm itself and cause a transformation, benefiting sustainable development if it is necessary.

However, why is it important to analyze the text in tourist publications? Because answers are given, mainly the ones regarding the studied theories by [62], who highlighted that: (a) Language is constituted as a graphic system that expresses the social behavior and its knowledge as semiology [63]; (b) through linguistic registers, the variations of expression are evidenced, so prediction is manifested; and (c) semantics contain the meanings of social context. For this reason, and in agreement with [64], these signs represent the relationship or influence of an object-that is expected to be the tourist environment-and an interpreter, who is a traveler or tourist. However, as suggested by [65], 
they naturally express physical phenomena, for example, a sunset or a dance, or unconscious human behaviors that, by the way, will serve to make sense of something that is not consciously conceived [66].

Finally, this research will serve to help tourism intermediaries manage sustainable development. Although it acknowledges the contributions that can be obtained through marketing practices, it is not oriented to the centralization of common management that considers the necessities of the visitors versus the products/services to motivate purchasing and consumption processes per se $[67,68]$. Nor does it express an analysis of the environment, and through the harnessing of power, the public relations and alliances with suppliers [69], but strives to reach sustainable development such as the one underpinned in the essential marketing paradigm that interprets the behavior and meanings associated with codes and social archetypes. This is so that a perceptual concept can be constituted by the physical concept and the imaginary concept, which comprehends cultural diversity, ethnic groups, geography, and socio-economy [70] to such an extent that symbolic goods, whose commercial value develops an understanding of their cultural values, can be defined [71].

In summary, because social networks are a communication trend and interaction with them promotes social transformation, the purpose of this research was to understand the reality that travel agencies must provide to improve the sustainable development of tourism. This requires the promotion of tourist destinations as a contribution to the value chain. Moreover, due to symbolic interactionism, where individual behavior is outlined over the meaning of things [72], it might be significant to promote a proposal that can sensitize the tourist toward an emotional connection with the territory and the country that they visit.

Thus, after the application of discourse analysis techniques, semantic analysis, and the analysis of emotions, this work tried to prove if the travel agencies promoted sustainable development practices, which, from their meaning, were of interest to the tourists. However, even if this research could identify linguistic icons associated with the tourist context, they would be constituted as a commercialized success of the offer, especially for airlines and accommodation providers. This finding motivates the continuation of further investigation that reviews the reality of the benefits of a sustainable environment.

\section{Fundamental Theories of Research and Sustainable Tourism}

This section supports theories that connect by shaping an approach toward sustainable tourism from the management of intermediation in the exploitation of digital content. In this sense, first, it is emphasized that thanks to the incursion of ICT, the traditional model of tourist intermediation has been transformed since agencies and operators have witnessed the arrival of specialist distribution agents through digital channels [29]. In addition, operators have found opportunities for direct negotiation with travelers, dispensing with the services of intermediaries. This reality has forced intermediaries to outline strategies to strengthen and compete in a way that favors their permanent place in the market $[73,74]$.

Therefore, by trying to facilitate new management models through digital technological adaptation, the research adheres to the value theory as it allows for the design, definition, and delivery of products as an intention of competitiveness [75] and differentiation, that is also conceived in a generation of awareness for the protection of the territory $[24,25]$. However, it must also contribute to the intelligent integration of the actors in the distribution chain, which involves the generation and exchange of information and knowledge $[26,27,33,76]$. In addition, it should help improve the tourist experience as an essential activity [77] by also encouraging the protection of resources, the rescue of culture, and sources of employment [2-17].

Therefore, if virtual channels are considered as the scenario in which the intermediation action takes place, it is appropriate to assume that the digital content should act as an input entity for the behavior analysis, as the information delivery of a sustainable message that, once again, improves travel practice and promotes the development of the tourist destination.

Consequently, this purpose was carried out through the practice of discourse analysis. This is mainly because digital channels, and mainly virtual social networks, encourage the exchange of 
information that demonstrates the behavior and expression of society. Manifestations through which it was sought to establish the basis for intelligence processes that, thanks to the theory of sets, could denote relationships between axiomatic elements [78] consisting of linguistic components and an assessment understood from the analysis of feelings.

Derivations that can ultimately be inferred in concept from the paradigm approach of digital marketing, while provoking a practice in such a way that the negotiator can build a sufficiently striking message, are products of the co-creation of knowledge [44,49]. It not only seeks to only close a sale, but to offer something that causes a truly pleasant feeling in the consumer as a new cultural reality by highlighting the characteristics of the object $[70,71]$ that, in this case, are semantically constituted in the cultural, natural, and social properties and values of the tourist environment [50-53,59-66].

\section{Materials and Methods}

\subsection{Discursive Methodological Configuration}

The discursive analysis of the text in this research was laid out through a scheme suggested by [79] that is illustrated in Figure 1. It represents sustainable tourism as a conceptual concept supported by the essential marketing and value theory as key concepts for development. Furthermore, for the application of the method, discourse analysis is the main discipline in an approach to social semiotics. Finally, the own structures of the language will be analyzed in distinct to the components of the grammatical phrases.

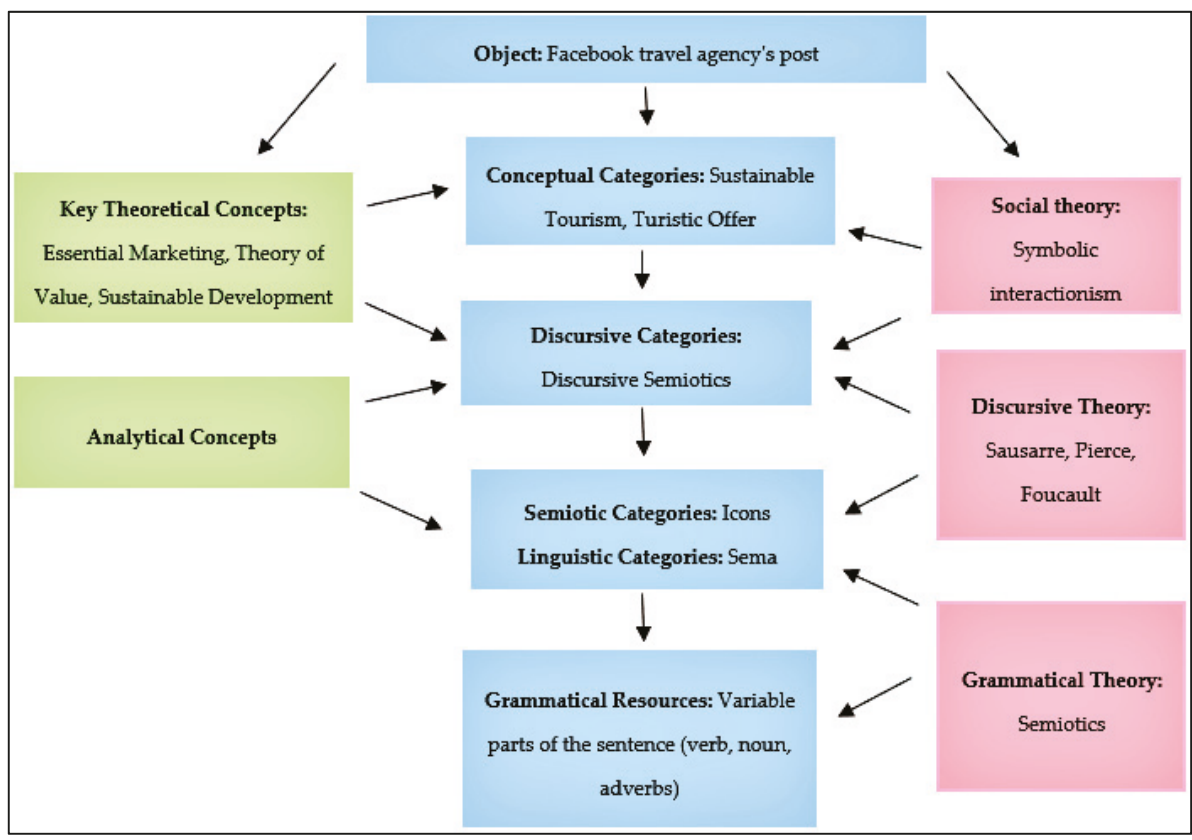

Figure 1. Discursive methodological configuration.

\subsection{Discursive Analysis}

The logic of discursive analysis was directed through procedures supported by the computing linguistics of (1) the object of study, for example, posts by Facebook travel agencies, as input data; (2) the morphology, semantics, and pragmatic knowledge as actions of the computing processing; and 
(3) the predictive icons of the language as output text. This process was adapted from [80] with the following phases:

A computing morphological analysis that:

- $\quad$ Automatically extracts posts made by travel agencies on Facebook. To do this, NCapture was used, which is a web browser extension of the Nvivo software. From here, the universe of the words to be studied was created.

- From the universe, words were classified by language, numeric characters, hashtags, and another called 'trash' that corresponded to those that did not provide semantic information such as symbols and email addresses as well as those with a length of one character as they did not represent semantic content.

- Produced a second classification that distinguished customer names, street names, prices expressed in letters, web addresses, and words like 'cell', 'cel', or 'tel' as they only refer to telephone information provided for contact, and consequently, they do not affect the semantic content.

- $\quad$ Spelling mistakes were corrected, mainly the ones regarding the use of tildes (e.g. the word 'acomodacion' (accommodation) was changed to 'acomodación'. Additionally, some compound words were identified and unified (e.g., the words 'Abu' and 'Dabi', which appeared separated were put together, resulting in 'Abu Dabi'.)

- A group of words that were called 'irrelevant' was recognized. Here, the grammatical prepositions (e.g., 'por' (by), 'para' [for], 'entre' (between)), articles, and conjunctions (e.g., 'pero' (but), 'porque' (because)) were included.

- Concluded with the conformation of elemental grammatical units through the free online lemmatizer developed by the Group of Data Structures and Computing Linguistics of the University of Las Palmas (http://www.gedlc.ulpgc.es/investigacion/scogeme02/lematiza.htm).

A semantic analysis that from the posts:

- Coded the meaning of the words, without distinction of the association of the tourist context, through the Nvivo software. Here, the nouns, adjectives, verbs, and adverbs were identified. Thus, what this research intended to do was to represent the tangible elements associated with the perception of the senses with nouns, quality of the feelings toward the nouns with adjectives, the exercise of action with verbs, and the conditions and circumstances linked with the ones above-mentioned with adverbs.

- Conducted a morphosyntactic analysis of these words, according to the different contexts of a sentence in the case of homonymy and polysemy through the Stilus (https://www.mystilus. com) software.

A pragmatic analysis that:

- $\quad$ Related the semantic content of the tourist environment through the associations of nodes as shown in Figure 2.

- $\quad$ This analysis used the Chi-Square $\left(X^{2}\right)$ statistical test with a significance level of $\alpha=0.05$, where the hypothesis to be tested was the association between the grammatical categories and the nodes of the tourist context if the p-value was superior to the critical value.

An analysis of feelings was made to validate the lexicon of touristic words in order to undertake a simulation on how much these words could be attractive to tourists, understanding that, according to [60], an expression of feeling coming from an individual impulses or impacts on the feelings of a collectivity; therefore, it is important to identify the positive words in different posts with the purpose of provoking positive semantic impacts. To accomplish that expressed above:

- Within the facilities of a travel agency, clients were observed who requested information motivated by undertaking an intention to travel. Of these, 20 volunteers of legal age, regardless of gender, 
purchasing power, or interest in tourism products, digitally evaluated the words of the lexicon. To do this, they used the sentiment scale that Facebook configures to assess the publications and resembles a 6-point Likert scale [81,82]. For instance, $1=$ Angry $\odot ; 2=\operatorname{Sad} \odot ; 3=$ Amazed $\bullet$; $4=$ Like 3 ; 1 I enjoy ; and 6 = I love 0 .

- To achieve a level of concordance, Kendall's W statistical test (Equation (1)) was applied and calculated using Statistical Package for the Social Science (SPSS) software for a value of W acceptance close to 1.

$$
W=\frac{12 \sum_{i=1}^{k} S_{i}^{2}-3 n^{2} K(K+1)^{2}}{n^{2} K^{2}(K-1)}
$$

where $K$ is the number of characteristics subjected to evaluation; $N$ is the number of elements of study; and $S$ is the addition of the marks obtained in each of the evaluated characteristics.

- The calculation algorithm found the best combination of judges for an acceptable value minimum of $\alpha=0.7$. The results were obtained by calculating the highest value between combinations from $2,3,4,5 \ldots n$ evaluators.



Figure 2. Pragmatic knowledge representation. Adapted from PLANDETUR 2020 (Design of the Strategic Development Plan of Sustainable Tourism for Ecuador. https://www.turismo.gob.ec/wpcontent/uploads/downloads/2013/02/PLANDETUR-2020.pdf).

\subsection{Predictive Analysis}

As a complement oriented to analysis intelligence, this research intended to discover the linguistic icons from the lexicon. This, according to [83], defines the horizon of the marketing expansion by means of placing each word into different ranks that follow the vital cycle of marketing via the knowledge of (a) the novelty, (b) the trend, (c) the new fashion, (d) the top, (e) the consolidation, and (f) the obsolescence. To do this, the probability thresholds considered are shown in Table 1.

In this sense, the normality of the frequencies was first studied through the Kolmogorov-Smirnov $(\mathrm{K}-\mathrm{S})$ test, with a significance level $\alpha=0.05$. In this way, if the $\mathrm{p}$-value obtained for the categories was higher than the significance level, the normality of the distribution would be accepted. Subsequently, the function of the density and the definite integral (Equation (2)) was undertaken with the study of the goodness-of-fit applied through the coefficient of determination $R^{2}$ to represent the behavior of the linguistic expressions and test the forecast model of each word set.

$$
P_{w}(a \leq X \leq b)=\int_{a}^{b} f(x) d(x)=F(b)-F(a)
$$


where $P_{w}$ is the probability of the word; $a$ is the lower limit of the area ( 1 for all cases); and $b$ is the upper limit of the area, which is the frequency value of the word.

Therefore, from the density function, by integrating the lower limits of 1 and upper limit equal to the frequency value of the word, the space in which each word would be located according to the horizon of market expansion could be determined later. The purpose for which, through Chebyshev's Theorem (Equation (3)) to find the probability of occurrence of an event for any random variable $X$ as a function of $k$ standard deviations concerning the arithmetic mean $\mu$, is detailed in [84].

$$
P(u-k \sigma<X<u-k \sigma) \geq 1-\frac{1}{k^{2}}
$$

where $K$ is the to the threshold of distribution of the area under the curve meeting $-3 \leq k \leq 3$; $\mu$ is the arithmetic mean; $\sigma$ is the standard deviation; and $X$ is the random variable word such $X \in S$.

Table 1. The threshold of probability for marketing expansion.

\begin{tabular}{ccc}
\hline Status & Area From & Area Up \\
\hline The novelty & $-3 \mathrm{k}$ & $-2 \mathrm{k}$ \\
The trend & $-2 \mathrm{k}$ & $-1 \mathrm{k}$ \\
The new fashion & $-1 \mathrm{k}$ & $\mu$ \\
The top & $\mu$ & $1 \mathrm{k}$ \\
The consolidation & $1 \mathrm{k}$ & $2 \mathrm{k}$ \\
The obsolescence & $2 \mathrm{k}$ & $3 \mathrm{k}$ \\
\hline
\end{tabular}

\subsection{Study Case}

To carry out the study and application of the methodology, the city of Cuenca in Ecuador $\left(2^{\circ} 53^{\prime} 51^{\prime \prime} \mathrm{S}\right.$, $79^{\circ} 00^{\prime} 16^{\prime \prime} \mathrm{W}$ ) was taken as a study case, with the purpose of contributing to the improvement of tourist activities in a city listed as a Cultural Heritage of the World site, thanks to its architectural, archeological, and natural potential. This city has received a World Travel Award in 2017 as the lead travel destination for short holidays in South America. In addition, the consolidation of the city as a sustainable destination is sought.

Conversely, reasons to use intermediation have responded to the fact that during the last three years, according to what has been observed by the author in the given inventory by the Ministry of Tourism of Ecuador, the travel agencies, operators, and wholesalers have registered an increase regarding the cessation of business, a fact that is affecting the economic development of the city. For this reason, it is expected that the results obtained in this research could provide development pathways through the practice of smart technological alternatives. Likewise, according to previous diagnostic studies, it is evident that businesses in this area are not strong about their digital practices for the promotion of their different offers due to:

1. The quality of their websites, which are deficient, as seen from the promotional content and their functionality [85].

2. The lack of estimates regarding basic management oriented to optimization practices in different search engines [86].

3. A lack of knowledge about the administration of social networks [31].

4. An average e-readiness of three on a scale of 1 to 5. This fact confirms the above-mentioned, aside from the lack of interest in the starting processes oriented to the adoption of smart digital technologies [31,87].

From this reality and in concordance with the inventory of tourism intermediation businesses in 2018, 151 travel agencies were recognized. However, of the 86 travel agencies who undertook activities on Facebook, only 49 had an official fan page, which limited the automatic extraction process with NCapture, and 22 demonstrated the constant activity with a minimum of 100 monthly posts. 
The number of entities was finally used for the analysis of their posts over a period between 1 January and 31 December 2018. During this period, travel agency administrators made 6057 posts, thus forming a total universe from which, with the Analysis Stats 2.0 software, a finite-sample was applied with a $95 \%$ confidence level and a margin of error of 1\%. Finally, we determined a sample size of 3714 posts (D).

Thus, finally the sampling was conducted at convenience and only studied the companies with a total number of posts that exceeded 100 monthly, because at the discretion of the digital marketing experts $[88,89]$, a frequency between two and five daily posts causes interactivity between the client and the company and substantially improves the return on investment. This added 5412 advertising discourses (X), which was 1968 more than the sample size, and corresponded to 22 businesses. Subsequently, to establish the percentage of the proportion of $69 \%$ between $\mathrm{D}$ and $\mathrm{X}$, the number of posts to study for the business was determined, as shown in Table 2.

Table 2. Sampling of posts.

\begin{tabular}{ccc}
\hline Enterprise & Posts (Q) & Post by a Company (69\%) \\
\hline E1 & 589 & 404 \\
E2 & 340 & 233 \\
E3 & 110 & 75 \\
E 4 & 125 & 86 \\
E 5 & 329 & 226 \\
E 6 & 219 & 150 \\
E 7 & 384 & 264 \\
E 8 & 259 & 178 \\
E 9 & 127 & 87 \\
E 10 & 149 & 102 \\
E 11 & 157 & 108 \\
E 12 & 288 & 198 \\
E 13 & 125 & 86 \\
E 14 & 254 & 174 \\
E 15 & 245 & 168 \\
E 16 & 111 & 76 \\
E 17 & 281 & 193 \\
E 18 & 117 & 80 \\
E 19 & 163 & 112 \\
E 20 & 109 & 75 \\
E 21 & 677 & 465 \\
E 22 & 254 & 174 \\
\hline
\end{tabular}

\section{Results}

After applying the methodology, the obtained results were as described below. These are mainly represented through the set theory to facilitate understanding.

\subsection{Morphological Analysis}

Some base sets were constructed for the classification of terms and to facilitate the morphological analysis, the results of which are presented in Figure 3, with some samples of the content of these sets shown in Figure 4.

Set $\mathbf{U}=$ \{all the terms included in the posts $\}$

Set $\mathbf{S}=\{$ Spanish language words $\}$

Set $\mathrm{E}=\{$ English language words $\}$

Set $\mathbf{I}=\{$ Italian language words $\}$

Set $\mathbf{F}=\{$ French language words $\}$

Set $\mathbf{A}=\{$ Austrian language words $\}$

Set $\mathbf{N}=\{$ numeric characters chain $\}$ 
Set $\mathbf{H}=\{$ hashtags $\}$

Set $\mathbf{T}=\{$ trash terms $\}$

Set $\mathrm{X}=$ \{length 1-character terms $\}$

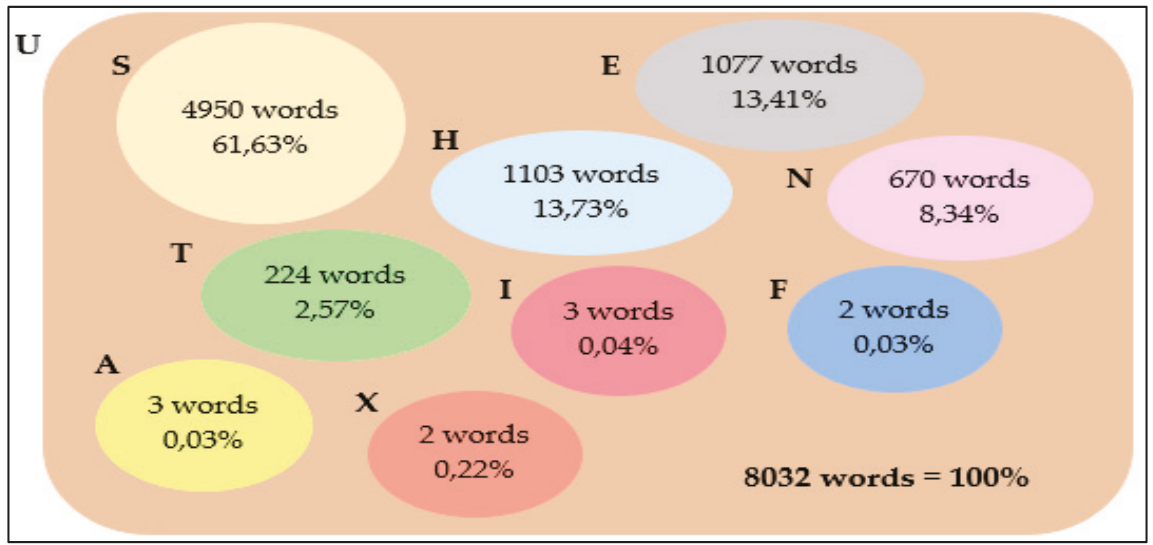

Figure 3. Word sets.



(a)



(b)

Figure 4. Subsets samples. Panel (a) shows the Spanish word set (S), and panel (b) shows the trash word set $(\mathrm{T})$.

From the obtained data, the study focused on the Spanish word set because the setting of this research mainly expressed the information in this language and because the size of the information was mainly in Spanish. Therefore, from the Spanish set (S), new subsets were configured as shown in the following.

$\mathbf{S}^{\prime}=$ (words that represent names of customers, names of streets, web addresses, and prices)

Some examples of words included in this set were: 'www. Teléfonos, Gabriel' (proper name referred to a customer and no to a character associated with the environment), 'Córdova' (derived from Presidente Córdova street).

$\mathbf{S}^{\prime \prime}=$ (words with corrected spelling mistakes)

Examples of this set were the words: Iguazu (it should be Iguazú), 'gastronomico' (it should be 'gastronómico').

$\mathbf{R}=$ (articles, prepositions, and grammatical conjunctions).

$\mathbf{S}_{2}=$ independent words that form compounds of two words $\}$ 
Examples of words included in this set are the words 'Abu' and 'Dabi', which appeared independently when the real word is 'Abu Dabi'.

$\mathbf{S}_{3}=$ \{independent words that would form a compound of three words\}

Examples of words included in this set are the independent terms 'Amari', 'Havodda', and the 'Maldives' that would form the compound word 'Amari Havodda Maldives', and refers to a proper name of a place of accommodation.

$\mathbf{S}_{4}=$ independent words that would form a compound of four words $\}$

Examples of words included in this set are the independent words 'Barceló', 'Maya', 'Grande', and 'Salinas', that would form the compound word 'Barceló Maya Grande Salinas', which also refers to a proper noun of a place of accommodation.

$\mathbf{S}_{5}=$ independent words that would form compound terms of five words $\}$

Some examples of this set are the independent words 'Museo', 'de', 'Cera', 'Madame', 'Tussauds' that would form the word phrase 'Museo de Cera Madame Tussauds', which refers to an attraction in the United Kingdom.

$\mathbf{S}_{6}=$ Independent words that would form phrases of six terms $\}$

Examples of words that were found in this set include 'Holiday', 'Inn', 'Express', 'Miami', 'Doral', 'Airport'. Written together, they make the phrase 'Holiday Inn Express Miami Doral Airport', which is also a place of accommodation.

S7 $=$ irrelevant words $\}$

S2a $=$ compound words of two terms $\}$

S3a $=\{$ compound words of three terms $\}$

$\mathbf{S} 4 \mathbf{a}=\{$ compound words of four terms $\}$

$\mathbf{S} 5 \mathbf{a}=\{$ compound phrases of five terms $\}$

$\mathbf{S} 6 \mathbf{a}=\{$ compound phrases of six terms $\}$

To count the number of words and obtain the total of terms for the subsets $\left(S_{2 a}\right),\left(S_{3 a}\right),\left(S_{4 a}\right),\left(S_{5 a}\right)$, and $\left(S_{6 a}\right)$, Microsoft Excel was used as shown in Equation (4). In this way, the final presentation of the (S) set and its subsets can be illustrated in Figure 5:

$=\operatorname{IF}($ LEN $($ TRIM(range_cell) $)=0 ; 0 ;$ LEN $($ TRIM(range_cell) $)-$ LEN (SUSTITUIR (range_cell; "“";"'”))) + 1

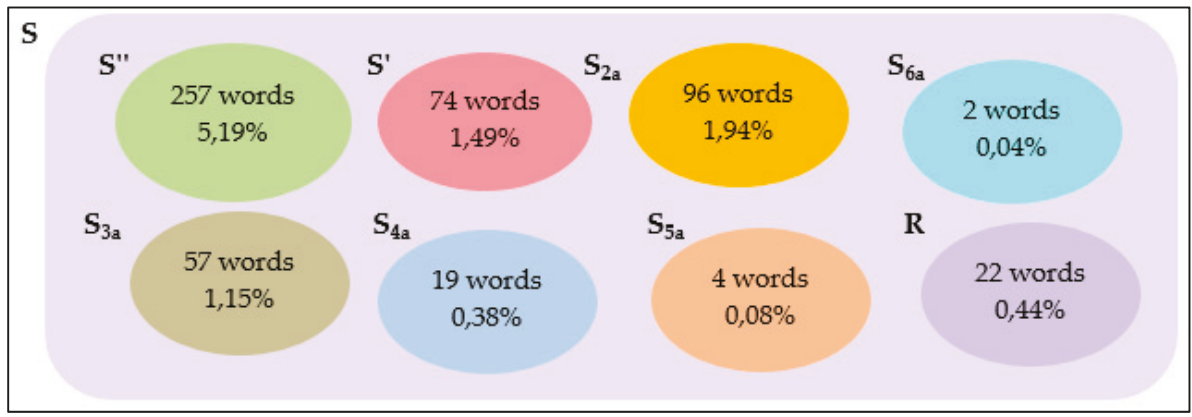

Figure 5. Spanish word subset distribution.

Thus, by operating the (S) set and all its subsets through Equation (5), the relative set (W) was built. Here, the lemmatization process was applied after identifying the canonical or lexeme forms, consolidating the last set, named Lexicon, with 1999 validated terms for the semantic content.

$$
W=\left(S \backslash S^{\prime} \backslash S^{\prime \prime} \backslash S_{2} \backslash S_{3} \backslash S_{4} \backslash S_{5} \backslash S_{6} \backslash S_{7} \backslash R\right) \cup S_{2 a} \cup S_{3 a} \cup S_{4 a} \cup S_{5 a} \cup S_{6 a}
$$




\subsection{Semantic Analysis}

In the Nvivo program, the words of the lexicon were coded according to four grammatical categories, whose distribution is shown in Table 3.

Table 3. Semantic grammatical distribution.

\begin{tabular}{ccc}
\hline Set & Number of Words & Percentage of the Lexicon \\
\hline Adjectives & 296 & $15 \%$ \\
Adverbs & 39 & $2 \%$ \\
Nouns & 1396 & $70 \%$ \\
Verbs & 268 & $13 \%$ \\
\hline
\end{tabular}

Additionally, the Stilus program was simultaneously used to avoid grammatical disambiguation and identify cases of polysemy and homonymy, as shown in Figure 6. The result would permit, not only the representation of a grammatical category but also the establishment of an adequate sense of the relationship with the other components of the sentence. Therefore, for instance, a term could be classified as an adjective, noun, or any verb form; however, when discovering their relationship in the 'corpus' of the sentence, it would be convenient to code it as a noun.

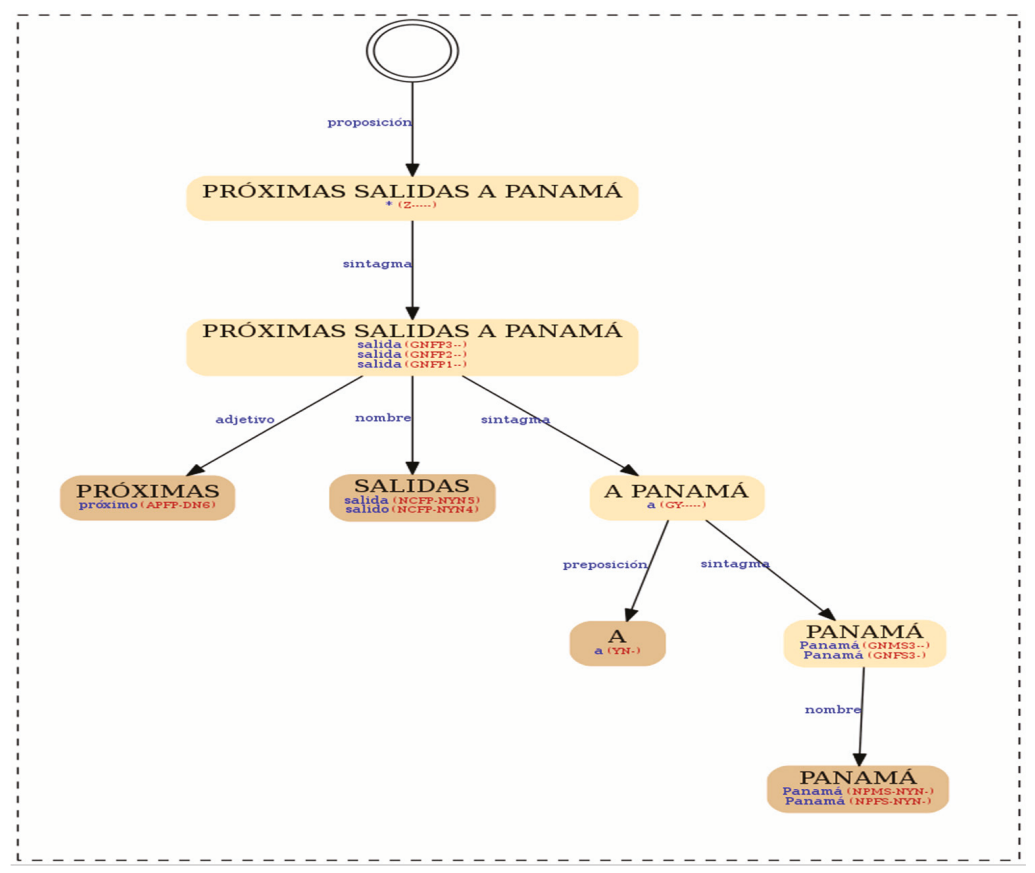

Figure 6. Example of grammatical disambiguation.

Finally, complementing the frequency distribution from the grammatical categories, the codification concludes by providing the repetition frequency per word, by following with Figure 7 . These results refer to the apparent preference of the intermediaries to mainly promote air transportation services and hosting. This situation would not place sustainable tourism as the fundamental core and purpose because the words regarding values, identity, culture, and attractive spaces that the countries offer, showed a low repetition. For example, 'airport' was mentioned 840 times, in contrast 
with 'Galapagos', which only appeared 118 times, 'happiness' appeared 60 times, 'culture' appeared 17 times, and 'archeology' or 'community', seven times.

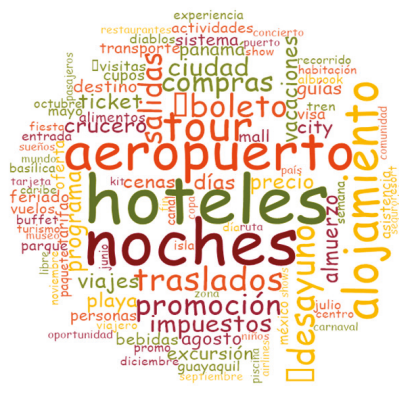

(a)

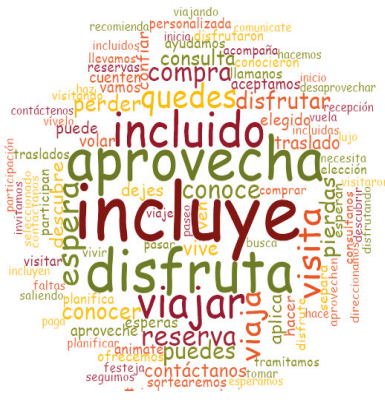

(b)



(c)

Figure 7. Words frequency. Panel (a) shows the nouns, panel (b) represents the verbs, and panel (c) illustrates the adjectives.

\subsection{Pragmatic Analysis}

To provide an additional sense to the corpus, the semantic content was compared with the tourist context. The results provided the grammatical categories that had the most influence in the interpretation of the message, as shown in Table 4.

Table 4. Relation of grammar sense versus touristic context.

\begin{tabular}{llllll}
\hline Tourism Context Variables & $\mathbf{X}^{2}$ & df & Critical Value & $\begin{array}{l}\text { Bilateral Asymptotic } \\
\text { Significance }\end{array}$ & Excluded Categories \\
\hline Sustainability & 26.69 & 16 & 26.2962 & 0.045 & Adverbs not relevant \\
\hline Touristic circuit & 336.48 & 16 & 26.2962 & 0.000 & $\begin{array}{l}\text { All grammatical categories and } \\
\text { circuit values are relevant }\end{array}$ \\
\hline Product & 796.85 & 40 & 55.7585 & 0.000 & Adverbs not relevant \\
\hline Product: Ecotourism & 150.80 & 8 & 15.5073 & 0.000 & Natural Reserves not relevant \\
\hline $\begin{array}{l}\text { Product: Cultural } \\
\text { Product: Sports and }\end{array}$ & 60.96 & 16 & 26.2962 & 0.000 & $\begin{array}{l}\text { Shamanism and adverbs not } \\
\text { relevant }\end{array}$ \\
\hline $\begin{array}{l}\text { Product: Health tourism } \\
\text { Prenture tourism }\end{array}$ & 10.08 & 2 & 5.9915 & 0.006 & $\begin{array}{l}\text { Adjectives and adverbs not } \\
\text { relevant }\end{array}$ \\
\hline
\end{tabular}

$\left({ }^{*}\right)$ Relationship hypothesis rejected. Therefore, the grammatical content does not provide a relationship with the tourist context.

In this sense, the results are interesting because, from a semantic point of view, nouns are the words that provide a strong relationship. Nouns provoke a feeling in tourists to start or develop a travel experience since they indicate the positive orientation of the speaker [90]. Nevertheless, other words should be outlined for the rescue and promotion of each country's identity and values, and to guide it toward sustainability and development.

\subsection{Sentiment Analysis}

Once the grammatical relationship and the touristic content of the significant relationship were discovered, this research tried to find the words that, from a cognitive order, would provoke a greater satisfaction or pleasure in the tourist. Consequently, the sentiment evaluation granted sets of words that were more attractive in terms of: 
Recognizing the criteria similarities toward the valuation that the judges would give to the nouns, adjectives, and verbs. When a p-value close to zero was obtained for all the categories, as shown in Table 5, it reflected non-significance for Kendall's W. Consequently, several iterations were performed until an acceptable coherence value was obtained, as shown in Tables 6-8. This was undertaken due to the wide number of variables, which might suggest subjectivity, thus impeding the ability to obtain an acceptable coherence value.

Table 5. Criteria similarity according to grammatical categories.

\begin{tabular}{ccc}
\hline Grammatical Category & Kendall's W Coefficient & \# Judges \\
\hline Nouns & 0.133 & 20 \\
Verbs & 0.195 & 20 \\
Adjectives & 0.116 & 20 \\
\hline
\end{tabular}

Table 6. Similarity coefficient for nouns.

\begin{tabular}{ccc}
\hline The Best Combination of Evaluators & Kendall's W Coefficient & \# Judges \\
\hline E3-E7 & 0.522 & 2 \\
E3-E7-E17 & 0.534 & 3 \\
E3-E7-E17-E13 & 0.481 & 4 \\
E3-E7-E17-E13-E16 & 0.628 & 5 \\
E3-E7-E17-E13-E16-E18 & 0.690 & 6 \\
E3-E7-E17-E13-E16-E18-E6 & 0.663 & 7 \\
E3-E7-E17-E13-E16-E18-E6-E2 & $0.719 *$ & 8 \\
\hline
\end{tabular}

$\left.{ }^{*}\right)$ Combinations that meet the similarity criterion for $\alpha=0.70$.

Table 7. Similarity coefficient for verbs.

\begin{tabular}{ccc}
\hline Best Combination of Evaluators & Kendall's W Coefficient & \# Judges \\
\hline E4-E13 & 0.380 & 2 \\
E4-E13-E3 & 0.209 & 3 \\
E4-E13-E3-E6 & 0.423 & 4 \\
E4-E13-E3-E6-E11 & 0.537 & 5 \\
E4-E13-E3-E6-E11-E15 & 0.627 & 6 \\
E4-E13-E3-E6-E11-E15-E8 & $0.732 *$ & 7 \\
E4-E13-E3-E6-E11-E15-E8-E2 & $0.767 *$ & 8 \\
E4-E13-E3-E6-E11-E15-E8-E2-E9 & $0.802 *$ & 9 \\
\hline
\end{tabular}

$\left.{ }^{*}\right)$ Combinations that meet the similarity criterion for $\alpha=0.70$.

Table 8. Similarity coefficient for adjectives.

\begin{tabular}{ccc}
\hline Best Combination of Evaluators & Kendall's W Coefficient & \# Judges \\
\hline E7-E13 & 0.356 & 2 \\
E7-E13-E10 & 0.401 & 3 \\
E7-E13-E10-E15 & 0.497 & 4 \\
E7-E13-E10-E15-E18 & 0.586 & 5 \\
E7-E13-E10-E15-E18-E6 & 0.712 & 6 \\
E7-E13-E10-E15-E18-E6-E9 & $0.808 *$ & 7 \\
\hline
\end{tabular}

$\left.{ }^{*}\right)$ Combinations that meet the similarity criterion for $\alpha=0.70$.

From the valuations, the methodological trial finally provided new subsets of words that were grouped according to the sentiments shown in Figure 8. These grant a significant derivation and might represent the linguistic icons that should be used to promote sustainable tourism. This miscellaneous constitutes an important input of analysis in which to plan strategic marketing. Similarly, travel agencies might strengthen their business through the promotion of transportation and accommodation. 
Tourists might be attracted by the promotions if nouns were used such as 'love', 'happiness', and 'friendship'; and adjectives like 'anthropological', 'ancestral', 'fun', 'exclusive', and 'delicious'.



Figure 8. Set distributions according to the sentiment evaluation.

\subsection{Predictive Analysis}

The study conducted through K-S, as shown in Table 9, demonstrated that the frequency distribution for the grammatical categories was not adjusted to a homogenous reality with the significance level of $\alpha=0.05$. This confirms the frequency polygons in Figures 9-11, which would justify the use of Chebyshev's Theorem because it is independent of the type of distribution that the variable has [82]. Therefore, to accomplish the predictive analysis, the density functions were built through the equation tests of tendency, and the results are shown in the mentioned figures that correspond to those functions where the best level of adjustment for the determination coefficient was obtained as $\mathrm{R}^{2}$.



Figure 9. Adjective frequency distributions. Six-degree polynomial function. 




Figure 10. Noun frequency distributions. Potential function.

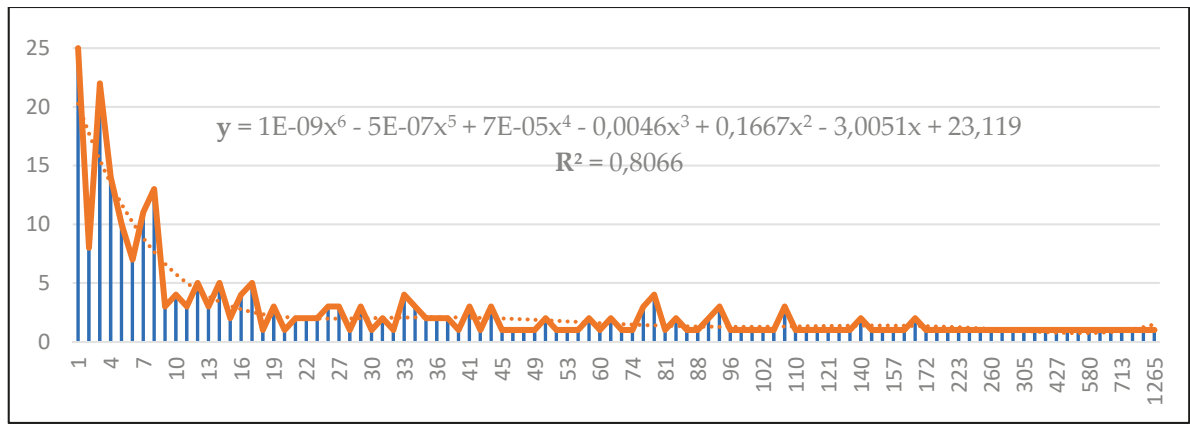

Figure 11. Verb frequency distributions. Six-degree polynomial function.

Table 9. Normality test.

\begin{tabular}{ccc}
\hline Categories & Z Kolmogorov-Smirnov & p-Value \\
\hline Adjectives & 0.352 & 0.000 \\
Nouns & 0.376 & 0.000 \\
Verbs & 0.389 & 0.000 \\
\hline
\end{tabular}

Where, after the determination of probabilities through density functions, they were obtained for the noun, adjective, and verb sets, and the position in which each word was placed on the marketing horizon. The results are exemplified in Table 10 and correspond to the terms that, from the analysis of feelings, received the highest assessment (love) that the tourist intermediary should try to reach the threshold, called 'the top'.

In this way, the usefulness of the study allows for the recognition of words both in feeling and threshold of probability that could benefit advertising practices. Thus, for example, it could be assumed that the combination 'Dream' + 'Enjoy' + 'Aquatic' + 'Ancestral', would attract the attention of tourists and possibly represent benefits for both the intermediary company and the territory as it derives an approximate publication with the value and focus of sustainable tourism.

On the other hand, after the application of the prediction and probability models, words were discovered, for example, that turned out to be located at a threshold of 'the novelty' and that casually receive the best evaluation of feelings. This means that, after the study, travel agencies can use words in their advertising messages that, while being attractive to customers, also promote sustainable tourism. 
Table 10. Predictive analysis.

\begin{tabular}{|c|c|c|c|c|c|}
\hline Word & Set & Frequency & Probability Value & $\begin{array}{c}\text { Probability } \\
\text { Threshold }\end{array}$ & Status \\
\hline Feeding & Nouns & 19 & 0.61 & $2 \mathrm{k}$ & The consolidation \\
\hline Lunch & Nouns & 147 & 0.86 & $3 \mathrm{k}$ & The obsolescence \\
\hline Love & Nouns & 25 & 0.65 & $2 \mathrm{k}$ & The consolidation \\
\hline Rainbow & Nouns & 1 & 0 & $-1 \mathrm{k}$ & The new fashion \\
\hline Happiness & Nouns & 1 & 0 & $-1 \mathrm{k}$ & The new fashion \\
\hline Friendship & Nouns & 2 & 0.8 & $3 \mathrm{k}$ & The obsolescence \\
\hline Aircraft & Nouns & 9 & 0.49 & $2 \mathrm{k}$ & The consolidation \\
\hline Amazon & Nouns & 10 & 0.51 & $2 \mathrm{k}$ & The consolidation \\
\hline Handicraft & Nouns & 11 & 0.52 & $2 \mathrm{k}$ & The consolidation \\
\hline Eat & Verbs & 1 & 0 & $-1 \mathrm{k}$ & The new fashion \\
\hline Dream & Verbs & 6 & $1.66611 \times 10^{-10}$ & $-3 k$ & The novelty \\
\hline Enjoy & Verbs & 115 & $-1.59091 \times 10^{-8}$ & $-3 k$ & The novelty \\
\hline Aquatic & Adjectives & 5 & $4.1770 \times 10^{-9}$ & $-3 k$ & The novelty \\
\hline Aereo & Adjectives & 202 & 1 & $1 \mathrm{k}$ & The top \\
\hline Ancestral & Adjectives & 7 & $4.26504 \times 10^{-9}$ & $-3 k$ & The novelty \\
\hline
\end{tabular}

\section{Discussion}

The exploration and study of web content is a topic that contributes to intelligence, knowledge management, and business management. Technical areas might see this as advantageous because the representation of their reality tends to be objective. For social studies, this topic might be more complex because investigations such as the one presented here, base their experience on subjectivity and phenomenology analysis.

In this scenario, a previous semantic analysis conducted by [87] showed a contrast between supply and demand by using digital social network content, which facilitated the ability to attract travelers and promote the creation of new products to improve some brands. Therefore, to continue to manage value, this research complements the state of the art by mainly establishing an identification practice of the linguistic icons of social content inside the tourism context. This fact constitutes a base in which to go beyond the generation of Web 3.0 and Web 4.0 content, which were also of interest in this work.

Subsequently, an extraction and data analysis alternative was systematized through set theory and constructed from the discourse analysis theory. These theories contributed to codify and structure the information to forming a lexicon that represented the semantic value for sustainable tourism. It also sought to motivate the defense of the territory and cultural rescue precisely as part of that semantic value that, according to [91] and in accordance with the paradigm of essential marketing, advertising content favors a positive reaction to the enjoyment of travel and respect for the cultural, ethnic, geographical, and socio-economic diversity of the environment [92]. The contributions of this work, with the construction of signs that transform the traveler's psychology, have allowed for the generation of an interactive culture that provides apparent, circumstantial, and manifest evidence [70] that can be given, afterward, to the social-cultural system of the receptor. The findings of this work constitute part of the acculturation process [93] of social networks and in the paradigm of sustainability [94,95].

From a pragmatic point of view, it is evident that the advertising intentions of the studied intermediation agencies do not seem to be aligned with the purpose of sustainable tourism. The reality indicates, through linguistic signs in the sets of words, that the intermediaries prefer to contribute to building a better relationship with places of accommodation and transportation than with the country or territory. The semantic relationship did not observe a close connection with social identity and another paradigm that [93] acknowledged as city-brand, where the values and attractions are stimulated toward new development schemes.

Finally, focusing on the future, this investigation will continue with the development of a monitoring system, which will allow us to measure the evolution of the words within the scheme of the marketing life cycle. Additionally, it will be necessary to develop a study to prove that, 
indeed, the semantics of development and sustainable tourism favors the commercial activity of the intermediary companies. What this study expects is to start a configuration of artificial analytics based on qualitative data mining, whose main objective is to structure deterministic and probabilistic rules that, through the application of structural equation models (SEM) and expert stochastic models, favor not only the construction of algorithms and automated platforms for the extraction and analysis of the data, but also for the reply of the information.

Author Contributions: Conceptualization, J.P.V.L.; Formal analysis, J.P.V.L., A.P.-T.; Methodology, J.P.V.L. and A.P.-T.; Investigation, J.P.V.L.; Resources, J.P.V.L.; Software, J.P.V.L.; Data Curation, A.P.-T.; Writing-original draft preparation, J.P.V.L., K.M.D.C.; Translation, K.M.D.C.

Funding: This research received no external funding.

Acknowledgments: We would like to thank the Group of Data Structures and Computational Linguistics of the University of Las Palmas for providing extended access to the use of the online lemmatizer as the quantity of information exceeded the number of allowable maximum transactions meant that we required a special connection to finish this research.

Conflicts of Interest: The authors declare no conflicts of interest.

\section{References}

1. UNWTO. 2017 Annual Report World Tourism Organization. Available online: https://www.e-unwto.org/doi/ pdf/10.18111/9789284419807 (accessed on 7 January 2019).

2. Taizeg, R.; Muhlis, C.; Sudharshan, R.P.; Jianchun, F.; Wanshan, W. The impact of tourism quality on economic development and environment: Evidence from mediterranean countries. Sustainability 2019, 11, 2296. [CrossRef]

3. Nepal, R.; al Irsyad, M.I.; Nepal, S.K. Tourist arrivals, energy consumption and pollutant emissions in a developing economy-implications for sustainable tourism. Tour. Manag. 2019, 72, 145-154. [CrossRef]

4. UNWTO. Tourism and the Sustainable Development Goals-Journey to 2030, Highlights. Available online: https://www.e-unwto.org/doi/book/10.18111/9789284419340 (accessed on 7 January 2019).

5. Cortese, F.; D'Ambrisio, I.; Petracca, M. A possible synergy between culture and religion for sustainability of tourism of Pompeii. Sustainability 2019, 11, 2231. [CrossRef]

6. Bulatovic, I.; Stranjancevic, A. Integrated model of religious tourism in underdeveloped destinations. J. Geograph. Inst. Jovan Cvijic Sasa 2019, 69, 53-66. [CrossRef]

7. Yoder, S.D. Ecotourism, Religious Tourism, and Religious Naturalism. J. Study Relig. Nat. Cult. 2017, 11, 291-314. [CrossRef]

8. Sheppard, V.A.; Fennell, D.A. Progress in tourism public sector policy: Toward an ethic for non-human animals. Tour. Manag. 2019, 73, 134-142. [CrossRef]

9. Lee, D.E. Evaluating conservation effectiveness in a Tanzanian community wildlife management area. J. Wildl. Manag. 2018, 8, 1767-1774. [CrossRef]

10. Gao, J.; Zhang, C.; Huang, Z. Chinese tourists' views of nature and natural landscape interpretation: A generational perspective. J. Sustain. Tour. 2018, 26, 668-684. [CrossRef]

11. Edgar, G.J.; Bustamante, R.H.; Fariña, J.M.; Calvopiña, M.; Martínez, C.; Toral-Granda, M.V. Bias in evaluating the effects of marine protected areas: The importance of baseline data for the Galapagos Marine Reserve. Environ. Conserv. 2004, 31, 212-218. [CrossRef]

12. Vainova, N.; Arcibashev, D.; Aliushin, R.; Malina, V. Interacción of agricultural and ethnographic tourism for the development of Russian regions. J. Cult. Herit. Manag. Sustain. Dev. 2019, 9, 246-262.

13. Farsani, N.T.; Ghotbabadi, S.S.; Altafi, M. Agriculture heritage as a creative tourism attraction. Asia Pac. J. Tour. Res. 2019, 24, 541-549. [CrossRef]

14. Loyola, J. Conocimientos y prácticas ancestrales y tradicionales fortalecen la sustentabilidad de los sistemas hortícolas de la parroquia de San Joaquín. La Granja 2016, 24, 29-42. [CrossRef]

15. Vera, P.; Jeanette, M. Community tourism in conflict territories. The case of Mapuche indigenous communities in the Los Rios Region in Chile. Geopolíticas-Revista de Estudios Sobre Región y Poder 2017, 8, 11-28. [CrossRef]

16. Saiz, J.M. Turismo sostenible y emprendimiento social. El pueblo Mágico del Tequila, México. Retos 2018, 8, 51-67. [CrossRef] 
17. Nicula, V.; Popsa, R.E. Involvement of rural tourism operators in the project "SIBIU European Gastronomic Region". Anfiteatru Econ. 2018, 20, 951-966. [CrossRef]

18. Butowski, L. Tourist sustainability of destination as a measure of its development. Curr. Issues Tour. 2019, 9, 1043-1061. [CrossRef]

19. Kotler, P. Mercadotecnia de las Localidades; Editorial Diana: Ciudad de México, DF, México, 1992.

20. Pulido, J.I.; Sánchez, M. Measuring tourism sustainability: Proposal for a composite index. Tour. Econ. 2009, 15, 277-296. [CrossRef]

21. World Economic Forum. The Travel \& Competitiveness Index. 2015. Available online: http://www3. weforum.org/docs/TT15/WEF_Global_Travel\&Tourism_Report_2015.pdf (accessed on 17 January 2019).

22. Asmelasha, A.G.; Kumar, K. Assessing progress of tourism sustainability: Developing and validating sustainability indicators. Tour. Manag. 2019, 71, 67-83. [CrossRef]

23. Perkumiene, D.; Pransk, R. Overtourism: Between the right to travel and resident's rights. Sustainability 2019, 11, 2138. [CrossRef]

24. Minube. Libro Blanco Sobre Un Turismo Sostenible y Responsable. Available online: file://C: /Users/pablo/Dropbox/Espa na/Bibliografia/turismo\%20nuevo/turismo\%20sostenible/libro\%20blanco\% 20del\%20turismo\%20sostenible.pdf (accessed on 15 April 2019).

25. López, A.L. Sistema integrado de gestión para empresas turísticas. Estudios Gerenciales 2009, 25, 131-150. [CrossRef]

26. Ibarnia, I. La Sostenibilidad de la Cadena de Intermediación Turística. El Caso de las Agencias de Viaje del País Vasco. Master's Thesis, Universitat Oberta de Catalunya, Barcelona, Spain, 2 July 2018.

27. Flores, D.; Salazar, L.; Santana, M. ¿Desaparecerán los tour operadores? El papel de los intermediarios en la distribución turística: Análisis del caso de Tenerife. Pasos Revista de Turismo y Patrimonio Cultural 2011, 9, 341-359.

28. Berné, C.; García-González, M.; García-Uceda, M.E.; Múgica, J.M. Modelización de los cambios en el sistema de distribución del sector turístico debidos a la incorporación de las tecnologías. Cuadernos de Economía y Dirección dela Empresa 2012, 15, 117-129. [CrossRef]

29. Berné, C.; García-González, M.; García-Uceda, M.E.; Múgica, J.M. Identificación y análisis de los criterios de cambios del sistema de distribución turístico asociados al uso intensivo de las tecnologías de la información y comunicación. Investigaciones Europeas de Dirección y Economía de la Empresa 2013, 19, 90-101. [CrossRef]

30. López, A.; Tabares, G.; Vega, R. Sistemas Integrados para la Gestión Empresarial (SIGE): Guía Práctica para Integrar la Gestión Empresarial Otros Sistemas de Gestión Mediante el Cuadro de Mando Integral; Fondo Editorial Universidad Antonio Nariño: Bogotá, Colombia, 2008; p. 53.

31. Vázquez, J.P. Las TIC Como Creación de Valor al Proceso de Gestión de Distribución Turística para Formulación de Proyectos de Adopción Tecnológica. Ph.D. Thesis, Universidad Internacional Iberoamericana, Campeche, México, February 2018.

32. Kapiki, S.; Fu, J.; Mou, L. Managing the knowledge for Chinese tourists: Establishment of Greece as a preferred destination. In Proceedings of the 2nd International Conference on Contemporary Marketing Issues (ICCMI), Athens, Greece, 18-20 June 2014; pp. 81-85.

33. Gómez, G.; Menoya, S.; Rodríguez, M. La cadena de valor como hilo conductor de la investigación de los destinos turísticos. Avances 2015, 17, 239-249.

34. Panadea, H.; Handayani, P.W.; Pinem, A.A. The analysis of tourism information to enhance information quality in e-tourism. In Proceedings of the Second International Conference on Informatics and Computing (ICIC), Jayapura, Indonesia, 1-2 November 2017. [CrossRef]

35. Tribe, J.; Mkono, M. Not such smart tourism? The concept of e-lienation. Ann. Tour. Res. 2017, 66, $105-115$. [CrossRef]

36. Rickly-Boyd, J.M. Alienation: Authenticity's forgotten cousin. Ann. Tour. Res. 2013, 40, 412-415. [CrossRef]

37. Xue, L.; Manuel-Navarrete, D.; Buzinde, C.N. Theorizing the concept of alienation in tourism studies. Ann. Tour. Res. 2014, 44, 186-199. [CrossRef]

38. MacCannell, D. The Tourist: A New Theory of the Leisure Class; Schocken Books: New York, NY, USA, 1976.

39. Porter, G.; Kakabadse, N.K. HRM perspectives on addiction to technology and work. J. Manag. Dev. 2006, 25, 535-560. [CrossRef]

40. Prattipati, S.N. Sustainability and the rol of information and communication technologies. Bus. Renaiss. Q. 2010, 5, 23-40. 
41. Elkington, J. Cannibals with Forsk-The Tripe Bottom Line of 21st Century Business; New Society Publisher: Stoney Creek, ON, Canada, 1997.

42. Amos, O.A.; Uniamikogbo, E. Sustainability and triple bottom line: An overview of two interrelated concepts. Igbinedion Univ. J. Account. 2016, 2, 88-125.

43. Youn, M.; Park, B. Sustainable corporate social media marketing based on structural features: Firm size plays a significant role as a moderator. Sustainability 2018, 10, 1167. [CrossRef]

44. Casaló, L.V.; Flavián, C.; Guinalíu, M. Redes sociales virtuales desarrolladas por organizaciones empresariales: Antecedentes de la intención de participación del consumidor. Cuadernos de Economía y Dirección de la Empresa 2012, 15, 42-51. [CrossRef]

45. Kim, S.E.; Lee, K.Y.; Shin, S.I.; Yang, S.B. Effects of Tourism Information Quality in Social Media on Destination Image Formation: Tha Case of Sina Weibo; Elsevier: Amsterdam, The Netherlands, 2017.

46. Redfield, R.; Linton, R.; Herskovits, M.J. Memorandum for the study of acculturation. Am. Anthr. 1936, 38, 149-152. [CrossRef]

47. Makarova, E.; Birman, D. Cultural transition and academic achievement of students from ethnic minority backgrounds: A content analysis of empirical research on acculturation. Educ. Res. 2015, 57, 305-330. [CrossRef]

48. Berno, T.; Ward, C. Innocence abroad: A pocket guide to psychological research on tourism. Am. Psych. 2005, 60, 593-600. [CrossRef] [PubMed]

49. Yen, D.A.; Dey, B. Acculturation in the social media: Myth or reality? Analysing social-medialed integration and polarization. Technol. Forecast. Soc. Chang. 2019, in press. [CrossRef]

50. Urra, E.; Muñoz, A.; Peña, J. El análisis del discurso como perspectiva metodológica para investigadores de la salud. Enferm. Univ. 2013, 10, 50-57. [CrossRef]

51. Mills, S. Discourse; Routledge: New York, NY, USA, 1997.

52. Iñiguez-Rueda, L. Análisis del Discurso: Manual para las Ciencias Sociales, 2nd ed.; Editorial UOC: Barcelona, Spain, 2006.

53. Morales-Ramirez, I.; Meshesha Kifetew, F.; Perini, A. Speech-acts based analysis for requirements discovery from online discussions. Inform. Syst. 2019, in press. [CrossRef]

54. Foucault, M. El Orden del Discurso; Fabula Tusquest Editores: Barcelona, Spain, 2005.

55. Ashlee, L.D. Who empowers the Cuban people? Agency and agentivity in the media. Lang. Commun. 2019, 64, 1-11. [CrossRef]

56. Foucault, M. La Arqueología del Saber; Siglo XXI Editores: Ciudad de México, México, 1969.

57. Goffman, E. Frame Analysis; Harper: New York, NY, USA, 1974.

58. Suurmond, J.M. Our Talk and Walk. Discourse Analysis and Conflict Studies; Clingendael: The Hague, The Netherlands, 2005.

59. Van Dijk, T.A. Context and cognition: Knowledge frames and speech act comprehension. J. Pragmat. 1977, 1, 211-231. [CrossRef]

60. Van Dijk, T.A. Opinions and attitudes in discourse comprehension. Adv. Psychol. 1982, 9, 35-51. [CrossRef]

61. Bordieu, P. The field of cultural production, or: The economic world reversed. Poetics 1983, 12, 311-356. [CrossRef]

62. Halliday, M.A.K. El Lenguaje como Semiótica Social; Fondo de Cultura Económica: Ciudad de México, México, 1979.

63. Saussure, F. Curso de Lingüística General, 24th ed.; Editorial Losada, S.A.: Buenos Aires, Argentina, 1945.

64. Pierce, C. The Collected Papers of Charles Sanders Pierce; Harvard University Press: Cambridge, MA, USA, 1931.

65. Eco, U. Tratado de Semiótica General, 5th ed.; Editorial Lumen: Barcelona, Spain, 2000.

66. Bevir, M. Lo inconsciente en la explicación social. Areté Revista de Filosofía 2011, 23, $223-262$.

67. Middleton, V.T.C.; Fyall, A.; Morgan, M. Marketing in Travel and Tourism, 4th ed.; Butterworth-Heinemann: Ljubljana, Slovenia, 2009.

68. Goeldner, C.; Brent, J.R. Tourism: Principles, Practices, Philosophies, 12th ed.; John Wiley \& Sons: Hoboken, NJ, USA, 2011.

69. Bigné, J.E.; Font, X.; Andreu, L. Marketing de Destinos Turísticos: Análisis y Estrategias de Desarrollo; ESIC: Madrid, Spain, 2000.

70. París, J.A. Diseño Esencial: Desarrollo Mercadológico de Nuevos Productos y Servicios; Diseño: Buenos Aires, Argentina, 2018. 
71. Bordieu, P. The market of symbolic goods. Poetics 1985, 14, 13-44. [CrossRef]

72. Perlo, C. Aportes al interaccionismo simbólico a las teorías de la organización. Invenio 2006, 9. Available online: http://www.redalyc.org/articulo.oa?id=87701607 (accessed on 27 August 2019).

73. Sellers, R.; Azorín, A. El comercio electrónico y el futuro del canal de distribución turístico. Investigaciones Europeas de Dirección y Economía de la Empresa 2001, 7, 13-36.

74. Regalado, O.; Viardot, E. El futuro de la desintermediación en los servicios turísticos. Una evolución en las competencias? Escuela de Administración de Negocios para Graduados 2002, 10, 6-21.

75. Gómez, G. Procedimiento metodológico de diseño de productos turísticos para facilitar nuevos emprendimientos. Retos 2014, 4, 158-171.

76. Dewan, A.M.; Nazmin, S.A. The opportunities and barriers of using ICT by small and medium enterprises in Bangladesh: Case of SMEs in BSCIC industrial estates. In Proceedings of the International Conference on Computer and Communication Engineering (ICCCE08), Kuala Lumpur, Malaysia, 13-15 May 2008.

77. Menoya, S.; Gómez, G.; Pérez, I.; Cándano, L. Modelo basado en enfoque de cadena de valor para gestión del turismo desde el gobierno local en municipios de vocación turística. Retos de la Dirección 2017, 11. Available online: https://revistas.reduc.edu.cu/index.php/retos/article/view/265 (accessed on 27 August 2019).

78. Hajnal, A.; Hamburger, P. Set Theory; Cambridge University Press: Cambridge, UK, 1999.

79. Santander, R. Por qué y cómo hacer el análisis de discurso. Cinta Moebio 2011, 41, 207-224. [CrossRef]

80. Villayandre, M. Aproximación a la lingüística computacional. Ph.D. Thesis, Universidad de León, León, Spain, 2010.

81. Rojas, Soriano. R. Investigación-Acción en Facebook: Aspectos Humanos en Comunidad Virtual; Mil Libros Editorial: Ciudad de México, México, 2017.

82. Auerbach, D. Bitwise: A Life Code; Patheon Books: Toronto, ON, Canada, 2018.

83. París, J.A. Tendencias Mercadológicas Esenciales; CP67: Buenos Aires, Argentina, 2019.

84. Walpole, R.; Myers, R.; Myers, S.; Ye, K. Probabilidad y Estadística para la Ingeniería y las Ciencias; Pearson Education: Ciudad de México, México, 2012.

85. Vázquez, J.P. Aportes al comercio turístico a través de websites: Mejoramiento para la evaluación de calidad. In Un Espacio para la Ciencia; Patricia, N., Ed.; Manglar Editores: Guayaquil, Ecuador, 2018; Volume 1.

86. García, F.E.; Vázquez, J.P. Mipymes distribuidors turísticas: Recomendaciones SEO a partir del análisis de palabras claves. Riturem 2018, 2, 43-54. [CrossRef]

87. Vázquez, J.P.; Gómez, G.P. Gestión de valor en la distribución turística: Resultados preliminares desde la valoración de e-readiness aplicados a Cuenca-Ecuador. I + D Tecnológico 2018, 14, 18-28. [CrossRef]

88. Guerrero, J.A. Facemoney: Cómo Ganar Dinero Fácilmente en Facebook; Mestas Ediciones: Madrid, Spain, 2016.

89. Levy, J. Facebook Marketing Tutorial: Design Your Next Marketing Campaign with Facebook; QUE Publishing: Indianapolis, IN, USA, 2010.

90. Taboada, M.; Brooke, J.; Tofiloski, M. Lexicon-based methods for sentiment analysis. Comput. Linguist. 2011, 37, 267-307. [CrossRef]

91. Gorgadze, A.; Gordin, V.; Belyakova, N. Semantic analysis of the Imperial Topic: Case of St. Petersburg. ERev. Tour. Res. 2019, 16, 3-12.

92. París, J.A. Comunicación Esencial. El Paradigma del Marketing Esencial Aplicado al Diseño y la Comunicación Visual; Diseño: Buenos Aires, Argentina, 2018.

93. Li, C.; Guo, S.; Want, C.L.; Zhang, J. Veni, vidi, vici: The impact of social media on virtual acculturation in tourism. Inform. Manag. 2017, 54, 687-702. [CrossRef]

94. Oteo. L.A. La gestión del conocimiento: Un paradigma sostenible. Revista de Calidad Asistencial 2003, 18, 139-140. [CrossRef]

95. Valenzuela, M.E. La estrategia marca-ciudad en la función de turismo. El Periplo Sustentable 2015, 28, 59-80. 
Article

\title{
Forecasting Hotel Accommodation Demand Based on LSTM Model Incorporating Internet Search Index
}

\author{
Binru Zhang ${ }^{1}$, Yulian Pu ${ }^{2}$, Yuanyuan Wang ${ }^{3, *}$ and Jueyou $\mathrm{Li}^{4, *}$ \\ 1 School of Finance and Economics, Yangtze Normal University, Chongqing 408100, China \\ 2 School of Management, Yangtze Normal University, Chongqing 408100, China \\ 3 School of Economics and Management, Hainan Normal University, Haikou 571158 China \\ 4 School of Mathematcal Science, Chongqing Normal University, Chongqing 401331, China \\ * Correspondence: wangyy010906@hainnu.edu.cn (Y.W.); lijueyou@cqnu.edu.cn (J.L.)
}

Received: 7 August 2019; Accepted: 24 August 2019; Published: 29 August 2019

\begin{abstract}
Accurate forecasting of the hotel accommodation demands is extremely critical to the sustainable development of tourism-related industries. In view of the ever-increasing tourism data, this paper constructs a deep learning framework to handle the prediction problem in the hotel accommodation demands. Taking China's Hainan province as an empirical example, the internet search index is used from August 2008 to May 2019 to forecast the overnight passenger flows for hotels accommodation in Hainan Province, China. Forecasting results indicate that compared to benchmark models, the constructed forecasting method can effectively simulate dynamic characteristics of the overnight passenger flows for the hotel accommodation and significantly improve the forecasting performance of the model. Forecasting results can provide necessary references for decision-making in tourism-related industries, and this forecasting framework can also be extended to other similar complex time series forecasting problems.
\end{abstract}

Keywords: internet search index; deep learning framework; LSTM model; hotel accommodation demands; forecasting performance

\section{Introduction}

The tourist hotel is an important part of the tourism industry. The tourist destination hotels flow is the indicator of hotel revenue; accurate passenger flow forecasting is the key link in the hotel revenue management [1], which helps related companies and organizations allocate limited tourism resources scientifically and reasonably to maintain market competitiveness [2]. However, the tourism demands such as the overnight passenger flow of hotels has characteristics of complex nonlinear fluctuations. The uncertainty of the passenger flow during the tourist season makes the decision-making of relevant departments into a dilemma, either overestimating or underestimating of the passenger flow will result in unnecessary waste of resources in tourism-related industries; additionally, the actual overnight passenger flow released by the statistical department has serious hysteresis. On the other hand, existing non-linear prediction methods are difficult to adapt to the increasing experimental data, and unable to extract feature information automatically, affecting the forecasting accuracy. With the all-round development of the Internet, a large amount of online query index generated by the consumer information search provides a new direction for an overnight traffic forecasting of tourist hotels [3]. This study addresses the aforementioned problems and expands the previous research by introducing appropriate nonlinear forecasting methods and constructing deep learning (DL) forecasting frameworks.

Existing prediction methods of tourism demands include linear and nonlinear technologies. Linear forecasting technologies mainly include the time series forecasting models represented by the autoregressive integrated moving average (ARIMA) and econometric models. Nevertheless, 
these methods need to meet the stability of the economic environment and the stability assumptions of the time series. In practice, it is often unable to fully simulate complex nonlinear characteristics of the destination demands [4]. The nonlinear technologies represented by the regression version of the support vector machine (SVR) method have certain nonlinear forecasting abilities when dealing with small sample data sets [4-6], but these methods are shallow learning technologies. Hence, in the aspect of practical applications, it's hard for these methods to meet the growing data samples. Additionally, these methods cannot automatically extract features information, but also easily fall into the local optimum as well as over-fitting problems.

With the comprehensive development of the Internet, the information query has become a crucial basis for decision-making [7,8]. A large number of records generated by information query possess real-time and accessible features. These data mainly from the Baidu or Google search engine are objective reflections of consumers' latent demands for travel and have become increasingly important for tourism demand forecasting [3].

Existing literatures mainly use the consumer search data to forecast the tourist flow in scenic areas. Predictive results based on the linear model suggested that the Internet search index can improve the forecasting performance [9-13]. For instance, Yang et al. [11] applied the web index from Google and Baidu as input sets of the ARIMA model for a comparative study on the Chinese tourist volume. Huang et al. [12] used the query data from Baidu as a predictive variable of the ARIMA model to forecast the tourist arrivals of the Imperial Palace in Beijing. Taking Xi'an as an example, Wei and Cui [13] used the seasonal adjustment method to explore the correlation between the search data from Baidu and the tourist flow. However, the linear model needs to satisfy the stationary assumption of the time series and the stable economic environment, and it is difficult to effectively simulate the nonlinear relationship of tourism demands.

In order to cope with the nonlinear, existing literature used the Internet query index as input sets of nonlinear tools such as the artificial neural network (ANN) and the regression version of the support vector machine, to predict the tourist flow [5,6,14]. For example, Sun et al. [6] applied the web query data to construct a single-layer feed-forward neural network (FFNN) to simulate the tourist flows in Beijing. The empirical analysis shows that the search query data can effectively fit the dynamic characteristics of the tourist arrivals and improve the predictive accuracy of the constructed method. Li et al. [14] developed a composite forecasting tool using the back propagation algorithm (BPNN) and used the Baidu index to predict the tourist volume. Despite this, models such as the SVR and ANN are essentially shallow learning methods that are difficult to meet the growing samples of the tourism data, and challenge the predictive accuracy.

Previous studies forecasted the demands of tourist hotels mainly based on linear models [15-19]. For example, Choi [18] identified key economic indicators of the hotel industry in the US and built synthetic indicators to forecast the US hotel demands successfully. Aliyev et al. [19] used fuzzy time series models to forecast the hotel occupancy. There was very rare research specializing in the hotel demand forecasting using the Internet search data. For example, Pan et al. [20] utilize the Google trend index as model inputs to forecast the hotel occupancy. The results indicated that the addition of network queries can obviously reduce the prediction error. However, these studies mainly use the Google trend data as predictive variables of linear models. In China, consumers mainly use the Baidu search engine for information search. There is no relevant literature using the Baidu search data to forecast the demands for the tourist hotel accommodation. Whether the Baidu search data has a predictive effect on the demands of tourist hotels remains to be investigated. In addition, with the increase in the data samples, linear-based forecasting techniques are difficult to fully simulate the nonlinearity of the hotel accommodation demands.

In recent years, with the popularity of artificial intelligence, neural network models with more hidden layers can learn the characteristic information and the relevance behind the complex dataset. The DL technology has attached increasing importance in both academia and the industry [21]. According to the consensus of most current researches, for traditional machine learning algorithms, 
as the data sample increases, the forecast performance increases according to the power law, but tends to be stable after a while. But for the DL method, its performance increases logarithmically with the increased sample capacity [22]. Compared to other DL models, the long short-term memory (LSTM) exhibits unique advantages in terms of forecasting with sequence as inputs [23-25]. In the field of tourism, for example, Chang and Tsai [26] used the deep neural network (DNN) model based on official statistics to forecast Taiwan's tourist flow. There is no research on the hotel accommodation demand forecasting based upon such DL methods.

The application of the DL models in the complex time series forecasting of tourism demands is explored in this paper. Taking Hainan as an example, the internet search data generated by the consumers' information search and LSTM models with excellent forecasting ability for the complex time series are used to forecast the overnight passenger flows of tourist hotels. For the purpose of comparing the forecasting power of the developed models, the deep belief network (DBN), BPNN, and C-LSTM (only using past observations of the overnight passenger flow as predictive variables) were constructed as benchmark counterparts. With the empirical results suggesting that the developed LSTM network can effectively forecast hotel demands compared to its competitors.

The contribution of this study to the existing research is twofold. Firstly, we construct a theoretical analysis framework based on the tourism motivation theory and information search behaviour theory for the first time, which provides a theoretical basis for the tourism demand forecasting research based on the web search data. Secondly, unlike previous studies, forecasting tools such as the ANN and SVR cannot adapt to the ever-increasing tourism data. This paper introduces the LSTM with an excellent prediction ability for the complex time series data and constructs an empirical analysis framework to forecast hotel accommodation demands. This method provides a feasible solution for other complex time series predictions under relatively large sample conditions.

The rest of the study proceeds as follows: Section 2 is the theoretical analysis. In Section 3, the design of the forecasting method is shown. Section 4 gives the empirical results of the overnight passenger flow forecasting. Section 5 presents the conclusions.

\section{Theoretical Analysis}

It is observed from the tourism motivation theory $[27,28]$ and tourist information search behavior theory $[7,29]$ that tourism is a dynamic process in the temporal and spatial dimension, which can be divided into three stages namely, the pre-tour plan, in-tour experience and post-tour evaluation. The logic framework of the tourist information search is shown in Figure 1.

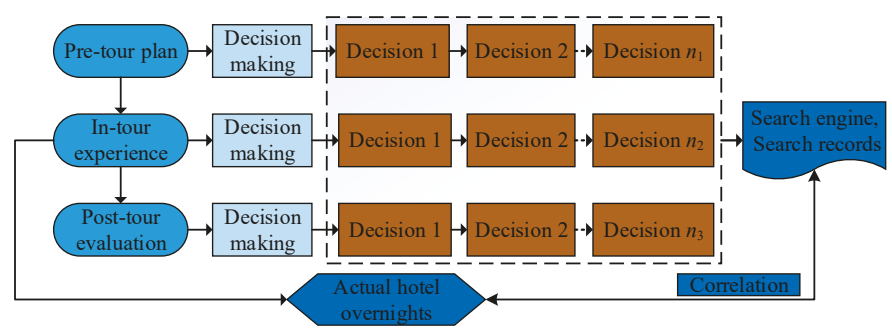

Figure 1. The logic framework of the tourist information search.

The decision-making of tourism at each stage in the Internet environment relies heavily on the Internet information search. Once a tourism decision is made, tourists will try to fulfill their specific tourism demands. The pre-tour plan refers to a series of plans made by the consumers inspired by the tourism demands. They make tourism decisions by using the Internet to search information thereby, developing an optimal travel plan. The in-tour experience refers to the entire tourism implementation process from the source to the tour destination. It is the process of the tourists' actual experience on tourism products and services. At this stage, tourists mainly use mobile communication devices such 
as mobile phones and tablet phones to inquire the tourism-related information they care about, thereby making travel decisions. Post-tour evaluation is an objective evaluation of witnessed tourism products or services after the end of the tour, visitors often use various social media tools to comment on tourism products and services and share their travel experiences.

Jeng and Fesenmaier [30] noted that in the whole process of the pre-tour plan and in-tour experience, tourists would make different tourism decisions for six elements of tourism such as eating, accommodation, transportation, travelling, shopping and entertainment. During this process, the tourists' potential tourism demands are expressed by the Internet information search on the search engine, which makes a true record of the search information. The consumer information search objectively reflects the tourists' potential travel motivation. The characteristic information that has the potential influence on the tourism demands can be determined from the Internet information search. The information is the pre-reflection of the passenger flow of tourists destination hotels hence, it becomes an important data source in tourism demand forecasting [3].

\section{Design of Forecasting Method}

\subsection{LSTM Network}

The advantage of the traditional recurrent neural network (RNN) model is that it can learn complex temporal dynamic characteristics through the following recurrent equations when dealing with forecasting tasks of sequence input objects:

$$
\begin{gathered}
Z_{t}=f\left(W_{x z} X_{t}+W_{z z}+b_{x}\right) \\
Y_{t}=f\left(W_{h z} Z_{t}+b_{z}\right)
\end{gathered}
$$

where, $X_{t}$ represents the inputs of the model, $Z_{t}$ denotes a hidden layer with the $\mathrm{N}$ hidden units, $Y_{t}$ denotes the output at the moment $t$, and $(W, b)$ represent the weight and offsets parameters that need to be learned. For the input sequence with the length $\mathrm{T}$, the update of the data is handled in a cycle way.

Although RNN has been successfully applied in areas such as speech recognition as well as text generation [31,32], this method has some difficulties in learning and storing long-term memory information, which can be attributed to disappearing and the explosion of gradients when RNN is optimized in some time steps. The consequence is that the model cannot retain the past memory information over a long time.

LSTM is a variant of RNN, proposed by Hochreiter and Schmidhuber [23] whose core contribution is the introduction of the ingenious concept of self-looping. LSTM provides a solution for a fusion memory cell unit that allows the network to learn the previously forgotten hidden unit and update the hidden unit based on the new information. In addition to the hidden unit $Z_{t}$, the LSTM network also includes the input gate, forgotten and input adjustment ones, and memory cell. The memory cell unit fuses the state of the previous memory cells, these memory cell units are adjusted by the forgotten gate and the input adjustment gate as well as the previous hidden state, which is adjusted by the input gate. These additional memory cell units enable the LSTM architecture to learn extremely complex long-term time dynamics, ensuring the long-term memory function of the LSTM. The architecture of an LSTM model can be expressed as follows:

$$
\begin{gathered}
F_{t}=\sigma\left(W_{f}^{T} \cdot\left[Z_{t-1}, X_{t}\right]+b_{f}\right) \\
I_{t}=\sigma\left(W_{i}^{T} \cdot\left[Z_{t-1}, X_{t}\right]+b_{i}\right) \\
\bar{C}_{t}=\tanh \left(W_{c}^{T} \cdot\left[Z_{t-1}, X_{t}\right]+b_{c}\right)
\end{gathered}
$$




$$
\begin{gathered}
C_{t}=F_{t} \otimes C_{t-1}+I_{t} \otimes \bar{C}_{t} \\
Z_{t}=O_{t} \otimes \tanh \left(C_{t}\right) \\
\tanh (\mathrm{x})=\frac{e^{x}-e^{-x}}{e^{x}+e^{-x}}
\end{gathered}
$$

where, tanh represents the activation function.

The biggest contribution from RNN is the increased hidden state $C_{t}$ in LSTM, which determines how much information to add or remove from the previous memory state by using the sigmoid activation function $\sigma(x)=\left(1+e^{-x}\right)^{-1}$ and the point multiplication defined layer. The first gate is the forgotten gate $F_{t} \otimes C_{t-1}$, which controls how much data is discarded from the previous memory state. This is followed by the input gate, which remembers some of the current information and determines which values will be updated. Then, new cell state merges the past and present memory information and selects the information of vector $\left[Z_{t-1}, X_{t}\right]$ through the forgotten gate, which provides a mechanism for deleting past irrelevant information and adding relevant information from the current time step. Finally, the output layer $O_{t} \otimes \tanh \left(C_{t}\right)$ controls how much memory data will be utilized in the update of the next phase [33].

\subsection{Training Method and Model Selection}

The back propagation through time (BPTT) commonly used in the RNN network was adopted to train the LSTM network, which is the standard algorithm for training RNN-like network models. The RMSProp, an improved stochastic gradient descent algorithm, was selected for parameter iterative updating. In the LSTM network, in addition to the default activation functions of the model, the other layers use the tanh function as the activation function, which has a more stable gradient and is commonly used in the regression problem.

Over-fitting is an unavoidable phenomenon in the field of DL. The Dropout algorithm developed by Hinton et al. [34] was utilized for solving this defect. This method is a model selection algorithm and a powerful tool to solve the over-fitting in the current DL field.

\subsection{Forecasting Framework Construction}

After the introduction of the LSTM model, a prediction framework based upon consumer queries was constructed (as shown in Figure 2). This framework illustrates the entire empirical analysis, including keyword selection, variable observations acquisition and cleaning, keyword variable screening, predictive variable selection, experimental dataset construction, forecasting experiment and predictive accuracy test. The detailed steps are as follows:

Step 1: Experimental dataset acquisition. After determining the search engine, for the purpose of handling the information omission, we selected six elements related to the destination as the benchmark queries, and then inquired extended keywords related to the benchmark keywords circularly. Eventually, we used Python to crawl the structured query volume data of each keyword, and obtained an alternate experimental dataset composed of data of the overnight passenger flow of tourist hotels.

Step 2: Data cleaning. The passenger flow is very sensitive to promotion schemes, emergencies, etc., thereby data may have abnormal values in different periods. In addition, some keyword variables or predicted variables have the problem of missing data, which will affect the prediction of the model. Thus, the individual outliers were replaced by the moving average method, which eliminated the influence of the noise while retaining the basic data characteristics.

Step 3: Predictive variable screening. In order to further find predictive variables that are significantly correlated with the predicted variables, the cross-correlation analysis was used to analyze the connection between the keyword variables and lag variables of the predicted variables. The Pearson cross-correlation analysis is a statistical analysis method, which acquired the Pearson correlation coefficient between the 1-12 order lag variables of the predictive variable and the predicted variable, 
respectively. The lag variable corresponding to the maximum correlation coefficient was taken as an alternate predictive variable. The threshold $m$ was defined, and the keyword variable with the correlation coefficient exceeding $m$ was retained as the keyword predictive variable. The same method was used to find the lag variable of the predicted variable as the predictive variable.

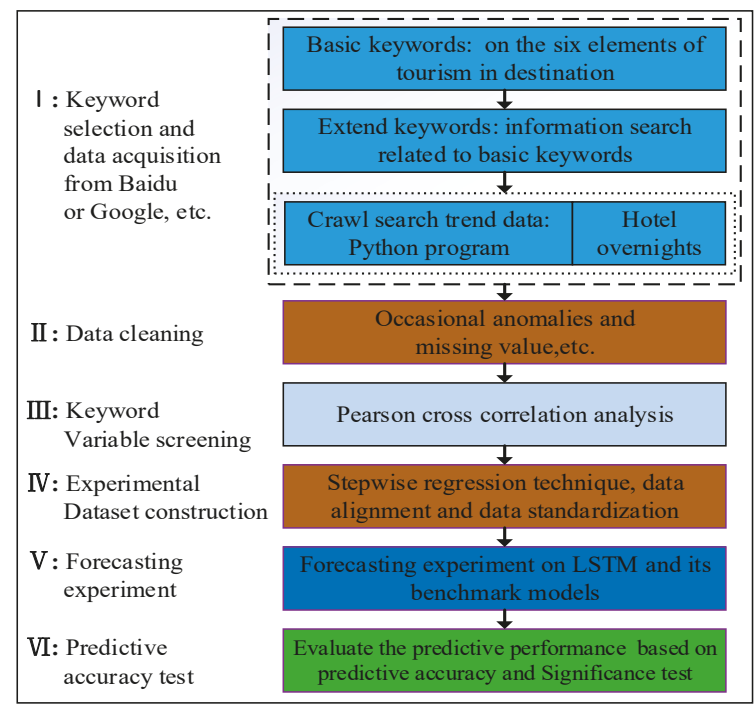

Figure 2. Logic diagram of the forecasting framework.

Step 4: Experimental dataset construction. For the purpose of reducing the complexity of model training, the stepwise regression analysis was further performed on the potential predictive variables to obtain the final predictive variable with excellent predictive ability. To reduce the training complexity, help the network converge faster, and reduce the prediction error rate, a standardized method $\left(x_{t}-x_{\min }\right) /\left(x_{\max }-x_{\min }\right)$ was used to standardize the experimental dataset, where $x_{t}$ represents the value of the time series in the experimental dataset at point $t, x_{\min }, x_{\max }$ represent the minimum and maximum values of $x_{t}$, respectively. Eventually, all the standardized variables were then aligned based on the optimal lag structure of each variable and composed experimental dataset.

Step 5: Forecasting experiment. The experimental sample was split into the training section and the test section. The former was utilized for training and the latter was utilized for the predictive test. Predictive experiments were conducted under the Keras framework [35].

Step 6: Predictive accuracy test. The predictive accuracy was determined by metric indices including the root mean squared error (RMSE), mean absolute percent error (MAPE), relative mean bias (PBIAS) and goodness-of-fit index R. The calculations of these statistical indicators are shown in Equations (9) - (12). A significant test of the difference in the predictive accuracy between LSTM and its benchmark models was performed using the Paired $t$ test [36].

$$
\begin{gathered}
\operatorname{RMSE}\left(y_{t}, \hat{y}_{t}\right)=\left[\frac{1}{N} \cdot \sum_{t=1}^{N}\left(y_{t}-\hat{y}_{t}\right)^{2}\right]^{\frac{1}{2}} \\
\operatorname{MAPE}\left(y_{t}, \hat{y}_{t}\right)=\frac{1}{N} \cdot \sum_{t=1}^{N}\left|\frac{y_{t}-\hat{y}_{t}}{y_{t}}\right| \cdot 100 \% \\
\operatorname{PBIAS}\left(y_{t}, \hat{y}_{t}\right)=\frac{\sum_{t=1}^{N}\left(y_{t}-\hat{y}_{t}\right)}{\sum_{t=1}^{N} y_{t}} \cdot 100 \%
\end{gathered}
$$




$$
\operatorname{PBIAS}\left(y_{t}, \hat{y}_{t}\right)=\frac{\sum_{t=1}^{N}\left(y_{t}-\bar{y}\right)\left(\hat{y}_{t}-\bar{Y}\right)}{\sqrt{\sum_{t=1}^{N}\left(y_{t}-\bar{y}\right)^{2}} \sqrt{\sum_{t=1}^{N}\left(\hat{y}_{t}-\bar{Y}\right)^{2}}}
$$

where, $y_{t}, \hat{y}_{t}$ represent the actual tourist flows and simulated records, respectively, $N$ represents the forecasting period, and $\bar{y}, \bar{Y}$ are the average of $y_{t}, \hat{y}_{t}$, respectively.

The absolute indicator RMSE and the relative indicator MAPE were designed to determine the forecasting accuracy between the actual and the fitted records. The smaller the score, the higher was the predictive accuracy [5]. The relative metric indicator PBIAS measured the average result of the deviations between the fitted and actual observed values [37]. The expected score of the PBIAS was zero. The positive and negative scores implied underestimating or overestimating the actual passenger flow in the sense of average, respectively. The purpose of $R$ was to describe the goodness of fit between the predictive and the predicted variables. The closer its score to one, the better was the simulating effect.

\section{Case Study}

\subsection{Collection and Analysis of Experimental Data}

For the purpose of confirming the validity of the constructed prediction framework, China's Hainan province was selected as an application case in this paper to forecast the overnight passengers flow to tourist hotels. Hainan is an excellent tourist destination in the southernmost part of China. In 2018, the added value of the tourism industry in Hainan was 39.282 billion Yuan with annual increase of $8.5 \%$. Tourism hotels received 40.256 million passengers with a year-on-year increase of $7.5 \%$. The monthly passengers flow varies significantly with the seasons. The lower monthly passengers flow was less than 1 million passengers, which increased in the tourism-peak season to over 4 million, the periodic non-linear fluctuation characteristics of the slack and boom season were obvious. The overnight passengers flow data of hotels comes from the leading financial database Wind in China. Considering the availability of the network search data, the data collection time ranged from August 2008 to May 2019.

Similar to the Google trend, the Baidu Index (http://index.baidu.com) provides the daily and weekly index with absolute data. These data are real-time, more sensitive to tourists' behavior, and more reflective of tourists' potential tourism demands [5], offering preferable data support to researchers for tourism demand forecasting. In step 1, of the forecasting framework, 82 keywords related to the Hainan tourism were selected, and a weekly query volume of the keyword search from August 2008 to May 2019 was crawled through the Python program, which was converted to a monthly data by the average weighted summation method. Taking the threshold $m=0.8$, and eight keyword variables and the 1-2 order lag variables of the predicted variables obtained through step 2-4 were taken as the final predictive variables.

Figure 3 shows the dynamic fluctuation trend between the two keyword variables of "Hainan map" as well as "Hainan fruit" and the predicted variables, respectively. From this figure, the Internet information search and the overnight passenger flows of the tourist hotel receptions exhibited cyclical fluctuations, the fluctuation trend was consistent, and each cycle exhibited a complex nonlinear characteristic. The fluctuation characteristics of different keyword variables had slight differences, which indicated that the information implied by the keywords had heterogeneous characteristics, and different information queries reflected different tourism demands of tourists. Additionally, due to the warm season of winter in Hainan, each year the passenger flow was at peak in January and December, and the school summer vacations lead to small peaks in July each year. 


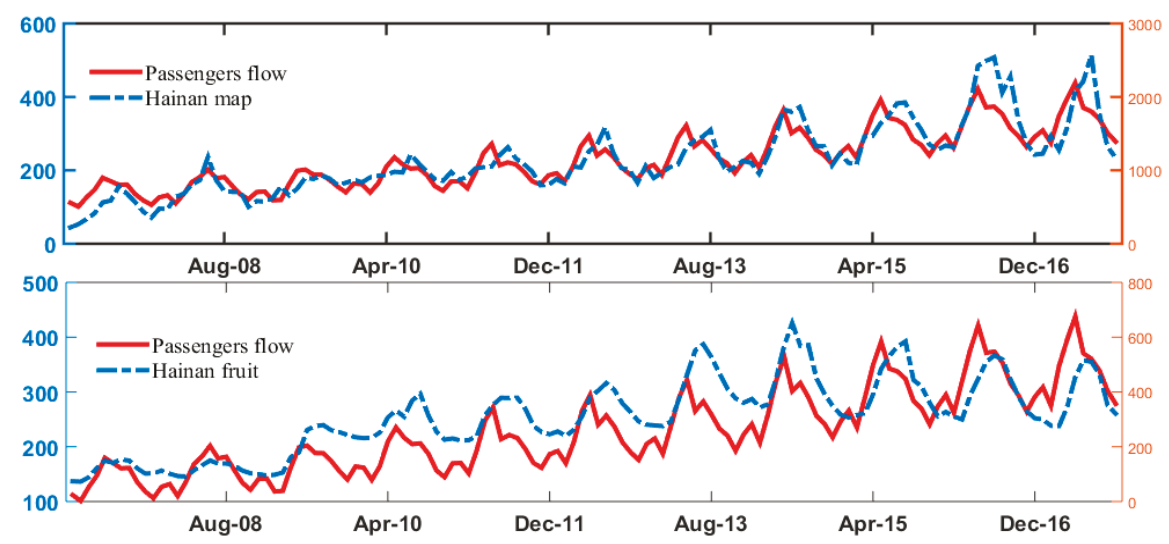

Figure 3. Trend diagram between the "Hainan map" as well as the "Hainan fruit" and predicted variables.

The correlation analysis between all the predictive variables and the predicted variables in the experimental dataset is listed in Table 1. It can be seen that the lag order of the keyword predictive variables obtained by the cross-correlation analysis was $0-5$, most of them were $0-1$, and these variables had a significant correlation with the predicted variables, which fully reflected the potential tourism demands of tourists. For example, tourists inquired about travel guides, weather, maps and scenic spots information about one month in advance. Considering the periodic nonlinear characteristics of the forecasted variable and the excellent predictive ability of LSTM for the complex time series, it was assumed that the selected keyword variable as the input set of LSTM can effectively forecast the overnight passengers flow of tourist hotels. According to step 4 in the forecasting framework, the standardized dataset finally used in this paper can be expressed as follows:

$$
\Omega=\left\{\mathrm{y}_{-1}, y_{-2}, x_{1}, x_{2}, \cdots, x_{8} ; y\right\}
$$

Each of which contains 125 observations, where, $\mathrm{y}_{-1}, y_{-2}, x_{1}, x_{2}, \cdots, x_{8}$ refer to the predictive variables, and $y$ refers to the predicted variable. Each variable is aligned according to the lag order. The first 113 sample points in the experimental dataset $\Omega$ were used for training, and the last 12 months of data were used for the testing.

Table 1. Correlation analysis of the predictive variable.

\begin{tabular}{ccccccc}
\hline No. & Predictive Variable & Code & Lag Order & Correlation & t-Value & $p$-Value \\
\hline 1 & One-order lag of $\mathrm{y}$ & $\mathrm{y}_{-1}$ & 1 & $0.915^{* * *}$ & 25.179 & $<0.01$ \\
2 & Two-order lag of $\mathrm{y}$ & $\mathrm{y}_{-2}$ & 2 & $0.806^{* * *}$ & 15.127 & $<0.01$ \\
3 & Sanya weather & $\mathrm{x}_{4}$ & 0 & $0.877^{* * *}$ & 20.262 & $<0.01$ \\
4 & Hainan map & $\mathrm{x}_{1}$ & 0 & $0.873^{* * *}$ & 19.820 & $<0.01$ \\
5 & Qionghai & $\mathrm{x}_{3}$ & 1 & $0.864^{* * *}$ & 19.049 & $<0.01$ \\
6 & Hainan weather & $\mathrm{x}_{7}$ & 0 & $0.856^{* * *}$ & 18.354 & $<0.01$ \\
7 & Sanyaattractions & $\mathrm{x}_{5}$ & 1 & $0.823^{* * *}$ & 16.079 & $<0.01$ \\
8 & SanyaSelf-driving tour & $\mathrm{x}_{8}$ & 1 & $0.811^{* * *}$ & 15.369 & $<0.01$ \\
9 & Hainan coconut & $\mathrm{x}_{2}$ & 5 & $0.773^{* * *}$ & 13.528 & $<0.01$ \\
10 & Hainan fruit & $\mathrm{x}_{6}$ & 0 & $0.756^{* * *}$ & 12.433 & $<0.01$ \\
\hline
\end{tabular}

Note: ${ }^{* * *}$ indicates significance at $1 \%$ level. 


\subsection{Benchmark Models and Experimental Setup}

For the purpose of confirming the forecasting power of the LSTM network under the forecasting framework, DBN, BPNN and the C-LSTM models were constructed as benchmark counterparts. Among them, DBN was a non-convolution architecture using deep framework training successfully [38], which was essentially a generation network. DBN was introduced to illustrate the advantages of LSTM in the complex time series forecasting. BPNN is a shallow learning method with only one hidden layer. It is a FFNN model and adds a BP algorithm to the structure of the feed-forward network. The introduction of BPNN was aimed to compare the forecasting ability of the DL technology with that of shallow learning methods. C-LSTM however, used only the historical data of the predicted variables as the model inputs, which was introduced to further confirm the importance of the Internet search data.

In terms of the experimental setup, to solve the phenomenon of over-fitting, the randomization selection rate of Dropout for the hidden layer was set to 0.5 for regularization [34]. For the purpose of compromising between the complexity of model training and the local optimal solution, according to the recommendations of Hinton et al. (2012), the initialization learning rate of all models was set to one. BPNN used the classical gradient descent algorithm (GDA) to optimize parameters, and the other forecasting tools used the RMSProp for an iterative updating of the parameters [34]. Taking into account a fewer experimental dataset, the batch size was set to four. In terms of the activation function, tanh was utilized as the activation function of all layers in the BPNN. In addition to the default activation function of the model, the other three models used the tanh function as the activation function of all layers. For the purpose of ensuring the convergence of the loss function RMSE when iteration was stopped during the model training process, epoch was set to 150. Except that the BPNN was a shallow learning model with only one hidden unit, the rest were the DL network architecture with three hidden units.

\subsection{Empirical Results and Discussion}

According to step 5 of the forecasting framework, the training experiment was conducted on the training dataset, the optimal architecture after training was used as the predictive model to perform the predictive test. The prediction outcomes of the various models on the testing dataset are displayed in Table 2. The monthly optimal forecasting values are shown in bold. For the 12-month forecasting results, LSTM performed the best. The optimal forecasting results of LSTM, DBN, BPNN and C-LSTM were five, four, two and one month, respectively. Figure 4 demonstrates the forecasting curve of each model on the test dataset more intuitively. Overall, LSTM better fits the dynamic characteristics of the passenger flow whereas, the C-LSTM performs the worst, and all the benchmark models had a slightly poor fit performance in the last five months. The specific predictive power of each network is yet to be analyzed from the statistical indicators.

Table 2. Predictive results of each model.

\begin{tabular}{cccccc}
\hline Time & Actual Flow & LSTM & C-LSTM & DBN & BPNN \\
\hline June 2018 & 264.05 & 259.591 & 269.049 & $\mathbf{2 6 6 . 3 4 2}$ & 269.113 \\
July 2018 & 291.06 & $\mathbf{2 9 8 . 4 9 3}$ & 280.918 & 283.213 & 281.788 \\
August 2018 & 308.65 & $\mathbf{3 1 7 . 5 9 1}$ & 295.308 & 319.315 & 299.221 \\
September 2018 & 274.63 & 265.681 & $\mathbf{2 8 3 . 5 7 4}$ & 286.209 & 265.477 \\
October 2018 & 347.47 & 340.195 & $\mathbf{3 4 0 . 3 1 4}$ & 335.343 & 338.275 \\
December 2018 & 395.29 & 403.600 & 404.685 & 402.440 & $\mathbf{3 9 0 . 7 3 9}$ \\
November 2018 & 437.74 & $\mathbf{4 4 3 . 6 5 2}$ & 430.186 & 444.988 & 450.599 \\
January 2019 & 370.66 & 377.013 & 385.391 & 358.045 & 379.493 \\
February 2019 & 360.36 & 348.891 & 344.764 & 369.626 & 347.134 \\
March 2019 & 339.01 & 330.525 & 330.551 & 331.271 & 330.509 \\
April 2019 & 301.81 & $\mathbf{3 0 9 . 1 0 1}$ & 319.596 & 289.241 & 313.687 \\
May 2019 & 278.30 & 286.992 & 289.207 & $\mathbf{2 8 5 . 0 8 3}$ & 289.161 \\
\hline
\end{tabular}




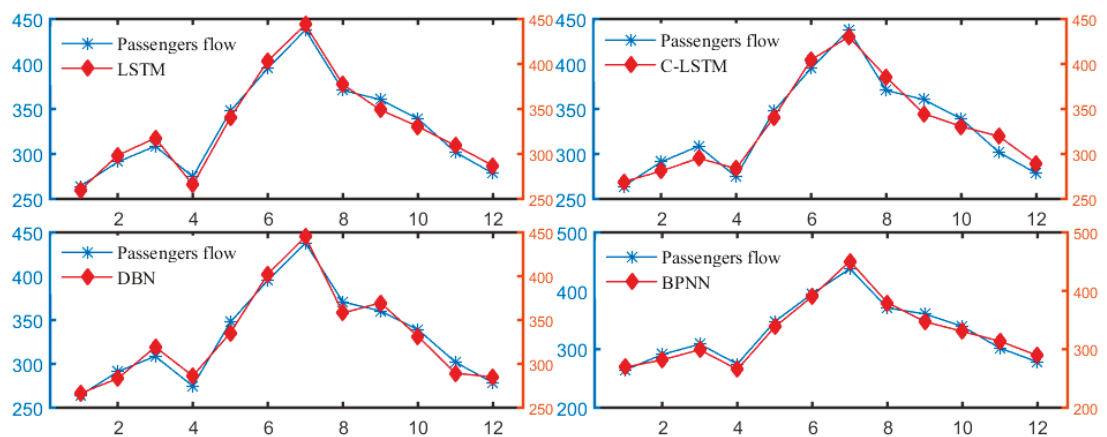

Figure 4. Comparison of the fitting curves of the various models.

To further explore the predictive power of our proposed method, the statistic scores calculated on the experimental dataset are shown in Table 3, and the best score for each metric indicator was indicated in bold. In general, in addition to PBIAS, LSTM exhibited best on the scores of the other metric indicators. It is worth noting that the predictive accuracy of LSTM and DBN on the test set was better or very close to that of the training section, but the other three models are just the opposite, which suggests LSTM and DBN had a better generalization performance.

Table 3. Metric indicator scores for each model on the experimental dataset.

\begin{tabular}{ccccccccc}
\hline \multirow{2}{*}{ Model } & \multicolumn{2}{c}{ RMSE } & \multicolumn{2}{c}{ MAPE (\%) } & \multicolumn{2}{c}{ PBIAS (\%) } & \multicolumn{2}{c}{ R (\%) } \\
\cline { 2 - 9 } & Train & Testing & Train & Testing & Train & Testing & Train & Testing \\
\hline LSTM & $\mathbf{8 . 0 1 5}$ & 7.983 & $\mathbf{2 . 5 0 1}$ & $\mathbf{2 . 4 0 7}$ & 0.143 & -0.310 & $\mathbf{0 . 9 9 0}$ & $\mathbf{0 . 9 8 9}$ \\
C-LSTM & 9.922 & 11.363 & 3.297 & 3.311 & $-\mathbf{0 . 0 4 9}$ & -0.114 & 0.979 & 0.975 \\
DBN & 9.450 & 9.462 & 2.750 & 2.754 & -0.051 & $-\mathbf{0 . 0 5 3}$ & 0.988 & 0.984 \\
BPNN & 9.637 & 9.743 & 2.758 & 2.885 & 0.227 & 0.349 & 0.985 & 0.984 \\
\hline
\end{tabular}

On the testing dataset, the LSTM score was the smallest and the C-LSTM score was the highest in terms of the RMSE and MRE indicators, indicating that the deviation between the predicted record and the actual observation of LSTM was smaller with a better predictive accuracy than the benchmark models while, C-LSTM had the worst predictive accuracy. In terms of the goodness-of-fit indicator R, four models performed very close, and can fit the passengers flow well, but the fitting effects of LSTM and C-LSTM were the best and worst, respectively. In terms of PBIAS, the scores of all the models were small and all the score ranking were "excellent" [39]. However, C-LSTM and DBN performed better, while BPNN exhibited the worst. Except that BPNN underestimated the actual value on an average, the other three models overestimated the actual value on average.

\subsection{Predictive Accuracy Test among Groups}

In order to determine whether there exists a sharp distinction in the predictive accuracy between LSTM and its counterparts, the percent error $\Delta=\left(y_{t}-\hat{y}_{t}\right) / y_{t}$ of each network was applied for the t-test, where $y_{t}$ and $\hat{y}_{t}$ represented the actual passenger flows and the predicted values, respectively. The essence of the t-test was to confirm whether the average value of the predictive accuracy between the developed network and each benchmark counterpart was equal. The following statistical assumptions were made:

Hypothesis $\mathbf{0}\left(\mathbf{H}_{\mathbf{0}}\right)$. There is no difference in the predictive accuracy between LSTM and the benchmark model.

Hypothesis $\mathbf{1}\left(\mathbf{H}_{\mathbf{1}}\right)$. The predictive accuracy between LSTM and its competitor model is not equal. 
The testing outcomes are illustrated in Table 4 . As seen from the table, the $10 \%$ significance level rejects the hypothesis that the predictive accuracy between LSTM and DBN is equal; while for LSTM, C-LSTM and BPNN, the 5\% significance level rejects the null hypothesis. This implies that there exists an obvious distinction in the predictive accuracy between the constructed method and its competitors.

Table 4. Test of significance between LSTM and its competitors.

\begin{tabular}{cccc}
\hline Model & M_Diff & t-Statistic & $p$-Value \\
\hline C-LSTM & $-4.434 \times 10^{-4 * *}$ & -3.046 & 0.013 \\
DBN & $-2.045 \times 10^{-3 *}$ & -0.177 & 0.064 \\
BPNN & $8.691 \times 10^{-4 * *}$ & -2.263 & 0.044 \\
\hline
\end{tabular}

Note: M_Diff represents the mean of the relative error between LSTM and its competitor model; ** and * respectively denote significance at $5 \%$ and $10 \%$ levels.

In general, because the LSTM model can detect and learn the long-time dynamic information of the time series, it produces minimum error rate for the monthly passengers flow with periodic fluctuation characteristics, which agree with the conclusions of Aggarwal and Aggarwal [24] as well as Heaton et al. [40]. As C-LSTM failed to utilize the consumer query index as its inputs, its predictive accuracy was obviously different from that of LSTM at a 5\% level of significance, and the error rate MAPE on the test section increased by $27.303 \%$, which fully proved that the addition of the search query data drastically improved the forecasting performance of the models thereby, further confirming the conclusions of Zhang et al. [5] and Law et al. [25]. BPNN had a poor predictive ability due to its difference in the model structure from the DL method. Due to the disadvantages of the DBN in learning and storing long-term information, the learning ability of DBN was slightly worse than that of LSTM, and the predictive accuracy was slightly different at the $10 \%$ level of significance.

\section{Conclusions}

Hotel accommodation demands exhibit a cyclical fluctuation and complex nonlinear characteristics. Considering that the traditional prediction techniques cannot meet the ever-increasing data samples, and unable to automatically extract feature information, a forecasting framework based on DL was constructed in this paper. Taking Hainan in China as an empirical example, the LSTM model with a good predictive power for the complex time series was developed, and the Internet query index was used as the model inputs to forecast the overnight passengers flow of tourist hotels. The experimental outcomes implied that as compared to the benchmark models, LSTM improved the model predictive ability to different degrees, displayed satisfactory prediction ability and powerful generalization, and can simulate the dynamic characteristics of the passenger flow as well.

The preferable forecast performance can be attributed to the following three aspects. Firstly, additional memory units and special network structures enable the LSTM to learn the complex dynamic information of the passengers flow time series with a relatively large sample. Therefore, as compared to the DBN model, the LSTM model can learn the characteristic information of the passenger flows, which obviously improves the predictive ability of the model. Secondly, with the advent of the Internet environment, the consumer's information query objectively reflects the potential demands for travel, and can forecast the trend of the overnight passenger flows of tourist hotels in advance. Therefore, the incorporation of the network query index makes the LSTM model better fit the dynamics of the overnight passenger flow in tourist hotels, and significantly improves the predictive performance of the developed LSTM network, which agree with the theoretical analysis. Finally, different optimization algorithms and a special network structure design make the learning ability and predictive ability of the LSTM significantly different from that of BPNN.

The research in this paper has a prominent theoretical significance. Firstly, an empirical framework based on web queries was constructed for the ever-growing sample of tourism data. Secondly, the LSTM deep learning model was introduced for the first time to forecast the hotel accommodation 
demands, extending the application of DL methods in hotel demand forecasting. Finally, it is confirmed that LSTM can simulate the relationship between the Internet queries and the tourism demands of hotels. This breaks through the limitations of the traditional forecasting technology and provides a typical application case for the deep integration of tourism data with a relatively large dataset, artificial intelligence and real economy.

As far as applications are concerned, the constructed forecasting framework provides a new solution for the hotel accommodation demand forecasting done by managers of tourism-related departments under the Internet environment, which helps tourism-related departments to dynamically monitor the hotel overnights; it provides decision support for realizing the information of the destination management. In addition, the constructed empirical framework can be used to forecast other destination demands such as hotel revenues, etc. It can further be extended to other similar prediction fields.

Nevertheless, in the context of the voluminous data, there may be other characteristic information that may reflect the tourists' potential tourism demands. In future research, it is necessary to further expand other sources of information reflecting the dynamic characteristics of the hotel accommodation demands. In addition, the volume of the available sample data collection limits the research results. As the data sample further increases, the validity of the empirical framework can be tested by the actual cases.

Author Contributions: Conceptualization, B.Z.; formal analysis, Y.P.; methodology, B.Z.; project administration, J.L.; software, B.Z. and Y.P.; visualization, Y.W. and J.L.; writing-original draft, B.Z.; writing-review \& editing, Y.P., Y.W. and J.L.

Funding: This research received no external funding.

Acknowledgments: This work was jointly supported by grants from the Chongqing Social Science Planning of China under grant No. 2017YBGL137, and a funding project for the Science and Technology Research Program of Chongqing Municipal Education Commission of China under grant No. KJQN201800520. The authors are grateful to the editors and the anonymous reviewers for their valuable comments and suggestions.

Conflicts of Interest: The authors declare no conflict of interest.

\section{References}

1. Weatherford, L.R.; Kimes, S.E. A comparison of forecasting methods for hotel revenue management. Int. J. Forecast. 2003, 19, 401-415. [CrossRef]

2. Song, H.; Li, G. Tourism demand modelling and forecasting-A review of recent research. Tour. Manag. 2008, 29, 203-220. [CrossRef]

3. Li, X.; Pan, B.; Law, R.; Huang, X. Forecasting tourism demand with composite search index. Tour. Manag. 2017, 59, 57-66. [CrossRef]

4. Chen, R.; Liang, C.R.; Hong, W.C.; Gu, D.X. Forecasting holiday daily passenger flow based on seasonal support vector regression with adaptive genetic algorithm. Appl. Soft Comput. 2015, 26, 435-443. [CrossRef]

5. Zhang, B.; Huang, X.; Li, N.; Law, R. A novel hybrid model for tourist volume forecasting incorporating search engine data. Asia Pac. J. Tour. Res. 2017, 2, 245-254. [CrossRef]

6. Sun, S.; Wei, Y.; Tsui, K.L.; Wang, S. Forecasting tourist arrivals with machine learning and internet search index. Tour. Manag. 2019, 70, 4165-4169. [CrossRef]

7. Pan, B.; Fesenmaier, D.R. Online information search: Vacation planning process. Ann. Tour. Res. 2006, 3, 809-832. [CrossRef]

8. Fesenmaier, D.R.; Cook, S.D.; Zach, F.; Gretzel, U.; Stienmetz, J. Travelers' Use of Theinternet; Travel Industry Association of America: Washington, DC, USA, 2009.

9. Choi, H.; Varian, H. Predicting present with Google trends. Econ. Rec. 2012, 88, 2-9. [CrossRef]

10. Yang, Y.; Pan, B.; Song, H. Predicting hotel demand using destination marketingorganization's Network traffic data. J. Travel Res. 2014, 53, 433-447. [CrossRef]

11. Yang, X.; Pan, B.; James, A.; Lv, B. Forecasting Chinese tourists volume with search engine data. Tour. Manag. 2015, 46, 386-397. [CrossRef] 
12. Huang, X.; Zhang, L.; Ding, Y. The Baidu Index: Uses in predicting tourism flows-A case study of the Forbidden City. Tour. Manag. 2017, 58, 301-306. [CrossRef]

13. Wei, J.R.; Cui, H.M. The Construction of Regional Tourism Index and Its Micro-Dynamic Characteristics: A Case Study of Xi'an. J. Syst. Sci. Complex. 2018, 38, 177-194.

14. Li, S.; Chen, T.; Wang, L.; Ming, C. Effective tourist volume forecasting supported by PCA and improved BPNN using Baidu index. Tour. Manag. 2018, 68, 116-126. [CrossRef]

15. Andrew, W.P.; Cranage, D.A.; Lee, C.K. Forecasting hotel occupancy rates with time series models: An empirical analysis. Hosp. Res. J. 1990, 14, 173-182. [CrossRef]

16. Schwartz, Z.; Hiemstra, S. Improving the accuracy of hotel reservations forecasting: Curves similarity approach. J. Travel Res. 1997, 36, 3-14. [CrossRef]

17. Pfeifer, P.E.; Bodily, S.E. A test of space-time arma modelling and forecasting of hotel data. J. Forecast. 1990, 9 , 255-272. [CrossRef]

18. Choi, J.G. Developing an economic indicator system (a forecasting technique) for the hotel industry. Int. J. Hosp. Manag. 2003, 2, 147-159. [CrossRef]

19. Aliyev, R.; Salehi, S.; Aliyev, R. Development of fuzzy time series model for hotel occupancy forecasting. Sustainability 2019, 11, 793. [CrossRef]

20. Pan, B.; Chenguang Wu, D.; Song, H. Forecasting hotel room demand using search engine data. J. Hosp. Tour. Technol. 2012, 3, 196-210. [CrossRef]

21. LeCun, Y.; Bengio, Y.; Hinton, G. Deep learning. Nature 2015, 521, 436-444. [CrossRef]

22. Zhu, X.; Vondrick, C.; Fowlkes, C.C.; Ramanan, D. Do we need more training data? Int. J. Comput. Vis. 2016, 119, 76-92. [CrossRef]

23. Hochreiter, S.; Schmidhuber, J. Long short-term memory. Neural Comput. 1997, 9, 1735-1780. [CrossRef]

24. Aggarwal, S.; Aggarwal, S. Deep Investment in financial markets using deep learningmodels. Int. J. Comput. Appl. 2017, 162, 40-43.

25. Law, R.; Li, G.; Fong, D.K.C.; Han, X. Tourism demand forecasting: A deep learning approach. Ann. Tour. Res. 2019, 75, 410-423. [CrossRef]

26. Chang, Y.W.; Tsai, C.Y. Apply deep learning neural network to forecast number of tourists. In Proceedings of the IEEE International Conference on Advanced Information Networking and Applications Workshops, Taipei, Taiwan, 27-29 March 2017; pp. 259-264.

27. Gnoth, J. Tourism motivation and expectation formation. Ann. Tour. Res. 1997, 24, 283-304. [CrossRef]

28. Pearce, P.L. Tourist Behaviour and the Contemporary World; Channel View Publications: Bristol, UK, 2011.

29. Vila, T.D.; Vila, N.A.; Alén González, E.; Brea, J.A.F. The role of the internet as a tool to search for tourist information. J. Glob. Inf. Manag. 2018, 26, 58-84. [CrossRef]

30. Jeng, J.; Fesenmaier, D.R. Conceptualizing the travel decision-making hierarchy: A review of recent developments. Tour. Anal. 2002, 7, 15-32. [CrossRef]

31. Dean, J.; Corrado, G.S.; Monga, R.; Chen, K.; Ng, A.Y. Large Scale Distributed Deep Networks; Advances in Neural Information Processing Systems: Vancouver, BC, Canada, 2012; pp. 1223-1231.

32. Lake, B.M.; Salakhutdinov, R.; Tenenbaum, J.B. Human-level concept learning through probabilistic program induction. Science 2015, 350, 1332-1338. [CrossRef]

33. Goodfellow, I.; Bengio, Y.; Courville, A. Deep Learning; MIT Press: Cambridge, MA, USA, 2017.

34. Hinton, G.; Deng, L.; Dong, Y.; Dahl, G.E.; Mohamed, A.; Jaitly, N.; Senior, A.; Vanhoucke, V.; Nguyen, P.; Sainath, T.N. Deep neural networks for acoustic modelling in speech recognition: The shared views of four research groups. IEEE Signal Process. Mag. 2012, 29, 82-97. [CrossRef]

35. Chollet, K. Keras. Available online: https://github.com/fchollet/keras.2015 (accessed on 5 September 2017).

36. Hadavandi, E.; Shavandi, H.; Ghanbari, A.; Abbasian-Naghneh, S. Developing a hybrid artificial intelligence model for outpatient visits forecasting in hospitals. Appl. Soft Comput. 2012, 12, 700-711. [CrossRef]

37. Gupta, H.V.; Sorooshian, S.; Yapo, P.O. Status of automatic calibration for hydrologic models: Comparison with multilevel expert calibration. J. Hydrol. Eng. 1999, 4, 135-143. [CrossRef]

38. Hinton, G.E.; Osindero, S.; Teh, Y. A fast learning algorithm for deep belief nets. Neural Comput. 2006, 18, 1527-1554. [CrossRef] [PubMed] 
39. Moriasi, D.N.; Arnold, J.G.; Liew, M.W.V.; Bingner, R.L.; Harmel, R.D.; Veith, T.L. Model evaluation guidelines for systematic quantification of accuracy in watershed simulations. Trans. ASABE 2007, 50, 885-900. [CrossRef]

40. Heaton, J.B.; Polson, N.G.; Witte, J.H. Deep Learning in Finance. Working Paper. Available online: https://arxiv.org/pdf/1602.06561.pdf (accessed on 10 April 2018).

(C) 2019 by the authors. Licensee MDPI, Basel, Switzerland. This article is an open access article distributed under the terms and conditions of the Creative Commons Attribution (CC BY) license (http://creativecommons.org/licenses/by/4.0/). 
Article

\title{
"On Holidays, I Forget Everything... Even My Ecological Footprint": Sustainable Tourism through Daily Practices or Compartmentalisation as a Keyword?
}

\begin{abstract}
Amélie Anciaux
Institute for the Analysis of Change in Contemporary and Historical Societies, Interdisciplinary Research Centre for Democracy, Institutions, Subjectivities, Université catholique de Louvain, 1348 Louvain-la-Neuve, Belgium; amelie.anciaux@uclouvain.be

Received: 27 June 2019; Accepted: 18 August 2019; Published: 30 August 2019

Abstract: In today's struggle against climate change and for less dependence on fossil fuels, why do people who adopt practices with a lower impact on the environment forget them during their holidays? This contribution sheds new light on sustainable tourism by focusing on daily practices during holidays. Based on the concrete practices of holidaymakers, this contribution proposes to understand some factors and contexts favouring the persistence, the transformation or the abandonment of sustainable practice(s) during holidays. The theoretical framework of this research mainly draws on social practice theories. The empirical material is made of 38 biographical in-depth and crossed interviews: twenty on daily practices with young adults (25-35 years old) who have adopted at least one more sustainable daily practice and who went on holidays for the past year reinforced by 18 interviews with some of their parents.
\end{abstract}

Keywords: tourism; compartmentalisation; sustainable daily practices; young adults

\section{Introduction}

Alternative consumption is of growing interest in today's society and every area seems to be affected. Eating local products, saving energy, wearing second hand clothes, and shopping in bulk have become fashionable and encourage new forms of practices. Tourism is not to be outdone. With the rise of this new way of consuming and travelling, the adoption of practices with a lower impact on the environment could be considered as a homogeneous and common phenomenon. The purpose of this article is to show that it is not the case, as demonstrated by comparing practices in the everyday life and practices during holidays. Do the more sustainable practices adopted during daily life persist during touristic holidays? How and why?

For the last twenty years or so, there is an abundant scientific literature on sustainable consumption [1-4] and "green" tourism [5-7]. Nevertheless, over the last decade, these first waves of research have been widely criticized [8-13], particularly because they systematically consider that the individual is the main driver of change. This article is part of this critical movement in applying social practice theories $[14,15]$ as a theoretical framework.

The second special feature of this article is that it develops a theme that is not yet well explored, namely the persistence of sustainable practices during holidays. Indeed, while there is research on the relationship between tourism and the ecological footprint [16-18], or between tourism and transport use [19-21] and still other studies on sustainable tourism practices [22-25], there is very little research linking home-based and tourism-based sustainable practices $[10,26]$.

The originality of this article is therefore to observe sustainable tourism through the daily practices adopted by holidaymakers. The approach of this article is to consider holidays as a period delimited in 
time in order to compare (un)sustainable practices adopted on holidays with those of everyday life in two areas: mobility and food. Since the focus is on tourists' practices, this article may be of interest to tourism professionals so that they could better understand their customers' levers and barriers about maintaining sustainable practices even while they travel.

To this end, this paper adopts an innovative theoretical framework based on theories of social practices. Data are collected through twenty in-depth interviews with young adults (25-35 years old) from all of the French-speaking provinces of Belgium. These interviews were crossed with those of some parents of these young adults in order to reinforce the quality and veracity of the information obtained. After a theoretical framing on sustainable consumption, tourism, and practices, the presentation of results is divided into two distinct parts: the first answers the titular question by a descriptive comparison between the practices of daily life and those adopted during holidays, and the second attempts to identify some avenues for better highlighting some distinct dimensions of these practices.

\section{Theoretical Framework}

The theoretical part of this article focuses successively on sustainable consumption, tourism, and social practices. Each term will be defined and the position of this article in relation to each topic is explained.

\subsection{Sustainable Consumption}

In June 1992, the Earth Summit took place in Rio de Janeiro. In line with the Brundtland Report published in 1987 [27], 179 head of states took the decision to address sustainable development issues. It is on this occasion that the terminology "sustainable consumption" appears for the first time on the international political agenda [28,29]. In 1994, at a round table during the Oslo Symposium on Sustainable Consumption, the Norwegian Ministry of the Environment proposes this working definition of sustainable consumption and production: "The use of services and related products, which respond to basic needs and bring a better quality of life while minimising the use of natural resources and toxic materials as well as the emissions of waste and pollutants over the life cycle of the service or product so as not to jeopardise the needs of future generations" [30].

While this definition is regularly criticized (in particular because it combines the concepts of sustainable production and sustainable consumption in the same definition), it must be noted that no other definition has so far been unanimously accepted. Moreover, other criticisms, including those of Latouche [31,32], also highlight the fact that "consumption that is called critical, responsible, or ethical and Fair Trade can appear to be oxymorons on a par with sustainable development. The need to free ourselves from consumerism is as great as, if not greater than, that of putting an end to developmentism. Slogans such as 'consume ethically' and consumption in a 'de-growth' perspective 'buy fair' are contradictory and perverse, for they conserve the core problem, i.e., the consumption imperative" [32] (p. 181).

While it is difficult if at all possible to define what sustainable development is, it is equally complicated to define what sustainable practices are. Indeed, outlining the exhaustive limits of what exactly a "green" practice is a complex exercise that has not yet been achieved in the current literature. The core of the problem is that defining the "sustainability" feature is a combination of environmental, technological, social, ethical, and philosophical dimensions that are difficult to delimit. As an example, taking the train to go to work could be considered a sustainable practice. Nevertheless, taking the train implies favoring nuclear energy over fossil energy (at least in Belgium), which may be questionable given the risks (environmental and human) associated with nuclear power plants. On the other hand, taking the train is considered a "green" practice, especially if it replaces the car because it limits global warming. However, is it still a "green" practice if the bike is abandoned in favor of the train? 
In the context of this article, "green" practices are what is commonly accepted as such by public opinion (e.g., using public transport, reducing daily meat consumption) without implying that "green" practice refers to a necessary environmental motivation behind the practice [33].

\subsection{Tourism and Sustainable Tourism}

As in other Western societies [34,35], Belgian touristic demand has been growing every year since 1945. At the same time, deeper attention to sustainable tourism seem to be making a real breakthrough in the area over the last years. The United Nation World Tourism Organization (UNWTO) defines sustainable tourism as "tourism activities that can be maintained, or sustained, indefinitely in their social, economic, cultural and environmental contexts" [35] (p. 1). This concept has led to an impressive literature: the International Centre for Tourist Research and Studies (CIRET) [36] lists no less than 150,000 tourism-related items, including around 5000 dealing specifically with sustainable tourism.

According to Buckley [37], who conducted an extensive state-of-the-art review on the subject, studies on sustainable tourism issues are divided into two phases. The first appeared at the end of the 1980s and was mainly carried out by geographers. These works were based on the assumption that "sustainable development is inherently good and appropriate for tourism, and that its adoption will solve many of the negative problems that have resulted from the development of tourism" [17] (p. 8). The second period comes ten years later and is mainly based on the criticism of this concept $[11-13,38,39]$.

In addition, many sociologists also draw attention to the fact that framing of sustainable tourism is also being taken over by social psychologists and social marketers who are developing theories that emphasize individual will and responsibility [34,40]. Hall [33] reviews different approaches to studying the adoption of sustainable holiday practices and concludes that: "without facing up to the implications of structure and institutions then the likelihood of tourism activities and behaviours being "locked-in" to particular unsustainable socio-technical systems of provision is greatly increased" [34] (p. 1103).

This article is part of this critical trend as it proposes to analyze sustainable tourism through the persistence or non-persistence of sustainable daily practices during the holidays.

\subsection{Studying Sustainable Behaviours vs. Sustainable Practices}

The popularization of the concept of sustainable development leads to various initiatives, declarations and watchwords [41], political and private companies decisions [42,43], and activist movements $[44,45]$. The main objective of these initiatives was to "expect consumers to exert a significant favourable influence [on the environment]" [41] (p. 1). Indeed, according to Shove and Spurling, "[i]n popular and policy discourses, it is usual to explain such changes as outcomes of individual choices" [46].

Moreover, in the academic sphere, social psychologists and economists took up the field of sustainable consumption [9] and mainly used the rational action paradigm [1,2] based on individuals and behaviours. These reflections lead to the creation of different "green" consumer behaviours $[3,4,47]$ based on variables such as environmental values, education or personal motivations [48]. These psychosocial theories have two points in common: the unit of analysis is systematically the individual and the basic premise is that "moving towards a more sustainable society depends on helping people to make better choice" [46] (p. 1). From this point of view, the adoption of sustainable practice therefore depends only on an individual's willingness to change. Sociologist E. Shove [8] ironically reinvests the ABC (Attitudes, Behaviour, Context) model developed by P. Stern by changing the "Context" by "Choices." She explains that the intervention strategies put in place for the adoption of sustainable behaviours are based on a presupposition that considers "that environmental damage is a consequence of individual action and that given better information or more appropriate incentives damaging individuals could choose to act more responsibly and could choose to adopt "pro-environmental behaviours" [8] (p. 1275). 
Nevertheless, over the past two decades or so, consumption theories have experienced a "practice turn" [49] in the sense that "attention has turned from individual consumers to the cultural, material and economic structuring of consumption" [46] (p. 3). By shifting the focus from behaviours to practices, theories of social practices "provides some new insights into how consumption is organized and how it might best be analysed" [50] (p. 132).

\subsection{Social Practices Theories}

Following this line of thought, the theoretical framework of this article is based on the theories of social practices. This stream of thought was initially inspired by the philosophy of Wittgenstein, the sociology of Bourdieu, Giddens' theory of structuration [51] but also by scientific concepts from the area of science and technology [52]. These theoretical frameworks do not constitute a corpus of homogeneous contributions but represent "a multiple theory that commonly adopts a conceptual position towards culturally oriented research" [53] (p. 638).

Concerning the definition of the practice, most authors of this theoretical stream agree on the two definitions given by Schatzki that define practice as a performance and as "a temporally unfolding and spatially dispersed nexus of doings and sayings" [14] (p. 89). For Schatzki, practice as performance refers to "the doing, the actual activity or energization, at the heart of action. (...) It designates the continuous happening at the core of human life, which is one of the most important features of the world" [14] (p. 90). To exist, a practice therefore must be performed, in other words, translated into concrete action. From the second definition of a practice, Schatzki lists various components that make up a practice: know-how and routines, institutionalized procedures and teleoaffective structures. Reckwitz [15] adds a fourth component, technologies and physical structures. The components are therefore constitutive of a practice.

A major characteristic of this framework is that the practice becomes the unit of social analysis. The objective of these theories is indeed to "put the practice in the foreground and therefore the individual in the background" [54] (p. 22). Therefore, it is no longer the individual who adopts a practice, but the practice itself that recruits the individual. The individual is also called "practitioner" [14] and is therefore the "carrier" of the practice in the sense that he constitutes "the unique crossing point of practices, of bodily-mental routines" [15] (p. 256). In this way, practices do not necessarily appear homogeneous, either among themselves nor among the different practice carriers. This line of thought will be applied empirically in the first section of the results below.

Warde [55] distinguishes two successive waves in social practices theories. The first generation lays the foundations of this framework and is invested by various theorists of the twentieth century (Bourdieu [56], Foucault, Giddens, de Certeau, ... ). The initial objective of the first wave was to overcome the traditional dualism between structure (holist vision) and actor (individualistic vision) [50]. This willingness to reconcile the holistic view with the individualist is originally articulated by A. Giddens who states that "the basic domain of study of social science, according to the theory of structuration, is neither the experience of individual actor, nor the existence of any form of societal totality, but social practices ordered across space and time" [57] (p. 2).

The second generation aims to test and deepen the theoretical concepts established by the first wave of theorists. Therefore, they have aimed to abandon a static vision of the practice that would manifest in an individual, either passive and undergoing structural dictates, or totally self-determined. To do this, they focus on the practices as such and consider that they are "structured and organized through three dimensions: practical understanding; explicit rules; and teleoaffectivity “[58] (p. 300). These different dimensions inspire the analysis of the second part of the results' section.

\section{Data and Methods}

The following presentation is based on Tong's article of [59] that provides a set of 32 items to be explained how reporting on a qualitative research. Data were collected in Belgium as explained below. 


\subsection{Data}

The qualitative method used in this research is the in-depth interview, defined by Boyce and Neale as a "qualitative research technique that involves conducting intensive individual interviews with a small number of respondents to explore their perspectives on a particular idea, program, or situation" [60]. My objective was to obtain a narrative of practices in the sense of Bertaux [61], that is to say a set of in-depth and meticulous descriptions of personal experiences as far back the interviewees could remember.

The topics of these interviews include the following: practices related to food, to shopping for grocery and clothes, as well as practices related to mobility. The 'history' of these practices was searched for by the researcher with each participant.

This research includes 36 in-depth interviews: 20 in-depth interviews with young adults reinforced by 16 in-depth interviews with some of their parents. In this article, only the practices of young adults will be studied, but all the interviews will be considered. These cross-interviews on two generations $[62,63]$ as well as between siblings are interesting because they solidify the quality of the data collected individually while providing key information for understanding family dynamics and the construction and evolution of consumption practices. I conducted the face-to-face interviews from September to November 2018 in all the provinces of French-speaking Belgium. I always met the interviewees at their home.

I interviewed 22 young adults, of whom 20 went on holiday during the last year and are therefore included in this study. All the young adults interviewed are between 24 and 36 years old and were born between 1982 and 1994. These generations are very relevant because they were born with the issues of sustainable development and environmental protection. This age group is also one experiencing many changes: entering the labour market, leaving their parents' home, having children, and so forth. The situations specific to this period of life can also encourage or hinder the adoption of practices with a lower impact on the environment. Indeed, it is during this transition period that young adults adopt their first real consumption practices. For example, how and with what to fill the fridge? Where to go for groceries? How to get there? Which products to buy? Where and how to go on holiday? How to get around on a daily basis? As long as they live with their parents, they are always dependent on them.

The young adults have been selected on three common characteristics: they have all left their parents' family home; they have all adopted in their daily lives at least one practice presumed to have a lower impact on the environment; they all have at least one parent who was available for an interview. Among these young adults, three are only children, three are couples, and in two cases both of two siblings were interviewed. They are also young people with a relatively high socioeconomic level and belonging to the upper-middle social class. Twenty out of 22 have a higher degree (POA or Master's degree). It can therefore be assumed that financial resources are rather homogenous within the sample. Sociodemographic data of the young adults are provided in the Appendix A (Table A1). To preserve anonymity, all first names have been changed.

The interviewees were recruited from different channels: by sending emails to managers of local transition initiatives linked with sustainable consumption (such as groups buying local, organic and seasonal food products; Repair Cafés; etc.) and by attending events about sustainable practices (such as conferences on zero waste or vegetarianism). The particularity of the presentation of the research to the respondents is to be highlighted, as the initial topic announced did not mention reflexion on the sustainability dimension of the practice. Respondents were told that the work focused on the transmission of habits across generations. The aim of this approach was to try to avoid social desirability bias [64] that would encourage a consciously or unconsciously "greening" of practices by respondents.

Regarding interviews with parents, the recruitment process is obviously different. I asked for their contact information once I had finished the interview with the young adults. The interview with the parents usually took place a few weeks after their children's interview. Even if the topics remained 
the same, the interview grids were enriched on a case-by-case basis according to the interviews of their children previously recorded. For example, if a young adult had related an interesting situation to me, I would be careful to have his/her parent(s) tell it to me as well. This allowed me to clarify some of the data but also to obtain a reinforcement and a new perspective on the data already collected.

The analysis below focuses on mobility and food practices compared in two different periods: in everyday life and during the holidays. Concerning holidays, only leisure tourism was considered. In other words, business travel was systematically excluded from the data used in this contribution. In addition, only stays of three nights or more were taken into consideration. The interests concerning daily living practices were similar to those during the holiday period. The objective was to obtain the most detailed description for each practice studied.

\subsection{Method}

All interviews were recorded before being entirely transcribed and custom-coded using the qualitative analysis software NVivo. The coding made it possible to obtain cross-tabulated information between the different practices (related to food and mobility), the different age groups (young adults and their parents) and the different periods analysed (daily life and holidays).

Using Kaufmann's approach [64], an in-depth vertical analysis was carried out for each interview in order to prepare to trace the career of each practice described by the young adults. The parents' interview reinforced the data previously collected by providing new insights into certain situations. This first step was followed by an overall horizontal analysis that revealed some recurrences and other trends that are explained in the Results section of this article just below.

Without claiming that these results may be exhaustive in any way (due to the number of observations and the limited number of the participants), the data collected by the in-depth interviews and consolidated by the cross-interviews provide numerous information that is to be processed. The results presented below are based on two ways of processing the data from these in-depth interviews: first, a more quantitative-oriented approach to observe certain interesting trends regarding mobility practices, second, content analyses to describe in detail food and grocery practices.

\section{Results}

The first section compares daily living practices in the categories of mobility and food with those adopted during holidays in order to see whether sustainable daily practices persist during the holidays. From these results, the second section analyses each component of the practice in order to highlight its impact on the adoption of sustainable practices.

\subsection{Which Holiday Destination and Which Mean of Transport?}

Out of the 22 young adults, 20 went on holidays during the last year. The destinations were the following ones: Belgium for one out of the twenty, France for eight, other Europeans countries (Denmark, Norway, Italy, The Netherlands and Spain for two of them [who are not in a relationship together]) for six others and non-European countries for the last five (Malaysia, Columbia, Indonesia and Costa Rica for two of them [who are in a relationship together]) (Table 1).

Table 1. Means of transport used in relation to the holiday destination.

\begin{tabular}{cccccc}
\hline & Belgium & France & Other Europ. Countries & Non-Europ. Countries & Total \\
\hline Plane & 0 & 1 & 5 & 4 & 10 \\
Car & 1 & 7 & 0 & 0 & 8 \\
Carpooling & 0 & 1 & 0 & 0 & 1 \\
Hitchhiking & 0 & 0 & 1 & 0 & 1 \\
Total & 1 & 9 & 6 & 4 & 20 \\
\hline
\end{tabular}

Source: In-depth interviews conducted with 20 young adults who left on holidays (2017-2018). 
Regarding the means of transport to reach their destination, ten took a plane: four to reach a non-European destination, five to reach a European country other than France, and one to reach France. The other ten used a car: mainly to go to France (this is the case for eight of them, including one who carpooled with friends), one to go to the Belgian coast and one who hitchhiked to Denmark. These trends corroborate these observed by Eurostat [65] the official European statistics website: France is the favourite tourist destination of Belgians and flying is the most popular for stays of more than four nights.

Table 2 allows having a look at the daily mode of transportation (rows) in relation to the mode of transportation adopted to travel to the holiday destination (columns). As for the nine adults who use a car as a main daily means of transportation, six of them flew: three of them to a non-European destination and three of them to a European destination (one of whom was flying to France). The other three took a car, one of which was a carpool.

Table 2. Daily transport (rows) vs. transport to reach the vacation destination (columns).

\begin{tabular}{cccccc}
\hline & Plane & Car & Carpooling & Hitchhiking & Total \\
\hline Public transport & 3 & 6 & 0 & 1 & 10 \\
Car & 6 & 2 & 1 & 0 & 9 \\
Bicycle & 1 & 0 & 0 & 0 & 1 \\
Total & 10 & 8 & 1 & 1 & 20 \\
\hline
\end{tabular}

Source: In-depth interviews conducted with 20 young adults who left on holidays (2017-2018).

Out of the 11 people who use public transport on a daily basis, 10 went on holiday. Three took the plane (two of them to a non-European destination while the remaining one went to Spain), and six others took a car to go to France, the Netherlands, or stay in Belgium.

These results are interesting in the sense that it appears there is no apparent persistence (or continuity) between daily practice and the mode of reaching the holiday destination. Moreover, it seems that the means of transport adopted to reach the holiday destination is, in most cases, "less sustainable" than the transport used on a daily basis. Indeed, six out of nine daily drivers flew, while six out of ten daily users of public transport mainly used a car for their travel.

\subsection{On-Site Mobility: By Car}

Regarding holiday mobility, once on-site, there is an obvious heterogeneity between the observed practices. First, everything depends on the means of transport used to get there (Table 3). Indeed, generally those who have travelled by car continue to use it during their stay. Only one exemption is observed: a woman traded her car for a bike once at her holiday spot (she went to the Netherlands).

Table 3. Transport to reach the holiday destination (rows) vs. transport on-site (columns).

\begin{tabular}{ccccccc}
\hline & Public transport & Car & Carpooling & Bicycle & Foot & Total \\
\hline Plane & 6 & 3 & 0 & 0 & 1 & 10 \\
Car & 0 & 7 & 0 & 1 & 0 & 8 \\
Carpooling & 0 & 0 & 1 & 0 & 0 & 1 \\
Hitchhiking & 1 & 0 & 0 & 0 & 0 & 1 \\
Total & 7 & 10 & 1 & 1 & 1 & 20 \\
\hline
\end{tabular}

Source: In-depth interviews conducted with 20 young adults who left on holidays (2017-2018).

For those who arrived by plane, mobility at the holiday destination is performed either by car rental or by use of public transport. Of those who opted for public transport once they landed, half do not have a driving license, therefore excluding use of the car. Those who went on holidays in non-European countries rent a car more easily.

Finally, Table 4 compares the daily means of transport (rows) with those used at holiday sites (columns). Car use represents half of the answers. Out of the nine who use a car as their main means 
of transport on a daily basis, five also adopt it to travel on holiday. Out of the ten who use public transport on a daily basis, half also opted for a car. Nevertheless, this comparison presents the highest homogeneity in the persistence of daily practices during the holidays: most people who drive a car daily also use a car for mobility once at their holiday destination.

Table 4. Daily mobility (rows) vs. holiday mobility (columns).

\begin{tabular}{ccccccc}
\hline & Public transport & Car & Bicycle & Carpooling & Foot & Total \\
\hline Public transport & 4 & 5 & 0 & 1 & 0 & 10 \\
Car & 2 & 5 & 1 & 0 & 1 & 9 \\
Bicycle & 1 & 0 & 0 & 0 & 0 & 1 \\
Total & 7 & 10 & 1 & 1 & 1 & 20 \\
\hline
\end{tabular}

Source: In-depth interviews conducted with 20 young adults who left on holidays (2017-2018).

These comparisons between home-based and tourism-based practices do not pretend to be exhaustive but draw attention to certain main trends. It can therefore be seen that with regard to mobility, the adoption of sustainable holiday practices takes place in a heterogeneous way, without necessarily corresponding to the sustainable practices adopted in daily life.

\subsection{Eating and Grocery Shopping}

Concerning the comparison between food in everyday life and food on holiday, four aspects evoked during the interviews are analysed: whether or not to follow a vegetarian diet, whether to eat local products, whether or not to eat organic products, whether to source or not bulk products.

Of the 20 young adults studied here, five are vegetarians in daily life, of whom three said they had eaten meat and/or fish during their holiday: "Well, when we're on vacation with our parents, we eat a little organic and fair trade fish. We're taking it upon ourselves. You see, I think you have to stay grounded in your own family". (Madeleine, F., 26-year-old, in couple without children, public transport user and vegetarian in daily life). Sometimes, the acknowledgment does not come from the person concerned but from his or her relatives as Clara about her partner: "Actually, my boyfriend doesn't eat meat at home, but he could eat meat when he goes out, or on vacation... for example if we go once to a restaurant. On vacation, let's just say it happens a little more often" (Clara, F., 25-year-old, without children, car driver and vegetarian) or Lise (F., 51-year-old) about her daughter and her son-in-law: "Yes, they had started by avoiding meat and fish but in fact, on holidays, they could eat some fish...even chicken." These first quotes already provide an insight into the role of relatives in the persistence of sustainable daily practices during holidays.

Seven young adults (including one vegetarian) reported that they use bulk supplies in their daily lives. However, only one mentioned it when it came to holiday food. Not mentioning bulk does not mean that no one buys bulk during the holidays. Nevertheless, this marks a difference between daily consumption where bulk is mentioned spontaneously and holiday food where almost no one refers to it. In addition, the only time bulk products are discussed during the holidays is to show how difficult this practice is.

"I'm trying to buy only bulk and not go to the supermarket anymore! But for example, when you go on a hike, I have to make a compromise. When we're on a hike, we're trying to lighten up so I bought soup bags in a supermarket. And while I was there, I bought some pasta... It is still local pasta but it is plastic wrapped. Then I also bought chocolate, because bulk chocolate is really very expensive... It's the same for dried fruit: it's single or double [the price]! When I buy things for the group, I don't dare to buy everything in bulk." (Lola, F., 30-year-old, in couple, without child, bulk consumer in daily life).

This quotation highlights again that sustainable practices of daily life are not especially transferred during holidays. But this quote also shows the influence of relatives and of friends in adopting practices and the compromises that must be made. 
Concerning the other two criteria (local food and organic food), the analysis proved to be more complicated because these are assimilated as systematically linked for some respondents; however, these links are not necessarily valid. As a result, most of the interviews focus on local food on holiday but few address the organic characteristic of their food. Jean-Baptiste's quotation clearly shows that conflation is quickly achieved: "At home, we eat only local and organic food. So, on holidays, food is basically the same as what we do here. We go grocery shopping, we eat local, we try to find local products." (Jean-Baptiste, M., local and organic food consumer in daily life). Finally, when the discussion came to local and organic food, it was essentially to demonstrate the complexity of getting it on holiday as Liliane says, "It is true that on a daily basis, eating organic food is one of my priorities. On the other hand, on holiday, clearly I am less attentive.... Actually, I don't know all the available options and I'm going to keep it simple" (Liliane, F., 32-year-old, local and organic food consumer in daily life).

Another recurrent conflation was to confuse locally produced food and local food specialities as Alix does: "I eat local food home and away. For example, in Asian countries, I eat the typical dish. I'm not going to a French restaurant while I'm in India. I prefer to eat local!" (Alix, F., 26-year-old, became vegetarian after her three-month trip in Malaysia). There is no guarantee that the typical dish will be cooked with local products but Alix seems to think so.

Concerning food, it is clear once again that the adoption of more sustainable practices during holidays does not take place in the same way as in everyday life. Here too, it seems difficult to observe recurrences or homogeneity across the various interviews, but it must be noted that more the sustainable practices adopted in everyday life are not systematically transferred to holidays. Except for daily mobility versus holiday on-site mobility, there is little consistency between sustainable practices during periods of tourism versus everyday.

\subsection{Understanding Compartmentalisation Through the Lenses of Social Practice Theories}

Based on the three components of practice defined by Schatzki [14] as well as the one added by Reckwitz [15], this second part of the article attempts to better understand the reasons for variations observed between the adoption of sustainable practices in daily life and on holidays. This section provides an opportunity to empirically apply the conceptual framework of social practices theories by starting once again from the practices related to the means of transport used to reach the holiday destination, to mobility on-site, and then to eating and grocery shopping. The last subsection highlights some dimensions that are not yet (or very seldom) taken into account by these theories.

\subsubsection{Material Structures: Planning a Trip without Leaving One's Sofa}

Today, a set of material arrangements (such as low-cost airlines, online accommodation booking platforms, travel agencies, etc.) allow planning for tailor-made, fast and cheap holidays. These new structures correspond to material structures and are defined as "objects, infrastructures, tools, hardware and the body itself" [66]. Material structures are essential to the realization of any practice since they are the concrete "equipment" necessary for the realization of the practice. This quote of Nathan clearly illustrates this dimension:

"I wanted to go to Spain and I was really sick of everything, so I booked it in two minutes: fast and efficient from my couch. I packed my backpack, took a plane and found myself in northern Spain without really knowing where I was going." (Nathan, M., 32-year-old, vegetarian and car-driver in daily life)

Indeed, it is nowadays possible to plan a trip without leaving one's sofa. Regularly, new material structures appear (e.g., the Airbnb platform, which now allows renting a room or entire accommodation in any city of the world) to facilitate tourism. These material structures obviously encourage going on holidays, making the various planning and booking processes much more accessible and further, encouraging destinations beyond the country's borders. 
Sustainable tourism is no exception. Nevertheless, even if sustainable tourism offers are increasingly developing, it is still not enough to allow systematically the adoption of practices with a lower impact on the environment. Indeed, sustainable alternatives are sometimes lacking or are too expensive, impending the adoption of sustainable practice during holidays as Caroline explains "If I had more money, I would go on holiday by train rather than by plane, I think! But flying is easy, it's cheap. When I'll be rich and famous, I'll take the train!" (Caroline, F., 28-year-old, cyclist in daily life). These material structures can also be mobilized to justify the non-adoption of sustainable practice, as is the case in the two quotations above. Michel uses the lack of material structures as an excuse. He considers that material structures do not allow him to travel in any other way: "We do not like all-inclusive hotels, but sometimes we have no choice but to go there" (Michel, M., 35-year-old, car-driver and vegetarian in daily life). According to him, he is "forced" to adopt an unsustainable practice because of the limited offers. These contradicts the ABC psychology model and is therefore in line with Shove's approach [8] who demonstrates that the adoption of sustainable practices is not only a matter of personal willingness to change. Nevertheless, it seems that the desire to go on vacation outweighs ecological considerations. At no time does Michel question going on holiday. This observation also corroborates [10] who says that people who are aware about the impact of their practices on the environment are "not actually willing to reduce their flying habits significantly" (p. 480).

Therefore, it can be concluded that the lack of a sustainable material structure does not prevent people from going on holiday, even for environmentally sensitive individuals. If a sustainable option can be found among the material structures, so much the better for them, if not, never mind.

\subsubsection{A Matter of Habit}

Out of these 22 young adults, 20 said they went on holidays annually when they lived with their parents. Therefore, all the stories of practices report annual holidays, and this as far back as they can go back in the narration. Indeed, when the question of holidays during childhood is asked, all informants could describe certain family routines, such as Alix Luc and Aude.

"During the family holidays ... We never went to a hotel, it was always camping. It was in Spain or in South of France. We went once to Turkey, to the hotel. This is the year my dad sold some land, so we had a little more money (she laughs). But it has never been a luxury vacation." (Alix, F., 26-year-old, vegetarian, public transport user in daily life, went to Malaysia last year).

"With my parents, it was always the North Sea ... because my mother is extremely scared of the plane. I think she does not like the train too much, nor the boat ... (... ). And then, we went 2-3 weeks a year to the North Sea. I would say that we went maximum three times elsewhere, that is to say: in France." (Lucas, M., 29-year-old, vegetarian, car-driver in daily life, went to the North Sea last year).

"Every year, since I was as young as I remember, we always went to the mountains with my parents during the summer. The tradition stopped last year as Coralie and I, and our boyfriends, are working, so it was difficult to coordinate everyone." (Maud, F., 26-year-old, vegetarian, public transport user in daily life, went to France last year).

If the destinations are less exotic than those described previously (perhaps namely because all the tools facilitating accessibility for far away destinations did not exist and/or were much more expensive at the time), these quotes show the regularity that these young adults experienced in their childhood vacations: each year they left with their family during the summer. Once adults, they reclaim this practice (choosing nevertheless more exotic destinations) but continue the tradition. The routines adopted beginning in childhood continue to adulthood even if they are updated. It is therefore a deep anchoring and this observation testifies to the routine nature of a practice [14] while highlighting the difficulty in changing practices. 


\subsubsection{Teleoaffective Structures: Between Social Distinction and Guilt}

Another of the main components of the practice is the teleoaffective structure that Schatzki [14] defines as "embracing ends, projects, tasks, purposes, beliefs, emotions and moods" (p. 89). The justifications given by young adults are part of teleoaffective structures. In a spirit of synthesis, only two dimensions are addressed in this section. The first one concerns the symbolic importance of holidays, especially concerning which holiday destinations and the means of transport used to get there. The second dimension deals with feelings of guilt about holidays. Why does going on holidays remain non-negotiable while the guilt of leaving is sometimes heavy to bear individually?

The two quotations below show indeed the existing societal standard for the holiday area. Indeed, Lucas clearly justify his type of vacation by implying that some are better than others:

"As I have more money, my life stabilizes; I make sexier trips ... Like Tuscany, Southern Spain, and South of France, places where I was not especially before ... and I also did City trips to Paris, London, and Amsterdam." (Lucas, M., 28-year-old, vegetarian in daily life).

Mégane's quote goes in the same direction when she explains this:

"I went for a month in Peru. The year after, I went to Nicaragua... That's the way it is: I like to go to the South, generally. But last year ... You know, with the opening of the store [hers], I could not make big follies. So we just went to the South of France with a caravan." (Mégane, F., 27-year-old, public transport driver in daily life)

Here, Mégane's quote is enlightening. While at the beginning of the interview, she explained how practical it was to travel in a caravan, she nevertheless admits later that this style of vacation is a default option because of a lack of financial resources. She also implied that if she had had the opportunity, she would have gone to another destination.

These quotes show the gradation between the different destinations and means of transport: travelling to the North Sea or the South of France by caravan does not mean the same thing as going to Peru or Nicaragua by plane. This may reflect the importance of holidays in the current social system and the role of holidays in identifying with a social class. That is what Crick says: "the world of tourism is rife with the class distinction in our everyday world" [67] (p. 334). In this sense, holidays could be seen as a form of ostentatious consumption in the sense of Veblen [68]. Moreover, the two young adults of the sample who did not go on holiday during the last year are two women who have a slightly lower socio-economic level compared to the rest of the sample. These reflections emphasize the importance of social classes according to the holiday style adopted.

While holidays are socially normalized [69] and routinized in the daily lives of the rather well-off young adults, some feel a strong sense of guilt. Indeed holidays can be seen as a parenthesis of pleasure often avoided in daily routines sometimes strict, but still a source of guilty for young adults who have internalized environmental issues. Nevertheless, it is also interesting to note that just because guilt is present individually, it does not mean that the practices that have the greatest impact on the environment cease as Aude's testimony shows: "We know that flying is not good for environment, but we still do it: we need it too much!"(Aude, F., 35-year-old, practicing voluntary simplicity) or the quotes of Camille and Alix:

"I love spending Christmas in the mountains [that means at least $700 \mathrm{~km}$ away from her place] because I love the spirit that prevails there. But at the same time, I feel quite guilty because I succumb to a commercial trend... Lights, gifts, packaging, ice rink... I'm participating in a huge ecological disaster!" (Camille, F., 24-year-old, went to Norway by plane last summer)

"When you fly over Malaysia, you only see palm fields, and already you think it's a problem. Then you land and you see the pollution of the sea and then you think about biodiversity, nature, animals. You see the streets filled with dirt, and garbage. I was just obsessing about it, and I felt so bad... I was 
so shocked. And at the same time I felt responsible and helpless." (Alix, F., 26-year-old, became vegetarian after her three-month trip in Malaysia).

Here, these quote show that responsibility is individualized, placed on the shoulders of each individual. This gives the impression that climate and environmental issues are a set of problems that can be solved personally rather than as a global problem beyond the individual level. These results corroborate Barr who explains that over the last 20-25 years, a fundamental shift has occurred in environmental issues: "policy has begun to shift from a 'top-down' approach to a 'bottom-up'" one [70] (p. 51). As Barr explains it, initially ecological problems were discussed on a macro scale such as related to governments and major organisations. However "in recent years, there has been a growing emphasis on the role of individual consumers and their potential to mitigate against global, as well as local, environmental problems" [10] (p. 474).

Therefore, the adoption of a sustainable practice does not result solely from an individual's desire for change. Good will is not enough to green everyday practices. Holidaymakers are aware of the impact of their practices on the environment, some even feel guilty, yet they continue to leave. These results corroborate Shove [69] saying that "the vast majority of environmentally significant consumption is not a matter of individual choice, green or otherwise. It is instead bound with, and constitutive of, irredeemably social practices governed by norms like respectability, appropriateness, competence and excellence" (p. 198).

4.4.4. "Thinking Globally, Acting Locally": The Focus of Institutionalized Procedures on Individual Practices

The fourth component of a practice is institutionalized procedures which refer to "the structural properties involv[ing] elements of meaning and communication, control and power relations, and legitimacy" [71] (p. 2491). Some institutionalized procedures could also have an influence on whether or not sustainable practices are adopted during holidays. So, the non-taxation of kerosene by European countries and paid holidays just before summer holidays (in Belgium) are two elements of institutionalised procedures.

First, a leaked report commissioned by the European Commission finds that the European aviation sector is chronically undertaxed relative to other aviation markets and other means of transport. The report was completed last year. It has not yet been made public but has been distributed by the NGO Transport \& Environment. The report focused on three different forms of taxation: a tax on the ticket purchased by the passenger, value added tax (VAT) on the same ticket, and the tax on kerosene which is used for jet fuel. For now, no European member country applies a tax on kerosene, while other countries such as the United States, Japan or Canada do (1 cent, 14 cents and 8 cents/litre, respectively). VAT was defined at $0 \%$ by an EU directive (2006/112/EC) but this did not prevent several countries from applying VAT, from $6 \%$ in Portugal to $25 \%$ in Croatia. By the way, seven Member States apply taxes on kerosene at an average of $€ 11$ per ticket. By comparison, Australia, Brazil or Mexico apply a tax on kerosene of around $€ 30-40$ per airline ticket [72]. Such state decisions are likely to influence whether or not practices with a lower environmental impact are adopted.

Moreover, people working full time in Belgium generally benefit from four week of holidays. During these holidays, employees continue to receive their salaries. In addition, between May and June, they receive a double holiday allowance based on their last working year [73]. This nest egg may probably be an additional incentive (or even a legitimization?) to take a vacation.

However, this information must be taken with some caution because none of the twenty interviewees mentioned these dimensions explicitly. The influence of material structures therefore seems to be the least empirically testable component of a practice. But this doesn't diminish its possible impact of the adoption, transformation or abandonment of sustainable practices during holidays. 


\subsubsection{Holidays with Children and Partners: The Role of the Relatives}

This last topic is rarely mentioned in research using social practices theories. Indeed, Bartiaux and Reátegui Salmón [26] claim that "these theories do not provide an explicit place [for] social interactions" (p. 206). Beyond these two authors, no others using this theoretical framework seem to consider that the carrier of a practice is intertwined in a family and social fabric. In this sense, this section argues that relatives also play a role in the recruiting or not of practices with a lower impact on the environment as compromises must be made with the different family members.

First, all the young adults with children interviewed went on holiday last year. Nevertheless, having or not child(ren) seems to be one of the factors determining the destination and the means of transport. Indeed, among the eight young adults who went to France, five are parents with children aged 4 or younger. The only parents who did not go to France went to Costa Rica but their children are older (6 and 8 years old).

Among these five parents who went to France, three claimed to have chosen France because of their young children. They explained that their previous trips (before the birth of the children) were more exotic but that they had recently went for France for practical reasons.

"Before being in my thirties, I travelled a lot. It was something that really meant a lot to me. I went to Finland, Australia, India, the Reunion Island, and I regularly did city-trips. Then I settled down, we had a baby and we're becoming more reasonable." (Elodie, F., 34-year-old, mother of a 15-month-old baby)

"We did Cuba, Namibia, Australia, Indonesia, Laos, and Thailand... And we did one or two city-trips per year: Stockholm, Berlin, Prague, Lisbon, Porto... Now, for the past two years, we've changed our habits because of the little chip... We are going much closer. This year, it was exclusively France." (Louise, F., 32-year-old, mother of a 14-month-old baby)

"And then I got a taste for holidays in the South and everything... But this year, since we have the baby and he's a little annoying, and he doesn't sleep through the night, etc., we went to the North Sea [in Belgium]!" (Lucas, M., 28-year-old, father of a 2-year-old baby).

So, having children or not seems to be a key factor concerning the holiday destination. Indeed, while young parents in this sample have always travelled and continue to do so once they have children, their destinations are changing according to their new constraints. Having children can also determine the means of transport to reach the destination and/or to move on-site.

"It's much easier to go by car and stay by car with the little one. We thought we were going to go back to the sun, but when you do the counting, the plane with the stroller, the bags, the stuff, arriving with nothing, renting a car... Forget about it. Forget about it. It's not a vacation anymore, is it?" (Etienne, M., 29-year-old, father of a 14-month-old baby)

In the same way, some young adults reported that they take advantage of being childless to make long trips as Michelle: "I like to go far away. My starting-point is that as long as you do not have children, you have to take advantage of it." (Michelle, F., 27-year-old, in couple without children). However, Michelle's case show compromises. Indeed, since she met her partner, she has changed her on-site mobility during her holidays.

"But it's true that I love going far away, discovering a new language, a new culture, different food, feeling a little globe-trotting in my soul, with my backpack, having to take the bus... or whatever. Well, when I started dating [name of her partner], we found compromises because he wasn't into taking the bus. So, instead of taking the bus, we rent cars." (Michelle, F., 27-year-old, in couple without children and car driver in daily life). 
As pointed by Hall [34] "people do not act as isolated individuals" (p. 1099). These observations highlight a limitation of social practice theories: that they take too little into account the role of relatives in the adoption, transformation, persistence of abandonment of sustainable practices. However, these relatives, whether children or companions, seem to have a significant influence on the destination or modes of travel, as the above quotes show. Only the fact of going on holiday does not seem to be questioned by relatives.

\section{Conclusions}

On methodological grounds, while the data used in this article cannot claim either saturation of results or exhaustiveness because of the small number of interviewees, the 20 in-depth interviews conducted with young adults and consolidated through eighteen cross-interviews with some of their relatives provide interesting and sufficiently well-founded trends. Indeed, the richness of these in-depth interviews allows empirically applying the conceptual framework of social practices theories with precision in order to understand the importance of each practice component in the persistence or lack of persistence of sustainable practices during the holidays. In addition, crossing these first interviews with those of their parents, partners and/or siblings strongly consolidates the data by qualifying them, a richness that would never have been obtained without this method.

The first part of the results demonstrates a form of heterogeneity both in the adoption of sustainable practices in daily life as well as in their persistence during the holidays. Indeed, in everyday life, those who are vegetarians are not especially those who do not use the car as their main means of transport, while commuters are not necessarily attentive to the organic and local quality of their food. In addition, the results showed that the sustainable practices adopted on a daily basis did not persist especially during the holidays: some daily public transport users took the car to reach their holiday destination while some vegetarians ate meat during holidays.

These observations can be related to the concept of "compartmentalisation" defined by Halkier [74]. Based on Iversen's work [75], Halkier defines compartmentalisation as the way in which "reflected and chosen consumption practices can become 'crowded out' by tangible routinization" [74] (p. 39). This concept is then reinvested by Bartiaux [76] and Bartiaux and Reátegui Salmón [33] to express the idea that certain "green" practices can be adopted in some areas of consumption (e.g., food) and not in others (e.g., mobility). They explain that "eclecticism seems to be the norm and that 'green' considerations, if any, do not transmigrate among all practices" [33] (p. 476).

This contribution makes it possible to deepen this concept via a distinction between different forms of compartmentalisation: inter-thematic compartmentalisation, intra-thematic compartmentalisation and periodic compartmentalisation. The inter-thematic compartmentalisation is the adoption of "green" practices in some but not all consumption areas. Indeed, compartmentalisation occurs from one routine to another: sometimes the "green" focus is placed on food, sometimes on mobility but no regularity can be observed within the different consumption routines whose combination appears to be unique. An illustration of this inter-compartmentalisation is that among the young adults interviewed, some are attentive to eating organic, local and seasonal products but drive more than $100 \mathrm{~km}$ per day alone in their car.

The second type of compartmentalisation that I have observed is between two practices belonging to the same area of consumption. The adoption of eco-consumption practices is therefore not done in a homogeneous way, even within the same area. On the contrary, sustainable practices appear in a dispersed way within the same area of consumption. An example of intra-compartmentalisation is to fly to a rather close holiday destination (let's say a few hundred kilometres) and then use public transport once on-site.

Finally, I call a third form of observed compartmentalisation as "periodic". This form of compartmentalisation takes place only at certain times or during certain events. Here, the idea is that certain periods or certain events (a party with friends, Christmas, or holidays...) engender 
compartmentalisation. All the discrepancies between more sustainable practices of daily life and those of holidays are typical examples of periodic compartmentalisation.

These three types of compartmentalisation make it possible to answer the first question of this article: very few sustainable daily practices persist during the holidays. These observations can be characterized as periodic compartmentalisation in the sense that "green" practices are put in brackets for a specific period of time. However, at least one interviewee was enrolled in a vegetarian food practice during and after her long stay in Malaysia, even though she was not previously a vegetarian.

The second part of this contribution used an empirical application of the different components of practice developed by Schatzki [14] and Reckwitz [15] to show that the non-adoption (and even the non-persistence) of sustainable practices does not result from an oversight, or a lack of will or determination of practitioners. These sections showed the need to take into account the different dimensions allowing the adoption of a "greener" practice underlining the importance of each component of the practice. Indeed, material structures, routines, teleoaffective structures, and institutional dimensions must be considered as a whole constituting the practice, each component playing a role in the persistence, the transformation or the abandonment of sustainable practices. All of these components are required for the practice to take place. In this sense, the use of theories of social practices to study sustainable tourism through daily practices has proved to be relevant: the importance of each of the four components of the practice has been empirically demonstrated for understanding the adoption, persistence, or abandonment of sustainable practices.

Nevertheless, the last subsection has also shown one of the limitations of current theories of social practices. Indeed, it was observed that relatives also have an impact in the persistence or in the abandonment of practices. The section devoted to relatives highlighted that compromises and negotiations have to be made concerning whether the destination, the mode of transport or the food. This dimension remains insufficiently considered in theories of social practices (except in the work of Bartiaux and Reátegui Salmón).

Obviously, these initial reflections open up new avenues for reflection. From a theoretical point of view, a general reflection on the development of a definition of sustainable practice would be an important step forward in the field. On the other hand, future lines of research are also emerging, in particular by completely reversing the research question: are some more sustainable practices adopted during holidays? And if so, do they persist on a daily basis? In the light of the results relating to periodic compartmentalization, how can we envisage the career of practice? To what extent can it be fragmented? Are there other situations where sustainable practices are put in brackets?

Finally, this article has demonstrated that sustainable tourism is not limited to the material structures and other offers proposed by tourism professionals. On the contrary, sustainable tourism is also embodied in everyday practices: eating, travelling, grocery shopping, etc. However, these dimensions remain under-exploited in the area of sustainable tourism and the ambition of this article was to underline the relevance of deepening these questions especially since it was shown that some sustainable daily practices did not persist during the holidays. Sustainable tourism therefore concerns everybody - travel professionals, policy makers, consumers, governments, etc.—and it is played out at all levels. To encourage it, no component and no contributor should be omitted.

Funding: This research received no external funding.

Acknowledgments: This work was supported by the Fonds de la Recherche Scientifique; Amélie Anciaux is a Research Fellow of the Fonds de la Recherche Scientifique-FNRS. I warmly thank Françoise Bartiaux (Université catholique de Louvain, Belgium) for advice and detailed revisions. I am also grateful to Mithra Moezzi (QQForward, United States) who made helpful comments on the final version of this paper. I also thank the Institute for the Analysis of Change in Contemporary and Historical Societies for the support.

Conflicts of Interest: The author declares no conflict of interest. 


\section{Appendix A}

Table A1. Sociodemographic data for the 20 young adults in the sample.

\begin{tabular}{ccc}
\hline & Male & Female \\
\hline In couple & 6 & 12 \\
With children & 4 & 4 \\
Master's degree & 4 & 9 \\
PAO & 3 & 4 \\
Semi-rural environment & 3 & 7 \\
Urban environment & 4 & 6 \\
Brother/sister in the sample & 2 & 2 \\
Partner in the sample & 4 & 4 \\
Total & 7 & 13
\end{tabular}

Source: In-depth interviews conducted with 20 young adults who left on holidays (2017-2018).

\section{References}

1. Ajzen, I.; Fishbein, M. Understanding Attitudes and Predicting Social Behaviour; Prentice-Hall: Englewood Cliffs, NJ, USA, 1980; Available online: http://www.citeulike.org/group/38/article/235626 (accessed on 7 August 2019).

2. Ajzen, I. From Intentions to Actions: A Theory of Planned Behavior. In Action Control; Springer: Berlin/Heidelberg, Germany, 1985; pp. 11-39.

3. Gilg, A.; Barr, S.; Ford, N. Green Consumption or Sustainable Lifestyles? Identifying the Sustainable Consumer. Futures 2005, 37, 481-504. [CrossRef]

4. Bozonnet, J.-P. Socialisation et Engagement Écologiste en Europe. L'école, la Famille et L'environnementalisme en Héritage. In Proceedings of the Congrès de l'AISLF, Turquie, İstanbul, 7-11 July 2008.

5. Mathieson, A.; Wall, G. Tourism, Economic, Physical and Social Impacts; Longman: Harlow, UK, 1982.

6. Murphy, P.E. Tourism: A community approach. New York: Methuen. In National Parks Today: Green Guide for Tourism; Methuen: New York, NY, USA, 1991; pp. 224-238.

7. Place, S.; Hall, C.M.; Lew, A. Sustainable Tourism: A Geographical Perspective; Addison Wesley Longman: London, UK, 1998.

8. Shove, E. Beyond the ABC: Climate Change Policy and Theories of Social Change. Environ. Plan. A 2010, 42, 1273-1285. [CrossRef]

9. Spaargaren, G. Theories of practices: Agency, technology, and culture: Exploring the relevance of practice theories for the governance of sustainable consumption practices in the new world-order. Glob. Environ. Chang. 2011, 21, 813-822. [CrossRef]

10. Barr, S.; Shaw, G.; Coles, T.; Prillwitz, J. 'A holiday is a holiday': Practicing sustainability, home and away. J. Transp. Geogr. 2010, 18, 474-481. [CrossRef]

11. Sharpley, R. Tourism and sustainable development: Exploring the theoretical divide. J. Sustain. Tour. 2000, 8, 1-19. [CrossRef]

12. Casagrandi, R.; Rinaldi, S. A theoretical approach to tourism sustainability. Conserv. Ecol. 2002, 6, 13. [CrossRef]

13. Liu, Z. Sustainable tourism development: A critique. J. Sustain. Tour. 2003, 11, 459-475. [CrossRef]

14. Schatzki, T.R. Social Practices: A Wittgensteinian Approach to Human Activity and the Social; Cambridge Univ Press: Cambridge, UK, 1996.

15. Reckwitz, A. Toward a theory of social practices a development in culturalist theorizing. Eur. J. Soc. Theory 2002, 5, 243-263. [CrossRef]

16. Hunter, C. Sustainable tourism and the touristic ecological footprint. Environ. Dev. Sustain. 2002, 4, 7-20. [CrossRef]

17. Butler, R.W. Sustainable tourism: A state-of-the-art review. Tour. Geogr. 1999, 1, 7-25. [CrossRef]

18. Lorenzoni, I.; Pidgeon, N.F. Public views on climate change: European and USA perspectives. Clim. Chang. 2006, 77, 73-95. [CrossRef] 
19. Anable, J. 'Complacent car addicts' or 'aspiring environmentalists'? Identifying travel behaviour segments using attitude theory. Transp. Policy 2005, 12, 65-78. [CrossRef]

20. Böhler, S.; Grischkat, S.; Haustein, S.; Hunecke, M. Encouraging environmentally sustainable holiday travel. Transp. Res. Part A Policy Pract. 2006, 40, 652-670. [CrossRef]

21. Dallen, J. Sustainable transport, market segmentation and tourism: The Looe Valley branch line railway, Cornwall, UK. J. Sustain. Tour. 2007, 15, 180-199. [CrossRef]

22. Blamey, R.K.; Braithwaite, V.A. A social values segmentation of the potential ecotourism market. J. Sustain. Tour. 1997, 5, 29-45. [CrossRef]

23. Becken, S.; Hay, J.E. Tourism and Climate Change: Risks and Opportunities; Multilingual Matters: Bristol, UK, 2007; Volume 1.

24. Mowforth, M.; Munt, I. Tourism and Sustainability: Development, Globalisation and New Tourism in the Third World; Routledge: London, UK, 2015.

25. Shaw, S.; Thomas, C. Discussion Note: Social and Cultural Dimensions of Air Travel Demand: Hyper-Mobility in the UK? J. Sustain. Tour. 2006, 14, 209-215. [CrossRef]

26. Bartiaux, F.; Reátegui Salmón, L. Family Dynamics and Social Practice Theories: An Investigation of Daily Practices Related to Food, Mobility, Energy Consumption, and Tourism. Nat. Cult. 2014, 9, $204-224$. [CrossRef]

27. Brundtland, G.H. Rapport Brundtland. In L'Odyssée du Développement Durable; Ministère des Affaires étrangères et du Développement international: Paris, France, 1987.

28. Seyfang, G. Shopping for sustainability: Can sustainable consumption promote ecological citizenship? Environ. Politics 2005, 14, 290-306. [CrossRef]

29. Jackson, T.; Michaelis, L. Policies for Sustainable Consumption; Sustainable Development Commission: London, UK, 2003.

30. Ofstad, S. (Ed.) Symposium: Sustainable Consumption; Ministry of Environment: Oslo, Norway, 1994

31. Latouche, S. L'imposture du développement durable ou les habits neufs du développement. Mondes En Développement 2003, 1, 23-30. [CrossRef]

32. Latouche, S. Sustainable Consumption in a De-Growth Perspective. In Sustainable Consumption, Ecology and Fair Trade; Routledge: London, UK, 2007; pp. 178-185.

33. Bartiaux, F.; Reátegui Salmón, L. Are there domino effects between consumers' ordinary and 'green' practices? An analysis of quantitative data from a sensitisation campaign on personal carbon footprint. Int. Rev. Sociol. 2012, 22, 471-491. [CrossRef]

34. Hall, C.M. Framing behavioural approaches to understanding and governing sustainable tourism consumption: Beyond neoliberalism,"nudging" and "green growth"? J. Sustain. Tour. 2013, 21, 1091-1109. [CrossRef]

35. World Tourism Organization. UNWTO Tourism Highlights 2012 Edition; World Tourism Organization: Madrid, Spain, 2012.

36. Encyclopedia of Worldwide Tourism Research. Available online: http://www.ciret-tourism.com/links/links. html (accessed on 14 August 2019).

37. Buckley, R. Sustainable tourism: Research and reality. Ann. Tour. Res. 2012, 39, 528-546. [CrossRef]

38. Gössling, S.; Hall, C.M.; Peeters, P.; Scott, D. The future of tourism: Can tourism growth and climate policy be reconciled? A mitigation perspective. Tour. Recreat. Res. 2010, 35, 119-130. [CrossRef]

39. Saarinen, J. Traditions of sustainability in tourism studies. Ann. Tour. Res. 2006, 33, 1121-1140. [CrossRef]

40. Barr, S.; Gilg, A.; Shaw, G. 'Helping people make better choices': Exploring the behaviour change agenda for environmental sustainability. Appl. Geogr. 2011, 31, 712-720. [CrossRef]

41. Zaccaï, E. Sustainable Consumption, Ecology and Fair Trade; Routledge: London, UK, 2007.

42. Bartiaux, F. Greening Some Consumption Behaviours: Do New Routines Require Agency and Reflexivity. In Sustainable Consumption, Ecology and Fair Trade; Routledge: London, UK, 2007; pp. 105-122.

43. Sahakian, M.; Wilhite, H. Making practice theory practicable: Towards more sustainable forms of consumption. J. Consum. Cult. 2014, 14, 25-44. [CrossRef]

44. Pleyers, G. La Consommation Critique: Mouvements Pour une Alimentation Responsable et Solidaire; Desclée de Brouwer: Perpignan, France, 2011.

45. Pleyers, G. La Consommation Critique Comme Action Collective; Barricade: Liège, Belgium, 2013. 
46. Shove, E.; Spurling, N. Sustainable Practices: Social Theory and Climate Change. In Sustainable Practices; Routledge: London, UK, 2013; pp. 17-30.

47. Gatersleben, B.; Steg, L.; Vlek, C. Measurement and Determinants of Environmentally Significant Consumer Behavior. Environ. Behav. 2002, 34, 335-362. [CrossRef]

48. Sayer, A. Power, Sustainability and well being: An outsider's view. In Sustainable Practices; Routledge: London, UK, 2013; pp. 183-196.

49. Cetina, K.K.; Schatzki, T.R.; Von Savigny, E. The Practice Turn in Contemporary Theory; Routledge: London, UK, 2001.

50. Warde, A. Consumption and Theories of Practice. J. Consum. Cult. 2005, 5, 131-153. [CrossRef]

51. Giddens, A. Les Conséquences de la Modernité [1990]; L'Harmattan: Paris, France, 1994.

52. Callon, M.; Latour, B. Comment suivre les Innovations. Clefs pour l'analyse socio-technique; Pandore: Paris, France, 1986.

53. Seo, Y.; Jung, S.U. Beyond solitary play in computer games: The social practices of eSports. J. Consum. Cult. 2014, 16, 635-655. [CrossRef]

54. Dubuisson-Quellier, S.; Plessz, M. La théorie des pratiques. Quels apports pour l'étude sociologique de la consommation? Sociologie 2013, 4, 451-469.

55. Warde, A. After taste: Culture, consumption and theories of practice. J. Consum. Cult. 2014, 14, $279-303$. [CrossRef]

56. Bourdieu, P. Esquisse d'une Théorie de la Pratique. Geneva: Droz. Trans. Outline of a Theory of Practice, rev. and Extended edn; Cambridge University Press: Cambridge, UK, 1977.

57. Giddens, A. The Constitution of Society; University of California Press: Berkeley, CA, USA, 1984; pp. 584-602.

58. Schatzki, T.R. Practices and actions a Wittgensteinian critique of Bourdieu and Giddens. Philos. Soc. Sci. 1997, 27, 283-308. [CrossRef]

59. Tong, A.; Sainsbury, P.; Craig, J. Consolidated criteria for reporting qualitative research (COREQ): A 32-item checklist for interviews and focus groups. Int. J. Qual. Health Care 2007, 19, 349-357. [CrossRef] [PubMed]

60. Boyce, C.; Neale, P. Conducting In-Depth Interviews: A Guide for Designing and Conducting In-Depth Interviews for Evaluation Input; Pathfinder International: Watertown, MA, USA, 2006.

61. Bertaux, D. Les Récits de vie: Perspective Ethnosociologique; Nathan: Paris, France, 1997.

62. Delcroix, C. Des récits de vie croisés aux histoires de famille. Curr. Sociol. 1995, 43, 61-67. [CrossRef]

63. Delcroix, C.; Lagier, E. Intergenerational transmissions in transnational families and national affiliations. Zeitschrift für Qualitative Forschung 2014, 15, 25-38. [CrossRef]

64. Kaufmann, J.-C. L'entretien Compréhensif; Armand Colin: Paris, France, 2011.

65. Tourism trips of Europeans. Available online: https://ec.europa.eu/eurostat/statistics-explained/index.php/T ourism_trips_of_Europeans (accessed on 22 June 2019).

66. Shove, E.; Pantzar, M.; Watson, M. The Dynamics of Social Practice: Everyday Life and How it Changes; Sage Publications: New York, NY, USA, 2012.

67. Crick, M. Representations of international tourism in the social sciences: Sun, sex, sights, savings, and servility. Annu. Rev. Anthropol. 1989, 18, 307-344. [CrossRef]

68. Veblen, T. The Theory of the Leisure Class: An Economic Study of Institutions; Macmillan: New York, NY, USA, 1902.

69. Shove, E. Comfort, Cleanliness and Convenience: The Social Organization of Normality; Berg: Oxford, UK, 2003; Volume 810 .

70. Barr, S. Environment and Society: Sustainability, Policy and the Citizen; Routledge: London, UK, 2008.

71. Røpke, I. Theories of practice-New inspiration for ecological economic studies on consumption. Ecol. Econ. 2009, 68, 2490-2497. [CrossRef]

72. Détaxer le kérosène n'aurait pas d'effet négatif sur l'emploi. Available online: https://www.rtbf.be/info /economie/detail_taxer-le-kerosene-n-aurait-pas-d-effet-negatif-sur-l-emploi?id=10219058 (accessed on 22 June 2019).

73. Congés, crédits temps et interrepution de carrières. Available online: https://www.socialsecurity.be/citizen/fr /conges-credit-temps-et-interruption-de-carriere/vacances-annuelles (accessed on 26 June 2019).

74. Halkier, B. Routinisation or Reflexivity? Consumers and Normative Claims for Environmental Consideration. In Ordinary Consumption; Gronow, J., Warde, A., Eds.; Routledge: London, UK, 2001; pp. 25-44. 
75. Iversen, T. Miljøproblematikken i Hverdagslivet. En kognitiv Antropologisk Undersøgelse af Forståelser, Handlingsmotivation og Handlerum; Institut for Antropologi, Københavns Universitet: København, Denmark, 1996.

76. Bartiaux, F. Does environmental information overcome practice compartmentalisation and change consumer's behaviours? J. Clean. Prod. 2008, 16, 1170-1180. [CrossRef]

(C) 2019 by the author. Licensee MDPI, Basel, Switzerland. This article is an open access article distributed under the terms and conditions of the Creative Commons Attribution (CC BY) license (http://creativecommons.org/licenses/by/4.0/). 
MDPI

St. Alban-Anlage 66

4052 Basel

Switzerland

Tel. +41616837734

Fax +41 613028918

www.mdpi.com

Sustainability Editorial Office

E-mail: sustainability@mdpi.com

www.mdpi.com/journal/sustainability

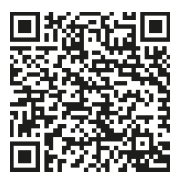



MDPI

St. Alban-Anlage 66

4052 Basel

Switzerland

Tel: +41 616837734

Fax: +41 613028918 